Florida International University FIU Digital Commons

$11-7-2012$

\title{
Developing an Enhanced Model for Combined Heat and Air Infiltration Energy Simulation
}

Chadi Younes

Florida International University, chadi.younes@fiu.edu

DOI: $10.25148 /$ etd.FI12112705

Follow this and additional works at: https://digitalcommons.fiu.edu/etd

\section{Recommended Citation}

Younes, Chadi, "Developing an Enhanced Model for Combined Heat and Air Infiltration Energy Simulation" (2012). FIU Electronic Theses and Dissertations. 743.

https://digitalcommons.fiu.edu/etd/743 


\title{
FLORIDA INTERNATIONAL UNIVERSITY
}

Miami, Florida

\section{DEVELOPING AN ENHANCED MODEL FOR COMBINED HEAT AND AIR INFILTRATION ENERGY SIMULATION}

\author{
A dissertation submitted in partial fulfillment of the \\ requirements for the degree of \\ DOCTOR OF PHILOSOPHY \\ in \\ CIVIL ENGINEERING \\ by
}

Chadi Younes

2012 
To: Dean Amir Mirmiran

College of Engineering and Computing

This dissertation, written by Chadi Younes, and entitled Developing an Enhanced Model for Combined Heat and Air Infiltration Energy Simulation, having been approved in respect to style and intellectual content, is referred to you for judgment.

We have read this thesis and recommend that it be approved.

Hector Fuentes

Arindam Chowdhury

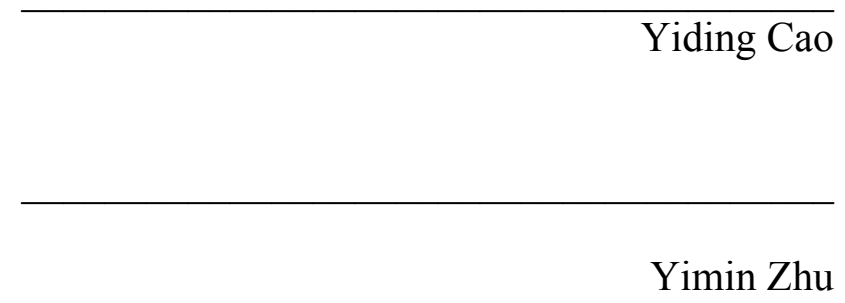

Caesar Abi Shdid, Major Professor

Date of Defense: November 7, 2012

The dissertation of Chadi Younes is approved.

Dean Amir Mirmiran
College of Engineering and Computing

Florida International University, 2012 
C Copyright 2012 by Chadi Younes

All rights reserved. 


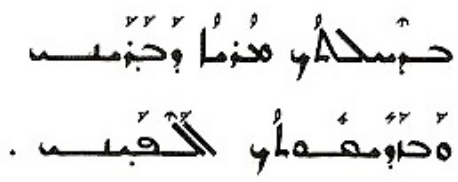




\section{DEDICATION}

I dedicate this dissertation to my parents for their devotion, continuous encouragement and prayers; and to Ruba, Rana \& Nawal for their unlimited love and support. 


\section{ACKNOWLEDGMENTS}

I wish to thank my major professor, Dr. Caesar Abi Shdid for the guidance and mentorship he provided me throughout my graduate studies. His dedication, guidance and support made this work possible and successful. I am truly fortunate for having the opportunity to work with him.

I also wish to thank the members of my committee for their support and guidance. Drs. Hector R. Fuentes, Arindam Chowdhury, Yiding Cao and Yimin Zhu input on my research was particularly helpful. I would especially like to acknowledge the dedication of Dr. Fuentes to insure the quality and clarity of this manuscript.

I wish to acknowledge the support of the University Graduate School at Florida International University, especially for awarding me the Dissertation Year Fellowship which allowed me to concentrate my time and efforts on completing this dissertation. In addition, I profoundly appreciate the support of the Department of Civil and Environmental Engineering for in the form of graduate assistantships throughout my graduate studies at FIU. I also owe special thanks to the Civil \& Environmental Engineering Department personnel and to the FIU libraries staff.

Finally, it is a great pleasure to thank everyone who helped me write my dissertation successfully. 


\title{
ABSTRACT OF THE DISSERTATION \\ DEVELOPING AN ENHANCED MODEL FOR COMBINED HEAT AND AIR \\ INFILTRAION ENERGY SIMULATION
}

\author{
by
}

Chadi Younes

Florida International University, 2012

Miami, Florida

\section{Professor Caesar Abi Shdid, Major Professor}

The need for efficient, sustainable, and planned utilization of resources is ever more critical. In the U.S. alone, buildings consume 34.8 Quadrillion $\left(10^{15}\right)$ BTU of energy annually at a cost of $\$ 1.4$ Trillion. Of this energy $58 \%$ is utilized for heating and air conditioning.

Several building energy analysis tools have been developed to assess energy demands and lifecycle energy costs in buildings. Such analyses are also essential for an efficient HVAC design that overcomes the pitfalls of an under/over-designed system. DOE-2 is among the most widely known full building energy analysis models. It also constitutes the simulation engine of other prominent software such as eQUEST, EnergyPro, PowerDOE. Therefore, it is essential that DOE-2 energy simulations be characterized by high accuracy.

Infiltration is an uncontrolled process through which outside air leaks into a building. Studies have estimated infiltration to account for up to $50 \%$ of a building's energy demand. This, considered alongside the annual cost of buildings energy 
consumption, reveals the costs of air infiltration. It also stresses the need that prominent building energy simulation engines accurately account for its impact.

In this research the relative accuracy of current air infiltration calculation methods is evaluated against an intricate Multiphysics Hygrothermal CFD building envelope analysis. The full-scale CFD analysis is based on a meticulous representation of cracking in building envelopes and on real-life conditions. The research found that even the most advanced current infiltration methods, including in DOE-2, are at up to $96.13 \%$ relative error versus CFD analysis.

An Enhanced Model for Combined Heat and Air Infiltration Simulation was developed. The model resulted in $91.6 \%$ improvement in relative accuracy over current models. It reduces error versus CFD analysis to less than $4.5 \%$ while requiring less than $1 \%$ of the time required for such a complex hygrothermal analysis. The algorithm used in our model was demonstrated to be easy to integrate into DOE-2 and other engines as a standalone method for evaluating infiltration heat loads. This will vastly increase the accuracy of such simulation engines while maintaining their speed and ease of use characteristics that make them very widely used in building design. 


\section{TABLE OF CONTENTS}

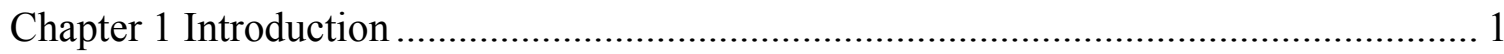

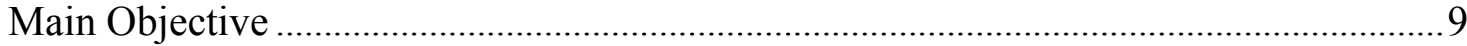

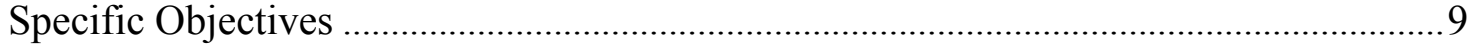

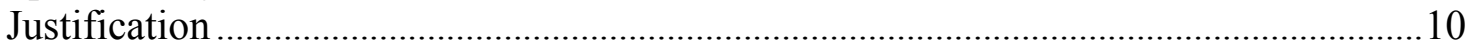

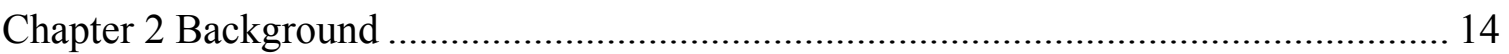

Building Energy Simulation Programs.........................................................................

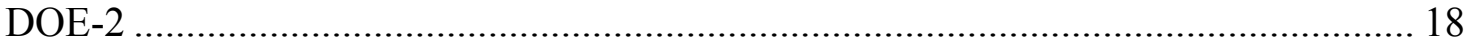

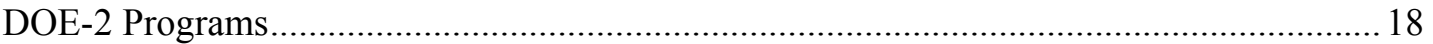

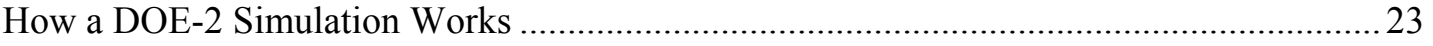

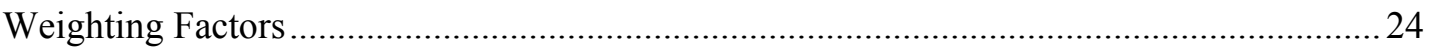

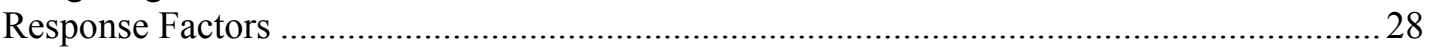

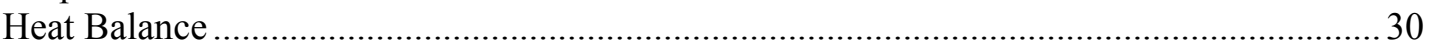

Heat-Gain Weighting Factors …………………………………………………….....

Determination of Hourly Loads \& Space Temperatures..........................................................37

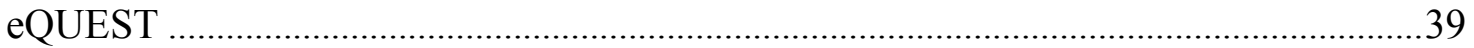

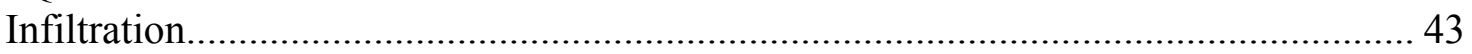

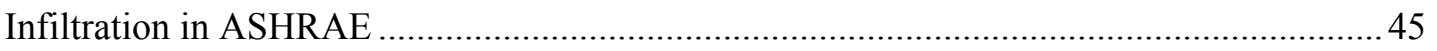

Residential Calculation Models ................................................................................ 47

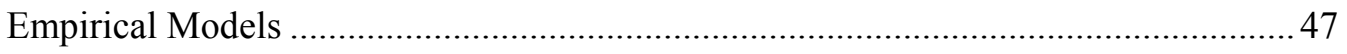

Multizone Models.................................................................................................... 47

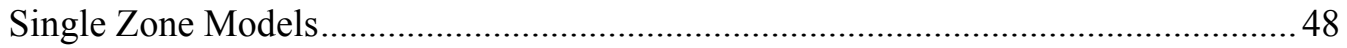

Superposition of Wind and Stack Effects ............................................................ 48

Infiltration in Commercial Buildings ......................................................................... 48

Air Infiltration Calculation Techniques \& Methods …………................................... 52

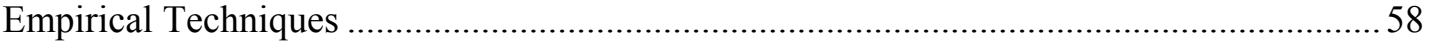

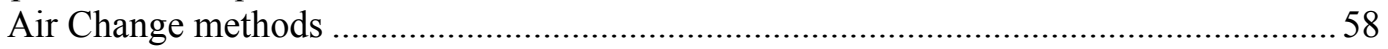

Reduction Pressurization Test Data ………………………………………………..59

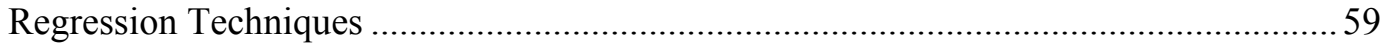

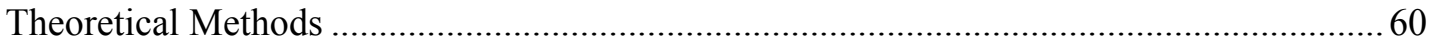

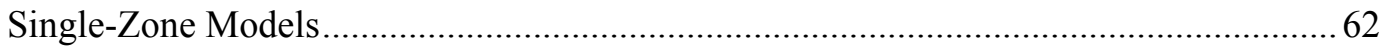

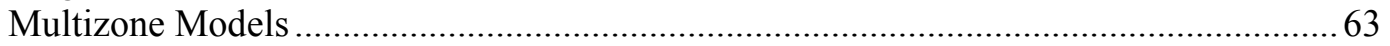

CFD, FFD, AND COMBINED MULTIZONE-CFD METHODS ......................................6

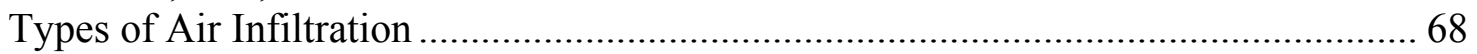

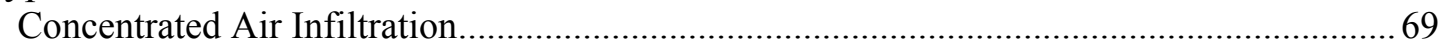

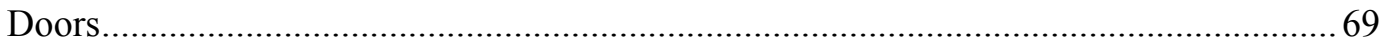

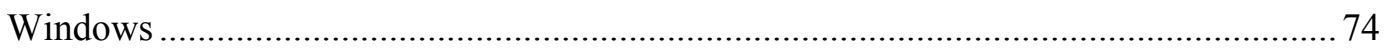

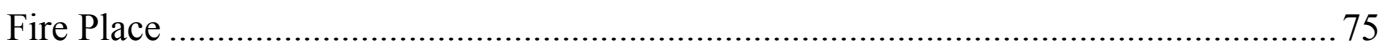

Diffuse Air Infiltration: Heat Recovery ……………………………………………..... 77

Building Energy Simulation Infiltration Evaluation Approach ........................................85

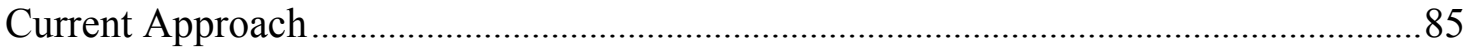

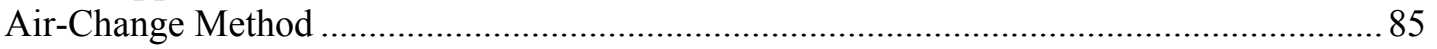

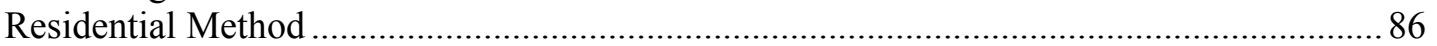

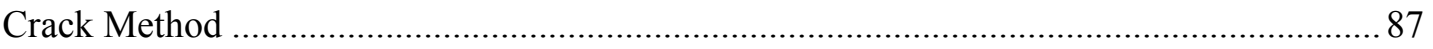

Sherman - Grimsrud Method \& ASHRAE Enhanced Method ...........................................8 87 


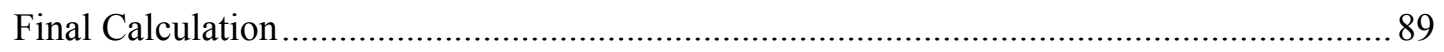

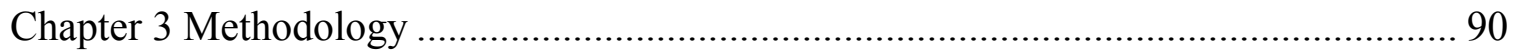

Combined Infiltration, Conduction \& Solar Model ................................................. 90

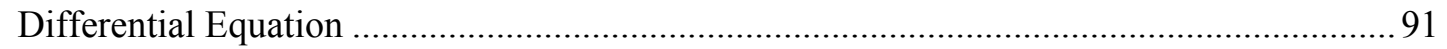

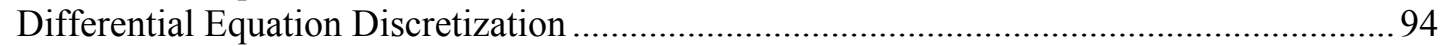

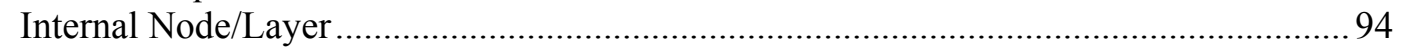

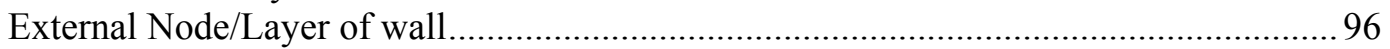

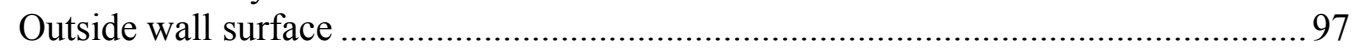

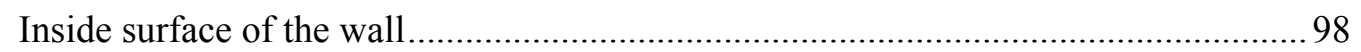

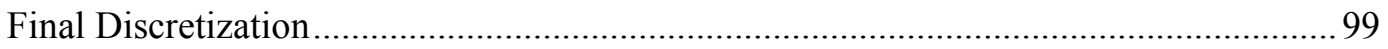

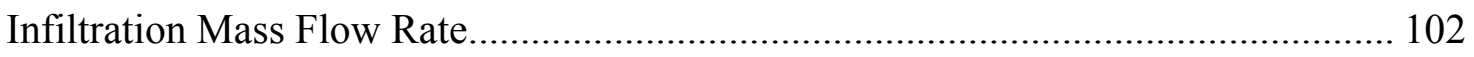

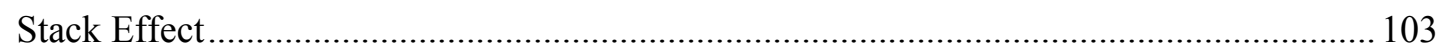

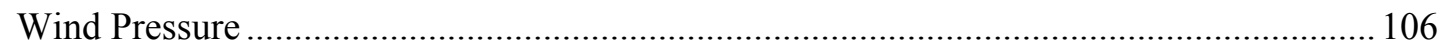

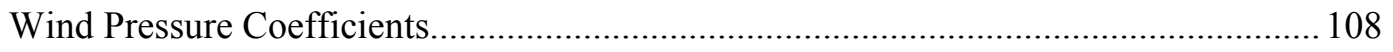

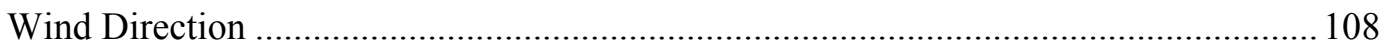

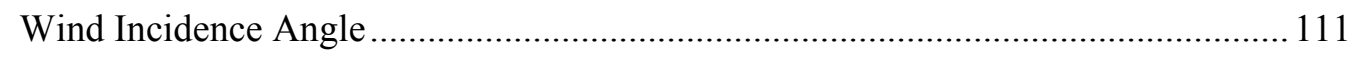

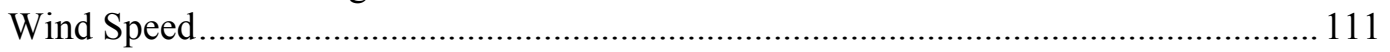

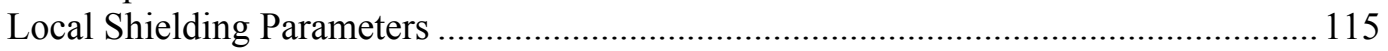

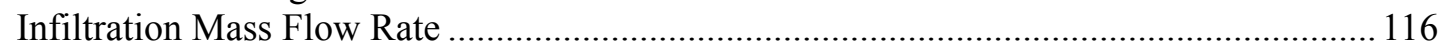

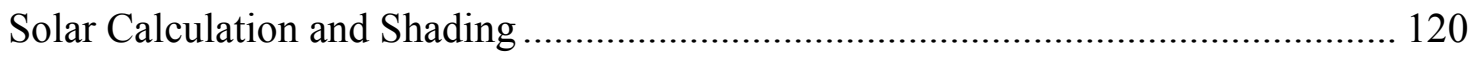

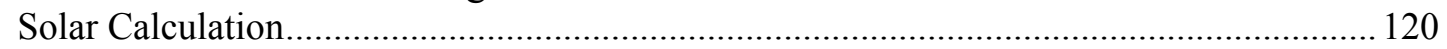

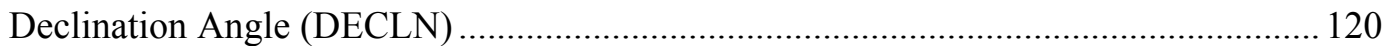

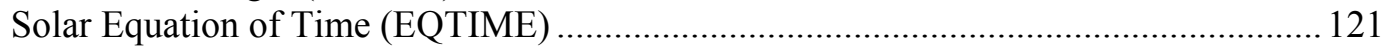

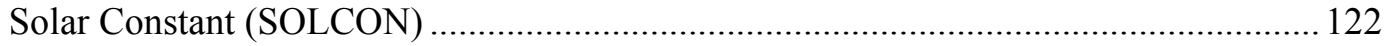

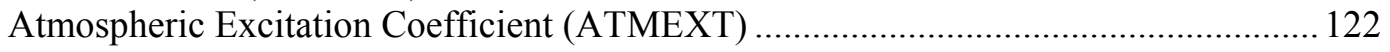

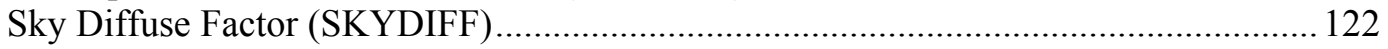

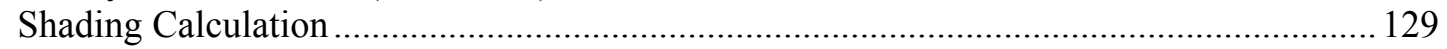

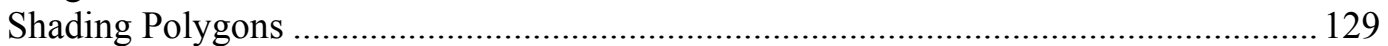

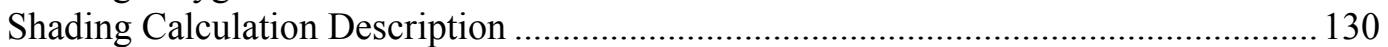

CFD Modeling of Cracks and Airflow Paths .......................................................... 132

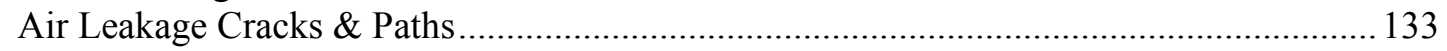

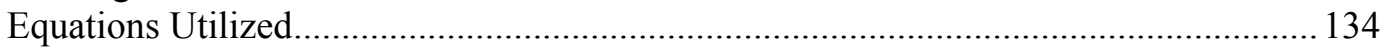

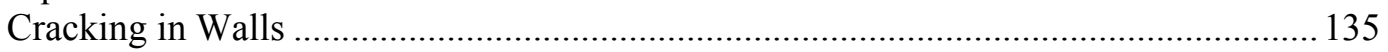

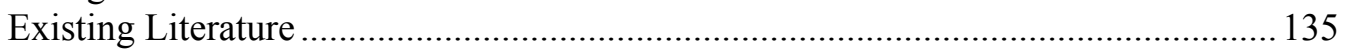

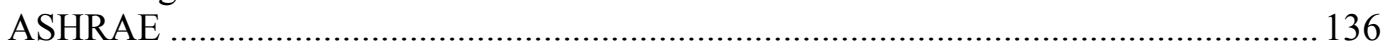

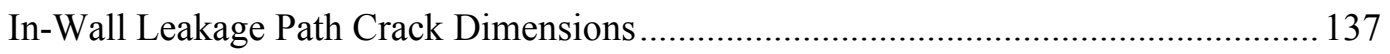

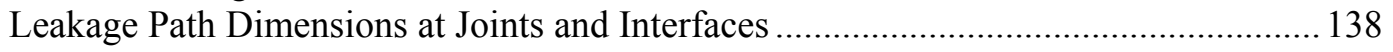

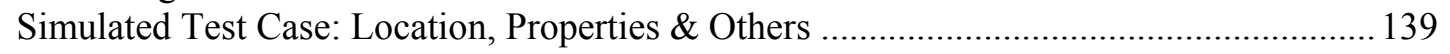

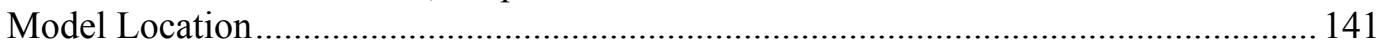

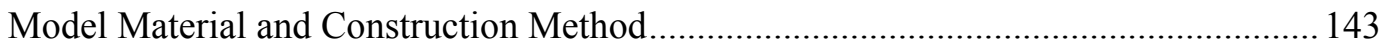

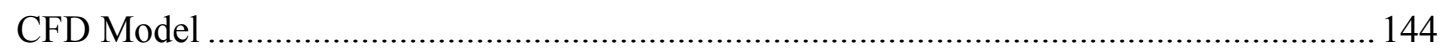

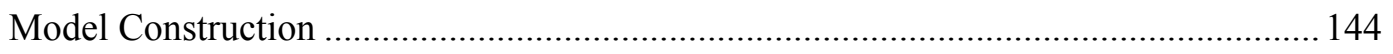

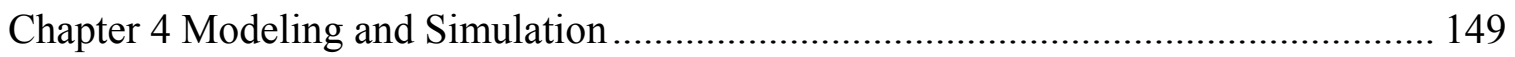

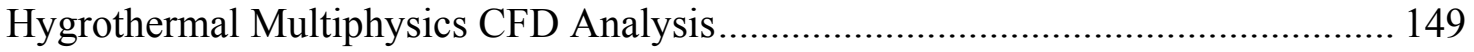

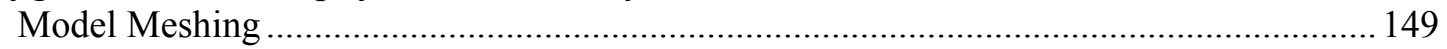

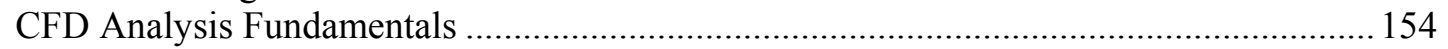

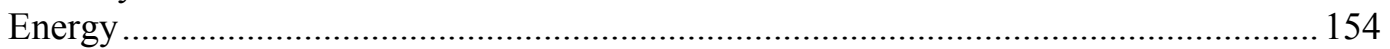

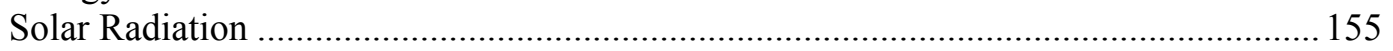




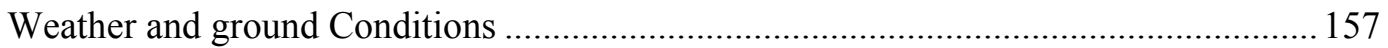

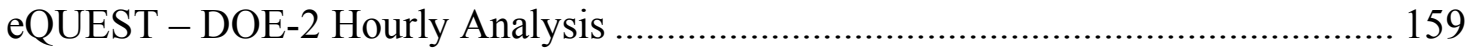

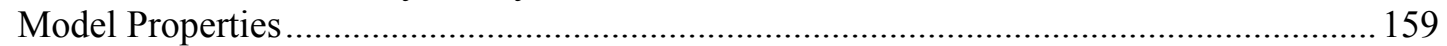

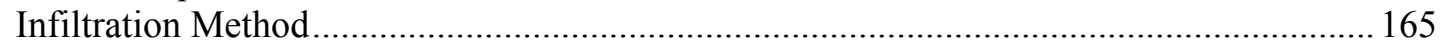

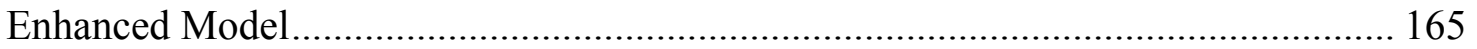

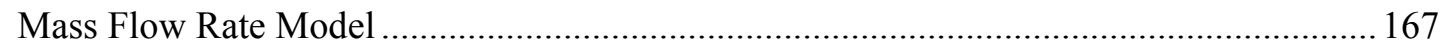

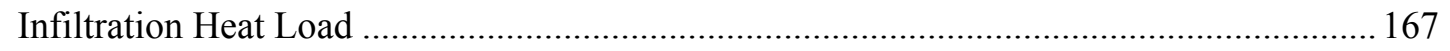

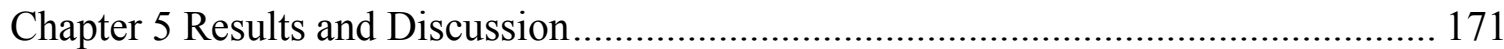

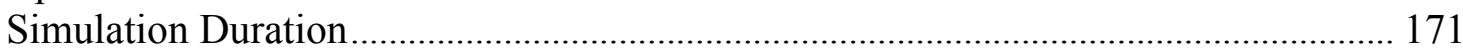

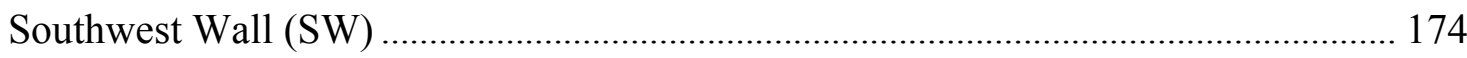

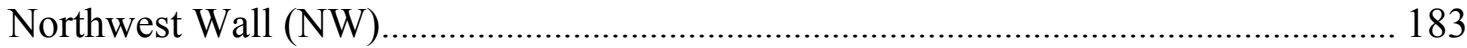

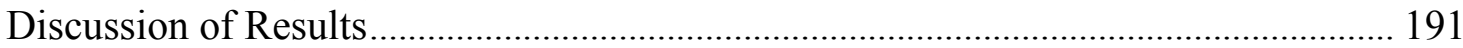

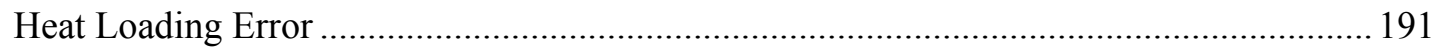

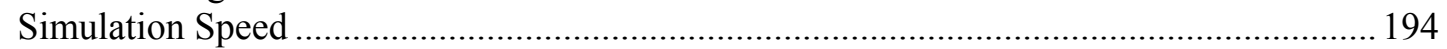

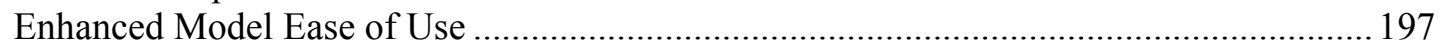

Infiltration Heat Recovery .......................................................................................... 198

Chapter 6 Conclusions and Recommended Future Work .......................................... 205

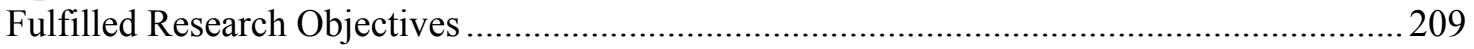

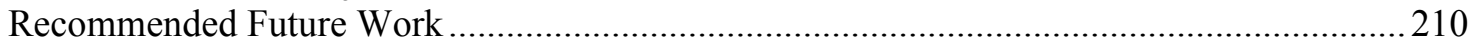

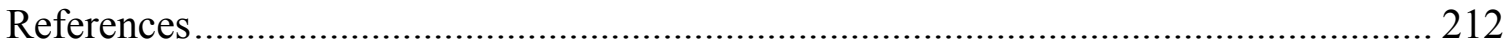

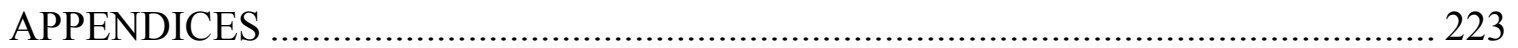

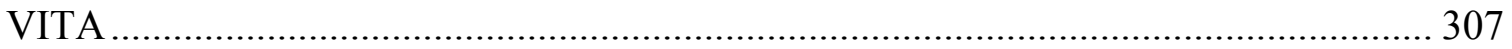


Figure 2-1: Overlapping triangular pulses defining a function (DOE-2 Engineers manual, 1982)

Figure 2-2: Flow of Energy through a multilayer wall (DOE-2 Engineers manual, 1982)

Figure 2-3: Typical Infiltration \& Ventilation Airflow .................................................. 45

Figure 3-1: Heat flux flow control volume ………………….................................. 92

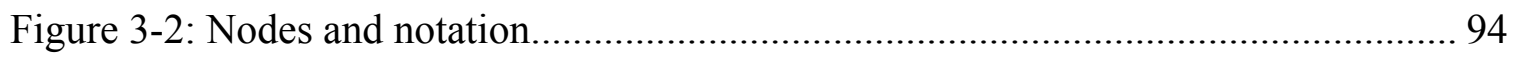

Figure 3-3: Node on the outside surface of the wall ....................................................... 97

Figure 3-4: Node on the inside surface of the wall .................................................... 98

Figure 3-5: A wall with multiple layers and $\mathrm{n}$ nodes.................................................... 100

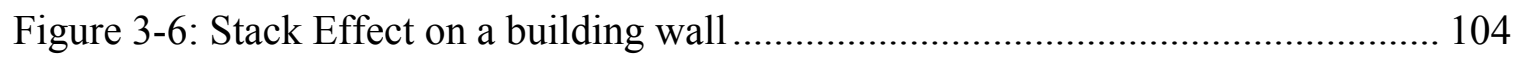

Figure 3-7: Wind pressure on a typical Gable, Hip roof house (Figure 6-6, ASCE 7-05)

Figure 3-9: Hourly Temperature and Wind data available from weather file (DOE-

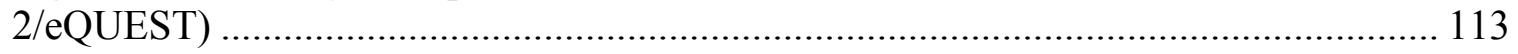

Figure 3-10: Effective air leakage are, ASHRAE Handbook Chapter 25 Table 1

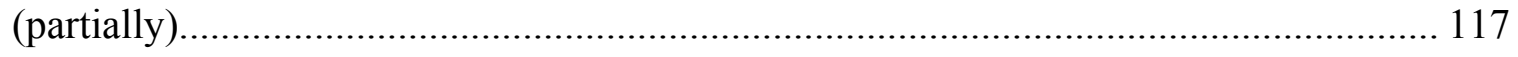

Figure 3-12: Daily Solar Geometry (DOE-2 Engineers Manual, 1982) …………….... 125

Figure 3-13: Shading calculations related polygons ................................................... 129

Figure 3-14: Shading calculation strips .................................................................... 131

Figure 3-15: Sample 2-D Infiltration CFD Models ...................................................... 132

Figure 3-16: Sample 2-D Infiltration CFD Models With Loading Induced Cracks....... 133

Figure 3-17: Crack Shape and Dimensions ............................................................. 136

Figure 3-18: Crack Shape and Dimensions ........................................................... 136 
Figure 3-19: Chosen Location of Building Envelope, Vicinity of Fargo Intl, Fargo, North Dakota 142

Figure 3-20: Air Leakage By County (Sherman and McWilliams, 2007)..................... 142

Figure 3-21: Basic Block with Angled Crack and Electrical Inlet Crack ....................... 144

Figure 3-22: Basic Block with Angled Crack and Electrical Outlet Crack .................... 144

Figure 3-23: A Mixed Crack Wall Created by Assembling 36 of the Basic Building

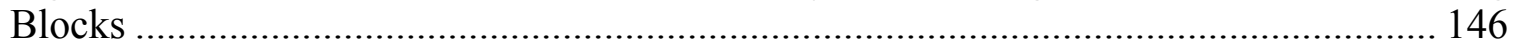

Figure 3-24: A Resulting Representative Concrete Cavity Wall .................................... 146

Figure 3-25: Wall Section Showing Internal Cavity and In-plain Cracks ..................... 147

Figure 3-26: Close-up Showing Corner/Joint Cracks.................................................... 147

Figure 3-27: An X-ray of A Resulting 3D Model Showing All In-plain and Joint Cracks 147

Figure 4-1: Sample Full Model and Domain Mesh ..................................................... 150

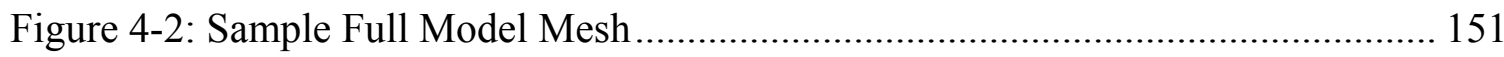

Figure 4-3: Meshing of Minute Airflow Cracks ........................................................... 151

Figure 4-4: Tessellation of Thin Sections and Proper Mesh Attachment (contact) Between Fluid Outside the Envelope (1), Infiltrating Through Cracks (2), Inside Wall Cavity (3), In Corner Joints (4), and In Inner Domain(5) .......................................................... 152

Figure 4-5: Meshing of Cavity Brick Walls, Proper Contact Between Solid \& Fluid Meshes, and Close Up on a Sample Leakage Crack Mesh........................................... 153

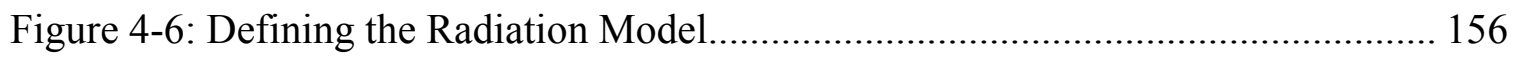

Figure 4-7: Setting the Solar Ray Tracing Model....................................................... 157

Figure 4-8: Sample Hourly Temperature Profile .......................................................... 158

Figure 4-9: Applying Ground Temperature on the Defined Ground Boundary with Ground (Soil) Material Properties ............................................................................ 158

Figure 4-10: Thermostat Settings in eQUEST to Match 72F in CFD Analysis ............. 160

Figure 4-11: Defining Cavity Brick Wall in eQUEST ……….................................... 160 
Figure 4-12: Defining Building Orientation in eQUEST to Match the CFD Analysis .. 161

Figure 4-13: Defining Ground Temperature and Building Coordinates........................ 161

Figure 4-14: Building Operation set to 24 Hours Daily ........................................... 162

Figure 4-15: No Holiday Defined, Continuous Building Operation............................ 162

Figure 4-16: Defining Electric Baseboards for Heating .......................................... 164

Figure 4-17: Defined HVAC System for The Building Model .................................. 164

Figure 4-18: Built Enhanced Model Input Interface............................................... 166

Figure 4-19: Hourly DOE-2/eQUEST Input into the Enhanced Model ........................ 168

Figure 4-20: Built Interface for the Mass Flow Rate Calculation Model ...................... 169

Figure 4-21: BUILT Enhanced Model Output Interface ......................................... 170

Figure 5-1: Lateral-Section Temperature Contour Plot Across a CFD Model with Angled (Zig-Zag) Cracks............................................................................................. 201

Figure 5-2: Lateral-Section Temperature Contour Plot Across a CFD Model with Mixed

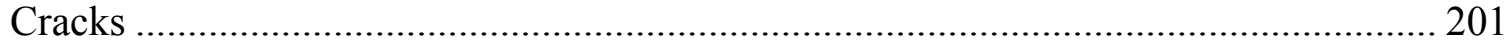

Figure 5-3: Lateral-Section Temperature Contour Plot Across a CFD Model with Straight

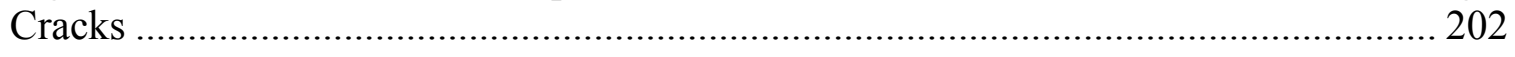

Figure 5-4: Lateral-Section Velocity Vector Plot Across a CFD Model with Angled (zig-

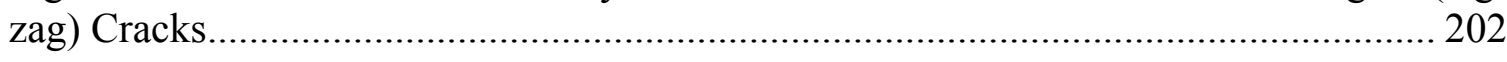

Figure 5-5: Vertical-Section Velocity Vector Plot Across a CFD Model with Mixed Straight and Angled Cracks ............................................................................ 203

Figure 5-6: Vertical-Section Combined Velocity Vector and Temperature Contour Plot Across a CFD Model with Straight Cracks, with the Effect of Solar Heating Showing on the Envelope's Southern Wall 203

Figure 5-7: Vortex Plot Revealing Air Leakage Across In-wall Caracks (1), Corner

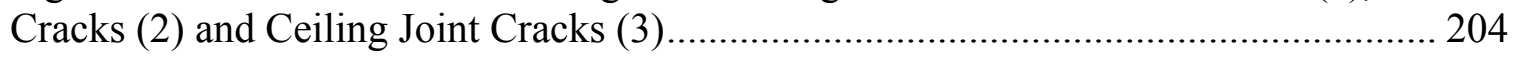




\section{LIST OF TABLES}

TABLE

PAGE

Table 2-1: Choice of pulsated term in the heat balance equation ................................. 34

Table 2-2: Empirical Infiltration techniques (Based on Liddament (1986)) ................... 57

Table 2-3: Theoretical Infiltration techniques; Based on Liddament (1986) ................... 57

Table 2-4: Air Changes per Hour $(\mathrm{ACH})$ estimated by Construction Tightness

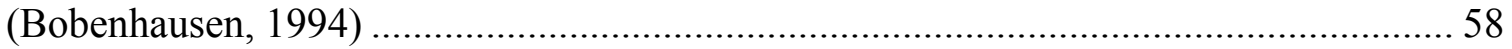

Table 2-5: Infiltration Through Entrances - Doors in One Wall Only (Infiltration

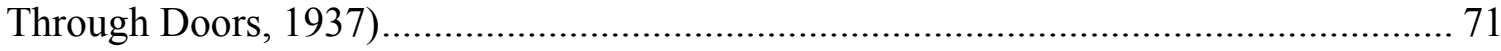

Table 2-6: Infiltration through Entrances - Doors in More Than one Wall (Infiltration

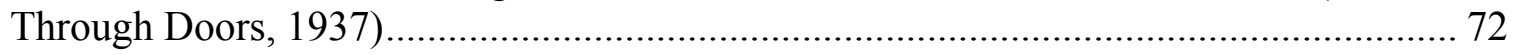

Table 2-7: Stack Coefficient $C_{\mathrm{s}}$ (ASHRAE Handbook of Fundamentals, 2009) ............. 88

Table 2-8: Local shelter classes (ASHRAE Handbook of Fundamentals, 2009) ............. 88

Table 2-9: Wind Coefficient $\mathrm{C}_{\mathrm{w}}$ (ASHRAE Handbook of Fundamentals, 2009) ............ 89

Table 3-1: External Pressure Coefficient, Cp (ASCE 7-05, Figure 6-6) ....................... 108

Table 3-2: Surface Roughness Coefficients (Simu and Miyata, 2006) ......................... 112

Table 3-3: Normalized shielding coefficients from Deru and Burns (2003) based on

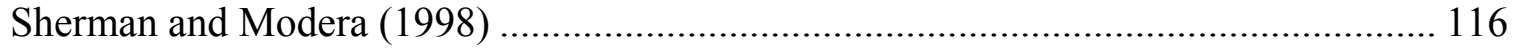

Table 3-4: ASHRAE 1977 Handbook of Fundamentals............................................ 123

Table 3-5: Fourier series equation constants ........................................................... 124

Table 3-6: Sample ASHRAE Material leakage Data................................................ 137

Table 3-7: In-Plain Crack Diameter for Brick Cavity Wall....................................... 137

Table 3-8: Summary of Adopted Crack and Gap Dimensions ................................... 139

Table 3-9: Averaged Weather Conditions for Fargo Over the Simulation Span Time Period..... 
Table 5-1: Comparison of Cumulative Extrapolated 31 Day Data versus Actual

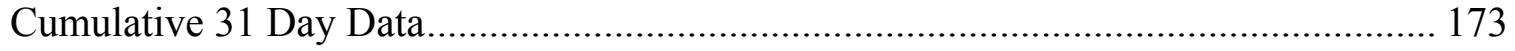

Table 5-2: Hourly Infiltration Heat Load Data for Southwest Wall ............................ 175

Table 5-3: Cumulative Infiltration Heat Load Data for Southwest Wall....................... 179

Table 5-4: Cumulative Monthly Heat Load on Southwest Wall ................................ 182

Table 5-5: Hourly Infiltration Heat Load Data for Northwest Wall ............................. 184

Table 5-6: Cumulative Infiltration Heat Load Data for Northwest Wall...................... 187

Table 5-7: Cumulative Monthly Heat Load on Northwest Wall ................................ 190

Table 5-8: Cumulative Monthly Heat Load on Northwest Wall ................................. 196

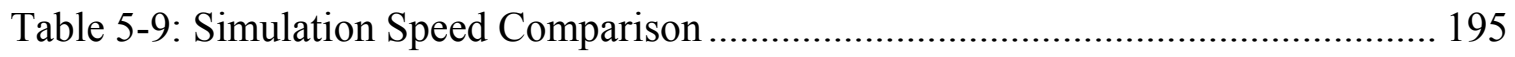




\section{LIST OF FLOWCHARTS}

CHART

PAGE

Flowchart 1-1: Major Steps Followed to Achieve the Stated Objectives ....................... 13

Flowchart 2-1: Summary of DOE-2 Program Components and Program Tasks............. 22

Flowchart 2-2: Flow of DOE-2 Core Simulation Process ........................................... 38

Flowchart 2-3: Possible Model Flows In eQUEST ..................................................... 42

Flowchart 2-4: Role of Air Infiltration Model in the Energy Design/Analysis Process

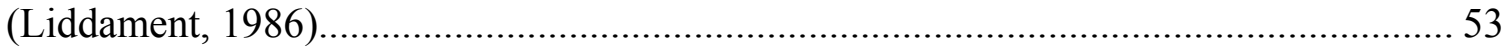

Flowchart 2-5: Hierarchal order of Infiltration Calculation Techniques (Liddament, 1986) 56

Flowchart 2-6: Multizone Models Calculation Models (Feustel, 1985 - Modified)......... 64

Flowchart 3-1 : Model Incorporation into hourly calculations .................................... 91

Flowchart 3-2 : Bule Print of the Enhanced Model .................................................. 101

Flowchart 3-3: Wind Pressure calculation based on local factors and building

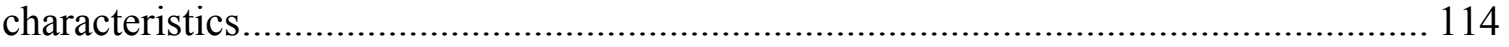

Flowchart 3-4: Mass flow rate calculation and components ..................................... 119

Flowchart 3-5: Crack Properties Determination Process.......................................... 134 


\section{LIST OF CHARTS}

CHART

PAGE

Chart 2-1: Air Leakage Rates of Elevator Shaft Walls (2009 ASHRAE® Handbook of Fundamentals). 49

Chart 2-2: Air Leakage Rate of Door versus Average Crack Width (2009 ASHRAE® Handbook of Fundamentals) .................................................................................. 51

Chart 2-3:Airflow Coefficient for Automatic Doors (2009 ASHRAE® Handbook of

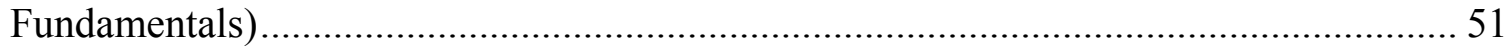

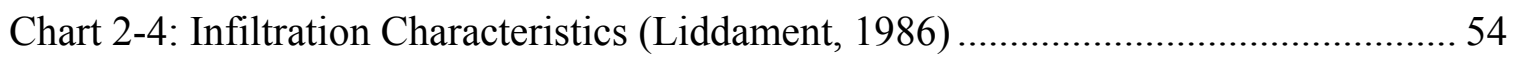

Chart 2-5: Orifice Flowmeter Coefficient (ASHRAE 1977) (Walton, 1980) .................. 62

Chart 2-6: Entrance Coefficients for Single Bank Entrances (Min, 1958) ...................... 73

Chart 2-7: Infiltration versus RPM and indoor-outdoor temperature difference (Revolving Door)....... 73

Chart 2-8: The intersection point of the two curves in this chart shows the point where there is no addition or loss of heat (Anon, 1937) - Reproduced 77

Chart 3-1: Surface pressure coefficient as a function of wind incidence angle for the Walton model and Swami \& Chandra model (Deru and Burns, 2003).... 109

Chart 3-2: Plot of solar equation of time, minute correction by day of the year. 122

Chart 5-1: Hourly Infiltration Heat Load at the Southwest Wall by Various DOE2/eQUEST Methods. 176

Chart 5-2: Hourly Infiltration Heat Load at the Southwest Wall versus Angled (zig-zag) cracks CFD Output for the wall.... 176

Chart 5-3: Hourly Infiltration Heat Load at the Southwest Wall versus Mixed cracks CFD Output for the wall

Chart 5-4: Hourly Infiltration Heat Load at Southwest Wall versus Straight cracks CFD Output for the wall

Chart 5-5: Cumulative Monthly Infiltration Heat Load at Southwest Wall versus Angled (zig-zag) cracks CFD Output for the Wall. 180 
Chart 5-6: Cumulative Monthly Infiltration Heat Load at Southwest Wall versus Mixed cracks CFD Output for the Wall

Chart 5-7: Cumulative Monthly Infiltration Heat Load at Southwest Wall versus Straight cracks CFD Output for the Wall 181

Chart 5-8: Hourly Infiltration Heat Load at Northwest Wall by Various DOE-2/eQUEST Methods. 185

Chart 5-9: Hourly Infiltration Heat Load at Northwest Wall versus Angled (zig-zag) cracks CFD Output for the Wall 185

Chart 5-10: Hourly Infiltration Heat Load at Northwest Wall versus Mixed cracks CFD Output for the Wall 186

Chart 5-11: Hourly Infiltration Heat Load at Northwest Wall versus Straight cracks CFD Output for the Wall 186

Chart 5-12: Cumulative Monthly Infiltration Heat Load at Northwest Wall versus Angled (zig-zag) cracks CFD Output for the Wall. 188

Chart 5-13: Cumulative Monthly Infiltration Heat Load at Northwest Wall versus Mixed cracks CFD Output for the Wall 189

Chart 5-14: Cumulative Monthly Infiltration Heat Load at Northwest Wall versus Straight cracks CFD Output for the Wall 189

Chart 5-15: Comparison of Cumulative Monthly Infiltration Heat Load for the Southwest Wall 192

Chart 5-16: Comparison of Cumulative Monthly Infiltration Heat Load for the Northwest Wall. 192

Chart 5-17: Infiltrating Air Temperature Rise Across the Building Envelope 199

Chart 5-18: Infiltrating Air Velocity Drop Across the Building Envelope 200 


\section{NOMENCLATURE}

\begin{tabular}{|c|c|}
\hline A & Area (Area of opening) \\
\hline$A_{e}$ & Approximate leakage area \\
\hline $\mathrm{ACH}$ & Air changes per hour \\
\hline ATMEXT & Atmospheric extinction coefficient \\
\hline$\alpha$ & Non-dimensional airflow rate \\
\hline $1 / \alpha$ & Surface roughness coefficient \\
\hline$\beta$ & Surface tilt \\
\hline BSUN & Diffuse solar radiation \\
\hline C (solid) & Specific heat of solid material \\
\hline C (air flow) & Flow coefficient \\
\hline $\mathrm{C}_{\mathrm{p}}$ (heat) & Specific heat of air \\
\hline $\mathrm{C}_{\mathrm{p}}$ (wind) & Wind pressure coefficients \\
\hline $\mathrm{C}_{\mathrm{P}}{ }^{\prime}$ & Pressure coefficient corrected for wind direction \\
\hline Classical & Conventional infiltration calculation method \\
\hline$\gamma$ & Porosity of wall \\
\hline$\gamma_{\mathrm{s}}$ & Surface azimuth \\
\hline $\mathrm{E}$ & East node \\
\hline EQTIME & Equation of time \\
\hline$\varepsilon$ & Infiltration Heat Exchange Effectiveness \\
\hline $\mathrm{g}$ & gravitational acceleration constant \\
\hline$g_{0}, g_{1}, g_{2}, g_{3}, p_{1}, p_{2}$ & Air - temperature weighitng factors \\
\hline GUNDOG & Hour angle of sunrise/sunset \\
\hline $\mathrm{H}$ & Zone height \\
\hline $\mathrm{I}$ & Intensity of solar radiation \\
\hline IHR & Hour of the day \\
\hline K & Heat conductance \\
\hline $\mathrm{k}$ & Flow coefficient \\
\hline$\dot{m}$ & Infiltration air flow rate \\
\hline
\end{tabular}




\section{NOMENCLATURE}

\begin{tabular}{|c|c|}
\hline $\mathrm{n}$ & Flow exponent \\
\hline$\rho$ & Density of solid material \\
\hline$\rho_{\text {air }}$ & Density of air \\
\hline$\rho_{\text {in }}$ & Density of inside air \\
\hline$\rho_{\text {out }}$ & Density of outside air \\
\hline $\mathrm{P}$ & Center node \\
\hline $\mathrm{P}_{\mathrm{o} \text { in }}$ & Internal pressure at base of wall \\
\hline $\mathrm{P}_{\mathrm{o} \text { out }}$ & Outside pressure at base of wall \\
\hline$P_{w}$ & Wind Pressure \\
\hline$P_{w}+$ Shielding & Wind pressure including shielding effect \\
\hline$q_{i}$ & hourly heat gain/loss \\
\hline$q_{d}$ & Combined conduction and infiltration heat flux \\
\hline $\mathrm{Q}_{\mathrm{i}}$ & hourly cooling/heating load \\
\hline$Q_{\text {inf }}$ & Air infiltration energy load \\
\hline$\delta Q$ & Heat storage rate in control volume \\
\hline $\mathrm{R}$ & Multiplication/Reduction factor \\
\hline R (ideal gas law) & Specific gas constant \\
\hline $\operatorname{RAYCOS}(1)$ & \\
\hline $\operatorname{RAYCOS}(2)$ & Solar direction angles \\
\hline $\operatorname{RAYCOS}(3) J$ & \\
\hline RDN & Direct solar radiation \\
\hline $\mathrm{RP}$ & Receiving polygon \\
\hline $\mathrm{SC}$ & Shielding coefficient \\
\hline SKYDFF & Sky diffuse factor \\
\hline SOLCON & Solar constant \\
\hline SP & Shading polygon \\
\hline $\mathrm{T}$ & Temperature \\
\hline$\delta \mathrm{T}$ & Temperature difference \\
\hline
\end{tabular}




\section{NOMENCLATURE}

$\begin{array}{ll}\mathrm{T}_{\mathrm{i}} & \text { Inside(indoor) room temperature } \\ \mathrm{T}_{\mathrm{o}} & \text { Outside (ambient) air Temperature } \\ \mathrm{T}_{\mathrm{R}} & \text { The reference temperature } \\ T_{s a} & \text { Sol-air temperature } \\ \tau & \text { Time } \\ \Delta \tau & \text { Time step } \\ U A_{0} & \text { Heat loss factor due to conduction only } \\ U A & \text { Actual heat loss factor with airflow included } \\ V & \text { Wind speed } \\ \mathrm{V}_{\mathrm{Zref}} & \text { Measured wind speed at reference height } \\ v_{0}, v_{1}, v_{2}, w_{1}, w_{2} & \text { Heat - gain weighitng factors } \\ \mathrm{W} & \text { West node } \\ \mathrm{y}_{\mathrm{np}} & \text { Height of neutral pressure level } \\ \mathrm{y} & \text { Height above bottom of zone } \\ \Psi & \text { Wind direction from weather file } \\ \mathrm{Z} & \text { Elevation } \\ \mathrm{Z}_{\mathrm{g}} & \text { Gradient height of terrain } \\ \mathrm{Z}_{\mathrm{ref}} & \text { Elevation of wind speed measuring point }\end{array}$




\section{Chapter 1}

\section{Introduction}

A wealth of Building Energy Simulation software and tools is available. The United States Department of Energy Building Technologies Program lists under its "Building Energy Software Tools Directory" three hundred and eighty nine building software and tools from 28 different countries. These software and tools range between databases, component and system analysis tools, spreadsheets, and whole-building energy performance simulation programs (Building Technologies Program, 2010).

Traditionally, the two primary reasons for performing building thermal performance calculations are to (1) size and select the required mechanical equipment, or to (2) obtain a prediction of the building's annual energy consumption and costs. Some programs can handle either of these tasks while others can handle both (Paradis, 2010). Sizing programs are mainly designed to perform hourly calculations of peak heating and cooling loads. Many of these programs are based on algorithms established by ASHRAE. Energy cost programs, on the other hand, are principally set up to predict building annual energy consumption in BTUs, dollars, or pollution/pollution avoidance (Paradis, 2010).

DOE-2 is one of the most widely well-known full building energy simulation

models. It also serves, either fully or partially, as the simulation engine of several other renowned software such as eQUEST, PowerDOE, Energy Plus, Energy Pro and others. DOE-2 was developed by James J. Hirsch \& Associates (JJH) in collaboration with Lawrence Berkley National Laboratory (LBNL). (www.DOE2.com, 2010).

"DOE-2 is an hourly whole building Energy Analysis program calculating Energy Performance and life cycle cost of operation" (Building Technology program, 2010). 
Using a description of a building layout, construction, operating schedules, conditioning system along with user-provided utility rates, and weather data, DOE-2 is capable of performing hourly energy simulations of a building and providing an estimation of the various building utility bills (www.DOE2.com, 2010). Other features include its use in rebate programs, comparison and implementation of energy efficiency standards and compliance certification (Building Technology Program, 2010).

A subsequent development to DOE-2 is eQuest. DOE-2 is eQUEST's "simulation engine”. eQUEST provides the sophisticated building energy simulation of DOE-2 in an easy-to-use Graphical User Interface (GUI) and wizards medium. eQUEST can be simply defined as (www.doe2.com/equest, 2010):

\section{eQUEST $=$ DOE-2 + Wizards + Graphics}

DOE-2 \& eQUEST have been both time proven and are well known and widely used. DOE-2 is well recognized as an industry standard. It is used by more than 800 major user organizations within the United States and 200 organizations internationally; where each organization includes of up to 20 users or more. Similarly, eQUEST is one of the most widespread building energy simulation programs. eQUEST registers more than 10,000 full program downloads annually (Building Technologies Program, DOE-2 \& Building Technologies Program eQUEST , 2010).

The simulation capabilities of DOE-2 and eQUEST and their widespread use make them of high significance and impact. This also highlights the essentiality of accuracy in their building energy simulation. Both eQUEST and its simulation engine DOE-2 have been proven in many aspects by experimentation and are based on ASHRAE in many algorithms. Examples include Kerrisk et al. (1980), Meldem et al. 
(1998), Loutzenhiser and Maxwell (2006), Hong et al. (2009), and others. However, some major energy demand components are treated by the software with less complexity and are accounted for using overly simplified approaches and algorithms. It is therefore essential that such shortcomings be improved in order to provide a more accurate building energy simulation. With the prevalent use of these two software packages, any improvement in their calculation model of a major energy load would be of high importance and impact. Therefore, all building energy simulation model improvements developed in this work will be applied using DOE-2 \& eQUEST as the demonstration software. However, these improvements should be easily applicable to any alternate building energy simulation software.

Any work to be done shall focus on DOE-2. Since DOE-2 is the simulation engine of eQUEST (also of EnergyPro, PowerDOE, EnergyPlus - in part- and others). Then, any developed improvements to DOE-2 shall be consequentially incorporated into eQUEST.

Improvements to DOE-2 can be of different levels and from many aspects. One aspect could be the improvement of an existing DOE-2 algorithm to correct a built-in flawed. For example, in the Design Day weather feature, users can define their own weather. This would create an hourly weather that is used in the building energy simulation and in the HVAC sizing process. The algorithm, however, doesn't revise the user-inputted weather which could be defining indoor humidity levels exceeding $100 \%$ humidity (indoor rain!). Another improvement approach could be to add to an existing DOE-2 subprogram. Therefore, allowing it to account for more heating/cooling load sources. For instance, the software accounts for shading of a building by adjacent 
structures and bodies. Yet, it overlooks the solar radiation reflected onto the building under study from surrounding surfaces. Especially important are surrounding surfaces with a high Surface Reflectance Index (SRI), such as surrounding buildings with white painted (light colored) or mirror glass facades. Such veneers could reflect a considerable portion of the solar radiation incident on them onto the building being simulated. A third DOE-2 improvement approach could be to add or create an entirely new feature into the software. For example, developing green roofs as a material with different variations and properties (R-value, Insulation...etc). This will make green roofs available as a feature for use in the Energy Simulation of Green Buildings.

Infiltration is an uncontrolled process through which outside air leaks into a conditioned space in a building (Brownell, 2002). Air infiltration affects both indoor air quality and building energy consumption. It significantly contributes to the overall heating and cooling loads in a building. The magnitude of the impact of infiltration on the overall heating/cooling load depends on several factors. These include environmental conditions, building design and operation and construction quality (Buchanan \& Sherman, 2000). A $40 \%$ of the heating/cooling cost in homes is attributed to infiltration as was shown by field measurement of residential buildings (Caffey, 1979). Estimates by the National Institute of Standards \& Technology (NIST) attributed, based on a study of U.S. office buildings, $15 \%$ of the heating loads in office buildings to air infiltration (NIST 1996). Other studies estimated air infiltration to account for up to $25 \%$ to $50 \%$ of space heating demands for both commercial and domestic buildings (Nevrala \& Etheridge, 1977; Kirkwood, 1977). Similarly, Persily (1982) concluded that infiltration 
accounts for one-third of the heating and cooling requirements of a building. A comparable conclusion was also affirmed by Sherman \& Matson (1993) who studied the Ventilation-Energy liabilities in U.S. dwellings. They inferred that a large fraction of the space conditioning load in U.S. residential buildings is due to infiltration.

The prediction and measurement of infiltration rates for buildings has been the subject of extensive work and research. An example is the Feustel \& Kendon (1988) comprehensive review of the multitude of available methods. However, determining the energy consumption due to this infiltration has been the subject of limited research (Bhattacharyya \& Claridge, 1992). The energy impact of air infiltration has been classically evaluated as a product of the infiltrating air mass flow rate, the air specific heat capacity and the inside-outside temperature gradient. The classical expression for heat loss due to infiltration is given by equation 1-1.

$$
Q_{\text {inf }}=\dot{m} C_{p}\left(T_{i}-T_{o}\right)
$$

Where:

- $\quad Q_{\text {inf }}=$ Air infiltration energy load (W)

- $\quad \dot{m}=$ Air infiltration mass flow rate $(\mathrm{kg} / \mathrm{s})$

- $\quad \mathrm{T}_{\mathrm{i}}=$ Inside(indoor) room temperature $\left({ }^{\circ} \mathrm{C}\right)$

- $\quad \mathrm{T}_{\mathrm{o}}=$ Outside (ambient) air Temperature $\left({ }^{\circ} \mathrm{C}\right)$

- $\quad \mathrm{C}_{\mathrm{p}}=$ Specific heat of air $\left(\mathrm{J} / \mathrm{kg}^{\circ} \mathrm{C}\right)$

The classical method and current design methods assume that solar radiation, conduction and air infiltration are independent and behave independently. Those methods overlook the interaction between these three phenomena. However, such an assumption is 
unrealistic and embracing it can result in extensive errors in the evaluation of design loads and annual energy consumption by a building (Liu \& Claridge, 1992).

Cold air infiltrating into a room or a building through porous material can attain a temperature closer to the room temperature than the outside air temperature (Claridge et. al, 1995). Especially through brick, concrete masonry, concrete and other material commonly used in building construction. Heat exchange occurs between the infiltrating air and the building envelope allowing the air to absorb/release energy and become closer to the indoor space temperature; a phenomenon known as "Heat Recovery". While, as shown in equation (1-1), the general assumption is that the amount of energy required for heating/cooling infiltrating air is the same as that required for heating/cooling the outside air to indoor conditions (Bhattacharyya \& Claridge, 1992). It has been shown by Anderlind (1985) that the infiltration energy load can attain a maximum value of equation (1-1); however it is generally smaller due to heat exchange occurring in the walls between the walls and the infiltrating air. This has also been confirmed experimentally by Claridge, Liu and Bhattacharyya (1990, 1992, 1995, 1996 and 1999), Anderlind (1985) and Guo \& Liu (1985).

Anderlind (1985) introduced a reduction factor to the classical equation (equation 1-1) to account for the heat recovery. Thus, modifying the classical equation as shown in equation 1-2 below:

$$
Q_{\text {inf }}=R \dot{m} C_{p}\left(T_{i}-T_{o}\right)
$$

Where:

- $\mathrm{R}=\mathrm{a}$ multiplier ranging between 0 and 1 , depending on the structure and construction of the walls 
Claridge and Bhattacharyya (1992) put forward the Infiltration Heat Exchange Effectiveness (IHEE). Where, IHEE $(\varepsilon)$ represents the fraction of energy consumption that was recovered during the Heat Recovery process. The expression for $\varepsilon$ is given in equation 1-3:

$$
\varepsilon=1-\frac{Q_{\text {inf }}}{\dot{m} C_{p}\left(T_{i}-T_{o}\right)}
$$

Where:

- $\quad \varepsilon=$ Infiltration Heat Exchange Effectiveness

- $\quad Q_{\text {inf }}=$ Air infiltration energy load $(\mathrm{W})$

- $\quad \dot{m}=$ Air infiltration mass flow rate $(\mathrm{kg} / \mathrm{s})$

- $\quad \mathrm{T}_{\mathrm{i}}=$ Inside(indoor) room temperature $\left({ }^{\circ} \mathrm{C}\right)$

- $\quad \mathrm{T}_{\mathrm{o}}=$ Outside (ambient) air Temperature $\left({ }^{\circ} \mathrm{C}\right)$

Several building energy simulation software account for the impact of infiltration by utilizing a variety of models. However most of the models utilized are either overly simplified or at best suffer from several deficiencies and fail to capture the full physics of the phenomenon. As a sample software, DOE-2 in its building energy simulation accounts for infiltration. In the DOE-2 Engineers Manual, the major impact of infiltration on the building energy load is well acknowledged and infiltration is defined as "One of the largest components contributing to heating loads" (DOE-2 Engineers Manual, 1982). However, in defining the models used to simulate the energy impact of infiltration it is prominently stated that Infiltration in building Energy Analysis is "Usually treated by 
very simple approximate models" (DOE-2 Engineers Manual, 1982). In modeling infiltration, DOE-2 employs five different models:

- Air Change Method

- Crack Method

- Residential (Achenbach - Coblentz) Method.

- Sherman \& Grimsrud

- ASHRAE Enhanced

These models are (respectively) overly simplified, purely empirical and based on curve fitting, or deficient in considering the various factors contributing to air infiltration.

Like the majority of building energy simulation software available, DOE-2 infiltration models overlook a variety of aspects that significantly contribute to the infiltration energy load. This inadequacy becomes more critical when considering the significant contributions of infiltration to the heating/cooling load in buildings, as discussed earlier. Among the aspects unaccounted for by the DOE-2 infiltration models are:

- Infiltration heat recovery

- Neglecting the resistance to intra-room airflow

- Infiltration through doors : manual, automatic, revolving and others

- Infiltration through windows

- Infiltration through doors and windows sealings

- Infiltration due to a fireplace

- Others 


\section{Main Objective}

The main objective of this research is to build a comprehensive infiltration energy load model that integrates the interaction between solar radiations, conduction and infiltration into building energy load calculations along with a better evaluation of the infiltration airflow rate; and to apply this model onto prominent building energy simulation software. The model developed in this research will be referred to throughout this research as the Enhanced Model.

\section{Specific Objectives}

The main objective of this work are to improve the accuracy of building energy simulations by incorporating into their calculations the impact of the interaction between solar radiation, conduction and infiltration in contrast with current methods that consider these three phenomena to act independently. Also, to provide a better evaluation of the infiltration airflow rate, for use in the infiltration load calculations, based on local conditions, terrain and building characteristics. Therefore this study performs a comprehensive review of infiltration and how it is accounted for in current models and in prominent building energy simulation software. It also determines the latest research on studying the interaction among these three phenomena and to decide on a model to build upon, further develop and later apply onto prominent building energy simulation software. Next it develops a dynamic model for evaluating the infiltration airflow rate (to be used in the infiltration energy load model) that accounts for wind speed, wind direction, topography, terrain, building characteristics, and others. The third objective is to build a comprehensive infiltration energy load model that integrates (1) heat recovery, (2) interaction between conduction, solar radiation and infiltration and (3) incorporates 
the developed airflow rate model. The fourth objective is to verify the relative accuracy of the developed Enhanced Model versus a hygrothermal multiphysics computational fluid dynamics (CFD) model. This is done by comparing the simulation output of the Enhanced Model for a demonstrative building to the results of a finite elements CFD analysis of the same building. The final objective is to demonstrate the improvement in infiltration load calculation relative accuracy (versus complex CFD analysis) by comparing the obtained Enhanced Model's simulation output to the regular DOE-2 output for the same building. Flowchart 1-1 highlights the major steps followed to achieve the stated objectives.

\section{Justification}

The significance of the work lies in building a comprehensive model that incorporates into building energy load calculations, the interaction between solar radiation, infiltration and conduction, while considering factors such as building height, topography, terrain roughness, wind speed and direction, and others. The developed Enhanced Model is a tool that helps designers to quickly, accurately and efficiently simulate infiltration heat loads. The the current dilemma of accuracy versus efficiency is overcome by reducing by six orders the simulation time necessary for obtaining an accurate simulation while compromising relative accuracy by $2 \%$ only. The classical method for evaluating the infiltration energy loads which considers infiltration to act independently from conduction in the building envelope and other phenomena has been proven to result in significant errors in building energy loads estimation. Building energy simulation software are of wide spread use and high impact, yet most still deploy the classical infiltration load calculation method or other overly simplified methods. 
Therefore, it would be of large significance and impact to apply the obtained Enhanced Model onto building energy simulation software, which could significantly improve their simulation accuracy, most importantly to an industry standard and widespread software such as DOE-2. Aside from DOE-2 and the software that it is a simulation engine for, the built model shall be easy to incorporate into other building energy simulation software. The resulting improvement in building energy simulation accuracy will allow several benefits including:

- More accurate HVAC (Heating Ventilation and Air Conditioning) equipment sizing. Oversized equipment will not efficiently perform and result in higher operating costs. Also HVAC over sizing leads to increased initial costs, larger than required meters, low system distribution pressures during peak demand, and others (Regester and Reinauer, 1981)

- Improved energy audits and more accurate energy utility estimation costs. In sustainable building design, during the parametric comparison of various design alternatives, this allows a more confident selection of the most energy efficient building design.

- Controllable ventilation rates that fallout onto a healthier building. Since the infiltration energy load can be more accurately calculated, controlled natural ventilation through infiltration can be Permitted (Brownell, 2002).

- Allowing an optimal distribution of insulation, due to enhanced knowledge of conduction losses. 
- Making available the application of dynamic insulation: Replacing ventilation systems with "breathing walls" that provide fresh yet thermally condition air (through heat recovery) (Brownell, 2002).

The various outcomes of the Enhanced Model amount to a better evaluation of the energy requirements of a building. This, results in a building with less energy demand, lower lifecycle costs, and increased occupant comfort. 


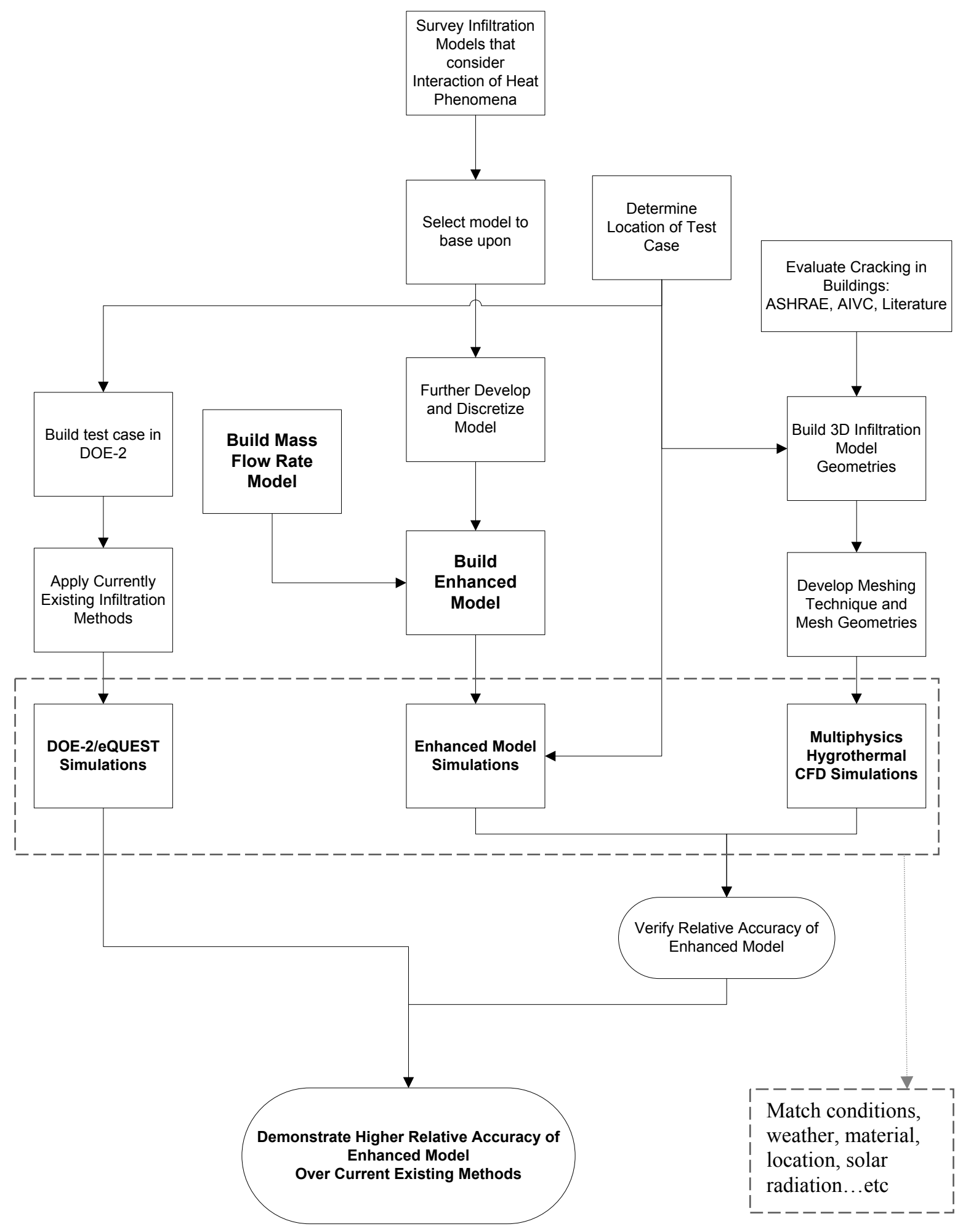

Flowchart 1-1: Major Steps Followed to Achieve the Stated Objectives 


\section{Chapter 2}

\section{Background}

The Energy Information Agency reports that 99.402 Quadrillion $\left(10^{15}\right)$ BTU's of energy were consumed in the United States in 2008. This includes energy used in residential, commercial, industrial and transportation applications. All at a total cost of \$1,396.69 Billion (U.S. Energy Information Administration, 2010). Buildings consume $36 \%$ of all the energy produced (Brownell, 2002); the equivalent of 35.784 quadrillion BTU's. Of all the energy consumed annually by buildings, $58 \%$ is utilized for heating and air conditioning (Brownell, 2002). This represents 20.75 Quadrillion BTU's a year. That, by proportion, stands for $\$ 291.56$ Billion spent annually on heating and cooling of buildings. As a result, even minor factors influencing the heating/cooling of buildings become of significant importance, much less factors such as infiltration that can contribute to more than a third of the heating/cooling load of a building.

The large and constant need of energy for heating and cooling in buildings results from undesired thermal losses in these structures. The primary forms of thermal loss are: (1) conduction losses through the building envelope, (2) heat loss due to ventilation, and (3) unwanted heat loss due to air leakages known as infiltration. With infiltration representing up to $40 \%$ of the heating/cooling load cost (Caffey, 1979) and the magnitude and cost of energy consumption discussed earlier; the importance of accurate simulation and modeling of infiltration energy loads becomes evident and highly necessary. 
This literature review includes a discussion of DOE-2 and it various components. Since a common basic structure is shared by DOE-2 and several other hourly building energy simulation software, the following discussion can be made applicable to understanding the layout and inner workings of similar energy simulation software. An overview of the component programs LOADS, SYSTEMS, PLANTS and ECONOMICS common to several hourly building energy simulation software and their interaction is presented. Included also is a discussion of weighting factors and response factors and their use in DOE-2. An explanation of DOE-2 basic principles and the underlying philosophy of load calculations is also presented. The progress of a DOE-2 Energy simulation is illustrated through especially developed flow charts. Similarly, the review includes a general overview of eQUEST, its component wizards and principles. The literature review also contains a discussion of the presentation of Infiltration in ASHRAE according to the ASHRAE 2009 and 2007 Handbooks. The final section of this literature review is dedicated to a comprehensive review of infiltration. The various methods of evaluating infiltration energy loads and their classification as well as the two major categories of air leakage and infiltration, concentrated and diffuse are discussed. Presented is a breakdown and a discussion of each, including the role of heat recovery and all relevant research done. 


\section{Building Energy Simulation Programs}

A diverse body of building energy analysis programs is available. This includes a wide array of spreadsheets, databases, component and system analysis tools, and whole building energy simulation programs. The U.S. Department of Energy Building Technologies program directory lists a set of 389 of these tools and software with varying capabilities and origins (Building Technology Program, 2010). Two prominent entries on this list are DOE-2 and eQUEST. Both software are full hourly Building Energy Simulation software, with DOE-2 representing the simulation engine of eQUEST. They are both widely recognized, time proven, widely used and considered to be an "Industry Standard" (Building Technologies Program, 2010). 800 large organizations in the United States and 200 other international organizations use DOE-2 for building energy simulation. Similarly, eQUEST averages more than 10,000 full program downloads annually (Building Technologies Program, 2010). The widespread use of these two software makes them of high impact and emphasizes the importance of their simulation accuracy. Consequently, improvements made to DOE-2 (and accordingly eQUEST) would reflect in considerable energy and cost savings.

The majority of the following discussions will involve DOE-2 since it concurrently represents the simulation engine of eQUEST. Included in the literature review is an explanation of the basics of DOE-2. This entails and overview of the software's basic equation, essential and core operations, main programs and subprograms, and the interaction between its various components. 


\section{Origins of Energy Simulation Programs: Historic Overview}

Early on efforts for the use of computers in building mechanical/electrical service design were first acknowledged by the industry in 1965 (Lau \& Ayres, 1979). Automated Procedures for Engineering Consultants Inc. (APEC) was created by a group of mechanical engineering consultants. They developed their first program The "APEC Heating and Cooling Peak Load Calculation (HCC) program (HCC-Heating/Cooling Load Calculation program, 1967). The program was used in the design of heating, ventilating and air conditioning systems in buildings. The work on the program was concluded in 1967. It was designed to calculate peak heating and cooling loads and air quantities. The calculations were performed based on input summer and winter design days climatic data. This primal program alleviated design engineers from tedious hand calculations as well as provided essential data for the selection of suitable heating and cooling equipment and the design of air distribution systems (Lau and Ayres, 1979)

The American Society of Heating, Refrigerating and Air Conditioning engineers (ASHRAE) formed in 1976 the ASHRAE Task Group on Energy Requirements (TGER). As a result, building heat transfer sub-routines, algorithms, and HVAC system and component simulation procedure for computerized energy calculations where established (Lau and Ayres, 1979). The availability of such procedures permitted the development of

the first generation of Loads/Energy programs. This Includes the National Bureau of Standards (Kusuda, 1974) and the U.S. Post Office (Lokmanhekin, 1971) who developed public domain energy software. Simultaneously energy calculation computer software developed by the private sector thrived (Lau and Ayres, 1979). 
The major systems involved in building energy analysis are particularly thermal loads calculation, system simulation and central plant simulation (Lau and Ayres, 1979). Building Energy Analysis programs are commonly structured in such composition and order with sub-programs performing each of these sub-steps. A number of building energy programs, such as DOE-2, expands further to include economic analysis. Accordingly, building energy simulation programs are usually composed of four fundamental analysis programs: LOADS, SYSTEMS, PLANT, and ECONOMICS (shortly known as LSPE), as shown in Flowchart 2-1. Various software simply differ in the degree of mathematical complexity of their chosen models and the extent they match real world conditions (Lau and Ayres, 1979).

\section{DOE-2}

The DOE-2 Engineers Manual (1982) illustrates the philosophy of the DOE-2 computer program. It describes and explains "What happens to the input data". The following section describes the inner operations of DOE- 2 and is mostly based on the latest DOE-2 engineers manual available; DOE-2 ENGINEERS Manual, Version 2.1 A, November 1982.

\section{DOE-2 Programs}

A building's energy consumption is governed by its shape, thermal properties of its constituting materials, size, location \& orientation, and the positions of walls, floors, roofs, windows and doors. Also contributing are the transient affects of shading, occupancy patterns, lighting schedules, equipment operation, ambient conditions, and temperature and humidity conditions. Finally, is the role of the building HVAC systems and their efficiencies. A Building Description Language (BDL) was therefore written for 
use in DOE-2. This language helps in describing a building and its various properties that contribute to the energy consumption calculations. Following, is a general description of the various processor and program components of DOE-2 and their role.

\section{BDL Processor}

The BDL Processor successively checks every BDL instruction. It verifies each instruction's form, syntax and content. Additionally, the BDL Processor checks input values and verifies that they fall within the input range. The BDL Processor also retrieves from various libraries user specified data (e.g. Materials Library). Also, it calculates the Response Factors. These factors characterize the transient heat flow through exterior walls and roofs and are used by the LOADS program. Moreover, it calculates the custom weighting factors, if required by the user, which account for thermal lag in heating and cooling. Finally, the BDL processor assembles and prepares the LOADS, SYSTEM, PLANT and ECONOMICS (LSPE) simulators input files.

\section{LOADS Program}

The LOADS Program uses an array of algorithms to calculate hourly heating and cooling loads. LOADS performs a separate calculation for heat gains and losses through walls, roofs, floors, windows and doors. It utilizes the response factors generated by the BDL processor to calculate heat transfer through the building skin by conduction and radiation. The impacts of thermal mass, insulation placement, sun angle, cloud cover, building location and orientation are all considered in the weighting factors generated by the BDL processor and used in LOADS. In LOADS, each generated weighting factors set is placed in a designated file to be consequently used by LOADS and SYSTEMS programs. Loads due to infiltration are also calculated based on the difference between 
the inside and outside conditions using the "Crack Method" or "Air Change Method". Heat gains due to lighting, equipment and occupants are also calculated in LOADS based on user-assigned schedules and occupancy hours.

It is essential to note that all LOADS computations are performed based on a fixed temperature for each space. The LOADS output is then modified in the SYSTEMS program to produce the factual thermal loads based on variable hourly internal zone temperatures.

\section{SYSTEMS Program}

The SYSTEMS program includes a set of algorithms for simulating the performance of secondary HVAC systems. These systems control building zones temperatures and humidity. An array of preprogrammed space conditioning systems is available for the user to pick from. To use the SYSTEMS program, the user has to select one of these preprogrammed systems and provide the necessary input data.

The LOADS output along with the user defined airflow rate, thermostat settings, equipment operation schedules and other user-defined system characteristics are used by SYSTEMS to calculate hour-by-hour energy requirements of the secondary HVAC system. Finally, SYSTEMS program recalculates all the thermal loads previously calculated in the LOADS program (based on a fixed space temperature), adjusting them based on variable zone temperature conditions. 


\section{PLANT Program}

Boilers, absorption chillers, compression chillers, cooling towers, hot water storage tanks, solar heaters and other Plant components have their operation modeled in the PLANT Program. This program contains all the equations essential for calculating the performance of various primary energy equipment. Hourly outputs of LOADS and SYSTEMS Programs are also used by PLANT Program to calculate the electrical and thermal energy consumption of the building. Finally, the life cycle cost of Plant equipments is calculated by PLANT using subroutines contained in the program.

\section{ECONOMIC Program}

The ECONOMIC Program utilizes user-input utility rates, interest rates, building and equipment costs and others, along with the output of previous programs. It is used to calculate the life-cycle costs of a building. ECONOMICS Program can also perform economic comparisons of possible project alternatives.

\section{REPORT Program}

Data and information from the output files of all the LSPE programs are collected by REPORT. The output data are then arranged by REPORT into lists, tables and others. Various types (by complexity and detail level) of reports are provided by REPORT, including reports with extensive details and hourly values 


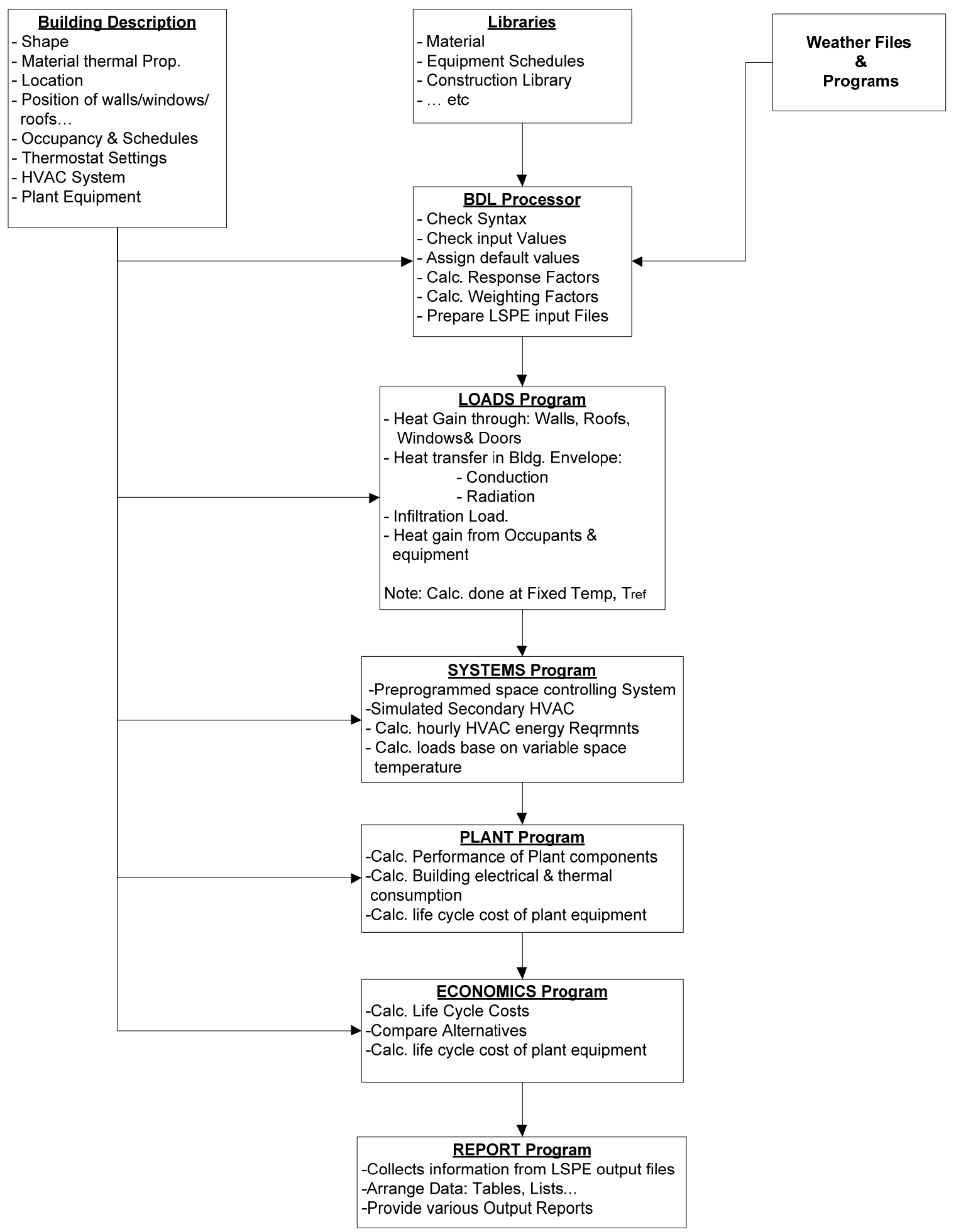

Flowchart 2-1: Summary of DOE-2 Program Components and Program Tasks 


\section{How a DOE-2 Simulation Works}

The fundamental concept at the core of a DOE-2 simulation it that input brought together with a Transfer Function results in the output. The Input represents heat gain or loss, the output is the cooling/heating load and the Transfer Function is the weighting factors. This concept can be represented by the relationships in equations 2-1 and 2-2.

$$
\begin{aligned}
\text { Output } & =(\text { Transfer Function }) x \text { Input } \\
\therefore \quad \text { Heating } / \text { Cooling Load } & =(\text { Weighting Factors }) x \text { Heat Gain } / \text { Loss } \quad(2-2)
\end{aligned}
$$

Where: The use of weighting factors represents a compromise between the use of complex methods, such as full energy balance, and overly simplified methods, such as steady state.

The core thermal simulation process of DOE- 2 can be summed up in two major phases. The first phase happens in the LOADS program and is heavily dependent on processes performed by the BDL Processor (i.e. weighting factors calculation, response factors calculation and others). The second major phase of simulation occurs in the SYSTEMS Program and produces the actual space air temperatures, corresponding thermal loads, and others.

In the calculations of Phase I, LOADS assumes a fixed reference air temperature for each space, $\mathrm{T}_{\text {ref. }}$ Then, using a list of available algorithms and user-defined buildingspecific data, LOADS calculates instantaneous heat gains/losses due to solar radiation, lighting, people and occupants, equipment, conduction in walls and so on. LOADS then 
deploys the relationship represented in equation 2-1 and the various sets of weighting factors calculated by the BDL Processor to calculate the resulting space cooling/heating loads resulting from each of the heat gains previously mentioned. This represents the energy needed to maintain the temperature of the space fixed at $T_{\text {ref }}$ in response to the recorded heat gain/loss. Phase II is then subsequently performed in the SYSTEMS Program. In this phase, cooling/heating loads from Phase I are combined with HVAC system data and air temperature weighting factors. As a result, the actual space air temperatures, total heat extraction, and thermal loads (based on variable space temperature) are determined. The output of Phase II is then used by subsequent components of the software. For example, it is used by ECONOMICS Program to calculate various utility costs and lifecycle costs.

\section{Weighting Factors}

Weighting Factors are utilized by DOE-2 in calculating thermal loads and room air temperatures (York and Tucker, 1980). They represent a z-transfer function relating the heat gained to the resulting cooling load. The weighting factors method is one of several methods that are commonly used in building energy simulation. It was first introduced by Mitalas and Stephenson (Stephanson \& Mitalas, 1967; Mitalas and Stephenson, 1967). This method represents a compromise between overly simplified methods, such as steady-state computations that disregard thermal mass storage; and overly complicated methods like energy balance calculations. As a result, the weighting factor method is - according to DOE-2 ENGINEERS Manual - an efficient, simple, 
flexible and fast method that at the same time considers all important parameters affecting building energy analysis.

The use of weighting factors in DOE-2 entails 2 general assumptions. First, since heat gains due to various sources are calculated individually and then summed up (by superposition) to obtain the total load; all modeled processes are assumed to be adequately represented by linear differential equations. As a result, linear approximations of nonlinear processes, such as natural convection and radiation, must be made. Second, it is assumed that all system properties influencing the weighting factors are constant. Namely, these system properties are not functions of time or temperature. Therefore, any varying system properties are represented by an averaged value. These Two major assumptions signify some limitations arising from the use of weighting factors and the weighting factor method.

DOE-2 operates using either precalculated weighting factors or custom weighting factors. Precalculated weighting factors, as the name implies, have been precalculated for typical building rooms. They are stored in DOE-2 and can be selected for use. These factors are largely based on ASHRAE original weighting factors for rooms with Light, Medium and Heavy construction; characterized by 30, 70, and $130 \mathrm{lb} / \mathrm{ft}^{2}$ construction weights respectively (Lokmanhekim, 1975; ASHRAE Handbook and Product Directory, 1977). For floor weights other than those stated, interpolation and extrapolation is used to obtain the required precalculated weighting factors. The use of these precalculated weighting factors entail a set of assumptions in addition to the two general assumptions of linearity and constant system properties (associated with the general use of the weighting factors method). Foremost, the user is accepting the "Typical Construction" of 
the "Standard Rooms" that were used in the precalculated weighting factors calculation. Among others, this includes: Wall construction and thermal properties, window area and orientation, furniture quantity and properties, incident solar radiation properties and distribution, walls radiative properties (absorptivity, reflectivity and others), and interior film coefficients. Therefore, precalculated weighting factors are approximate descriptions of building rooms and their use is rarely encouraged.

Custom weighting factors are especially calculated for every room by DOE-2 based on the room's actual description. Custom weighting factors can be of two categories, either Heat-Gain or Air-Temperature weighting factors. A Separate set of custom heat-gain weighting factors is calculated for each source of heat gain. Namely, solar radiation, lighting, task lighting, occupant people and equipment in a room, and heat conduction into a room. Similarly, air-temperature gain weighting factors that relate a specific room's air temperature to the net energy load on the room are calculated. Since custom weighting factors are particularly calculated for each room, they represent a major improvement over precalculated weighting factors. Their use is therefore recommended. Furthermore, the use of custom weighting factors is a must when modeling buildings with heavy construction, indirect gain, passive solar buildings, and in buildings where a significant part of the load is due to solar energy.

Custom weighting factors represent z-transfer functions that relate the hourly cooling/heating load to instantaneous heat gains/losses (heat-gain weighting factors); and a room air temperature to net energy loads on a room (air-temperature weighting factors). 
This relationship can be illustrated using equations 2-3 and 2-5 below for heat-gain and air-temperature weighting factors respectively

\section{Heat-Gain Weighting Factors:}

$$
\begin{gathered}
\frac{Q(z)}{q(z)}=\frac{v_{0}+v_{1} z^{-1}+v_{2} z^{-2}}{1+w_{1} z^{-1}+w_{2} z^{-2}} \\
\therefore Q_{\tau}=v_{0} q_{\tau}+v_{1} q_{\tau-1}+v_{2} q_{\tau-2}-w_{1} Q_{\tau-1}-w_{2} Q_{\tau-2}
\end{gathered}
$$

Where:

- $\quad q_{i}=q_{0}, q_{1}, q_{2} \ldots=$ hourly heat gain (Input)

- $Q_{i}=Q_{1}, Q_{2}, Q_{3} \ldots=$ hourly cooling load (Output)

- $\quad v_{0}, v_{1}, v_{2}, w_{1}, w_{2}$ are Heat - gain weighitng factors (Transfer function)

\section{Air-Temperature Weighting Factors:}

$$
\begin{gathered}
\frac{Q(z)}{t(z)}=\frac{g_{0}+g_{1} z^{-1}+g_{2} z^{-2}+g_{3} z^{-3}}{1+p_{1} z^{-1}+p_{2} z^{-2}} \\
\therefore Q_{\tau}=g_{0} t_{\tau}+g_{1} t_{\tau-1}+g_{2} t_{\tau-2}+g_{3} t_{\tau-3}-p_{1} Q_{\tau-1}-p_{2} Q_{\tau-2}
\end{gathered}
$$

But $Q_{\tau}$ can already be determined from the Heat-Gain weighting factors, equation 2-4, thus use equation 2-6 to determine $t_{\tau}$ : 


$$
\Rightarrow t_{\tau}=\frac{1}{g_{0}}\left[Q_{\tau}+p_{1} Q_{\tau-1}+p_{2} Q_{\tau-2}-g_{1} t_{\tau-1}-g_{2} t_{\tau-2}-g_{3} t_{\tau-3} p_{2} Q_{\tau-2}\right]
$$

Where:

- $g_{0}, g_{1}, g_{2}, g_{3}, p_{1}, p_{2}$ are Air - temperature weighitng factors

$-t_{\tau}=T(z)-T_{R}$

Where:

- $T(z)=z$-transform of the actual air space temperature

- $\mathrm{T}_{\mathrm{R}}=$ The Reference temperature used in LOADS calculations

Custom weighting factors are calculated by applying a unit pulse onto a network representing the heat balance for each room; with the heat balance incorporating response factors that characterize the heat flow through the room walls. The calculation of the weighting factors is performed at the onset of the simulation, using heat balance, by repeating the hourly simulation for the first day 3 times. Once the weighting factors stabilize (due to the repeated calculation) they are used from there on - repeatedly - to calculate hourly cooling (heating) loads from heat gains (losses) instead of performing an hourly full heat balance calculation.

\section{Response Factors}

With the inside temperature (user specified) and outside temperature (from weather file or other) known, the problem becomes finding the heat flux at both the inside and outside surfaces of the wall. DOE-2 considers a once dimensional heat flow across a wall. The equation is then defined by equation 2-9.

$$
\frac{\delta^{2} T}{\delta x^{2}}=\frac{1}{\alpha} \frac{\delta T}{\delta t}
$$


Where:

- $\quad \mathrm{T}=$ Temperature

$-\mathrm{t}=$ time

- $\quad \mathrm{x}=$ distance from the outside surface

$-\alpha=$ diffusivity $=k / C \rho$

- $\quad \mathrm{C}=$ Specific heat

- $\rho=$ Density

The solution to this equation defining the heat flow in the wall is obtained in DOE-2 by superimposing a series of simple cases in order to obtain the general solution. These simple cases represent triangular pulse excitations (Figure 2-1). As a result a series of response factors are obtained.

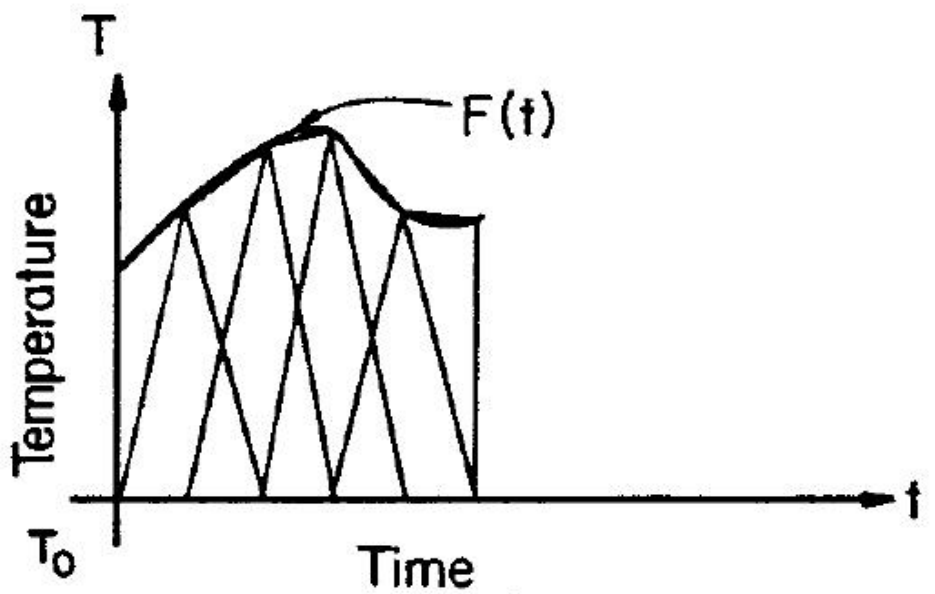

Figure 2-1: Overlapping triangular pulses defining a function (DOE-2 Engineers manual, 1982) 
These response factors represent the heat flux response to temperature excitations. DOE2 deploys three different series of response factors defined in DOE-2 Engineers manual as follows; and with reference to Figure 2-2.

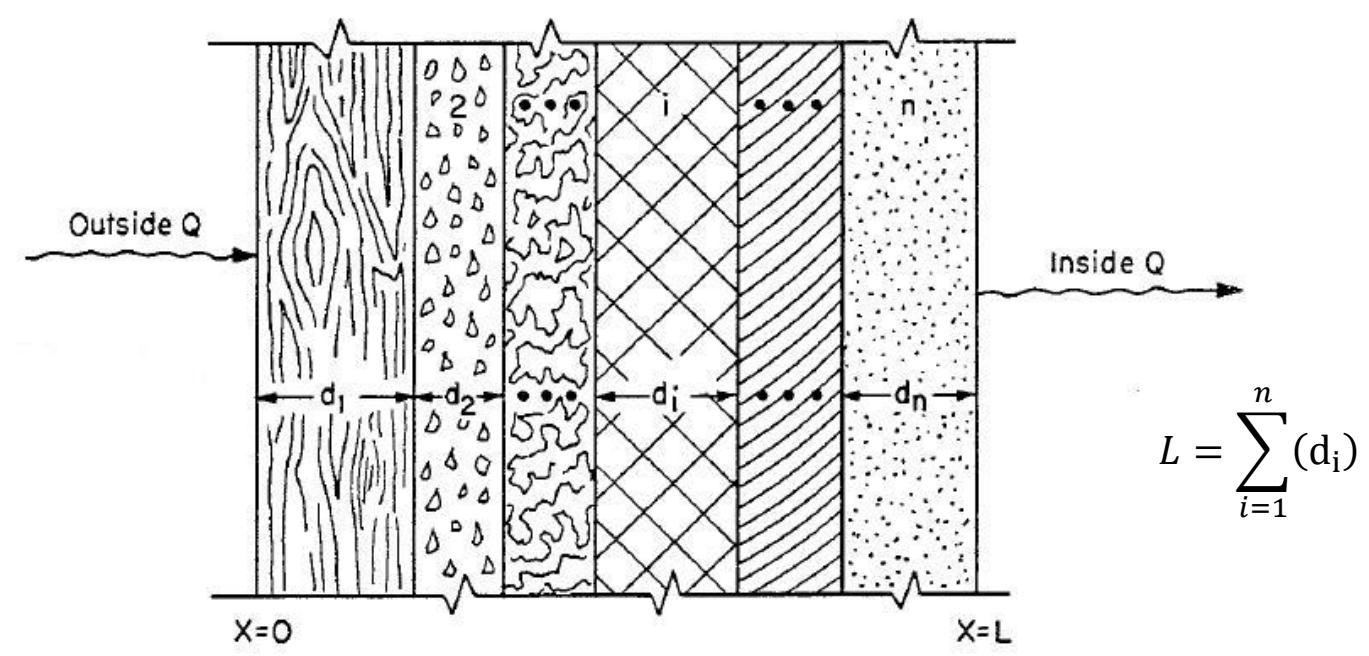

Figure 2-2: Flow of Energy through a multilayer wall (DOE-2 Engineers manual, 1982)

- $\quad \mathbf{X}$ Response Factor Series: Represents the response (heat flow out of the outside surface) at $\mathrm{x}=0$ to a triangular temperature excitation at $\mathrm{x}=0$

- $\quad \mathbf{Z}$ Response Factor Series: Represents the response (heat flow out of the inside surface) at $\mathrm{x}=\mathrm{L}$ to a triangular temperature excitation at $\mathrm{x}=\mathrm{L}$

- Y Response Factor Series: Represents the response (heat flow out of the inside surface) at $\mathrm{x}=\mathrm{L}$ to a triangular temperature excitation at $\mathrm{x}=0$ (outside surface)

\section{Heat Balance}

A heat balance network for each room is established. The heat balance is pulsated in order to determine the custom weighting factors for the room. The weighting factors 
are then used, to calculate hourly cooling/heating loads and space temperatures. The heat balance is constructed on the interior surface of the walls in the room. Four processes are considered in the heat balance of the room: conduction through the walls and furniture, Convection from interior surfaces to the room, radiation between the room's interior surface, and impinging radiation on the interior surfaces. Infiltration is considered in DOE-2 to be a direct communication between the air in the room and the outside; and therefore is not considered by DOE-2 as part of the heat balance equation.

Following, is an overview of the expressions representing each of the heat balance equation components. The equations generally resemble the standard conduction, convection and radiation equation; yet they involve z-transfer functions due to the nature of the data.

\section{Conduction through walls}

Conduction heat flow, $\mathrm{Q}_{\mathrm{Di}}(\mathrm{z})$, to the inside surface is represented by equation 210 below.

$$
Q_{D i}(\mathrm{z})=\mathrm{K}_{\mathrm{Di}}(\mathrm{z}) \mathrm{T}_{\mathrm{i}}(\mathrm{z})-\mathrm{K}_{\mathrm{Di}}^{\prime}(\mathrm{z}) \mathrm{T}_{\mathrm{i}}^{\prime}(\mathrm{z})
$$

Where:

- $\quad Q_{D i}(\mathrm{z})=$ z-transform of conduction heat flow into the interior surface of the wall $\mathrm{i}$

- $\quad \mathrm{T}_{\mathrm{i}}(\mathrm{z})=\mathrm{z}$ - transform of the wall's inside surface temperature

- $\quad \mathrm{T}^{\prime}{ }_{\mathrm{i}}(\mathrm{z})=\mathrm{z}$ - transform of the wall's outside surface temperature

- $\quad \mathrm{K}_{\mathrm{Di}} \& \mathrm{~K}_{\mathrm{Di}}^{\prime}=\mathrm{z}$-transfer function representing the conduction heat flow coefficient 
The thermal resistances $\left(\mathrm{R}_{\mathrm{i}}\right)$ of the wall layers are directly represented in $\mathrm{K}_{\mathrm{Di}}$ \& $\mathrm{K}_{\mathrm{Di}}^{\prime}$ transfer functions in the case of Quick Walls (walls with no thermal storage). Or, they are represented through the, previously discussed, response factors that are constituents of $\mathrm{K}_{\mathrm{Di}} \& \mathrm{~K}_{\mathrm{Di}}^{\prime}$ in the case of delayed walls (walls with thermal storage).

\section{Convection}

The convection component of the heat balance equation representing convective heat transfer between the wall surfaces is expressed by equation 2-11.

$$
Q_{C i}(\mathrm{z})=\mathrm{K}_{\mathrm{Ci}}(\mathrm{z})\left[\mathrm{T}_{\mathrm{a}}(\mathrm{z})-\mathrm{T}_{\mathrm{i}}^{\prime}(\mathrm{z})\right]
$$

Where:

- $Q_{C i}(\mathrm{z})=$ z-transform of convective heat flow from the room air to the wall, i, surface.

- $\quad \mathrm{T}_{\mathrm{a}}(\mathrm{z})=\mathrm{z}$ - transform of the air temperature

- $\quad \mathrm{T}^{\prime}{ }_{\mathrm{i}}(\mathrm{z})=\mathrm{z}$ - transform of the wall, $\mathrm{i}$, surface temperature

- $\quad \mathrm{K}_{\mathrm{ci}}=\mathrm{h}_{\mathrm{ci}} \mathrm{A}_{\mathrm{i}}=\mathrm{z}$-transfer function of the convective heat transfer process of the wall i.

Where:

- $\mathrm{h}_{\mathrm{ci}}=$ convective heat transfer coefficient for wall, $\mathrm{i}$

- $\quad A_{i}=$ Area of wall, $i$

\section{Radiative Heat Exchange Between walls}

The Radiative heat exchange between walls in a room is expressed in equation 2-13.

$$
Q_{\text {Rim }}(\mathrm{z})=\mathrm{K}_{\mathrm{Rim}}(\mathrm{z})\left[\mathrm{T}_{\mathrm{m}}(\mathrm{z})-\mathrm{T}_{\mathrm{i}}(\mathrm{z})\right]
$$


Where:

- $Q_{\text {Rim }}(\mathrm{z})=$ z-transform of the radiative heat flow from surface, i, to another surface, $\mathrm{m}$.

- $\quad \mathrm{T}_{\mathrm{m}}(\mathrm{z}) \& \mathrm{~T}_{\mathrm{i}}(\mathrm{z})=\mathrm{z}$ - transforms of the corresponding surface temperatures

- $\mathrm{K}_{\mathrm{Rim}}(\mathrm{z})=4\left(\varepsilon_{\mathrm{i}}\right) \sigma\left(\mathrm{T}_{\mathrm{R}}^{3}\right)\left(\mathrm{F}_{\mathrm{im}}\right) \mathrm{A}_{\mathrm{i}} \quad$ (McAdams, 1954)

Where:

- $\quad \varepsilon_{\mathrm{i}}=$ Surface emissivity (usually assumed by DOE-2 as: $\varepsilon_{\mathrm{i}}=0.9$ )

- $\quad \sigma=$ Stefan - Boltzman constant

- $\quad \mathrm{T}_{\mathrm{R}}=$ Surface reference temperature (usually assumed by DOE-2 as: $\left.\mathrm{T}_{\mathrm{R}}=530^{\circ} \mathrm{K} / 70^{\circ} \mathrm{F}\right)$

- $\quad A_{i}=$ Area of radiating surface

- $\quad F_{i m}=$ View factor between the 2 surfaces (if to surfaces don't see each other then $\left.F_{i m}=0\right)=\frac{A_{m}(\text { receiving surface })}{A_{T}(\text { Transmitting surface })}$

With all the terms Accounted for, the resulting heat balance equation is therefore give by equation 2-16.

$$
Q_{D i}(\mathrm{z})=Q_{C i}(\mathrm{z})+\sum_{\mathrm{m}=1}^{\mathrm{N}} Q_{R i m}(\mathrm{z})+Q_{s i}(\mathrm{z})
$$

Where $\mathrm{N}=$ Number of surfaces in a room.

By replacing each of the previous terms in the heat balance, the equation becomes 2-17:

$$
\begin{aligned}
\mathrm{K}_{\mathrm{Di}}(\mathrm{z}) \mathrm{T}_{\mathrm{i}}(\mathrm{z})-\mathrm{K}^{\prime}{ }_{\mathrm{Di}}(\mathrm{z}) \mathrm{T}^{\prime}{ }_{\mathrm{i}}(\mathrm{z})=\mathrm{K}_{\mathrm{Ci}}(\mathrm{z})\left[\mathrm{T}_{\mathrm{a}}(\mathrm{z})-\mathrm{T}^{\prime}{ }_{\mathrm{i}}(\mathrm{z})\right] \\
+\sum_{\mathrm{m}=1}^{\mathrm{N}} \mathrm{K}_{\mathrm{Rim}}(\mathrm{z})\left[\mathrm{T}_{\mathrm{m}}(\mathrm{z})-\mathrm{T}_{\mathrm{i}}(\mathrm{z})\right]+Q_{s i}(\mathrm{z})
\end{aligned}
$$


To determine the custom weighting factors, as described previously, the heat balance equation is pulsated. The term to be pulsed is chosen based on the type of custom weighting factors required. The "pulsated term" choice is illustrated in Table 2-1.

\begin{tabular}{|c|c|}
\hline Heat-Gain Weighting Factors & Air-Temperature weighting Factors \\
\hline $\begin{array}{c}\text { Pulse } \mathbf{Q}_{\mathrm{Si}} \\
\sum_{\mathrm{m}=1}^{\mathrm{N}} Q_{S i}(0)=1\end{array}$ \\
$Q_{S i}(\mathrm{k} \Delta)=0$ for $\mathrm{k}>0$ & $T_{a}(0)=1$ \\
$T_{a}(\mathrm{k} \Delta)=0$ for $\mathrm{k} \geq 0$ & $T_{a}(\mathrm{k} \Delta)=0$ for $\mathrm{k}>0$ \\
\hline
\end{tabular}

Table 2-1: Choice of pulsated term in the heat balance equation

\section{Heat-Gain Weighting Factors}

The determination of the heat-gain custom weighting factors from the heat balance equation is illustrated below. Air-temperature weighting factors are determined in a similar manner by pulsating the corresponding term. To obtain the heat-gain weighting factors, the heat balance equation is rearranged as shown in equation 2-18 and with a unit pulse of $Q_{s i}(\mathrm{z})$. 


$$
\begin{aligned}
Q_{i}(\mathrm{k} \Delta)=\mathrm{A}_{\mathrm{i}} \mathrm{h}_{\mathrm{ci}} \sum_{\mathrm{m}=1}^{\mathrm{N}} D_{i m}\left[\mathrm{~A}_{\mathrm{m}} \mathrm{Z}_{\mathrm{m}}(\mathrm{k}) \sum_{\mathrm{n}=1}^{\mathrm{N}} \mathrm{D}_{\mathrm{mn}} \mathrm{B}_{\mathrm{n}}(0)\right] \\
-\mathrm{A}_{\mathrm{i}} \mathrm{h}_{\mathrm{ci}} \sum_{\mathrm{m}=1}^{\mathrm{N}} D_{i m}\left\{\frac{1}{\mathrm{~h}_{\mathrm{cm}}} \sum_{\mathrm{n}=1}^{\mathrm{N}} \mathrm{Z}_{\mathrm{m}}(\mathrm{J}) \mathrm{Q}_{\mathrm{m}}[(\mathrm{k}-\mathrm{j}) \Delta]\right\}
\end{aligned}
$$

Where:

- $Q_{i}(\mathrm{k} \Delta)$ : Represents the cooling load from each wall at time $\mathrm{k} \Delta$, expressed in terms of previous values of $Q(\mathrm{k} \Delta)$

- $\quad D \& B$ : Characteristic matrices resulting from incorporating the various wall layers into the heat balance equation.

The cooling loads $Q(\mathrm{k} \Delta)$ at each $\mathrm{k} \Delta$ represent the coefficients of the temperature $\mathrm{z}-$ transfer function described earlier. Therefore $T(z)$ is expressed as shown in equation 2-19 below:

$$
\begin{aligned}
& T(z)=\underbrace{Q(0)}_{\mathrm{d}_{0}}+\underbrace{Q(\Delta) \mathrm{z}^{-1}}_{\mathrm{d}_{1}}+\underbrace{Q(2 \Delta) \mathrm{z}^{-2}}_{\mathrm{d}_{2}}+\ldots \\
& \therefore T(z)=d_{0}+d_{1} \mathrm{z}^{-1}+d_{2} \mathrm{z}^{-2}+\ldots
\end{aligned}
$$

However Q ( $\mathrm{z}$ ) has been already expressed in equation 2-3 as:

$$
\frac{Q(z)}{q(z)}=\frac{v_{0}+v_{1} z^{-1}+v_{2} z^{-2}}{1+w_{1} z^{-1}+w_{2} z^{-2}}
$$

$\therefore T(z)$ is expressed in a similar format resulting in :

$$
T(z)=d_{0}+d_{1} z^{-1}+d_{2} z^{-2}+\ldots=\frac{v_{0}+v_{1} z^{-1}+v_{2} z^{-2}}{1+w_{1} z^{-1}+w_{2} z^{-2}}
$$

Therefore, by combining coefficients of the same power we obtain:

$$
v_{0}=d_{0}
$$




$$
\begin{gathered}
v_{1}=d_{1}+d_{0} w_{1} \\
v_{2}=d_{2}+d_{1} w_{1}+d_{0} w_{2} \\
\ldots \text { etc. }
\end{gathered}
$$

Solving the resulting system of 5 equations with 5 unknowns yields the values of the Heat-Gain weighting factors. The heat-gain weighting factors can now be used to determine the cooling/heating loads from instantaneous heat gains/losses using equation 2-4 shown earlier. This is the way by which cooling loads are calculated in DOE-2.

$$
\therefore Q_{\tau}=v_{0} q_{\tau}+v_{1} q_{\tau-1}+v_{2} q_{\tau-2}-w_{1} Q_{\tau-1}-w_{2} Q_{\tau-2}
$$

Where:

- $\quad q_{i}=q_{0}, q_{1}, q_{2} \ldots=$ hourly heat gain

- $Q_{i}=Q_{1}, Q_{2}, Q_{3} \ldots=$ hourly cooling load

- $v_{0}, v_{1}, v_{2}, w_{1}, w_{2}$ are Heat - gain weighitng factors

The air-temperature weighting factors are determined in a similar manner as the heat gain weighting factors. Once determined, $g_{o}, g_{1}, g_{2}, g_{3}, p_{1}, \& p_{2}$, can be used to determine the space temperature using equation 2-7 shown below.

$$
t_{\tau}=\frac{1}{g_{0}}\left[Q_{\tau}+p_{1} Q_{\tau-1}+p_{2} Q_{\tau-2}-g_{1} t_{\tau-1}-g_{2} t_{\tau-2}-g_{3} t_{\tau-3} p_{2} Q_{\tau-2}\right]
$$

Where: $t_{\tau}=T(z)-T_{R}$

\section{Custom Weighting Factors "Modification" by Heat Load Type}

DOE-2 considers heat gain due to (1) Solar radiation in the room, (2) People and equipment, (3) Lighting \& task lighting, (4) Heat conduction through the walls, and (5) Heat conduction through furniture. Therefore, a variety of models is utilized in the heat 
load calculation, one for each category of heat gain. The custom weighting factors are therefore, for each category of heat gain (input), tailored to provide a transfer function specific for calculating the required hourly cooling load (output). As a result, 5 different sets of custom weighting factors are obtained, corresponding to each of the above stated categories of heat gain.

\section{Determination of Hourly Loads \& Space Temperatures}

LOADS deploys a variety of algorithms and subroutines to calculate the hourly heat gains, by category. The respective weighting factors are applied to each set of heat gain to result in sets of hourly cooling/heating loads. These cooling/heating loads (due to each separate category) are then summed up to result in a Total Hourly Cooling/Heating Load. This is the method by which DOE-2 calculates hourly cooling/heating loads. SYSTEMS then applies the air-temperature weighting factors onto the calculated hourly heat gains/losses and cooling/heating loads to correct for using a fixed room temperature, $\mathrm{T}_{\text {ref, }}$ in LOADS calculations; and to calculate the actual hourly space temperatures. SYSTEMS also simulates the distribution equipment that provide heating, ventilation, and/or air conditioning in the building.

The use of the fixed reference temperature in DOE-2 in LOADS alleviates the computational time and load. Also, it results in a tight coupling between the calculations of the cooling/heating loads in LOADS program and the HVAC equipment calculation in SYSTEMS. The disadvantage of using a fixed reference temperature, however, is that it introduces slight approximations. The DOE-2 core simulation process is depicted in Flowchart 2-2 


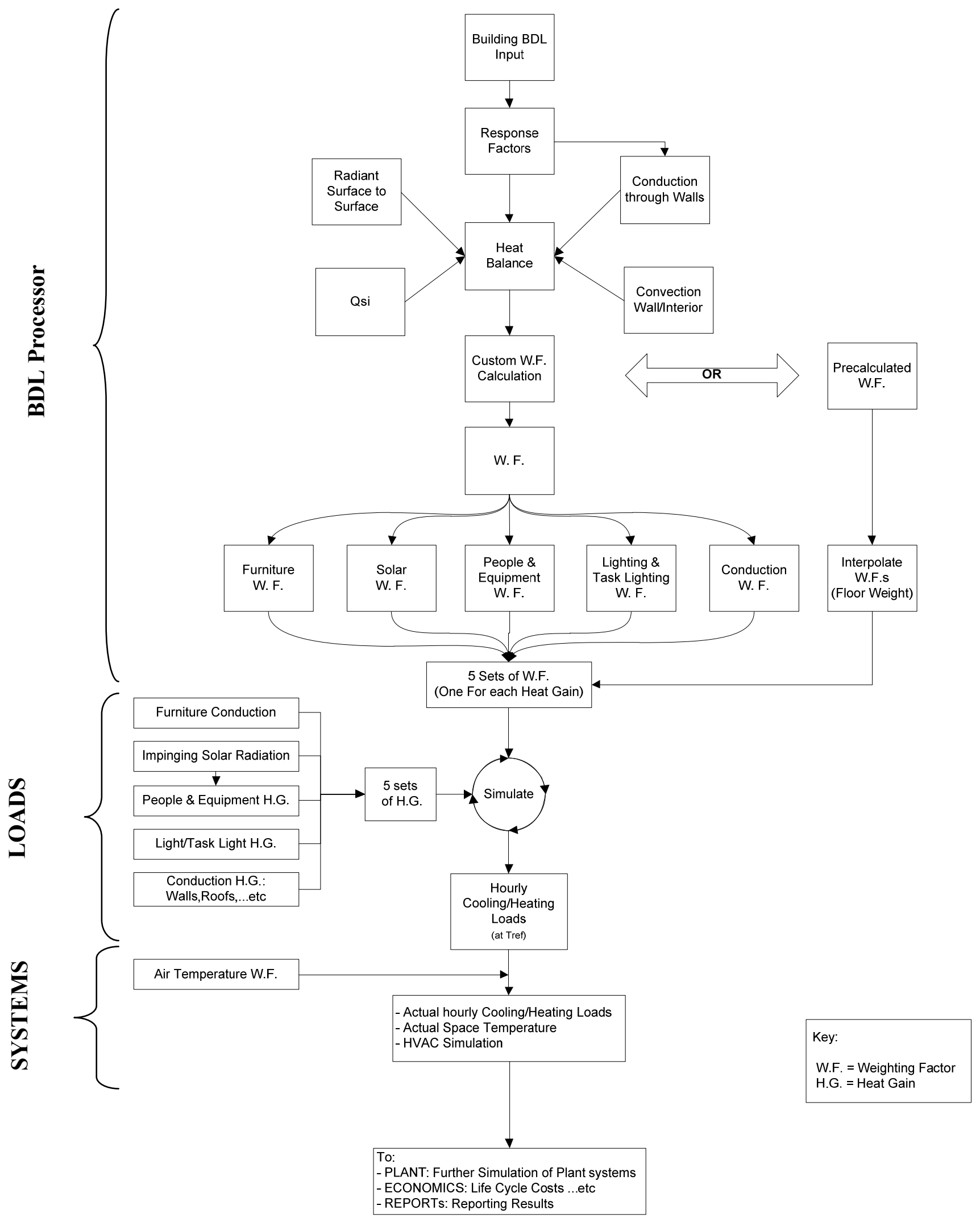

Flowchart 2-2: Flow of DOE-2 Core Simulation Process 


\section{eQUEST}

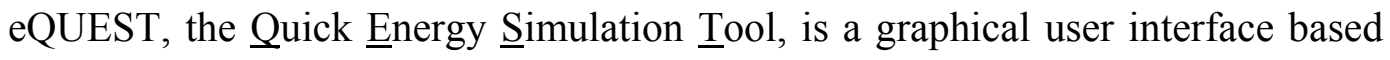
tool that facilitates for users the creation of DOE-2 building models. It includes building creation wizards that generate the DOE-2 model based on the user input. The wizards also help in automatically running parametric simulations for comparing alternative designs. Another important aspect of eQUEST is providing graphical outputs with key charts, values, and tables; along with the detailed regular DOE-2 output files. The following section contains an overview of the eQUEST wizards and distinctive properties that make it a very popular building energy simulation tool. Information in the following synopsis are obtained from the "Q eQUEST Introductory Tutorial, version 3.63" by James J. HIRSCH \& Associates, April 2009; the "Q eQUEST Modeling Procedures Quick Reference Guide" by James J. HIRSCH \& Associates, May 2007; and other software documentation on the eQUEST website (www.equest.com).

eQUEST includes three main wizards, the Schematic Design Wizard (SD Wizard), the Design Development (DD Wizard), and the Energy Efficiency Measure Wizard (EEM Wizard). Both the SD and DD wizards are used in creating a building model. The EEM wizard is used, on the other hand, for evaluating and comparing design alternatives. The main difference between the SD and DD wizards is the degree of complexity of the models being created. The SD wizard is most suitable for smaller and simpler structures or for obtaining rough estimates in the early design phase of a structure. It has within it predefined generic shapes that can be manipulated by the user to define a simple building's plan and layout. Users can instead import drawing files 
containing the building layout. Another limitation on the SD wizard is the number of HVAC systems that can be simulated. This is limited to a maximum of 2 HVAC templates per shell, with a maximum of 2 building shells allowed with this wizard. The SD wizard offers choice of simplified building schedules and allows defining no more than 2 seasons per year.

The Design Development wizard is designed to be used for large and more complicated buildings. Also, for buildings with complex HVAC system assignments and/or intricate internal loads and schedules. The DD wizard has no limit on the number of different HVAC systems that can be used. Schedules and season options in the DD wizard are also more intricate and detailed. The DD wizard is preferably used during late stages of a building design, a phase where most of the building data essential for a more detailed building energy simulation are available.

Energy Efficiency Measures wizard (EEM) provides a quick and easy tool for comparing the energy performance of various design alternatives. EEM permits defining and comparing up to 9 alternatives at the same time. This wizard makes available for designers a valuable means of comparing the impact and evaluating the tradeoff of alternative designs. For example, the designer is able to evaluate the cost tradeoff of adding extra insulation versus the resulting savings on reduced heating/cooling costs. Similarly individual alternatives (up to 9) can be compared individually versus each other, or collectively (i.e. modifying two or more alternative versus a third for example). Examples of the possible alternative comparison runs include:

- Modifying/adding roof insulation

- Introducing top day lighting 
- Installing high efficiency lighting

- Installing high efficiency chillers

- Switching to high performance glass

- Others

In addition to the wizards, eQUEST allows users to modify and edit models directly without using a wizard. This is known as the Detailed Interface. The detailed interface allows modifying specific/individual components. It also allows copying, creating, and linking of objects. Furthermore, it allows modifications to the building geometry and/or individual components. The detailed interface also includes an abundance of methods to define shades, including fixed shades and shades that rotate with the change of a building's orientation. Another aspect of the detailed interface is allowing users to adjust HVAC zone assignments. Comparison of alternatives is available in the detailed interface and is defined as Parametric Runs. These runs are similar to the EEM wizard used with the SD and DD wizards. However, parametric runs offer more detailed and comprehensive methods of investigating design alternatives. Some examples of possible parametric runs in the detailed interface include:

- Varying the properties of HVAC systems (performance curve, head ...etc)

- Varying the solar/optical characteristics of user-defined glass types

- Varying the windows glass type assignments

- Modifying the walls and roofs insulation

- Changing the building orientation

- Modifying operating schedules of light, equipment and people occupancy 
- Modifying the geometry of building components (walls, roofs, shades...etc)

- The impact of adding skylights

- The impact of utilizing daylight controls

- The impact of installing/adding shades

- Others

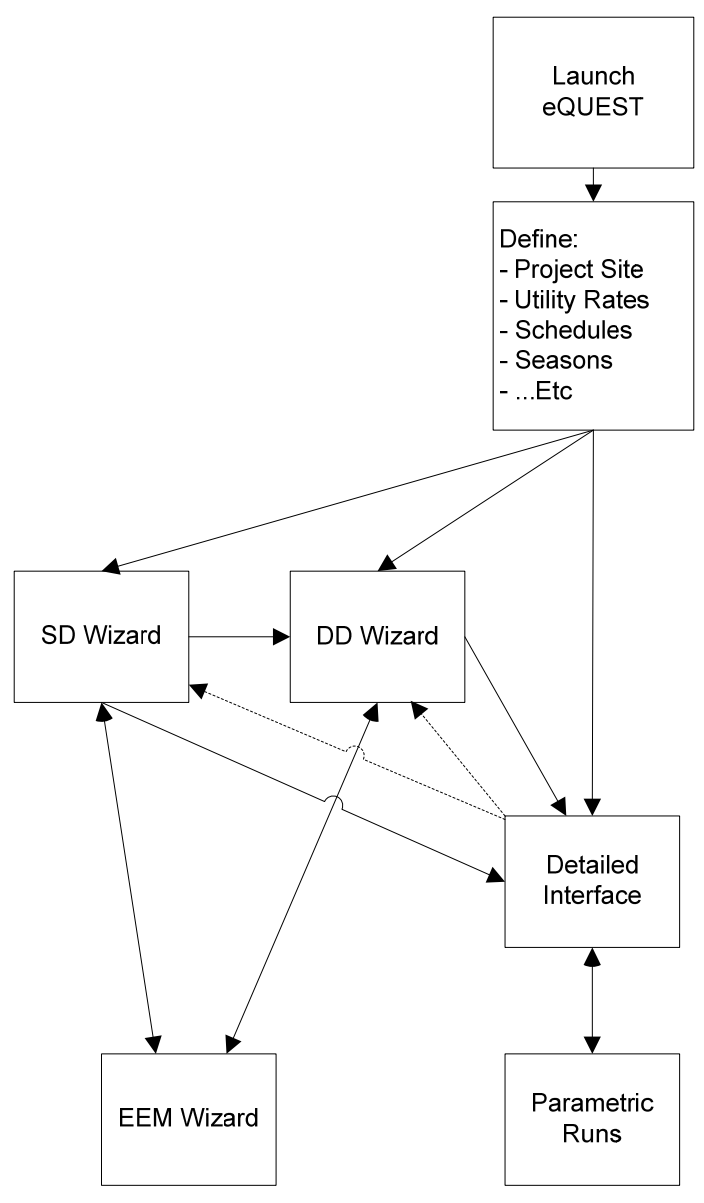

$4 \quad=$ Loss of Modifications Made in Detailed Interface

Flowchart 2-3: Possible Model Flows In eQUEST 


\section{Infiltration}

Infiltration is a significant aspect of heat loss calculation. The determination of the thermal load resulting from the passage of outside air into the interior of a building is necessary. This thermal load is traditionally viewed as principally dependent on the flow rate of the infiltrating air and the inside-outside air temperature gradient. The driving pressure of outside airflow into the building is mostly caused by one of 2 forces or a combination of both. This driving pressure is either caused by the influence of outside gusting winds or the pressure difference across the building envelope resulting from the difference between inside and outside air temperatures (Jackman, 1974). In most situations, a combination of both persists as the driving force. The pressure gradient on the face of a building resulting from gusting wind is mostly the controlling infiltration driving force in low rise buildings (under 3-story rise buildings). In high rise buildings, the driving force of infiltration is primarily the stack effect. The difference in air temperature across the building envelope and height results in air buoyancy differences and as a result a pressure difference between the inside and outside of the building is established. During the heating season, for example, warm air rises inside a high rise building creating an inside positive pressure at the top and a lower pressure in the bottom floors, thus resulting in air infiltration at the bottom of the building (Brownell, 2002). The two infiltration driving mechanisms do not act independently. The air leakage driving force is usually an inside-to-outside pressure difference caused by a combination of both mechanisms (Blomsterberg and Harrje, 1979). Air infiltration, along with ventilation, has a major influence on a building's internal environment. Most importantly, infiltration has 
a profound impact on the energy demand of a building. Relatively high infiltration rates excessively burden a building's heating and/or air conditioning system. This results in unnecessary waste and over-consumption of energy; or in surpassing the heating and cooling ability of the HVAC system in a building and resulting in a thermally uncomfortable interior environment (Liddament, 1986).

Studies estimate that infiltration accounts for $25 \%$ to $50 \%$ of the heating load in both residential and commercial buildings (Nevrala and Ethridge, 1977; Kirkwood, 1977). Caffey (1979) attributed $40 \%$ of the heating/cooling load in houses to infiltration. Similarly, Persily (1982) concluded that one third of the heating and cooling loads in a building are due to infiltration. The National Institute of Standards and Technology (1996) estimates that $15 \%$ of the heating loads in commercial building to be due to air infiltration. Similarly, other studies assert the significant impact of air infiltration on thermal loads in a building.

The following sections include a review of ASHRAE definitions, guidelines, and procedure for dealing with infiltration as well as an overview of infiltration calculation methods and their categorizations. A review of different infiltration types, the corresponding sources and gateways, and the impact of each is also presented. Finally, a discussion of major problems and inadequacies with the currently adopted infiltration load calculation models. 


\section{Infiltration in ASHRAE}

Infiltration is primarily addressed in Chapter 16 of the 2009 ASHRAE Handbook of Fundamentals ${ }^{\circledR}$ "Ventilation and Infiltration".. According to ASHRAE infiltration, along with ventilation, is classified under "Air Exchange" of outdoor air with a building's indoor air. Ventilation is defined as the intentional introduction of outside air into the inside of a building. Ventilation can be natural, through naturally planned openings in a building envelope, or forced (mechanical) ventilation. On the other hand, infiltration (air leakage) is defined by ASHRAE as "The flow of outdoor air into a building through cracks and other unintentional openings and through the normal use of exterior doors for entrance and egress". Infiltration is either driven by natural or artificial pressure differences.

Wind

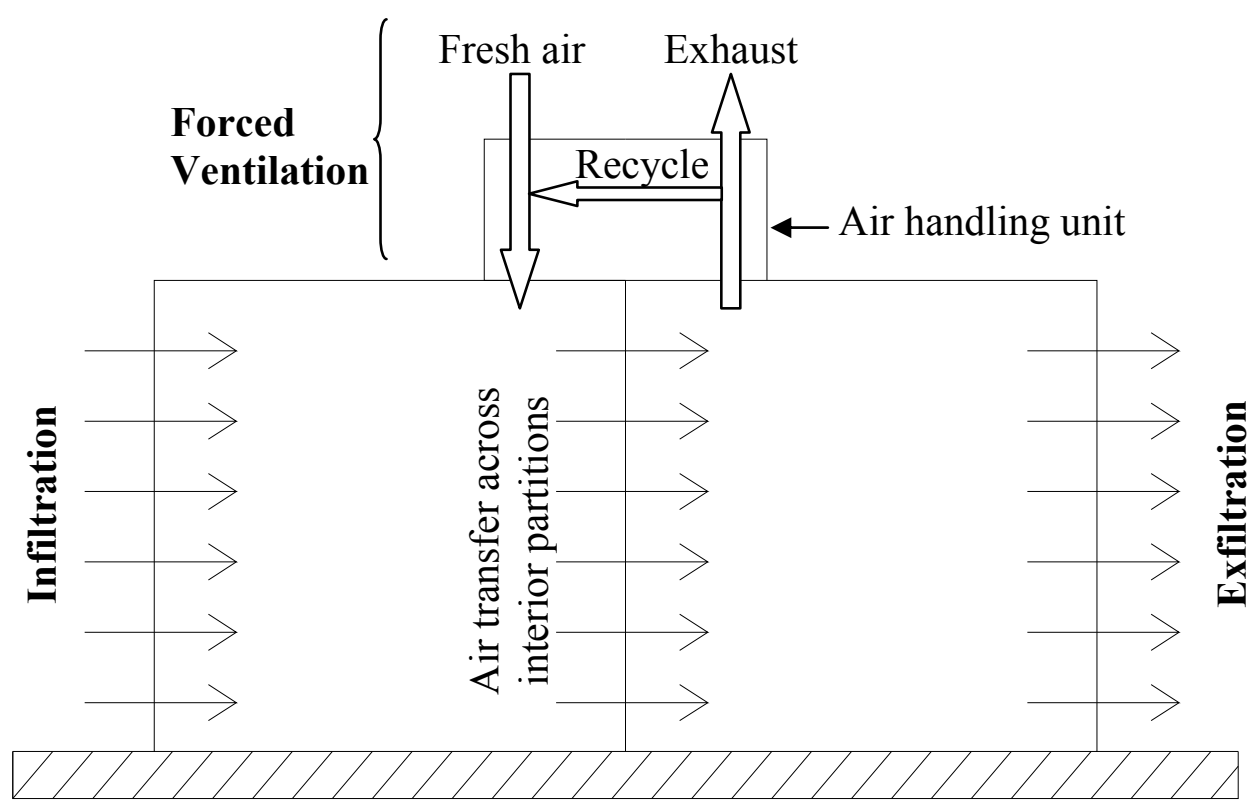

Figure 2-3: Typical Infiltration \& Ventilation Airflow 
ASHRAE emphasizes the discussion of infiltration majorly in residential houses, while in commercial buildings the focus in ASHRAE is on ventilation. However, it clearly advises that infiltration in commercial buildings should not be ignored. This is in agreement with the previously discussed literature overview were studies showed infiltration to account for $40 \%$ of the heating/cooling load in residential buildings versus $15 \%$ in commercial buildings (Caffey, 1979; NIST, 1996).

ASHRAE, with reference to Dickerhoff et al. (1982) and Harrje and Bur (1982), estimates the percentage distribution of infiltration air leakage by building components as follows:

- Walls: $18 \%$ to $50 \%$, with an average of $35 \%$.

- Ceiling Details: $3 \%$ to $30 \%$, with an average of $18 \%$. This leakage undermines the purpose of insulation in attics, residential houses, and ceiling insulation in buildings.

- Forced-air and/or Cooling systems: $3 \%$ to $28 \%$, with an average of $18 \%$. This category represents air leaks in conditioning/heating air paths and ducts.

- Windows and Doors: $6 \%$ to $22 \%$, with a $15 \%$ average. The infiltration air leakage in windows is a matter of the window type rather than age (Weidt et al., 1979). It is important to note that this percentage represents the infiltration through doors and windows seals and cracks, not due to the opening of doors by passing individuals, for instance.

- Fire Place: $0 \%$ to $30 \%$, with an average of $12 \%$. Similar to the case of doors and windows, this percentage represents the air leakage through a "cold fireplace"; not a running fire place with open dampers, plugs, caps or such. 
- Vents in conditioned spaces: $2 \%$ to $12 \%$ with an average of $5 \%$. This refers to undamped or improperly damped small exhaust vents in a conditioned space.

Other infiltration (air leakage) sources count for $1 \%$ or less of the total leakage.

\section{Residential Calculation Models}

ASHRAE references a list of simplified models for use in the calculation of infiltration in residential buildings. The referenced calculation models vary between simple estimation models and more advanced models. The model categories include:

\section{Empirical Models}

These residential infiltration models are found on statistical fits of infiltration rate data collected from specific houses. The data used is collected from pressurization tests on houses and reduced to a low order equation. These models define, at most, a very simple relationship between infiltration rate, some air tightness factor and a weather condition. The referenced models include Sherman (1987), Kronvall (1980), Reeves et al. (1979) and Shaw (1981).

\section{Multizone Models}

Multizone models consider the building to be a series of interconnected zones, assuming a well mixed air within each. They are based on a mass balance requiring a balance between the inflow and outflow in each of the interconnected zones. Among the Multizone methods referenced in ASHRAE Fundamentals Handbook are: Allard and Herrlin (1989), Etheridge and Alexander (1980), Herrlin (1985), Liddament and Allen (1983), and Walton and Dols (2003). Multizone models require a user input describing 
the leakage in the building envelope, wind pressure on the building envelope, zone temperatures, and ventilation air flow rates. Estimates from available literature are usually used and assumed as input.

\section{Single Zone Models}

These models are developed and based on the principal of accounting for the building interior as a single zone with no internal resistance of air flow. Some of the ASHRAE referenced models are: Cole et al. (1980), Sherman \& Grimsrud (1980), warren and Webb (1980), and Walker and Wilson (1998). All single zone models require inputs of wind speed, temperature, wind shelter and leakage distribution over the building envelope. These models are extremely sensitive to the required input data, which in turn are rather difficult to determine.

\section{Superposition of Wind and Stack Effects}

Infiltration is caused by two driving forces, wind and stack effect. Superposition models calculate the infiltration due to each driving force separately and then combine the two results.

\section{Infiltration in Commercial Buildings}

Commercial and institutional building envelopes, according to ASHRAE, are commonly assumed to be rather airtight. Conversely, ASHRAE emphasizes that according to Persily \& Grot (1986), if measured air leakage flow rates are normalized by building envelope area (rather than building volume), the results obtained show envelope air tightness levels in commercial buildings resembling those of typical residential 
American houses. Office building envelopes are therefore found to be leakier than expected. There are several negative consequences to infiltration in commercial buildings. This includes reduced thermal comfort, degradation of indoor air quality, increase in energy consumption, moisture damage, and others.

Important to evaluating air leakage in commercial buildings, according to ASHRAE, are leakages associated with internal partitions, elevators, stairs, shaft walls, doors and others. As a result, included in ASHRAE Handbook of Fundamentals are charts that help, for example, in quantifying the air leakage through elevator shafts and similar components.

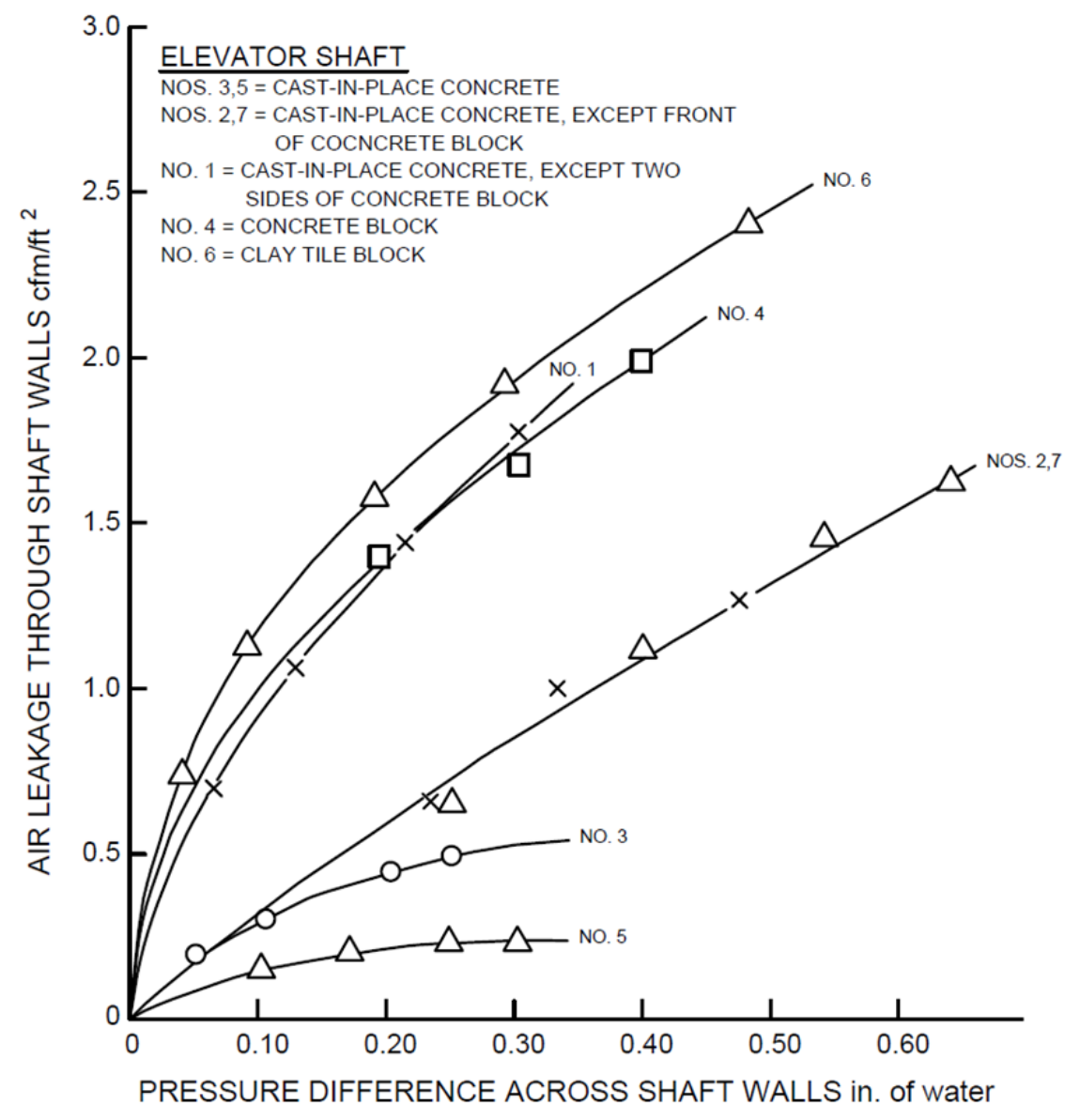

Chart 2-1: Air Leakage Rates of Elevator Shaft Walls (2009 ASHRAE® Handbook of Fundamentals) 
Infiltration through doors depends on several factors such as the type and use of the door, room and building. Also critical are the air speed and pressure differentials across the door. In residential and small buildings, infiltration through doors is more defined by air leakage through cracks and openings between the door and its frame; primarily due to the infrequent use of the doors. However, as the frequency of the door use increases, the infiltration calculation becomes dependant on the air flow through the door (when open). Automatic doors (swinging, sliding, or rotating), for example, represent a major venue of air infiltration. These doors stay open much longer than manual doors and allow significant amounts of air infiltration. In the case of a facing pair of doors, air flow becomes an even more significant issue to be considered in heating and cooling load calculations. In ASHRAE fundamentals, for doors, an air flow rate chart is provided (Figure 2-5) and air flow coefficients charts (Figure 2-6) along with the relevant equations necessary for calculating the resulting air flow. 


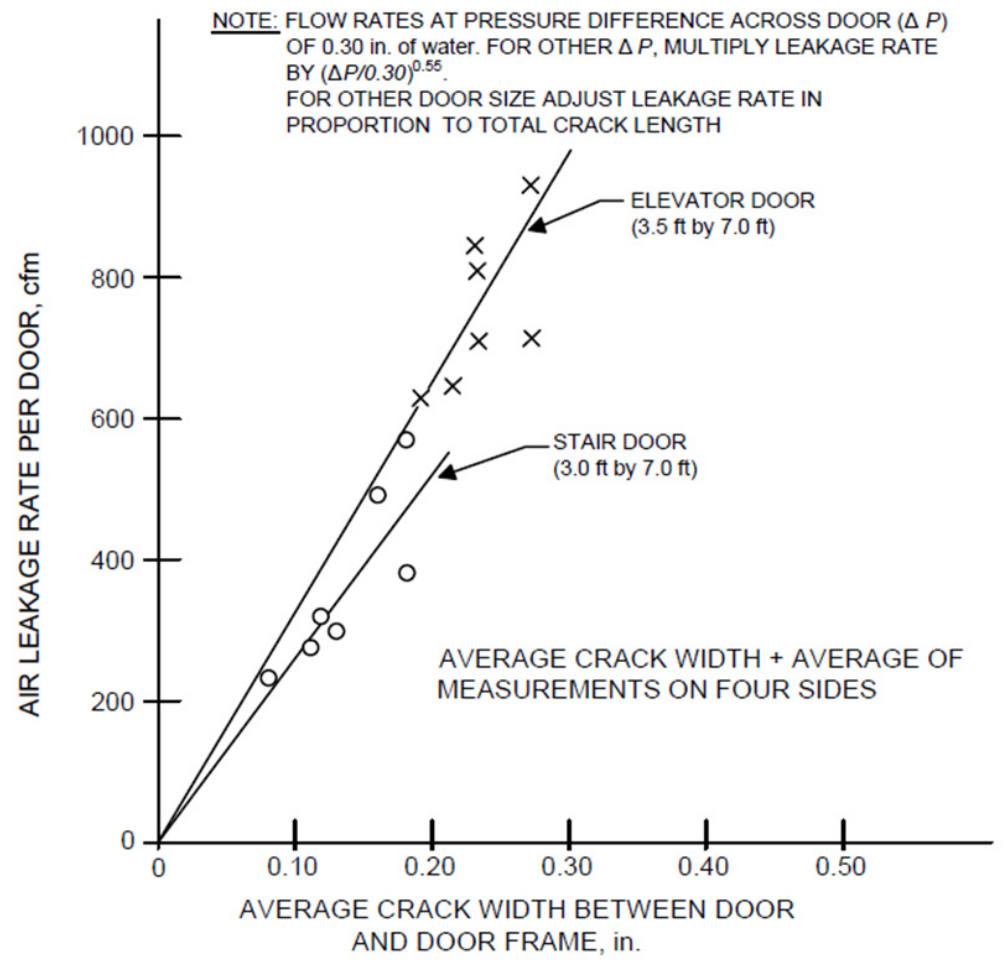

Chart 2-2: Air Leakage Rate of Door versus Average Crack Width (2009 ASHRAE® Handbook of Fundamentals)

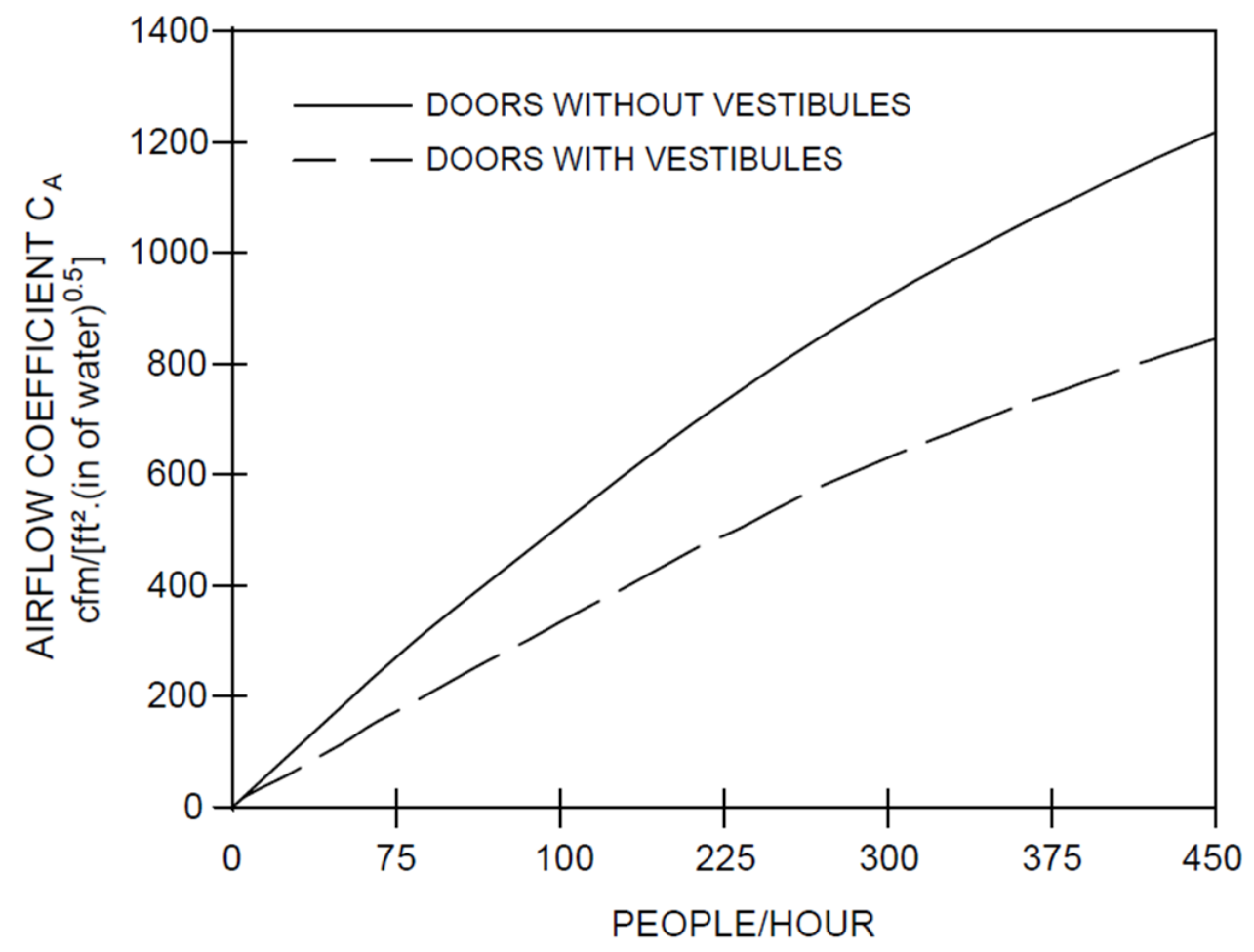

Chart 2-3:Airflow Coefficient for Automatic Doors (2009 ASHRAE® Handbook of Fundamentals) 


\section{Air Infiltration Calculation Techniques \& Methods}

Even though air infiltration is an important facet of building physics, it still involves substantial uncertainty. This is mostly due to the difficulty of measuring infiltration in buildings, which limits the experimental database available for use in developing infiltration evaluation techniques and methods. Another reason is the wide variety of available construction techniques and practices, each of which is distinguished by diverse infiltration characteristics (Liddament, 1986). Several models and algorithms have been developed for evaluation infiltration. Among these are Walton (1984), Jackman (1974), Reeves (1979), Crall (1983), Warren (1982) and several others. Following, is a general review and classification of the available infiltration techniques and methods.

Infiltration calculation models are essential in the building thermal design process. They are used in calculating the resulting air change rates, energy requirements, and, ultimately, costs. Flowchart 2-4 shows the role these models play in the design process. The output of a model can be used to modify the building properties and optimize the design.

Air infiltration calculation is primarily a measure for calculating the rate of air change in a building under given conditions (Liddament, 1986). The air change rate is a measure of the number of times the volume of air within a fixed airspace (room, building or other) is replaced by infiltrating outside air. The number of air changes per hour in a fixed space is defined by equation 2-23. 


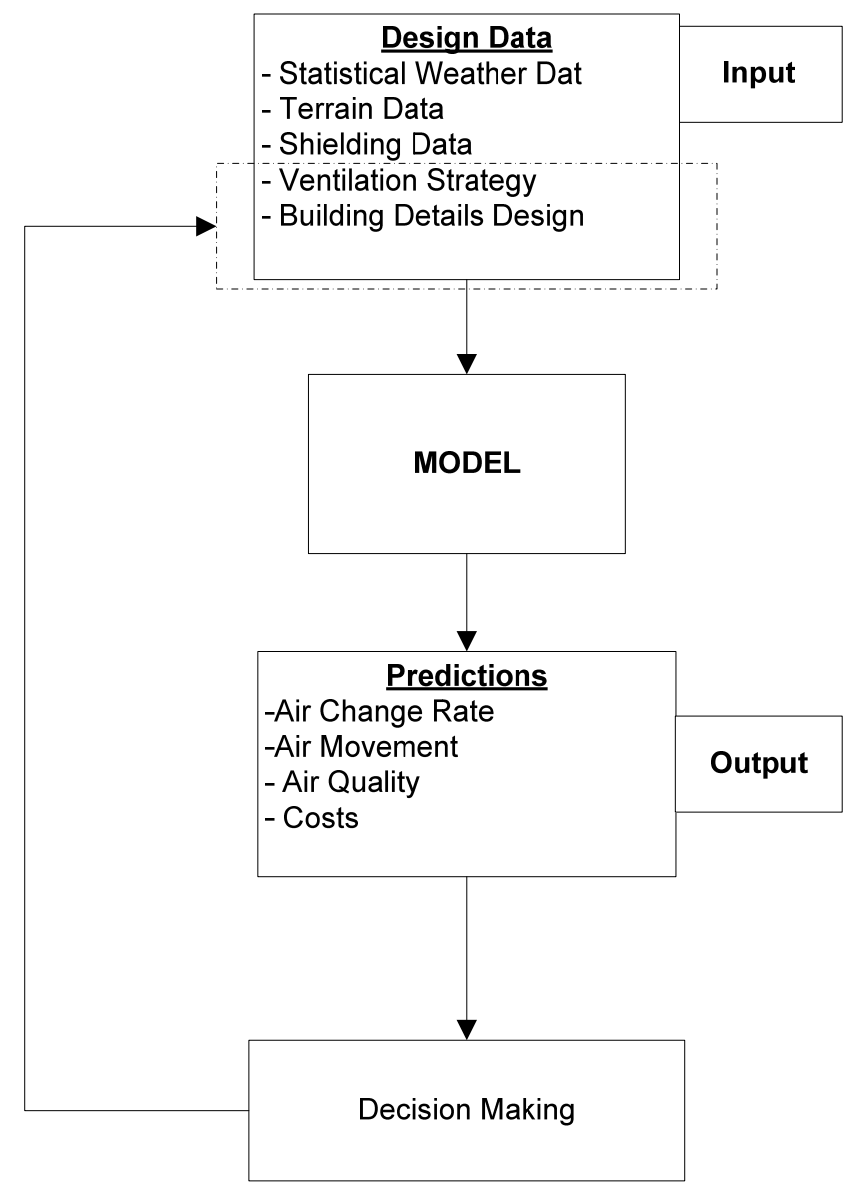

Flowchart 2-4: Role of Air Infiltration Model in the Energy Design/Analysis Process (Liddament, 1986) 


$$
N=\frac{60 Q}{V}
$$

Where:

- $\quad \mathrm{N}=$ Number of air changes per hour

- $\quad \mathrm{Q}=$ Volumetric flow rate of infiltration air

- Volume of Space

Air infiltration is primarily affected by the building overall tightness, the influence of climate (primarily wind speed and air temperature) on the driving mechanisms, and the location of the building (topography). The concurrent influence of these factors on infiltration can be represented in the following graphical form, Figure 2-7 (Liddament, 1986).

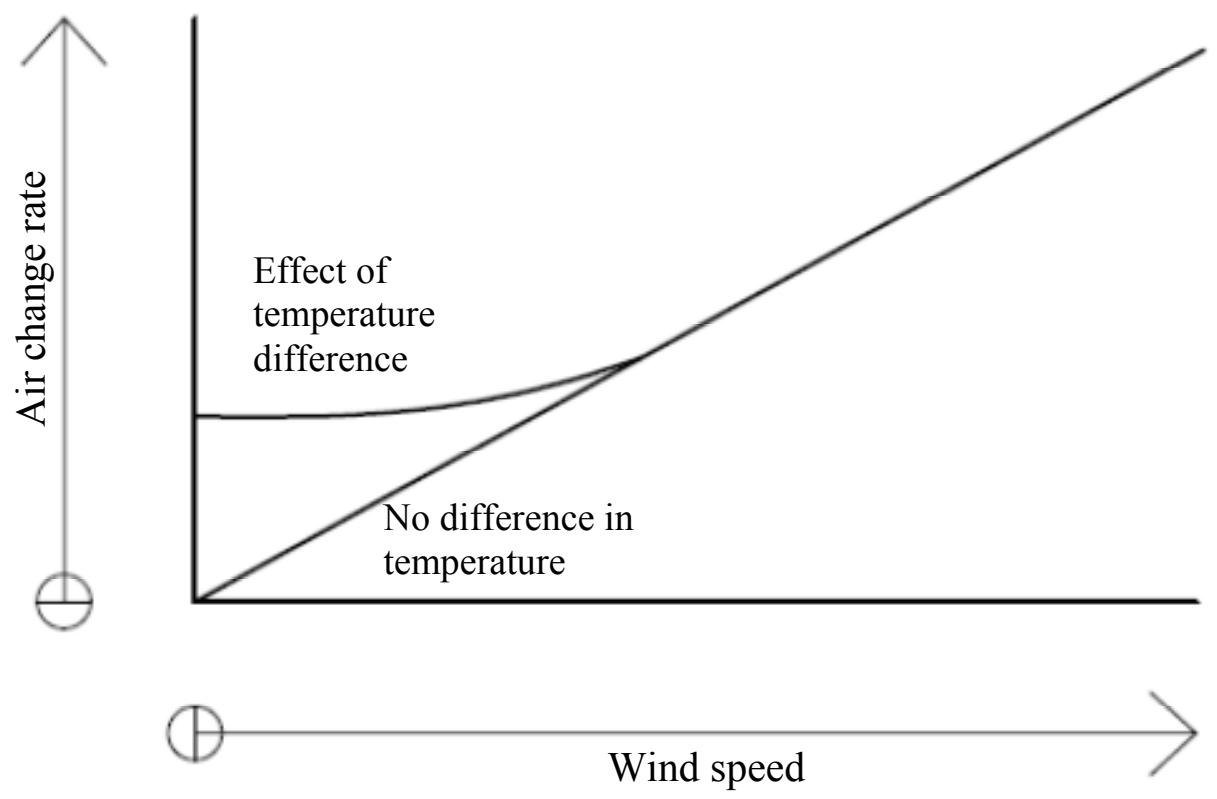

Chart 2-4: Infiltration Characteristics (Liddament, 1986) 
The various infiltration, and ventilation, calculation techniques fall into five general categories listed below.

\section{Air Change Methods}

2. Reduction of Pressurization Test Data

3. Regression techniques

4. Theoretical Network Methods

5. Simplified Theoretical Methods

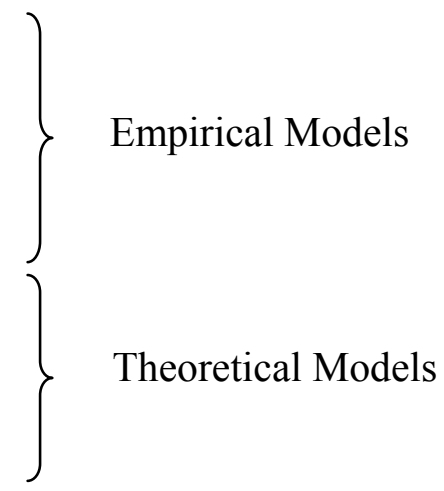

Air change methods, reduction of pressurization test data and regression techniques are all empirical models, while the remaining 2 methods are classified as numerical methods. These various categories can be organized in a hierarchal order in terms of complexity and range of applicability. Theoretical network multizone methods top the hierarchy in complexity; while air change methods are considered the least complex with the least range of applicability. Shown in Flowchart 2-5 is the infiltration calculation methods hierarchy as defined my Liddament (1986) along with a summary of the data requirements, advantages, and disadvantages of each in Tables 2-2 and 2-3. 


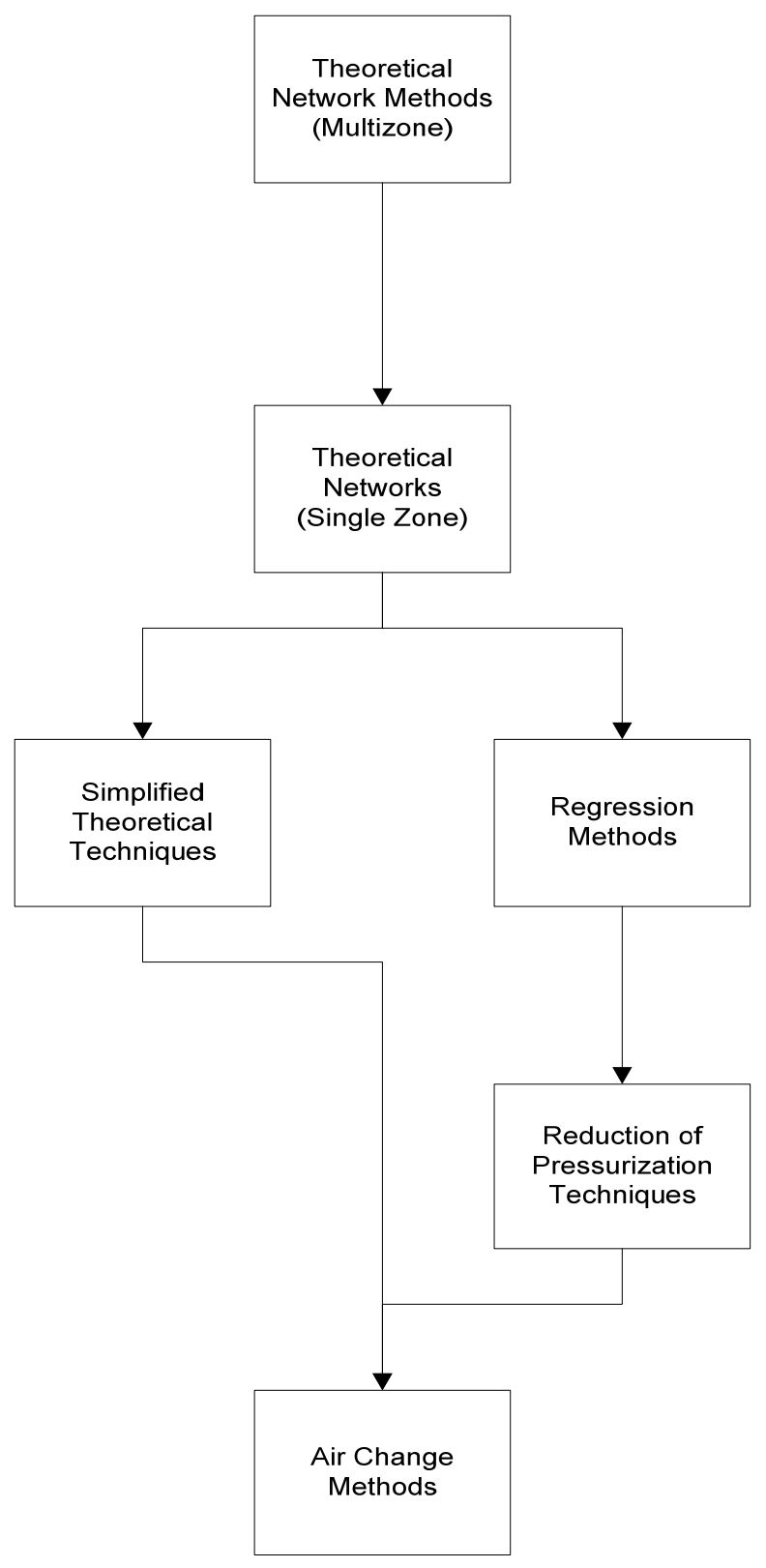

Flowchart 2-5: Hierarchal order of Infiltration Calculation Techniques (Liddament, 1986) 


\section{Summary of Calculation Techniques}

(A) Empirical Models

\begin{tabular}{|c|c|c|c|}
\hline Technique & Data Requirements & Advantages & Disadvantages \\
\hline Air Change Methods & $\begin{array}{l}\text { Basic Bldg Design } \\
\text { Details } \\
\text { - } \text { Size } \\
- \text { Height } \\
\text { - etc }\end{array}$ & $\begin{array}{l}\text { - Ease of use } \\
\text { - No computing } \\
\text { facilities required }\end{array}$ & $\begin{array}{l}\text { Doesn't provide } \\
\text { detailed infiltration } \\
\text { predictions }\end{array}$ \\
\hline $\begin{array}{c}\text { Reduction of } \\
\text { Pressurization test } \\
\text { data }\end{array}$ & $\begin{array}{l}\text { Pressurization test } \\
\text { data }\end{array}$ & $\begin{array}{l}\text { - Ease of use } \\
\text { - No computing } \\
\text { facilities required }\end{array}$ & $\begin{array}{l}\text { - Applies only to } \\
\text { existing buildings } \\
\text { (that have been } \\
\text { pressure tested) } \\
\text { - Doesn't indicate the } \\
\text { affects of weather, } \\
\text { sheltering and/or } \\
\text { terrain }\end{array}$ \\
\hline Regression Methods & $\begin{array}{l}\text { Infiltration } \\
\text { measurement data } \\
\text { with parallel wind and } \\
\text { temperature records }\end{array}$ & $\begin{array}{l}\text { - Fairly easy to use } \\
\text { - Gives weather } \\
\text { dependent } \\
\text { infiltration } \\
\text { prediction }\end{array}$ & $\begin{array}{l}\text { - Only applies to } \\
\text { existing buildings } \\
\text { (Tracer gas tested) } \\
\text { - Regression data } \\
\text { can give unreliable } \\
\text { results }\end{array}$ \\
\hline
\end{tabular}

Table 2-2: Empirical Infiltration techniques (Based on Liddament (1986))

\section{(B) Theoretical Models}

\begin{tabular}{|c|c|c|c|}
\hline Technique & Data Requirements & Advantages & Disadvantages \\
\hline Network Models & $\begin{array}{l}\text { - Bldg Description } \\
\quad-\quad \text { Size } \\
- \text { Height } \\
-\quad \text { Etc } \\
\text { - Surrounding Shield } \\
\text { data } \\
\text { - Terrain } \\
\text { - Flow data (location } \\
\text { and description of } \\
\text { leaks) }\end{array}$ & $\begin{array}{l}\text { - Predicts air } \\
\text { distribution pattern } \\
\text { - Determine internal } \\
\text { pressure } \\
\text { - Responds to } \\
\text { weather\& terrain } \\
\text { variations } \\
\text { - If moderate, it can } \\
\text { be run on regular } \\
\text { computers }\end{array}$ & $\begin{array}{l}\text { - Substantial data } \\
\text { required to } \\
\text { describe flow } \\
\text { - Considerable } \\
\text { computational } \\
\text { power required }\end{array}$ \\
\hline $\begin{array}{c}\text { Simplified Theoretical } \\
\text { Models }\end{array}$ & $\begin{array}{l}\text { - Building air } \\
\text { leakage } \\
\text { characteristics } \\
\text { - Shielding \& terrain } \\
\text { data }\end{array}$ & $\begin{array}{l}\text { - Compromise } \\
\text { between theoretical } \\
\text { models complexity } \\
\text { \& inaccurate } \\
\text { empirical } \\
\text { techniques }\end{array}$ & $\begin{array}{l}\text { - Applies to single } \\
\text { zone only } \\
\text { - No information on } \\
\text { air movement }\end{array}$ \\
\hline
\end{tabular}

Table 2-3: Theoretical Infiltration techniques; Based on Liddament (1986) 


\section{Empirical Techniques}

\section{Air Change methods}

The air change method depends on a tabulation of average air changes per hour, as shown in sample Table 2-4. The values in such tables are based on construction tightness. The tightness of the construction depends, largely, on workmanship. Typically, residential construction falls in the low end of the "Medium" category shown in Table 24 (Bobenhausen, 1994).

\begin{tabular}{|c|c|}
\hline $\begin{array}{c}\text { Tightness of Envelope } \\
\text { Construction }\end{array}$ & $\begin{array}{c}\text { Average Winter Air Changes per } \\
\text { Hour }\end{array}$ \\
\hline Tight & 0.2 to $0.6 \mathrm{ACH}$ \\
\hline Medium & 0.6 to $1.0 \mathrm{ACH}$ \\
\hline Loose & 1.0 to $2.0 \mathrm{ACH}$ \\
\hline
\end{tabular}

Table 2-4: Air Changes per Hour (ACH) estimated by Construction Tightness (Bobenhausen, 1994)

The calculation of heat loss due to infiltration using Air Change Methods is expressed by equation 2-24 (Bobenhausen, 1994)

$$
q_{\text {inf }}=(C) \times(A C H) \times 0.018
$$

Where:

- $\quad \mathrm{q}_{\text {inf }}=$ Infiltration heat loss $\left(\mathrm{Btu} /{ }^{\circ} \mathrm{F} \cdot \mathrm{hr}\right)$

- $\quad \mathrm{C}=$ Space volume $\left(\mathrm{ft}^{3}\right)$

- $\mathrm{ACH}=$ Air Change rate per hour

- $\quad$ 0.018: Air heat capacity $\left(\mathrm{Btu} /{ }^{\circ} \mathrm{F} . \mathrm{ft}^{3}\right)$ 


\section{Reduction Pressurization Test Data}

The reduction of pressurization test data method is a very simplified technique for calculating the average infiltration in a building. This method, as stated in Table 2-3, is limited to the evaluation of infiltration in pre-existing buildings. It depends on pressure data test results. This method doesn't offer any information on the impact of wind, temperature, terrain, or shielding on the infiltration levels in the building (Liddament, 1986). The mathematical expression of this method is shown in equation 2-25.

$$
Q_{\text {inf }}=\frac{Q_{50}}{20}
$$

Where:

- $\quad Q_{\text {inf }}=$ Infiltration rate/hr

- $\quad \mathrm{Q}_{50}=$ Measured air change rate at $50 \mathrm{~Pa}$, from building pressure testing

\section{Regression Techniques}

Regression techniques are based on curve fitting of statistical data. Accumulated long term infiltration data measurements are coupled with some climatic data into an empirical equation. The resulting expression can be of increasing complexity, starting with a linear relationship. The general format of the resulting relationship is shown in equation 2-26 and has been reported by several researchers including Jordon, et al. (1963), Tamura and Wilson (1964), Elkins and Wensman (1971), Hill and Kusuda (1975), and others.

$$
Q_{i n f}=a^{\prime}+b^{\prime} \Delta T+C^{\prime} V^{2}
$$

Where:

- $\quad Q_{\text {inf }}=$ Infiltration rate $\left(\mathrm{t}^{-1}\right)$

- $\quad \Delta T=$ Internal/external temperature difference 
- $\quad V=$ Wind speed

- $\quad a^{\prime}, b^{\prime}, \& c^{\prime}$ are regression coefficients

\section{Theoretical Methods}

Existing theoretical models vary in their degree of complexity in calculating infiltration. Correspondingly, the choice of a specific method depends on the building type and internal application (Liddament, 1986). The simplest form of theoretical models is single zone models. More complex methods are multizone models that breakdown a building into a series of interconnected zones. The underlying concept of all theoretical methods is mass balance. Infiltrating air displaces and equivalent volume of internal air; thus maintaining a mass flow balance (Liddament, 1986). Theoretical models require a description of the flow mechanism. The representation of the air flow varies between large openings and small cracks. In large openings, such as windows, doors and large cracks, the flow is usually turbulent. The flow is therefore commonly represented by an orifice equation as in equation 2-27.

$$
Q=C_{d} A\left[\frac{2}{\rho} \Delta P\right]^{\frac{1}{2}}
$$

Where:

- $\quad \mathrm{Q}=$ air flow rate $\left(\mathrm{m}^{3} / \mathrm{s}\right)$

- $C_{d}=$ Discharge coefficient

- $\rho=$ Air density

- $\quad$ A $=$ Area of opening 
Alternatively, in small cracks like those found in mortar or among tightly fitting components the flow tends to be laminar and controlled by the affect of viscosity. Such flow can be characterized by equation 2-28 (Liddament, 1986).

$$
Q=\frac{\Delta P}{\mu L}\left[\pi \mathrm{r}^{4}\right]
$$

Where:

- $\mu=$ dynamic viscousity

- $\quad L=$ Length of the flow path

- $\quad r=$ Radius of opening

In application, the flow mechanism is defined by an equation combining both flow schemes as in equation 2-29

$$
Q=k(\Delta P)^{n}
$$

Where:

$-\quad k=$ Flow coefficient

- $\mathrm{n}=$ Flow exponent $(0.5 \leq \mathrm{n} \leq 1)$ characteristic of the flow regime

- $\quad \Delta P=$ Pressure gradient across the crack/opening

An understanding of the value of $(k)$ can be acquired by referring to the equation of flow through an orifice (equation 2-30) (Walton, 1984)

$$
Q=c \cdot A \cdot \rho \cdot \sqrt{2 \cdot \frac{\Delta P}{\rho}}
$$

Where:

- $\quad C=$ Flow coefficient

- $A=$ Area of opening

- $\rho=$ Air density 
The flow coefficient, C, holds a value of 0.6 for a wide range of Reynold's Number, as shown in Figure 2-8. Therefore, $\mathrm{C}$ is usually assumed to be 0.6 .

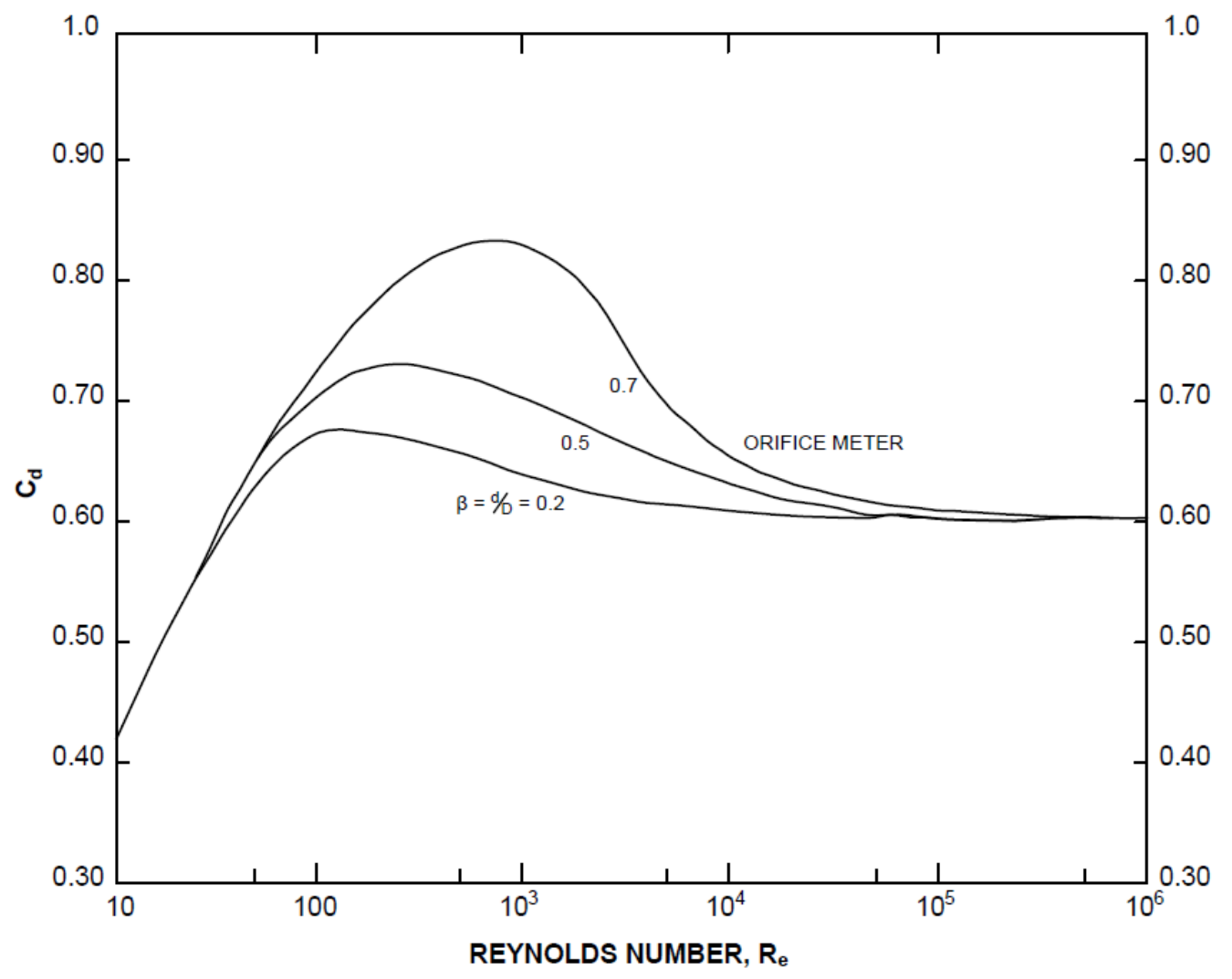

Chart 2-5: Orifice Flowmeter Coefficient (ASHRAE 1977) (Walton, 1980)

\section{Single-Zone Models}

Single zone models, as discussed previously, calculate infiltration by considering the whole building interior as one enclosed space. Essential to the single zone method calculation are (Liddament, 1986):

- Flow paths and flow characteristics ( $k \&$ A values)

- Building height

- Internal/External temperature gradient

- Area wind speed

- Any local shielding conditions 
- Terrain roughness factors

- Mechanical ventilation system properties

The total infiltration into a space is then quantified using equation 2-29 and following equation 2-31 below (Liddament, 1986)

$$
Q_{\text {in }}=\sum_{i=1}^{j} Q_{i}
$$

Where:

- $\quad j=$ Total number of flow paths

- $\mathrm{Q}_{\mathrm{i}}>0:$ Infiltration Flow

$\mathrm{Q}_{\mathrm{i}}<0$ : Exfiltration Flow

\section{Multizone Models}

Multizone models differ from single zone models by accounting for internal partitions. These partitions obstruct the internal movement of air. Similar to single zone models, multizone models require knowledge of flow paths details and characteristics, building geometry and others. Added to the mass balance in these methods are airflow equations representing the air flow/leakage across internal zones and partitions (Liddament, 1986). However, according to Etheridge (1998), internal room air flow is of secondary effect on infiltration. The influences of wind gust and room air buoyancy induced pressures are the prominent infiltration driving force. Therefore, for each case, the amount of effort involved in using multizone models has to be weighed against the significance of accounting for the impact of internal partitions on the infiltration load calculations. A general depiction of a multizone calculation model layout is presented in Flowchart 2-6. 


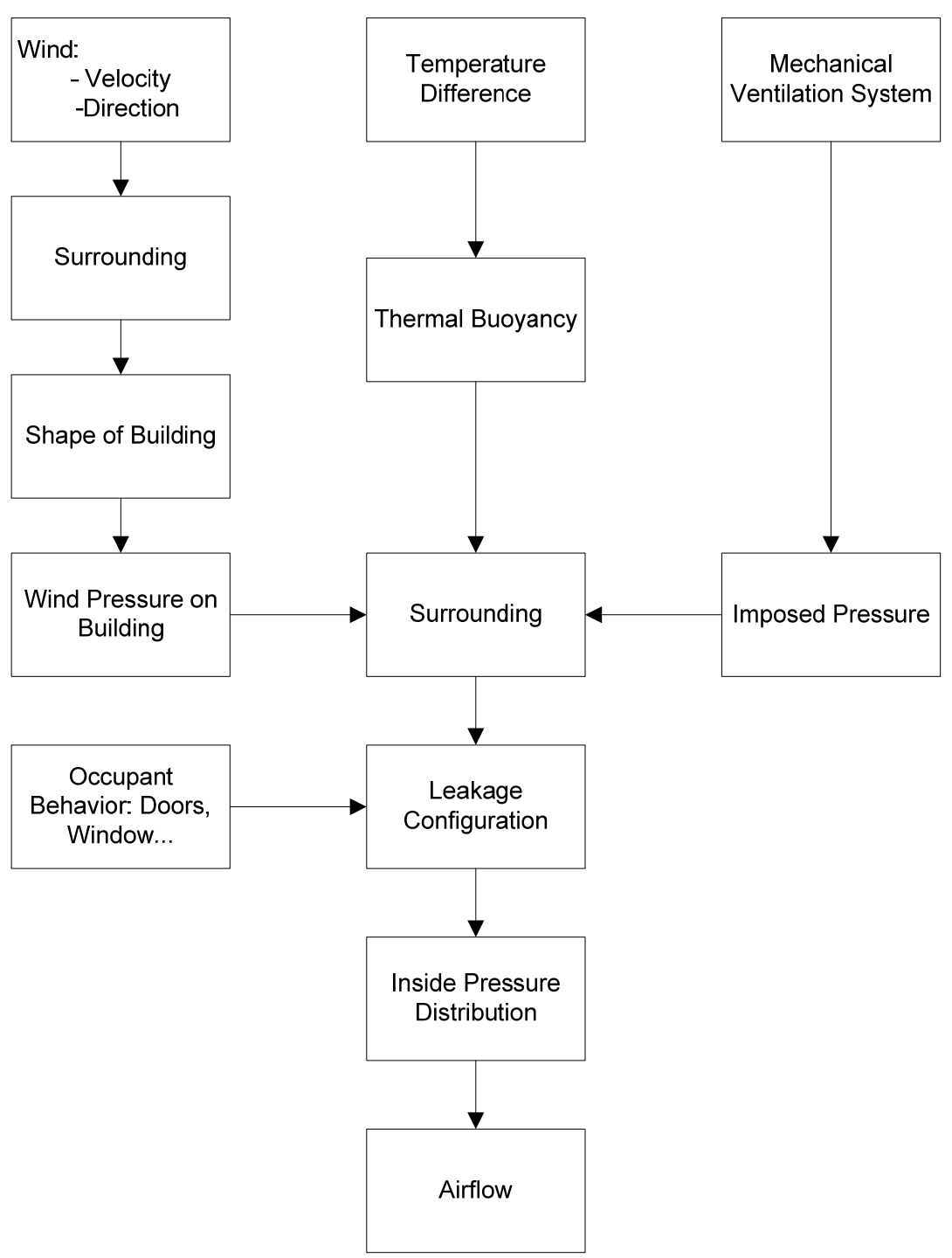

Flowchart 2-6: Multizone Models Calculation Models (Feustel, 1985 - Modified)

Single and multizone theoretical models represent an improvement over empirical methods. However, these methods require substantial data input and considerable computations. Multizone models also require a large amount of input and in many cases need for their variables values that are hard to obtain, such as wind and stack pressure coefficients and others. A building needs to be tested in order to obtain such coefficients, and therefore at a design stage obtaining such factors becomes problematic and a major 
source of simulation error. When these values are substituted for by scarce tabulated data, the level of simulation inaccuracy is elevated. This is due to the fact that generic coefficients are being used that do not represent local conditions, building characteristics, and other important building related factors. Furthermore, despite accounting for important infiltration related aspects, such as wind and stack pressure, using coefficient or some other form; existing multizone models still ignore other important factors that influence infiltration loads such as heat recovery and solar radiation.

\section{CFD, FFD, AND COMBINED MULTIZONE-CFD METHODS}

Multizone models, in addition to having the capability of simulating infiltration, can calculate the amount of mass flow between different zones within a building (interzonal airflow). Such information is essential for the design of heating/cooling and ventilation systems in buildings (Haghighat and $\mathrm{Li}, 2004$ ). However, the underlying assumption in most multizonal models is the presumption of perfect mixing of indoor air. This assumption of well-mixed zones permits these models to predict indoor conditions and the Hygrothermal performance of the building envelope (Steeman et al., 2009). Multizone models also assume a uniform temperature for each zone and neglect airflow momentum preservation inside a zone. These assumptions affect modeling accuracy and can result in errors (Wang and Chen, 2006). As a result was the promotion of Computation Fluid Dynamics (CFD) methods in modeling infiltration airflow. These methods reduce the number of assumptions otherwise necessary when using multizone methods. CFD methods are also capable of providing detailed airflow values, temperatures, and pollutant distribution conditions (Wang and Chen, 2006; Stamou and Katsiris, 2006). There are 3 general groups of CFD methods: Direct Numerical 
Simulation (DNS), Large Eddy Simulation (LES), and Raynolds Averaged Navier-Stokes (RANS) methods (Stamou and Katsiris, 2006).

Encountered flows can be turbulent and characterized with eddies falling into a wide range of lengths and time scales. Using a very fine grid resolution is required by DNS methods. Therefore though theoretically a direct solving of the Navier-Stokes equations is permissible, the use of DNS methods can be self-prohibitive. Alternatively, a filtering of eddies and Reynolds averaging can be performed. When filtering is applied, eddies smaller than the filter size (grid size is usually taken as filter size) are removed. Consequently large eddies are modeled using the filtered equations using what is known as LES (Large Eddy Simulation) CFD methods; small eddies are then separately modeled independent of the geometry of flow. Other methods rely on applying transport equations for quantities of mean flow only. These methods are known as RANS (Raynolds Averaged Navier-Stokes) CFD methods. The majority of CFD models utilize RANS Methods (Stamou and Katsiris, 2006).

One of the major draw backs of using CFD methods is simulation time. A single simulation of a building at even steady-state conditions can take from several hours up to several days. CFD methods are consequently unfeasible for use in hourly dynamic simulations of a building for the span of a full year (Wang and Chen, 2006). CFD is a very versatile and important tool for the study of flow and contaminant transport, yet when the simulated flow is complex and/or its domain is large a large and complex load of computation results. This could become severely prohibitive to the use of CFD in full building energy simulations (Zuo and Chen,2010). Therefore, the use of CFD has generally been reserved to air flow studies in single rooms (Mora et al., 2003). 
Combined multizone-CFD methods have been proposed in which CFD would be used for zones in which a uniform well-mixed condition assumption cannot be held, and a multizone model would be used for the remaining zones. As a result, since CFD would be applied to limited zones in a building, the computation load and required simulation time would be reduced compared to when applying the CFD method to the full building (Wang and Chen, 2006). Some proposed coupled multizone-CFD methods include Clark et al (1995), Negrao (1998) and Jayarman et al (2004). Another approach to reducing the computation complexity of CFD approaches are the proposed Fast Fluid Dynamics (FFD) methods such as Stam (1999). The same Navier-Stokes equations solved by CFD are solved by FFD methods. However, FFD methods utilize an alternative set of numerical methods in solving the governing differential equations which allow the model solution to proceed faster than when using a typical CFD method (Zou and Chen, 2010). Nevertheless, FFD methods are still not rapid enough for a real-time building simulation (Zou and Chen, 2010); setting aside performing an hourly simulation for a full building over a full 1 year time span. 


\section{Types of Air Infiltration}

Air infiltration results in higher energy consumption, thermal un-comfort and can cause moisture accumulation problems in walls and other infiltration flow paths. Air leakage can occur through two venues. Leakage can occur through large opening, through large cracks such as cracks in windows and door frames and seals and other large leakage points. Or, the air leakage can be spread over small cracks all over the building envelope. In reality, air infiltration occurs through a combination of both venues (Anerlind, 1985). Leakage through large openings, large leakage points, and cracks through which air follows short paths is referred to as "Concentrated" leakage. On the other hand, infiltration through small cracks in walls and others, in which air travels several feet before reaching the interior, is denoted as "Diffuse" leakage (Anderlind, 1985). Traditionally the energy load due to air infiltration is calculated as a product of the infiltration mass flow rate and the inside-outside enthalpy difference. This method of calculating infiltration loads might be well acceptable when calculating the load due to concentrated air infiltration. In diffuse infiltration, heat exchange (along the infiltrating air flow path) between the infiltrating air and the walls (or medium) results in a somewhat conditioning of the infiltrating air. Therefore, calculating the energy load due to diffuse infiltration using the classical infiltration calculating entails a considerable overestimation of the energy impact of this type of infiltration.

The subsequent sections include an overview of the quantification of the impact of both modes of infiltration, concentrated and diffuse. The infiltration through large openings such as doors, windows, fireplaces, and others will be discussed. Similarly, a recount of the impact of diffuse infiltration will be included. 


\section{Concentrated Air Infiltration}

\section{Doors}

Building entrance doors have always been a predicament for heating and air conditioning engineers. The problem is especially significant in stores and commercial buildings with an excessively heavy traffic of people utilizing the doors. During the summer cooling season entrance doors admit unwanted hot air from the outside; and during the heating season they let in cold air (Simpson, 1936). As in other forms of infiltration, air leakage through doors is driven by a pressure difference across the door. This pressure gradient is due to wind, stack effect or the ventilation system (Zmeuranu et al., 2001). Air infiltration through entrance doors cannot be considered as a good ventilation air. For example, during summer the air infiltrating through a door is a superheated and dust loaded air that has swept over hot pavements (Simpson, 1936). The air flow through doors influences, in addition to the heat load, the air circulation patterns and air contaminants distribution in a building (Wilson and Kiel, 1990). The amount of air infiltrating through doors is a summation of (1) the air infiltrating through cracks and openings between the door and its framing; and (2) the air infiltrating through open door as a function of the door area, open time, people traffic, temperature, and others. The amount infiltrating through a door, under a given pressure differential, varies from one door to another depending on (Min et al., 1985; Schuturm et al., 1961, Vatistas et al., 2006):

1. Entrance type : single bank door, vestibule...etc

2. Door dimensions

3. Doors arrangement: 
- Opposite doors

- Parallel doors

4. Direction of door swings:

- $\quad$ All swing out

- All swing in

- $\quad$ One swings out \& one swing in

5. Door rotational speed (for rotating doors)

6. Open time

7. Vestibule depth (if any)

8. Size of door cracks

9. Rates and patterns of traffic across the door

10. Tightness of other building parts and components

Several experimental studies have been performed in order to determine the infiltration through various forms of doors. The outcomes of such studies are charts and tables reporting the volumetric inflow of air as a function of the number of persons passing through the door per hour. Examples include Yuill (2000), Mc Quisten et al. (2000), Yuill (1996), Min et al. (1958) Simpson (1936) and others. Samples of such door charts and tables are shown in Tables 2-5 and 2-6 and Figures 2-9 and 2-10. Some works establish a neutral level in a door below which there is air inflow and air flow above such as Vatistas et al. (2007) 


\begin{tabular}{|c|c|c|c|c|c|c|}
\hline \multirow[b]{2}{*}{$\begin{array}{l}\text { No. of } \\
\text { Passages } \\
\text { per Hour } \\
\text { upto }\end{array}$} & \multicolumn{2}{|c|}{ Single Swing Doors } & \multicolumn{2}{|c|}{$\begin{array}{c}\text { Swing Doors - } \\
\text { Vestibules }\end{array}$} & \multicolumn{2}{|c|}{ Revolving Doors } \\
\hline & $\begin{array}{c}\text { Infiltration } \\
\text { per Passage } \\
\mathrm{ft}^{3}\end{array}$ & $\begin{array}{c}\text { Heat Gain } \\
\text { per Passage } \\
\text { per Degree } \\
\text { Temp Diff. } \\
\text { BTU }\end{array}$ & $\begin{array}{c}\text { Infiltration } \\
\mathrm{ft}^{3} \text { Per } \\
\text { Passage }\end{array}$ & $\begin{array}{l}\text { Heat Gain } \\
\text { BTU per }{ }^{\circ} \mathrm{F} \\
\text { Per Passage }\end{array}$ & $\begin{array}{c}\text { Infiltration } \\
\mathrm{ft}^{3} \text { Per } \\
\text { Passage }\end{array}$ & $\begin{array}{l}\text { Heat Gain } \\
\text { BTU per }{ }^{\circ} \mathrm{F} \\
\text { Per Passage }\end{array}$ \\
\hline 100 & 110 & 1.98 & 83 & 1.49 & 30 & 0.54 \\
\hline 200 & 110 & 1.98 & 83 & 1.49 & 30 & 0.54 \\
\hline 300 & 110 & 1.98 & 83 & 1.49 & 30 & 0.54 \\
\hline 400 & 110 & 1.98 & 83 & 1.49 & 29 & 0.52 \\
\hline 500 & 110 & 1.98 & 83 & 1.49 & 29 & 0.52 \\
\hline 600 & 110 & 1.98 & 82 & 1.47 & 28 & 0.50 \\
\hline 700 & 110 & 1.98 & 82 & 1.47 & 27 & 0.49 \\
\hline 800 & 110 & 1.98 & 82 & 1.47 & 26 & 0.47 \\
\hline 900 & 109 & 1.96 & 82 & 1.47 & 25 & 0.45 \\
\hline 1000 & 109 & 1.96 & 82 & 1.47 & 24 & 0.43 \\
\hline 1100 & 109 & 1.96 & 82 & 1.47 & 23 & 0.41 \\
\hline 1200 & 108 & 1.95 & 82 & 1.47 & 21 & 0.38 \\
\hline 1300 & 108 & 1.95 & 82 & 1.47 & 19 & 0.34 \\
\hline 1400 & 108 & 1.95 & 81 & 1.46 & 18 & 0.32 \\
\hline 1500 & 108 & 1.95 & 81 & 1.46 & 17 & 0.31 \\
\hline 1600 & 108 & 1.95 & 81 & 1.46 & 16 & 0.29 \\
\hline 1700 & 107 & 1.93 & 81 & 1.46 & 15 & 0.27 \\
\hline 1800 & 105 & 1.89 & 80 & 1.44 & 14 & 0.25 \\
\hline 1900 & 104 & 1.87 & 80 & 1.44 & 13 & 0.23 \\
\hline 2000 & 100 & 1.80 & 79 & 1.42 & 12 & 0.22 \\
\hline 2100 & 96 & 1.73 & 79 & 1.42 & 11 & 0.20 \\
\hline
\end{tabular}

Table 2-5: Infiltration Through Entrances - Doors in One Wall Only (Infiltration Through Doors, 1937) 


\begin{tabular}{|c|c|c|c|c|c|c|c|c|}
\hline \multirow[b]{2}{*}{$\begin{array}{c}\text { No. of } \\
\text { Passage } \\
\text { s per } \\
\text { Hour } \\
\text { upto }\end{array}$} & \multicolumn{2}{|c|}{$\begin{array}{c}\text { Single Swing } \\
\text { Doors }\end{array}$} & \multicolumn{2}{|c|}{$\begin{array}{c}\text { Swing Doors - } \\
\text { Vestibules }\end{array}$} & \multicolumn{2}{|c|}{$\begin{array}{l}\text { Revolving Doors } \\
\text { (6ft x 6ft) }\end{array}$} & \multicolumn{2}{|c|}{$\begin{array}{c}\text { Revolving Doors } \\
\text { (7ft } \times 7 \mathrm{ft})\end{array}$} \\
\hline & $\begin{array}{c}\text { Infiltrati } \\
\text { on per } \\
\text { Passage } \\
\mathrm{ft}^{3}\end{array}$ & $\begin{array}{c}\text { Heat } \\
\text { Gain per } \\
\text { Passage } \\
\text { per } \\
\text { Degree } \\
\text { Temp } \\
\text { Diff. } \\
\text { BTU }\end{array}$ & $\begin{array}{c}\text { Infiltrati } \\
\text { on } \mathrm{ft}^{3} \\
\text { Per } \\
\text { Passage }\end{array}$ & $\begin{array}{c}\text { Heat } \\
\text { Gain } \\
\text { BTU per } \\
{ }^{\circ} \text { F Per } \\
\text { Passage }\end{array}$ & $\begin{array}{l}\text { Infiltrati } \\
\text { on } \mathrm{ft}^{3} \text { Per } \\
\text { Passage }\end{array}$ & $\begin{array}{c}\text { Heat } \\
\text { Gain } \\
\text { BTU per } \\
{ }^{\circ} \text { F Per } \\
\text { Passage }\end{array}$ & $\begin{array}{l}\text { Infiltrati } \\
\text { on } \mathrm{ft}^{3} \text { Per } \\
\text { Passage }\end{array}$ & $\begin{array}{c}\text { Heat } \\
\text { Gain } \\
\text { BTU per } \\
{ }^{\circ} \text { F Per } \\
\text { Passage }\end{array}$ \\
\hline 100 & 110 & 1.98 & 83 & 1.49 & 30 & 0.54 & 48 & 0.86 \\
\hline 200 & 110 & 1.98 & 83 & 1.49 & 30 & 0.54 & 48 & 0.86 \\
\hline 300 & 110 & 1.98 & 83 & 1.49 & 30 & 0.54 & 48 & 0.86 \\
\hline 400 & 110 & 1.98 & 83 & 1.49 & 29 & 0.52 & 47 & 0.85 \\
\hline 500 & 110 & 1.98 & 83 & 1.49 & 29 & 0.52 & 46 & 0.83 \\
\hline 600 & 110 & 1.98 & 82 & 1.47 & 28 & 0.50 & 4 & 0.81 \\
\hline 700 & 110 & 1.98 & 82 & 1.47 & 27 & 0.49 & 43 & 0.78 \\
\hline 800 & 110 & 1.98 & 82 & 1.47 & 26 & 0.47 & 41 & 0.74 \\
\hline 900 & 109 & 1.96 & 82 & 1.47 & 25 & 0.45 & 39 & 0.70 \\
\hline 1000 & 109 & 1.96 & 82 & 1.47 & 24 & 0.43 & 36 & 0.65 \\
\hline 1100 & 109 & 1.96 & 82 & 1.47 & 23 & 0.41 & 33 & 0.59 \\
\hline 1200 & 108 & 1.95 & 82 & 1.47 & 21 & 0.38 & 30 & 0.54 \\
\hline 1300 & 108 & 1.95 & 82 & 1.47 & 19 & 0.34 & 28 & 0.50 \\
\hline 1400 & 108 & 1.95 & 81 & 1.46 & 18 & 0.32 & 25 & 0.45 \\
\hline 1500 & 108 & 1.95 & 81 & 1.46 & 17 & 0.31 & 23 & 0.41 \\
\hline 1600 & 108 & 1.95 & 81 & 1.46 & 16 & 0.29 & 21 & 0.38 \\
\hline 1700 & 107 & 1.93 & 81 & 1.46 & 15 & 0.27 & 19 & 0.34 \\
\hline 1800 & 105 & 1.89 & 80 & 1.44 & 14 & 0.25 & 18 & 0.32 \\
\hline 1900 & 104 & 1.87 & 80 & 1.44 & 13 & 0.23 & 17 & 0.30 \\
\hline 2000 & 100 & 1.80 & 79 & 1.42 & 12 & 0.22 & 16 & 0.29 \\
\hline 2100 & 96 & 1.73 & 79 & 1.42 & 11 & 0.20 & 15 & 0.27 \\
\hline
\end{tabular}

Table 2-6: Infiltration through Entrances - Doors in More Than one Wall (Infiltration Through Doors, 1937) 


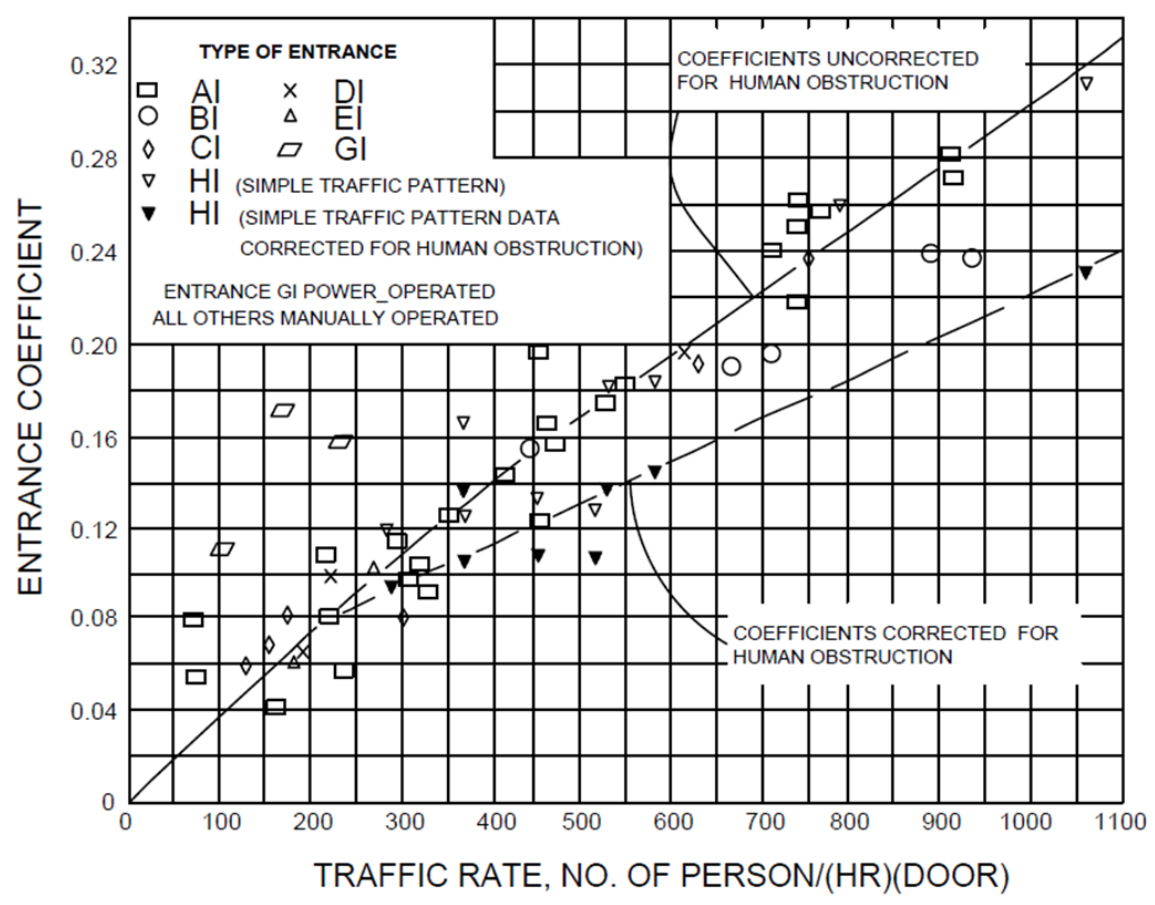

Chart 2-6: Entrance Coefficients for Single Bank Entrances (Min, 1958)

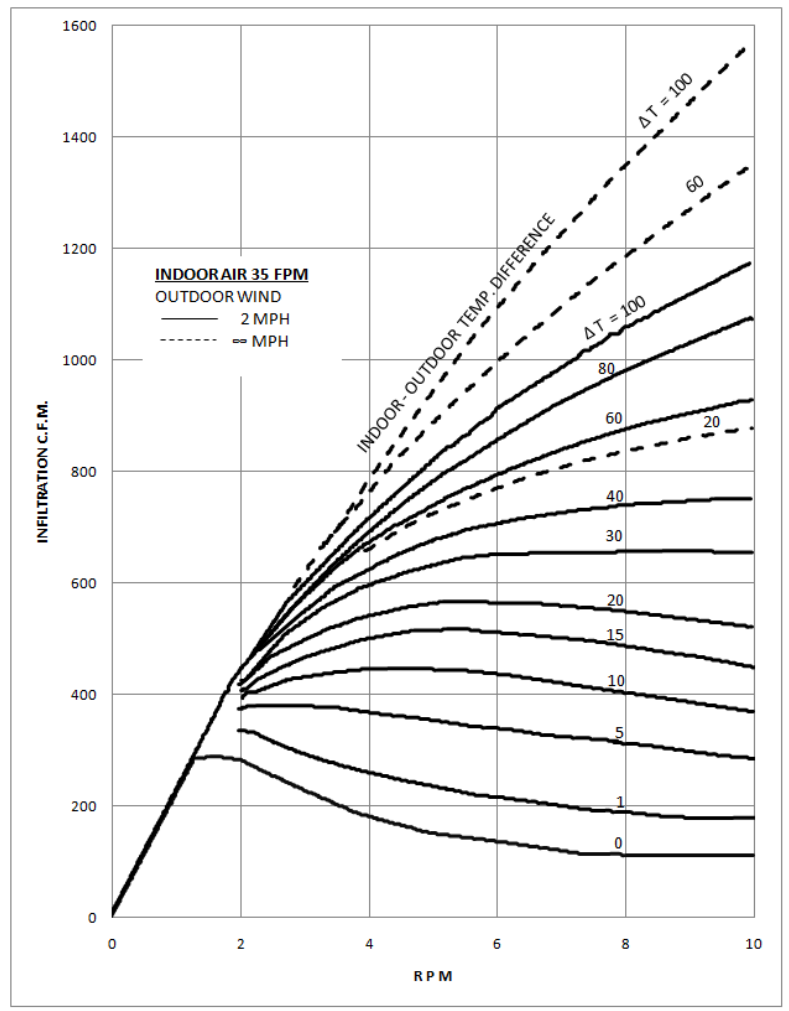

Chart 2-7: Infiltration versus RPM and indoor-outdoor temperature difference (Revolving Door) 
To reduce the energy load due to infiltration through doors, some designers resort to using air blowers. These blowers are installed above a door and blow in hot/cold air to compensate for the cold/hot infiltrating air. Such mechanisms also depend on charts and tables, similar to those shown above, to calculate the amount of air that needs to be introduced. Calculations are also done by equations similar to equation 2-32 (Fuller, 1949).

$$
A_{1}=\frac{A_{g}\left(T_{1}-T_{2}\right)}{\left(L T-T_{1}\right)}
$$

Where:

- $\mathrm{A}_{1}=$ Volume of Air introduced by blower

- $\mathrm{A}_{2}=$ Volume of inrushing outside air (from table/chart)

- $\quad \mathrm{T}_{3}=$ Outside temperature

- $\quad \mathrm{T}_{4}=$ Inside temperature

- $\quad \mathrm{LT}=$ Temperature of the Introduced (blown in) air.

\section{Windows}

Air infiltration through windows is of less bearing on the cooling/heating load of buildings then the infiltration through walls or open doors. The major energy impact of windows is rather through radiative heat flow. Studies of heat transfer in double glazed windows indicate that $70 \%$ of the heat flow is through radiation (Arasteh et al., 1985; Selkowitz, 1979). Nevertheless, the ramifications of air infiltration through windows are considerable. Significant damages to the building material can result from air leakage at the wall/window interface. This includes mold, fungal growth and damages to interior finishings, seals, insulation and even structural elements (ASHRAE Handbook - HVAC 
Applications, 2007). As with other venues of infiltration, air infiltration through windows is a function of: the inside-outside pressure difference, air speed, inside-outside air temperature difference, mechanical air balance, and the sealing characteristics of the window (Klems, 1983; Weidt and Weidt, 1980). In windows, the rate of infiltration is mostly affected by the construction quality, material used, weather stripping material and the method of operation (if any) (ASHRAE Handbook - HVAC Application, 2007).

The estimation of air infiltration through windows has 2 possible approaches; either calculating the air infiltration through a "particular" window, or evaluating the total infiltration through an average window. In the latter approach, all windows in a building level are considered to be identical and the net impact of window air leakage on the building is then calculated (Klem, 1983). Both methods deploy a form of the previously discussed orifice equation. Yet, when considering the averaging second approach, half of the windows are assumed to be in infiltration mode and the remaining windows are assumed to be experiencing exfiltration. Therefore a multiplication by half (1/2) factor is added to the orifice equation as shown in equation 2-33 (Klems, 1983).

$$
Q=\frac{1}{2} k\left(\Delta P_{w}\right)^{n}
$$

Where: $\mathrm{P}_{\mathrm{w}}$ account for both the stack and wind driven pressure across the window.

\section{Fire Place}

Fire places are used in many houses for heating during the heating season. A burning fire place adds a definite amount of heat to a room, especially in the vicinity of the fire place. However, fire places result also in a considerable air flow and the escape of warm air from the room up through the fire place flue (Anon, 1937). In order to maintain a mass balance, the warm air being lost through the flue of a fire place must be replaced. 
The only source of replacement air is the outside. Therefore, a volume of cold outside air will infiltrate into the house equivalent to the volume of warm air lost through the flue. Thus, even though the space temperature rises in the vicinity of a running fire place, the temperature of all the other rooms in the house will drop (Anon, 1937). Fire places, even when not burning, are venues for air leakage and even with the dampers (fire place throat) and the J-vent closed. In an experimental study, Dickson (1988) found that in a non-burning fire place a single opening (J-vent or throat) increases the infiltration rate from $0.15 / 0.2 \mathrm{ACH}$ (air changes per hour) to $02 / 0.4 \mathrm{ACH}$ in the whole house and from $0.15 \mathrm{ACH}$ to $1 \mathrm{ACH}$ in the room containing the fire place. This increase in air change rate adversely impacts the heating load since indoor warm air is now being replaced faster by large volumes of cold air that needs to be heated in order to maintain the set indoor room temperature. Also, under the common practiced "fault" of leaving both the fire place and the J-vent open the infiltration rate in the room hikes up to $2 \mathrm{ACH}$, seriously impacting the heating energy load. Finally, a burning fire place creates an infiltration rate of $5 \mathrm{ACH}$ in the room and an increase of up to $1 \mathrm{ACH}$ for the whole house (Dickson, 1988).

The net energy impact of a running fire place depends on the amount of heat being delivered by the fire place onto the house versus the amount of heat required to warm up the infiltrating cold air. In many situations the latter exceeds the former and as a result it would be more energy efficient to not run the fire place. This conclusion is evident in Figure 2-11 (Anon, 1937). Below a certain fire place heat production rate cutoff point, the energy needed to heat up the infiltrating air (due to the running fireplace) exceeds the amount of heat produced by the fire place. In Figure 2-11, for example, if the 
fire place is producing less than $\sim 16,000 \mathrm{Btu} / \mathrm{hr}$ it would be more efficient to shut it off, since heating up the infiltrating air (due to the running fire place) is consuming more heat energy than being put out by the fire place.

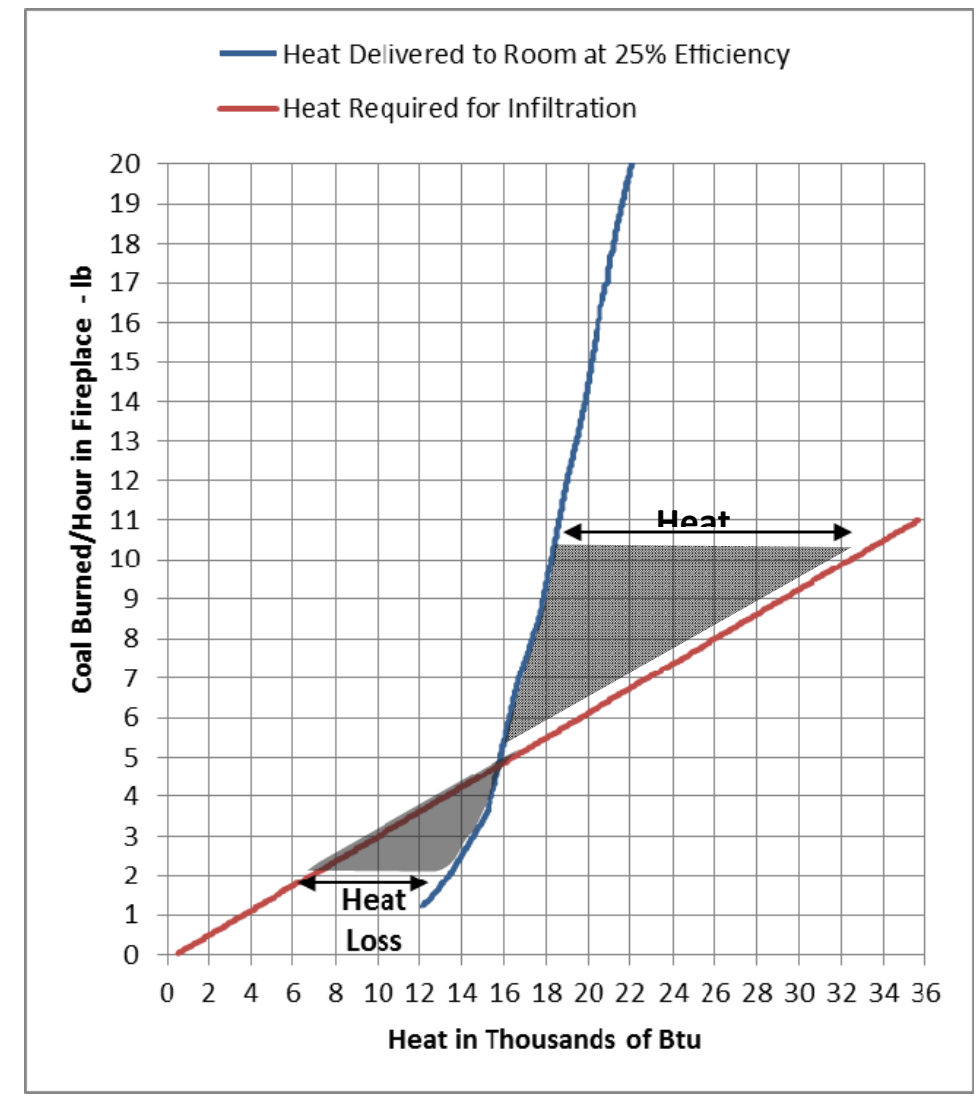

Chart 2-8: The intersection point of the two curves in this chart shows the point where there is no addition or loss of heat (Anon, 1937) - Reproduced

\section{Diffuse Air Infiltration: Heat Recovery}

Diffuse air infiltration occurs through minute cracks and paths in the walls and the overall building envelope. In diffuse infiltration, in contrast with concentrated infiltration, infiltrating air travels through the wall for several feet before reaching the interior. Air infiltration through cracks surrounding doors and windows is classified as concentrated infiltration. Even though the air is infiltrating through small openings and cracks, it doesn't travel a relatively long distance in the wall and therefore this infiltration is considered concentrated not diffuse. Diffuse leakage of air through a wall shifts the 
temperature distribution of the wall from a straight line distribution (if 1 layer on is considered, for example) to a curved distribution; thus changing the temperature distribution in the wall (Anderlind, 1985). A heat exchange occurs between the wall and the infiltrating air, a phenomena known as heat recovery. Heat recovery plays a significant role in evaluation the heating/cooling loads due to air leakage (Anderlind, 1985).

Early observations of heat recovery include Harrje (1977) and Beyea et al. (1977) who found that actual attic temperatures exceeded those predicted by typical insulation resistance models. Several other studies also reported the observed impact of heat recovery in reducing heating/cooling energy loads. Claridge et al. (1985) reported a calculated overall house energy loss factors $50 \%$ above those obtained through regression analysis of recorded experimental house data; indicating a "Heat Recovery" in infiltration energy. Other similar work includes Claridge and Bhattacharyya (1990) who measured infiltration loads equivalent to as low as $20 \%$ of those calculated using classical infiltration calculation methods. Classical methods for calculating the additional energy load due to infiltration, including computer models and hourly simulation programs, assume a load increase due to infiltration equal to the infiltrating air mass flow rate times the inside-outside air enthalpy difference. The classical expression for infiltration is shown in equation 2-34.

$$
Q_{\text {inf }}=\dot{m} C_{p}\left(T_{i}-T_{o}\right)
$$

Classical methods generally ignore the interaction between infiltration and conduction. The heat load is therefore calculated as a summation of the heat loss due to conduction and the heat loss due to infiltration (Claridge and Bhattacharyya, 1990; 
Claridge and Liu, 1996). A handful of combined heat loss models where therefore proposed to account for this interaction between conduction and infiltration; including Anderlind (1985), Liu (1987), Bailly (1987) and Arquis (1986). However, the model provided by Anderlind was considered to provide the most intuitive and logical expression (Liu, 1992). Anderlind considered the classical infiltration expression to give the maximum heat loss due to infiltration and therefore defined a reduction factor "R".R is defined as varying between 0 and $1(0<\mathrm{R}<1)$. For a purely concentrated flow infiltration $\mathrm{R}$ approaches 1 and as a result the heat loss is given by the classical expression (equation 2-34). Conversely, for purely diffuse flow infiltration R approached 0 . However, in reality, infiltration through a building envelope is a combination of both concentrated and diffuse flows. Therefore, $\mathrm{R}$ varies between 0 and 1 based on the flow distribution. The general expression given by Anderlind is shown in equation 2-35.

$$
Q_{\text {inf }}=R\left[\dot{m} C_{p}\left(T_{i}-T_{o}\right)\right]
$$

Where:

$$
\text { - } 0<\mathrm{R}<1 \quad\left\{\begin{array}{l}
\mathrm{R} \rightarrow 0 \text { : Diffuse Flow } \\
\mathrm{R} \rightarrow 1: \text { Concentrated Flow }
\end{array}\right.
$$

Claridge and Bhattacharyya (1990) introduced a new non-dimensional factor representing the effectiveness of heat recovery resulting from the heat exchange between infiltrating/exfiltrating air and the walls. This factor is known as the "Infiltration Heat

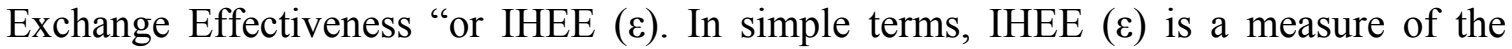
success of the building in "recovering" the otherwise lost (gained) heat due to infiltration of outside air (Claridge and Bhattacharyya, 1990). Research on IHEE has shown $\varepsilon$ to increase as (Claride and Bhattacharyya, 1990; Bhattacharyya and Claridge, 1996):

- Flow rate decreases 
- $\quad$ Flow path length increase

- Crack/hole size diminished

The general expression of IHEE is given by equation 2-36 (Claridge et al. 1995).

$$
I H E E=\varepsilon=\frac{U A_{0}+\dot{m} C_{p}-U A_{\text {actual }}}{\dot{m} C_{p}}
$$

Where:

- $\quad U A_{0}=$ heat loss factor due to conduction only

- $\quad \mathrm{C}_{\mathrm{p}}=$ Specific heat of air

- $\quad \dot{m}=$ Air infiltration mass flow rate

- $\quad U A_{\text {actual }}=$ Actual heat loss factor with airflow included

Consequently, the infiltration heat loss is expressed as in equation 2-37

$$
Q_{\text {inf }}=(1-\varepsilon)\left[\dot{m} C_{p}\left(T_{i}-T_{o}\right)\right]
$$

The value of IHEE $(\varepsilon)$ depends largely on the relative distribution of air leakage between concentrated and diffuse leakage (Claridge and Bhattacharyya 1990). The range of $\varepsilon$ was originally assumed to be $0 \leq \varepsilon \leq 1$.

The dependence of $(\varepsilon)$ on air flow rate is expressed in terms of a non-dimensional factor $\alpha$, defined in equation 2-38. For no air leakage flow ( $\left.\dot{m} C_{p}=0\right) \alpha=0$; and $\alpha=1$ for an infiltration loss coefficient $\left(\dot{m} C_{p}\right)$ equal to the conductive loss coefficient $\left(U A_{0}\right)$. Therefore, the dependence of $(\varepsilon)$ on air flow rate was approximated by equation 2-39 (Bhattacharyya and Claridge, 1990).

$$
\begin{gathered}
\alpha=\frac{\dot{m} C_{p}}{U A_{0}} \\
\varepsilon=\varepsilon(0)+m \alpha
\end{gathered}
$$


Further research by Claridge and Liu (1992) highlighted the dependence of heat recovery on an additional component, solar radiation. The combined impact and interaction between conduction, infiltration and solar radiation in walls and attics was studied. With the role of solar radiation included; the influence of flow rate and air leakage configuration (diffuse versus concentrated) on IHEE where still consistent with the previously stated observations. However, solar radiation further impacted the actual energy loss due to air leakage compared to the classical equation. The combined effect of solar radiation and infiltration helped carry more solar energy to the interior, further reducing the energy loss due to infiltration compared to the classically calculated value ( in the case of the heating season for example). In the cooling season, however, the same phenomenon helps increase the cooling load by carrying more solar energy inside. A reversed effect is observed due to exfiltration. Summer exfiltration helps enhance heat recovery in the walls by expelling to the outside incident solar radiation; however exfiltration has a reduced affect on IHEE (Claridge and Liu, 1996; Claridge and Liu, 1992). Due to the introduced impact of solar radiation $\varepsilon$ was found to now be capable of exceeding 1 or going below 0 (contrary to the initial assumption $0 \leq \varepsilon \leq 1$ ). Claridge and Liu (1996) suggested a modified heat recovery factor $\varepsilon$, incorporating the affect of solar radiation shown in equations 2-40 and 2-42.

$$
\varepsilon_{t}=\frac{U A_{\text {classical }}-U A_{\text {actual }}}{U A_{\text {classical }}}
$$

Where:

- $\varepsilon_{t}=$ Ration of recovered energy to the energy loss calculated using classical method

$$
\text { - } \quad U A_{\text {classical }}=U A_{0}+\dot{m} C_{p}
$$




$$
Q_{\text {inf }}=U A_{0}\left(T_{r}-T_{s a}\right)+(1-\varepsilon)\left[\dot{m} C_{p}\left(T_{i}-T_{o}\right)\right]
$$

Where:

- $\quad T_{s a}=$ Appropriate sol air temperature

Neglecting the interaction of conduction and solar radiation with infiltration explains a large portion of the overestimation/underestimation of building energy consumption due to air leakage. Models considering the simultaneous interaction of infiltration, conduction, and solar radiation (in an idealized situation) have shown a $38 \%$ to $100 \%$ saving on heating energy and up to $33 \%$ saving on cooling energy compared to a leaky house with no heat recovery (Liu and Claridge, 1992).

Buchanan and Sherman (1998 and 2002) performed 2D and 3D computational fluid dynamics (CFD) simulations for studying the fundamentals of infiltration heat recovery. They found infiltration heat recovery to be of substantial affect. At low leakage rates, the classical method vastly over predicted the loss by $80 \%$ to $95 \%$. Even at high leakage rates, the infiltration energy load was overestimated by $20 \%$ by the classical calculation method. Flow and energy transport were modeled using Navier-Stokes and the energy equations 2-43 and 2-44.

$$
\begin{gathered}
\frac{\varphi \rho}{\varphi t}+\frac{\varphi \rho U_{i}}{\varphi X_{i}}=0 \\
\frac{\varphi \rho T}{\varphi t}+C_{p} \frac{\varphi \rho U_{i} T}{\varphi X_{i}}=\mathrm{k} \frac{\varphi^{2} \rho T}{\varphi X_{i}^{2}}+\frac{\varphi \rho}{\varphi t}+U_{i} \frac{\varphi \rho}{\varphi X_{i}}
\end{gathered}
$$

Buchanan and Sherman's CFD model results compared within $10 \%$ in one case with Claridge and Bhattacharyya. Buchanan and Sherman (2000) also developed a simplified "macro-scale" mathematical model for infiltration heat recovery. The model is 
based on steady state one dimensional convection-diffusion. However, the purpose of the model is reported by the authors to be for giving a rough idea of the effect of heat infiltration recovery and "not (for) incorporation into network codes for dynamic building simulation" and "doesn't capture the full physics of the problem". (Buchanen and Sherman, 2000).

Brownell (2002) conducted experimental tests to collect data for verification of the Buchanan and Sherman model $(1998,2000)$ using a methodology resembling that of Bhattacharyya and Claridge $(1990,1995)$. The experimental data extended the range of the non-dimensional flow rate $\alpha$ measured. Claridge and Bhattacharyya (1990) expressed (ع) in a linear relationship with $\alpha$. However, Brownell data demonstrated a nonimmediately linear relationship (Brownell, 2002). The experimental data of Brownell agreed within $10 \%$ with Buchanan and Sherman (2000) in some aspects, yet the agreement was not quite good in the remaining sections; especially at high flow rates (Brownell, 2002).

Understanding the heat recovery phenomenon and its impact is of large significance; especially in the field of building science, building physics, and hygrothermal engineering. A better understanding of infiltration heat recovery allows a better estimation of the heating and cooling requirements of a building. This in turn reflects in a more accurate sizing of the required HVAC system. Also, allows a better management of required building tightness criteria. Engineers might, for example, rely on more natural ventilation by allowing a certain amount of air leakage; while depending on heat recovery in the walls to keep the building energy loads in hand. Or, in other cases, seek tighter construction (for example when $\varepsilon$ is low or below zero). Furthermore, a 
better understanding of this phenomenon helps better understand attic (and radiant barriers) and insulation behavior (Bhattacharyya, 1999).

The wide spread use of building energy simulation software makes important the integration of the heat recovery phenomenon impact into the calculation models of energy simulation software. As discussed earlier, most building energy simulation software predominantly deploy the classical methods in calculating infiltration energy loads. It is therefore essential to alter infiltration calculation models in building energy software from classical infiltration theories to models that take into account the interaction between conduction, solar energy, and infiltration. Thus incorporating the impact of heat recovery in their building energy loads calculations. Various literature discussed in this review have emphasized the large effect of heat recovery has on the calculation of air infiltration energy loads. It is therefore crucial that infiltration heat recovery be incorporated into the principal energy building energy analysis software. Especially, into DOE-2 (discussed in this review) due to its wide spread use, intricacy, and its role as the simulation engine of various prominent building energy analysis software. 


\section{Building Energy Simulation Infiltration Evaluation Approach}

\section{Current Approach}

Infiltration, as discussed in previously, is a major contributing factor to the heating/cooling load of a building. However, it is the component that most building energy simulation software struggle to model. Infiltration is primarily dependent on the building construction, tightness of the building envelope, building surrounding and local topography, wind speed, wind direction, local weather and others. Thus to avoid these complexities, infiltration is usually modeled using overly simplified and approximate models in building energy simulation software. Such models also ignore the impact of heat recovery in the building envelope on the infiltration load, and the interaction between solar radiation, conduction and infiltration despite of the proven key impact of the interaction of these phenomena. Among these prominent building energy simulation software is DOE-2. Three models were majorly employed by DOE-2 for evaluating the energy impact of infiltration: (1) Air change, (2) Crack Method and the (3) Residential (Achenbach - Coblentz) model. Recently added were also the (4) Sherman-Grimsrud method and (5) ASHRAE Enhanced Method. These methods are shortly described below with reference to DOE-2 Engineers Manual, Version 2.1A (1982) and DOE-2.2 Volum2: Dictionary (2009).

\section{Air-Change Method}

The air change method is based on evaluating infiltration based on the number of infiltration-caused air changes per hour. This method is based on a reference wind speed of $10 \mathrm{mph}$ accompanied by a wind speed correction factor. The air change method basic equation is described by equation 2-45. 


$$
\begin{aligned}
& \text { Infiltration }(\mathrm{cfm})=(\text { wind speed })(\text { Air changes } / \mathrm{hr}) \times \text { Volume of space } \\
& \qquad+(c f m / \text { space square foot })(\text { Space Area })(2-45)
\end{aligned}
$$

In equation $2-45$, only one of the two parts of the equation is utilized at one time while the other is set to zero, depending on the user input. If the first part of the equation is utilized it allows a linear wind speed correction to the local wind speed. However, neither term provides any correction/consideration for the prevalent temperature difference across the building envelope.

\section{Residential Method}

The residential method has no theoretical justification but rather represents a statistical fit to collected residential infiltration data (Achenbach and Coltz, 1963; Ross and Grimsrud 1978, Peterson 1979). The general expression of the residential method is given by equations 2-46 and 2-47.

$$
\begin{gathered}
\text { Air changes } / \text { hr }=A+(B)(\text { Wind Speed })+(C)\left(\left|T_{\text {zone }}-T_{\text {Dry bulb }}\right|\right) \quad(2-46) \\
\text { Infiltration }(\text { cfm })=(\text { Air changes } / \text { hr }) x(\text { Volume })\left(\frac{1}{60}\right) \quad(2-47)
\end{gathered}
$$

Where: A, B \& C are curve fit coefficients

The default values of $\mathrm{A}, \mathrm{B}$ and $\mathrm{C}$ are (Peterson, n.d.):

$$
\begin{aligned}
& A=0.252 \\
& B=0.0251 \\
& C=0.0084
\end{aligned}
$$




\section{Crack Method}

The crack method considers, yet inadequately, the impacts of wind velocity and the stack effect. The infiltration driving pressure caused by each of these two phenomena is evaluated separately as shown by equations $2-48 \& 2-49$.

$$
\begin{array}{r}
P_{\text {Wind }}=(\text { Constant })(\text { wind speed })^{2}(\cos (\text { wind direction })) \\
P_{\text {Stack }}=(\text { Constant })\left(P_{\text {atm }}\right)\left(\frac{1}{T_{\text {Dry bulb }}}-\frac{1}{T_{\text {zone }}}\right)(\text { Height above } N P L)
\end{array}
$$

Where: NPL $=$ Neutral Pressure Level

$$
\begin{aligned}
& \therefore \text { Total Driving Pressure: } P_{\text {Total }}=P_{\text {stack }}+P_{\text {Wind }} \\
& \quad \Rightarrow \quad \text { Infiltration }=(\text { constant }) \times P_{\text {Total }} \times \text { Area }
\end{aligned}
$$

\section{Sherman - Grimsrud Method \& ASHRAE Enhanced Method}

The Sherman-Grimsrud method and ASHRAE Enhanced method both apply only to single zones. The Sherman-Grimsrud incorporates the neutral level concept and leakage area distribution between floor, ceiling and other components. The ASHRAEEnhanced method was defined by Walter and Wilson (1998). It depends on leakage coefficients obtained using house pressurization tests. This method is highly dependant on these coefficients that are rather difficult to determine (DOE-2 Dictionary, 2009). DOE-2 employs for these coefficients default values given in a calculation example presented in the ASHRAE Handbook of Fundamentals with no other coefficient references or value lists. The infiltration air flow rate with this method is calculated using equations 2-52 and 2-53 (ASHRAE Fundamentals, 2009).

$$
Q_{\text {stack }}=c C_{s} \Delta t^{n}
$$




$$
Q_{w}=c C_{w}(S U)^{2 n}
$$

Where:

- $\mathrm{Q}_{\mathrm{s}}=$ Stack airflow rate, cfm

$-\mathrm{Q}_{\mathrm{w}}=$ Wind airflow rate, $\mathrm{cfm}$

- $\mathrm{C}=$ flow coefficient

$-\mathrm{C}_{\mathrm{s}}=$ Stack ceofficient

$-\mathrm{C}_{\mathrm{w}}=$ Wind coefficient

- $\mathrm{n}=$ pressure exponent

- $\Delta t=$ temperature difference between indoors and outdoors,

$-\mathrm{S}=$ Shelter factor

\begin{tabular}{|c|c|c|c|}
\cline { 2 - 4 } \multicolumn{1}{c|}{} & \multicolumn{3}{c|}{ House Height (Stories) } \\
\cline { 2 - 4 } \multicolumn{1}{c|}{ One } & Two & Three \\
\hline Stack Coefficient & 0.0150 & 0.0299 & 0.0499 \\
\hline
\end{tabular}

Table 2-7: Stack Coefficient $C_{s}$ (ASHRAE Handbook of Fundamentals, 2009)

\begin{tabular}{|c|c|}
\hline & Local Shelter Classes \\
\hline Shelter Class & Description \\
\hline 1 & No Obstruction or Local Shielding \\
\hline 2 & Typical shelter for an isolated rural area \\
\hline 3 & $\begin{array}{l}\text { Typical shelter caused by other buildings across street from building } \\
\text { under study }\end{array}$ \\
\hline 4 & $\begin{array}{l}\text { Typical shelter for urban buildings on larger lots where } \\
\text { sheltering obstacles are more than one building height away }\end{array}$ \\
\hline 5 & $\begin{array}{l}\text { Typical shelter produced by buildings or other structures } \\
\text { immediately adjacent (closer than one house height) }\end{array}$ \\
\hline
\end{tabular}

Table 2-8: Local shelter classes (ASHRAE Handbook of Fundamentals, 2009) 


\begin{tabular}{|c|c|c|c|}
\cline { 2 - 4 } \multicolumn{1}{c|}{} & \multicolumn{3}{c|}{ House Height (Stories) } \\
\hline Shelter Class & One & Two & Three \\
\hline $\mathbf{1}$ & 0.0119 & 0.0157 & 0.0184 \\
\hline $\mathbf{2}$ & 0.0092 & 0.0121 & 0.0143 \\
\hline $\mathbf{3}$ & 0.0065 & 0.0086 & 0.0101 \\
\hline $\mathbf{4}$ & 0.0039 & 0.0051 & 0.0060 \\
\hline $\mathbf{5}$ & 0.0012 & 0.0016 & 0.0018 \\
\hline
\end{tabular}

Table 2-9: Wind Coefficient $C_{w}$ (ASHRAE Handbook of Fundamentals, 2009)

\section{Final Calculation}

Once the infiltration flow rate is determined using any of the previously discussed five methods; the resulting sensible and latent infiltration loads are calculated using equations 2-54 and 2-55.

Sensible Infiltration Load

$$
=(\text { constant }) x \rho_{\text {air }} x(\text { Flow Rate }) x\left(T_{\text {Ambient }}-T_{\text {zone }}\right)
$$

Latent Infiltration Load $=($ constant $) x \rho_{\text {air }} x($ Flow Rate $)$

$$
x \text { (Outside humidity - Indoor Humidity) }(2-55)
$$

Several other building energy simulation software utilize these or other similar methods, especially that DOE-2 represents a simulation engine and a base for many other building energy simulation software. 


\section{Chapter 3}

\section{Methodology}

\section{Combined Infiltration, Conduction \& Solar Model}

Infiltration, conduction and incident solar radiation act jointly allowing heat recovery to occur in the building envelope and to impact the energy load due to infiltration. Several models have been suggested to enhance infiltration calculations and incorporate heat recovery into infiltration energy load calculations. Earlier models such as Anderlind (1985), Kohonen (1985), Kohonen and Nirtanen (1987) and others tend to be based on some linear reduction factor, depend on steady temperatures and a steady inside/outside enthalpy difference, and ignore the role and impact of solar radiation. Solar radiation has been shown by Liu (1992), through experimental testing, to contribute to infiltration heat recovery and affect the intensity of heat exchange efficiency (IHEE). A later model to incorporate the impact of heat recovery is the model by Sherman and Buchanan (1998). Similar to previous models, this model disregards the experimentally proven role of incident solar energy. CFD models created by the authors to verify the method suffered from convergence issues. A 3-D CFD grid reduction from 140,000 to 33,000 nodes was performed in order to obtain CFD model convergence, yet no verification was performed for grid dependency of the solution. Later experimental work (Brownell, 2002) revealed feeble agreement with the Sherman and Buchanan (1998) model results. Finally, according to the authors the model is not for incorporation into network codes and “doesn't capture the full physics of the problem" (Sherman and Buchanan, 1998). 
The model that will be used and built upon in this methodology was proposed by Liu and Claridge and presented in Liu (1992), Liu and Claridge (1992), Liu and Claridge (1995), Claridge and Liu (1996). The model presented is based on a second order nonlinear dynamic differential equation. This model accounts for variable temperatures, changes in infiltration flow rate $(\dot{m})$, accounts for the role of solar radiation, and finally considers the interdependence and interaction between solar radiation, conduction and infiltration. The model will be presented below based on Liu (1992) and using simplifications from Patankar (1980). This infiltration energy load model will be incorporated into the hourly calculations of hourly building energy simulation software for the calculation of infiltration energy load as shown in Flowchart 3-1.

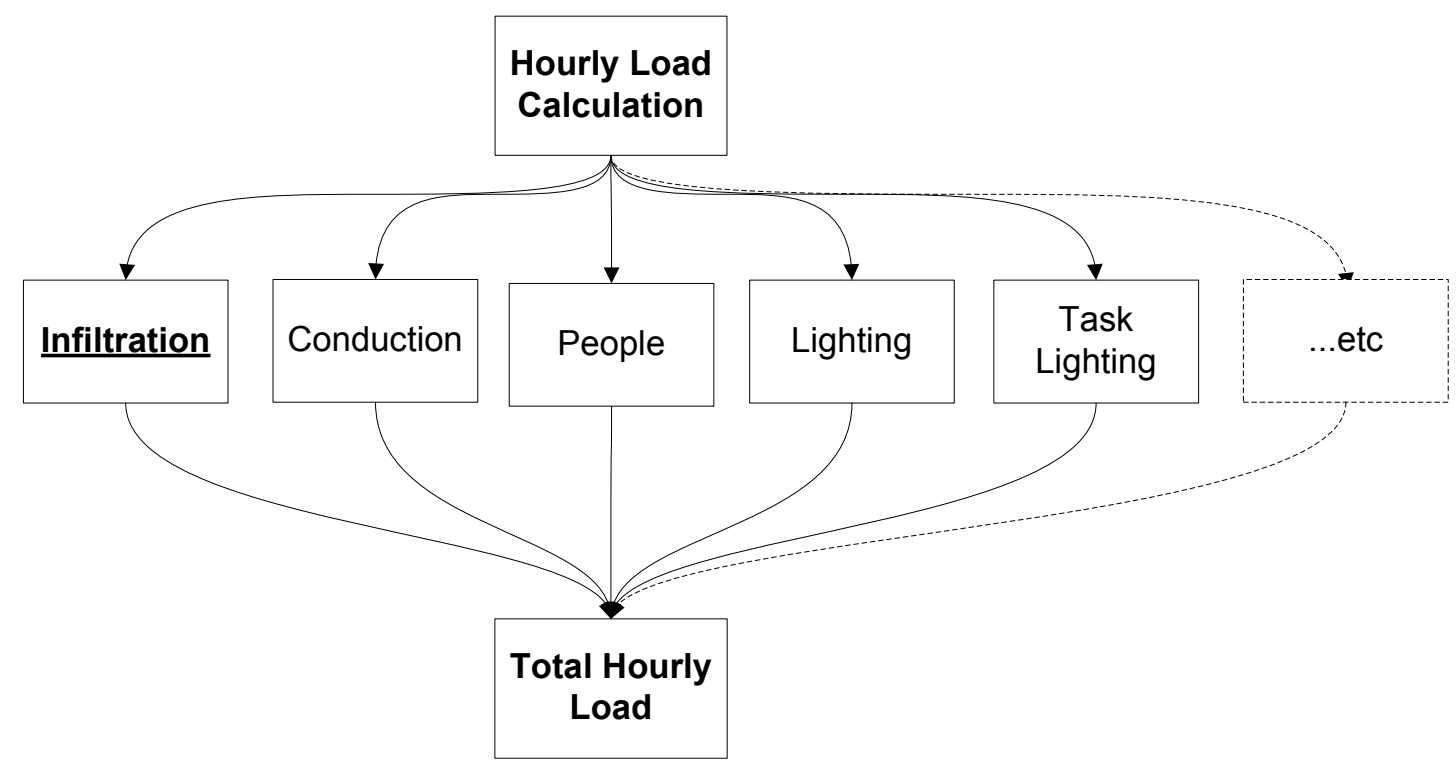

Flowchart 3-1 : Model Incorporation into hourly calculations

\section{Differential Equation}

The underlying concept of the differential equation is that the energy gained is equal to the difference between the "in" and "out" energy flux flows. There are 2 
assumptions inherent into the use of this equation. Primarily is the assumption that air and solid material have an identical temperature at any position and that the infiltration flow is represented by the air mass flow rate $\dot{m}$. The controlling differential equation is then defined by equation 3-1 and with reference to the control volume shown in Figure 31.

$$
Q_{x}-Q_{x+d x}+Q_{a, x}-Q_{a, x+d x}=\delta Q
$$

Where:

- $\quad \mathrm{Q}_{\mathrm{x}} \quad=$ Heat flux entering the control volume due to conduction

- $\quad \mathrm{Q}_{\mathrm{x}+\mathrm{dx}}=$ Heat flux leaving the control volume due to conduction

- $\mathrm{Q}_{\mathrm{a}, \mathrm{x}} \quad$ = Energy carried in by airflow

- $\quad Q_{a, x+d x}=$ Energy carried out by airflow

- $\delta Q=$ Heat storage rate in control volume

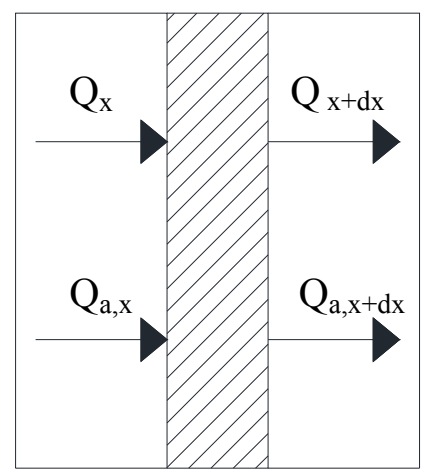

Figure 3-1: Heat flux flow control volume 
The terms in equation 3-1 can each be represented as:

$$
\begin{aligned}
& Q_{x}=-k \frac{\delta T}{\delta x} \delta \tau \\
& Q_{x+d x}=-k \frac{\delta T}{\delta x} \delta \tau-k \frac{\delta^{2} T}{\delta^{2} x} \delta x \delta \tau \\
& Q_{a, x}=\dot{m} C_{p} T \delta \tau \\
& Q_{a, x+d x}=\dot{m} C_{p} T \delta \tau+\dot{m} C_{p} \frac{\delta T}{\delta x} \delta x \delta \tau-C_{p} T \frac{\delta \dot{m}}{\delta x} \delta x \delta \tau \quad * 1 \\
& \delta Q=\frac{\delta T}{\delta \tau}\left(\rho C+\gamma \rho_{a} C_{p}\right) \delta x \delta \tau \quad * 2
\end{aligned}
$$

Note:

- ${ }^{* 1}$ There isn't much change in airflow rate with path, this term can be ignored

- ${ }^{* 2}$ Air heat capacity is $<<$ Solid heat capacity, thus this term can be ignored Where:

- $\quad \dot{m}=$ Air infiltration rate

- $\quad C_{p}=$ Specific heat of air

- $\quad \mathrm{C}=$ Specific heat of solid

- $\quad \rho=$ Density of solid material

- $\quad \rho_{a}=$ Density of air

- $\quad \gamma=$ Porosity of wall

- $\quad k=$ Conductivity of solid material

- $\quad T=$ Temperature

- $\tau=$ Time 
Replacing all the terms in equations 3-2 to 3-6 in equation 3-1 and reducing it results in equation 3-7 shown below, a one dimensional, second order non-linear equation.

$$
\rho C \frac{\delta T}{\delta \tau}=k \frac{\delta^{2} T}{\delta^{2} x}-\dot{m} C_{p} \frac{\delta T}{\delta x}
$$

The above equation is a second order nonlinear dynamic differential equation and therefore has no analytical solution. A numerical solution will therefore be used for the differential equation and the equation will be discretized as follows. The discretization will utilize expressions from Patankar (1980).

\section{Differential Equation Discretization}

The differential equation is discretized for a set of nodes. The central node is denoted as P. The node on its east is denoted as E and the node on the west is denoted as W. The midpoint of the distance between the nodes P \& E is denoted as e and that between $\mathrm{P}$ and $\mathrm{W}$ is denoted as $\mathrm{w}$. These nodes and notations are shown on Figure 3-2.

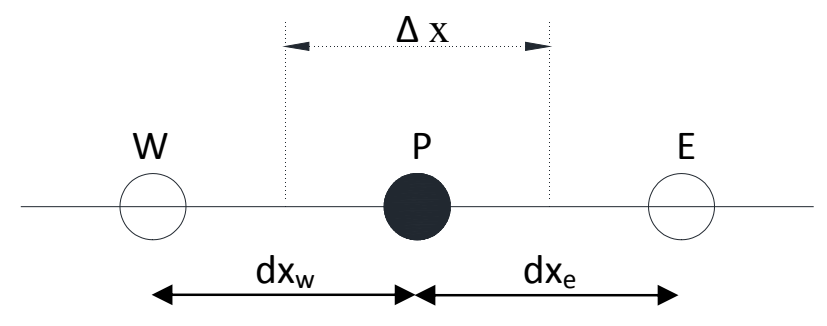

Figure 3-2: Nodes and notation

\section{Internal Node/Layer}

A control volume is taken over $\Delta \mathrm{x}$ between $\mathrm{w}$ and e and a double integration of equation 3-7 over time and space is performed as shown in equation 3-8. 


$$
\int_{\tau}^{\tau+\Delta \tau} \int_{x}^{x+\Delta x} \rho C \frac{\delta T}{\delta \tau} d x d \tau=\int_{\tau}^{\tau+\Delta \tau} \int_{x}^{x+\Delta x} k \frac{\delta^{2} T}{\delta^{2} x} d x d \tau-\int_{\tau}^{\tau+\Delta \tau} \dot{m} C_{p} \frac{\delta T}{\delta x} d x d \tau
$$

For a small enough control volume, $\frac{\delta T}{\delta \tau}, \rho, C, \dot{m}, C_{p} \& k$ are constant within the control volume. Therefore, integrating over space $(\Delta x)$, equation 3-8 results in equation 3-9.

$$
\int_{\tau}^{\tau+\Delta \tau} \rho C \frac{\delta T}{\delta \tau} \Delta x d \tau=\int_{\tau}^{\tau+\Delta \tau}\left[\left(k \frac{\delta T}{\delta x}\right)_{e}-\left(k \frac{\delta T}{\delta x}\right)_{w}\right] d \tau-\int_{\tau}^{\tau+\Delta \tau} \dot{m} C_{p}\left(T_{e}-T_{w}\right) d \tau
$$

Utilizing term simplification from Pantakar (1980) equation 3-9 can be expressed as:

$$
\begin{array}{r}
\int_{\tau}^{\tau+\Delta \tau} \rho C \frac{\delta T}{\delta \tau} \Delta x d \tau=\int_{\tau}^{\tau+\Delta \tau}\left[\left(\frac{k}{\delta x}\right)_{e}\left(T_{E}-T_{P}\right)-\left(\frac{k}{\delta x}\right)_{w}\left(T_{P}-T_{W}\right)\right] d \tau \\
-\int_{\tau}^{\tau+\Delta \tau} \dot{m} C_{p}\left(T_{e}-T_{w}\right) d \tau
\end{array}
$$

Integrating equation 3-10 over time results in equation 3-11

$$
\begin{aligned}
\rho C \Delta x\left(T_{P}-T_{P}^{0}\right)=\left(\frac{k}{\delta x}\right)_{e}\left(T_{E}-T_{P}\right) \Delta \tau-\left(\frac{k}{\delta x}\right)_{w} & \left(T_{P}-T_{W}\right) \Delta \tau \\
& -\dot{m} C_{p}\left(T_{E}-T_{W}\right) \Delta \tau
\end{aligned}
$$

Where:

- $\quad T_{P}^{0}=$ Previous temperature of center node

- $\quad T_{P}=$ Current temperature of center node

- $\quad T_{E}=$ Current temperature at east node

- $\quad T_{W}=$ Current temperature at west node 
Rearranging equation 3-11 results in equation 3-12:

$$
\begin{aligned}
T_{P}\left[\frac{\rho C \Delta x}{\Delta \tau}+\left(\frac{k}{\delta x}\right)_{e}+\left(\frac{k}{\delta x}\right)_{w}\right]+T_{W}[ & \left.-\left(\frac{k}{\delta x}\right)_{w}-\dot{m} C_{p}\right] \\
& +T_{E}\left[-\left(\frac{k}{\delta x}\right)_{e}+\dot{m} C_{p}\right]=\frac{\rho C \Delta x}{\Delta \tau} T_{P}^{0}
\end{aligned}
$$

Following simplifications from Liu (1992), let:

$$
\begin{aligned}
& a_{w}=-\left(\frac{k}{\delta x}\right)_{w}-\dot{m} C_{p} \\
& a_{e}=-\left(\frac{k}{\delta x}\right)_{e}+\dot{m} C_{p} \\
& a_{P}^{0}=\frac{\rho C \Delta x}{\Delta \tau} \\
& a_{p}=a_{P}^{0}-a_{w}-a_{e}
\end{aligned}
$$

Therefore equation 3-13 becomes:

$$
a_{w} T_{w}+a_{p} T_{p}+a_{e} T_{E}=a_{P}^{0} T_{P}^{0}
$$

Since conductivity is non-homogeneous and can vary between nodes, then define $K_{w}$ and $\mathrm{K}_{\mathrm{e}}$ as (Patankar, 1988) (Equations 3-15 and 3-16):

$$
\begin{gathered}
K_{w}=\frac{2}{\frac{\Delta x_{W}}{\delta x_{w} k_{W}}+\frac{\Delta x_{p}}{\delta x_{P} k_{p}}} \\
K_{e}=\frac{2}{\frac{\Delta x_{P}}{\delta x_{P} k_{P}}+\frac{\Delta x_{E}}{\delta x_{e} k_{E}}}
\end{gathered}
$$

\section{External Node/Layer of wall}

The outside surface of the wall receives the incident solar radiation and is also exposed to ambient air temperature. Similarly the inside surface of the wall is exposed to 
the indoor ambient temperature. Therefore, separate discretizations are presented for nodes on the outside surface and inside surfaces of a wall.

\section{Outside wall surface}

A node on the outside surface of the wall is subject to solar radiation, outside air temperature and the infiltrating air. The node $\mathrm{P}$ is taken on the surface of the wall and the control volume has half the volume of the regular control volume, as shown in Figure 33. The energy balance equation for the external node is therefore defined by equation 317.

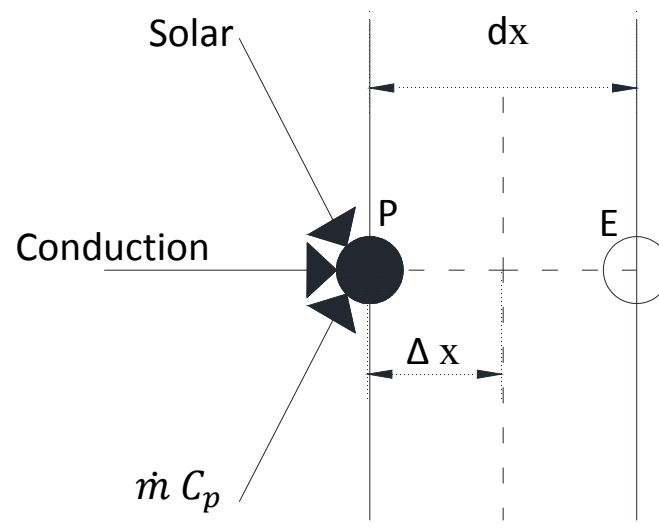

Figure 3-3: Node on the outside surface of the wall

$$
\begin{aligned}
T_{P} \dot{m} C_{p}-\frac{1}{2}\left(T_{P}-T_{E}\right) \dot{m} C_{p}+I+h_{o}\left(T_{a}-T_{p}\right)+ & \left(\frac{k}{\delta x}\right)_{e}\left(T_{E}-T_{P}\right) \\
& =\left(\frac{\rho C \Delta x}{2 \Delta \tau}\right)_{e}\left(T_{P}-T_{P}^{0}\right)
\end{aligned}
$$

Where:

- $\quad T_{P}=$ Temperature of outside surface

- $\quad T_{E}=$ Temperature of east node

- $I=$ Solar radiation absorbed by the wall 
- $\quad h_{0}=$ Heat transfer coefficient by outside boundary layer of the wall

- $T_{a}=$ Ambient air temperature

- $\Delta \tau=$ Time step

Therefore equation 3-17 is expressed as:

$$
a_{p} T_{p}+a_{e} T_{E}=a_{P}^{0} T_{P}^{0}+S
$$

$a_{e}=-\left(\frac{k}{\delta x}\right)_{e}+\frac{1}{2} \dot{m} C_{p}$

$a_{P}^{0}=\frac{\rho C \Delta x}{2 \Delta \tau}$

$a_{p}=a_{P}^{0}-a_{e}+h_{0}$

$S=I+h_{0} T_{a}$

\section{Inside surface of the wall}

A node on the inside surface of the wall is influenced by the indoor room air temperature and the temperature of the node on the west of it. The energy balance equation of the interior node is given by equation 3-20.

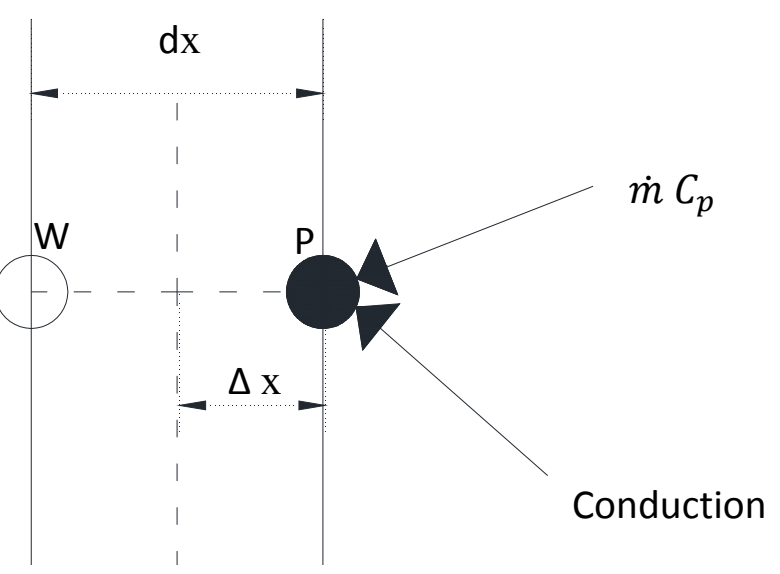

Figure 3-4: Node on the inside surface of the wall 
$\left(\frac{k}{\delta x}\right)_{w}\left(T_{W}-T_{P}\right)+\frac{1}{2}\left(T_{W}+T_{P}\right) \dot{m} C_{p}-\left(T_{p}-T_{r}\right) h_{i}-\dot{m} C_{p} T_{P}=\left(\frac{\rho C \Delta x}{2 \Delta \tau}\right) T_{P}^{0}$

Rearranging equation 3-20 (as previous), then:

$$
a_{p} T_{p}+a_{w} T_{W}=a_{P}^{0} T_{P}^{0}+S
$$

$a_{w}=-\left(\frac{k}{\delta x}\right)_{w}-\frac{1}{2} \dot{m} C_{p}$

$a_{P}^{0}=\frac{\rho C \Delta x}{2 \Delta \tau}$

$a_{p}=a_{P}^{0}-a_{e}+h_{i}$

$S=h_{i} T_{r}$

Where:

- $\quad T_{r}=$ Room temperature

- $\quad h_{i}=$ Heat transfer coefficient by inside boundary layer of the wall

\section{Final Discretization}

A wall with n-1 layers has $n$ nodes. Each node type has a specific equation as defined above, with special equations for each of the:

- Node on the outside surface of the wall

- Interior nodes (for interior layers)

- Node on the inside surface of the wall 


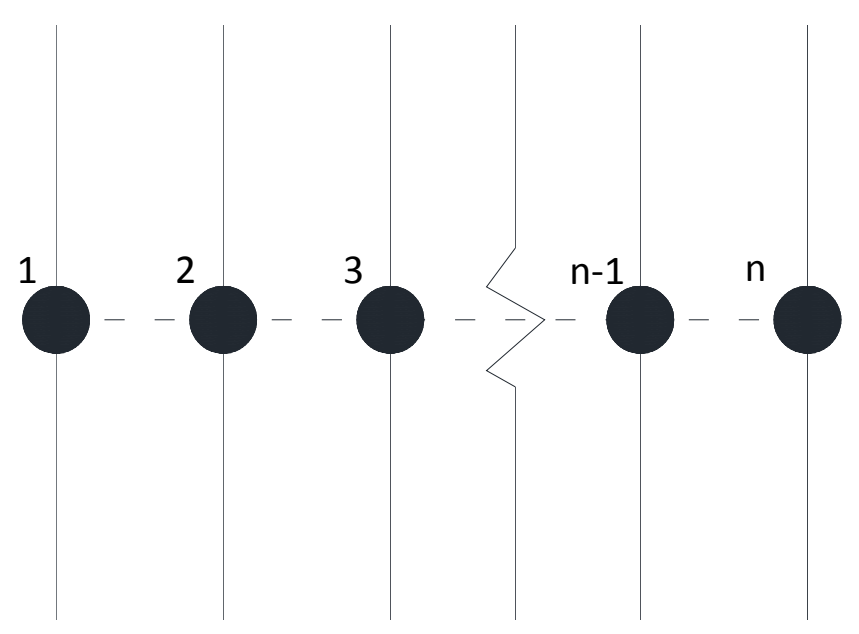

Figure 3-5: A wall with multiple layers and n nodes

All the equations (one for each node) are assembled into the matrix in equation 3-23. The solution for the matrix is the temperature of each node.

$$
\left(\begin{array}{cccccc}
a_{p}^{1} & a_{e}^{1} & 0 & 0 & \ldots & 0 \\
a_{w}^{2} & a_{p}^{2} & a_{e}^{2} & 0 & \ldots & 0 \\
\vdots & \vdots & \vdots & \vdots & \vdots & \vdots \\
& & & & a_{w}^{n} & a_{p}^{n}
\end{array}\right)\left(\begin{array}{c}
T_{1}^{1} \\
T_{2}^{1} \\
\vdots \\
T_{n}^{1}
\end{array}\right)=\left(\begin{array}{c}
a_{p}^{0}(1) T_{1}^{0} \\
a_{p}^{0}(2) T_{2}^{0} \\
\vdots \\
a_{p}^{0}(1) T_{n}^{0}
\end{array}\right)
$$

Once the layer temperatures are determined, the combined conduction and infiltration heat flux in the case of infiltration are determined using equation 3-24.

$$
q_{d}(i)=\left(h_{i}+\dot{m} C_{p}\right)\left(T_{r}(i)-T_{n}(i)\right)
$$

Where:

- $\quad \dot{m}=$ Infiltration mass flow rate

- $h_{i}=$ Heat transfer coefficient of inside boundary layer of the wall

- $\quad C_{p}=$ Specific heat capacity of air

- $\quad T_{r}=$ Room temperature

- $\quad T_{n}(i)=$ Node temperature

From this combined conduction and infiltration hourly heat flux, the hourly infiltration energy loads can be obtained by subtracting hourly conduction loads 
obtained from DOE-2 (calculated using the weighting factors method discussed in Chapter 2). The model's framework is presented in Flowchart 3-2.

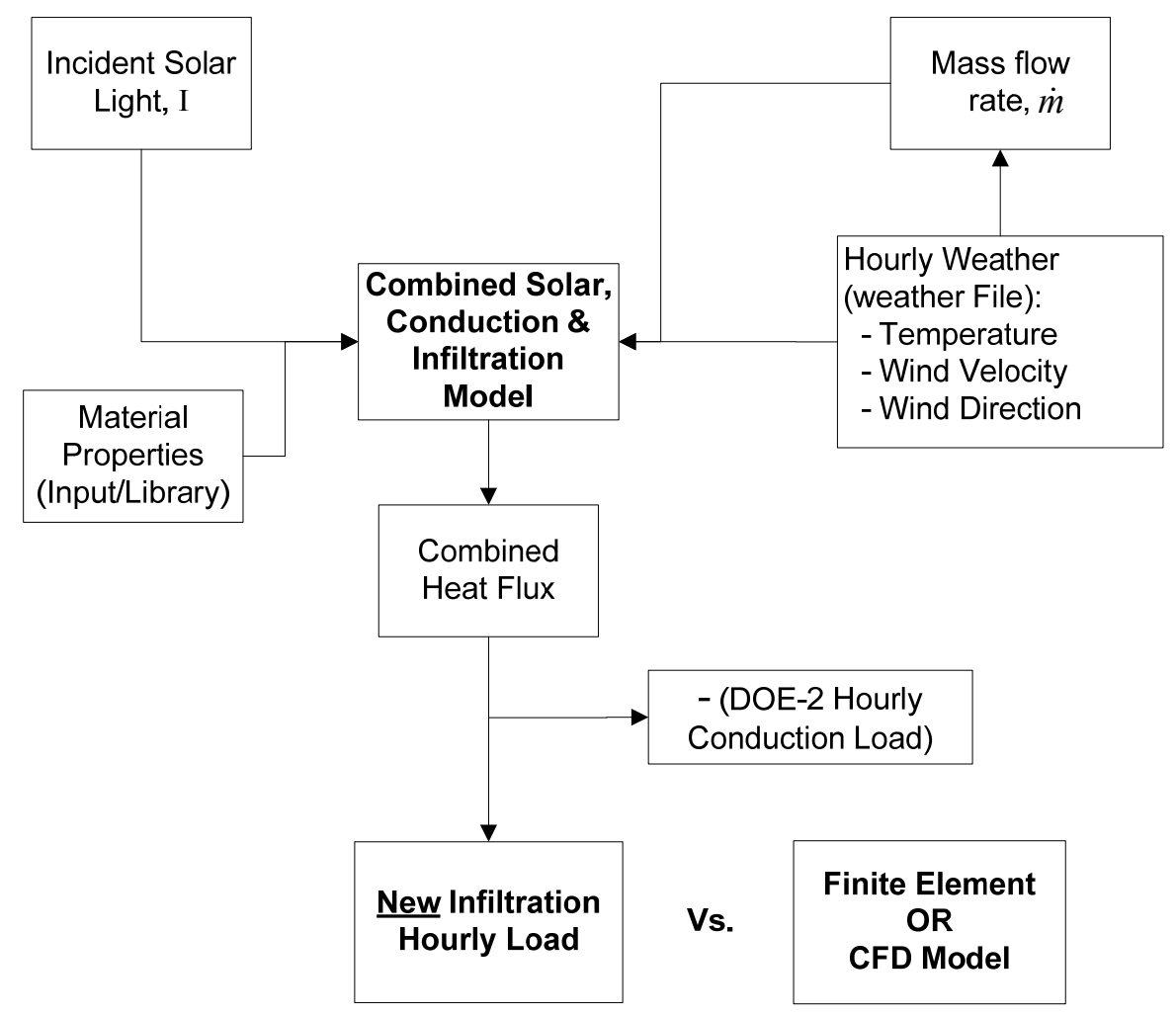

Flowchart 3-2 : Buleprint of the Enhanced Model 


\section{Infiltration Mass Flow Rate}

In order to evaluate the energy load of air infiltration, it is essential to determine the infiltration flow rate. This indicates the amount (volume) of air infiltrating into a building, based on which the energy load due to this infiltration flow rate can be determined. Air infiltration into a building is driven by pressure differences that emerge across the building envelope under various ambient conditions. Several traditional methods evaluate the infiltration flow rate using fixed constants or percentages. An example is the Air Change method, a widely used method. In the air change method the volume of infiltrating air per hour is defined as a fraction of the total volume of a room. For instance, an air change rate of $0.2 \mathrm{ACH}$ (air changes/hour) implies that the volume of infiltrating air is equal to $20 \%$ of the room/space volume. Such methods assign a fixed value to the infiltration flow rate and do not take into account various dynamic factors that control and fluctuate the infiltration flow rate. Weather conditions, air temperature, wind speed, wind direction and several other dynamic factors influence the air infiltration flow rate and therefore defining this flow rate using a fixed constant is a major source of inaccuracy. Consequently, it is essential to devise a methodology for calculating hourly infiltration airflow rates based on prevalent weather/climatic conditions and local characteristics.

Infiltration airflow is driven by a pressure gradient across the building envelope.

The driving pressure is composed of two primary components: Wind Pressure and Stack Pressure (Stack Effect). The stack pressure is a function of the building height and ambient air temperatures (indoor and outdoor); while the wind pressure is mainly affected by the wind velocity, wind direction, local terrain \& topography, and building shape 
characteristics. Evaluating infiltration airflow by considering the stack effect and local wind pressure allows various dynamic driving factors and building specific characteristics to be considered rather than using a generic fixed constant or even a statistical fit. Following is a discussion of the methodology utilized for evaluating the stack pressure and wind pressure.

\section{Stack Effect}

The roots of the stack effect lie in the temperature differences across the building envelope. As expresses by the ideal gas law (equation 3-25), air density is a function of temperature. Therefore the different temperatures on the inside and outside of a building result in a difference between the inside and outside air densities.

$$
\rho=\frac{P}{R T}
$$

Where:

- $\rho=$ air density

- $\mathrm{P}=$ air pressure

- $\mathrm{R}=$ Specific gas constant

- $\quad \mathrm{T}=$ Temperature

In turn, this difference in air density across the building envelope results in air buoyancy differences and different air pressures on the inside and outside of the building. This pressure difference across the building envelope results in a pressure gradient over the height of the building known as the "stack effect" which partially drives the flow of infiltrating air. The "stack pressure" gradient varies with the height of the building since 
as defined by equation $3-26$, at a specific air density $(\rho)$, the air pressure value varies with the height of the air column.

$$
P=\rho g h
$$

Where:

- $\mathrm{g}=$ gravitational acceleration constant

- $\mathrm{h}=$ height of air column

The neutral pressure level $\left(\mathrm{y}_{\mathrm{npl}}\right)$ is defined as the height at which the interior pressure equals the outside pressure as shown in Figure 3-6.

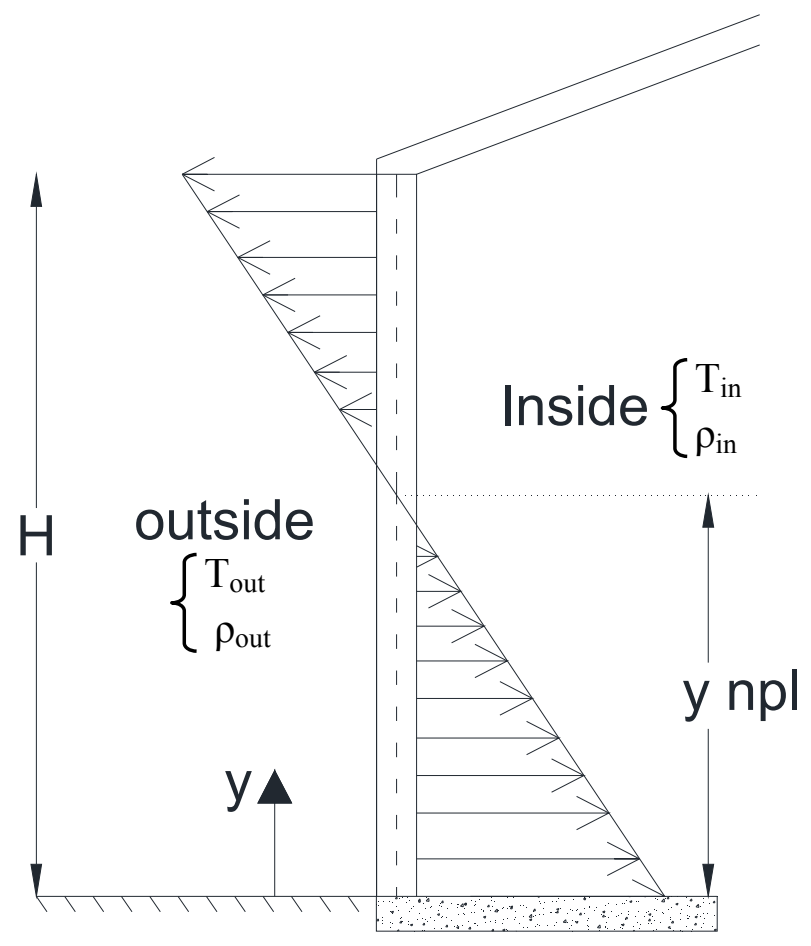

Figure 3-6: Stack Effect on a building wall 
The stack pressure can be defined by equations 3-27 to 3-32. The underlying assumption is that the air is well mixed on both sides of the building envelope.

$$
P_{\text {in }}(y)=P_{\text {o in }}-\rho_{\text {in }} g y
$$

Similarly

$$
\begin{gathered}
P_{\text {out }}(y)=P_{\text {o out }}-\rho_{\text {out }} g y \\
\Delta P_{S}(y)=P_{\text {in }}(y)-P_{\text {out }}(y) \\
\therefore \Delta P_{S}(y)=\left(P_{\text {o in }}-\rho_{\text {in }} g y\right)-\left(P_{\text {o out }}-\rho_{\text {out }} g y\right) \\
\Delta P_{S}(y)=\left(P_{\text {o in }}-P_{\text {o out }}\right)-g y\left(\rho_{\text {in }}-\rho_{\text {out }}\right)
\end{gathered}
$$

Define:

$$
\begin{aligned}
y^{\prime}=\frac{y}{H}= & \frac{\text { Height above bottom of the zone }}{\text { Zone Height }}(\text { Deru \& Burns, 2003) } \\
& \therefore \Delta P_{S}\left(y^{\prime}\right)=\left(P_{\text {o in }}-P_{\text {out }}\right)-y^{\prime}\left[g H\left(\rho_{\text {in }}-\rho_{\text {out }}\right)\right]
\end{aligned}
$$

Where:

- $\quad \mathrm{P}_{\mathrm{o} \text { in }}=$ Internal pressure at base of wall

- $\quad P_{o \text { out }}=$ Outside pressure at base of wall

- $\mathrm{y}=$ Distance from bottom of wall

- $\mathrm{H}=$ Total zone height

- $\quad y^{\prime}=\mathrm{Y} / \mathrm{H}=$ Ration of height above bottom of zone to total zone height

- $\rho_{\text {in }}=$ Density of inside air

- $\quad \rho_{\text {out }}=$ Density of outside air

- $\mathrm{g}=$ gravitational constant 
For simplification, a reference pressure is taken on the outside surface at the bottom of the wall. Therefore $P_{o \text { out }}$ is taken as $P_{o \text { out }}=0 . P_{o \text { in }}$ is therefore defined with respect to the reference pressure as follows:

$$
\begin{aligned}
& P_{\text {o in }}=\rho_{\text {in }} R T_{\text {in }} \\
& P_{\text {out }}=\rho_{\text {out }} R T_{\text {out }} \\
& \Rightarrow P_{\text {o in }}=\left(\rho_{\text {in }}-\rho_{\text {out }}\right) R\left(T_{\text {in }}-T_{\text {out }}\right) \quad\left(\text { for } P_{\text {o out }} \text { as reference } p t\right)(3-35)
\end{aligned}
$$

Where:

- $\quad \mathrm{R}=$ Specific gas constant

- $\quad \mathrm{T}=$ Zone temperature in ${ }^{\circ} \mathrm{K}$

\section{Wind Pressure}

The flow of air around a building creates a wind pressure on the building. The pressure intensity, distribution, and nature over the building envelope vary by location. A generic illustration of wind pressure distribution over a low rise building is shown in Figure 3-7. The wind pressure intensity depends on the air density, wind speed and building shape characteristics expressed as a pressure coefficient, $\mathrm{C}_{\mathrm{p}}$. The general expression of the wind pressure intensity is given by equation 3-36.

$$
P_{w}=\frac{1}{2} \rho_{\text {air }} C_{p} V^{2}
$$

Where:

- $\mathrm{P}_{\mathrm{w}}=$ Wind pressure

- $\quad \rho_{\text {air }}=$ Outside air density

- $\quad V \quad=$ Wind speed 


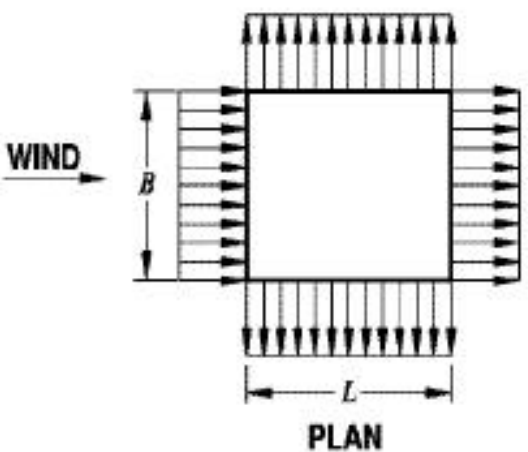

PLAN

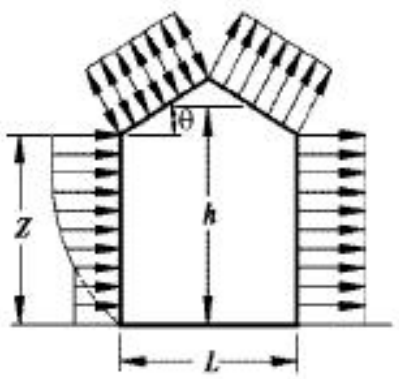

ELEVATION

Figure 3-7: Wind pressure on a typical Gable, Hip roof house (Figure 6-6, ASCE 7-05)

The wind speed is usually recorded by weather stations at a height of 10 meters ( 30 feet) over a flat terrain. However, this might not reflect the actual terrain, surroundings at the building location or the actual height of the building. Therefore, it is essential to incorporate a set of corrections to adjust the wind speed to local conditions and topography at the building site.

Wind pressure coefficients, $\mathrm{C}_{\mathrm{p}}$, are non-dimensional coefficients that represent the wind pressure distribution over a body and from which the wind pressure at a specific location over the building envelope can be calculated based on the local wind velocity and using equation 3-36. The general expression of the $C_{p}$ coefficient is given by equation 3-37. Pressure coefficients are generally calculated from data obtained through experimental testing, wind tunnel or full scale tests, on various building shapes and heights.

$$
C_{p}=\frac{P-P_{o}}{\frac{1}{2} \rho_{a i r} V^{2}}
$$

Following is a discussion of the methodology used for calculating all the components of the wind pressure expression (equation 3-36). Included is a discussion of all the 
corrections performed to account for wind direction, local shielding, terrain roughness and building shape properties.

\section{Wind Pressure Coefficients}

Wind pressure coefficients can be obtained from several sources and databases. However, the wind pressure coefficients can vary largely over the surface of a structure. This would make wind pressure computations for infiltration airflow rate calculations overly complicated and computationally expensive. Therefore, average $C_{p}$ values will be used for each surface. These values can be obtained from ASCE 7, Figure 6-6 shown in Table 3-1 below.

\begin{tabular}{|l|c|c|}
\hline \multicolumn{3}{|c|}{ Wall Pressure Coefficients, $\mathbf{C}_{\mathbf{p}}$} \\
\hline \multirow{2}{*}{ Surface } & L/B & $\mathbf{C}_{\mathbf{p}}$ \\
\hline \multirow{3}{*}{ Windward Wall } & All values & 0.8 \\
\hline \multirow{3}{*}{ Leeward Wall } & $0-1$ & -0.5 \\
\cline { 2 - 3 } & 2 & -0.3 \\
\cline { 2 - 3 } & $\geq 4$ & -0.2 \\
\hline Side Wall & All Values & -0.7 \\
\hline
\end{tabular}

Table 3-1: External Pressure Coefficient, Cp (ASCE 7-05, Figure 6-6)

\section{Wind Direction}

$\mathrm{C}_{\mathrm{p}}$ values are primarily based on a wind direction normal to the receiving surface.

However, under normal conditions wind directions vary and are not necessarily normal to the receiving surface. In order to correct the pressure coefficients for variations in wind direction the Swami and Chandra (1988) model will be used. Other possible choices are Walton (1982) and COMISGroup Fuestel and Rayner-Hooson (1990). However, the Swami and Chandra model is more intricate than the Walton (1982) model, yet less 
complex than the Fuestel and Rayner-Hooson (1990) model. The general expression of Swami and Chandra (1988) is given by equation 3-38, along with a comparison plot against Walton (1982) in Figure 3-9 (Deru and Burns, 2003).

$$
C_{p}^{\prime}=\frac{C_{p}}{C_{p}(\theta=0)} \ln \left[\begin{array}{c}
1.248-0.703 \sin \frac{\theta}{2}-1.175 \sin ^{2} \theta+0.131 \sin ^{3}(2 \theta G) \\
+0.769 \cos \frac{\theta}{2}+0.07 G^{2} \sin ^{2} \frac{\theta}{2}+0.717 \cos ^{2} \frac{\theta}{2}
\end{array}\right](3-38)
$$

Where:

- $\theta=$ Wind incidence angle

- $\quad \mathrm{G}=\ln (S)=\ln \left(l_{1} / l_{2}\right)$

$\mathrm{S}=$ Side ratio, ration of the length of adjacent walls $\left(l_{1} \& l_{2}\right)$

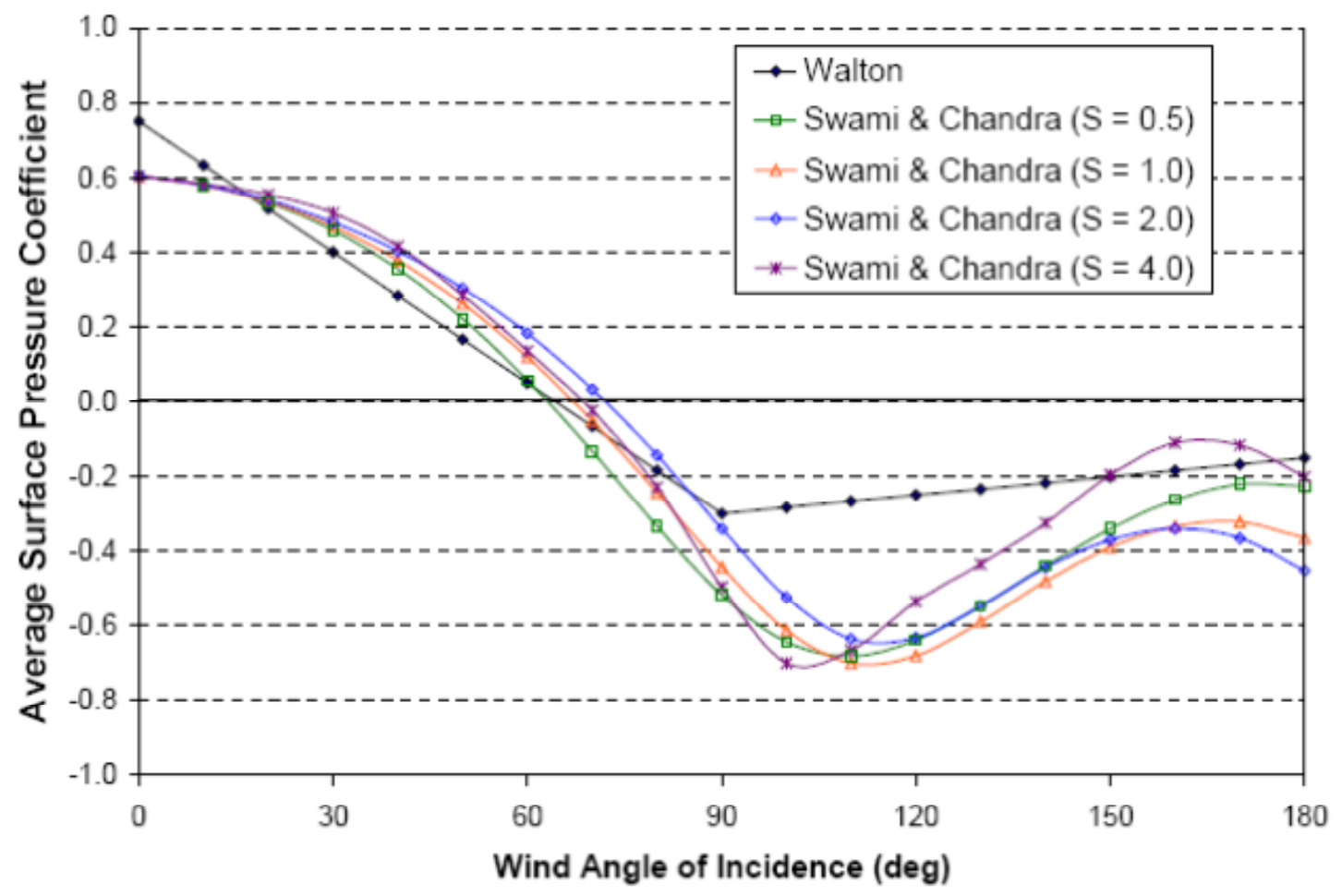

Chart 3-1: Surface pressure coefficient as a function of wind incidence angle for the Walton model and Swami \& Chandra model (Deru and Burns, 2003)

Note: As shown in Figure 3-9, when S varies from 0.5 to 4.0, the difference in pressure coefficients at each wind direction and for different $\mathrm{S}$ values is relatively small. 
Therefore, in order to simplify calculation $\mathrm{S}$ will be taken as: $\mathrm{S}=1$ (Deru and Burns, 2003), consequently $\mathrm{G}=\ln (S)=0$. Thus equation 3-38 can therefore be expressed as:

$$
C_{p}^{\prime}=\frac{C_{p}}{C_{p}(\theta=0)}=\ln \left[\begin{array}{c}
1.248-0.703 \sin \frac{\theta}{2}-1.175 \sin ^{2} \theta \\
+0.769 \cos \frac{\theta}{2}+0.717 \cos ^{2} \frac{\theta}{2}
\end{array}\right]
$$

The above relationship was developed for vertical surfaces and walls. Therefore, an expression is needed to determine the pressure coefficients for tilted surfaces such as gabled roofs. Deru and Burns (2003) proposed, for inclined surfaces, to calculate $\theta$ using equation 3-40, and to use a normal surface pressure coefficient of 1.0 (rather than 0.8 as in ASCE 7 Figure 2-2).

$$
\cos \theta=\sin \beta \cos \left(\gamma_{S}-\psi\right)
$$

Where:

- $\quad \beta=$ Surface tilt

- $\gamma_{\mathrm{s}}=$ Surface azimuth $\left(\right.$ South $=0^{\circ}$, East $\left.=-90^{\circ}\right)$

- $\quad 3 \psi=$ Wind direction from weather file $\left(\right.$ North $=0^{\circ}$, East $\left.=90^{\circ}\right)$

Results obtained using this method match published experimental results from Aikens (1976) for flat roofs and ASHRAE Handbook of fundamentals data for sloped roofs (Deru and Burns, 2003). Therefore this model will be adopted in this methodology for use in the case of tilted roofs. 


\section{Wind Incidence Angle}

The wind incidence angle will be obtained from DOE-2 location weather data. However, in DOE-2, wind angles are reported by sector number. The full $360^{\circ}$ is divided into 24 sectors of $15^{\circ}$ each. Therefore, in order to determine the wind direction, the wind incident angle will be taken to be at the middle of the DOE-2 reported sector. Therefore, the wind incident angle can be calculated using equation 3-41.

$$
\theta_{\text {deg }}=(\text { Weather file Sector \# })\left(15^{0}\right)+\frac{15^{0}}{2}
$$

\section{Wind Speed}

Wind speed measurements are usually performed in airports or local weather stations with an open terrain. The measurements are usually performed at a height of $30 \mathrm{ft}$ $(\sim 10 \mathrm{~m})$. Buildings, however, exist in various terrains that could differ in roughness from

a flat terrain, and at heights that could differ from the $30 \mathrm{ft}$ wind speed measurement height. In order to determine local wind speeds the power law is used. The recorded mean wind speed will be used along with coefficients that account for variation in terrain roughness, building height, and measuring station height in order to calculate the local wind speed. The general expression of the power law is given in equation 3-42.

$$
V=\left(V_{Z_{\text {ref }}}\right)\left(\frac{Z}{Z_{\text {ref }}}\right)^{1 / \alpha}
$$

Where:

- $\quad Z=$ Elevation

- $\quad Z_{\text {ref }}=$ Elevation of measuring point

- $\quad V_{\text {Zref }}=$ Measured wind speed at $Z_{\text {ref }}$

- $\quad \mathrm{V}=$ Wind speed at elevation $\mathrm{Z}$ 
- $1 / \alpha=$ Coefficient corresponding to surface roughness

\begin{tabular}{|c|c|c|c|c|l|}
\hline Class & \multicolumn{2}{|c|}{3 Sec Gust Speed } & \multicolumn{2}{|c|}{ Mean Hourly Speed } & \multicolumn{1}{c}{ Description } \\
\hline & $\mathbf{1} / \boldsymbol{\alpha}$ & $\mathbf{Z}_{\mathrm{g}} \mathrm{ft}(\mathrm{m})$ & $\mathbf{1} / \boldsymbol{\alpha}$ & $\mathbf{Z}_{\mathbf{g}} \mathrm{ft}(\mathrm{m})$ & \\
\hline I & $1 / 11.5$ & $700(213)$ & & $700(213)$ & Open water body/ocean \\
\hline II & $1 / 9.5$ & $900(274)$ & 0.16 & $900(274)$ & $\begin{array}{l}\text { Open terrain, flat terrain with } \\
\text { isolated obstacles }\end{array}$ \\
\hline III & $1 / 7$ & $1200(366)$ & 0.28 & $1200(366)$ & Suburban terrains, towns \\
\hline IV & & $1500(457)$ & 0.4 & $1500(457)$ & Centers of large cities \\
\hline
\end{tabular}

Table 3-2: Surface Roughness Coefficients (Simu and Miyata, 2006)

The general form of the power law can be used to calculate the wind speed at different heights for the same location. However, to calculate the wind speed at a location different from the wind speed measurement location and at a different height and surface roughness, a compound form of the power law will be used. The used expression is given by equation 3-43.

$$
V=\left(V_{Z \text { open }}\right)\left(\frac{Z_{\text {gopen }}}{Z_{\text {Open }}}\right)^{1 / \alpha \text { open }}\left(\frac{Z}{Z_{g}}\right)^{1 / \alpha}
$$



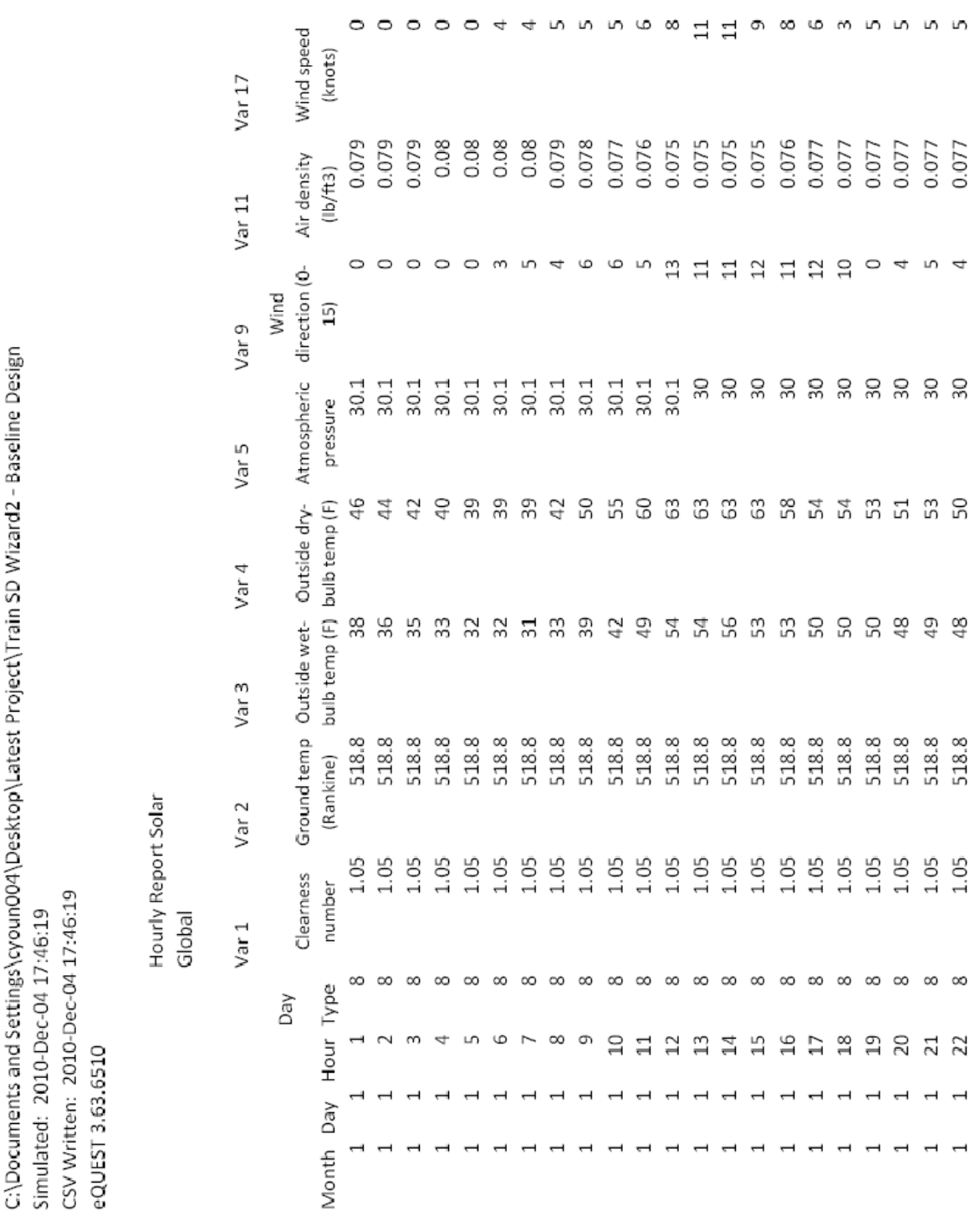

Figure 3-8: Hourly Temperature and Wind data available from weather file (DOE-2/eQUEST) 


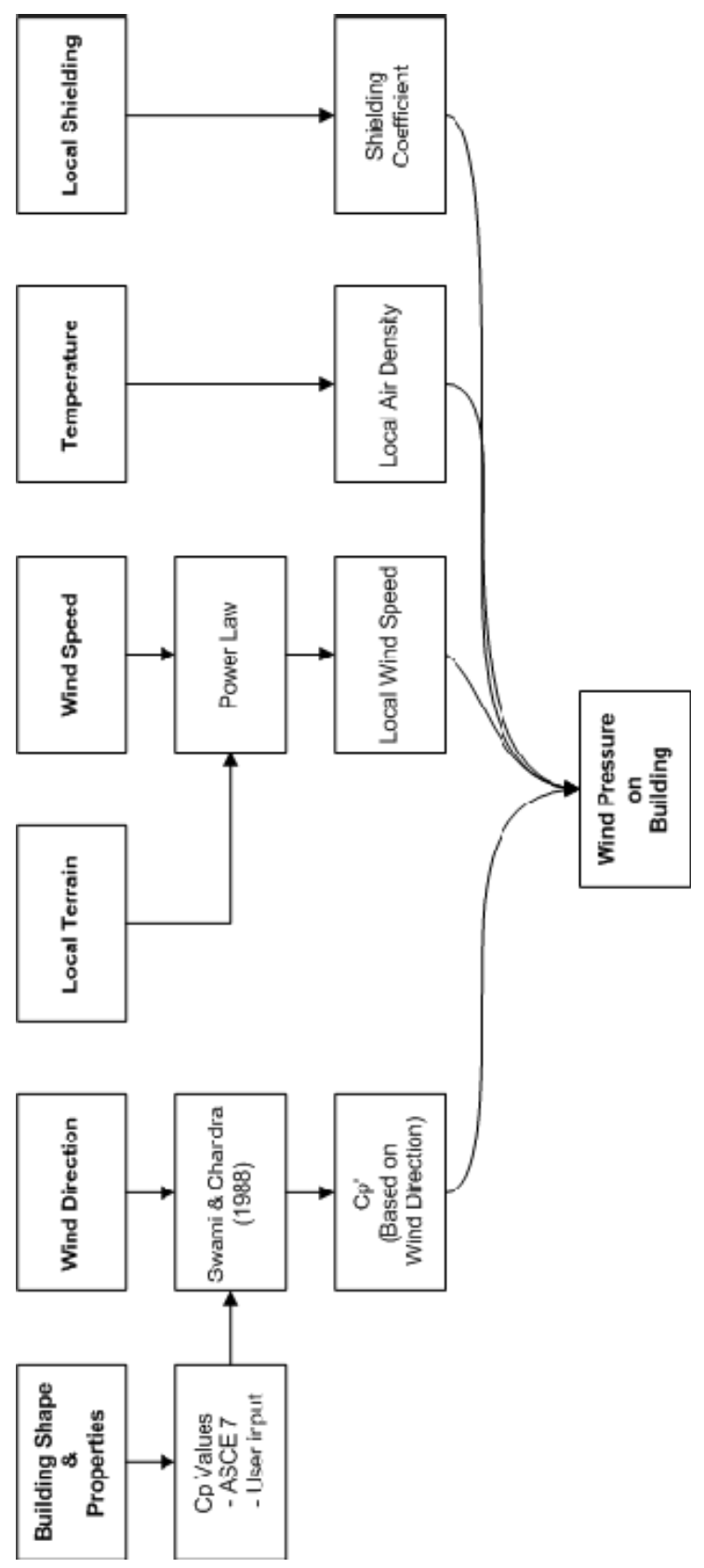

Flowchart 3-3: Wind Pressure calculation based on local factors and building characteristics 


\section{Local Shielding Parameters}

Local obstructions surrounding a building can actively shield it from the full impact of wind. For instance, large adjacent buildings, lines of trees, or such can shield the building under consideration consequently reducing the wind pressure incident on it. A single row of high-density wind shielding can result in a $60 \%$ reduction in infiltration airflow when present within four tree heights from a building (Stathopoulos et al., 1994). Therefore due to its proven impact, it is essential to take into account the affect of shielding in reducing the wind pressure, $\mathrm{P}_{\mathrm{w}}$, on a building and consequently the affect of shielding on infiltration airflow rate. Sherman and Modera (1986) developed coefficients that can be applied onto $\mathrm{P}_{\mathrm{w}}$ to account for shielding effects and accordingly reduced infiltration flow rates. Deru and Burns (2003) normalized those coefficients by the shielding coefficient of Class I (minimum shielding) for use in situations in which only the effects of local shielding are required. In this methodology, these shielding coefficients will be used and will be applied onto the wind pressure $\mathrm{P}_{\mathrm{w}}$ as shown in equation 3-44.

$$
\begin{gathered}
P_{w}=\frac{1}{2} \rho_{\text {air }} C_{p}{ }^{\prime} V^{2} \\
P_{w+\text { Shielding }}=(S C) P_{w}
\end{gathered}
$$

Where:

- $\quad \mathrm{P}_{\mathrm{w}+\text { Shielding }}=$ Wind pressure with shielding effects taken into account

- $\quad S C=$ Normalized shielding coefficient

- $\quad \mathrm{C}_{\mathrm{P}}{ }^{\prime}=$ Pressure coefficient corrected for wind direction

- $\quad V=$ Local wind speed corrected using the power law 


\begin{tabular}{|c|c|l|}
\hline Class & \multicolumn{1}{|c|}{ D } & \multicolumn{1}{c|}{ Description } \\
\hline I & 1.0 & No obstructions or local shielding \\
\hline II & 0.880 & Light local shielding with few obstructions \\
\hline III & 0.741 & Moderate local shielding, some obstructions within 2 house heights \\
\hline IV & 0.571 & Heavy shielding obstructions around most of the perimeter \\
\hline V & 0.315 & $\begin{array}{l}\text { Very heavy shielding, large surrounding obstructions within 2 house } \\
\text { heights }\end{array}$ \\
\hline
\end{tabular}

Table 3-3: Normalized shielding coefficients from Deru and Burns (2003) based on Sherman and Modera (1998)

\section{Infiltration Mass Flow Rate}

The infiltration flow rate through the building envelope can be represented by and orifice equation. The general expression for flow through an orifice is given by equation 3-45.

$$
\dot{m}=C_{D} A \sqrt{2 \rho \Delta P}
$$

Where:

- $\quad \dot{m}=$ Mass flow rate

- $\quad A=$ Opening Area

- $\quad \rho=$ Leaking air density

- $\Delta \mathrm{P}=$ Total driving pressure

Complex leakage through complex holes and small openings has been shown to have a slightly different dependence on the pressure difference. Therefore the flow rate is expressed in equation 3-46 (Deru and Burns, 2003).

$$
\dot{m}=C A_{e} \sqrt{2 \rho}(\Delta P)^{n}
$$

Where:

- $\quad C=$ Flow Coefficient 
- $A_{e}=$ Approximate leakage Area

- $\quad \rho=$ Density of infiltrating air

- $\quad \mathrm{n}=$ Flow exponent $(0.5<\mathrm{n}<1)$

In order to calculate the infiltration mass flow rate using equation 3-46, the various equation entries must be finalized and determined as shown below:

Effective leakage area: Material effective leakage area can be obtained from ASHRAE Handbook: Table 1 page 25.15. The effective leakage area for various materials has been determined in ASHRAE at a pressure difference of 0.016 in of water and a $C_{D}$ value of 1 . These values have been obtained through a study by Colliver et al.(1992).

Table 1 Effective Air Leakage Areas (Low-Rise Residential Applications Only)

\begin{tabular}{|c|c|c|c|c|c|c|c|c|}
\hline & $\begin{array}{c}\text { Units } \\
\text { (see note) }\end{array}$ & $\begin{array}{c}\text { Best } \\
\text { Estimate }\end{array}$ & $\begin{array}{l}\text { Mini- } \\
\text { mum }\end{array}$ & $\begin{array}{l}\text { Maxi- } \\
\text { mum }\end{array}$ & & $\begin{array}{c}\text { Units } \\
\text { (see note) }\end{array}$ & $\begin{array}{c}\text { Best } \\
\text { Estimate }\end{array}$ & $\begin{array}{l}\mathrm{Mi} \\
\mathrm{mi}\end{array}$ \\
\hline Ceiling & & & & & \multicolumn{4}{|l|}{ Piping/Plumbing/Wiring penetrations } \\
\hline General & $\mathrm{in}^{2} / \mathrm{ft}^{2}$ & 0.026 & 0.011 & 0.04 & Uncaulked & in $^{2}$ ea & 0.9 & 0.3 \\
\hline Drop & $\mathrm{in}^{2} / \mathrm{ft}^{2}$ & 0.0027 & 0.00066 & 0.003 & \multirow{2}{*}{\multicolumn{4}{|c|}{$\begin{array}{l}\text { Caulked } \\
\text { Vents }\end{array}$}} \\
\hline Ceiling penetrations & & & & & & & & \\
\hline Whole-house fans & in $^{2}$ ea & 3.1 & 0.25 & 3.3 & Bathroom with damper closed & in $^{2}$ ea & 1.6 & 0.3 \\
\hline Recessed lights & in $^{2}$ ea & 1.6 & 0.23 & 3.3 & Bathroom with damper open & $\mathrm{in}^{2}$ ea & 3.1 & 0.9 \\
\hline Ceiling/Flue vent & in $^{2}$ ea & 4.8 & 4.3 & 4.8 & Dryer with damper & $\mathrm{in}^{2} \mathrm{ea}$ & 0.46 & 0.4 \\
\hline Surface-mounted lights & in $^{2}$ ea & 0.13 & & & Dryer without damper & $\mathrm{in}^{2} \mathrm{ea}$ & 2.3 & 1.9 \\
\hline Chimney & in $^{2}$ ea & 4.5 & 3.3 & 5.6 & Kitchen with damper open & in $^{2}$ ea & 6.2 & 2.2 \\
\hline Crawl space & & & & & Kitchen with damper closed & $\mathrm{in}^{2}$ ea & 0.8 & 0.1 \\
\hline General (area for exposed wall) & $\mathrm{in}^{2} / \mathrm{ft}^{2}$ & 0.144 & 0.1 & 0.24 & $\begin{array}{l}\text { Kitchen with tight gasket } \\
\text { Wall (exterior) }\end{array}$ & \multicolumn{3}{|c|}{ Walls (exterior) } \\
\hline $\begin{array}{l}8 \text { in. by } 16 \\
\text { Door frame }\end{array}$ & & & & & $\begin{array}{l}\text { Walls (exterior) } \\
\text { Cast-in-place concrete }\end{array}$ & $\mathrm{in}^{2} / \mathrm{ft}^{2}$ & 0.007 & 0.0 \\
\hline General & in $^{2}$ ea & 1.9 & 0.37 & 3.9 & Clay brick cavity wall, finished & $\mathrm{in}^{2} / \mathrm{ft}^{2}$ & 0.0098 & 0.0 \\
\hline Masonry, not caulked & $\mathrm{in}^{2} / \mathrm{ft}^{2}$ & 0.07 & 0.024 & 0.07 & Precast concrete panel & $\mathrm{in}^{2} / \mathrm{ft}^{2}$ & 0.017 & 0.0 \\
\hline Masonry, caulked & $\mathrm{in}^{2} / \mathrm{ft}^{2}$ & 0.014 & 0.004 & 0.014 & Lightweight concrete block, & $\mathrm{in}^{2} / \mathrm{ft}^{2}$ & 0.05 & 0.0 \\
\hline Wood, not caulked & $\mathrm{in}^{2} / \mathrm{ft}^{2}$ & 0.024 & 0.009 & 0.024 & unfinished & & & \\
\hline Wood, caulked & $\mathrm{in}^{2} / \mathrm{ft}^{2}$ & 0.004 & 0.001 & 0.004 & Lightweight concrete block, & $\mathrm{in}^{2} / \mathrm{ft}^{2}$ & 0.016 & 0.0 \\
\hline Trim & $\mathrm{in}^{2} / \mathrm{ftc}$ & 0.05 & & & oninted or stucco & & & \\
\hline Jamb & $\mathrm{in}^{2} / \mathrm{ftc}$ & 0.4 & 0.3 & 0.5 & Heavyweight concrete block, & $\mathrm{in}^{2} / \mathrm{ft}^{2}$ & 0.0036 & \\
\hline Threshold & $\mathrm{in}^{2} / \mathrm{lftc}$ & 0.1 & 0.06 & & unfinished & & & \\
\hline Doors & & & & & Continuous air infiltration & $\mathrm{in}^{2} / \mathrm{ft}^{2}$ & 0.0022 & 0.0 \\
\hline Attic/crawl space, not & in $^{2}$ ea & 4.6 & 1.6 & 5.7 & & & & \\
\hline weatherstripped & $\therefore$ & $0 \Omega$ & ${ }^{2}$ & & Rigid sheathing & $\mathrm{in}^{2} / \mathrm{ft}^{2}$ & 0.005 & 0.0 \\
\hline
\end{tabular}

Figure 3-9: Effective air leakage are, ASHRAE Handbook Chapter 25 Table 1 (partially)

For different reference pressures, air flow rates and flow coefficients, the values of effective leakage area can be corrected using equations 3-47 from the ASHRAE Handbook.

$$
A_{r, 2}=A_{r, 1}\left(\frac{C_{D, 1}}{C_{D, 2}}\right)\left(\frac{\Delta P_{r, 2}}{\Delta P_{r, 1}}\right)^{n-0.5}
$$


Where:

- $\quad A_{r, 1}=$ Air leakage area at reference pressure difference $\Delta P_{r, 1}$

- $\quad A_{r, 2}=$ Air leakage area at reference pressure difference $\Delta P_{r, 2}$

- $\quad C_{D, 1}=$ discharge coefficient used to calculate $A_{r, 1}$

- $\quad C_{D, 2}=$ discharge coefficient used to calculate $A_{r, 2}$

- $\quad \mathrm{n}=$ Flow exponent

Flow Exponent: The flow exponent ranges between $0.5 \& 1.0(0.5 \leq n \leq 1)$. Where 0.5 is in the case of turbulent flow and 1.0 is for the case of laminar flow. Diffusive air infiltration is characterized by a laminar flow and therefore $\mathbf{n}=\mathbf{1}$ will be adopted in this methodology.

Pressure gradient, $\Delta \mathbf{P}$ : the driving pressure gradient is a combination of the Stack Effect and Wind Pressure. Thus $\Delta \mathrm{P}$ is calculated as follows:

$$
\begin{gathered}
\Delta P=P_{\text {Stack }}+P_{\text {Wind }+ \text { Shielding }} \\
\Delta P=P_{0 \text { in }}-\Delta P_{S, 0}-Y^{\prime} P_{S, H}+(S C) P_{w} \\
\Delta P=\left|P_{0 \text { in }}-\Delta P_{S, 0}-Y^{\prime} P_{S, H}+\frac{1}{2} C_{p}^{\prime} V^{2}\right|
\end{gathered}
$$




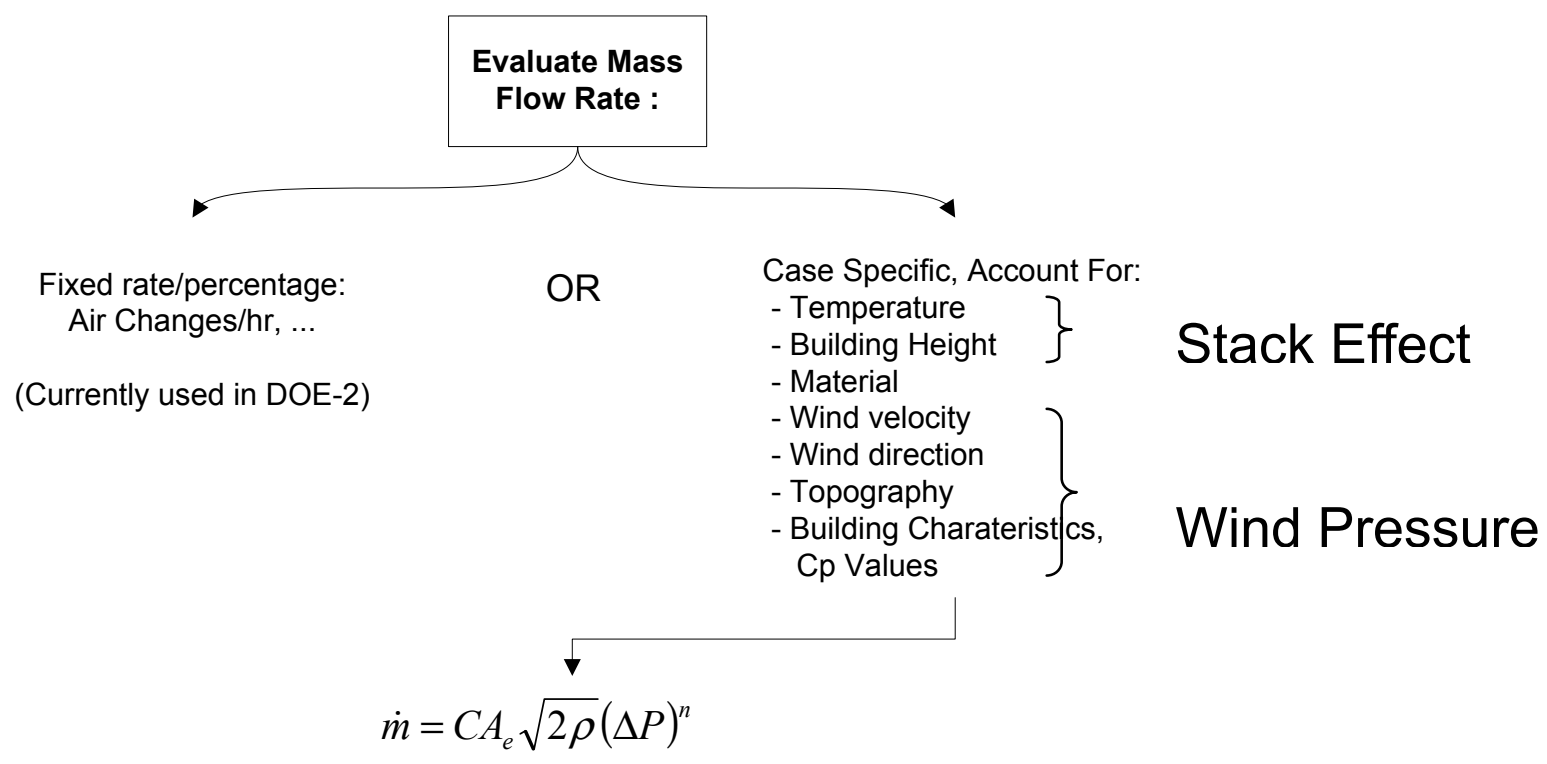

Flowchart 3-4: Mass flow rate calculation and components 


\section{Solar Calculation and Shading}

Integrating heat recovery and the interaction between solar radiation, conduction and infiltration into building energy simulation requires an evaluation of the intensity of solar radiation incident on the building. The incident solar radiation depends on several factors including: building location, season, day, time of the day, building orientation, cloud cover and others. Both direct normal solar radiation (incident radiation perpendicular to receiving space) and diffuse solar radiation (diffuse non-perpendicular radiation) must be considered. Shading should also be taken into account. A shade could reduce or eliminate the incident solar radiation onto a surface, this should be accounted for and therefore shading calculations are to be considered also. The solar and shading calculation model is based on the DOE-2 existing calculation model as defined on DOE-2 Engineers Manual Version 2.1 A (November 1982), along with Threlkand and Jordon (1958), Stephenson (1965), and ASHRAE Hanbook of Fundamentals.

\section{Solar Calculation}

A brief description of the deployed solar calculation model is provided below. Essential to the methodology is, primarily, defining the following fundamental quantities.

\section{Declination Angle (DECLN)}

The solar declination angle represents the angle formed between the earth's equatorial plane and the earth-sun line. Since the earth axis tilts to a maximum of $23.5^{\circ}$ and is perpendicular to the equatorial plane, the declination angle ranges between $+23.5^{\circ}$ (June) and $-23.5^{\circ}$ (December). 


\section{Solar Equation of Time (EQTIME)}

The equation of time is a correction term used to calculate the apparent solar time from local clock time. It is important to consider the solar equation of time since it takes into account the varying perturbations in the earth's orbit and rotation rate. The equation of time is given by equation 3-49 (Duffet-Smith, 1988) and plotted in Figure 3-11 over a year span.

$$
\Delta t=\frac{(\mu-\vartheta)+(\lambda-\alpha)}{w_{E}}
$$

Where:

- $\quad \mu$ : Sun mean anomaly (relating the position $\&$ time of an object in orbit)

$$
\mu=n t=\sqrt{\frac{G\left(M_{x}+m\right)}{a^{3}}} t(\text { Murry \& Dermott, 1999) }(3-50)
$$

Where:

- $\mathrm{n}=$ mean motion (measure of angular orbiting speed)

- $\mathrm{a}=$ length of orbit's semi-major axis

$-M_{x} \& m=$ mass of orbiting objects

$-\mathrm{G}=$ Gravitational constant

$\therefore$ For the sun:

$$
\mu=\frac{360}{365.242191} d_{\text {day }}(\text { Duffet }- \text { smith }, 1988)
$$

- $\vartheta=$ Sun's true anomaly (defines angular position of a mass in orbit)

- $\quad \lambda=$ Angle from vernal equinox to the sun in the elliptical plane

- $\quad \alpha=$ Angle from vernal equinox to the sun in equatorial plane

- $\quad \mathrm{W}_{\mathrm{E}}=$ Earth's axial rotation rate: $1 \mathrm{rev} / \mathrm{day}=0.001389 \pi / \mathrm{min}$ 


\section{Equation of Time}

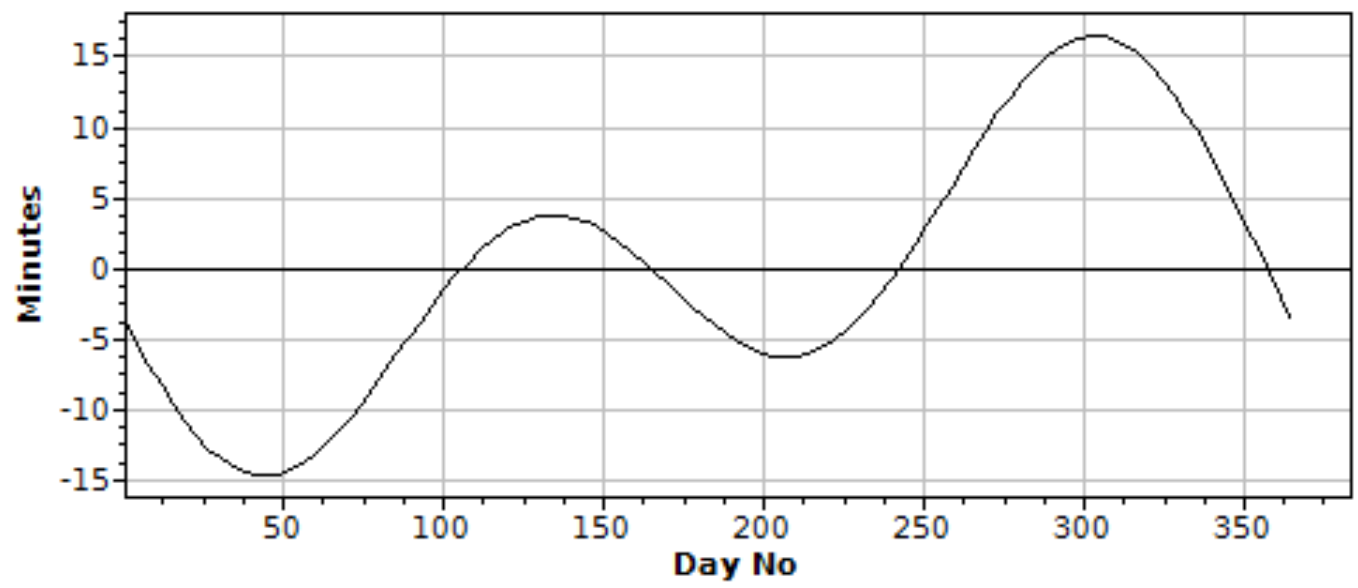

Chart 3-2: Plot of solar equation of time, minute correction by day of the year

\section{Solar Constant (SOLCON)}

The solar constant represents the intensity of solar radiation falling on a surface at the top of the atmosphere normal to the sun rays. It is obtained from a curve fit of measured solar data.

\section{Atmospheric Excitation Coefficient (ATMEXT)}

This coefficient corrects for the reduction of solar energy by the atmosphere. ATMEXT is also obtained from curve fitting of measured data (as in Threlkland and Jordan (1958) and Stephenson (1985)).

\section{Sky Diffuse Factor (SKYDIFF)}

The sky diffuse factor is obtained from curve fitting of measured experimental data (as in Threlkland and Jordan (1958) and Stephenson (1985)) and allows the calculation of diffuse radiation obtained from normal solar radiation.

Monthly values of the above listed entities are shown in Table 3-4 (ASHRAE, 1977). The listed values are for the $21^{\text {st }}$ day of each month. 


\begin{tabular}{|c|c|c|c|c|c|}
\cline { 2 - 5 } \multicolumn{1}{c|}{} & $\begin{array}{c}\text { DECLN } \\
(\mathbf{d e g})\end{array}$ & $\begin{array}{c}\text { EQTIME } \\
(\mathbf{h r s})\end{array}$ & SOLCON & ATMEXT & SKYDFF \\
\hline January & -20.00 & -0.19 & 390 & 0.142 & 0.058 \\
\hline February & -1.08 & -0.23 & 385 & 0.144 & 0.060 \\
\hline March & 0.0 & -0.123 & 376 & 0.156 & 0.071 \\
\hline April & 11.6 & 0.020 & 360 & 0.180 & 0.097 \\
\hline May & 20.0 & 0.060 & 350 & 0.196 & 0.121 \\
\hline June & 23.45 & -0.025 & 345 & 0.205 & 0.134 \\
\hline July & 20.6 & -0.103 & 344 & 0.207 & 0.136 \\
\hline August & 12.3 & -0.051 & 351 & 0.201 & 0.122 \\
\hline September & 0.0 & 0.113 & 365 & 0.174 & 0.042 \\
\hline October & -10.5 & 0.255 & 378 & 0.160 & 0.073 \\
\hline November & -19.8 & 0.235 & 387 & 0.149 & 0.063 \\
\hline December & -23.45 & 0.033 & 391 & 0.142 & 0.057 \\
\hline
\end{tabular}

Table 3-4: ASHRAE 1977 Handbook of Fundamentals

For ease of use in software, these five quantities have been expressed in a truncated Fourier series equation (equation 3-52).

$$
\begin{aligned}
& \tan (D C L N) \\
& \left.\begin{array}{c}
\text { QTIME } \\
\text { SOLCON } \\
\text { ATMEXT } \\
\text { SKYDFF }
\end{array}\right\}=A_{0}+A_{1} \cos (w)+A_{2} \cos (2 w)+A_{3} \cos (3 w) \\
& +B_{1} \sin (w)+B_{2} \sin (2 w)+B_{3} \sin (3 w)
\end{aligned}
$$

Where:

$$
\begin{aligned}
& -w=\frac{2 \pi}{366}(\text { Doy }) \\
& \text { - Doy = Day of the year }
\end{aligned}
$$




\begin{tabular}{|c|c|c|c|c|c|c|c|}
\cline { 2 - 7 } \multicolumn{1}{c|}{} & $\mathbf{A}_{\mathbf{0}}$ & $\mathbf{A}_{\mathbf{1}}$ & $\mathbf{A}_{\mathbf{2}}$ & $\mathbf{A}_{\mathbf{3}}$ & $\mathbf{B}_{\mathbf{1}}$ & $\mathbf{B}_{\mathbf{2}}$ & $\mathbf{B}_{\mathbf{3}}$ \\
\hline $\begin{array}{c}\text { Tan } \\
\text { (DECLN) }\end{array}$ & -0.00527 & -0.4001 & -0.003996 & -0.00424 & 0.0672 & 0.0 & 0.0 \\
\hline EQTIME & $\begin{array}{c}0.696 \mathrm{x} \\
10^{-4}\end{array}$ & 0.007006 & -0.0533 & -0.00157 & -0.122 & -0.156 & -0.00556 \\
\hline SOLCON & 368.44 & 24.52 & -1.14 & -1.09 & 0.58 & -0.18 & 0.28 \\
\hline ATMEXT & 0.1717 & 0.0344 & 0.0032 & 0.0024 & -0.0043 & 0.0 & -0.0008 \\
\hline SKYDFF & 0.0905 & -0.0410 & 0.0073 & 0.0015 & -0.0034 & 0.0004 & -0.0006 \\
\hline
\end{tabular}

Table 3-5: Fourier series equation constants

Using the 5 quantities discussed above, the solar calculations are performed using the following major steps (Method deployed by DOE-2).

\section{Determine the sunrise hour angle (GUNDOG)}

$$
G U N D O G=\cos ^{-1}[-\tan (S T A L A T) x \tan (D E C L N)]
$$

$($ hr angle of sunrise $)=\cos ^{-1}[-\tan ($ latitude $) x \tan ($ Declination $)] \quad(3-53)$ Where:

- $\quad$ DECLN = Solar declination angle

- $\quad$ STALAT $=$ Latitude

2. For each hour of the day : Calculate Hour Angle (HORANG)

$$
\begin{aligned}
\text { HORANG }= & \left(\frac{2 \pi(r d)}{24(h r)}\right)\left(I H R-12+\operatorname{ITIMZ}+\text { EQTIME }-\frac{1}{2}\right)-\operatorname{STALON} \quad(3-54) \\
= & \left(\frac{2 \pi(r d)}{24(h r)}\right)\left[(\text { hr of day }-12)+(\text { timing zone })+(\text { eqtn of time })-\frac{1}{2}\right] \\
& - \text { Longitude }
\end{aligned}
$$

Note: Subtracting $(1 / 2)$ is because all calculations are performed at the middle of the hourly interval. 


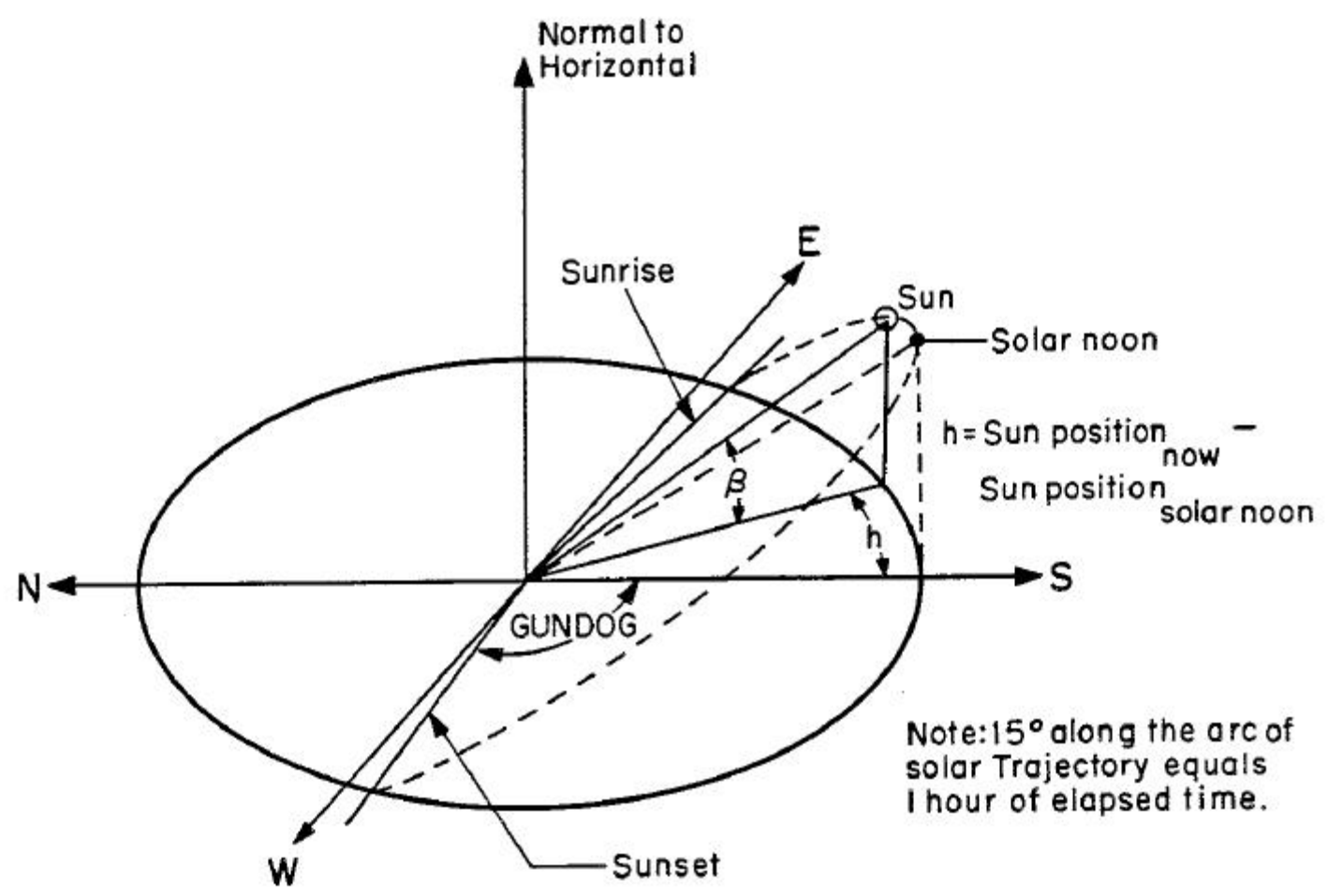

Figure 3-10: Daily Solar Geometry (DOE-2 Engineers Manual, 1982)

\section{Determine if sun is up or down for the current hour}

- Find the boundary of current interval nearest to noon (= TEST)

$$
\left.\begin{array}{l}
\text { If } I H R<12, T E S T=H O R A N G+\frac{2 \pi \mathrm{rad} / \text { day }}{48 \mathrm{half} \mathrm{hrs} / \text { day }} \\
\text { If } I H R>12, T E S T=H O R A N G-\frac{2 \pi \mathrm{rad} / \text { day }}{48 \mathrm{half} \mathrm{hrs} / \text { day }}
\end{array}\right\}
$$

Where: $I H R=$ Hour of the day

- If $|T E S T|>|G U N D O G| \Rightarrow$ Sun is down for the entire hour

If $\mid$ Boundary of current interval $|>|$ Sunrise/Sunset hour angle $\mid$

$$
\Rightarrow \text { Sun is down for the entire hour }
$$

4. Determine if the sun is up fully or partially for current hour 
- Find the difference between the hour angle and the boundary of the current interval:

$$
\begin{aligned}
D I F F & =\mid \text { GUNDOG }|-| T E S T \mid \\
(\text { Difference }) & =(\text { Sunrise } / \text { Sunset hour angle }) \\
& -(\text { Interval boundary closest to noon })
\end{aligned}
$$

- If $0<D I F F<\frac{2 \pi r d / d a y}{24 h r s / d a y}=0.2618 \Rightarrow$ Sunrise/Sunset in current interval

$\therefore$ Fraction of sun up $($ FSUNUP $)=$

$$
\left\{\begin{array}{c}
\text { FSUNUP }=1 \quad \text { if sun is fully up } \\
\text { FSUNUP }=\frac{24(\mathrm{hrs})}{2 \pi(r d)} \text { DIFF } \text { if Sunset/Sunrise }
\end{array}\right.
$$

\section{Determine the Solar Direction Cosines}

Three solar direction cosines define the position of the building with respect to the sun and sun rays. They are defined as RAYCOS (1), RAYCOS(2) and RAYCOS(3), in equations 3-58, 3-59, and 3-60.

$$
\begin{aligned}
& R A Y \operatorname{COS}(1)=[\cos (H O R A N G) \cos (D E C L N) \sin (S T A L A T) \\
& -\sin (D E C L N) \cos (S T A L A T)] \sin (B A Z I M) \\
& -\sin (H O R A N G) \cos (D E C L N) \cos (B A Z I M) \quad(3-58) \\
& R A Y C O S(2)=[\cos (H O R A N G) \cos (D E C L N) \sin (S T A L A T) \\
& -\sin (D E C L N) \cos (S T A L A T)] \cos (B A Z I M) \\
& -\sin (H O R A N G) \cos (D E C L N) \sin (B A Z I M) \quad(3-59) \\
& R A Y C O S(3)=\sin (S T A L A T) \sin (D E C L N) \\
& +\cos (S T A L A T) \cos (H O R A N G) \cos (D E C L N) \quad(3-60)
\end{aligned}
$$


Where : BAZIM = Building Azimuth angle measured from the north.

\section{Determine solar data}

Solar data are usually included in weather files. However, if not available in the weather file, the solar data are determined using the 5 previously discussed quantities; primarily the Solar constant (SOLCON), Atmospheric extinction (ATMEXT) and Sky diffusion (SKYDFF) factors. Both direct (RDN) and Diffuse (BSUN) solar radiations can now be determined. RDN and BSUN are defined in equations 3-61 and 3-62.

$$
\begin{gathered}
R D N=S O L C O N x C L R N E S x e^{-\frac{A T M E X T}{R A Y \cos (3)}} \\
B S U N=\left(\frac{S K Y D F F}{C L R N E S^{2}}\right) R D N
\end{gathered}
$$

Where : CLRNES = Clearness number. The atmospheric clearness number reflects the attenuation of solar radiation by the atmospheric conditions. Twelve local monthly clearness numbers are available. The clearness numbers are usually included in the weather file. However when not included/appropriate, twelve (monthly) ASHRAE defined numbers can be used for each locality.

\section{If Cloudy Conditions}

\section{Determine Cloud Cover}

Cloud cover presence reduces the incident solar energy intensity. Therefore on cloudy days a correction factor is defined to account for this reduction. The cloud cover correction factor (CLDCOV) is obtained by an empirical function of the third order and as a function of the clouds amount present (defined between 1 and 10) 


\section{Determine Normal and Diffuse Radiation (Cloudy condition)}

With all the necessary factors established, the amount of direct and diffuse solar radiation is determined. Taken into account are the cloud cover, atmosphere clearness, hour of the day, location and direction of the building and all the other discussed factors. The amounts of incident direct and diffuse solar radiation are therefore defined by equations 3-63, 3-64 and 3-65.

Total Solar Radiation: SOLRAD (considering possible cloud cover)

$$
\text { SOLRAD }=[R D N x \operatorname{RAYCOS}(3)+B S U N] C L D C O V \times F S N U P(3-63)
$$

Direct Normal Solar Radiation: RDNCC (considering possible cloud cover)

$$
R D N C C=R D N(1-C L D A M T / 10) x F S U N U P \quad(3-64)
$$

Diffuse Solar Radiation: BSCC (considering possible cloud cover)

$$
B S C C=S O L R A D-[R D N C C \times R A Y C O S(3)] \quad(3-65)
$$




\section{Shading Calculation}

Adjacent buildings, overhanging structures, and other miscellaneous objects and structures present in the vicinity of the building under study cast shadows onto it. These shadows affect the intensity of solar radiation incident on various parts of a building. It is therefore essential to perform shading calculations and account for the shading effect of surrounding sun obstructions. Presented below is a general description of the shading calculation method. This method is also utilized by DOE-2 and presented in the DOE-2 Engineers Manual (1982).

\section{Shading Polygons}

In the shading calculations three major polygons are defined. Those polygons are the Shading Polygon (SP), Receiving Polygon (RP), and Shadow Polygon. The surface on which the shadows fall is denoted as the receiving polygon, the surface casting the shadow is defined as the shading polygon, and the shape of the shadow falling on the receiving polygon is defined as the shadow polygon (Figure 3-13).

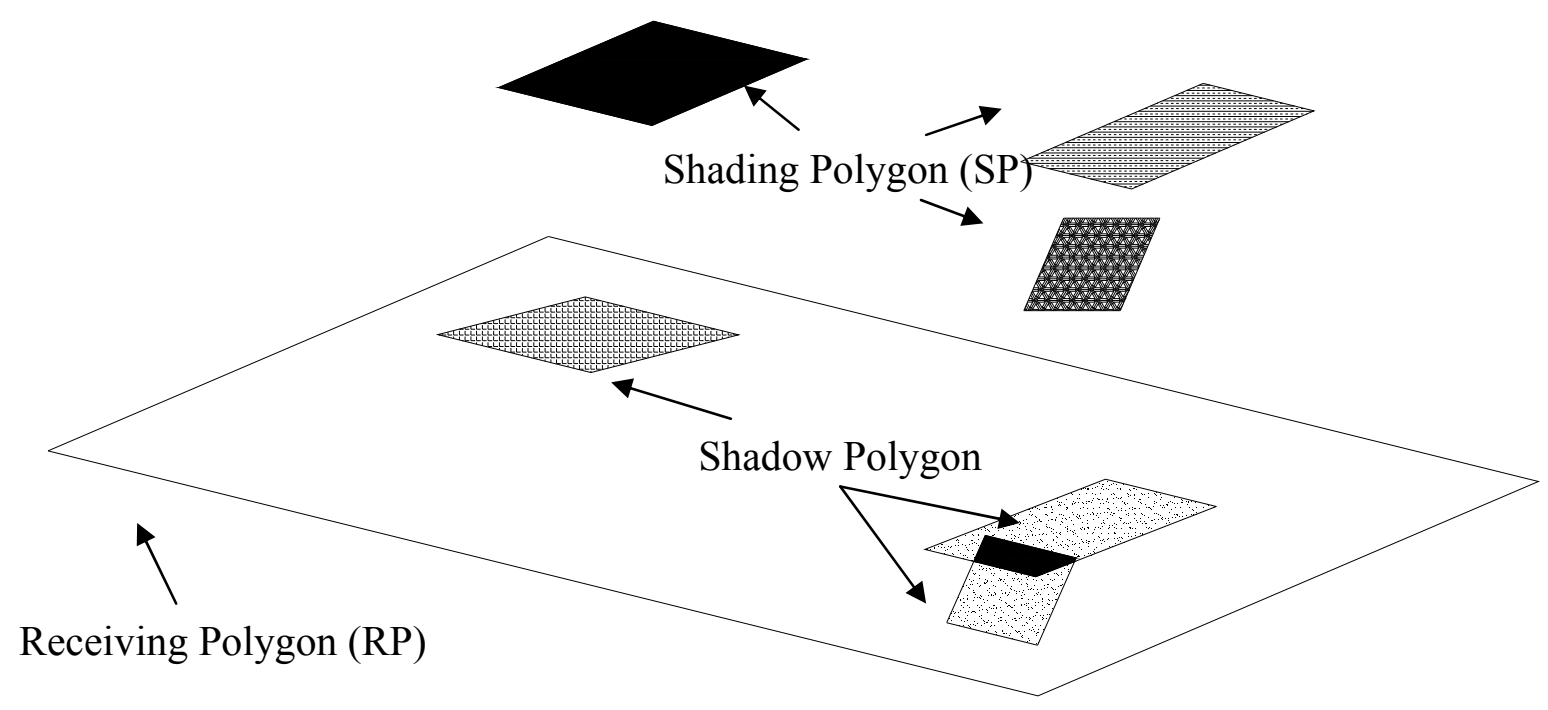

Figure 3-11: Shading calculations related polygons 
The shading calculations for each receiving surface area are performed 24 times a day (once for each hour) for 1 day of each month. The underlying assumption is that there is no major variation in the shading properties of a single hour over a period of 1 month.

\section{Shading Calculation Description}

The intensity of light falling on the RP polygon (depending on the SP polygon transmittance) is expressed as a function $f(x, y)$. As a result, the total amount of solar light incident on the RP polygon is defined by equation 3-66.

$$
\text { Light Amount }=\iint f(x, y) d x d y
$$

However, considering that for an individual shade the intensity $f(x, y)$ is constant, then the mount of incident light can be defined in equation 3-66.

$$
\text { Light Amount }=f(x, y) \times \text { Area of Shadow Polygon }
$$

In order to determine the shadow polygon area the following procedures are followed:

1. The receiving polygon is divided into a large number of bars/strips.

2. The points of intersection of the shadow polygon with the midlines of each strip are saved, thus defining the contour of the shadow polygon. As a result, the shadow polygon is transformed into a set of rectangular strips as shown in Figure $3-14$.

Therefore, the incident sunlight intensity is equal to the product of the constant $f(x, y)$ by the area of the covered portion of each rectangular strip. 


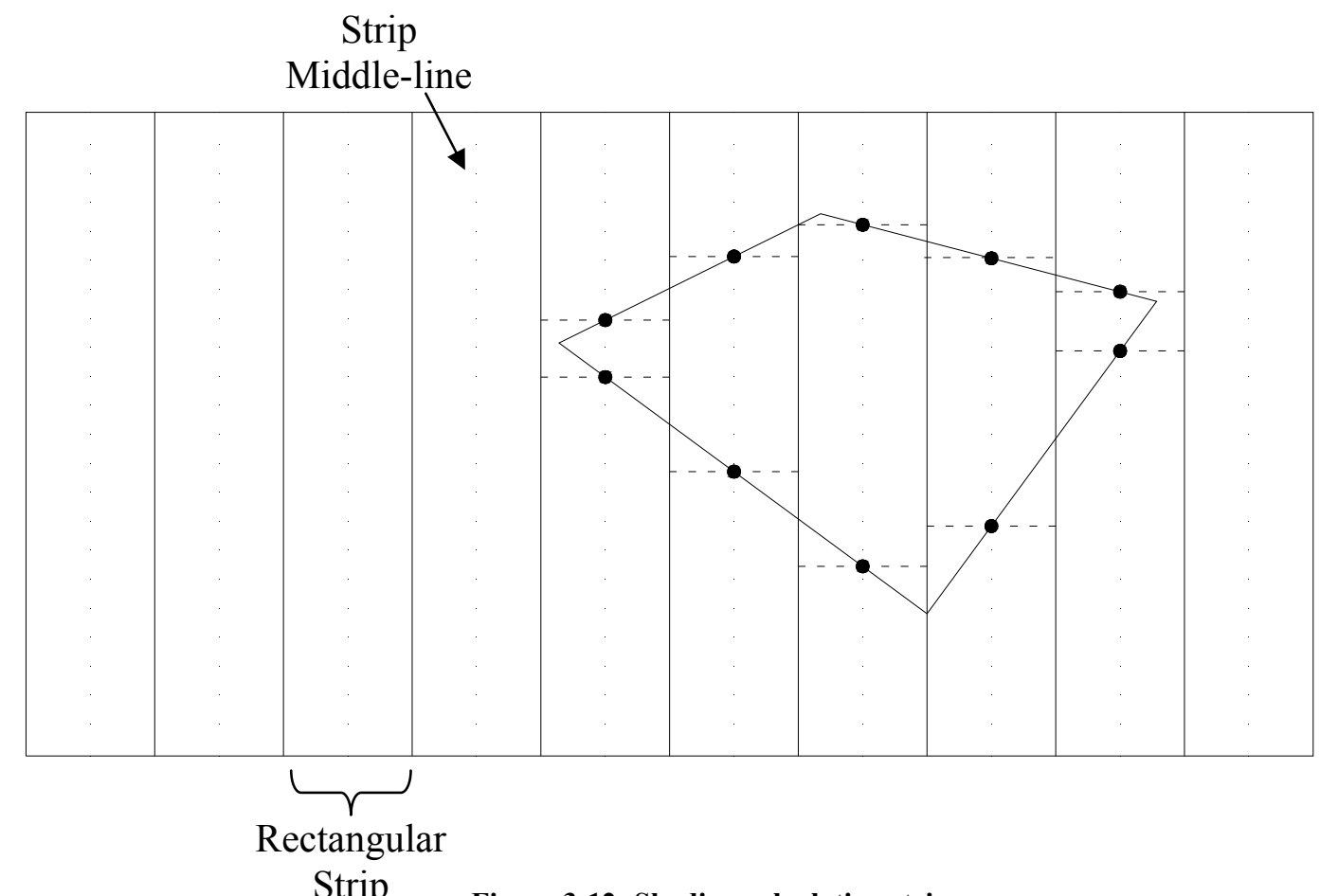

Strip

Figure 3-12: Shading calculation strips

Similar to the solar calculation, the position of the sun is checked (using the sun cosine angles defined previously) to verify that the sun is up, the location of sun, and the capability of the SP polygon to cast a shadow on the RP polygon. The SP polygon is then projected on to the RP polygon based on the sun position as defined by the sun cosine angles RAYCOS (1), RAYCOS(2), and RAYCOS(3). Also, any portions of the shading polygon dipping below the RP polygon are clipped off; since these part of the SP polygon cannot cast a shade on the RP polygon. 


\section{CFD Modeling of Cracks and Airflow Paths}

Air flows across the building envelope through a multitude of cracks and flow paths. These air leakage paths fall into 2 categories in terms of location. Air leakage paths can either be within the plane of a face/wall or at interfaces/joints. Examples of interfaces include wall-wall (corners), wall to ceiling, wall to floor, and others. Existing models of air flow through the building envelope have mostly had either a generalized representative area utilized in calculations of infiltration. On the other hand, CFD models of infiltration are few and have solely modeled a small 2-D section of a building envelope (wall) with a clearly defined single airflow path as shown in Figures 3-15 below. Examples Include Chebil et. Al (2003) and Boussa et. Al(2001). In generalized nonbuilding envelope related fluid flow through cracks simulations researchers have modeled cracks by inducing them in a model using an applied structural load rather than predefining the flow path's properties An example is shown in Figure 3-16 below. This technique is mostly used in nuclear leakage safety research as in Danko and Bahrami (2004).
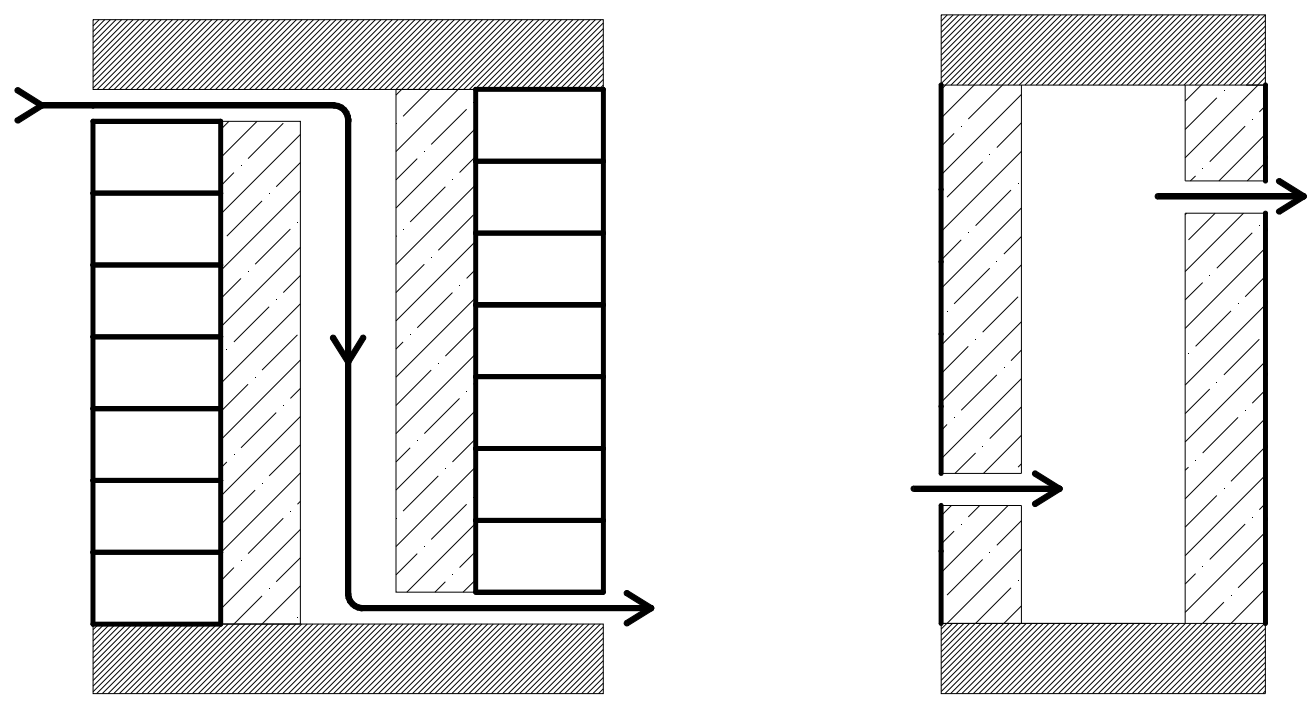

Figure 3-13: Sample 2-D Infiltration CFD Models 


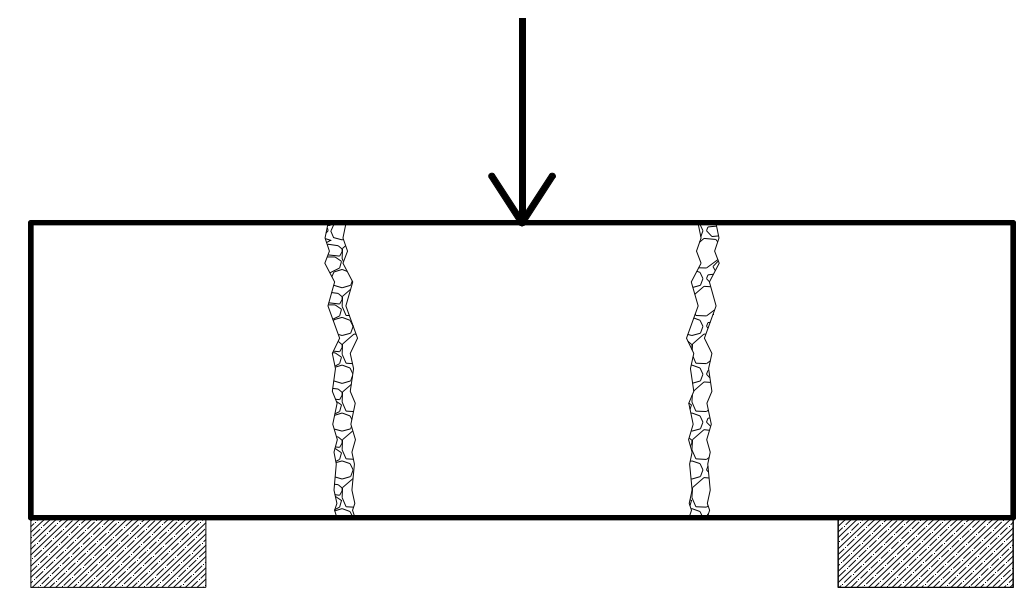

Figure 3-14: Sample 2-D Infiltration CFD Models With Loading Induced Cracks

In this research a full 3D representative building envelope will be modeled. Therefore, it is essential to identify all possible shapes and locations of air leakage paths for use in building the CFD model. Using a combination of data from available literature, the AIVC (Air Infiltration \& Ventilation Center), and ASHRAE it is possible to identify the most common crack shapes in building envelopes and their corresponding path dimensions. The following sections provide an insight into this process and the corresponding resulting 3-D building envelope models.

\section{Air Leakage Cracks \& Paths}

Emulating building cracks and air leakage paths entails 3 main stages:

1. Quantification of the amount of cracks existing in building envelopes within a representative area or span

2. Identification of possible shapes of cracks/flow paths

3. Identification of the dimensions/dimensional ratios of these flow paths in both:

a. Plain of a wall (Face)

b. At envelope joints, interfaces, and corners 
It is import to note that the data determined should be a realistic representation and applicable to the construction methods and materials being used whether brick, concrete, wood or other.

For each type of crack, the data adopted was obtained through a cross matching of at least 2 different sources. Flowchart 3-5 provides a representation of this process.

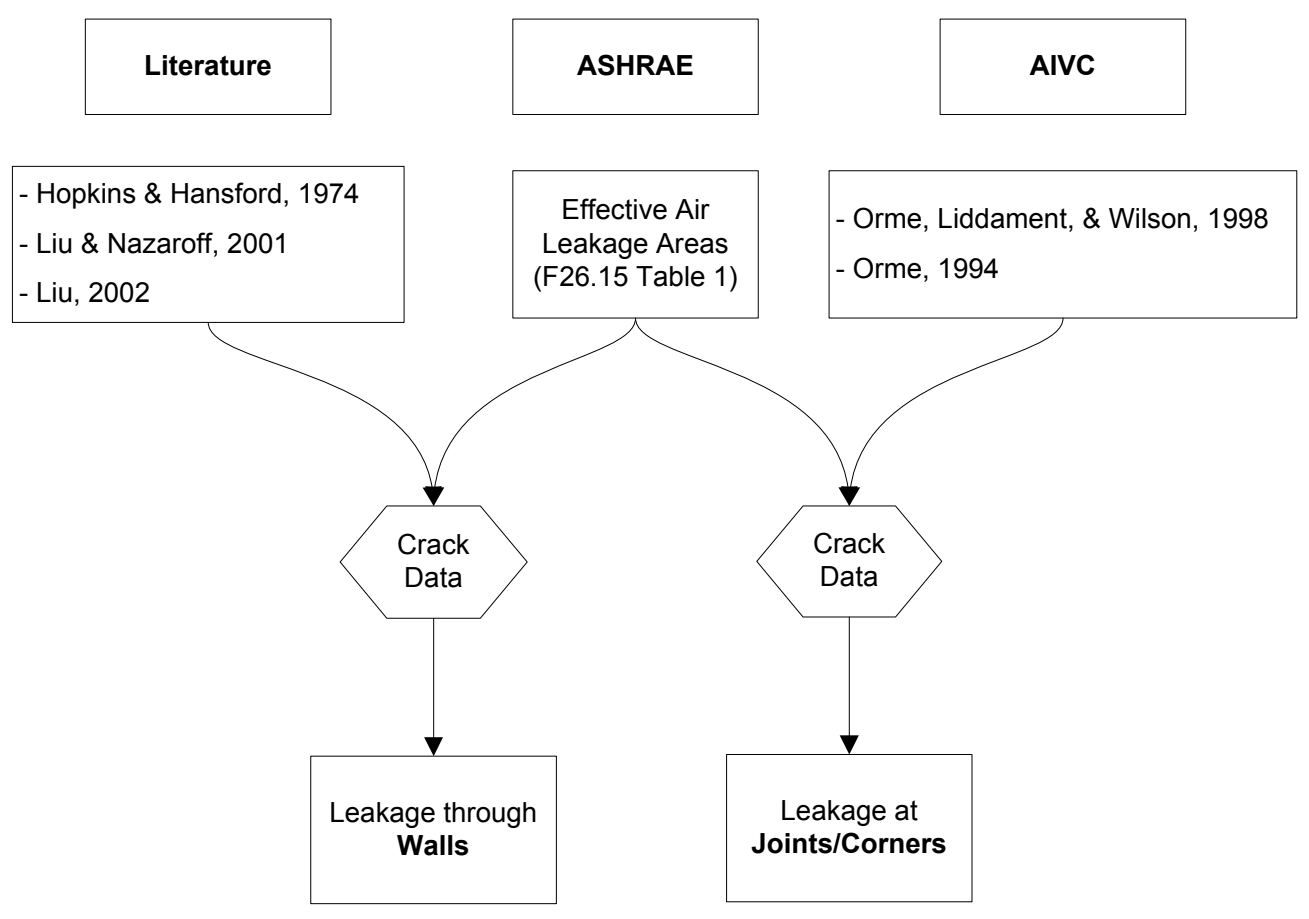

Flowchart 3-5: Crack Properties Determination Process

\section{Equations Utilized}

In some situations crack dimensional properties are not readily presented but rather back calculated from airflow rates and noted flow coefficient values. The situation is as such in the available AIVC databases. Consequently, Equations 3-68 through 3-71 shown below are utilized for calculating equivalent leakage areas (ELA) from the data provided.

$$
Q=C(\Delta P)^{n}
$$




$$
\begin{aligned}
& E L A_{4}=C 4^{n-0.5} \sqrt{\frac{\rho_{\text {air }}}{2}} \\
& E L A_{4}=Q_{4} \sqrt{\frac{\rho_{\text {air }}}{8}} \\
& d_{\text {crack }}=\sqrt{\frac{4 E L A}{\pi}}
\end{aligned}
$$

Where $: Q=$ Air Flow rate $\left(\mathrm{m}^{3} / \mathrm{Sec}\right)$

$$
\begin{aligned}
& C=\text { Flow Coefficient }\left(\mathrm{m}^{3} / \mathrm{Sec} . \mathrm{Pa}^{n}\right) \\
& \text { ELA } A_{4}=\text { Equivalent Leakage Area at } 4 \mathrm{~Pa}(0.016 \text { in water }) \\
& n=\text { Flow Coefficient } \\
& \rho=\text { Air Density }\left(\mathrm{Kg} / \mathrm{m}^{3}\right)
\end{aligned}
$$

\section{Cracking in Walls}

\section{Existing Literature}

A through literature review performed in search for air leakage cracks dimensional characteristics. In most literature, air leakage is presented using an overall estimated leakage area for the building envelope rather than crack specific dimensions. Few sources provided dimensional characteristics for cracks in the plain of a wall; primarily Hopkins \& Hansford (1974), Liu \& Nazaroff (2001), and Liu (2002). The results shown in Figures 3-17 and 3-18 below are obtained from Hopkins \& Hansford and have been cross matched and verified versus crack properties indicated in other literature as shown in flowchart 3-5. Two predominant crack shapes are observed to be reported in literature, straight cracks (Figure 3 - 17) and Angled Cracks (Figure 3-18). Therefore, these two shapes of cracks will be adopted in the following simulations. 


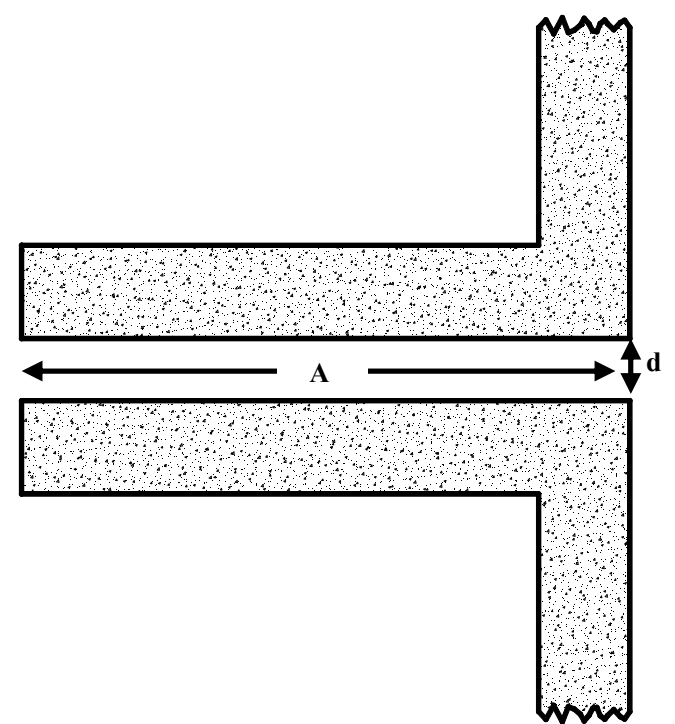

\begin{tabular}{|c|c|c|}
\hline & $\mathbf{A}(\mathbf{m m})$ & d (mm) \\
\hline 1 & 25 & \multirow{4}{*}{$\begin{array}{c}1,3, \underline{\mathbf{5}}, 8 \\
\mathrm{~mm}\end{array}$} \\
\hline 2 & 19 & \\
\hline 3 & 50 & \\
\hline 4 & 6 & \\
\hline
\end{tabular}

Figure 3-15: Crack Shape and Dimensions

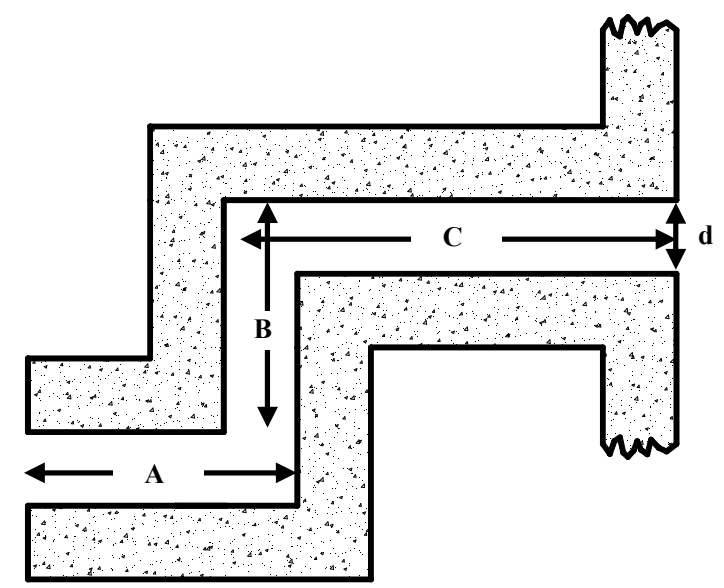

\begin{tabular}{|c|c|c|c|c|}
\hline $\mathbf{m m}$ & A & B & C & d \\
\hline $\mathbf{1}$ & 20 & 29 & 24 & 3.5 \\
\hline $\mathbf{2}$ & 25 & 29 & 32 & $\underline{\mathbf{5}}$ \\
\hline
\end{tabular}

Figure 3-16: Crack Shape and Dimensions

\section{ASHRAE}

In ASHRAE Fundamentals (2001) Chapter 26 Table 1 "Effective Air Leakage Area (Low Rise Applications only) "provides leakage areas for common construction material and building components. The data is provided as per a unit length or a unit area of the corresponding material/component. Backward calculations using equation 3-71 allow obtaining a crack dimension. An example of the data provided in ASHRAE is 
shown in Table 3-6 below. A representative crack dimension $/ \mathrm{ft}^{2}$ of a sample material can be calculated using the data provided in ASHRAE.

\begin{tabular}{|c|c|c|c|c|}
\cline { 2 - 5 } \multicolumn{1}{c|}{} & Unit & Best Estimate & $\begin{array}{c}\text { Minimum } \\
\text { Estimate }\end{array}$ & $\begin{array}{c}\text { Maximum } \\
\text { Estimate }\end{array}$ \\
\hline Cast-in-Place Concrete & $\mathrm{in}^{2} / \mathrm{ft}^{2}$ & 0.007 & 0.007 & 0.026 \\
\hline Precast Concrete & $\mathrm{in}^{2} / \mathrm{ft}^{2}$ & 0.017 & 0.004 & 0.024 \\
\hline
\end{tabular}

Table 3-6: Sample ASHRAE Material leakage Data

\section{In-Wall Leakage Path Crack Dimensions}

The simulated test case will utilize brick cavity walls. The choice of this type of construction is dependent on the chosen geographical location of the building envelope to be simulated. The choice of location and building material will be discussed in following section in this Chapter. Using data discussed in the 2 previous sections calculations for crack diameter characteristics are performed and summarized in Table 3-7 below. By matching the results obtained from literature sources versus ASHRAE data the representative crack diameter for in-plain brick cavity wall is taken as $5 \mathrm{~mm}$ for every $\mathrm{ft}^{2}$ of the wall surface. The length of the crack, both for straight and angled cracks, depends on the thickness of the wall. Proportions for crack span lengths presented in literature for angled cracks will be observed in dimensioning crack span length in the CFD test case.

\begin{tabular}{|cc|c||c|c|}
\hline \multicolumn{3}{|c||}{ ASHRAE $\left(\mathrm{in}^{2} / \mathrm{ft}^{2}\right)$} & \multicolumn{2}{c|}{ Literature } \\
\hline Best Estimate & Max Estimate & Use & Straight Crack & $\mathrm{d}=5 \mathrm{~mm}$ \\
\hline 0.0098 & 0.033 & 0.033 & Angled Crack & $\mathrm{d}=5 \mathrm{~mm}$ \\
\hline & $\Rightarrow$ & $\begin{array}{c}\mathrm{d}=5.12 \mathrm{~mm} \\
\left(0.205 \mathrm{in}^{2}\right)\end{array}$ & \\
\cline { 2 - 4 } & & &
\end{tabular}

Comparing Results from Both Sources $\Rightarrow$ use crack diameter $\mathbf{d}=\mathbf{5} \mathbf{~ m m}$ 


\section{Leakage Path Dimensions at Joints and Interfaces}

As previously discussed, tabulated data from ASHRAE data and AIVC databases are used to determine the dimensions of leakage paths at corners and Interfaces (i.e. wallceiling). A summary of the calculations and cross verification between the 2 sources is shown in Table 3-8 below.

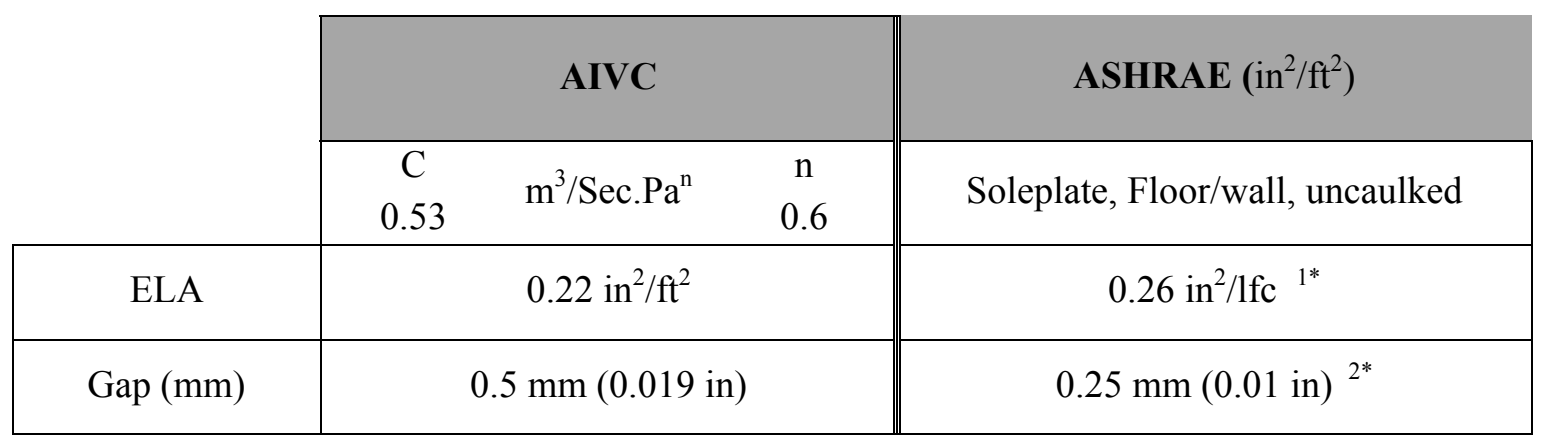

Comparing Results from Both Sources $\Rightarrow$ use Gap at corner/interface $=\mathbf{0 . 5} \mathbf{~ m m}$

$1 *:$ lfc $=$ Linear Foot of Crack

2*: Gap $=0.25 \mathrm{~mm}$ per single crack however multiple cracks can exist on a corner/interface.

The ASHRAE result is per linear foot of crack (lfc). However, in a building multiple cracks exist usually at an interface. Assuming 2 cracks exist per corner/interface, the result from ASHRAE will match that of AIVC. Consequently the crack opening dimension (gap) at corners and interfaces is taken to be:

$$
\text { Wall-Wall / Wall - Ceiling: Gap }=0.5 \mathrm{~mm}
$$

Notes:

1. At floor - wall interface the leakage gap opening is considered to be negligible. The bearing weight of the wall helps keep crack opening at the floor - wall interface negligible. 
2. The floor and ceiling are considered (in the current simulations) to be of material with minimal leakage properties. Emphasis is given to the leakage through cracks within the wall plain and at interfaces.

3. One (1) crack per wall is provided to account for leakage area resulting from an electrical outlet. According to the adopted building code at the chosen location of the test case geometry the electrical outlet should be no less than 12 inches from the top/bottom of the wall. According to ASHRAE, the estimated equivalent leakage area for an electrical outlet is $0.3 \mathrm{in}^{2}$ each. Consequently, the diameter of the cracks representing leakage through electrical outlets is $15.5 \mathrm{~mm}(0.61$ inches $)$ each.

\begin{tabular}{|c|c|}
\cline { 2 - 2 } \multicolumn{1}{c|}{} & Crack Diameter / Gap Opening (mm) \\
\hline In-wall & $\mathrm{d}=5.12 \mathrm{~mm}$ \\
\hline Wall - Wall (Corner) & Gap $=0.5 \mathrm{~mm}$ \\
\hline Wall - Ceiling & Gap $=0.5 \mathrm{~mm}$ \\
\hline Wall - Floor & Gap $=0 \mathrm{~mm}$ \\
\hline Electrical Outlet & $\mathrm{d}=15.5 \mathrm{~mm}$ \\
\hline
\end{tabular}

Table 3-8: Summary of Adopted Crack and Gap Dimensions

\section{Simulated Test Case: Location, Properties \& Others}

A sample location and construction method/material are selected for the building envelope to be simulated. The construction material, location and other properties of the building envelope should be emulated in both eQUEST and the ANSYS CFD simulation. 
The selection of the building envelope geographic location and construction characteristics is done with consideration to the following:

\section{Highlight Infiltration}

The selected building location should be as to provide ambient conditions that highlight infiltration. This is specifically in terms of weather and temperature conditions at the selected location. For example, selecting a location in a cold weather region provides conditions that promote infiltration as discussed in previous sections.

\section{Highlight Heat Recovery}

In addition to selecting a location with convenient weather conditions that highlight infiltration, the selected location should be characterized by building construction methods and materials that promote heat recovery

\section{Hourly Data Availability}

Essential to both the ANSYS and eQUEST simulations is the availability of hourly weather data. Therefore, the chosen location should have an hourly weather file available containing all necessary hourly data.

\section{Agreement with Published Statistical Data}

Statistical averaged infiltration rate maps are available for the United States. The maps depict the variation in the severity of air infiltration across building envelops by county. The choice of a sample location for simulation should agree with published maps in terms of statistically recorded infiltration levels. The chosen location should be in a county with typically high recorded infiltration rates. 


\section{Model Location}

The selected test case location is the City of Fargo, North Dakota. The location agrees with the up stated location guidelines. Provided below are detailed information of the location of choice.

- Location: Hector International Airport area, Fargo, North Dakota (Figure 3 -19).

Weather Station is located on site.

- Location matches published statistical infiltration data as shown in Figure $3-20$ below (Sherman and McWilliams, 2007).

- Latitude : $46^{\circ}, 52^{\prime}, 38^{\prime \prime}$; Longitude: $96^{\circ}, 47^{\prime}, 22^{\prime \prime}$

- Weather: Long, cold, windy \& snowy winters

- Season Chosen : Heating season

- Simulation Duration: 1 month, January. General weather conditions for January are shown in Table $3-9$.

\begin{tabular}{|c|c|c|}
\hline Month & Jan & Feb \\
\hline Record high ${ }^{\circ} \mathbf{F}\left({ }^{\circ} \mathbf{C}\right)$ & $54(12.2)$ & $66(18.9)$ \\
\hline Average high ${ }^{\circ} \mathbf{F}\left({ }^{\circ} \mathbf{C}\right)$ & $15.9(-18.9)$ & $22.8(-5.1)$ \\
\hline Average low ${ }^{\circ} \mathbf{F}\left({ }^{\circ} \mathbf{C}\right)$ & $-2.3(-19.1)$ & $5.4(-14.8)$ \\
\hline Record low ${ }^{\circ} \mathbf{F}\left({ }^{\circ} \mathbf{C}\right)$ & $-48(-44)$ & $-47(-44)$ \\
\hline Sunshine hours & 140 & 155 \\
\hline
\end{tabular}

Table 3-9: Averaged Weather Conditions for Fargo Over the Simulation Span Time Period 


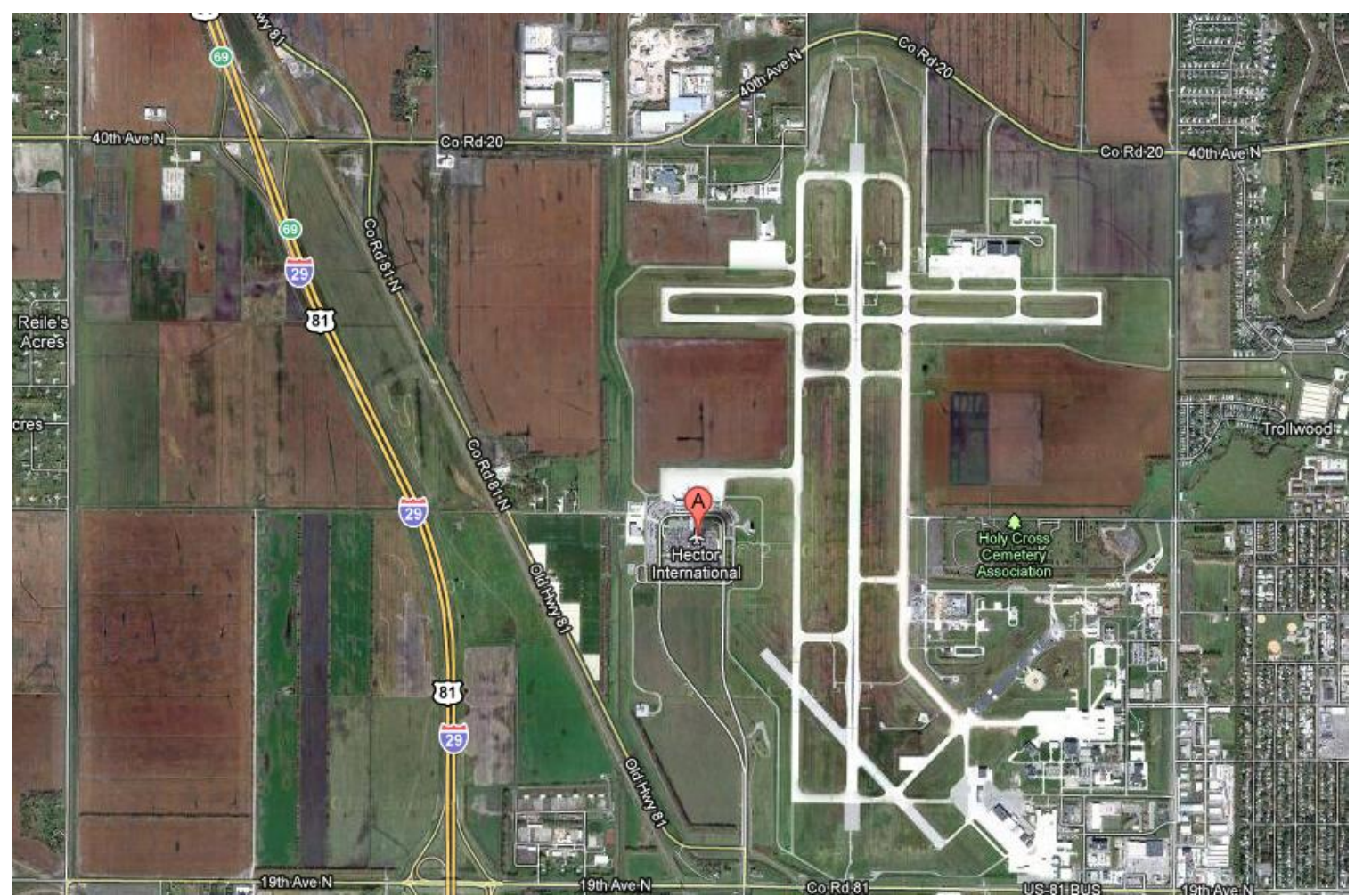

Figure 3-17: Chosen Location of Building Envelope, Vicinity of Fargo Intl, Fargo, North Dakota

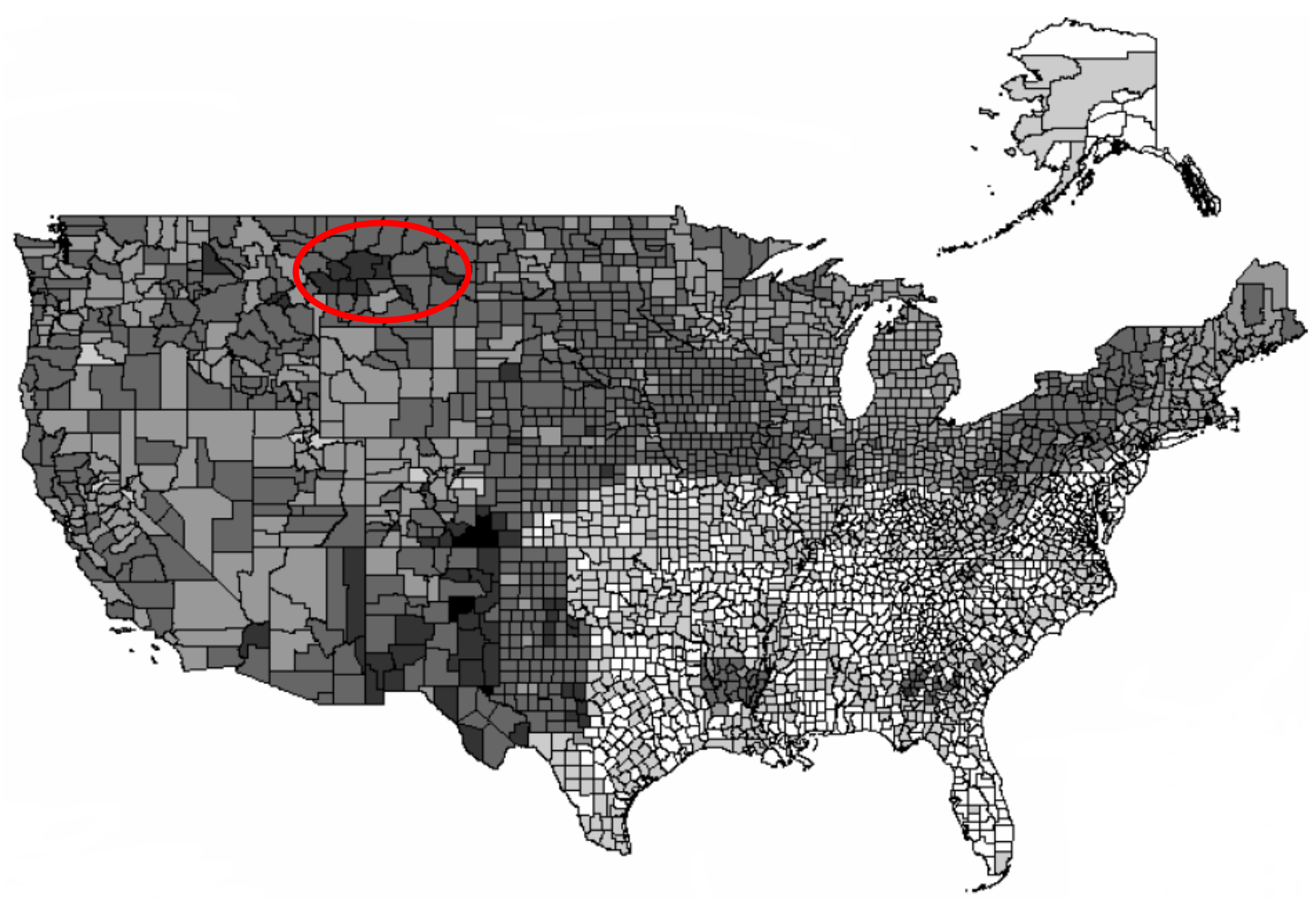

Figure 3-18: Air Leakage By County (Sherman and McWilliams, 2007) 


\section{Model Material and Construction Method}

The material and construction selected for the simulated test case resemble the construction methods and materials observed in the selected location. Following are the construction details of the model:

- Material: Brick and Concrete

- Walls : Running Board, Brick Cavity Walls

- Wall Dimensions: $6 \mathrm{ft}$ x $6 \mathrm{ft}$ each

- Crack Shapes:

- Wall Plain : Straight cracks \& Angled Cracks

- Joints/Interfaces : Open Gap (All-through Crack)

- Metal Ties : No Metal Ties

Following adopted construction codes the total number of required metal ties for a $6 \mathrm{ftx} 6 \mathrm{ft}$ wall are 2 ties per wall. Therefore it is elected to ignore the metal ties in the construction of the envelope walls. Calculation Details are shown below:

Horizontal Ties:

Building Code: Ties placed horizontally at $3 \mathrm{ft}$ intervals $\rightarrow 1$ Line of Ties / $6 \mathrm{ft}$ wide wall.

Vertical Ties:

Building Code: Ties placed horizontally at $2 \mathrm{ft}$ intervals $\rightarrow 2$ Line of Ties / $6 \mathrm{ft}$ Tall wall.

Therefore: Total $=2$ Ties $/$ Whole $6 \mathrm{ft} \times$ $6 \mathrm{ft}$ wall $\rightarrow$ Ignore 


\section{CFD Model}

\section{Model Construction}

The 3D Building Envelope was built following the guidelines of the calculated crack diameter. That is in terms of diameter of cracking per foot squared. Therefore, individual $1 \mathrm{ft} \times 1 \mathrm{ft} \times 10$ in basic building blocks were modeled each with built-in crack with a diameter corresponding to one of the calculated cracking diameters. This resulted in 4 types of $1 \mathrm{ft} \times 1 \mathrm{ft} \times 10$ in Basic Building Blocks:

- Block with a straight through crack

- Block with an angled crack

- Block with a straight through crack + Electrical outlet/inlet crack

- Block with an angled crack + Electrical outlet/ inlet crack

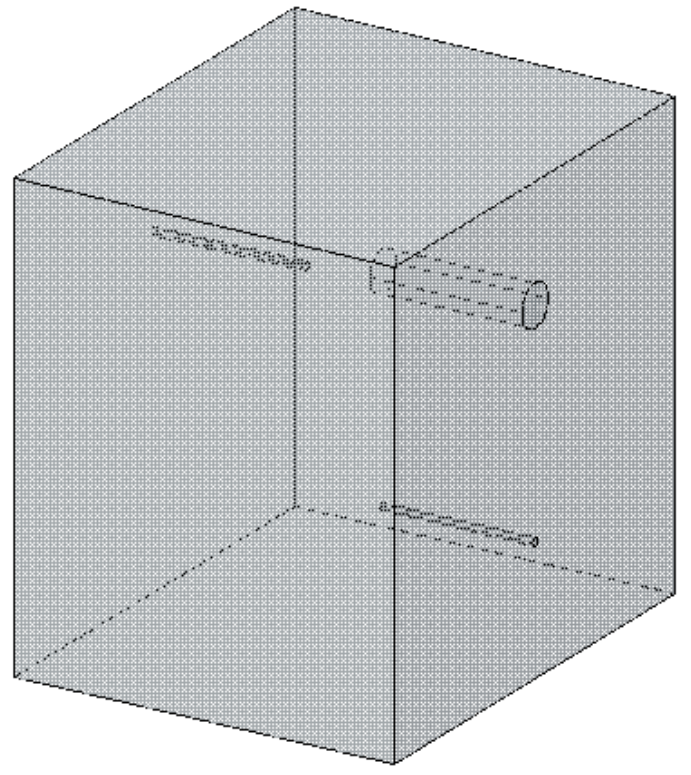

Figure 3-19: Basic Block with Angled Crack and Electrical Inlet Crack

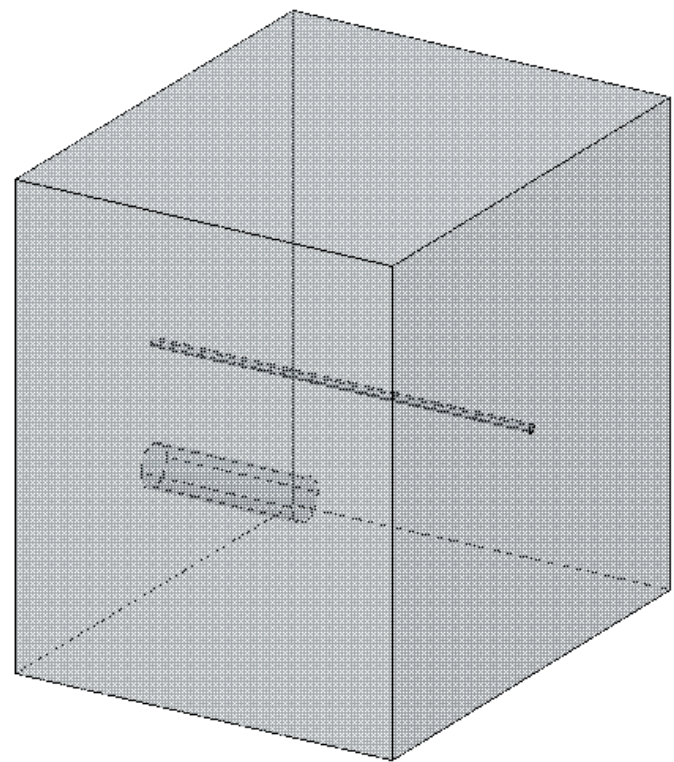

Figure 3-20: Basic Block with Angled Crack and Electrical Outlet Crack 
The individual basic building blocks were used to assemble the 3 required wall types to be simulated:

- Wall with Straight Cracks

- Walls with Angled Cracks

- Wall with mixed alternating straight Cracks and angled Cracks.

An example assembled wall consisting of mixed cracks (angled cracks + straight cracks) is shown in Figure 3-23. Individual blocks are then merged to create a uniform wall and then a cavity is introduced inside the wall to create the desired representative brick cavity wall. An example is shown in Figure 3 - 24. The resulting individual walls can then be used to assemble the 3 required CAD geometries for the CFD simulation:

- 3D Envelope with Straight Cracks

- 3D Envelope with Angled Cracks

- 3D Envelope with mixed alternating straight Cracks and angled Cracks.

The combined effects of conduction, solar radiation and infiltration significantly impact the energy load due to infiltration. Once this interaction the actual energy load due to infiltration deviates from that determined using the classical method of calculating infiltration energy load as merely a product of the inside/outside enthalpy difference by the specific heat of the infiltrating air. In this methodology an existing model that considers this interaction is built upon and further developed to calculate the energy load due to infiltration. The obtained model is then applied onto eQUEST/DOE-2 building energy simulation software. Though the developed model would be easily applicable to any other hourly building energy simulation software, these software packages were chosen due to their widespread use and their status as an industry standard. 


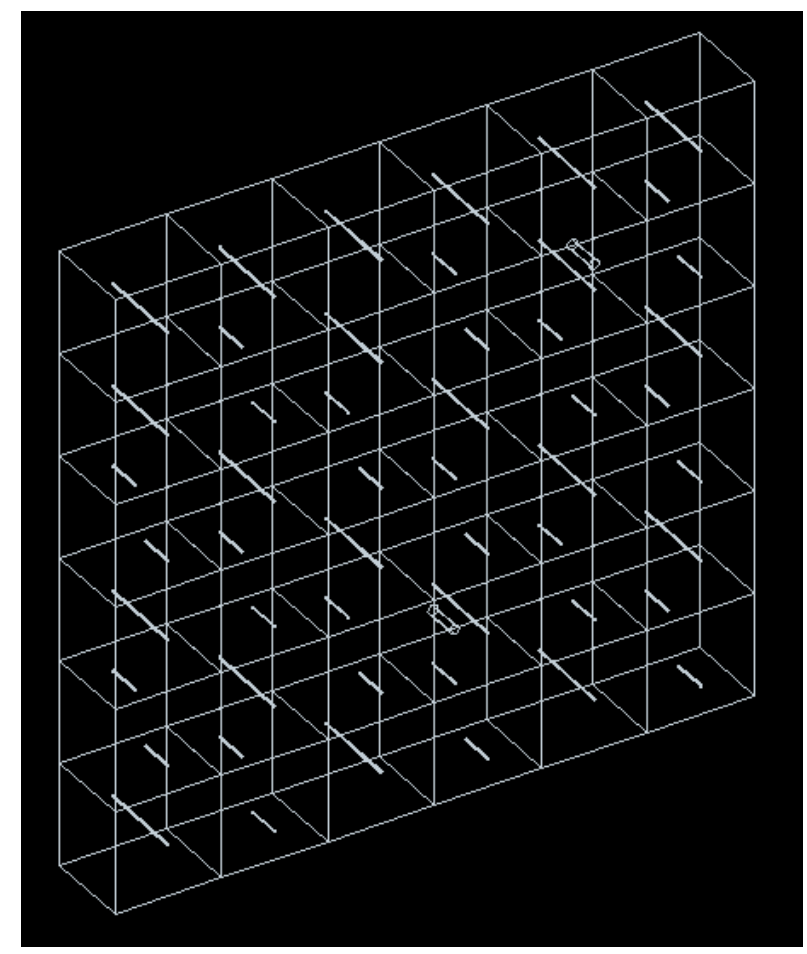

Figure 3-21: A Mixed Crack Wall Created by Assembling 36 of the Basic Building Blocks

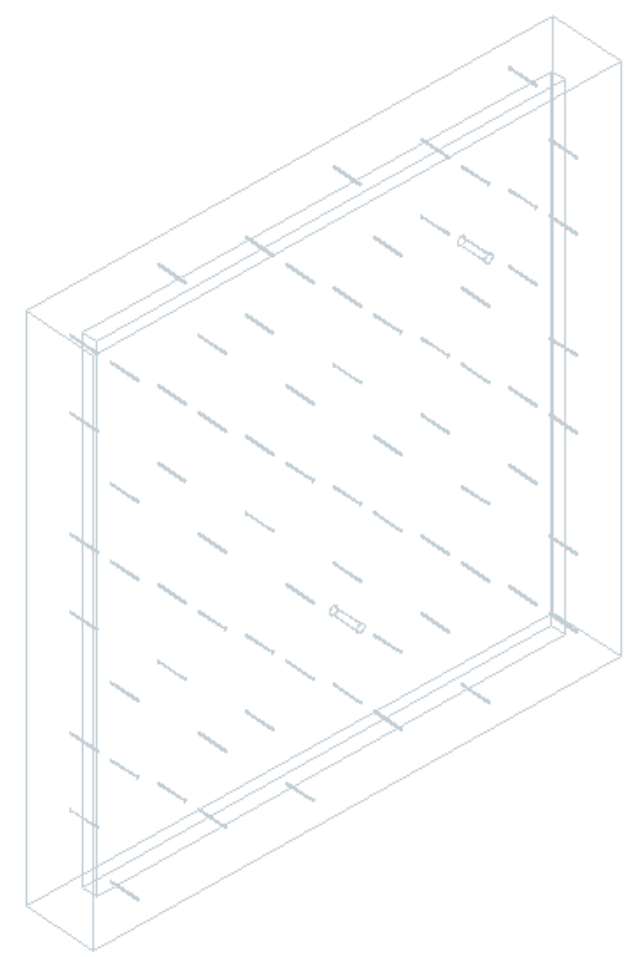

Figure 3-22: A Resulting Representative Concrete Cavity Wall 


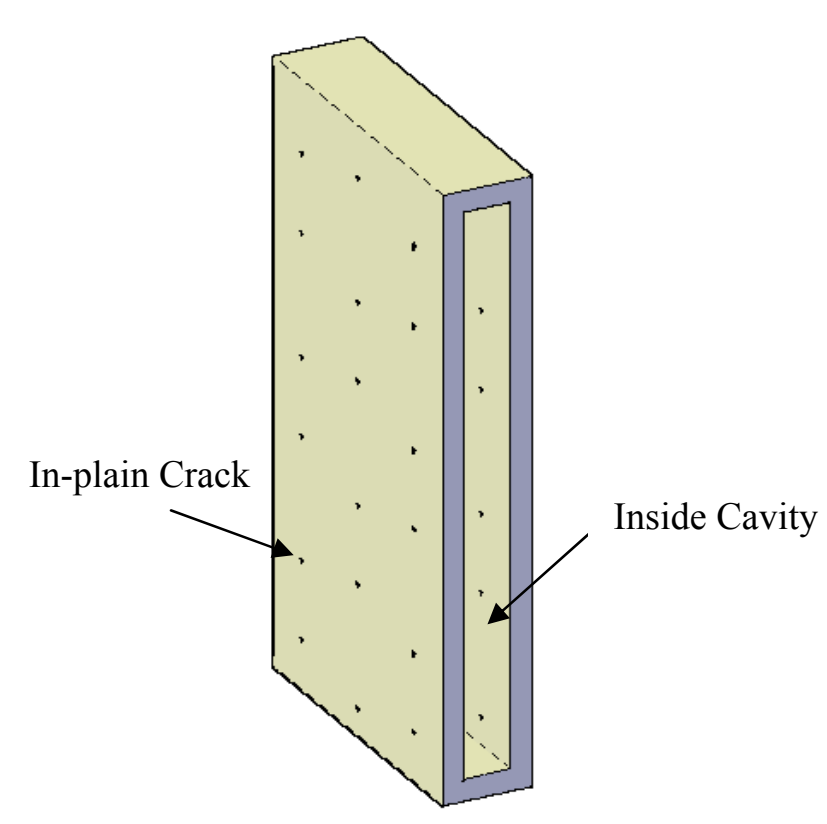

Figure 3-23: Wall Section Showing Internal Cavity and In-plain Cracks

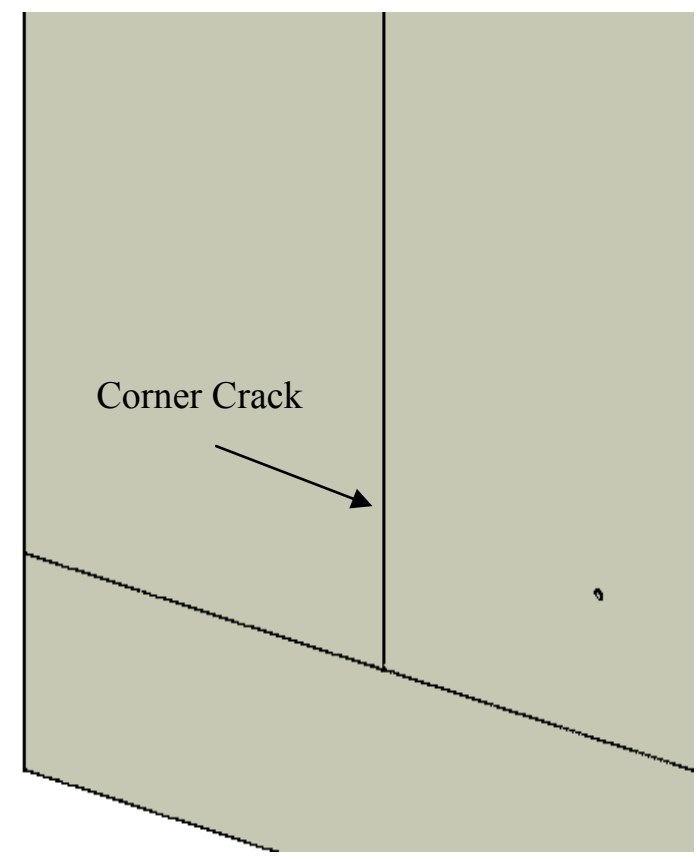

Figure 3-24: Close-up Showing Corner/Joint Cracks

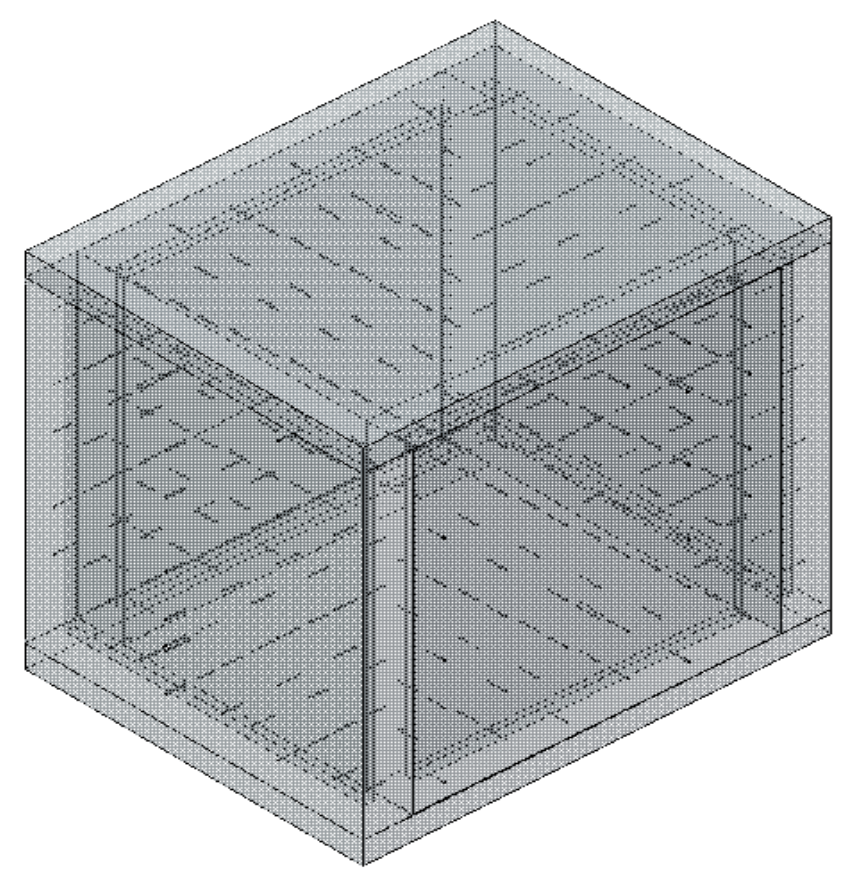

Figure 3-25: An X-ray of A Resulting 3D Model Geometry Showing All In-plain and Joint Cracks 
The majority of building energy simulation software utilize a form of the classical method or some other crude method for calculating the energy loads due to infiltration; despite acknowledging its considerable effect on building energy demand. With the wide spread use of building energy simulation software and the major impact that infiltration can have on the energy loads in a building; it is essential to develop such a model that represents the true physics of the problem and more accurately represents the energy loads on a building due to infiltration. Once the Infiltration energy load is calculated for a demonstrative structure using eQUEST/DOE-2 “+” the model developed applied upon, the simulation results will be compared to those obtained using a finite element CFD analysis of the same structure. Based on the comparison results with the finite element analysis, the developed model's accuracy will be established and consequently any necessary modifications to improve its accuracy will be determined. 


\section{Chapter 4}

\section{Modeling and Simulation}

The methodology and modeling methods discussed in Chapter 3 were utilized and followed in the building and simulation of all models. This includes the DOE-2/eQUEST analyses, CFD hygrothermal simulations, and the developed Enhanced Model. In this Chapter we present an overview of the modeling and simulation process of each of the aforementioned model types.

\section{Hygrothermal Multiphysics CFD Analysis}

\section{Model Meshing}

A good quality mesh is essential for obtaining a good solution and avoiding simulation errors. A mesh with poor element quality, high levels of element skewness, low orthogonality, and other issues adversely affects the accuracy and stability of the numerical solution.

In meshing the CFD infiltration models it is essential to pay close attention to additional critical factors beside the regular general mesh quality considerations. Particularly important are the following:

- Element size: particularly within in-wall cracks and joint cracks in order to insure the meshing of all airflow paths.

- Proper contact between fluid in cracks and inner domain fluid

- Contact between fluid in corner joints and inner domain fluid

- Contact between fluid in ceiling joint cracks and inner domain fluid 
- Proper mesh attachment between the mesh of fluid in cracks and the mesh of fluid in joint/corner cracks where applicable (the first 1 foot on each side of the two 7"8" walls).

- Proper tessellation of the mesh to avoid having a missing mesh or mesh gaps in thin sections. This is most critical in corner and ceiling joints.

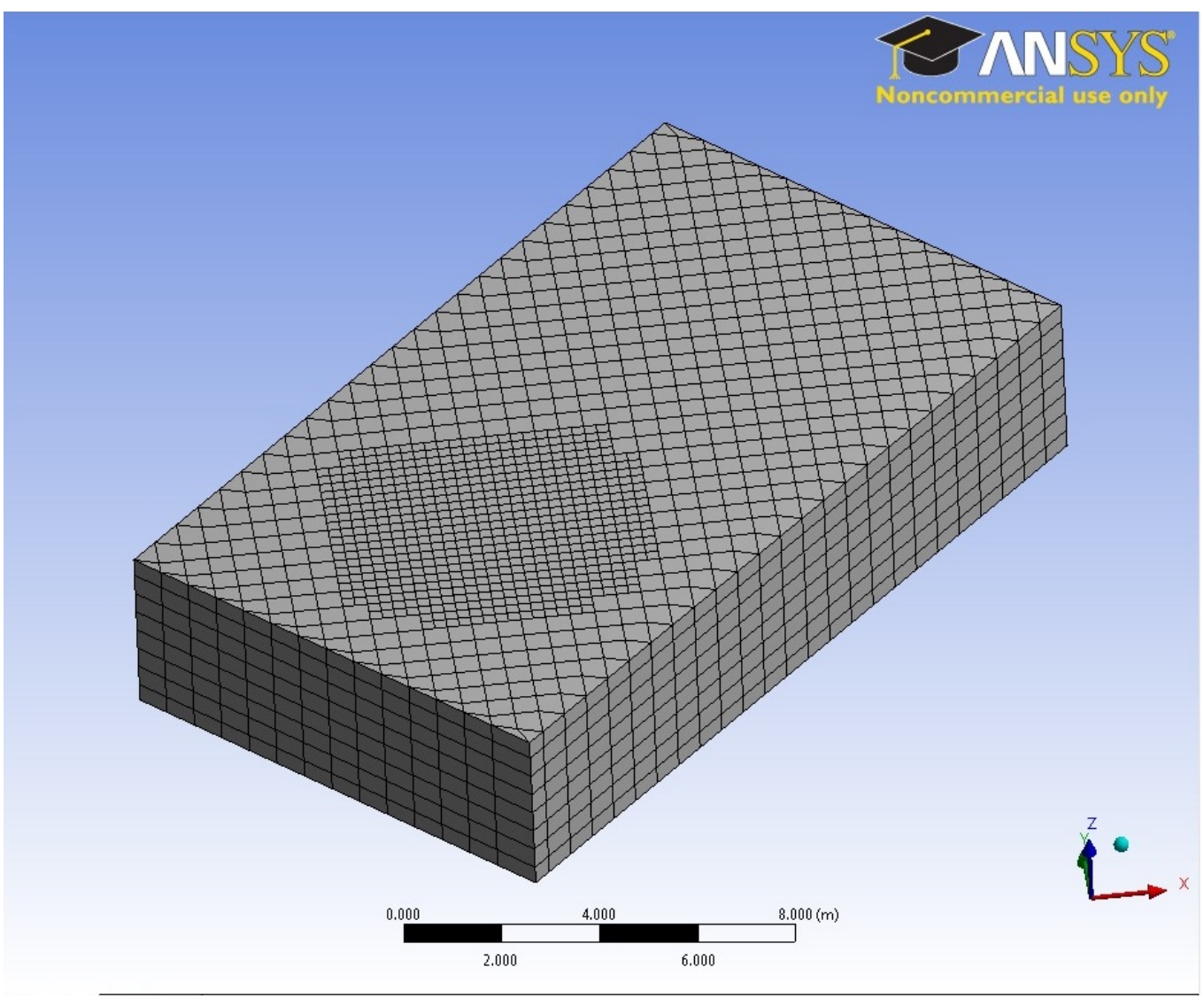

Figure 4-1: Sample Full Model and Domain Mesh

Assembly meshing is utilized in meshing the CFD models. Assembly meshing allows considering the meshing of the entire model as a single process rather than meshing each model by parts. This is particularly important due to the complex crack shapes and overlapping face geometries that exist in the infiltration models. Assembly meshing thus allows creating a good quality conformal mesh in this situation. The assembly meshing method utilized is CutCell meshing available in Ansys Fluent. 


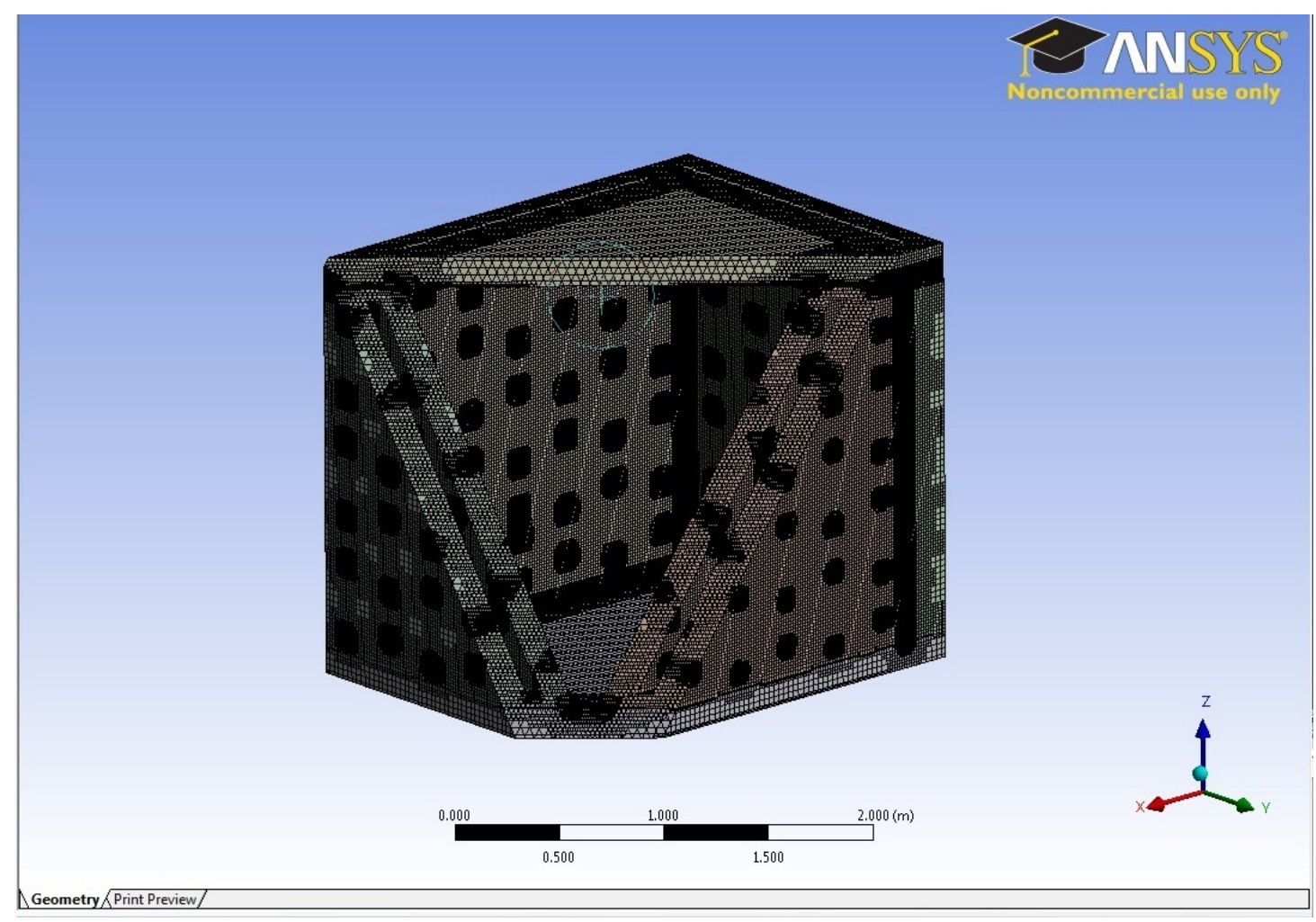

Figure 4-2: Sample Full Model Mesh

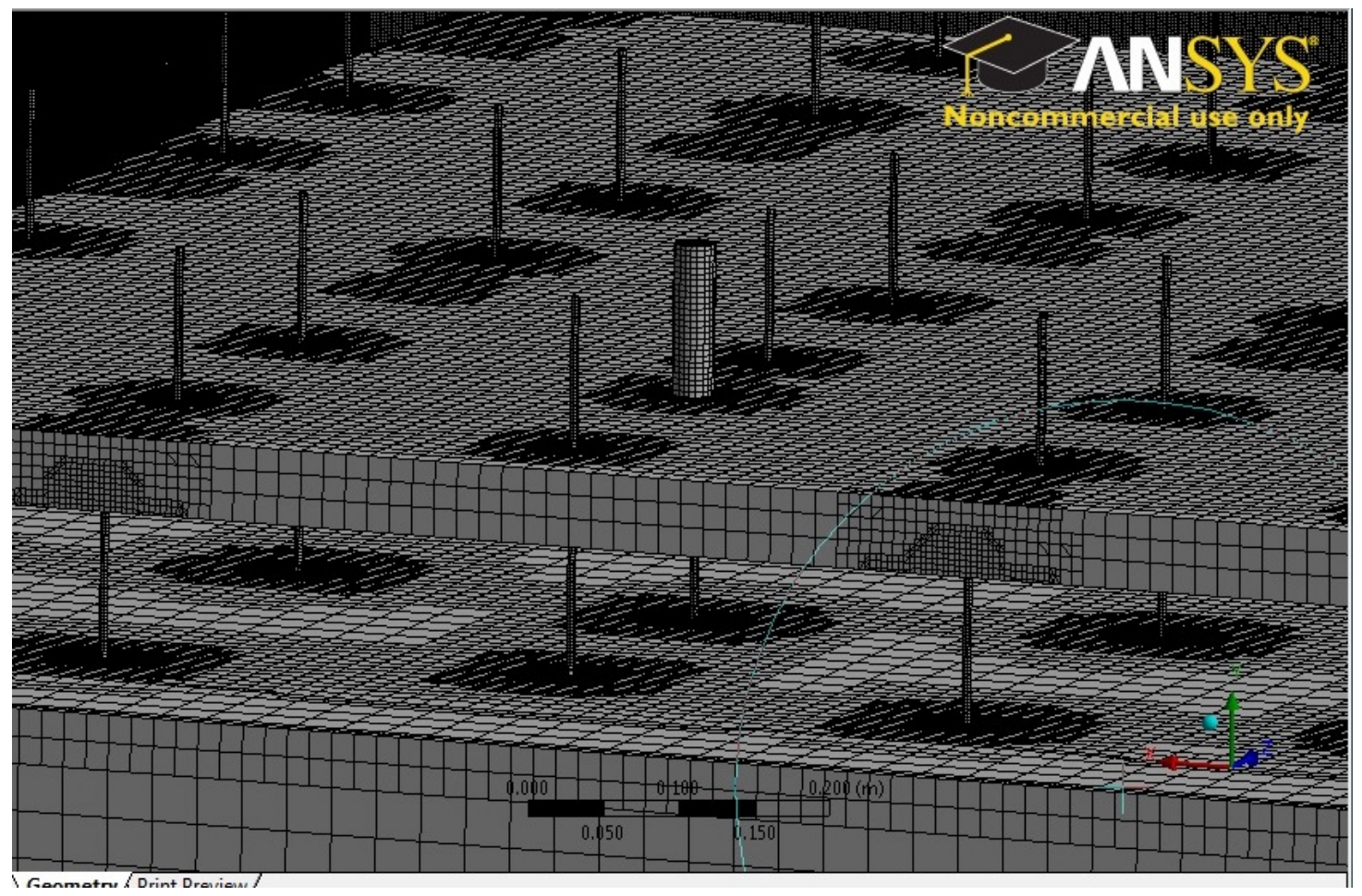

Figure 4-3: Meshing of Minute Airflow Cracks 
CutCell meshing is a Cartesian meshing method that performs patch independent volume meshing and utilizes advanced size functions (Ansys 14.0 Help, 2011). Furthermore, the advanced features included along with the CutCell meshing method allow addressing the major meshing concerns stated earlier. In particular, through applying advanced sizing functions on both edges and at proximity \& curvature. Thin sections and contacts were also defined and tessellation was utilized to insure mesh continuity in thin sections. Figures 4-1 thru Figure 4-5 highlight the mesh quality and the achieved connections and tessellations at points of interest common throughout each of the CFD models.

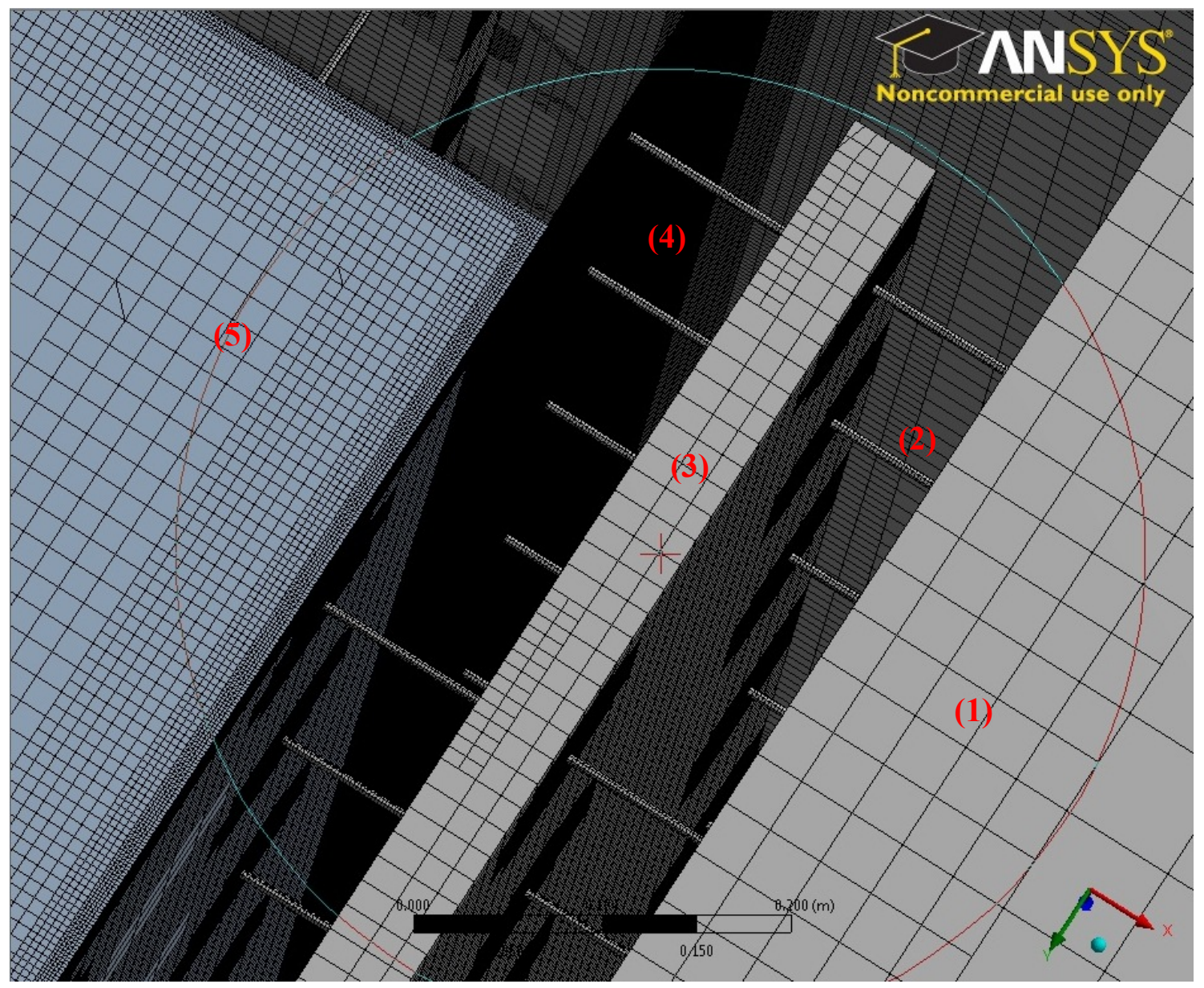

Figure 4-4: Tessellation of Thin Sections and Proper Mesh Attachment (contact) Between Fluid Outside the Envelope (1), Infiltrating Through Cracks (2), Inside Wall Cavity (3), In Corner Joints (4), and In Inner Domain(5) 

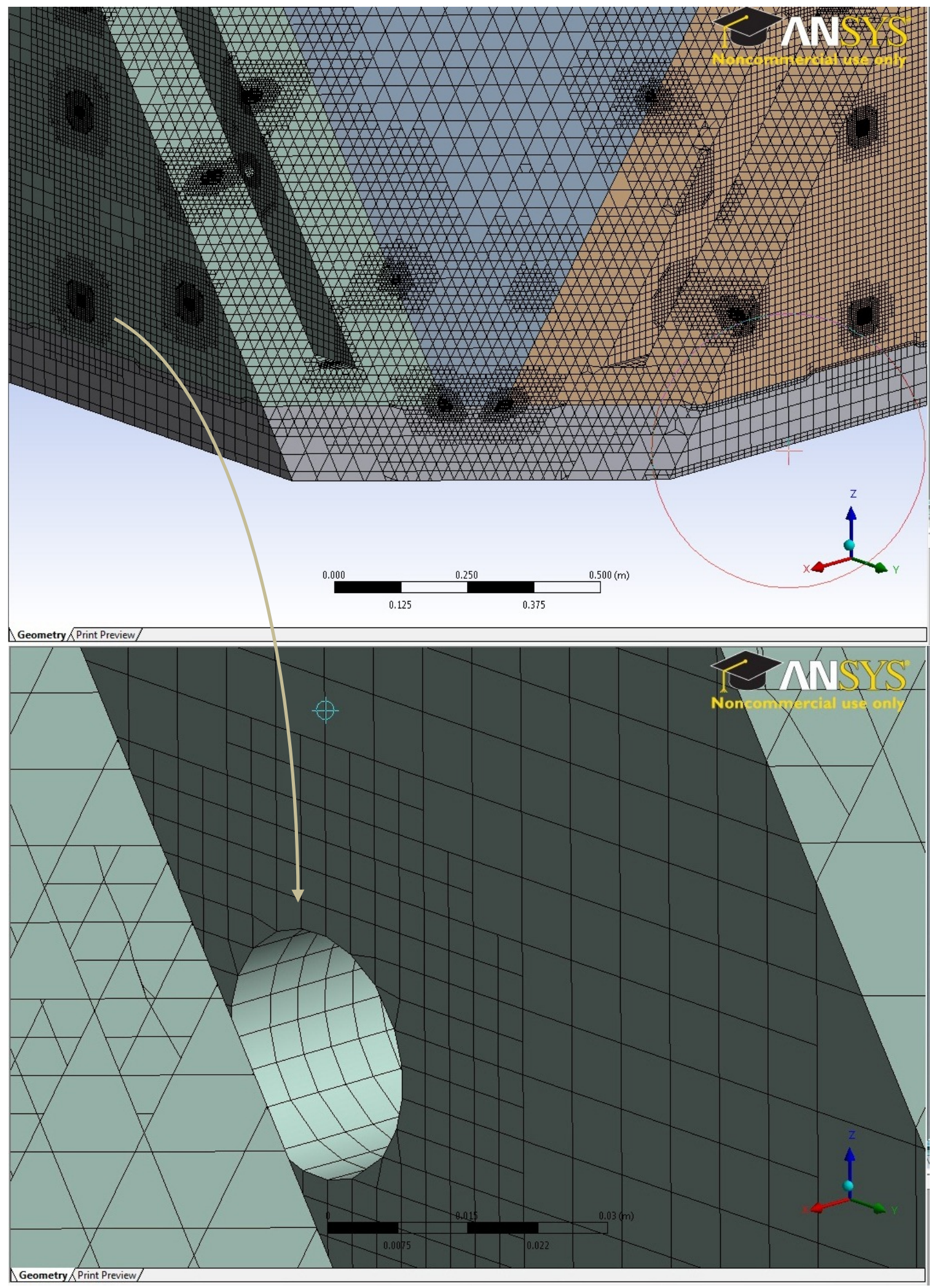

Figure 4-5: Meshing of Cavity Brick Walls, Proper Contact Between Solid \& Fluid Meshes, and Close Up on a Sample Leakage Crack Mesh 


\section{CFD Analysis Fundamentals}

The computational fluid dynamics multiphysics hygrothermal simulation of building air infiltration incorporates wind flow (and pressure), heat transfer, solar tracking (and irradiation), and site-dependent variable weather conditions and factors. The following sections discuss the main factors above as reflected and applied in each of the CFD simulations.

The transient simulation is of time steps of 1 hour (3600 seconds) and spans to 744 time steps. This is equivalent to 1 month of real time. The time step span and simulation duration are taken as such to be consistent with the DOE-2/eQUEST and the Enhanced Model simulations. Similarly are the location, weather properties, and other factors.

\section{Energy}

The underlying equation of the multiphysics CFD simulation is the energy equation shown in equation 4-1. The energy equation allows considering the effect all of the following heat phenomena:

- Convection in fluid

- Conduction in solids

- Thermal radiation

- External heat gains

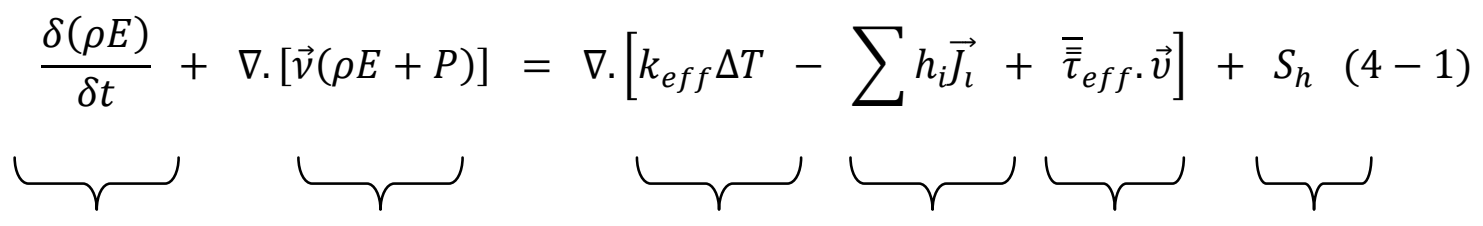


Where:

- $\quad \mathrm{k}_{\mathrm{eff}}=$ effective conductivity

- $\overrightarrow{J_{l}}=$ diffusion flux of species

- Viscous dissipation: represents viscous heating, mostly seen in lubricants and other high viscosity fluids. This term is not activated in our simulations.

- $\quad E=h-\frac{P}{\rho}+\frac{v^{2}}{2}$

- $\quad h \quad=$ Sensible enthalpy for ideal gas

A coupled momentum and pressure solver scheme is utilized. In addition, second order discretization is applied for momentum, energy, viscous dissipation rate, and turbulent kinetic energy. Pressure is treated by the Presto scheme available in Ansys Fluent. This scheme is usually utilized for swirling flows. Therefore, it is deemed suitable in particular due to the large existing number of minute cracks with variable shapes and flow paths.

\section{Solar Radiation}

Accounting for solar radiation is essential for a multiphysics hygrothermal model. Solar radiation is also incorporated into the underlying energy equation as seen previously in equation 4-1. Solar loading is applied onto the CFD models through the solar ray tracing algorithm available in Fluent. The solar ray tracing functionality (Figure 4-6) allows at each time step of the simulation (1 hour) the computation of incident solar radiation on the various surfaces of the building envelope. The resulting heat flux is consequently coupled into the simulation using the volumetric energy source $\left(\mathrm{S}_{\mathrm{h}}\right)$ in the energy equation. 


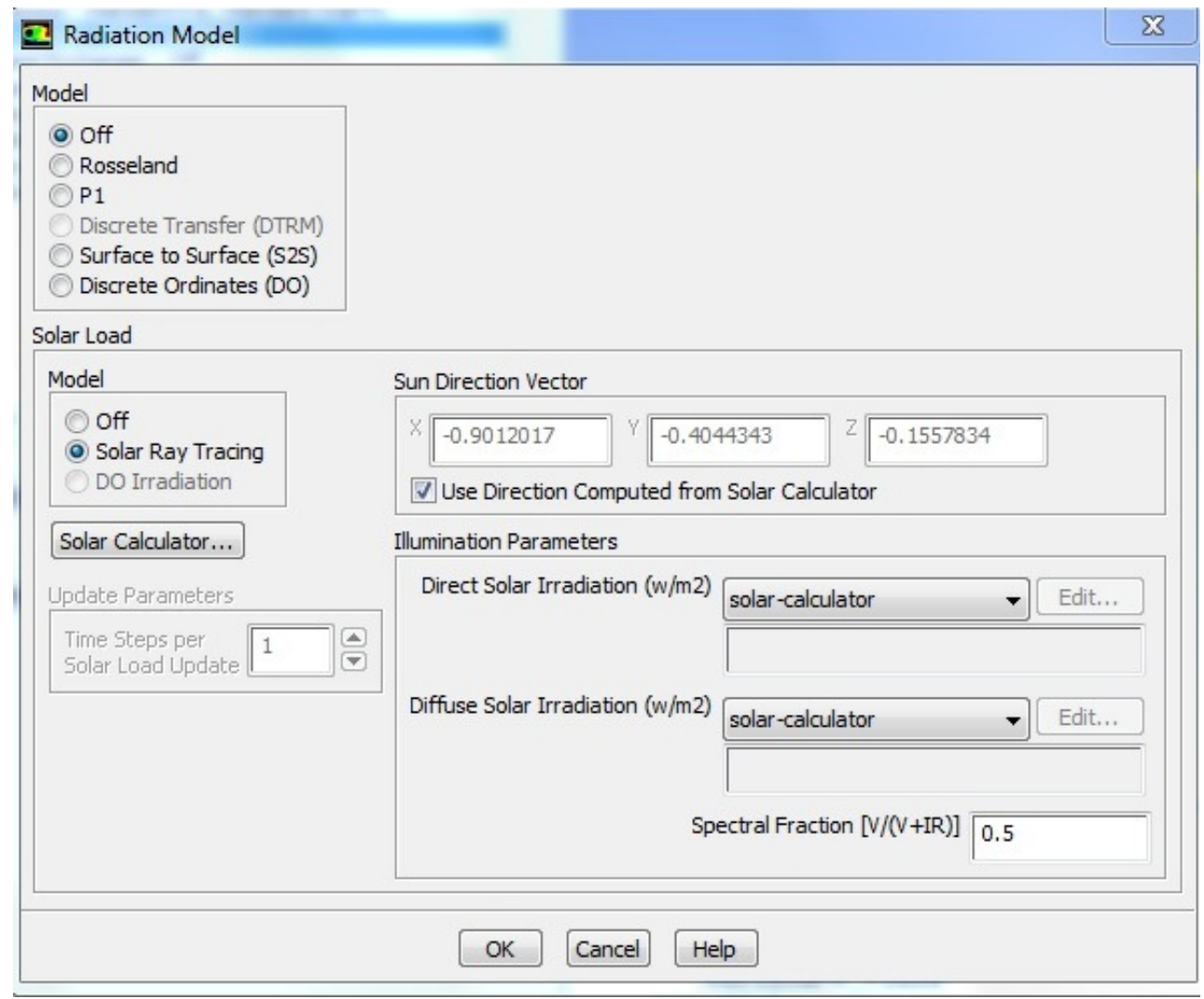

Figure 4-6: Defining the Radiation Model

The solar calculator is used in conjunction with the solar ray tracing model to provide the hourly input necessary for the model. The global position (latitude, longitude, and time zone), desired start time and date, mesh orientation, solar irradiation method, and sunshine factor are all defined (Figure 4-7). The algorithm then calculates the sun direction vectors, sunshine fraction, and direct and diffuse solar irradiation necessary for the solar ray tracing algorithm computations. The choice of sunshine fraction was set to theoretical maximum due to the geographical location being considered and the increased ground reflectivity associated with the surrounding snow cover. Since January is the sampled month for these simulations, a snow cover is expected to be present in Fargo, North Dakota. This is confirmed by looking on recorded weather data. 


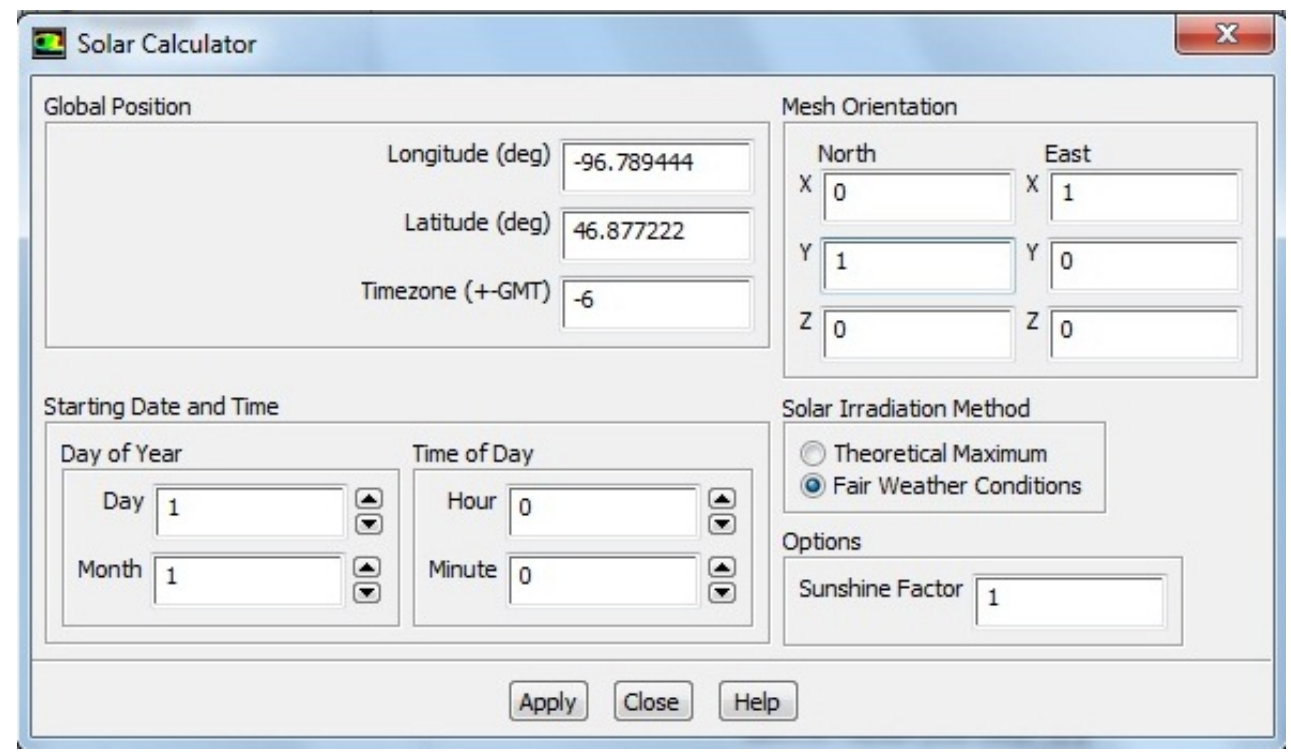

Figure 4-7: Setting the Solar Ray Tracing Model

\section{Weather and ground Conditions}

Weather variables considerably influence the hygrothermal performance of a building envelope. Air temperature, air density, and wind velocity are the major influencing factors. These variables affect both the stack and wind pressures which constitute the driving force of air infiltration. To insure consistency in the CFD models in comparison with the other models in this research the wind velocity is taken as the fixed averaged wind velocity for the time span of the transient simulation. The averaged wind velocity is therefore taken as $6.3 \mathrm{~m} / \mathrm{s}$ based on the recorded weather file for Fargo, North Dakota.

Variable hourly air temperatures from the Fargo weather file are applied to the CFD models as for DOE-2/eQUEST and the Enhanced Model. This is done in Fluent through custom defined temperature profiles. An example is shown in Figure 4-8. The air temperature associated with each corresponding hour of simulation time is applied at the fluid velocity inlet boundary of the CFD models. 


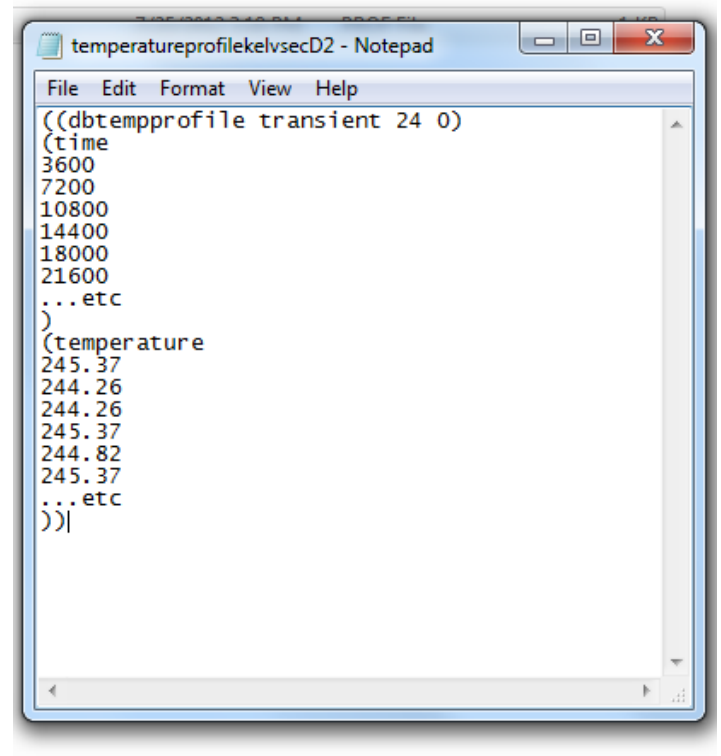

Figure 4-8: Sample Hourly Temperature Profile

Ground temperature is also considered due to its effect on the heat balance in a building envelope and on near-ground air layers' temperature. The ground temperature is applied at the boundary constituting the bottom of the building envelope's floor slab and on the ground surrounding the model (Figure 4-9).

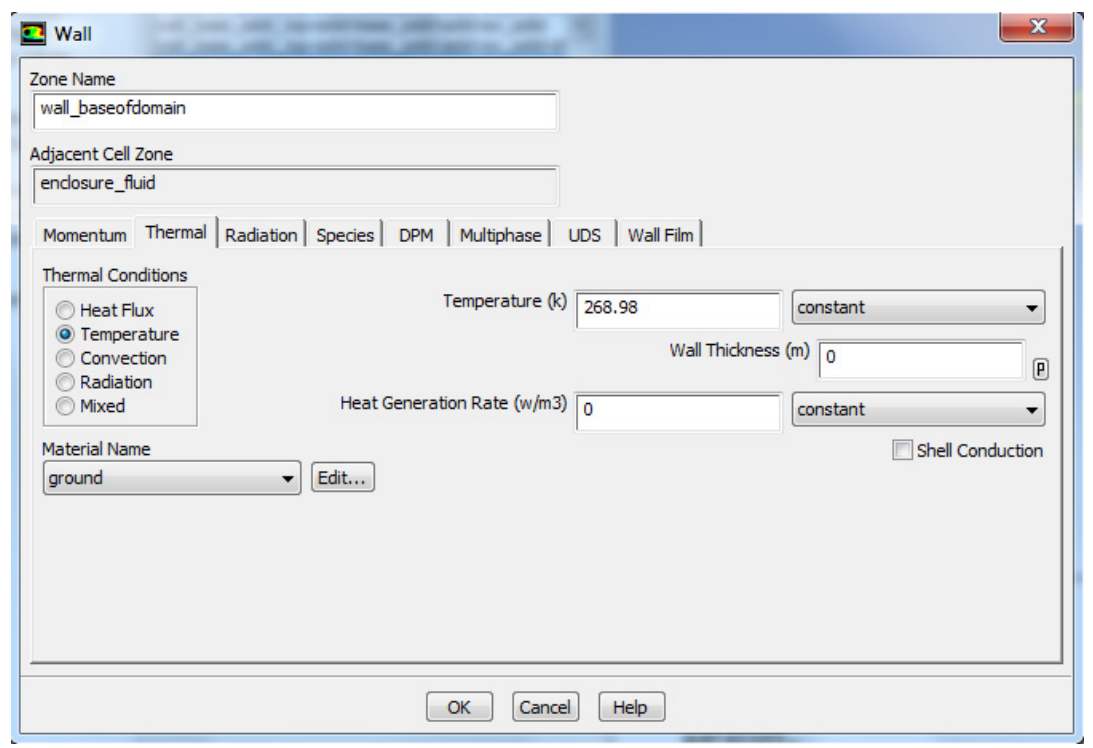

Figure 4-9: Applying Ground Temperature on the Defined Ground Boundary with Ground (Soil) Material Properties 


\section{eQUEST - DOE-2 Hourly Analysis}

\section{Model Properties}

In order to isolate the effect of infiltration, the eQUEST model must be built to match the CFD finite elements models in all aspects and properties. These include:

- Indoor air temperature

- Wall properties and construction

- Material properties

- Building envelope orientation

- Solar conditions and illumination/irradiation

- Ground temperature and weather conditions: wind velocity, ambient temperature, wind angle...etc.

- $\quad$ Building occupancy patterns

- Infiltration multipliers

- Heat source with no mechanical ventilation (no forced airflow)

The following sections briefly discuss the properties implemented in the BDL definition of the building envelope in eQUEST. These measures are to insure consistency in simulation properties between the CFD and eQUEST models, and to isolate the effect of air infiltration in each.

\section{Indoor Temperature}

The design indoor temperature settings are set to maintain a $72^{\circ} \mathrm{F}\left(295.37^{\circ} \mathrm{K}\right)$ indoor temperature at all times (Figure 4-10). This is in accordance with the "Fixed Value" of indoor fluid temperature of $295.37^{\circ} \mathrm{K}$ specified in the Fluent CFD analyses. 


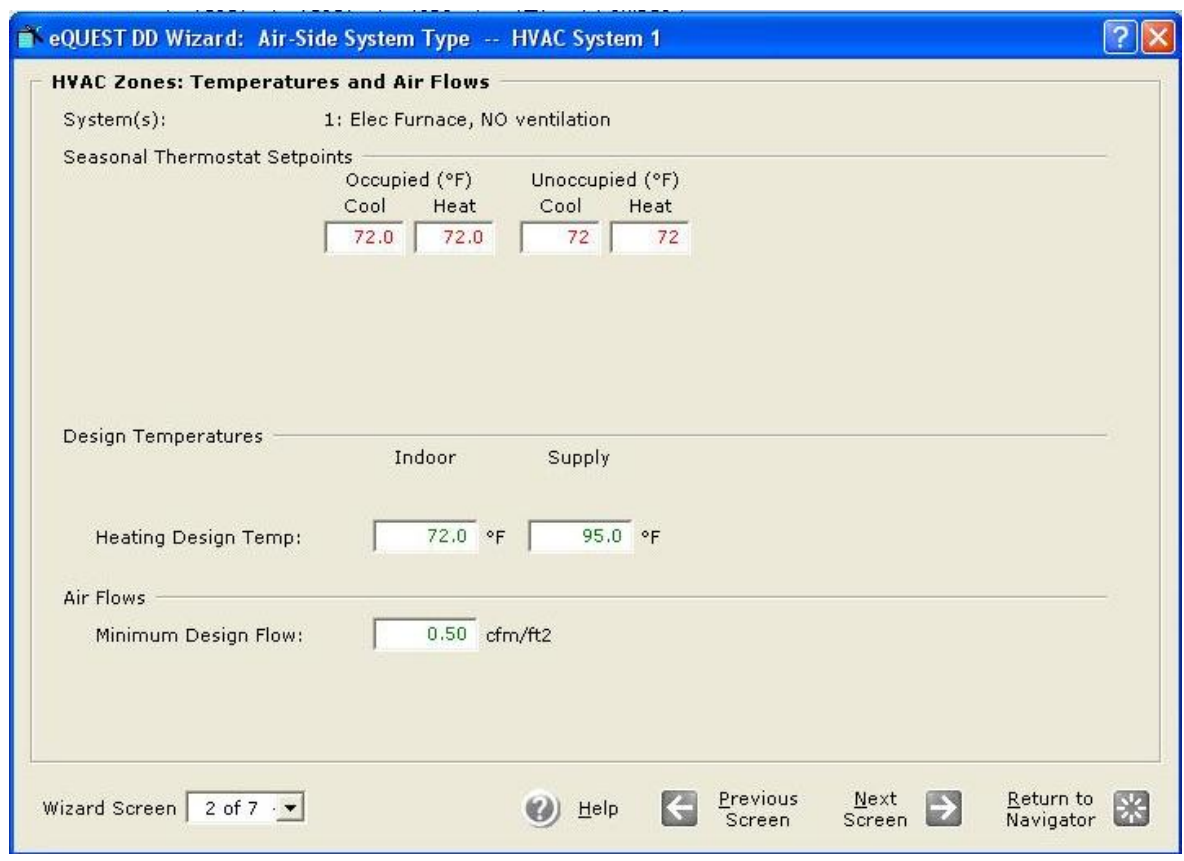

Figure 4-10: Thermostat Settings in eQUEST to Match 72F in CFD Analysis

\section{Walls and Construction}

Identical to the wall construction used in CFD analysis, brick walls are defined in eQUEST. The walls are of the same dimensions, thickness, and layers (Figure 4-11). The material properties of each of the layers are also held the same.

\begin{tabular}{|c|c|c|c|c|c|c|c|}
\hline & \multicolumn{2}{|l|}{ Material Name } & $\begin{array}{l}\text { Thickness } \\
\text { (ft) }\end{array}$ & $\begin{array}{l}\text { Conductivity } \\
\left.\text { (Btu/h-ft- }{ }^{\circ} \mathrm{F}\right)\end{array}$ & $\begin{array}{l}\text { Density } \\
\text { (lb/ft3) }\end{array}$ & $\begin{array}{l}\text { Spec, Heat } \\
\text { (Btu/lb- }{ }^{\circ} \text { F) }\end{array}$ & $\begin{array}{c}\text { R-Value } \\
\left.\text { (h-ft2- }{ }^{\circ} / \text { Btu }\right)\end{array}$ \\
\hline 1 & Com Brick 4in (BK01) & $\checkmark$ & 0.333 & 0.4167 & 120.00 & 0.200 & $n / a$ \\
\hline 2 & Air Lay $<3 / 4$ in Vert (AL11) & $\checkmark$ & $\mathrm{n} / \mathrm{a}$ & $n / a$ & $n / a$ & $n / a$ & 0.900 \\
\hline 3 & Com Brick 4in (BK01) & $\checkmark$ & 0.333 & 0.4167 & 120.00 & 0.200 & $n / a$ \\
\hline 4 & & 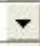 & $\mathrm{n} / \mathrm{a}$ & & & & \\
\hline 5 & & $\checkmark$ & $\mathrm{n} / \mathrm{a}$ & & & & \\
\hline 6 & & $\rightarrow$ & $n / a$ & & & & \\
\hline 7 & & $\checkmark$ & $n / a$ & & & & \\
\hline 8 & & - & $n / a$ & & & & \\
\hline 9 & & $\rightarrow$ & $n / a$ & & & & \\
\hline 10 & $n / a$ & & $n / a$ & & & & \\
\hline
\end{tabular}

Figure 4-11: Defining Cavity Brick Wall in eQUEST

\section{Orientation}

In the BDL description of the eQUEST models the building envelope is defined to be at an azimuth of $315^{\circ}\left(-45^{\circ}\right)$ from the north as shown in Figure 4-12. 


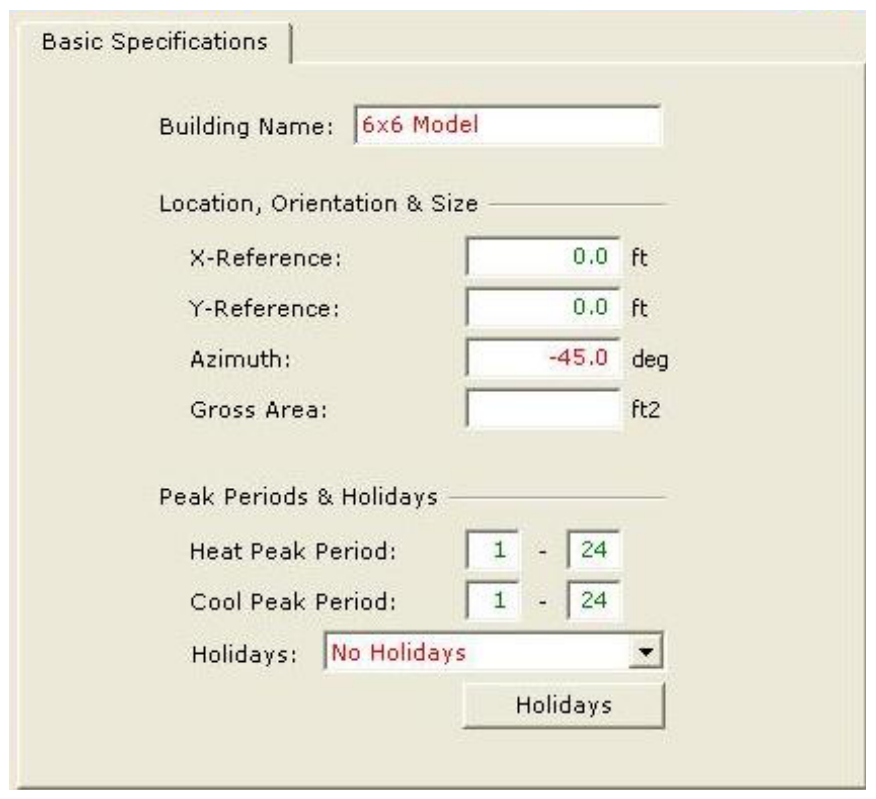

Figure 4-12: Defining Building Orientation in eQUEST to Match the CFD Analysis

\section{Weather conditions}

Weather conditions applied to the eQUEST models are also identical through custom profiles in the CFD analyses. The same Fargo Intl. weather file that is utilized to define the wind flow velocity, hourly temperature profiles, and other variables in the CFD analysis is applied to the eQUEST simulations. This insures that the component factors of both the stack and wind pressures which drive air leakage in the building envelope are uniform across all simulations and models. Identical ground temperatures are also defined in eQUEST (Figure 4-13).

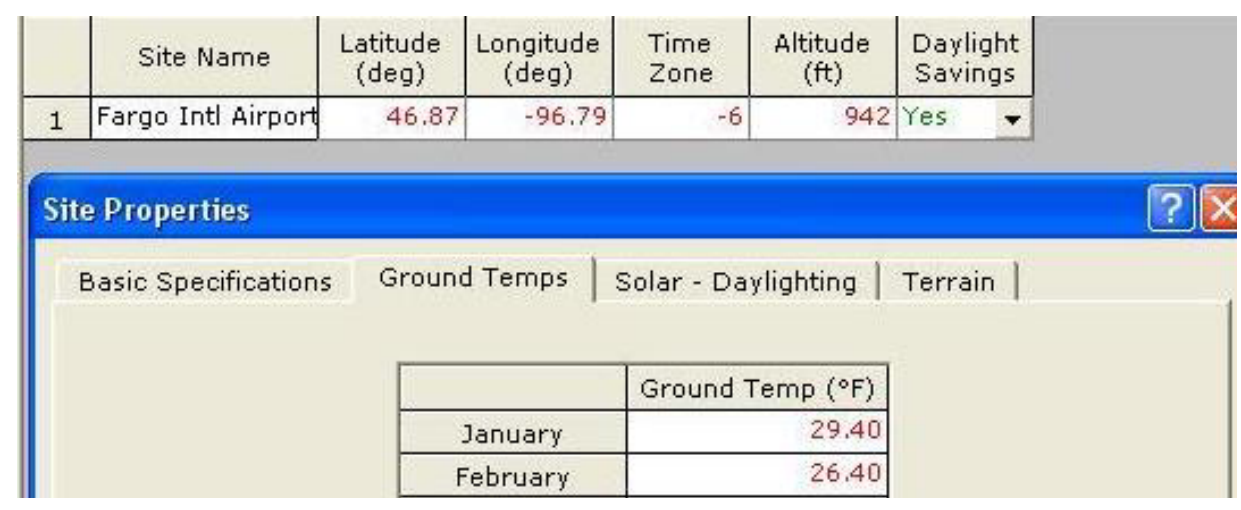

Figure 4-13: Defining Ground Temperature and Building Coordinates 


\section{Building Occupancy}

The DOE-2 engine allows considering the energy impact of building occupancy type, schedules, and number of occupants. However, in the CFD analysis air leakage is considered under ambient weather conditions and material leakage properties in the absence of any building occupancy effects. Consequently the same conditions are applied onto eQUEST as shown in Figure 4-14. For the same reasons no building closure or holidays are considered in eQUEST as shown in Figure 4-15.

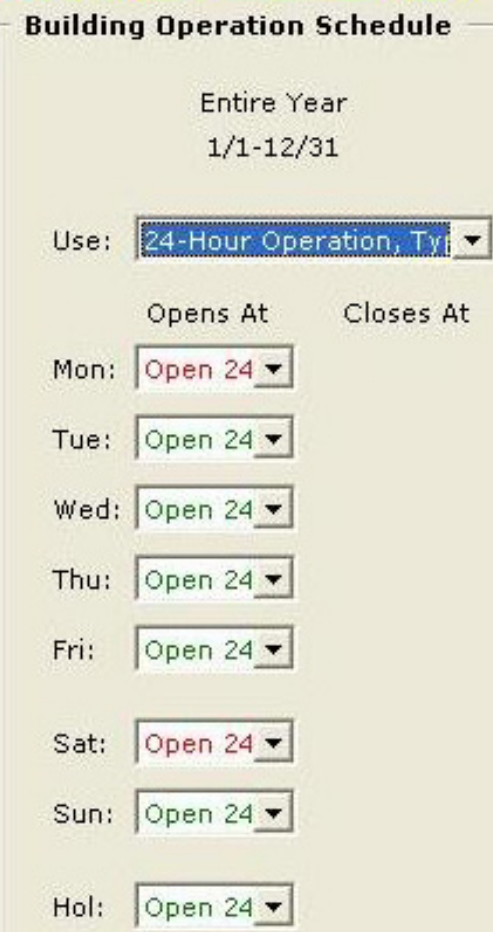

Figure 4-14: Building Operation set to 24 Hours Daily

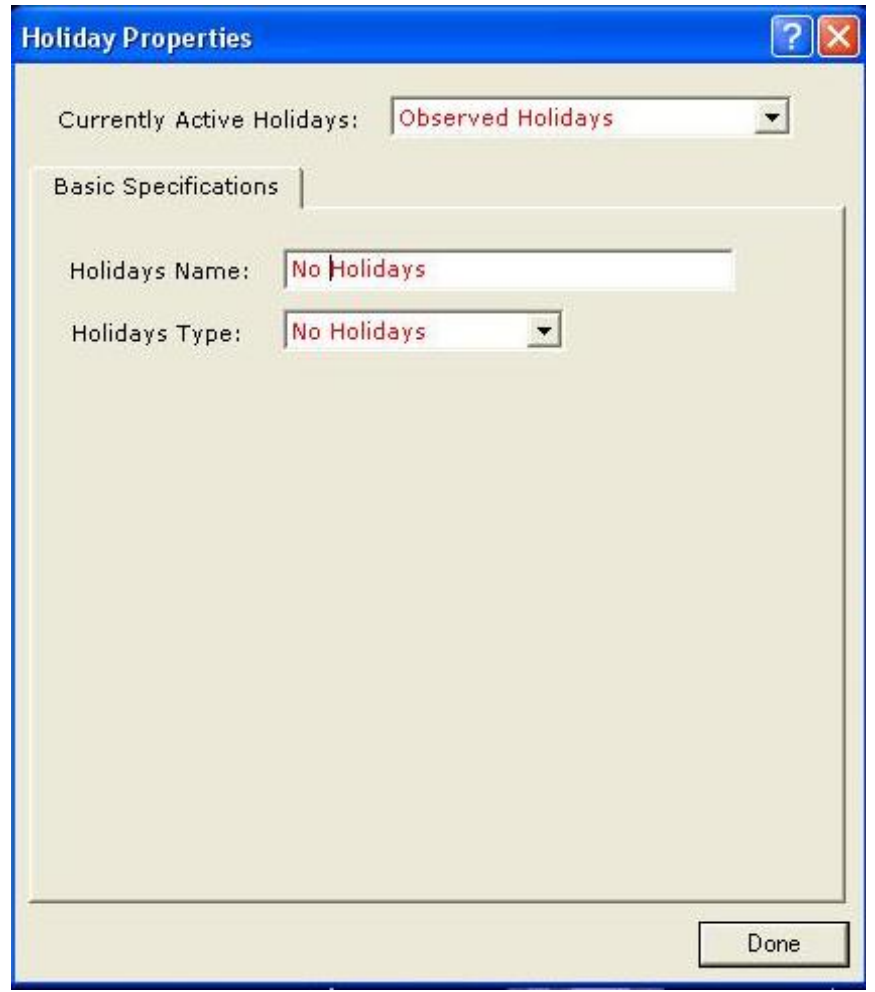

Figure 4-15: No Holiday Defined, Continuous Building Operation 


\section{Simulation Time}

As in the multiphysics CFD analysis, the simulation span in eQUEST is taken to be one month. The simulation duration spans from January 1 to January 31 in hourly intervals (744 hours).

\section{Multipliers and Reduction Factors}

eQUEST applies infiltration schedules by default. These schedules consist of reduction factors that are applied to hourly calculated sensible infiltration heat loads. The multipliers reduce the calculated loads by up to $50 \%$ depending on the time of the day and weekly schedule. No reductions are applied to infiltration heat loads obtained from the CFD analyses. Therefore, the built-in eQUEST reduction multipliers are overridden and disabled.

\section{HVAC System}

In order to maintain the indoor air temperature at $72^{\circ} \mathrm{F}$ it is essential to provide a form of heat input. In selecting the HVAC system it is important to define a system that will not create a forced airflow inside the building envelope, will not mechanically introduce outside air, and ill not mechanically expel air from the inside of the building envelope. The heating system is therefore defined in accordance with these constraints. The defined system consists of electric baseboards with no ventilation (Figures 4-16 and 4-17). No

mechanical fans or other forms of forced air inflow or outflow are designed into the systems. 
HVAC System Definition

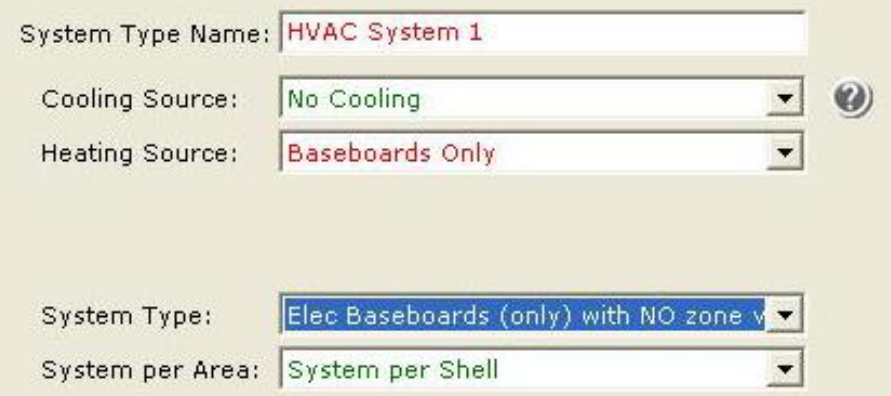

Figure 4-16: Defining Electric Baseboards for Heating

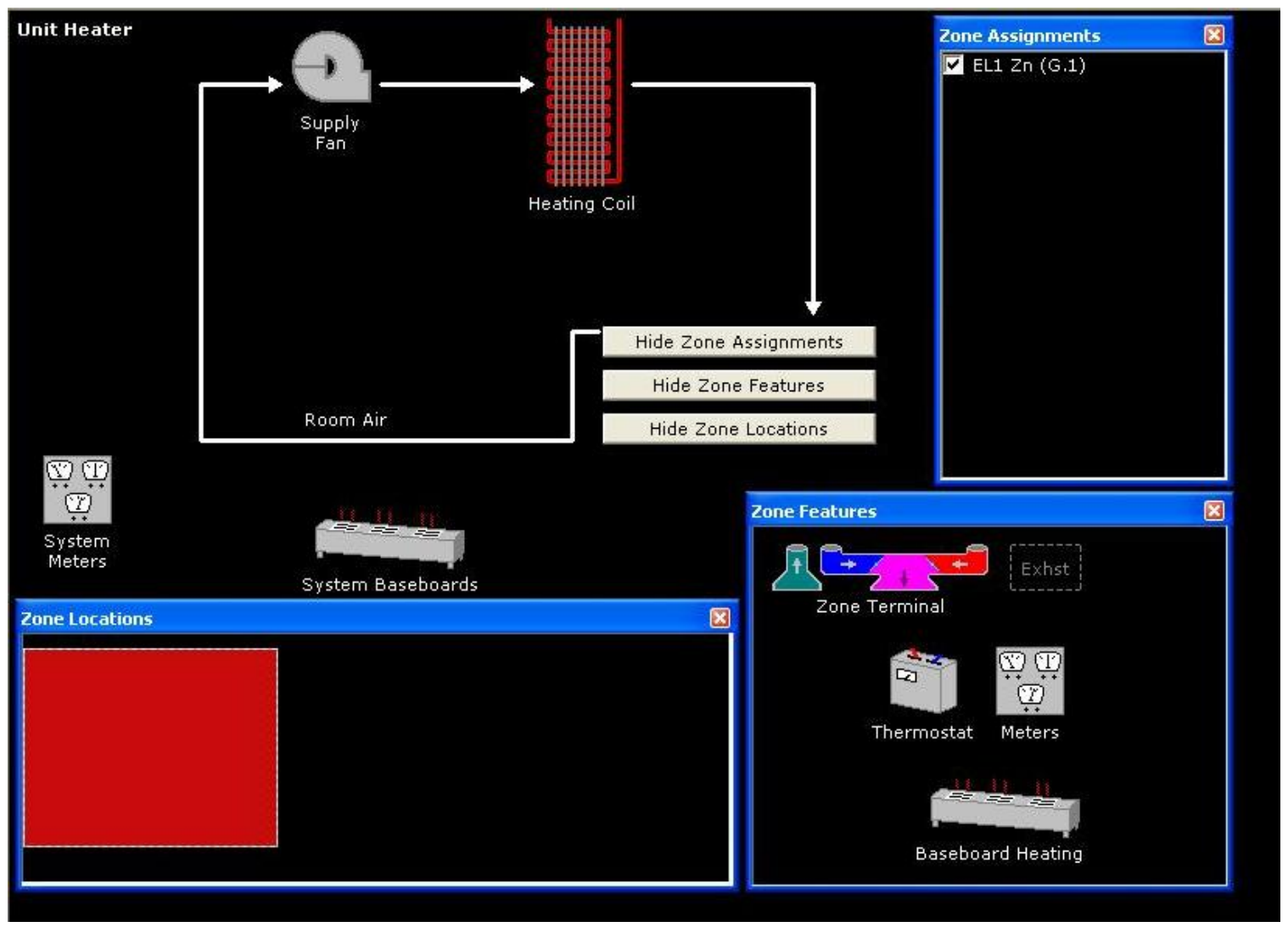

Figure 4-17: Defined HVAC System for The Building Model 


\section{Infiltration Method}

As discussed earlier, the calculated infiltration loads in eQUEST are to be utilized and evaluated in comparison with those obtained through CFD analyses and through the proposed Enhanced Model. The infiltration methods available in DOE-2/eQUEST have been discussed elaborately in Chapter 2. The air change method is the default method used in performing a building energy analysis in eQUEST. It is only through "Detailed Interface" manipulations that the advanced user is able to specify an alternate method. Therefore, this method is by default the method applied in many of the energy simulations performed in eQUEST. For this reason it is selected as one of the methods to utilize in our analyses and comparisons. The air change method is applied through 2 separate sets of simulations. Each set reflects one of the two alternative components of the air change equation. One set through specifying the number of air changes per hour (defined as $\mathrm{ACH}$ hereafter) and a second through specifying the infiltration airflow (defined as Basic Air Change method hereafter). ASHRAE Enhanced method is one for the latest additions to eQUEST and is considered to be among the most complex infiltration methods available in DOE-2/eQUEST. Therefore, it is selected as the third method to be used in simulations and analyses.

\section{Enhanced Model}

The developed Enhanced Model (Figure 4-18) is created as described in detail in Chapter 3. A Visual Basic program interface is built containing all the developed equations and algorithms. The Enhanced Model takes as input the following:

- $\quad$ Building wall dimensions

- Building material properties 
- Material air leakage data

- Other possible air leakage paths : plumbing openings or electrical outlets

- Wind data : wind speed, wind pressure coefficient (Cp), and wind angle

- Shielding class for the location based on surrounding terrain

- Initial iteration startup values for surface temperature.
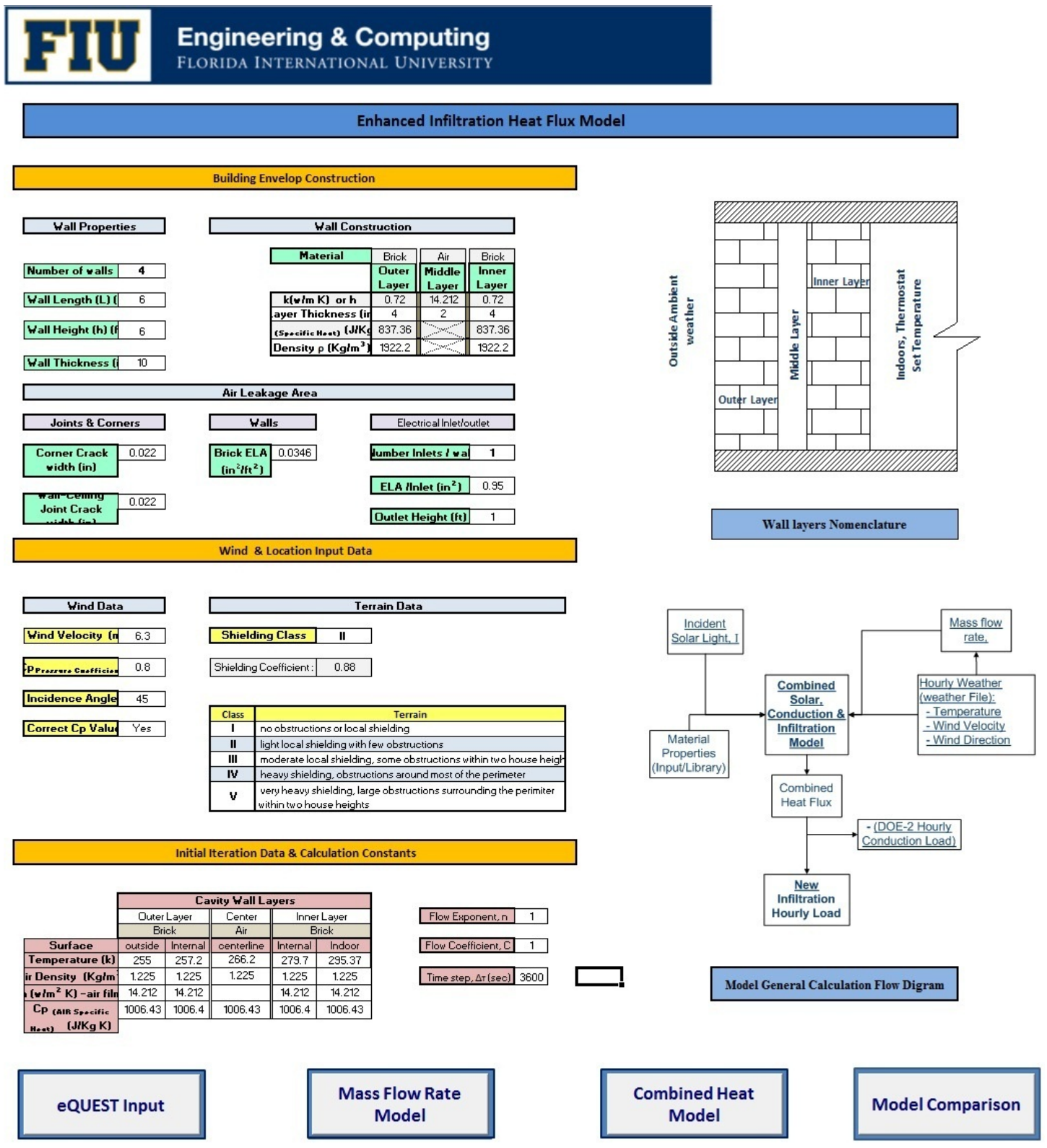

Figure 4-18: Built Enhanced Model Input Interface 
The Enhanced Model reads into its hourly calculations hourly output from the DOE-2/eQUEST engine. The read values are essential for calculating both the hourly infiltration mass flow rate and for the heat model calculations. The read hourly values are ambient air temperature, air density, incident solar radiation, and hourly conduction heat load. For comparison it also reads the hourly sensible infiltration heat loads calculated in eQUEST. These hourly variables are highlighted in red in Figure 4-19.

\section{Mass Flow Rate Model}

The first major component of the Enhanced Model is the proposed Mass Flow Rate model. Having a realistic evaluation of the infiltration mass flow rate is extremely essential for a model that evaluates the heat impact of this leakage flow. This importance was discussed elaborately in Chapters 2 and 3. The methodology and details of the developed Mass Flow Rate Model are also shown in Chapter 3. Figure 4-20 presents an example of the hourly output of the mass flow rate model.

\section{Infiltration Heat Load}

Hourly output from the Mass Flow Rate Model along with aforementioned hourly eQUEST data are read into the combined Enhanced Model. Following the equations developed in Chapter 3, the heat model calculates hourly infiltration heat loads while accounting for heat storage in the wall mass, variable hourly airflow rates; and the interaction between conduction, infiltration and incident solar radiation. A representation of the model's interface and hourly calculations is shown in figure 4-21.The Enhanced Model output is then examined in comparison with the multiphysics CFD simulation output to verify the accuracy of the Enhanced Model's calculations. Its output is also compared with the hourly infiltration heat load output of the various considered DOE- 
2/eQUEST built-in infiltration methods. Details of the output of the 3 methods and other corresponding models along with a detailed analysis of all output data is presented in detail in Chapter 5.

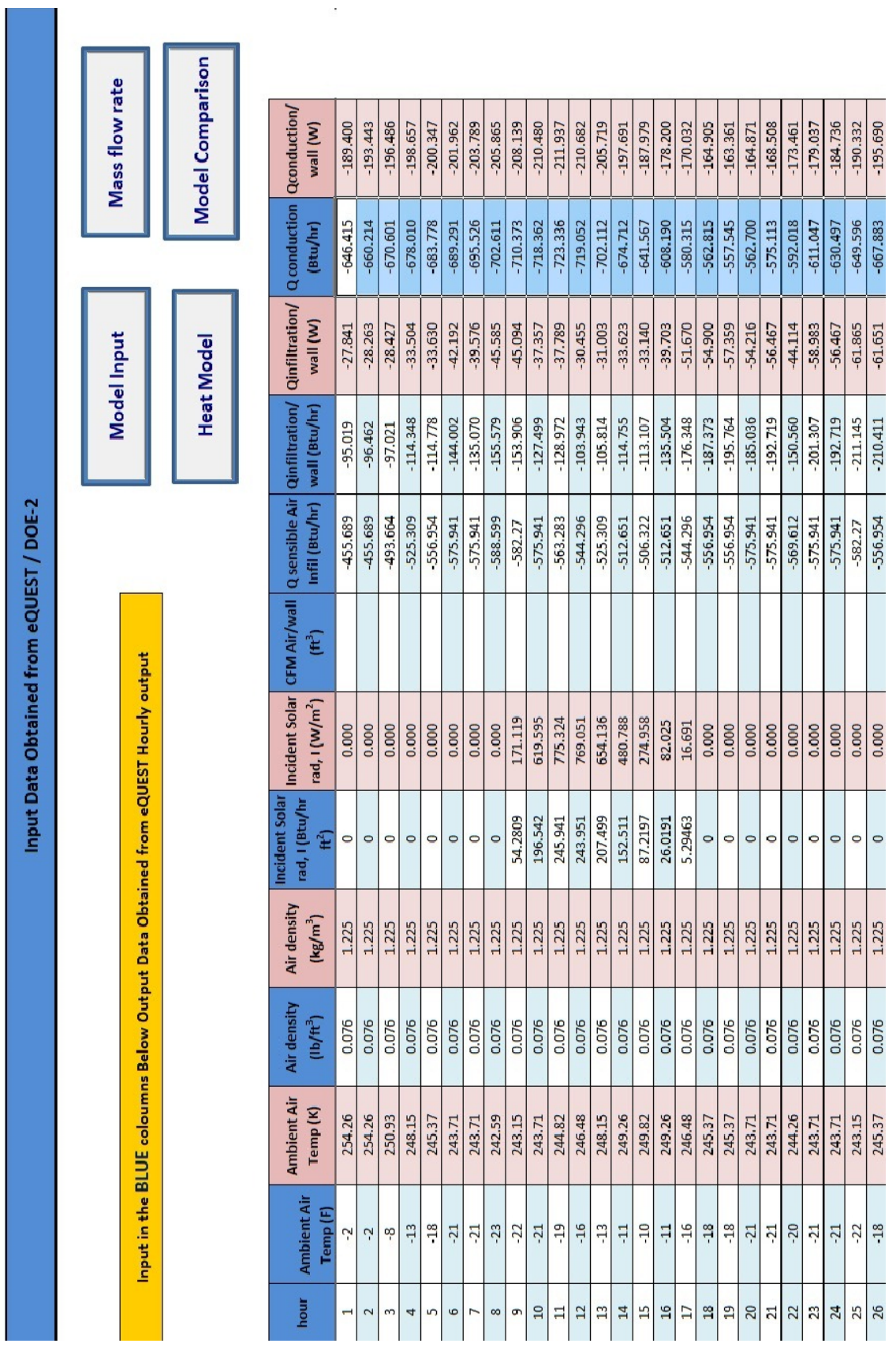

Figure 4-19: Hourly DOE-2/eQUEST Input into the Enhanced Model 

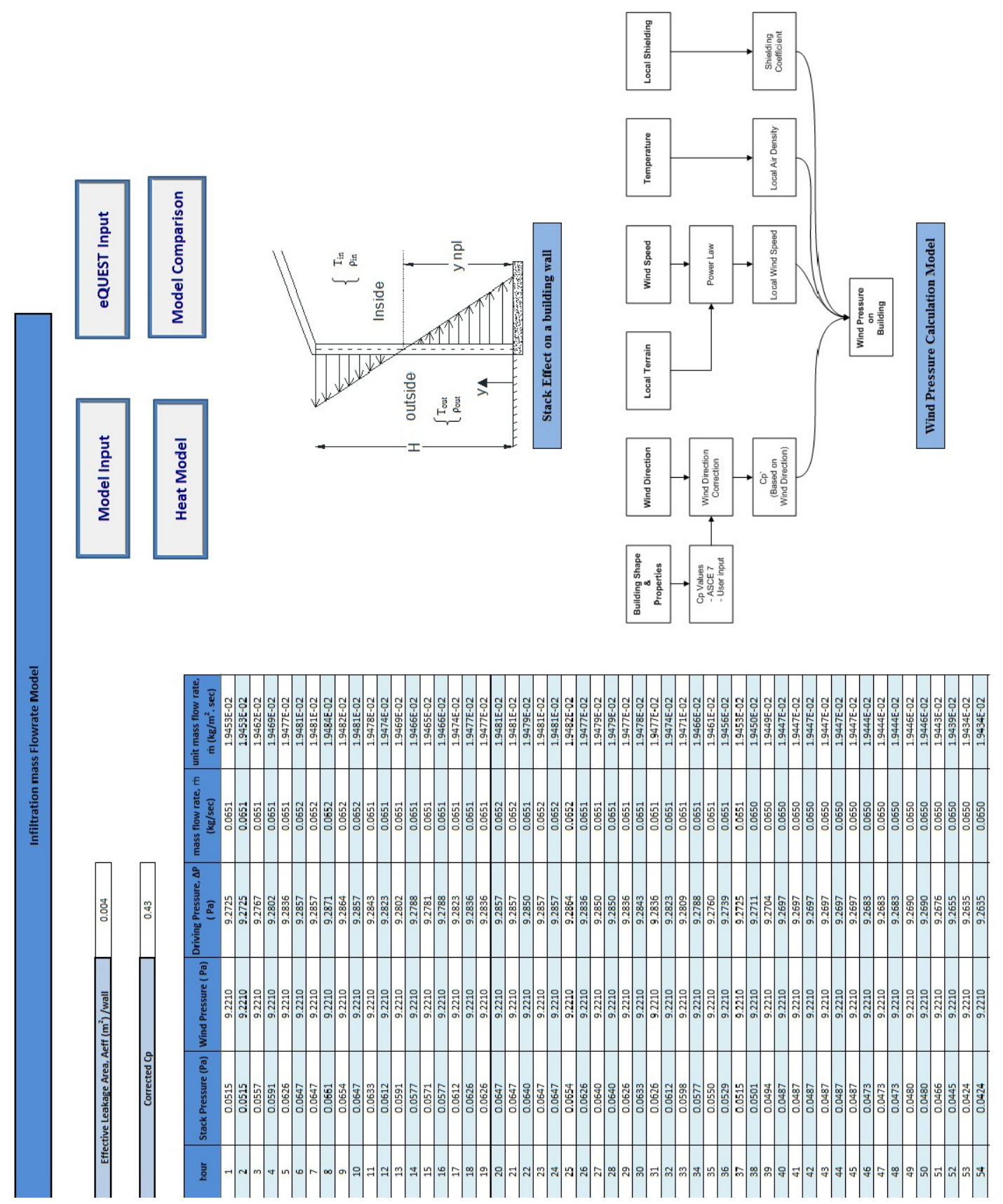

Figure 4-20: Built Interface for the Mass Flow Rate Calculation Model 


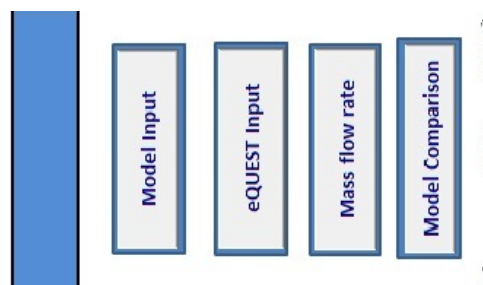

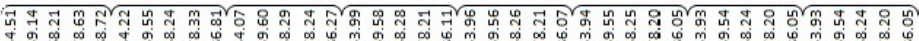

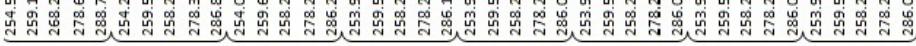

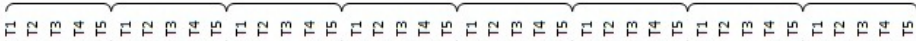

$\begin{array}{lllllllll}\uparrow & \uparrow & \uparrow & \uparrow & \uparrow & \uparrow & \uparrow & \uparrow\end{array}$

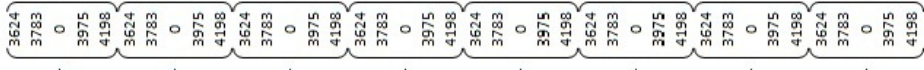

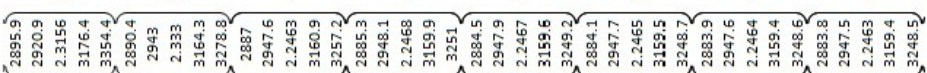
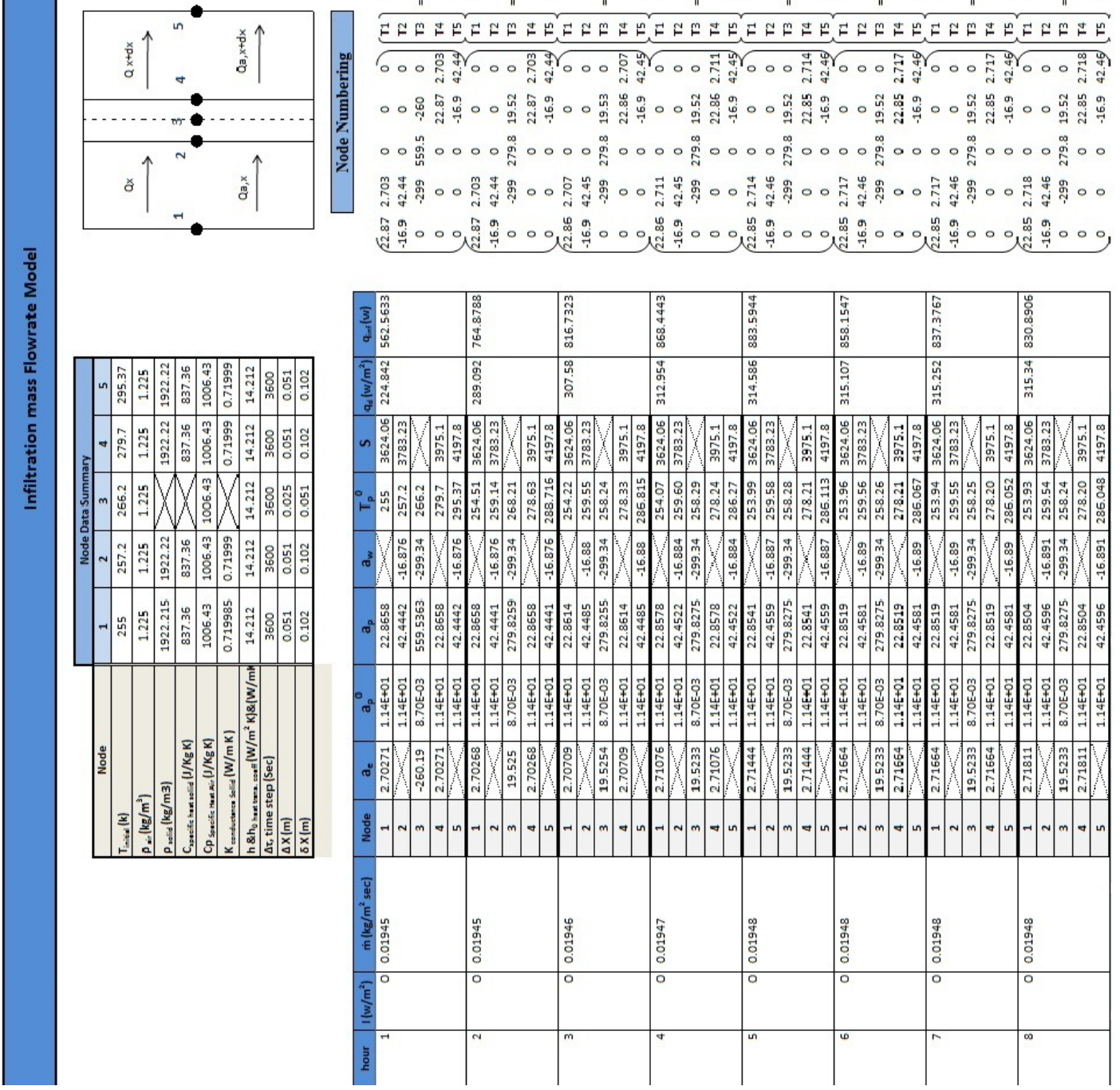

Figure 4-21: BUILT Enhanced Model Output Interface 


\section{Chapter 5}

\section{Results and Discussion}

The main objective of this research is to develop a model that better evaluates the energy impact of air infiltration in building envelopes. The method has to account for the combined interaction effect of heat conduction in the building walls, air flow through leakage paths and the effect of incident solar loading. The developed method is to be applied onto prominent building energy simulation engines in an aim to demonstrate its effectiveness and improve these engines' infiltration energy load calculations accuracy. Consequently, this improves the accuracy of their overall building energy simulations and energy audit calculations.

The Enhanced Model methodology and calculation flow was discussed in detail in Chapters 3 and 4. Similarly, the built multiphysics CFD models and their simulation process along with that of the eQUEST simulations were discussed in previous Chapters.

The hourly output of each of: The Enhanced Model, and the basic DOE2/eQUEST is presented and analyzed in this chapter. In conjunction, the hourly output obtained from CFD analyses is presented and incorporated into the analysis of the results and the verification of the Enhanced Model's method and output.

Analysis of obtained output data will be presented on a wall by wall basis. Subsequently the overall envelope results are presented and analyzed.

\section{Simulation Duration}

The adopted simulation duration is 744 hours (time steps in CFD analysis). This corresponds to one full month of the year. Performing a full month simulation in eQUEST and the Enhanced Model is a fast process and non resource intensive. However, 
the multiphysics CFD analysis for each of the CFD models is very resource intensive in terms of computing power. These simulations require extensive time durations to perform all necessary calculations and iterations. This issue is especially critical considering that each of the simulated CFD models contains more than 13 million elements and that simulations need to span a flow time of 31 days.

A full 31 day simulation was performed on the CFD model with Angular (zigzag) leakage cracks. The data obtained from the first 372 time steps (15 days of flow time) was extrapolated to predict cumulative infiltration data for 744 time steps (31 days of flow time). The extrapolated 31 day data was then compared against the actual simulation output of 31 days. As shown in Table 5-1. The cumulative full month (744 hours) extrapolated output based on 15 days of flow time simulation (372 time steps) fell within $-0.41 \%$ and $1.58 \%$ of the actual 744 time steps cumulative output for all the components in the building envelope. Therefore, due to the extensive computing time necessary for performing a full 744 time steps CFD analysis it was decided to perform 372 time steps (15 days) of flow time simulations for each of the remaining CFD models. The 15 day output is then extrapolated to obtain the full month cumulative output for each model. Based on the previously stated evaluation of extrapolated output data for the Angled (zig-zag) cracks model, extrapolation of data for the remaining CFD models is deemed accurate and reliable. 


\begin{tabular}{|c|c|c|c|c|}
\hline ن & $\begin{array}{l}\infty \\
\infty \\
n \\
n \\
\vdots \\
i\end{array}$ & $\begin{array}{l}\tilde{y} \\
n \\
n \\
o \\
\dot{+} \\
n\end{array}$ & $\begin{array}{l}\stackrel{P}{2} \\
i n \\
\underset{n}{n} \\
i n\end{array}$ & 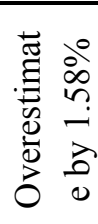 \\
\hline$\stackrel{\Xi}{0}_{0}^{0}$ & 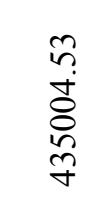 & 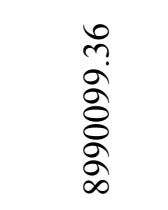 & $\begin{array}{l}\infty \\
\infty \\
0 \\
\infty \\
0 \\
0 \\
\infty \\
\infty\end{array}$ & 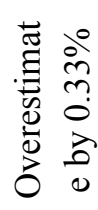 \\
\hline$\underset{0}{\stackrel{0}{e}}$ & 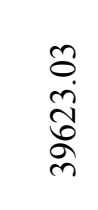 & $\begin{array}{l}8 \\
i \\
\infty \\
\infty \\
\infty\end{array}$ & $\begin{array}{l}\infty \\
0 \\
\dot{0} \\
\mathbb{Z} \\
\infty\end{array}$ & 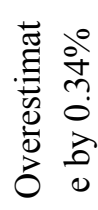 \\
\hline 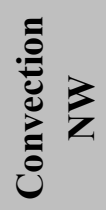 & 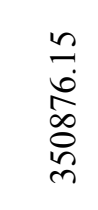 & 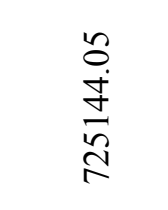 & 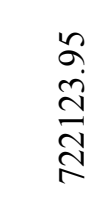 & 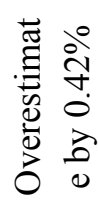 \\
\hline 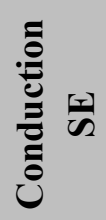 & 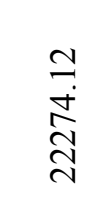 & 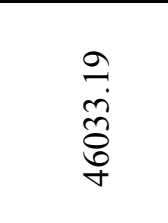 & $\begin{array}{l}\stackrel{\infty}{\infty} \\
\underset{\dot{\sigma}}{m} \\
\stackrel{n}{\sigma}\end{array}$ & 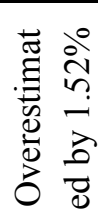 \\
\hline$\underbrace{\stackrel{0}{0}}_{0}$ & $\begin{array}{l}\vec{a} \\
\dot{q} \\
\dot{d} \\
m \\
m\end{array}$ & $\begin{array}{l}\tilde{6} \\
\text { ô } \\
8\end{array}$ & $\begin{array}{l}n \\
n \\
0 \\
n \\
n \\
\infty \\
\infty \\
0\end{array}$ & 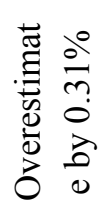 \\
\hline ڤ & 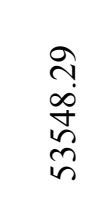 & 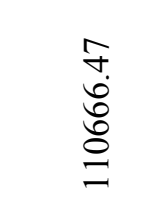 & 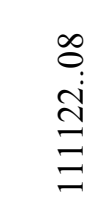 & 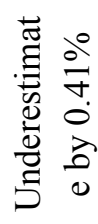 \\
\hline \multirow[t]{2}{*}{ 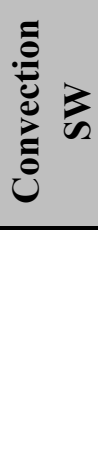 } & 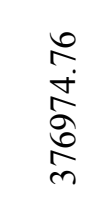 & 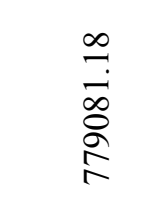 & $\begin{array}{l}n \\
n \\
\infty \\
\infty \\
n \\
n \\
n\end{array}$ & 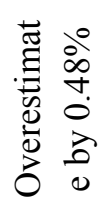 \\
\hline & 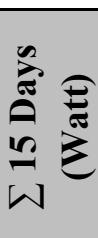 & 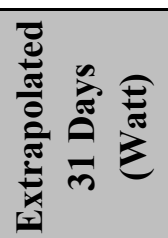 & 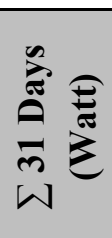 & 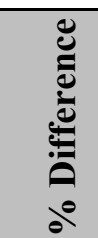 \\
\hline
\end{tabular}

Table 5-1: Cumulative Extrapolated 31 Day Data versus Actual Cumulative 31 Day Data for CFD Analyses 


\section{Southwest Wall (SW)}

Hourly data presented in Table 5-2 are for the calculated hourly infiltration heat load for:

1. EQUEST
a. Air Change Method (Basic : Airflow)
b. Air Change Method (ACH : air changes per hour)
c. ASHRAE Enhanced

2. Enhanced Model

3. Hygrothermal multiphysics CFD Analysis

The data shown in Table 5-2 is an excerpt of the hourly output for the southwest wall. It corresponds to the first 12 hours (midnight to noon) on January 1 and the last 12 hours (noon to midnight) of simulation flow time on January $31^{\text {st }}$. The full tabulated data is presented in Appendix A.

The plot in Chart 5-1 shows the calculated hourly output of sensible infiltration heat load on the SW wall for each of the 3 considered DOE-2/eQUEST methods. It is evident from the plot that the output is largely inconsistent among these different methods themselves. Also significantly different is the peak infiltration heat load reported by each method. The peak load obtained from the base Air Change method is 63.952 watts versus 97.002 watts obtained through Air Change method (ACH) and 238.63 from ASHRAE Enhanced. On the other hand, the peak hourly heat load calculated by the developed Enhanced Model is 1055.01 watts and compares very well against the peak hourly load of 1079.23 watts reported by the CFD analysis for the case of angled cracks. 


\section{Hourly Southwest (SW) Wall Data (Watts)}

\begin{tabular}{|c|c|c|c|c|c|c|c|}
\hline \multirow[b]{2}{*}{ hour } & \multicolumn{3}{|c|}{$\begin{array}{l}\text { eUEST/DOE-2 Hourly Values } \\
\text { (no reduction multiplier) }\end{array}$} & \multirow[b]{2}{*}{$\begin{array}{c}\text { Enhanced } \\
\text { Model }\end{array}$} & \multicolumn{3}{|c|}{ CFD Multiphysisc Simulation } \\
\hline & $\begin{array}{c}\text { Air } \\
\text { Change }\end{array}$ & $\begin{array}{c}\text { Air } \\
\text { Change } \\
\text { (ACH) }\end{array}$ & $\begin{array}{l}\text { ASHRAE } \\
\text { Enhanced }\end{array}$ & & $\begin{array}{l}\text { Angular } \\
\text { Cracks }\end{array}$ & $\begin{array}{c}\text { Mixed } \\
\text { Cracks* }\end{array}$ & $\begin{array}{l}\text { Straight } \\
\text { Cracks* }\end{array}$ \\
\hline 1 & 27.841 & 12.382 & 78.440 & 562.563 & 1033.902 & 1001.086 & 990.942 \\
\hline 2 & 28.263 & 12.570 & 79.632 & 764.879 & 1032.148 & 999.568 & 988.689 \\
\hline 3 & 28.427 & 15.172 & 85.301 & 816.732 & 1031.288 & 997.784 & 987.061 \\
\hline 4 & 33.504 & 14.901 & 103.464 & 868.444 & 1027.239 & 995.574 & 983.660 \\
\hline 5 & 33.630 & 17.948 & 108.929 & 883.594 & 1025.149 & 993.470 & 981.911 \\
\hline 6 & 42.192 & 11.259 & 136.746 & 858.155 & 1023.430 & 991.618 & 980.590 \\
\hline 7 & 39.576 & 14.081 & 128.847 & 837.377 & 1021.008 & 989.738 & 980.309 \\
\hline 8 & 45.585 & 20.274 & 151.554 & 830.891 & 1019.139 & 988.343 & 976.587 \\
\hline 9 & 45.094 & 16.045 & 147.876 & 873.207 & 1020.458 & 991.931 & 979.906 \\
\hline 10 & 37.357 & 16.615 & 122.458 & 881.855 & 1021.342 & 998.765 & 987.920 \\
\hline 11 & 37.789 & 16.807 & 122.098 & 872.546 & 1025.298 & 1007.328 & 995.728 \\
\hline 12 & 30.455 & 21.672 & 100.095 & 869.263 & 1027.725 & 1016.348 & 1005.657 \\
\hline
\end{tabular}
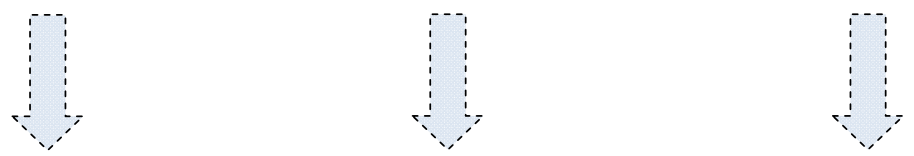

\begin{tabular}{||l||c|c|c||c||c|c|c||}
\hline $\mathbf{7 3 3}$ & 14.610 & 19.493 & 55.866 & 1053.425 & 1030.938 & 1069.436 & 1064.581 \\
\hline $\mathbf{7 3 4}$ & 11.944 & 19.123 & 51.364 & 1053.390 & 1034.757 & 1078.619 & 1076.438 \\
\hline $\mathbf{7 3 5}$ & 13.016 & 19.683 & 54.011 & 1053.446 & 1035.416 & 1084.796 & 1083.577 \\
\hline $\mathbf{7 3 6}$ & 15.210 & 20.294 & 58.740 & 1053.521 & 1036.224 & 1086.488 & 1084.065 \\
\hline $\mathbf{7 3 7}$ & 20.371 & 19.932 & 68.917 & 1053.535 & 1034.587 & 1084.207 & 1081.982 \\
\hline $\mathbf{7 3 8}$ & 20.063 & 19.631 & 68.312 & 1053.612 & 1031.302 & 1077.440 & 1075.818 \\
\hline $\mathbf{7 3 9}$ & 35.181 & 12.518 & 106.956 & 1053.697 & 1030.366 & 1071.414 & 1069.026 \\
\hline $\mathbf{7 4 0}$ & 37.148 & 9.913 & 112.348 & 1053.715 & 1027.498 & 1066.187 & 1062.234 \\
\hline $\mathbf{7 4 1}$ & 39.079 & 6.952 & 117.834 & 1053.722 & 1026.245 & 1061.116 & 1057.834 \\
\hline $\mathbf{7 4 2}$ & 40.683 & 10.856 & 124.034 & 1053.797 & 1023.751 & 1056.753 & 1053.215 \\
\hline $\mathbf{7 4 3}$ & 41.173 & 14.649 & 127.170 & 1053.881 & 1023.359 & 1052.888 & 1048.771 \\
\hline $\mathbf{7 4 4}$ & 33.906 & 18.096 & 107.430 & 1053.970 & 1020.565 & 1049.097 & 1045.088 \\
\hline
\end{tabular}

Table 5-2: Hourly Infiltration Heat Load Data for Southwest Wall

Note*: Last 12 Hourly CFD Data shown for Mixed and Straight Cracks in Table 5-2 are based on 15 Days of Flow time Simulation. 


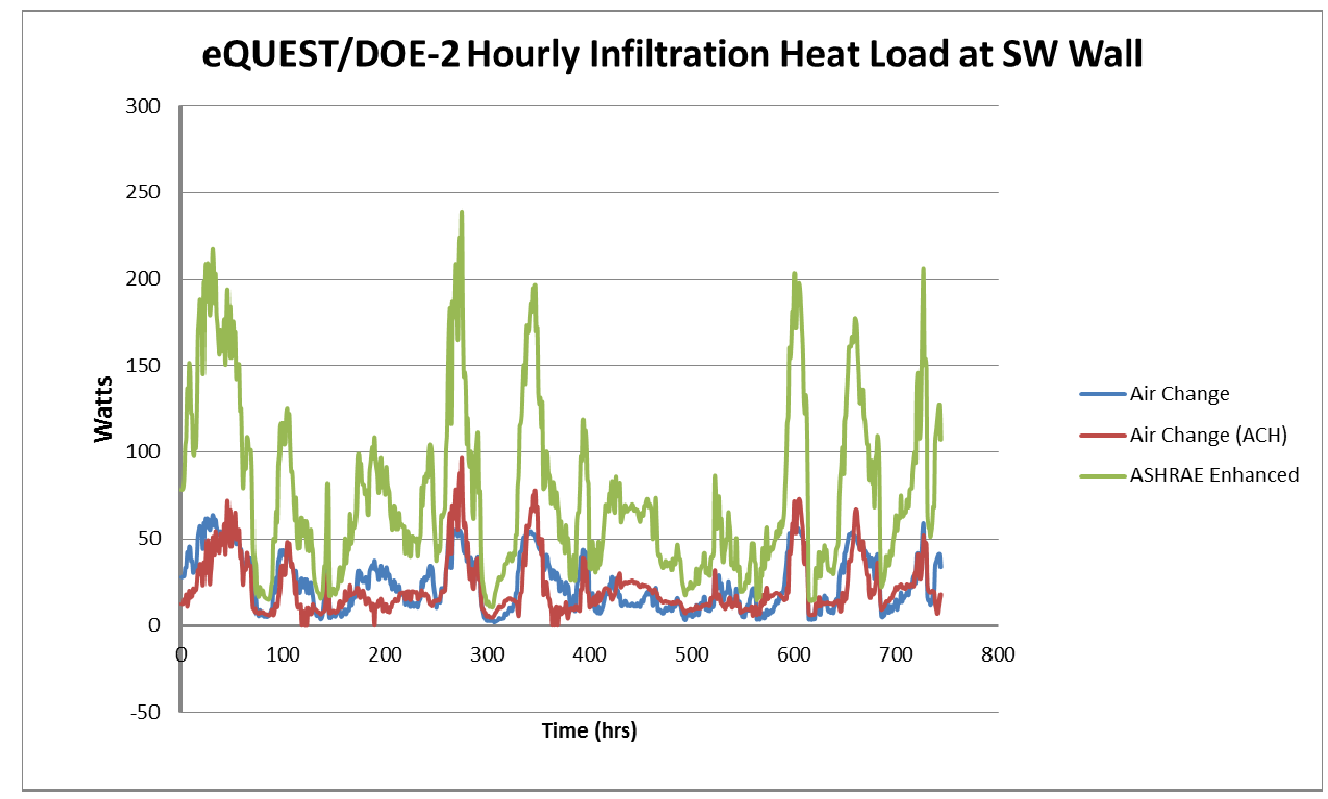

Chart 5-1: Hourly Infiltration Heat Load at the Southwest Wall by Various DOE-2/eQUEST Methods

Charts 5-2, 5-3 and 5-4 plot the hourly calculated infiltration heat load for the Southwest wall by the 5 previously stated methods. A separate chart is shown including each of the Three CFD cases (angled cracks, mixed cracks and straight cracks) versus the remaining models.

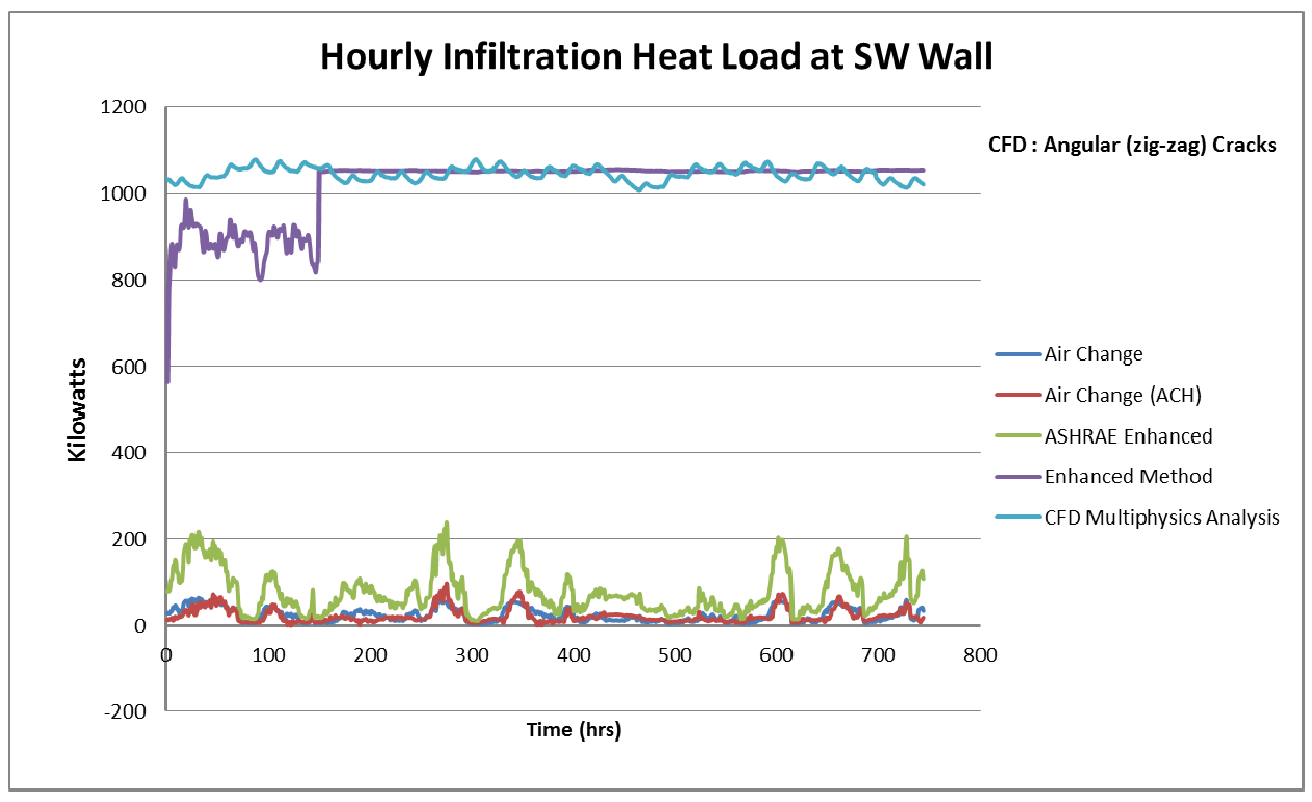

Chart 5-2: Hourly Infiltration Heat Load at the Southwest Wall versus Angled (zig-zag) cracks CFD Output for the wall 


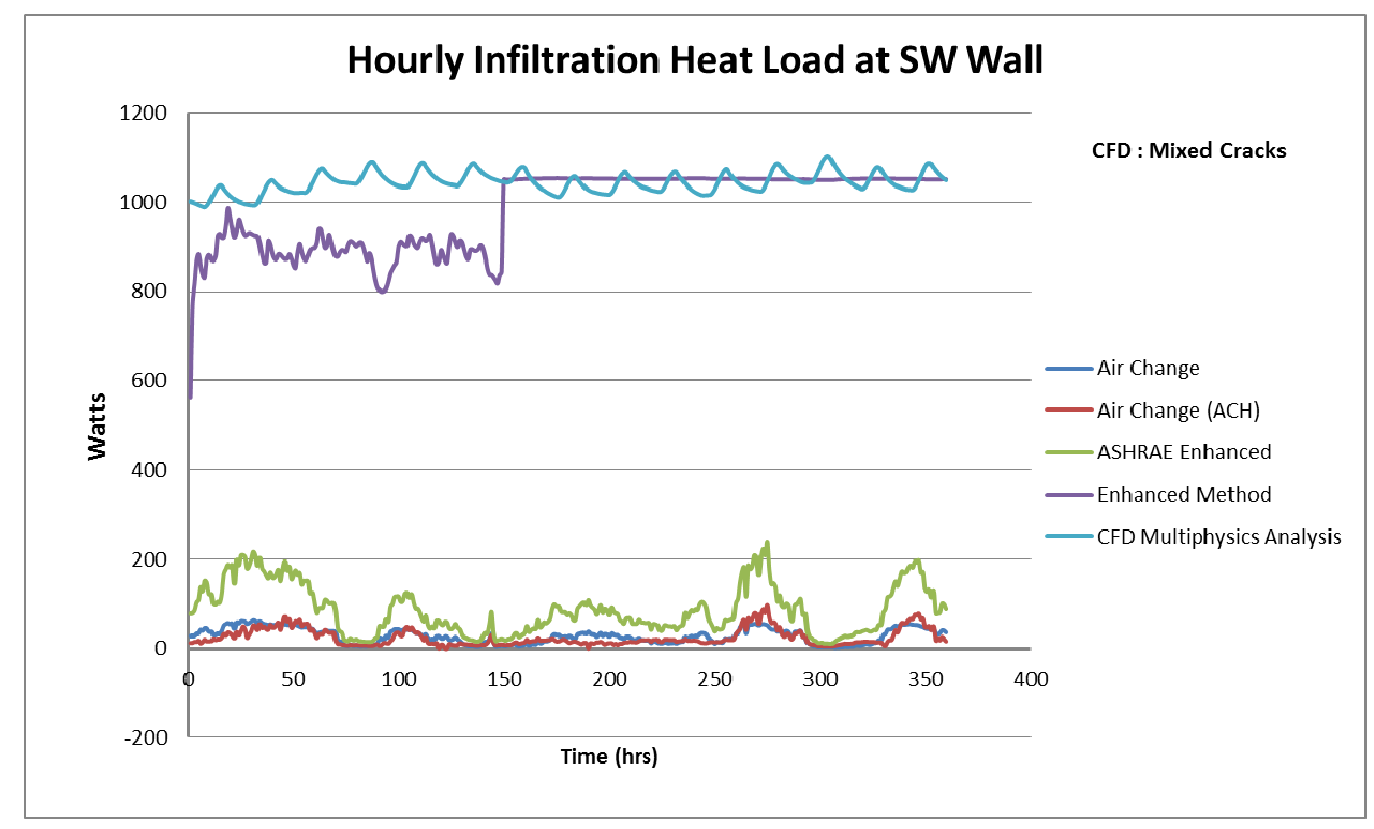

Chart 5-3: Hourly Infiltration Heat Load at the Southwest Wall versus Mixed cracks CFD Output for the wall

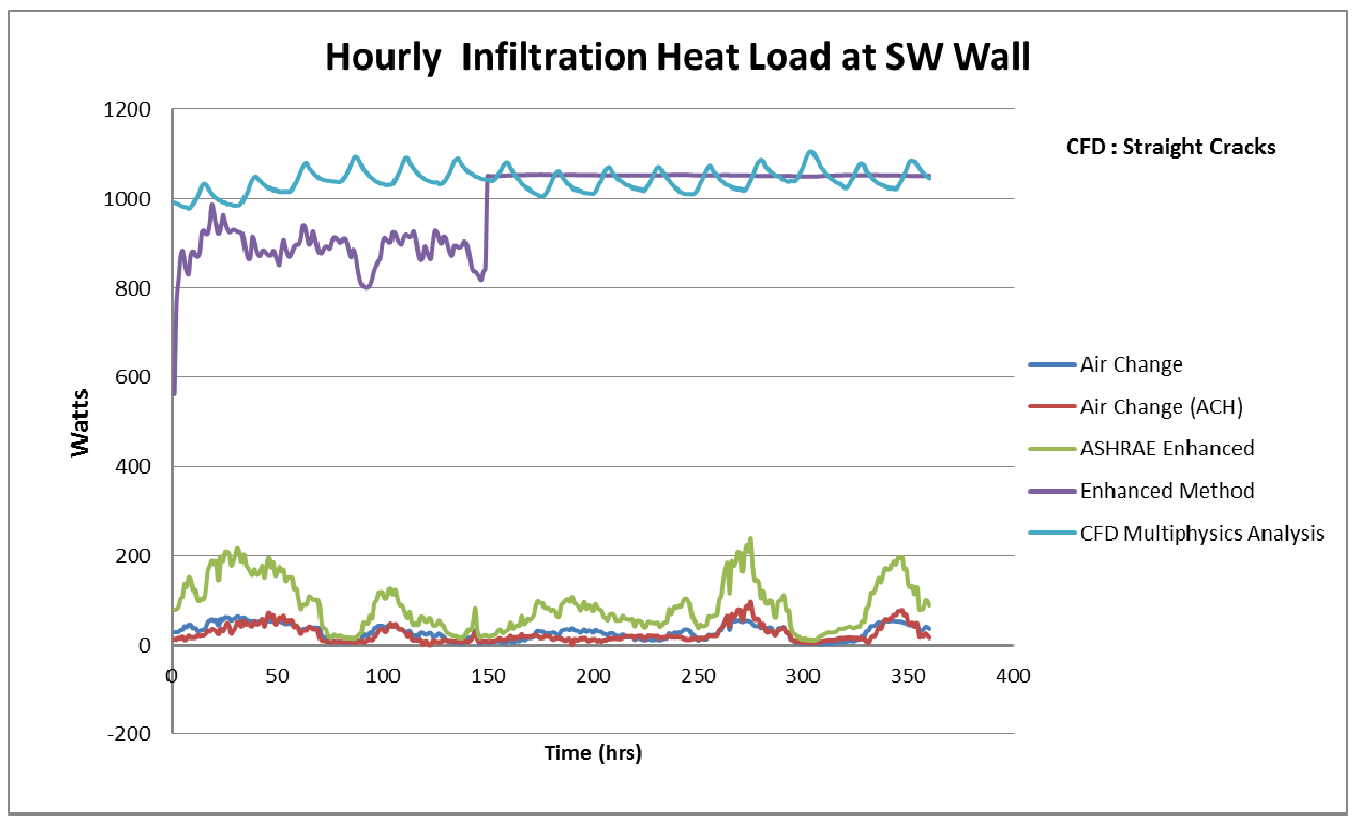

Chart 5-4: Hourly Infiltration Heat Load at Southwest Wall versus Straight cracks CFD Output for the wall

The output of the Enhanced Model is the same for the various types and combinations of cracks. Even though it is dependent on DOE-2/eQUEST hourly values, its output is independent of and invariable with the various DOE-2/eQUEST infiltration 
methods. The Enhanced Model was developed to be independent of previously existing infiltration heat load calculation methods. Also, as clear in the shown plots it is formulated to provide a highly accurate estimation of hourly infiltration loads without the need to specify or determine the type of cracks in the building envelope or the percentage of each type.

The cumulative heat load of infiltration is the major desired output and final objective of every energy analysis. It provides a quantifiable amount of the energy demand and expected energy costs over a measurable period of time. Table 5-3 presents an excerpt of the cumulative infiltration heat load calculated for the southwest wall by each of the methods and for the various crack types (CFD). A detailed hourly report is presented in Appendix A.

The plots in Charts 5-5, 5-6 and 5-7 reflect the cumulative infiltration load for the Southwest wall for the different DOE-2/eQUEST methods versus the CFD simulation results for the various crack types and versus the Enhanced Model output. From the charts shown, a major underestimation of the infiltration heat load by the DOE2/eQUEST methods versus the CFD analysis is clearly observed. On the other hand, the output of the Enhanced Model is observed to be highly consistent with the results of the multiphysics hygrothermal CFD analysis. A summary of the cumulative results calculated by each method for the Southwest wall is shown in Table 5-4. 


\section{Cumulative Southwest (SW) Wall Data (Watts)}

\begin{tabular}{|c|c|c|c|c|c|c|c|}
\hline \multirow[b]{2}{*}{$\begin{array}{c}\text { hou } \\
\text { r }\end{array}$} & \multicolumn{3}{|c|}{$\begin{array}{l}\text { eUEST/DOE-2 Hourly Values } \\
\text { (no reduction multiplier) }\end{array}$} & \multirow[b]{2}{*}{$\begin{array}{c}\text { Enhanced } \\
\text { Model }\end{array}$} & \multicolumn{3}{|c|}{ CFD Multiphysisc Simulation } \\
\hline & $\begin{array}{c}\text { Air } \\
\text { Change }\end{array}$ & $\begin{array}{c}\text { Air } \\
\text { Change } \\
(\mathrm{ACH})\end{array}$ & $\begin{array}{c}\text { ASHRAE } \\
\text { Enhance } \\
\text { d }\end{array}$ & & $\begin{array}{l}\text { Angular } \\
\text { Cracks }\end{array}$ & $\begin{array}{c}\text { Mixed } \\
\text { Cracks* }\end{array}$ & $\begin{array}{l}\text { Straight } \\
\text { Cracks* }\end{array}$ \\
\hline 1 & 27.841 & 12.382 & 78.440 & 562.563 & 1033.902 & 1001.086 & 990.942 \\
\hline 2 & 56.104 & 24.952 & 158.072 & 1327.442 & 2066.050 & 2000.654 & 1979.632 \\
\hline 3 & 84.531 & 40.124 & 243.374 & 2144.174 & 3097.338 & 2998.438 & 2966.693 \\
\hline 4 & 118.035 & 55.025 & 346.837 & 3012.619 & 4124.577 & 3994.012 & 3950.352 \\
\hline 5 & 151.665 & 72.973 & 455.766 & 3896.213 & 5149.727 & 4987.482 & 4932.263 \\
\hline 6 & 193.857 & 84.232 & 592.512 & 4754.368 & 6173.157 & 5979.100 & 5912.853 \\
\hline 7 & 233.433 & 98.314 & 721.360 & 5591.744 & 7194.165 & 6968.838 & 6893.162 \\
\hline 8 & 279.017 & 118.587 & 872.913 & 6422.635 & 8213.304 & 7957.180 & 7869.749 \\
\hline 9 & 324.112 & 134.632 & 1020.789 & 7295.842 & 9233.762 & 8949.111 & 8849.655 \\
\hline 10 & 361.469 & 151.247 & 1143.247 & 8177.697 & 10255.104 & 9947.876 & 9837.575 \\
\hline 11 & 399.258 & 168.054 & 1265.344 & 9050.244 & 11280.402 & 10955.204 & 10833.303 \\
\hline 12 & 429.713 & 189.726 & 1365.440 & 9919.506 & 12308.128 & 11971.552 & 11838.960 \\
\hline
\end{tabular}
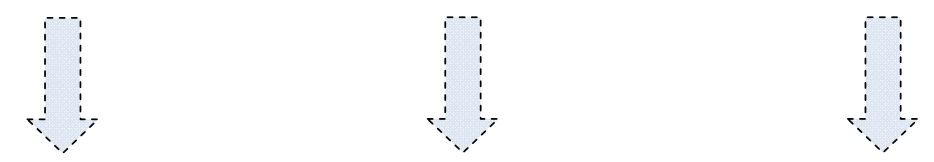

\begin{tabular}{||l||l|l|l||l||l|l|l||}
\hline $\mathbf{7 3 3}$ & 17822.14 & 16273.10 & 55806.29 & 746490.21 & 766131.51 & 364067.22 & 362813.83 \\
\hline $\mathbf{7 3 4}$ & 17834.09 & 16292.22 & 55857.66 & 747543.60 & 767166.27 & 365145.84 & 363890.27 \\
\hline $\mathbf{7 3 5}$ & 17847.10 & 16311.90 & 55911.67 & 748597.04 & 768201.69 & 366230.64 & 364973.85 \\
\hline $\mathbf{7 3 6}$ & 17862.31 & 16332.20 & 55970.41 & 749650.56 & 769237.91 & 367317.13 & 366057.91 \\
\hline $\mathbf{7 3 7}$ & 17882.68 & 16352.13 & 56039.33 & 750704.10 & 770272.50 & 368401.33 & 367139.89 \\
\hline $\mathbf{7 3 8}$ & 17902.75 & 16371.76 & 56107.64 & 751757.71 & 771303.80 & 369478.77 & 368215.71 \\
\hline $\mathbf{7 3 9}$ & 17937.93 & 16384.28 & 56214.59 & 752811.41 & 772334.17 & 370550.19 & 369284.74 \\
\hline $\mathbf{7 4 0}$ & 17975.07 & 16394.19 & 56326.94 & 753865.12 & 773361.66 & 371616.37 & 370346.97 \\
\hline $\mathbf{7 4 1}$ & 18014.15 & 16401.14 & 56444.78 & 754918.84 & 774387.91 & 372677.49 & 371404.81 \\
\hline $\mathbf{7 4 2}$ & 18054.84 & 16412.00 & 56568.81 & 755972.64 & 775411.66 & 373734.24 & 372458.02 \\
\hline $\mathbf{7 4 3}$ & 18096.01 & 16426.65 & 56695.98 & 757026.52 & 776435.02 & 374787.13 & 373506.79 \\
\hline $\mathbf{7 4 4}$ & 18129.92 & 16444.74 & 56803.41 & 758080.49 & 777455.58 & 375836.23 & 374551.88 \\
\hline
\end{tabular}

Table 5-3: Cumulative Infiltration Heat Load Data for Southwest Wall

Note*: Cumulative CFD Data for Mixed and Straight Cracks Simulation in Table 5-3 are based on 15 Days of Flow time Simulations. 


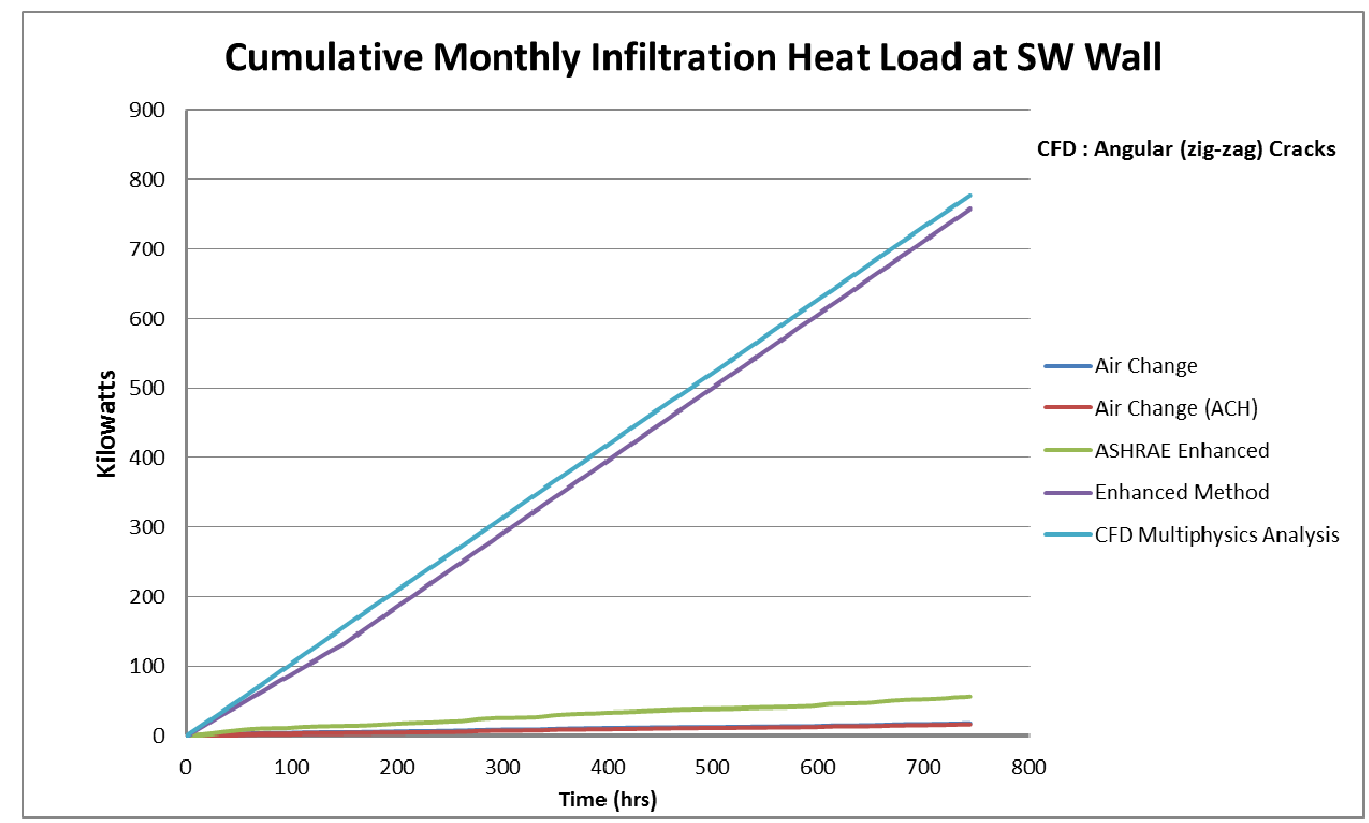

Chart 5-5: Cumulative Monthly Infiltration Heat Load at Southwest Wall versus Angled (zig-zag) cracks CFD Output for the Wall

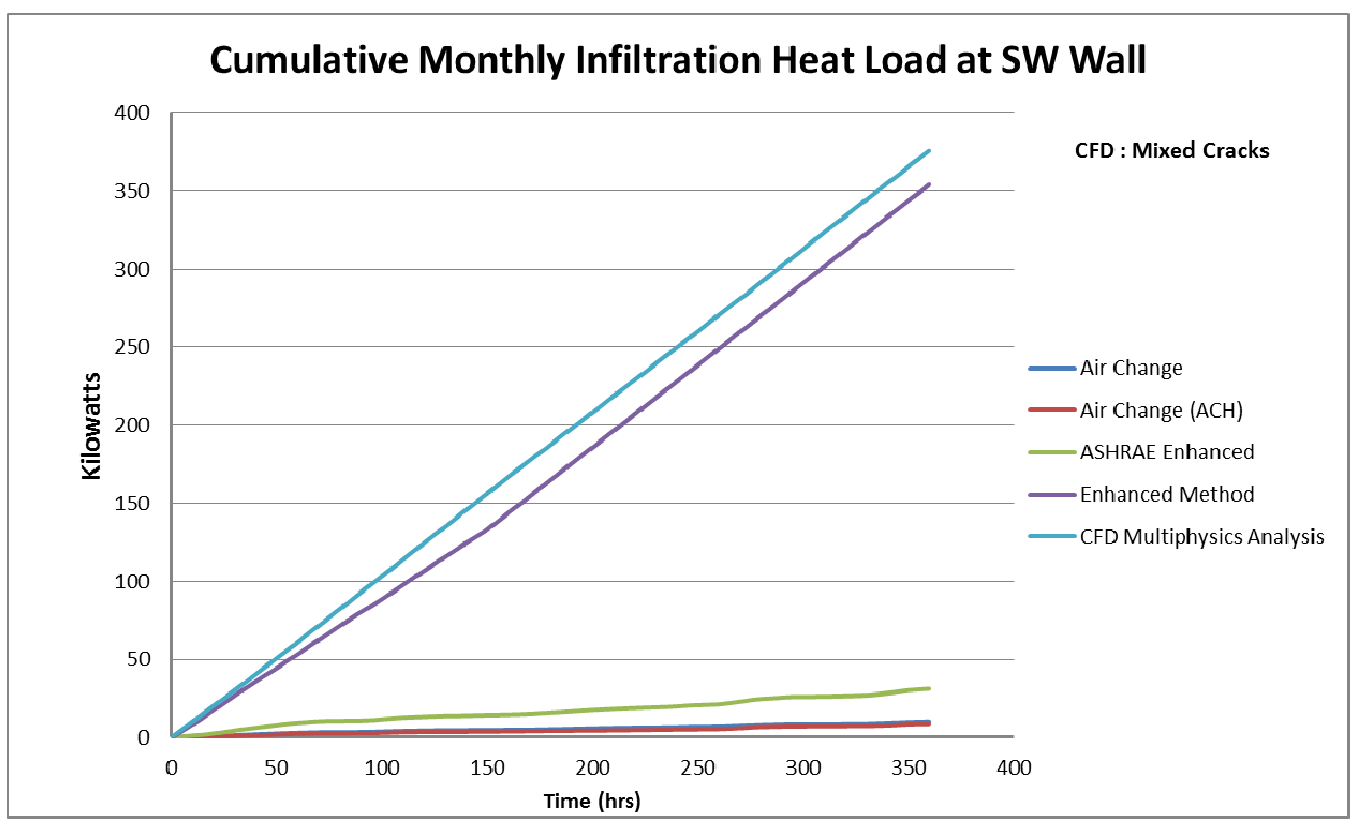

Chart 5-6: Cumulative Monthly Infiltration Heat Load at Southwest Wall versus Mixed cracks CFD Output for the Wall 


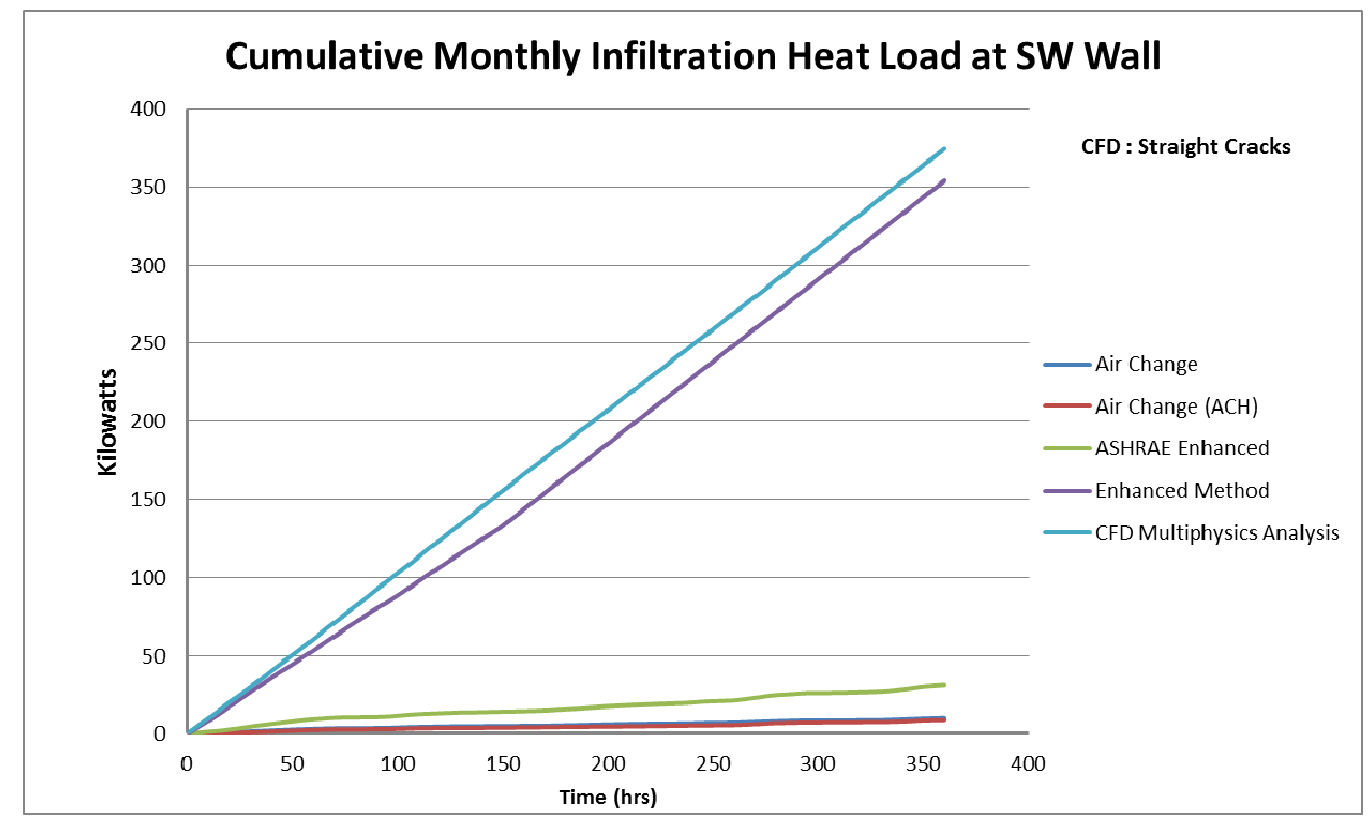

Chart 5-7: Cumulative Monthly Infiltration Heat Load at Southwest Wall versus Straight cracks CFD Output for the Wall

As shown in Table 5-4 a very high percentage of error in estimating the infiltration heat load is observed by the base Air Change method, Air Change (ACH), and ASHRAE Enhanced method. The underestimation error ranges between $91.66 \%$ and 97.88\%. In contrast, the output of the Enhanced Model is highly accurate in comparison with the complex CFD analysis. The underestimation error of the Enhanced Model ranges between $2.49 \%$ and $5.48 \%$ only. It is extremely important to note the capability of the Enhanced Model to very closely match the output of the complex CFD analysis while requiring less than $1 \%$ of the time required for running a CFD analysis for the same building envelope. This advantage will be discussed with further detail in the following sections. 


\begin{tabular}{|c|c|c|c|c|c|c|c|c|}
\hline & & \multicolumn{6}{|c|}{ SW- Wall Full Month Summary } & \\
\hline & & \multicolumn{3}{|c|}{$\begin{array}{l}\text { eQUEST/DOE-2 Infiltration Load V/s CFD } \\
\text { Analysis }\end{array}$} & \multicolumn{3}{|c|}{$\begin{array}{c}\text { Enhanced eQUEST/DOE-2 Infiltration Load } \\
\text { V/s CFD Analysis } \\
\end{array}$} & \\
\hline & & $\begin{array}{c}\text { DOE- } \\
\text { 2/eQUEST } \\
\text { (watts) } \\
\end{array}$ & $\begin{array}{c}\text { Ansys } \\
\text { (watts) }\end{array}$ & $\begin{array}{l}\text { Uner/over } \\
\text { Estimate }\end{array}$ & $\begin{array}{c}\text { Enhanced } \\
\text { Model (watts) }\end{array}$ & $\begin{array}{c}\text { Ansys } \\
\text { (watts) }\end{array}$ & $\begin{array}{l}\text { Uner/over } \\
\text { Estimate }\end{array}$ & \\
\hline \multirow{3}{*}{ 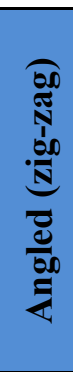 } & $\begin{array}{l}\text { Air Change } \\
\text { (base) }\end{array}$ & 18129.92 & 777455.58 & $\begin{array}{l}\text { Under Estimate } \\
97.67 \%\end{array}$ & 758080.49 & 777455.58 & $\begin{array}{c}\text { Under Estimate } \\
2.49 \%\end{array}$ & \multirow{3}{*}{ 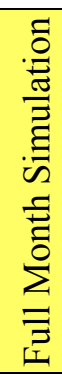 } \\
\hline & $\begin{array}{c}\text { Air Change } \\
(\mathrm{ACH})\end{array}$ & 16444.74 & 777455.58 & $\begin{array}{c}\text { Under Estimate } \\
97.88 \% \\
\end{array}$ & 758080.49 & 777455.58 & $\begin{array}{c}\text { Under Estimate } \\
2.49 \% \\
\end{array}$ & \\
\hline & $\begin{array}{l}\text { ASHRAE } \\
\text { Enhanced }\end{array}$ & 56803.41 & 777455.58 & $\begin{array}{c}\text { Under Estimate } \\
92.69 \% \\
\end{array}$ & 758080.49 & 777455.58 & $\begin{array}{c}\text { Under Estimate } \\
\text { by } \\
2.49 \% \\
\end{array}$ & \\
\hline \multirow{3}{*}{ 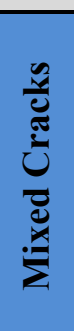 } & $\begin{array}{l}\text { Air Change } \\
\text { (base) }\end{array}$ & 10177.45 & 375836.23 & $\begin{array}{l}\text { Under Estimate } \\
\quad 97.29 \%\end{array}$ & 354017.23 & 375836.23 & $\begin{array}{c}\text { Under Estimate } \\
5.81 \%\end{array}$ & \multirow{3}{*}{$\begin{array}{l}\infty \\
\stackrel{\infty}{\pi} \\
n\end{array}$} \\
\hline & $\begin{array}{l}\text { Air Change } \\
(\mathrm{ACH})\end{array}$ & 8829.61 & 375836.23 & $\begin{array}{l}\text { Under Estimate } \\
97.65 \%\end{array}$ & 354017.23 & 375836.23 & $\begin{array}{l}\text { Under Estimate } \\
5.81 \%\end{array}$ & \\
\hline & $\begin{array}{l}\text { ASHRAE } \\
\text { Enhanced }\end{array}$ & 31247.49 & 375836.23 & $\begin{array}{l}\text { Under Estimate } \\
\quad 91.69 \%\end{array}$ & 354017.23 & 375836.23 & $\begin{array}{l}\text { Under Estimate } \\
5.81 \%\end{array}$ & \\
\hline \multirow{3}{*}{ 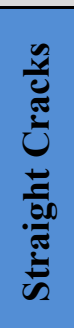 } & $\begin{array}{l}\text { Air Change } \\
\text { (base) }\end{array}$ & 10177.45 & 374551.88 & $\begin{array}{c}\text { Under Estimate } \\
97.28 \%\end{array}$ & 354017.23 & 374551.88 & $\begin{array}{c}\text { Under Estimate } \\
5.48 \%\end{array}$ & \multirow{3}{*}{$\begin{array}{l}\sum_{\overparen{\pi}}^{n} \\
0 \\
n\end{array}$} \\
\hline & $\begin{array}{c}\text { Air Change } \\
(\mathrm{ACH}) \\
\end{array}$ & 8829.61 & 374551.88 & $\begin{array}{c}\text { Under Estimate } \\
97.64 \% \\
\end{array}$ & 354017.23 & 374551.88 & $\begin{array}{c}\text { Under Estimate } \\
5.48 \% \\
\end{array}$ & \\
\hline & $\begin{array}{l}\text { ASHRAE } \\
\text { Enhanced }\end{array}$ & 31247.49 & 374551.88 & $\begin{array}{c}\text { Under Estimate } \\
91.66 \% \\
\end{array}$ & 354017.23 & 374551.88 & $\begin{array}{c}\text { Under Estimate } \\
5.48 \% \\
\end{array}$ & \\
\hline
\end{tabular}




\section{Northwest Wall (NW)}

Similar to the Southwest wall analyses discussed in the previous section in this section an analysis for the infiltration heat load calculations for the Northwest wall façade of the building envelope is presented. The data shown in Table 5-5 is an excerpt of the hourly infiltration heat load at the Northwest wall at the first 12 time steps and the final 12 time steps of each hourly analysis. The full hourly data is presented in appendix B.

The plot in Chart 5-8 shows the calculated hourly output of sensible infiltration heat load on the SW wall for each of the 3 considered DOE-2/eQUEST methods. As in the case of the Southwest wall, it is evident from the data plots that the output is largely inconsistent among these different methods themselves. Also significantly different is the peak infiltration heat load reported by each method. The peak load obtained from the base Air change method is 146 watts versus 344.31 watts obtained through Air Change $(\mathrm{ACH})$ and 894.692 watts from ASHRAE Enhanced. On the other hand, the peak hourly load calculated by the developed Enhanced Model is 1055 watts and compares very well against the peak hourly load of 1007.212 watts reported by the CFD analysis for the case of angled cracks for example.

Charts 5-9, 5-10 and 5-11 plot the hourly calculated infiltration heat load for the Northwest wall by the 5 previously stated methods. A separate chart is shown including each of the Three CFD cases (angled cracks, mixed cracks and straight cracks) versus the remaining models. 


\section{Hourly Northwest (NW) Wall Data (Watts)}

\begin{tabular}{|c|c|c|c|c|c|c|c|}
\hline \multirow[b]{2}{*}{ hour } & \multicolumn{3}{|c|}{$\begin{array}{l}\text { eUEST/DOE-2 Hourly Values } \\
\text { (no reduction multiplier) }\end{array}$} & \multirow[b]{2}{*}{$\begin{array}{c}\text { Enhanced } \\
\text { Model }\end{array}$} & \multicolumn{3}{|c|}{ CFD Multiphysisc Simulation } \\
\hline & $\begin{array}{c}\text { Air } \\
\text { Change }\end{array}$ & $\begin{array}{c}\text { Air } \\
\text { Change } \\
\text { (ACH) }\end{array}$ & $\begin{array}{l}\text { ASHRAE } \\
\text { Enhanced }\end{array}$ & & $\begin{array}{l}\text { Angular } \\
\text { Cracks }\end{array}$ & $\begin{array}{l}\text { Mixed } \\
\text { Cracks }\end{array}$ & $\begin{array}{c}\text { Straight } \\
\text { Cracks }\end{array}$ \\
\hline 1 & 56.029 & 24.919 & 157.860 & 525.783 & 954.536 & 867.704 & 916.750 \\
\hline 2 & 54.852 & 24.395 & 154.544 & 746.408 & 953.216 & 866.990 & 915.432 \\
\hline 3 & 65.523 & 34.970 & 196.614 & 805.611 & 951.399 & 865.908 & 914.195 \\
\hline 4 & 60.664 & 26.981 & 187.338 & 805.096 & 950.079 & 864.373 & 912.754 \\
\hline 5 & 69.586 & 37.138 & 225.392 & 821.346 & 946.745 & 862.458 & 909.881 \\
\hline 6 & 42.192 & 11.259 & 136.746 & 826.700 & 944.771 & 860.788 & 908.104 \\
\hline 7 & 58.600 & 20.850 & 190.787 & 823.588 & 942.659 & 859.075 & 906.221 \\
\hline 8 & 45.585 & 20.274 & 151.554 & 819.754 & 941.388 & 857.656 & 905.070 \\
\hline 9 & 45.094 & 16.045 & 147.876 & 818.078 & 942.205 & 860.151 & 907.145 \\
\hline 10 & 64.774 & 28.809 & 212.331 & 841.410 & 944.555 & 864.975 & 912.290 \\
\hline 11 & 59.864 & 26.625 & 193.424 & 854.493 & 947.400 & 871.483 & 918.960 \\
\hline 12 & 74.712 & 53.166 & 245.551 & 862.263 & 950.602 & 878.035 & 926.349 \\
\hline 733 & 103.980 & 138.737 & 397.612 & 1053.425 & 960.809 & 920.923 & 976.938 \\
\hline 734 & 111.401 & 178.364 & 479.080 & 1053.390 & 963.164 & 927.357 & 982.118 \\
\hline 735 & 110.269 & 166.744 & 457.551 & 1053.446 & 964.905 & 931.944 & 986.280 \\
\hline 736 & 106.019 & 141.457 & 409.442 & 1053.521 & 964.809 & 933.747 & 986.164 \\
\hline 737 & 91.655 & 89.681 & 310.087 & 1053.535 & 963.339 & 931.977 & 984.390 \\
\hline 738 & 94.366 & 92.333 & 321.303 & 1053.612 & 960.226 & 927.629 & 979.750 \\
\hline 739 & 54.141 & 19.264 & 164.595 & 1053.697 & 957.846 & 923.448 & 976.381 \\
\hline 740 & 48.668 & 12.987 & 147.189 & 1053.715 & 957.264 & 919.926 & 972.738 \\
\hline 741 & 43.294 & 7.702 & 130.546 & 1053.722 & 954.380 & 916.497 & 969.594 \\
\hline 742 & 40.683 & 10.856 & 124.034 & 1053.797 & 953.315 & 912.969 & 967.552 \\
\hline 743 & 41.173 & 14.649 & 127.170 & 1053.881 & 951.212 & 910.672 & 964.076 \\
\hline 744 & 63.253 & 33.758 & 200.412 & 1053.970 & 951.220 & 907.971 & 961.581 \\
\hline
\end{tabular}

Table 5-5: Hourly Infiltration Heat Load Data for Northwest Wall

Note*: Last 12 Hourly CFD Data shown for Mixed and Straight Cracks in Table 5-5 are based on 15 Days of Flow time Simulations. 


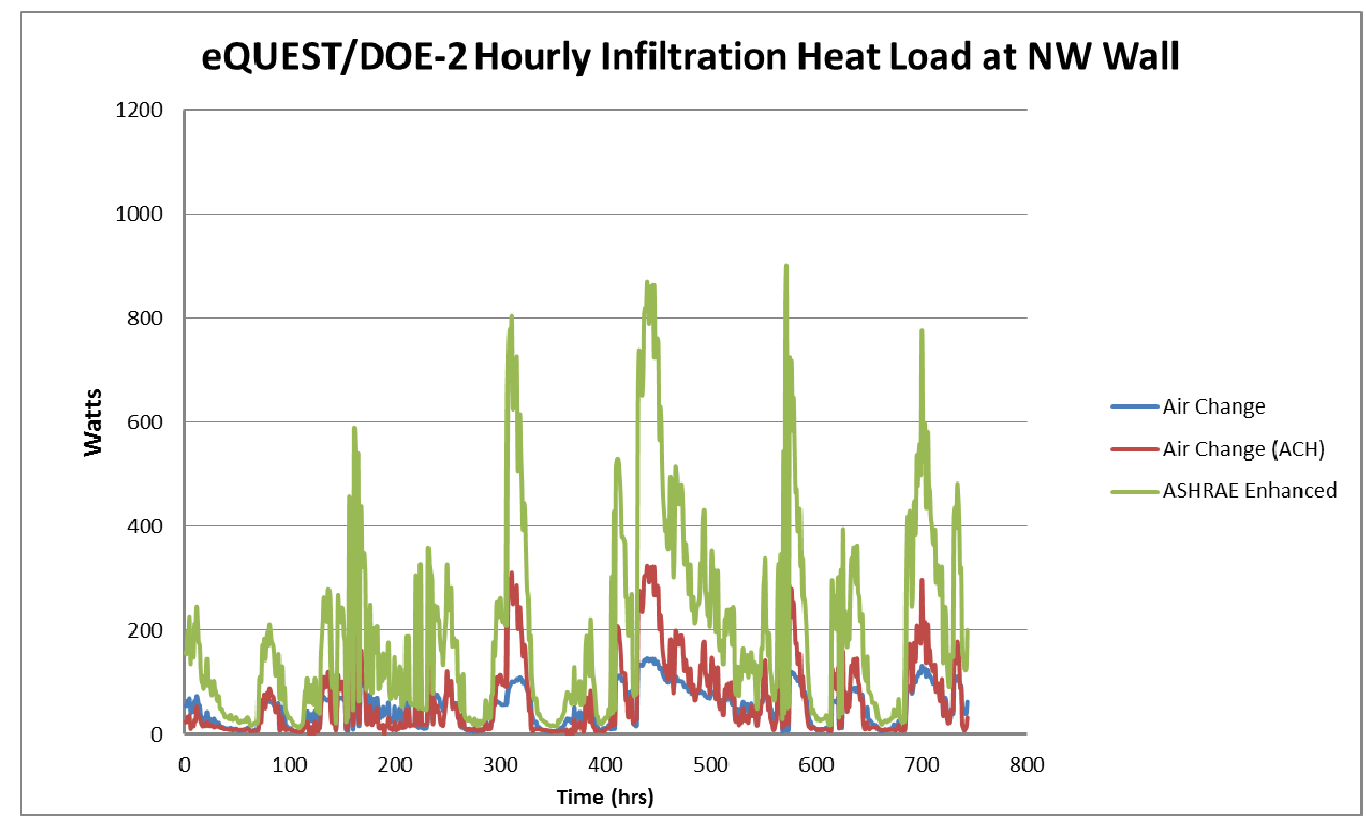

Chart 5-8: Hourly Infiltration Heat Load at Northwest Wall by Various DOE-2/eQUEST Methods

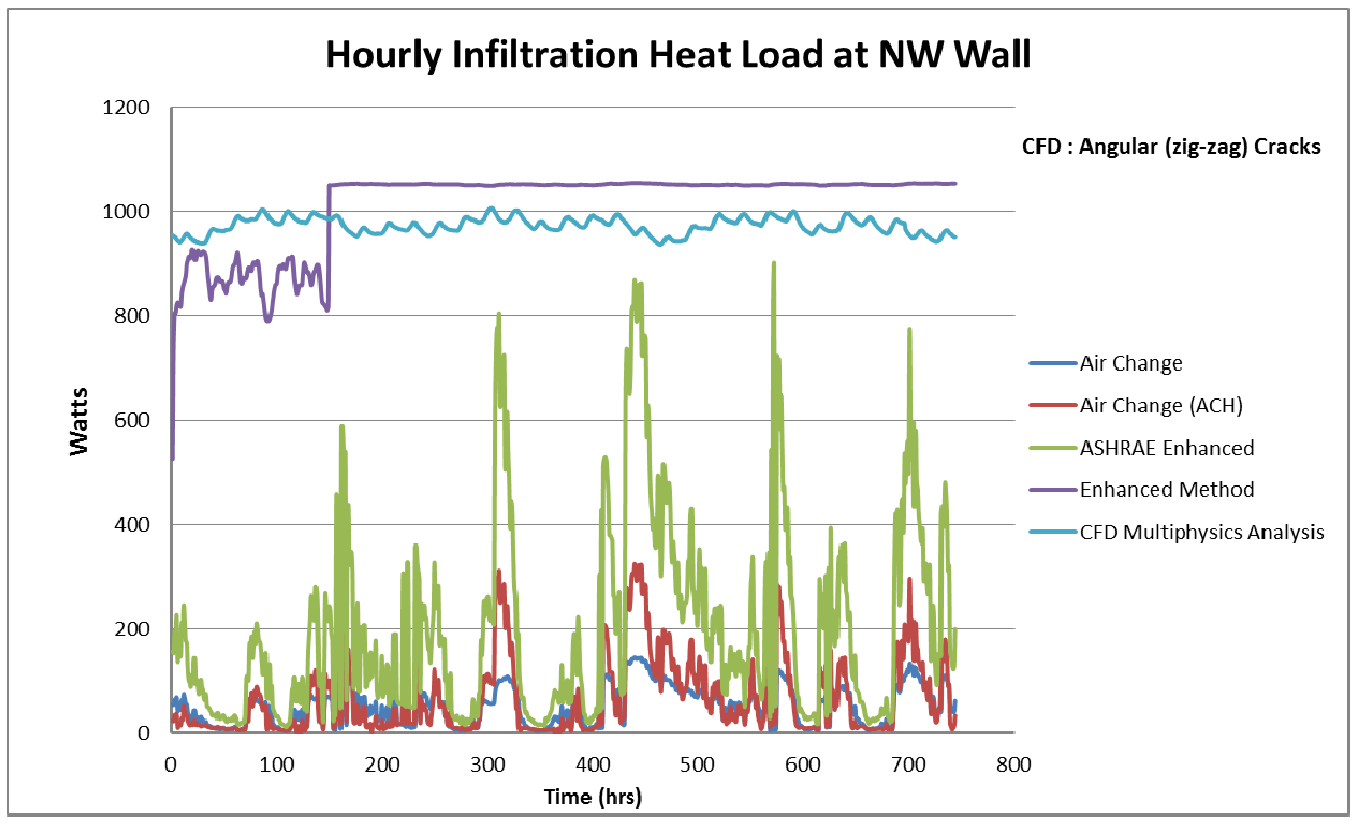

Chart 5-9: Hourly Infiltration Heat Load at Northwest Wall versus Angled (zig-zag) cracks CFD Output for the Wall 


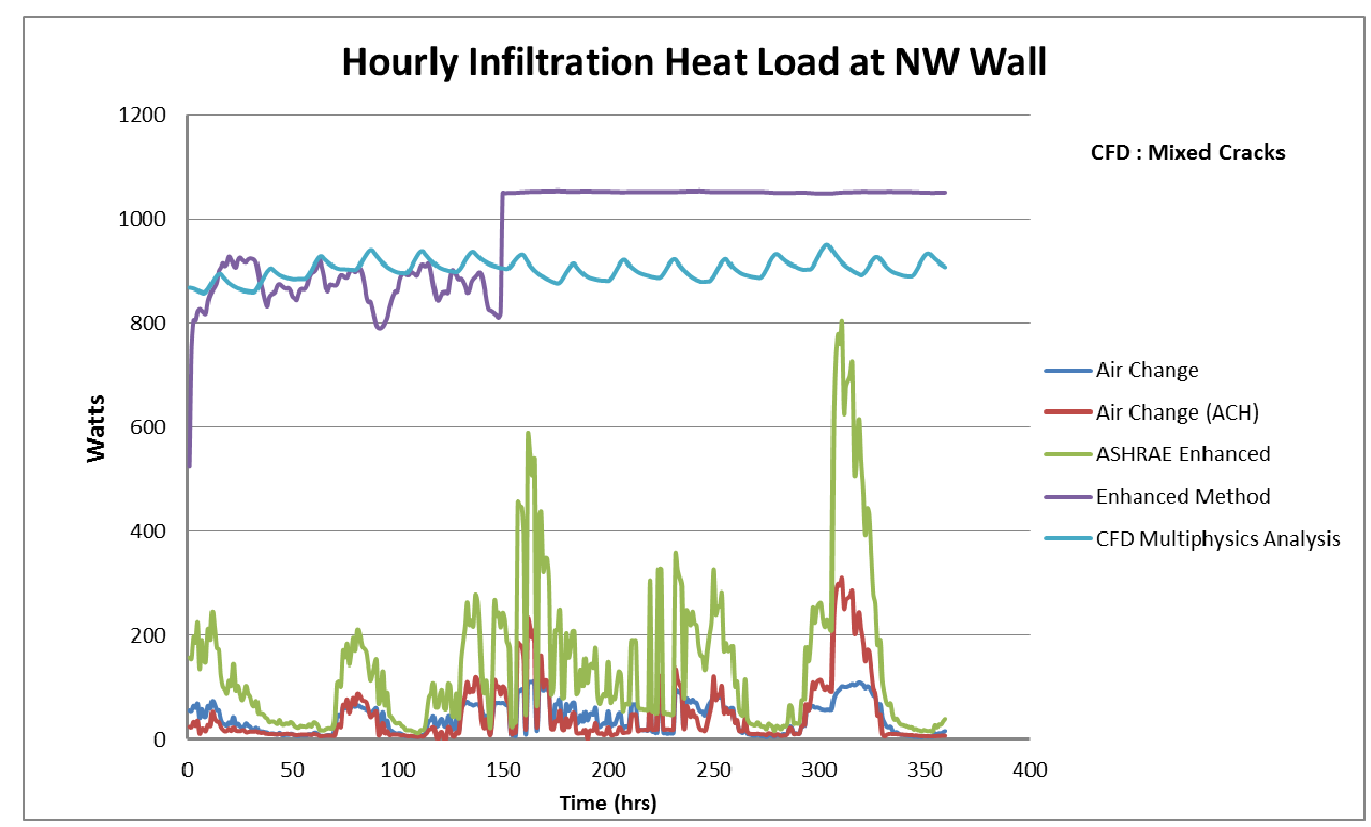

Chart 5-10: Hourly Infiltration Heat Load at Northwest Wall versus Mixed cracks CFD Output for the Wall

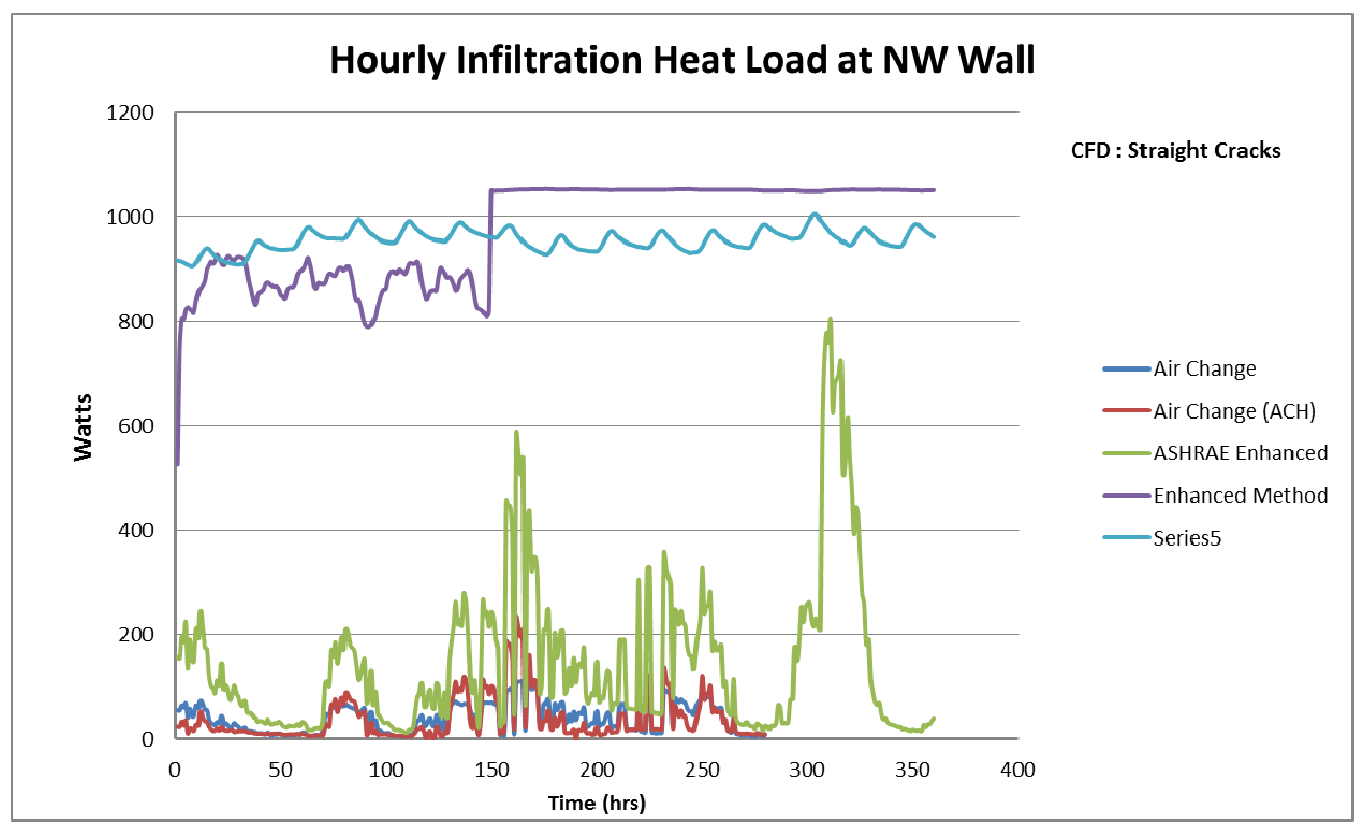

Chart 5-11: Hourly Infiltration Heat Load at Northwest Wall versus Straight cracks CFD Output for the Wall 


\section{Cumulative Southwest (SW) Wall Data (Watts)}

\begin{tabular}{|c|c|c|c|c|c|c|c|}
\hline \multirow[b]{2}{*}{$\begin{array}{c}\text { hou } \\
\text { r }\end{array}$} & \multicolumn{3}{|c|}{$\begin{array}{l}\text { eUEST/DOE-2 Hourly Values } \\
\text { (no reduction multiplier) }\end{array}$} & \multirow[b]{2}{*}{$\begin{array}{c}\text { Enhanced } \\
\text { Model }\end{array}$} & \multicolumn{3}{|c|}{ CFD Multiphysisc Simulation } \\
\hline & $\begin{array}{c}\text { Air } \\
\text { Change }\end{array}$ & $\begin{array}{c}\text { Air } \\
\text { Change } \\
\text { (ACH) }\end{array}$ & $\begin{array}{l}\text { ASHRAE } \\
\text { Enhanced }\end{array}$ & & $\begin{array}{l}\text { Angular } \\
\text { Cracks }\end{array}$ & $\begin{array}{c}\text { Mixed } \\
\text { Cracks* }\end{array}$ & $\begin{array}{l}\text { Straight } \\
\text { Cracks* }\end{array}$ \\
\hline 1 & 56.03 & 24.92 & 157.86 & 525.78 & 954.54 & 867.70 & 916.75 \\
\hline 2 & 110.88 & 49.31 & 312.40 & 1272.19 & 1907.75 & 1734.69 & 1832.18 \\
\hline 3 & 176.40 & 84.28 & 509.02 & 2077.80 & 2859.15 & 2600.60 & 2746.38 \\
\hline 4 & 237.07 & 111.26 & 696.36 & 2882.90 & 3809.23 & 3464.98 & 3659.13 \\
\hline 5 & 306.65 & 148.40 & 921.75 & 3704.24 & 4755.98 & 4327.43 & 4569.01 \\
\hline 6 & 348.85 & 159.66 & 1058.49 & 4530.94 & 5700.75 & 5188.22 & 5477.12 \\
\hline 7 & 407.45 & 180.51 & 1249.28 & 5354.53 & 6643.40 & 6047.30 & 6383.34 \\
\hline 8 & 453.03 & 200.79 & 1400.84 & 6174.29 & 7584.79 & 6904.95 & 7288.41 \\
\hline 9 & 498.12 & 216.83 & 1548.71 & 6992.36 & 8527.00 & 7765.10 & 8195.55 \\
\hline 10 & 562.90 & 245.64 & 1761.04 & 7833.77 & 9471.55 & 8630.08 & 9107.84 \\
\hline 11 & 622.76 & 272.26 & 1954.47 & 8688.27 & 10418.95 & 9501.56 & 10026.80 \\
\hline 12 & 697.48 & 325.43 & 2200.02 & 9550.53 & 11369.55 & 10379.60 & 10953.15 \\
\hline 733 & 39193.4 & 50492.8 & 147491.2 & 743970.2 & 713490.0 & 314865.5 & 333305.3 \\
\hline 734 & 39304.8 & 50671.1 & 147970.3 & 745023.6 & 714453.2 & 315792.9 & 334287.5 \\
\hline 735 & 39415.1 & 50837.9 & 148427.8 & 746077.1 & 715418.1 & 316724.8 & 335273.7 \\
\hline 736 & 39521.1 & 50979.3 & 148837.3 & 747130.6 & 716382.9 & 317658.6 & 336259.9 \\
\hline 737 & 39612.7 & 51069.0 & 149147.4 & 748184.1 & 717346.2 & 318590.5 & 337244.3 \\
\hline 738 & 39707.1 & 51161.4 & 149468.7 & 749237.7 & 718306.5 & 319518.2 & 338224.0 \\
\hline 739 & 39761.2 & 51180.6 & 149633.3 & 750291.4 & 719264.3 & 320441.6 & 339200.4 \\
\hline 740 & 39809.9 & 51193.6 & 149780.4 & 751345.1 & 720221.6 & 321361.5 & 340173.2 \\
\hline 741 & 39853.2 & 51201.3 & 149911.0 & 752398.9 & 721176.0 & 322278.0 & 341142.8 \\
\hline 742 & 39893.9 & 51212.2 & 150035.0 & 753452.7 & 722129.3 & 323191.0 & 342110.3 \\
\hline 743 & 39935.1 & 51226.8 & 150162.2 & 754506.5 & 723080.5 & 324101.7 & 343074.4 \\
\hline 744 & 39998.3 & 51260.6 & 150362.6 & 755560.5 & 724031.7 & 325009.6 & 344036.0 \\
\hline
\end{tabular}

Table 5-6: Cumulative Infiltration Heat Load Data for Northwest Wall

Note*: Cumulative CFD Data for Mixed and Straight Cracks Simulation in Table 5-3 are based on 15 Days of Flow time Simulation. 
Similar to what was presented for the Southwest wall, an excerpt of the cumulative infiltration heat load for the Northwest wall is shown in Table 5-6. The full data is presented in Appendix B. Charts 5-12, 5-13, and 5-14 present a plot of the cumulative DOE-2/eQUEST and Enhanced Model data in correspondence with the cumulative data for each crack type from the CFD models.

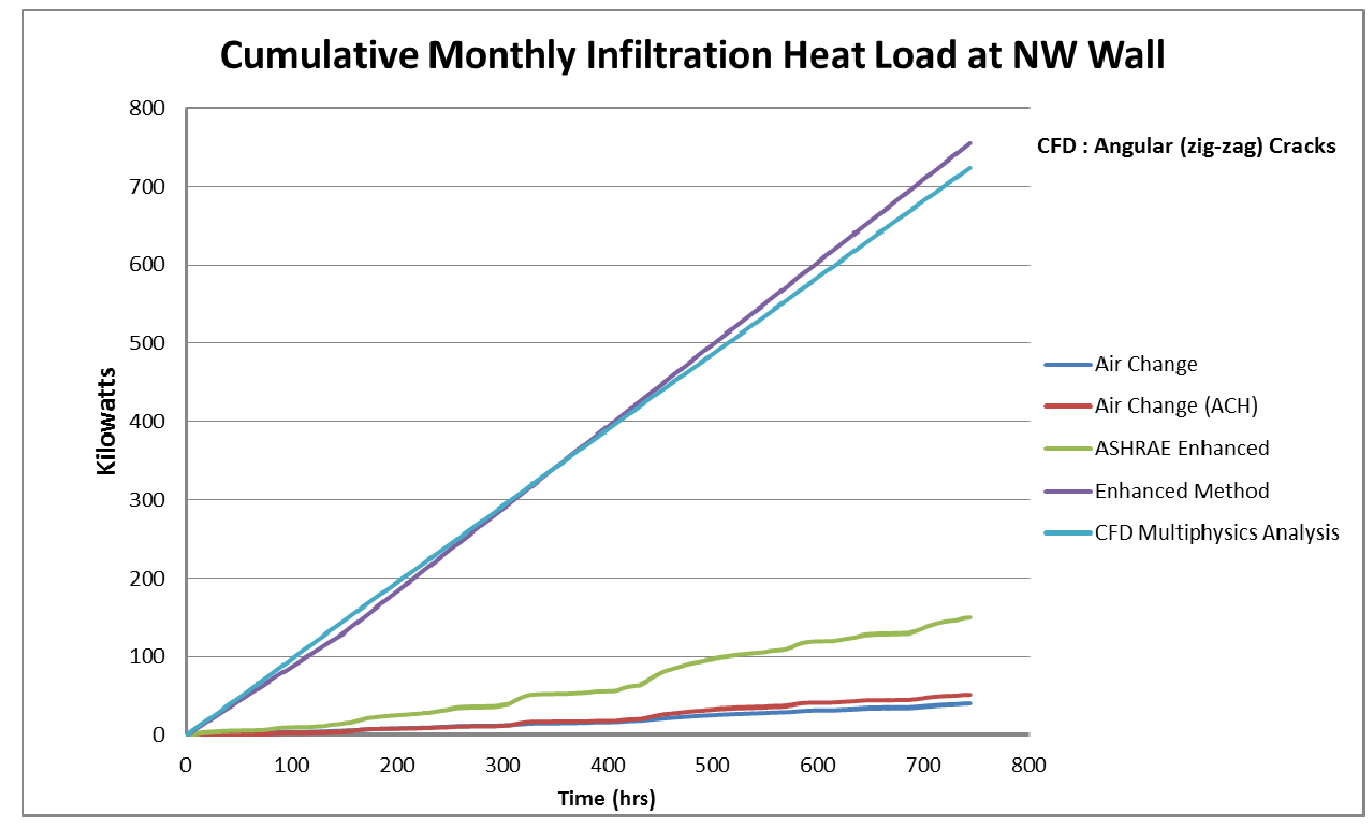

Chart 5-12: Cumulative Monthly Infiltration Heat Load at Northwest Wall versus Angled (zig-zag) cracks CFD Output for the Wall

From the cumulative charts a major underestimation of the infiltration heat load by the various DOE-2/eQUEST methods versus finite elements analysis is observed in this case too. The output of the Enhanced Model is however observed to be highly consistent and very close to that of the hygrothermal CFD analysis. A very slight overestimation is observed by the Enhanced Model. A summary of the cumulative results is shown in Table 5-7. 


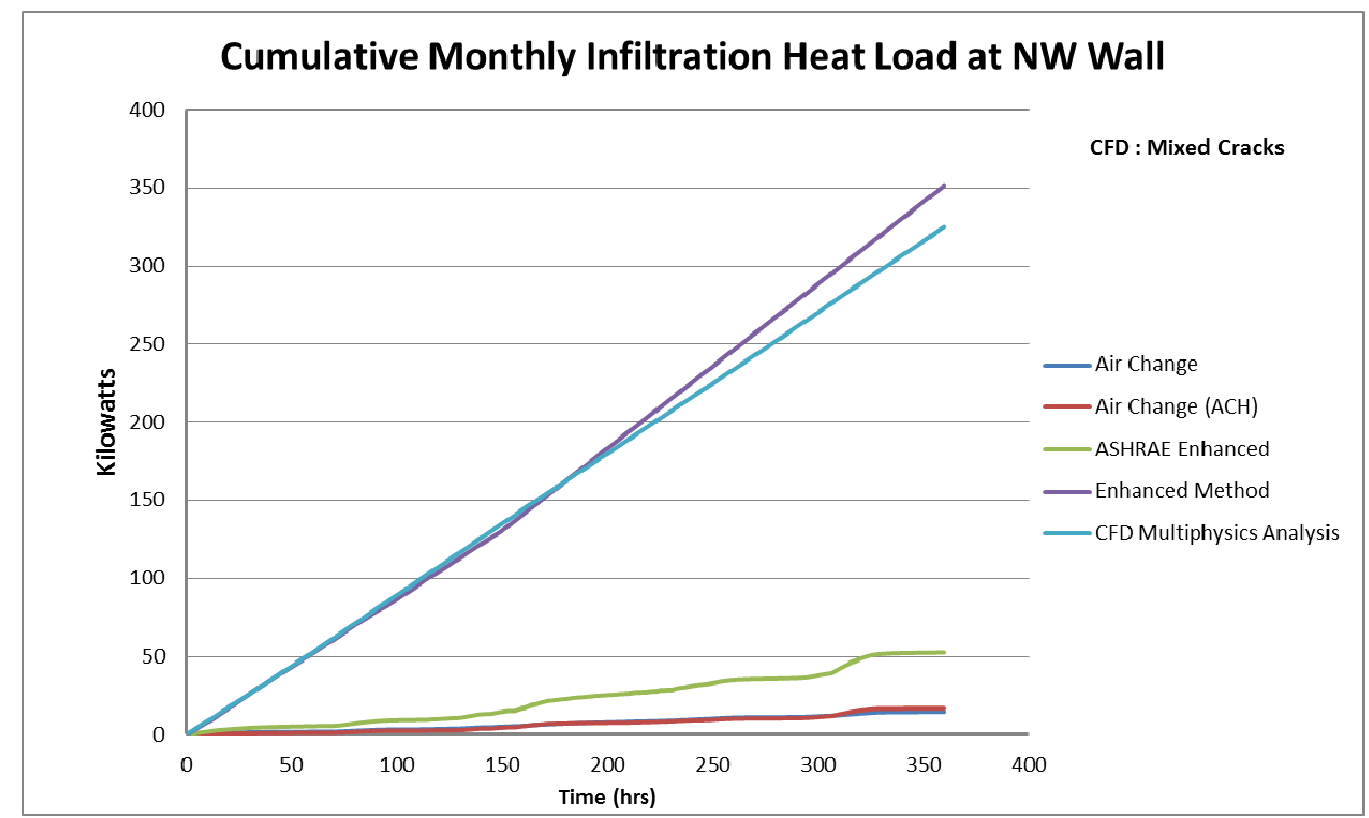

Chart 5-13: Cumulative Monthly Infiltration Heat Load at Northwest Wall versus Mixed cracks CFD Output for the Wall

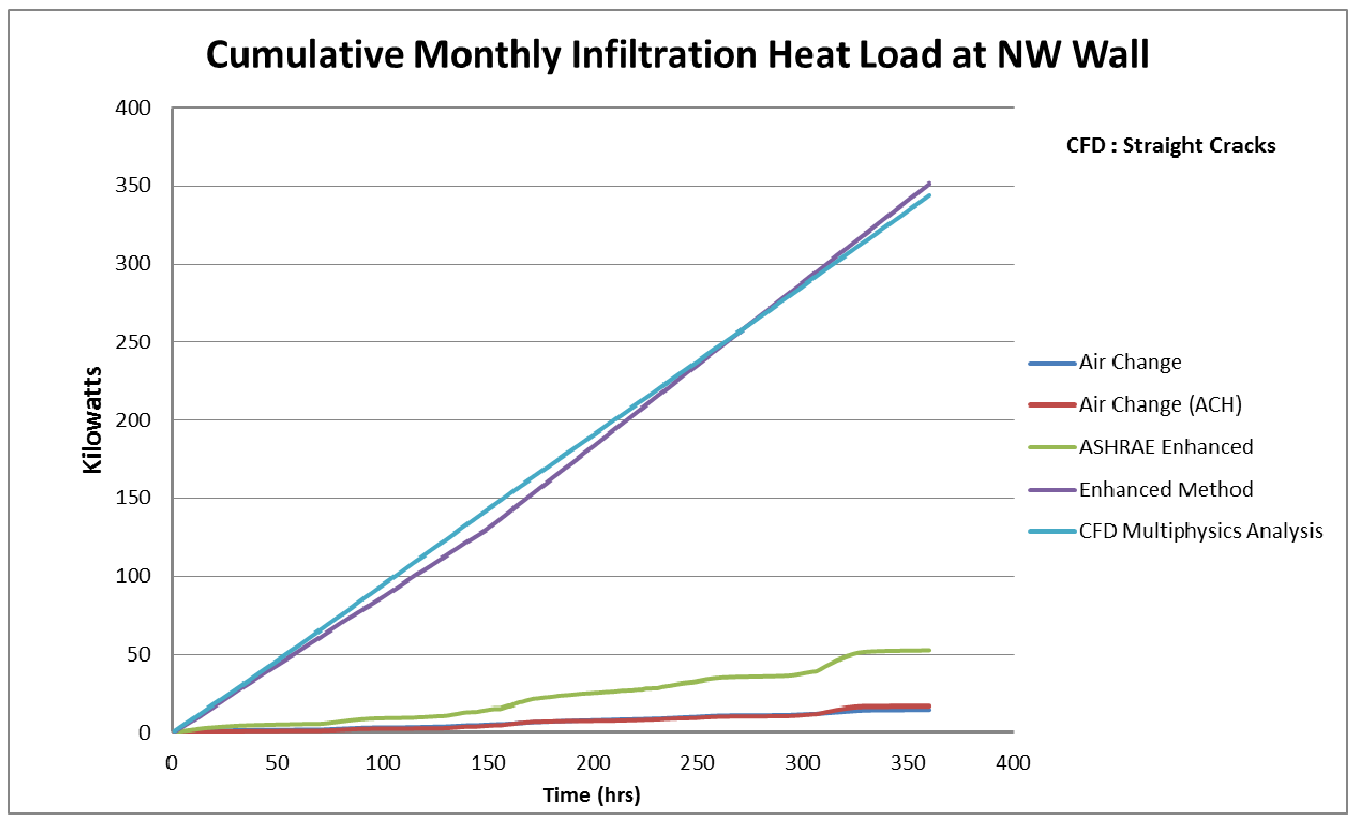

Chart 5-14: Cumulative Monthly Infiltration Heat Load at Northwest Wall versus Straight cracks CFD Output for the Wall 


\begin{tabular}{|c|c|c|c|c|c|c|c|c|c|}
\hline & & & \multicolumn{6}{|c|}{ NW- Wall Full Month Summary } & \\
\hline & & & \multicolumn{3}{|c|}{$\begin{array}{c}\text { eQUEST/DOE-2 Infiltration Load V/s CFD } \\
\text { Analysis }\end{array}$} & \multicolumn{3}{|c|}{$\begin{array}{c}\text { Enhanced eQUEST/DOE-2 Infiltration Load } \\
\text { V/s CFD Analysis }\end{array}$} & \\
\hline \multirow{12}{*}{ 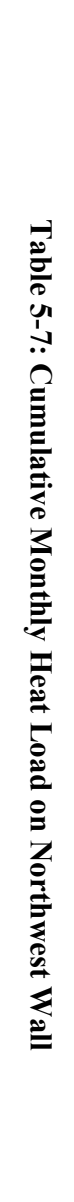 } & & & $\begin{array}{c}\text { DOE- } \\
\text { 2/eQUEST } \\
\text { (watts) } \\
\end{array}$ & $\begin{array}{l}\text { Ansys } \\
\text { (watts) }\end{array}$ & $\begin{array}{l}\text { Uner/over } \\
\text { Estimate }\end{array}$ & $\begin{array}{c}\text { Enhanced } \\
\text { Model (watts) }\end{array}$ & $\begin{array}{l}\text { Ansys } \\
\text { (watts) }\end{array}$ & $\begin{array}{l}\text { Uner/over } \\
\text { Estimate }\end{array}$ & \\
\hline & \multirow{3}{*}{ 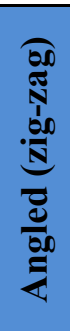 } & $\begin{array}{c}\text { Air Change } \\
\text { (base) }\end{array}$ & 39998.32 & 724031.70 & $\begin{array}{c}\text { Under Estimate } \\
94.48 \%\end{array}$ & 755560.52 & 724031.70 & $\begin{array}{c}\text { Over Estimate } \\
4.35 \%\end{array}$ & \multirow{3}{*}{ 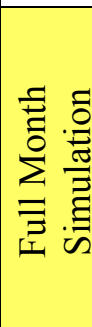 } \\
\hline & & $\begin{array}{c}\text { Air Change } \\
\text { (ACH) }\end{array}$ & 51260.57 & 724031.70 & $\begin{array}{c}\text { Under Estimate } \\
92.92 \%\end{array}$ & 755560.52 & 724031.70 & $\begin{array}{c}\text { Over Estimate } \\
4.35 \%\end{array}$ & \\
\hline & & $\begin{array}{l}\text { ASHRAE } \\
\text { Enhanced }\end{array}$ & 150362.61 & 724031.70 & $\begin{array}{c}\text { Under Estimate } \\
79.23 \%\end{array}$ & 755560.52 & 724031.70 & $\begin{array}{c}\text { Over Estimate } \\
4.35 \%\end{array}$ & \\
\hline & & & & & & & & & \\
\hline & \multirow{3}{*}{ 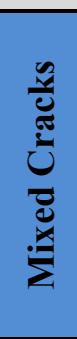 } & $\begin{array}{c}\text { Air Change } \\
\text { (base) }\end{array}$ & 14854.99 & 325009.64 & $\begin{array}{c}\text { Under Estimate } \\
95.43 \%\end{array}$ & 351497.25 & 325009.64 & $\begin{array}{c}\text { Over Estimate } \\
8.15 \%\end{array}$ & \multirow{3}{*}{$\sum_{n}^{\infty}$} \\
\hline & & $\begin{array}{l}\text { Air Change } \\
\text { (ACH) }\end{array}$ & 17033.46 & 325009.64 & $\begin{array}{c}\text { Under Estimate } \\
94.76 \%\end{array}$ & 351497.25 & 325009.64 & $\begin{array}{c}\text { Over Estimate } \\
8.15 \%\end{array}$ & \\
\hline & & $\begin{array}{l}\text { ASHRAE } \\
\text { Enhanced }\end{array}$ & 52691.29 & 325009.64 & $\begin{array}{c}\text { Under Estimate } \\
83.79 \%\end{array}$ & 351497.25 & 325009.64 & $\begin{array}{c}\text { Over Estimate } \\
8.15 \%\end{array}$ & \\
\hline & & & & & & & & & \\
\hline & \multirow{3}{*}{ 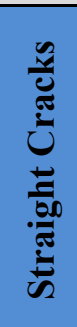 } & $\begin{array}{c}\text { Air Change } \\
\text { (base) }\end{array}$ & 14854.99 & 344035.97 & $\begin{array}{c}\text { Under Estimate } \\
95.68 \%\end{array}$ & 351497.25 & 344035.97 & $\begin{array}{c}\text { Over Estimate } \\
2.17 \%\end{array}$ & \multirow{3}{*}{$\begin{array}{l}\sum_{\bar{E}}^{n} \\
\hat{n} \\
n\end{array}$} \\
\hline & & $\begin{array}{c}\text { Air Change } \\
\text { (ACH) }\end{array}$ & 17033.46 & 344035.97 & $\begin{array}{c}\text { Under Estimate } \\
95.05 \%\end{array}$ & 351497.25 & 344035.97 & $\begin{array}{c}\text { Over Estimate } \\
2.17 \%\end{array}$ & \\
\hline & & $\begin{array}{l}\text { ASHRAE } \\
\text { Enhanced }\end{array}$ & 52691.29 & 344035.97 & $\begin{array}{c}\text { Under Estimate } \\
84.68 \%\end{array}$ & 351497.25 & 344035.97 & $\begin{array}{c}\text { Over Estimate } \\
2.17 \%\end{array}$ & \\
\hline
\end{tabular}


As in the case of the Southwest wall, a very high percentage of error in estimating the infiltration heat load is observed for the various DOE-2/eQUEST methods. The underestimation error ranges between $83.79 \%$ and $95.68 \%$. Instead, the output of the Enhanced Model is highly accurate. It had a slight tendency to overestimate the CFD analysis results in this case. However, this overestimation is limited to a maximum of $8.15 \%$. This is while maintaining a high simulation speed and a high level of simplicity and ease of use.

\section{Discussion of Results}

The previous sections closely examined the hourly and cumulative differences in infiltration heat load output for the same building envelope using different methods. The results show a vast underestimation by the different the DOE-2 engine methods in comparison with a complex multiphysics hygrothermal CFD analysis. The proposed Enhanced Model on the other hand performed very favorably and matched the CFD output with high accuracy. The sections below discuss various observations on the performance and aspects of the Enhanced Combined Heat and Air Infiltration Simulation Model. Charts 5-15 and 5-16 show for different walls the cumulative difference in kilowatts between the DOE-2/eQUEST methods, Enhanced Model, and the CFD analyses.

\section{Heat Loading Error}

The foremost reason for performing a building energy analysis is to physically quantify with a good degree of accuracy the energy demands and associated expected energy costs of a building. In previous chapters we discussed the major problems that result from an inaccurate building energy analysis. Primarily, the impact it has on 


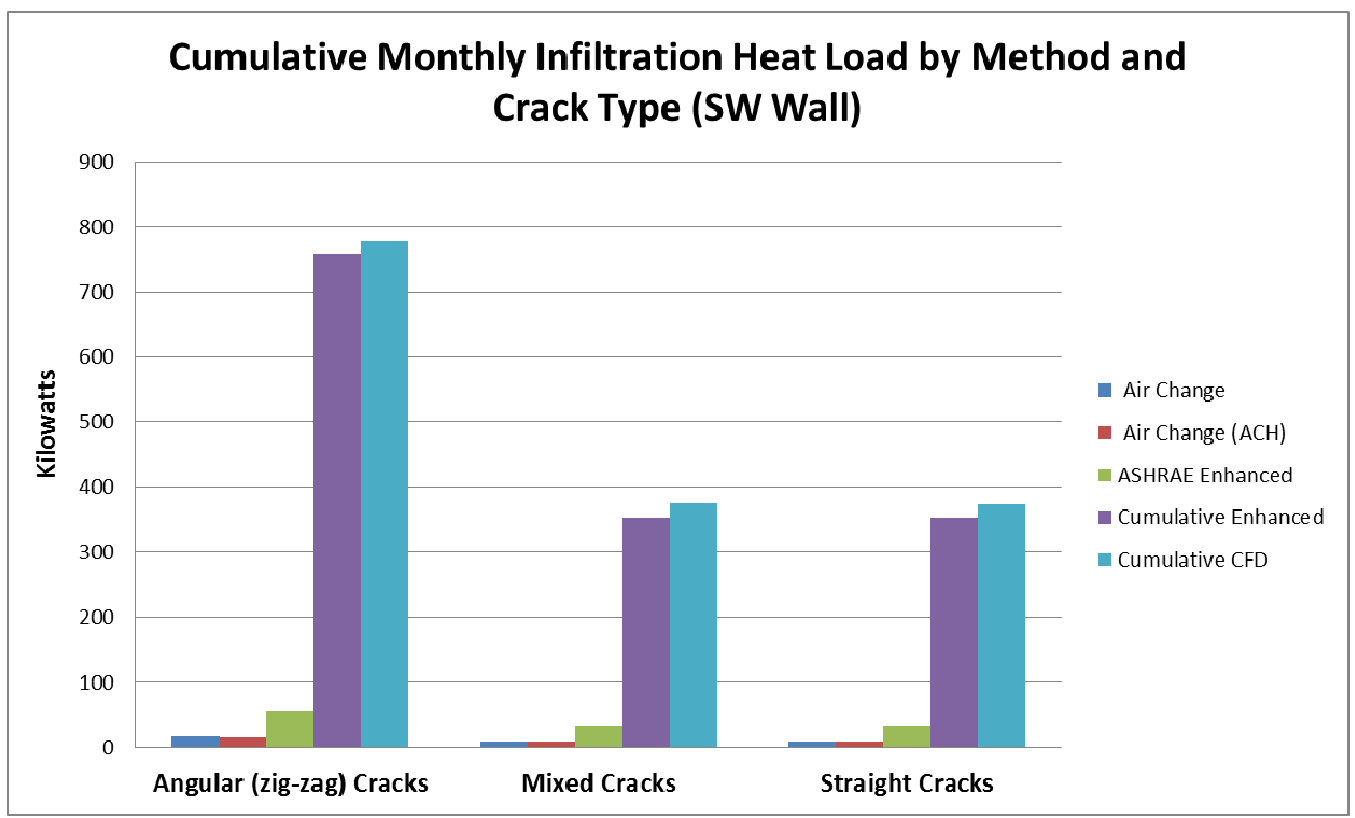

Chart 5-15: Comparison of Cumulative Monthly Infiltration Heat Load for the Southwest Wall

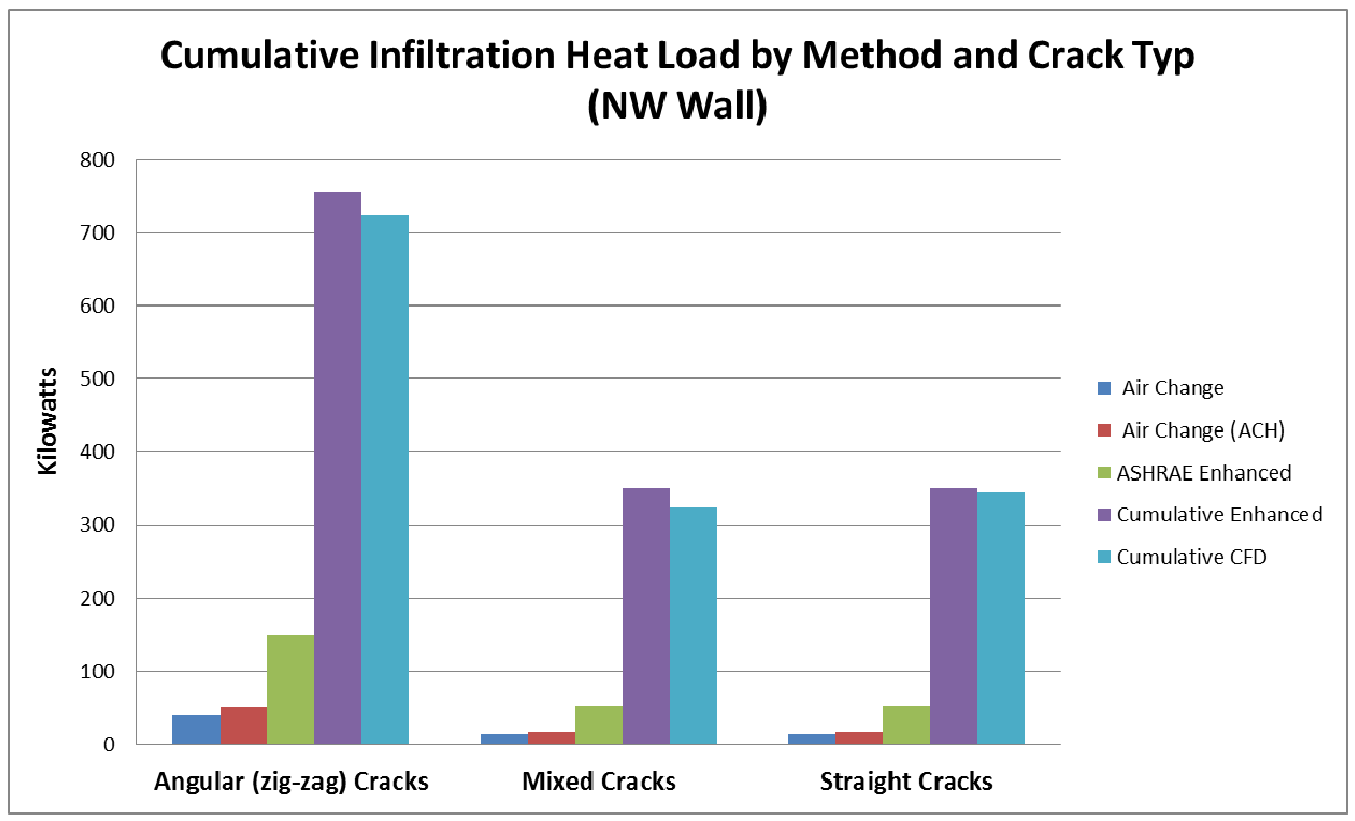

Chart 5-16: Comparison of Cumulative Monthly Infiltration Heat Load for the Northwest Wall

Note*: Cumulative CFD Data for Mixed and Straight Cracks Simulation in Charts 5-15 and 5-16 are based on 15 Days of Flow time Simulations. 
designing a building's HVAC system. As discussed, an overdesigned system results in higher than needed initial costs and in reduced efficiency during operation throughout the lifespan of a building. This results in large quantities of wasted energy and money. On the other side an underestimation of the building energy demands results in an undersized HVAC system. Consequently, the system has to run continuously in order to meet the building heating and cooling demands. In addition to the increased cost of non-stop operation, this mode of operation has a heavy toll on the mechanical aspects of the HVAC system. It results in an increased and repeated need for maintenance along with the associated increased costs. It also shortens the life span of the HVAC system and necessitates its overhaul and replacement more frequently than planned for the building's lifecycle. Table 5-8 shows in percentages and kilowatts the projected infiltration heat demand for the simulated building envelope over a month period (considering windward walls). The average overestimation error by the Enhanced Model ranges between $0.81 \%$ and $4.5 \%$. While in DOE-2/eQUEST the error ranges between $85.70 \%$ and $96.13 \%$ of underestimation depending on the method used. In terms of watts, this represents a net error of 12.15 to 65.23 kilowatts versus an error of 1241.25 to 144.36 Kilowatts respectively.

The shown error in estimating the infiltration heat load is for a 6 feet cubed building envelope. Extrapolating this error onto a full size building highlights the immense misevaluation of the building's energy demands that would be involved. For a full size family house or an office building the errors in estimating infiltration heat loads would therefore be immense. In particular when considering all the various material types, construction methods, and joints that are involved in a full size building. This error 
reflects on the overall building energy analysis results and the dependent resulting HVAC system design. The proposed Enhanced Model gives users the accuracy of a complex multiphysics CFD analysis within a maximum error of $4.5 \%$ while maintaining the high speed and ease of use of the common methods used in DOE-2 and other simulation engines.

\section{Simulation Speed}

The Enhanced Model supersedes current methods by accuracy as was shown through output analysis. But the additional characteristic feature of this model is the combination of both high calculation speed and high accuracy. Accurate methods such as the finite element CFD models developed in this research for verification purposes already exist. However as shown, these methods are extremely complex. The complexity is in all of their modeling aspects: geometry construction (cracks modeling...etc.), meshing, simulation, and extraction of results and necessary data. In the CFD models used in this research upwards of 13 million mesh elements were necessary per model in order to obtain a good quality solution. This number of elements is just for a cube-shaped building envelope with $6 \mathrm{ft}$ by $6 \mathrm{ft}$ walls. Simulating a full size building with the potential number of millions of elements required and the computing power necessary is selfprohibitive and insurmountable. High Performance Computing (HPC) power was used in simulating the CFD models in this research. Nonetheless, 248 hours of simulation were required per model. With the same analogy, the required simulation and computing power for a full size building envelope multiphysics hygrothermal simulation would be immense and unaffordable. Such a simulation could easily require months and perhaps even years to complete depending on the building size. On the other hand escaping the 
complexities of CFD analysis into faster and simplified methods has been shown to negatively affect the accuracy of simulation results and the overall building energy analysis validity in a drastic manner.

The Enhanced Model combines the accuracy of a CFD analysis and the speed of current DOE-2 infiltration calculation methods. It is able to maintain a higher than $96 \%$ level of accuracy in comparison with complex CFD analysis while requiring less than $1 \%$ of the time required for a full CFD analysis. As shown in Table 5-9 the Enhanced Model is 892,800 times faster than a multiphysics CFD analysis while maintaining an error range of less than $4.5 \%$ and resulting in $91.63 \%$ increase in accuracy over existing methods used in DOE-2 and other simulation engines, or the numerous software they power.

\begin{tabular}{|c|c|l|}
\cline { 2 - 3 } \multicolumn{1}{c|}{} & Simulation Time & \multicolumn{1}{c|}{ Notes } \\
\hline CFD Analysis & $\begin{array}{c}248 \text { hours on HPC } \\
\text { Computing }\end{array}$ & $\begin{array}{l}\text { Excluding model geometry } \\
\text { building \& meshing time }\end{array}$ \\
\hline \hline Enhanced Model & $<1$ minute & $-\quad 892,800$ times faster than CFD \\
& $-\quad$ Decreases Error by $>91 \%$ \\
\hline
\end{tabular}

Table 5-8: Simulation Speed Comparison 


\begin{tabular}{|c|c|c|c|c|c|c|c|c|c|}
\hline & & & \multicolumn{6}{|c|}{ Building Envelope Full Month Summary } & \\
\hline & & & \multicolumn{3}{|c|}{$\begin{array}{c}\text { eQUEST/DOE-2 Infiltration Load V/s CFD } \\
\text { Analysis }\end{array}$} & \multicolumn{3}{|c|}{$\begin{array}{c}\text { Enhanced eQUEST/DOE-2 Infiltration Load } \\
\text { V/s CFD Analysis }\end{array}$} & \\
\hline \multirow{12}{*}{ 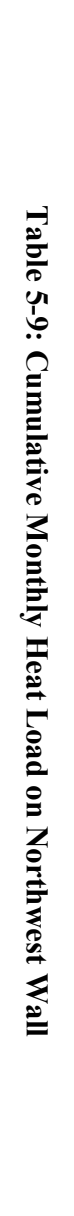 } & & & $\begin{array}{c}\text { DOE- } \\
\text { 2/eQUEST } \\
\text { (watts) } \\
\end{array}$ & $\begin{array}{l}\text { Ansys } \\
\text { (watts) }\end{array}$ & $\begin{array}{l}\text { Uner/over } \\
\text { Estimate }\end{array}$ & $\begin{array}{c}\text { Enhanced } \\
\text { Model (watts) }\end{array}$ & $\begin{array}{c}\text { Ansys } \\
\text { (watts) }\end{array}$ & $\begin{array}{l}\text { Uner/over } \\
\text { Estimate }\end{array}$ & \\
\hline & \multirow{3}{*}{ 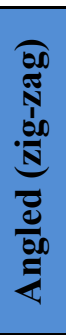 } & $\begin{array}{l}\text { Air Change } \\
\text { (base) }\end{array}$ & 58128.23 & 1501487.28 & $\begin{array}{c}\text { Under Estimate } \\
96.13 \%\end{array}$ & 1513641.01 & 1501487.28 & $\begin{array}{c}\text { Over Estimate } \\
0.81 \%\end{array}$ & \multirow{3}{*}{ 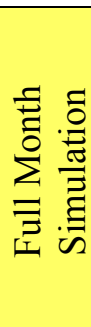 } \\
\hline & & $\begin{array}{c}\text { Air Change } \\
(\mathrm{ACH})\end{array}$ & 67705.31 & 1501487.28 & $\begin{array}{c}\text { Under Estimate } \\
95.49 \%\end{array}$ & 1513641.01 & 1501487.28 & $\begin{array}{c}\text { Over Estimate } \\
0.81 \%\end{array}$ & \\
\hline & & $\begin{array}{l}\text { ASHRAE } \\
\text { Enhanced }\end{array}$ & 207166.02 & 1501487.28 & $\begin{array}{c}\text { Under Estimate } \\
86.20 \%\end{array}$ & 1513641.01 & 1501487.28 & $\begin{array}{c}\text { Over Estimate } \\
0.81 \%\end{array}$ & \\
\hline & & & & & & & & & \\
\hline & \multirow{3}{*}{ 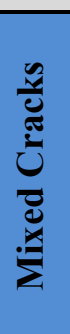 } & $\begin{array}{l}\text { Air Change } \\
\text { (base) }\end{array}$ & 58128.23 & 1448414.79 & $\begin{array}{c}\text { Under Estimate } \\
95.99 \%\end{array}$ & 1513641.01 & 1448414.79 & $\begin{array}{c}\text { Over Estimate } \\
4.50 \%\end{array}$ & \multirow{3}{*}{ 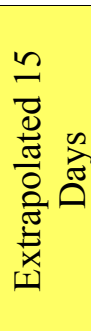 } \\
\hline & & $\begin{array}{l}\text { Air Change } \\
\text { (ACH) }\end{array}$ & 67705.31 & 1448414.79 & $\begin{array}{c}\text { Under Estimate } \\
95.33 \%\end{array}$ & 1513641.01 & 1448414.79 & $\begin{array}{c}\text { Over Estimate } \\
4.50 \%\end{array}$ & \\
\hline & & $\begin{array}{l}\text { ASHRAE } \\
\text { Enhanced }\end{array}$ & 207166.02 & 1448414.79 & $\begin{array}{c}\text { Under Estimate } \\
85.70 \%\end{array}$ & 1513641.01 & 1448414.79 & $\begin{array}{c}\text { Over Estimate } \\
4.50 \%\end{array}$ & \\
\hline & & & & & & & & & \\
\hline & \multirow{3}{*}{ 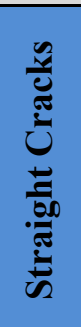 } & $\begin{array}{l}\text { Air Change } \\
\text { (base) }\end{array}$ & 58128.23 & 1485081.55 & $\begin{array}{l}\text { Under Estimate } \\
\quad 96.09 \%\end{array}$ & 1513641.01 & 1485081.55 & $\begin{array}{c}\text { Over Estimate } \\
1.92 \%\end{array}$ & \multirow{3}{*}{ 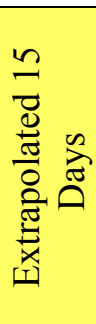 } \\
\hline & & $\begin{array}{c}\text { Air Change } \\
(\mathrm{ACH})\end{array}$ & 67705.31 & 1485081.55 & $\begin{array}{c}\text { Under Estimate } \\
95.44 \%\end{array}$ & 1513641.01 & 1485081.55 & $\begin{array}{c}\text { Over Estimate } \\
1.92 \%\end{array}$ & \\
\hline & & $\begin{array}{l}\text { ASHRAE } \\
\text { Enhanced }\end{array}$ & 207166.02 & 1485081.55 & $\begin{array}{c}\text { Under Estimate } \\
86.05 \%\end{array}$ & 1513641.01 & 1485081.55 & $\begin{array}{c}\text { Over Estimate } \\
1.92 \%\end{array}$ & \\
\hline
\end{tabular}




\section{Enhanced Model Ease of Use}

The advantage of DOE-2, eQUEST, energyPlus, energyPro and others is their ease of use. Especially easy are the software with a GUI interface such as eQUEST. This ease of use is a major driving force behind making these software extremely popular and widely used in building energy analysis and design.

The Enhanced Model as shown in Figure 5-1 and in previous figures has a very easy to use and user friendly interface. It only requires basic and readily available input coefficients. In contrast, other methods (such as ASHRAE Enhanced) require input that can only be obtained through costly experimental testing of the fully built building. For optimal benefit, building energy analysis is however usually performed during the design phase of a building rather than post construction. This drives users and designers to resort to a limited list of tabulated generic coefficients and data for use in analyses input. And results in dramatic inaccuracies in studying the building energy performance as has been demonstrated in this research.

In addition to the ease of use, simple interface, and quick simulation performance, the Enhanced Model can be easily integrated into existing simulation engines. The model's enhanced algorithm can be adopted and integrated into the hourly calculations of DOE-2, eQUEST and other similar programs as demonstrated in this research. Especially that all the hourly input values necessary for the Enhanced Model's calculations are already a part of the DOE-2 engine and other simulation engines' hourly calculations rather than being an added calculation load. 


\section{Infiltration Heat Recovery}

The phenomenon of infiltration heat recovery was discussed in Chapters 1 and 2. Conductive heat flowing through the building envelope interacts with air infiltrating through leakage paths in the envelope walls. This heat exchange allows the heating of cold infiltrating outside air as it leaks through the envelope into the building interior. This effect is reversed during the cooling season as discussed in Chapter 2. By the time the infiltrating air reaches the building interior its temperature is considerably warmer than its original outside air temperature.

The classical theory for evaluating infiltration heat loads was discussed in Chapters 1 and 2. It assumes that the temperature of infiltrating air remains equivalent to that of the outside air temperature. The outside ambient temperature is then used in calculating the inside/outside air temperature gradient used in calculating infiltration heat loads. However, due to the effect of heat recovery infiltrating air is expected to have a temperature closer to the indoor air temperature rather than the outside air temperature. Thus, using the outside air temperature in heat loading calculations results in errors in estimating the infiltration heat load. In our multiphysics hygrothermal CFD models we aimed at examining and validating the heat recovery phenomena. Our true multiphysics models allow a realistic evaluation of this phenomenon and its effect. Especially that these CFD simulations are of a full scale enclosed building envelope rather than of isolated portions of a standalone wall model.

The presence of heat recovery is clearly observed in the CFD simulations. All temperature contour plots taken at various lateral sections across each of the CFD models reveal the presence of air heating as air infiltrates through the building envelope. As 
infiltrating air approaches the inner surface of the building envelope its temperature is observed to be significantly higher than its original outside ambient air temperature. In some instances it's observed to be very close and within few degrees from the indoor air temperature. A streamline is plot along the centerline of an individual straight crack across the building envelope. Chart 5-17 represents a plot of the rise in the infiltrating air temperature along this streamline as it flows across the building envelope. The variation in the flow velocity of the infiltrating air as it flows across the building envelope is shown in Chart 5-18. As shown in Chart 5-17, the air's temperature rises to within 5 degrees from the indoor air temperature.

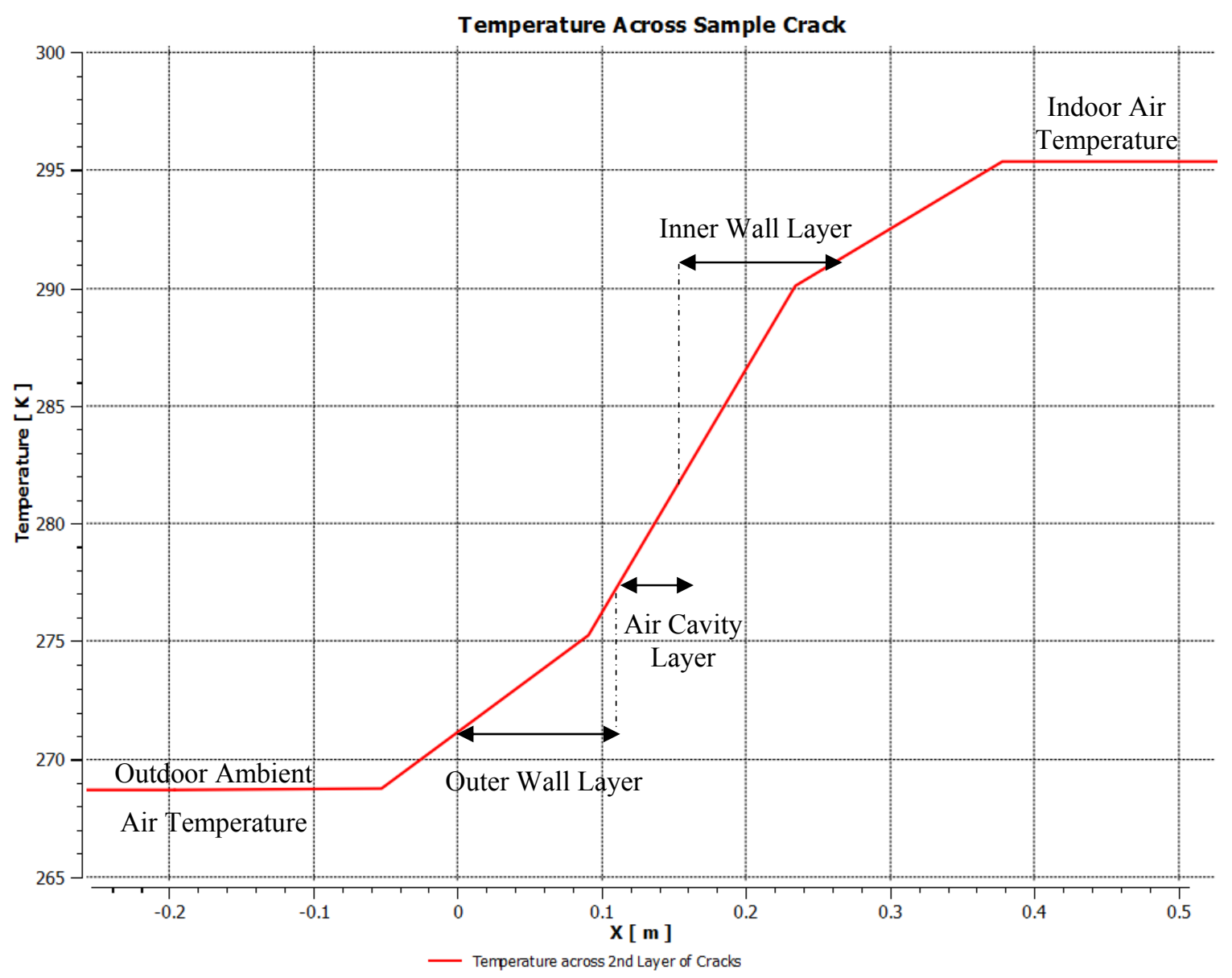

Chart 5-17: Infiltrating Air Temperature Rise Across the Building Envelope 
Figures 5-1 to 5-3 are of temperature contour plots for various CFD models of various crack types and at various lateral section heights. Examining the air temperature variation as it flows through the leakage cracks reveals a gradual rise in the infiltrating air temperature. This is particularly observed as the air flows past the inner wall cavity and through the inner layer of the cavity wall. In parallel, Figures 5-4 to 5-7 show examples of the velocity and airflow vectors highlight air leakage flow through the cracks in the building envelope into the building interior. Both, Lateral and Vertical sample section plots are presented.

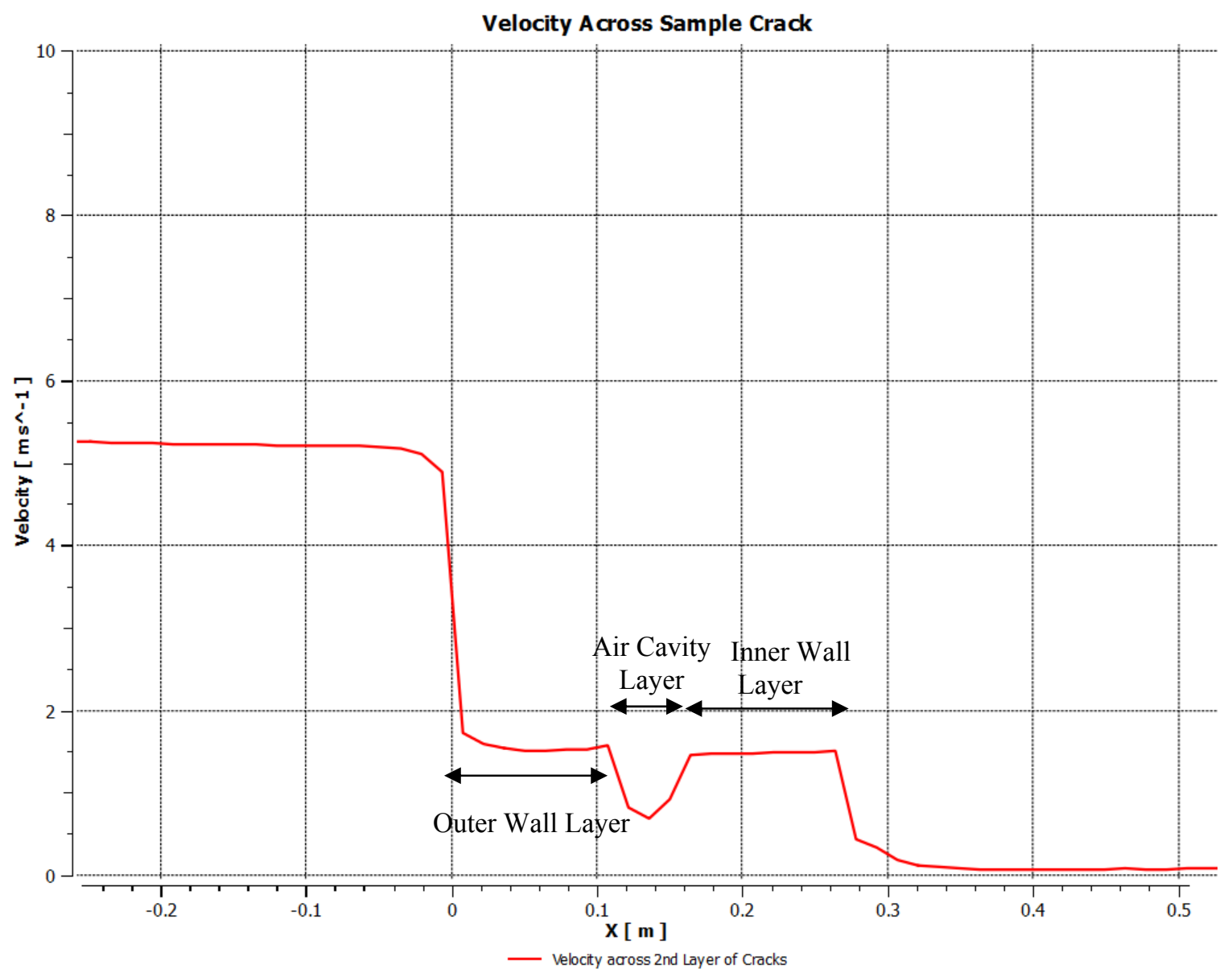

Chart 5-18: Infiltrating Air Velocity Drop Across the Building Envelope 


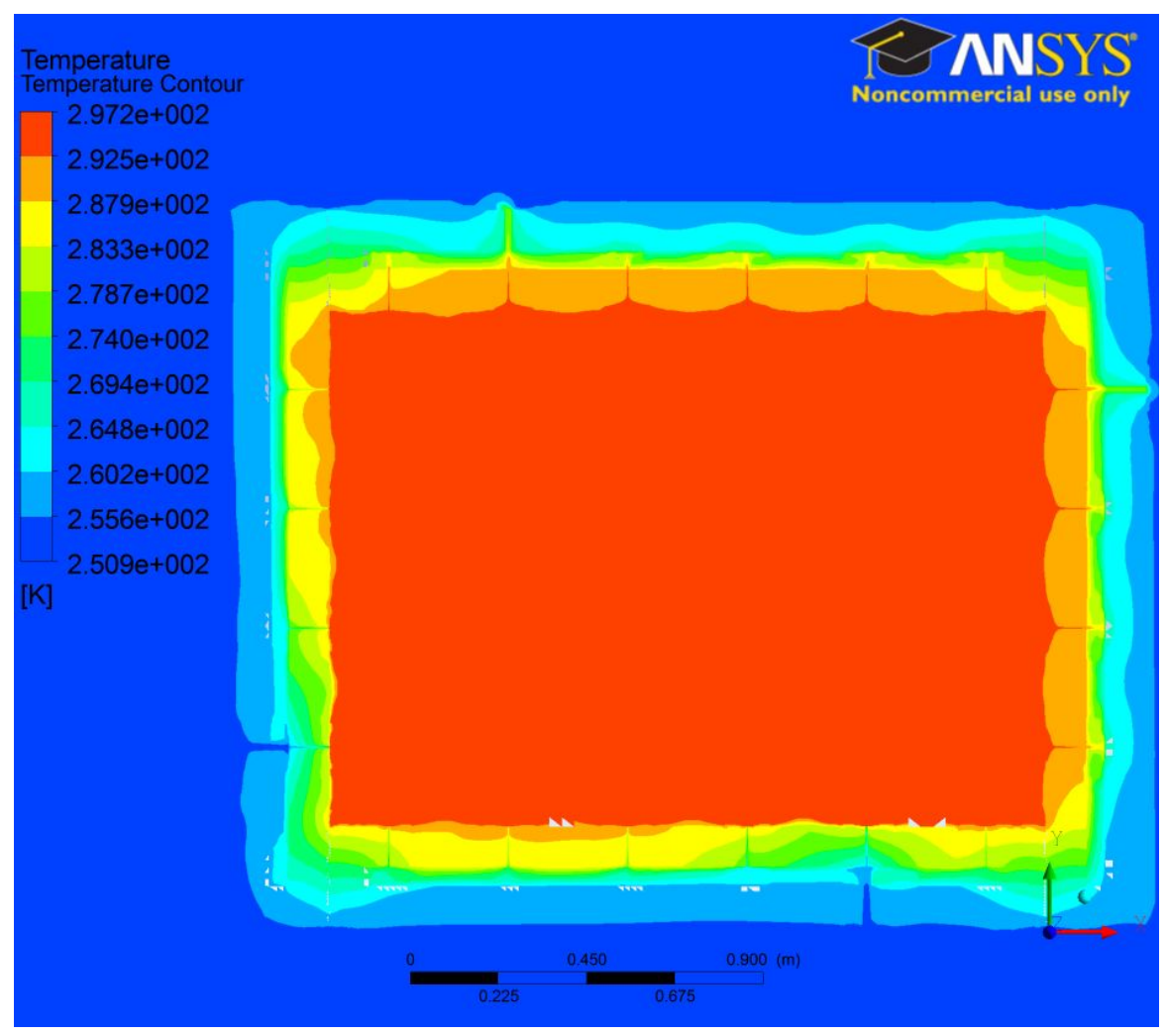

Figure 5-1: Lateral-Section Temperature Contour Plot Across a CFD Model with Angled (Zig-Zag) Cracks

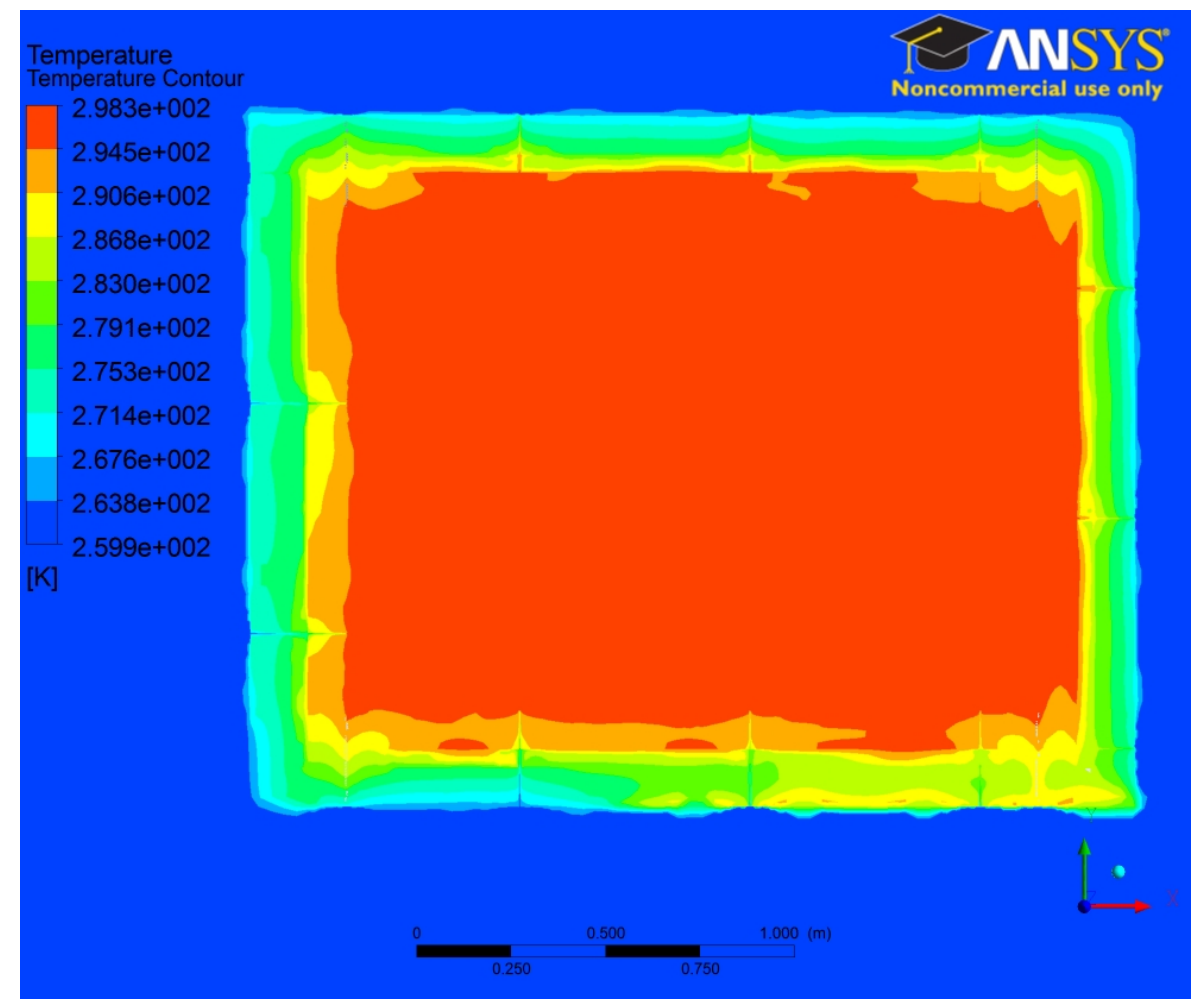

Figure 5-2: Lateral-Section Temperature Contour Plot Across a CFD Model with Mixed Cracks 


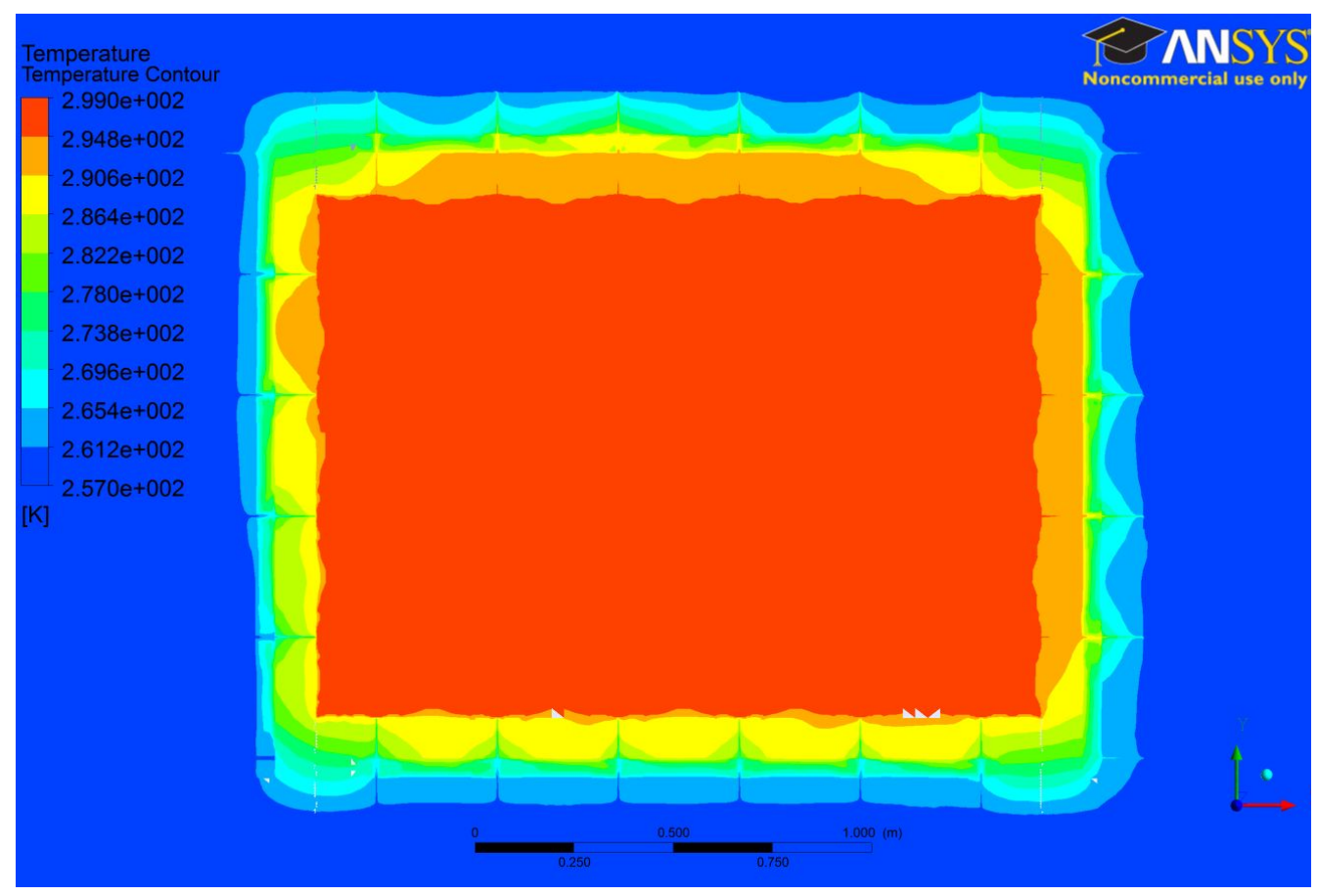

Figure 5-3: Lateral-Section Temperature Contour Plot Across a CFD Model with Straight Cracks

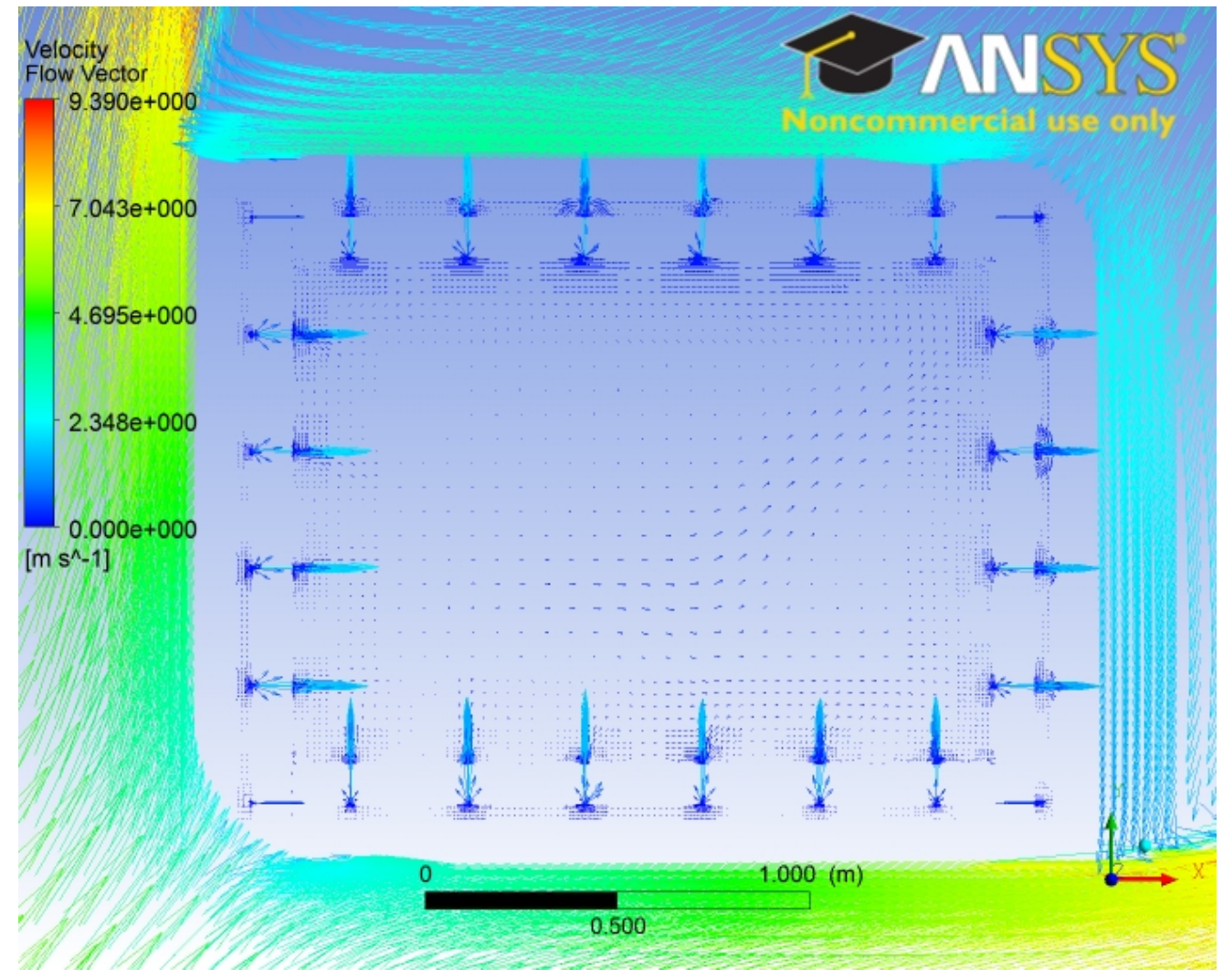

Figure 5-4: Lateral-Section Velocity Vector Plot Across a CFD Model with Angled (zig-zag) Cracks 


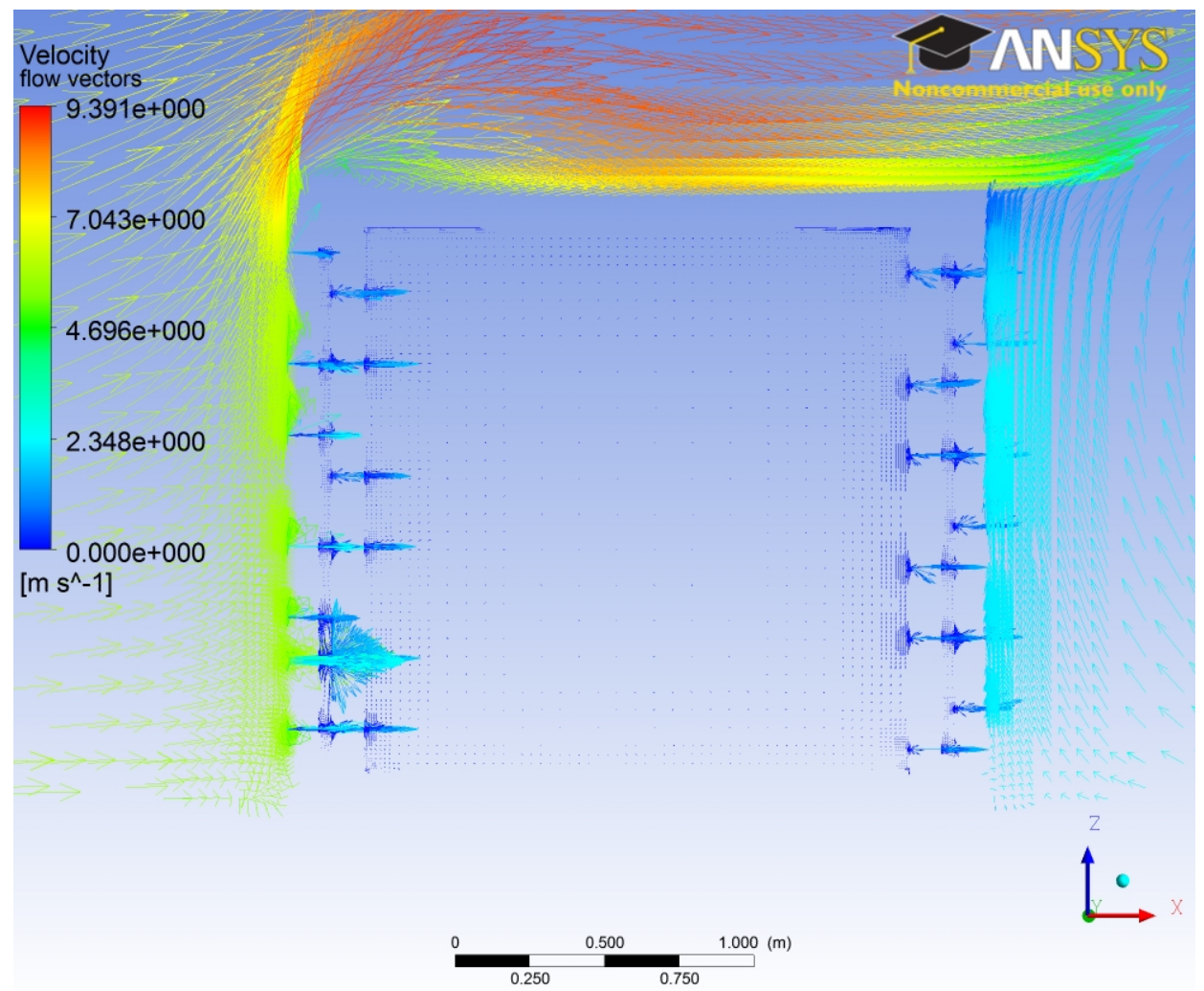

Figure 5-5: Vertical-Section Velocity Vector Plot Across a CFD Model with Mixed Straight and Angled Cracks

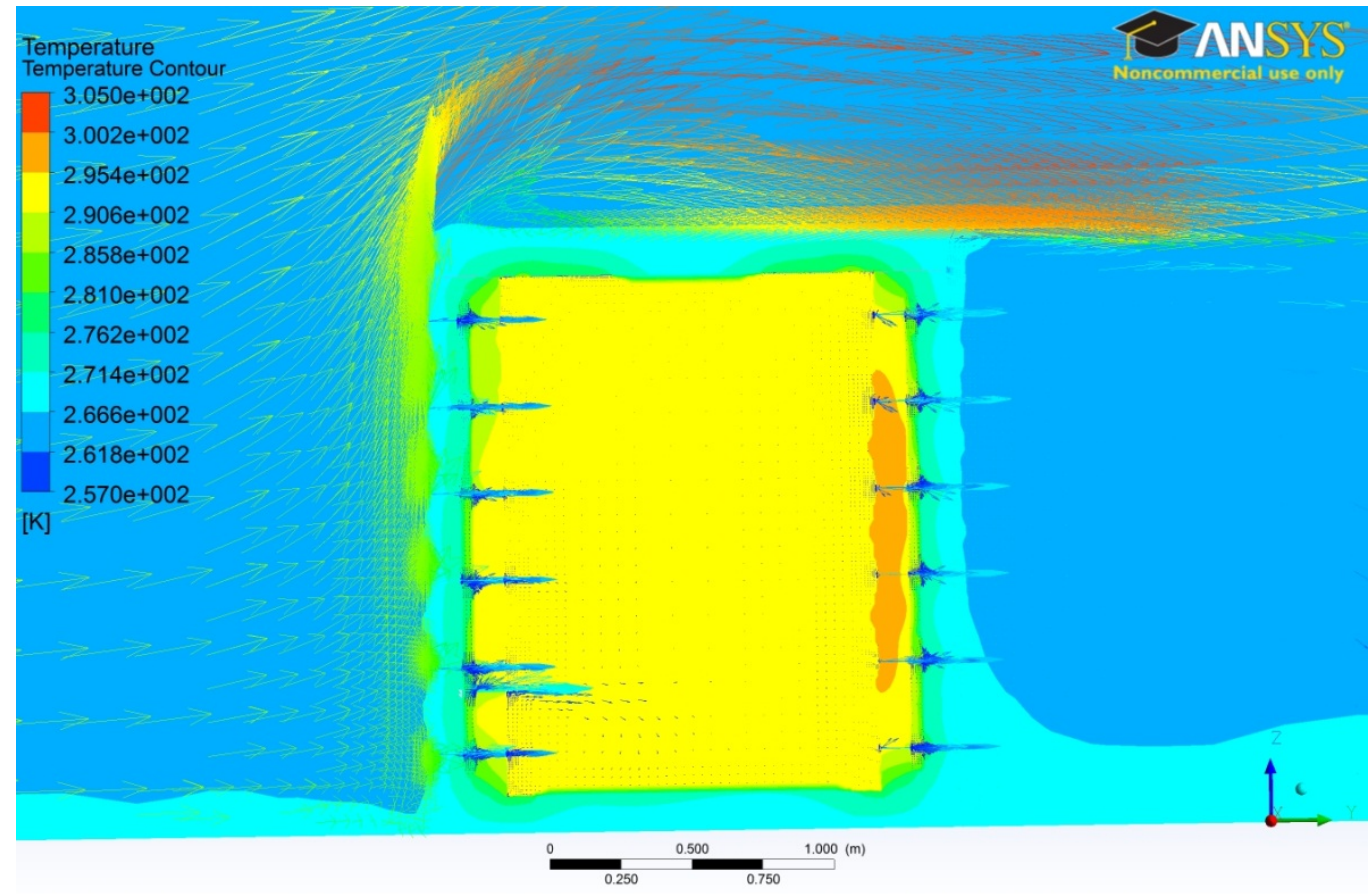

Figure 5-6: Vertical-Section Combined Velocity Vector and Temperature Contour Plot Across a CFD Model with Straight Cracks, with the Effect of Solar Heating Showing on the Envelope's Southern Wall 


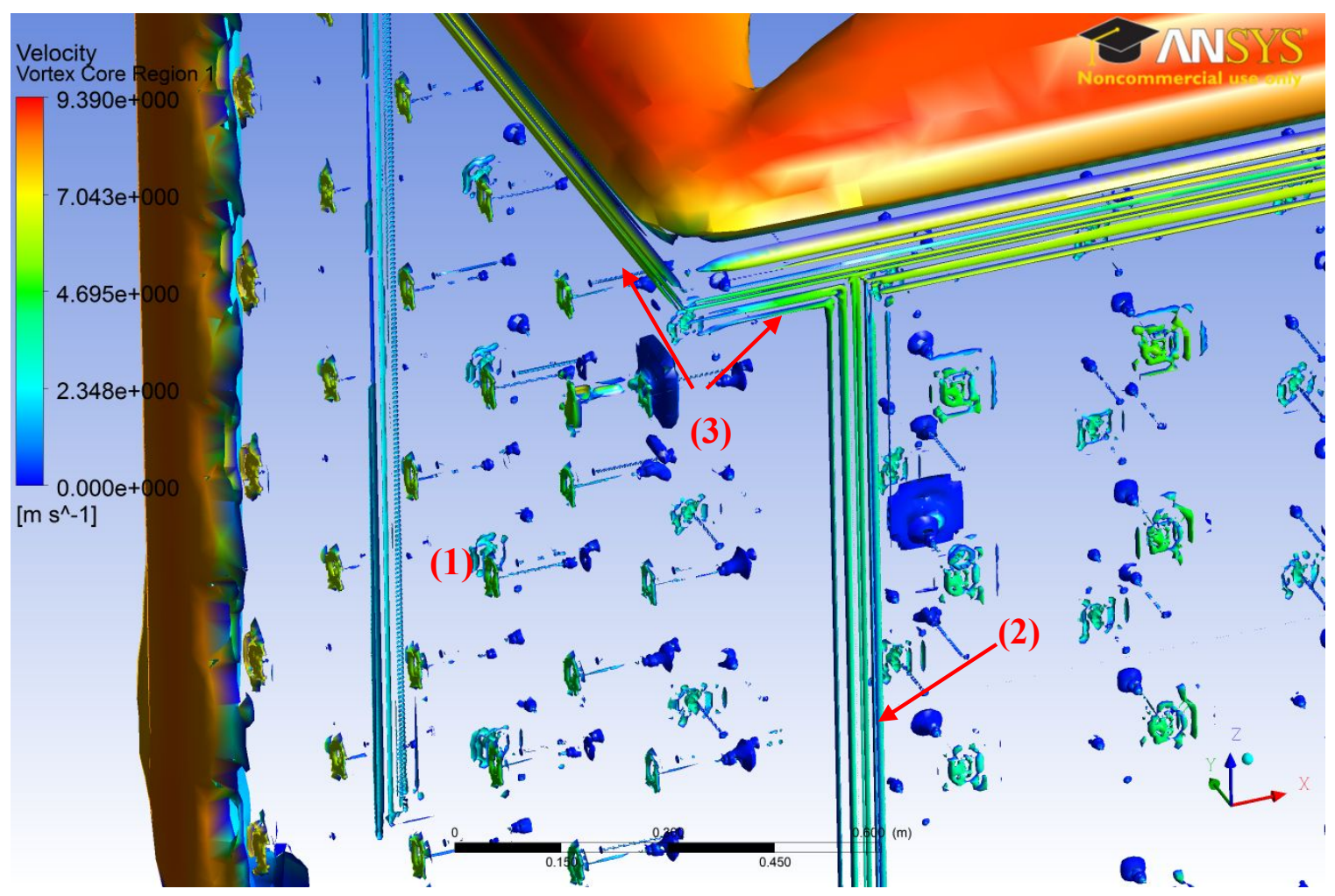

Figure 5-7: Vortex Plot Revealing Air Leakage Across In-wall Caracks (1), Corner Cracks (2) and Ceiling Joint Cracks (3) 


\section{Chapter 6}

\section{Conclusions and Recommended Future Work}

Energy efficiency in general and building energy efficiency and design sustainability in particular continue to emerge as an increasingly critical concern. This is leading to an increasing need for tools to evaluate the energy demand and life span energy costs in buildings. As a result a large number of building energy analysis programs have been and continue to be developed and improved. These tools range between simple databases, component specific analysis tools, spreadsheets, and full building energy analysis programs. Advanced programs among these various tools provide detailed hourly energy analyses in buildings. In their analyses they account for various heat transfer phenomena including convection, conduction and incident solar heat. The ease of use and quick simulation speeds make them very popular among building energy modelers. They facilitate obtaining an energy demand analysis and facilitate performing parametric analyses that compare the energy efficiency of various design alternatives.

The primary reason for performing a building energy analysis is to obtain a solid understanding of a building's energy needs. This is particularly critical for designing an efficient HVAC system. As discussed in detail in Chapters 2 and 5, it is extremely critical and cost-wise significant to have a properly sized HVAC system. Expected life cycle energy costs are a leading driver of the need for a building energy analysis. The ability to study the efficiency of various design alternatives on energy demand is extremely essential for designers. It permits designers to reach a design that meets the building's 
occupancy needs while optimizing its expected energy demand. This results in life time cost savings while insuring a comfortable living and working environment.

DOE-2 is a leading building energy analysis program. It is well known, widely used, and considered to be a standard for building energy simulation engines and software. DOE-2's powerful simulation engine has also been evolved to be incorporated into later and similarly popular energy simulation programs. A prominent example is eQUEST. It is based on the DOE-2 engine and coupled with wizards and graphics that facilitate its use through a GUI interface. The widespread use of these programs makes them of high significance and impact. Most importantly, it highlights the need for a high level of accuracy and reliability in their building energy simulations.

Building air leakage is a natural uncontrolled phenomenon in buildings. Air infiltration and leakage in buildings depends on various aspects of the building envelope. Construction materials and adopted construction methods are a primary factor. They provide the paths that allow air leakage through the building envelope. Air infiltration is primarily driven by the wind pressure on a building face and by other factors compiled as a driving stack pressure (stack effect). As discussed in Chapter 2, the energy toll of infiltration can represent as much as $50 \%$ of the total energy demand in a building.

The experimentally proven significant energy impact of air infiltration was a driving reason for investigate current methods for calculating air infiltration energy loads on buildings. A primary source of interest are the methods utilized in widely used simulation engines such as DOE-2. After these methods' accuracy is evaluated, an enhanced infiltration load calculation method to improve accuracy was to be developed if 
deemed necessary. The developed Enhanced Model would also be easy to adopt and incorporate into other software and energy simulation models.

In order to verify the accuracy of both the existing models and the proposed model's experimental data is necessary. Due to the lack of experimental data, a Multiphysics Hygrothermal CFD model was developed and used to provide the necessary verification data. The constructed model is based on actual experimentally obtained building properties and data. Hundreds of representative cracks were embedded into the various components of the building envelope. The cracks quantification is based on experimental databases such as the AIVC database, on data obtained from research on cracking in buildings, and on available ASHRAE data. Considered factors in the multiphysics CFD model include: solar radiation, variable outside temperature, wind velocity, variable material properties, thermostat settings, construction methods, and others. Three main CFD models are constructed reflecting the different variations of cracking patterns in building envelopes.

Transient hourly analysis on the CFD models versus DOE-2/eQUEST analyses results revealed large inaccuracies in calculated infiltration loading in these simulation engines. Several of the methods available in DOE-2 where simulated and compared with CFD analyses results. The methods ranged between the basic Air Change method and the more advanced ASHRAE Enhanced method. As discussed in detail in Chapter 5, underestimation of infiltration heat loading by these methods ranged between $85.70 \%$ and $96.13 \%$ (underestimation error).

Developing and enhanced infiltration load calculation model was therefore deemed necessary. The model has to improve infiltration heat loading calculations 
accuracy. It also has to maintain the speed and ease of use advantage of current methods versus complex CFD analysis. A combined conduction, air infiltration, and solar radiation model was developed. The model accounts for heat recovery and exchange. This heat interaction occurs as air leaks through the walls of the building envelope. The Enhanced Model also considers the effect of solar air heat. Finally, it performs hourly heat load calculation in accordance with advanced full hourly building energy analysis programs such as DOE-2.

The Enhanced Model resulted in a $91.63 \%$ increase in the relative accuracy of calculated building infiltration loads. As discussed in details in Chapter 5, the relative error in heat loading calculations was reduced to a below $4.5 \%$ when compared to all CFD analyses results. Another important aspect is the ability of the Enhanced Model to maintain the speed and ease of use characteristics of current methods. The Enhanced Model closely attains the simulation results of a complex multiphysics hygrothermal CFD analysis while requiring less than $1 \%$ of the time necessary to run a CFD analysis.

In conclusion, the developed Enhanced Model for combined heat and air infiltration simulation is successful. It meets all the stated requirements of increased accuracy, ease of use, and speed of calculations. The developed algorithms are easy to apply into any other building energy simulation program in the same manner as demonstrated in this research on the DOE-2 engine through eQUEST.

Improving by $91.63 \%$ the relative accuracy of calculating a component that represents $40 \%$ to $50 \%$ of the energy demand in buildings is extremely significant. This improvement in calculating building infiltration heat loads will help designers design more efficient building HVAC systems. It also paves the path for incorporating more 
sustainable building design practices and components. Examples include controllable ventilation rates, optimal insulation distribution, effective utilization of solar energy, healthier building indoor environments, and others.

\section{Fulfilled Research Objectives}

The main objective of this research was broken down into five specific objectives that needed to be fulfilled to meet the main objective of this work. In Chapter 2 a comprehensive review of infiltration and how it is accounted for in current models and in prominent building energy simulation software was performed. Also was a study of the latest research on studying the interaction between infiltration, conduction and solar radiation. Objective two was also met by developing a Mass Flow rate model in Chapter 3 and implementing it in the Visual Basic built program and interface we presented in Chapter 5. Similarly the third objective was met by building a Visual Basic program and interface based on the algorithms and equations of the Enhanced Model presented in Chapter 3. Another achievement of this research was to develop a geometry building technique, a meshing method, and a simulation approach for performing full 3D multiphysics hygrothermal CFD simulations of air leakage in building envelopes. This also allowed obtaining the data necessary to calibrate and validate the relative accuracy of the developed enhanced model in accordance with objective four of this research. In Chapter 5 the relative accuracy (versus the complex CFD analysis) of the developed Enhanced Model was compared to the relative accuracy of current DOE-2 methods in calculating infiltration heat loads. As discussed previously in detail, the Enhanced Model achieved less than $4.5 \%$ relative error versus the results of a complex CFD analysis while requiring less than $1 \%$ of time necessary for performing a CFD analysis. This 
represented up to $91.63 \%$ improvement in relative accuracy versus currently available methods and a fulfillment of the fifth objective of this research.

\section{Recommended Future Work}

In this research, the accuracy of the developed enhanced model was verified relative to a developed multiphysics hygrothermal CFD model. A critical follow up research to this work would be to perform experimental validation. The same test case simulated by the three models (DOE-2, Enhanced Model, and CFD) would be constructed with identical construction characteristics and material and then tested experimentally. The built envelope should be instrumented with necessary data collection devices to obtain all the required experimental data. This could be done in a full scale testing facility with capabilities to induce variable wind flow along with a heat source representing solar radiation. The Wall of Wind experimental testing facility at Florida International University is an ideal facility for performing these experimental tests. It allows subjecting a building envelope to a variable wind velocity, at variable wind angles (wind direction), with adjustable heat elements to represent solar radiation for variable longitudes and latitudes. The collected experimental data will help calibrate and validate the developed Enhanced Model. This is essential for supporting the use of the Enhanced Model as a new and more accurate method for evaluating infiltration heat loads. The experimental data can also be used to validate the CFD analyses performed. As discussed previously, special techniques for building, meshing and simulating 3D multiphysics hygrothermal CFD simulations of air infiltration were developed in this work. Experimentally validating this methodology for 3D CFD simulations of air infiltration 
allows for higher confidence in the results of CFD analyses of air infiltration. Once validated experimentally these CFD analyses can be more confidently used in further research as a more cost and time efficient alternative to experimental testing.

Further research also should include testing the enhanced model and also performing CFD analyses for a test case located in a different climate. The current test case was located in Fargo, North Dakota in a cold, windy and snowy climate. The location for a future test case could be in a city with a warmer or subtropical weather. This will help validate the relative accuracy of the Enhanced Model in various climates. Most importantly, it will also highlight the role of the solar radiation as part of the interaction of the various heat phenomena, as discussed in this research and defined in the Enhanced Model's equations and algorithm. 


\section{References}

U.S. Energy Information Administration. (2009). Annual Energy Outlook 2010. Retrieved September 2010, from U.S. Energy Information Administration.

U.S. Energy Information Administration. (2010, September). Energy Overview. Retrieved September 2010, from U.S. Energy Information Administration/ Monthly Energy Review September 2010: http://www.eia.doe.gov/mer/overview.html

Achenbach, P. R., \& Coblentz, C. W. (1963). Field Measurement of Air Infiltration in Ten Electrically Heated House. ASHRAE Transactions , 358-365.

Allard, F., \& Herrlin, M. (1989). Wind-induced ventilation. ASHRAE Transactions , 95 (2), 722-728.

American Society of Heating, Refrigerating, and Air-Conditioning Engineers, Inc. (1977). Chapter 25. In R. a.-C. American Society of Heating, ASHRAE Handbook and Product Directory, 1977 Handbook of Fundamentals. New York, NY: American Society of Heating, Refrigerating, and Air-Conditioning Engineers, Inc.

American Society of Heating, Refrigeration, and Air-Conditioning Engineers. (1977). ASHRAE 1977 Hanbook of Fundamentals. New York: American Society of Heating, Refrigeration, and Air-Conditioning Engineers.

American Society of Heating, Refrigetrating and Air-Conditioning Engineers. (2009). Chapter 16 : Ventilation and Infiltration. In 2009 ASHRAE Handbook - Funamentals (pp. 16.1 - 16.36). Atlanta, GA: American Society of Heating, Refrigerating and AirConditioning Engineers, Inc.

American Society of Heating, Refrigetrating and Air-Conditioning Engineers. (2007). Chapter 43 : Building Envelopes. In 2007 ASHRAE Handbook - HVAC Applications (pp. 43.1 - 43.12). Atlanta, GA: American Society of Heating, Refrigerating and AirConditioning Engineers, Inc.

Anderlind, G. (1985). Energy consumption due to air infiltration. Proceedings of the 3rd ASHRAE/DOE/BTECC Conference on Thermal Performance of Exterior Envelopes of Buildings, (pp. 201-208). Clear Water Beach, FL.

Anon. (1937). Fireplace - Does it add to or subtract from the total heat ? Domestic Engineers , 149 (1), 85-93.

ANSYS ${ }^{\circledR}$ Academic Research, Release 14.0, Help System, ANSYS, Inc., 2011]

Arasteh, D. K., Selkowitz, S., \& Hartman, J. (1985). A versatile procedure for calculating heat transfer through windows. Proceedings of the 3rd ASHRAE/DOE/BTECC 
Conference on Thermal Performance of Exterior Envelopes of Buildings, (pp. 830-845). Clear Water Beach, FL.

Arquis, E., \& Langlais, C. (1986). What Scope for Dynamic Insulation ? Batiment International Building Research and Prectice, 19, 84-93.

ASHRAE Task Group on Energy Requirements for Heating and Cooling of Buildings. Procedure for Determining Heating and Cooling Loads for Computerizing Energy Calculations. Algorithms for Building Heat Transfer Subroutines. (M. Lokmanhekim, Ed.) New York, NY: American Society of Heating, Refrigerating, and Air-Conditioning Engineers, Inc.

Automated Procedures for Engineering Consultants, Inc. (November 1967). HCCHeating/Cooling Load Calculation Program. Dayton, Ohio.

Bailly, N. R. (1987). Dynamic Systems and Energy Conservation in Buildings. ASHRAE Transactions , 93 (1), 447-466.

Beyea, J., Dutt, G., \& Wotecki, T. (1977). Critical Significance of Attics and Basements in the Energy Balance of Twin Rivers Townhouses. Energy and Buildings , 1, 261-269.

Bhattacharyya, S. (1999). Modelling and the phenomenon of infiltration heat exchange. International journal of power \& energy systems , 19 (1), 87-91.

Bhattacharyya, S., \& Claridge, D. E. (1995). Energy impact of air leakage through insulated walls. Journal of Solar Energy Engineering , 117 (3), 167-172.

Bhattacharyya, S., \& Claridge, D. E. (1992). The energy impact of air leakage through insulated walls. Solar Engineering , 1, 451-458.

Blomsterberg, A. K., \& Harrje, D. T. (1979). Approaches to evaluation of air infiltration energy losses in buildings. ASHRAE Trasactions, 85 Part I, 797.

Blomsterberg, A. K., \& Harrje, D. T. (1979). Reduction of Air Infiltration Due to Window and Door Retrofits in an Older Homes, Report PU/CEESS 85. Princeton University, Center of Environmental Studies.

Bobenhausen, W. (1994). Heat Loss from Buildings. In W. Bobenhausen, Simplified Design of HVAC Systems (pp. 63-93). U.S.A.: John Wiley \& Sons, Inc.

Brownell, C. (2002). Infiltration Heat Recovery.

Buchanan, C. R., \& Sherman, M. H. (2000). A Mathematical Model for Infiltration Heat Recovery, LBNL-44294. Lawrence Berkeley National laboratory, Indoor Environment Department. 
Buchanan, C. R., \& Sherman, M. H. (September 28-30, 1998). CFD Simulation of Infiltration Heat Recovery. Proceedings of the 19th AIVC Annual Conference on Ventilation Technologies in Urban Areas. Oslo, Norway.

Building Energy Software Tools Directory: DOE-2. (2008, Month August). Retrieved October 4, 2010, from DOE-2:

http://apps.1.eere.energy.gov/buildings/tools_directory/software.cfm/ID $=34$

Building Energy SOftware Tools Directory: eQuest. (2008, August 8). Retrieved October 4, 2010, from eQUEST:

http://apps.1.eere.energy.gov/buildings/tools_directory/software.cfm/ID=575

Boussa, H., Tognazzi-Lawrence, C., \& La Borderie, C. (2001). A model for computation of leakage through damaged concrete structures. Cement \& Concrete Composites, 23 (2001), 279-287

Building Technologies Program: Building Energy Software Tools Directory. (2010, September 9). Retrieved October 4, 2010, from http://apps.eeere.energy.gov/building/tools_directory

Burns, P., \& Deru, M. (2003). Infiltration and Natural Venditaltion Model for WholeBuilding Energy Simulation of Residential Buildings NREL/CP-550-33698. Midwest Research Institute. National Renewable Energy Laboratory.

Caffey, G. E. (1979). Residential Air Infiltration. ASHRAE Transactions , 85, 919-926.

Chebil, S., Galanis, N., \& Zameureanu, R. (2003). Computer Simulation of Therml Impact of Air Infiltration Through Multilayered Exterioir Walls. Proceedings of the Eighth International IBPSA Conference. Eindhoven, Netherlands, 2003

Claridge, D. E., \& Bhattacharyya, S. (1990). The Measured Energy Impact of "Infiltration" in a Test Cell. ASME Journal of Solar Energy Engineering, 112, 132-139.

Claridge, D. E., \& Bhattacharyya, S. (April 1989). The measured energy impact of "infiltration" in a test cell. Proceedings of the Eleventh Annual ASME Solar Energy Conference. San Diego, CA.

Claridge, D. E., \& Liu, M. (1996). The measured Energy Impact of Infiltration in an Outdoor Test Cell. Journal of Solar Energy Engineering , 118 (3), 162-167.

Claridge, D. E., Jeon, H., \& Bida, M. (1985). A Comparison of Traditional Degree-Day and Variable-Base Degree-Day Prediction with Measured Consumption of 20 Houses in the Denver Area. ASHRAE Transactions , 91 (2), 865-874. 
Claridge, D. E., Liu, M., \& Bhattacharyya, S. (1995). Impact of air infiltration in frame walls on energy loads: taking advantage of the interaction between infiltration, solar radiation, and conduction. ASTM Special Technical Publication (1255), 178-196.

Clarke JA, Dempster WM and Negrao COR (1995) The implementation of a computational fluid dynamics algorithm within ESP-r system. Building Simulation 95 Coference, Madison, Wisconsin, USA, August 14-16.

Cole, J. T., Zawacki, T. S., Elkins, R. H., Zimmer, J. W., \& Macriss, R. A. (1980). Application of a generalized model of air infiltration to existing homes. ASHRAE Transactions , 86 (2), 765.

Crall, C. (1983). Development of the Air Infiltration Morel for the Energy Performance Desigh System. ASHRAE Transactions , 89 (2), 201-210.

Danko, G., \& Bahrami,D. (July 2004). Heat and Moisture Flow Simulation with Multiflux. Proceedings of ASME Heat Transfer/Fluid Engineering. July 11-15, 2004, Charlotte, North Carolina, USA

Dickerhoff, D. J., Grimsrud, D. T., \& Lipshutz, R. D. (1982). Componenet leakage testing in residential buildings, Report LBL 14735. Proceedings of the American Council for an Energy-Efficient Economy, 1982 Summer Study, Santa Cruz,CA, Lawrence Berkeley National Laboratory, Berkeley, CA.

Dickson, D. J. (1988). Infiltration rates in low energy house with a fireplace. The International Journal of Research, Development and Demonstration , 21 (4), 237-245.

DOE2.com Home Page. (2010). Retrieved October 4, 2010, from Welcome to DOE2.com The Home of DOE-2 Based Building Energy Use and Cost Analysis Software: http://www.doe2.com

Duffet-Smith, P. (1988). Prectical astronomy with your calculator (Third Edition ed.). Cambridge, Great Britain: Cambridge University Press.

Elkins, R. H., \& Wensman, C. E. (February 28- March 3, 1971). Natural Ventilation of Modern Tightly Constructed Homes. Paper presented at the American Gas Association Institute of Gas Technology, Conference on Natural Gas Research and Technology. Chicago, Illinois.

eQUEST. (2010). Retrieved October 4, 2010, from eQUEST the Quick Energy Simulation Tool: http://doe2.com/equest/index.html

Etheridge, D. W. (1977). Crack flow equations and scale effect. Building and Environment , 12, 181. 
Etheridge, D. W. (1988). Modeling of air infiltration in single and multi-cell buildings. Energy and Buildings , 10 (3), 185-192.

Etheridge, D. W., \& Alexander, D. K. (1980). The British gas multi-cell model for calculating ventilation. ASHRAE Transactions , 86 (2), 808.

Feustel, H. E., \& Kendon, V. M. (1985). Infiltration Models for Multicellular Structures Aliterature Review. Energy and Buildings , 8 (2), 123-136.

Feustel, H. E., \& Rayner-Hooson, A. (1990). COMIS Fundamentals, LBL-28560. Applied Science Division, Lawrence Berkeley National Laboratory, Berkeley, CA.

Fuller, L. R. (1949). How to figure heating for store entrances. Heating, piping and air conditioning , 21 (4), 79-81.

Grenville, Y. (2000). Air leakage through automatic doors. ASHRAE Transactions , 106, 145-160.

Grot, R. A., \& Clark, R. E. (1986). Measured air infiltration and ventilation rates in eight large office buildings, STP 904. In H. R. Treschel, \& P. Lagus, Measured air leakage of buildings (p. 151). West Conshohocken, PA: American Society of Testing and Materials.

Guo, J., \& Liu, M. (August 1985). The energy saving effect of double frame windows. Proceedings of the CLIMA 2000 World Congress in Heating, Ventilating and AirConditioning, Vol. 2. Copenhagen.

Haghighat, H., \& Li, H. (2004). Building Airflow Movement-Validation of Three Airflow Models. Journal of Architectural Planning Research, 21 (4), 331-349

Harrje, D. T., \& Blomsterberg, A. K. (1979). Approaches to evaluation of air infiltration energy losses in buildings. ASHRAE Transactions, 85 (1), 797-815.

Harrje, D. T., \& Born, G. J. (1982). Catalouging air leakage componenets in houses. Proceedings of the American Council for an Energy-Efficient Economy, 1982 Summer Study, Santa Cruz,CA. Washigton, D.C.: American Council for an Energy-Efficient Economy.

Harrje, J., Dutt, G., \& Beyea, J. (1979). Locating and Elimination Obscure but Major Energy Losses in Residential Housing. ASHRAE Transactions , 85 (2), 521-559.

Herrlin, M. K. (1985). MOVECOMP: A static-multicell-airflow-model. ASHRAE Transactions , 91 (2B), 1989.

Hill, J. E., \& Kusuda, T. (1975, June). Dynamic Charateristics of Air Infiltration. ASHRAE REPORT \#2337, Presented at Boston, Mass., Annual Meeting . 
Hong, T., Mathew, P., Sator,D., \& Yazdanian, M. (2009). Comparisons of HVAC Simulations between Energy Plus and DOE-2.2 for Data Centers. ASHRAE Transactiona , CH-09-039, 373-6381.

Hopkins, L.P., \& Hansford, B. (1974). Air flow through cracks. The Building Service Engineer, 42, 123-131

Infiltration through doors. (1937). Heating and ventilating , 34 (8), 2-2.

Jackman, P. (1974). Heat loss in buildings as a result of infiltration. The Building services engineer , 42, 6-15.

James J. Hirsch \& Associates. (April 2009). Q eQUEST Introductory Tutorial, version 3.63. Camarillo, CA: James J. Hirsch \& Associates.

James J. Hirsch \& Associates. (May 2007). Q eQUEST Modeling Procedures Quick Reference Guide. Camarillo, CA: James J. Hirsch \& Associates.

Jayaraman B, Lorenzetti D and Gadgil A (2004) Coupled model for simulation of indoor airflow and pollutant transport. Lawrence Berkeley National laboratory, Berkeley, CA, USA.

Jordon, R. C., Erickson, G. A., \& Leonard, R. R. (1963). Infiltration Measurements in Two Research Houses. ASHRAE Report, Vol. 69, p. 344.

Kerrisk, J. F., Moore, J.E., Schnurr, N.M. \& Hunn, B. D. (1980). Passive Solar Design Calculations with the DOE-2 Computer Program, Los Alamos Scientific Laboratory, Fifthe National Passive Solar Conference, Amhert, Massachussets, October 19-26

Kirkwood, R. C. (1977). Fuel consumption in industrial buildings. Building Services Engineer , 45 .

Klems, J. H. (1983). Methods of Estimating Air Infiltration through Windows. Energy and Buildings , 5 (4), 243-252.

Kohonen, R. (1985). Thermal effects of airflows and moisture on exterior wall structures. Proceedings of the 3rd ASHRAE/DOE/BTECC conference on Thermal Performance of Exterior Envelopes of Buildings, (pp. 583-605). Florida.

Kohonen, R., \& Virtanem, M. (1987). Thermal coupling of leakage flows and heating load of buildings. ASHRAE Transactions , 93, 2303-2318.

Kronvall, J. (1980). Correlating pressurization and infiltration rate data tests of an heuristic model. Lund, Sweden. 
Kusuda, T. (November 1974). NBSLD, Computer Program for Heting and Cooling Loads in Buildings. National Bureau of Standards, Washington, D.C.

Lau, H., \& Ayres, J. M. (1979). Building Energy Analysis Programs. Winter Simulation Conference, (pp. 283-289).

Lawrence Berkeley National Laboratory ; James J. Hirsch \& Associates. (March 2009). DOE-2.2 Building Energy Use and Cost Analysis Program (Vol. 2: Dictionary). Camarillo, CA.

Liddament, M. (1983). The Air Infiltration Center's Program of Model Validation. ASHRAE transactions , 89 (2), 129-145.

Liddament, M. W. (June 1986). Air Infiltration Calculation Techniques - An Application Guide. University of Warwick. Coventry, Great Britain: The Air Infiltration and Ventilation Center.

Liddament, M., \& Allen, C. (1983). The validation and comparison of mathematical models of air infiltration. Technical Note 11, International Energy Agency Air Infiltration and Ventilation Centre, Sint-Stevens-Woluwe, Belgium.

Liu, D.L., \& Nazaroff, W.W. (2001). Modeling Pollutant Penetration Across Building Envelopes, Atmospheric Environment, 35, 4451-4462

Liu, D.L. (2002). Air Pollutant Penetration through Airflow Leaks into Building. Ph.D. Dissertation, Department of Civil and Environmental Engineering, University of California Berkeley

Liu, M. (1992). Study of Air Infiltration Energy Consumption. Ph.D. Dissertation, Texas A\&M University, Department of Mechanical Engineering.

Liu, M. (1987). Thermal Techniques in Buildings. Harbin Architectural and Civil Engineering Institute Press, Harbin, China. pp 3.85-3.90.

Liu, M., \& Claridge, D. E. (1995). Heat flux error of steady-state method for building components under dynamic conditions. Jornal of Solar Engineering , 1, 219-227.

Liu, M., \& Claridge, D. E. (1992). The energy impact of combined SolarRadiation/Infiltration/Conduction effects in Walls and Attics. Thermal performance of the exterior envelopes of buildings $\mathrm{V}$ : proceedings of the ASHRAE/DOE/BTECC Conference, December 7-10, 1992, Clearwater Beach, Florida.

Lokmanhekim, M.; et. al. (August 1971). Computer Program for Analysis of Energy Utilization in Postal Facilities. U.S. Postal Service Symposium, (pp. Vols. I, II and III). Washington, D.C. 
Los Alamos National Laboratory \& Lawrence Berkeley Laboratory. (1982). DOE-2 ENGINEERS Manual, Version 2.1A. (D. A. York, \& C. C. Cappiello, Eds.)

Loutzenhiser, P.G., \& Maxwell, G.M. (2006). Comparisons of DOE-2.1E Daylighting and HVAC System Interactions to Actual Building Performance. ASHRAE Transactiona , QC-06-037, 409-417.

McAdams, W. H. (1954). Heat Transmission. pp. 55-82 and 165-183. New York, NY: McGraw-Hill Book Co., Inc.

McQuiston, F. C., Parker, J. D., \& Spitler, J. D. (2000). Heating, ventilating and air conditioning - analysis and design. New York: John Wiley \& Sons.

Melden, R., and Winkelmann, F. (1998). Comparison of DOE-2 with Temperature Measuremts in the Pala Test Houses. Energy and Buildings , 27 (1998), 69-81.

Min, T. C., \& Auburn, A. (1958). Winter Infiltration Through Swinging-Door Entrances in Multi-Story Buildings. Heating, Piping \& Air Conditioning , 30 (2), 121-128.

Mora,L., Gadgil, A.J., \& Wurtz,E. (2003). Comparing zonal and CFD model predictions of isothermal indoor airflows to experimental data. Indoor Air, 13, 77-85.

Murray, C. D., \& Dermott, S. F. (1999). Solar System Dynamics. Cambridge: Cambridge University Press.

Negrao COR (1998) Integration of computational fluid dynamics with building thermal and mass flow simulation. Energy and Buildings 27(2): 155-165

Nevrala, D. J., \& Etheridge, D. W. (1977). Natural ventilation in well-insulated houses. Proceedings of International Centre for Heat and Mass Transfer,International Seminar, UNESCO, Volume 3.

NIST estimates nationwide energy impact of air leakage in U.S. buildings. (1996). Journal of Research of the NIST, 101 (3), 413.

Orme, M., Liddament, M. W., \& Wilson, A. (1998). Numerical Data for Air Infiltration \& Natural Ventilation Calculations. International Energy Agency, Air Infiltration and Ventilation Centre. Technical Note AIVC 44. Coventry, Great Britain.

Orme, M. S.(1994). Applications of the Air Infiltration and Ventilation Centre's Numerical Database. Air Infiltration and Ventilation Centre, University of Warwick Science Park, Coventry, United Kingdom.

Paradis, R. (2010). Energy Analysis Tool : Whole Building Design Guide. Retrieved October 4, 2010, from Energy Analysis Tools:

http://www.wbdg.org/resources/energyanalysis.php 
Persily, A. K., \& Grot, R. A. (1986). Ressurization testing of federal buildings, STP 904. In H. R. Treschel, \& P. Lagus, Measured air leakage of buildings (p. 184). West Conshohocken, PA: American Society of Testing and Materials.

Persily, A. (1982). Understanding Air Infiltration in Homes. Report PU/CEES \# 129, Princeton University Center for Energy and Environmental Studies, Princeton, New Jersey.

Peterson, J. (1979). ASHRAE Journal , 21, 60.

Peterson, S. (n.d.). National Bureau of Standards.

Reeves, G., McBride, M. F., \& Sepsy, C. (1979). Air infiltration model for residences. ASHRAE Transactiona , 85 (1), 667-677.

Robert, R. H., \& Reinauer, R. H. (1981). SIZING OF RESIDENTIAL HEATING EQUIPMENT. Proceedings of the American Gas Association, Operating Section (pp. D. 73-D. 75). Atlanta, Ga and Anaheim, Calif, USA: American Gas Association.

Ross, H. D., \& Grimsrud, D. T. (1978). Air Infiltration in Buildings: Literature Survey and Proposed Research Agenda. Lawrence Berkeley Laboratory Report LBL-7822 .

Schutrum, L. F., Ozisik, N., Humphreys, C. M., \& Baker, J. T. (1961). Air infiltration through revolving doors. ASHRAE Journal , 3 (11).

Selkowitz, S. E. (1979). Thermal performance of insulating window systems. ASHRAE Transaction , 85 (2), 669-685.

Shaw, C. Y. (1981). A correlation between air infiltration and air tightness for a house in a developed residential area. ASHRAE Transactions , 87 (2), 333.

Sherman, M. H., \& Grimsrud, D. T. (1980). Infiltration-pressurization correlation: Simplified physical modeling. ASHRAE Transactions , 86 (2), 778.

Sherman, M. H., \& Modera, M. P. (1986). Comparison of Measured and Predicted Infiltration Using the LBL Infiltration Model. Proceedings Measured Air Leakage of Buildings (pp. 325-347). Philadelphia: ASTM STP 904 ASTMS.

Sherman, M., \& Matson, N. (1993). Ventilation-Energy liabilities in U.S. dwellings. Proceedings of the 14th AVIC Conference: Energy impact of ventilation and air infiltration, September 21-23, (pp. 23-41). Copenhagen.

Sherman, M., \& McWilliams, J. (2007). Air Leakage of U.S. Homes: Model Prediction. Lawrence Berkeley Natioanl Laborator Report LBNL-62078. Lawrence Berkeley Laboratory, Berkeley, CA. 
Simpson, A. M. (1936). Infiltration characteristics of entrance doors. Refrigerating Engineering , 31 (6), 345-350.

Simpson, A. M. (1936, November). New data on entrance door infiltration with air conditioning. American Architect and Architecture, 85-88.

Stam J (1999) Stable Fluids. Proceedings of the 26th international conference on computer graphics and interactive techniques, SIGGRAPH'99, Los Angeles

Stamou,A., \& Katsiris, I. (2006). Verification of a CFD model for indoor airflow and heat transfer. Building and Environment, 41 (2006), 1171-1181

Stathopoulos, T., Dhiovitii, D., \& Dodaro, L. (1994). Wind Shielding Effects of Trees on Low Buildings. Building and Environments , 29 (2), 141-150.

Steeman, H.J., Janssens,A., Carmeliet,J., \& De Paepe,M. (2009). Modeling indoor air and hygrothermal wall interaction in building simulation: Comparison between CFD and a well-mixed zonal model. Building and Environment, 44 (2009), 572-583

Stephenson, D. G. (1965). Equations for Solar Heat Gain Through Windows. Solar Energy , 9 (2), 81 .

Stephenson, D. G., \& Mitalas, G. P. (1967). Cooling Load Calculations by Thermal Response Factor Method. ASHRAE Transactions , 73 (1).

Tamura, G. T. (1975). Measurement of air leakage characteristics of house enclosures. ASHRAE Transactions , 81, 202.

Tamura, G. T., \& Wilson, A. G. (1964). Air Leakage and Pressure Measurements on Two Occupied Houses. ASHRAE Report \#1869, 20. p. 110.

Threlkland, J. L., \& Jordan, R. C. (1958). Direct Solar Radiation Available on Clear Days. ASHRAE Transactions, 64 (45).

Vatistas, G. H., Chen, D., Chen, T.-F., \& Lin, S. (2006). Prediction of infiltration rates through and automatic door. Journal of Applied Thermal Engineering , 27 (2007), 545550 .

Walker, I. S., \& Wilson, D. J. (1998). Field validation of algebric equations for stack and wind driven air infiltration calculations. International Journal of HVAC\&R Research , 4 (2), 119-140.

Walton, G. (1982). Airflow and Multiroom Thermal Analysis. ASHRAE Transactions, 88 (2), 78-91.

Walton, G. N. (1984). Computer Algorith ForR Predicting Infiltration and Interrom Airflows. ASHRAE Transactions , 90 (pt 1B), 601-610. 
Walton, G., \& Dols, W. S. (2003). CONTAM 2.1 supplemental user guide and program documentation. NISTIR Report 7049, National Institute of Standards, Gaithersburg, MD.

Warren, P. R., \& Webb, B. C. (1980). The relationship between tracer gas and pressurization techniques in dwellings. Proceedings of the 1st IEA Conference of the Air Infiltration Centre. London.

Wang, L., \& Chen, Q. (2006). Validation of Coupled Multizone-CFD Program for Building Airflow and Contaminant Transport Simulations. International Journal of HVAC\&R Research , 13 (2), 267-281.

Warren, P. (1982). Simple Method of Predicting Infiltration Rates In Housing. Energy Conservation in the Built Environment, Proceedings of CIB W67 3rd International Symposium (pp. 6. A. 85-6. A. 104). Dublin, Ireland: An Foras Forbartha.

Weidt, J. L., \& Weidt, J. (1980). Field air leakage of newly installed residential windows. LBL Report 11111. Lawrence Berkeley Laboratory, Berkeley, CA.

Weidt, J. L., Weidt, J., \& Selkowitz, S. (1979). FIeld Air Leakage of Newly Installed Residential Wondws Report LBL-9937. Lawrence Berkeley Laboratory.

Wilson, D. J., \& Kiel, D. E. (1990). Gravity Driven Counterflow Through an Open Door in a Sealed Room. Building and Environment , 25 (4), 379-388.

York, D. A., \& Tucker, E. F. (May 1980). DOE-2 Reference Manual (Version 2.1), Los Alamos Scientific Laboratory report LA-7689-M (Report LBL-8706, Rev.1, Lawrence Berkeley Laboratory).

Yuill, G. K. (1996). Impact of high use automatic doors on infiltration, ASHRAE Research Project 763-TRP. Atlanta: American Society of Heating, Refrigerating and AirConditioning Engineers, Inc.

Yuill, G. K., Upham, R., \& Chen, H. (2000). Air leakage through automatic doors. ASHRAE Transactiona , 106 (2), 145-160.

Zmeureanu, R., Stathopoulos, T., Schopmeijer, M. E., Siret, F., \& Payer, J. (2001). Measurements of Air Leakage Through Revolving Doors of Institutional Building. Journal of Architectural Engineering, 131-137.

Zuo, W., \& Chen, Q. (2010). Fast and informative flow simulations in a building by using fast fluid dynamics model on graphics processing unit. Building and Environment, 45 (2010), 747-757 
APPENDICES 


\begin{abstract}
Appendix A
Hourly and Cumulative Data for Southwest Wall Obtained from the DOE-2/eQUEST, CFD Analyses, and Enhanced Model Simulations
\end{abstract}

Supporting Data for Charts 5-1 to 5-7 


\section{Hourly Data for Southwest Wall}

\begin{tabular}{|c|c|c|c|c|c|c|c|}
\hline \multicolumn{8}{|c|}{ Hourly Southwest (SW) Wall Data (Watts) } \\
\hline \multirow[b]{2}{*}{ hour } & \multicolumn{3}{|c|}{$\begin{array}{l}\text { eUEST/DOE-2 Hourly Values } \\
\text { (no reduction multiplier) }\end{array}$} & \multirow[b]{2}{*}{$\begin{array}{l}\text { Enhanced } \\
\text { Model }\end{array}$} & \multicolumn{3}{|c|}{ CFD Multiphysisc Simulation } \\
\hline & $\begin{array}{c}\text { Air } \\
\text { Change }\end{array}$ & $\begin{array}{c}\text { Air } \\
\text { Change } \\
\text { (ACH) }\end{array}$ & $\begin{array}{l}\text { ASHRAE } \\
\text { Enhanced }\end{array}$ & & $\begin{array}{l}\text { Angular } \\
\text { Cracks }\end{array}$ & $\begin{array}{c}\text { Mixed } \\
\text { Cracks }\end{array}$ & $\begin{array}{l}\text { Straight } \\
\text { Cracks }\end{array}$ \\
\hline 1 & 27.841 & 12.382 & 78.440 & 562.563 & 1033.902 & 1001.086 & 990.942 \\
\hline 2 & 28.263 & 12.570 & 79.632 & 764.879 & 1032.148 & 999.568 & 988.689 \\
\hline 3 & 28.427 & 15.172 & 85.301 & 816.732 & 1031.288 & 997.784 & 987.061 \\
\hline 4 & 33.504 & 14.901 & 103.464 & 868.444 & 1027.239 & 995.574 & 983.660 \\
\hline 5 & 33.630 & 17.948 & 108.929 & 883.594 & 1025.149 & 993.470 & 981.911 \\
\hline 6 & 42.192 & 11.259 & 136.746 & 858.155 & 1023.430 & 991.618 & 980.590 \\
\hline 7 & 39.576 & 14.081 & 128.847 & 837.377 & 1021.008 & 989.738 & 980.309 \\
\hline 8 & 45.585 & 20.274 & 151.554 & 830.891 & 1019.139 & 988.343 & 976.587 \\
\hline 9 & 45.094 & 16.045 & 147.876 & 873.207 & 1020.458 & 991.931 & 979.906 \\
\hline 10 & 37.357 & 16.615 & 122.458 & 881.855 & 1021.342 & 998.765 & 987.920 \\
\hline 11 & 37.789 & 16.807 & 122.098 & 872.546 & 1025.298 & 1007.328 & 995.728 \\
\hline 12 & 30.455 & 21.672 & 100.095 & 869.263 & 1027.725 & 1016.348 & 1005.657 \\
\hline 13 & 31.003 & 19.304 & 98.090 & 879.652 & 1032.188 & 1025.572 & 1016.419 \\
\hline 14 & 33.623 & 20.936 & 104.793 & 923.966 & 1034.425 & 1033.401 & 1026.598 \\
\hline 15 & 33.140 & 20.635 & 102.502 & 928.111 & 1035.710 & 1037.293 & 1032.240 \\
\hline 16 & 39.703 & 24.721 & 123.741 & 920.548 & 1035.179 & 1036.331 & 1030.898 \\
\hline 17 & 51.670 & 32.172 & 167.101 & 921.072 & 1030.190 & 1029.530 & 1024.118 \\
\hline 18 & 54.900 & 29.300 & 177.824 & 945.536 & 1029.099 & 1023.798 & 1017.510 \\
\hline 19 & 57.359 & 35.715 & 188.161 & 986.180 & 1026.581 & 1018.225 & 1010.697 \\
\hline 20 & 54.216 & 33.758 & 181.594 & 967.011 & 1022.710 & 1013.398 & 1005.666 \\
\hline 21 & 56.467 & 30.136 & 186.845 & 940.164 & 1022.880 & 1009.544 & 1001.527 \\
\hline 22 & 44.114 & 23.544 & 144.947 & 921.302 & 1019.865 & 1006.109 & 997.716 \\
\hline 23 & 58.983 & 36.726 & 197.562 & 936.365 & 1017.847 & 1003.242 & 994.831 \\
\hline 24 & 56.467 & 30.136 & 186.845 & 961.769 & 1017.517 & 1000.521 & 991.415 \\
\hline 25 & 61.865 & 38.521 & 208.631 & 948.632 & 1016.081 & 999.027 & 991.520 \\
\hline 26 & 61.651 & 49.355 & 209.315 & 933.645 & 1016.429 & 997.093 & 987.507 \\
\hline 27 & 60.742 & 43.224 & 205.166 & 924.793 & 1014.335 & 995.630 & 986.987 \\
\hline 28 & 55.205 & 24.553 & 179.668 & 926.249 & 1014.685 & 994.700 & 986.410 \\
\hline 29 & 57.022 & 30.433 & 184.697 & 930.246 & 1014.577 & 993.881 & 984.306 \\
\hline
\end{tabular}




\begin{tabular}{|c|c|c|c|c|c|c|c|}
\hline hour & $\begin{array}{c}\text { Air } \\
\text { Change }\end{array}$ & $\begin{array}{c}\text { Air } \\
\text { Change } \\
(\mathbf{A C H})\end{array}$ & $\begin{array}{l}\text { ASHRAE } \\
\text { Enhanced }\end{array}$ & $\begin{array}{c}\text { Enhanced } \\
\text { Model }\end{array}$ & $\begin{array}{l}\text { Angular } \\
\text { Cracks }\end{array}$ & $\begin{array}{c}\text { Mixed } \\
\text { Cracks }\end{array}$ & $\begin{array}{c}\text { Straight } \\
\text { Cracks }\end{array}$ \\
\hline 32 & 62.718 & 50.209 & 210.129 & 923.967 & 1013.996 & 992.880 & 984.674 \\
\hline 33 & 57.345 & 40.807 & 185.834 & 922.689 & 1017.099 & 997.799 & 989.897 \\
\hline 34 & 61.202 & 54.439 & 202.888 & 906.037 & 1021.823 & 1006.194 & 998.177 \\
\hline 35 & 57.077 & 45.693 & 179.542 & 882.402 & 1025.969 & 1016.055 & 1008.670 \\
\hline 36 & 54.767 & 48.715 & 172.951 & 864.225 & 1031.606 & 1026.018 & 1018.344 \\
\hline 37 & 53.876 & 43.130 & 163.216 & 865.180 & 1035.119 & 1035.913 & 1031.268 \\
\hline 38 & 52.581 & 42.094 & 156.828 & 913.238 & 1039.699 & 1043.261 & 1041.314 \\
\hline 39 & 54.355 & 53.184 & 170.758 & 906.145 & 1041.136 & 1048.039 & 1047.856 \\
\hline 40 & 52.562 & 46.754 & 158.789 & 885.759 & 1043.459 & 1049.599 & 1049.267 \\
\hline 41 & 52.562 & 46.754 & 158.789 & 873.139 & 1041.362 & 1044.810 & 1042.675 \\
\hline 42 & 53.656 & 52.500 & 167.368 & 871.524 & 1040.436 & 1039.970 & 1039.282 \\
\hline 43 & 54.593 & 58.273 & 176.333 & 883.176 & 1038.711 & 1035.615 & 1033.630 \\
\hline 44 & 51.278 & 41.051 & 150.520 & 882.670 & 1037.512 & 1031.985 & 1029.686 \\
\hline 45 & 54.593 & 58.273 & 176.333 & 877.086 & 1038.150 & 1029.415 & 1025.853 \\
\hline 46 & 54.008 & 72.060 & 194.144 & 872.217 & 1038.134 & 1027.226 & 1023.854 \\
\hline 47 & 52.604 & 60.829 & 174.187 & 873.195 & 1037.653 & 1025.492 & 1022.282 \\
\hline 48 & 53.352 & 66.440 & 183.927 & 883.424 & 1037.824 & 1023.542 & 1018.953 \\
\hline 49 & 51.883 & 46.150 & 155.542 & 872.970 & 1037.013 & 1022.393 & 1018.989 \\
\hline 50 & 52.955 & 51.815 & 164.001 & 858.710 & 1037.343 & 1021.213 & 1017.146 \\
\hline 51 & 53.348 & 61.689 & 175.542 & 852.861 & 1037.407 & 1020.802 & 1015.986 \\
\hline 52 & 51.105 & 59.095 & 164.966 & 887.296 & 1038.832 & 1020.960 & 1015.333 \\
\hline 53 & 48.917 & 65.268 & 169.290 & 906.999 & 1038.689 & 1021.063 & 1016.116 \\
\hline 54 & 46.985 & 50.152 & 142.594 & 889.213 & 1040.386 & 1021.163 & 1015.570 \\
\hline 55 & 47.721 & 55.182 & 151.052 & 874.585 & 1040.425 & 1021.291 & 1016.310 \\
\hline 56 & 47.721 & 55.182 & 151.052 & 868.966 & 1039.887 & 1021.293 & 1015.687 \\
\hline 57 & 47.721 & 55.182 & 151.052 & 879.986 & 1043.882 & 1025.786 & 1020.501 \\
\hline 58 & 44.474 & 39.560 & 123.990 & 891.985 & 1045.917 & 1033.622 & 1028.856 \\
\hline 59 & 44.049 & 43.100 & 125.473 & 897.105 & 1050.950 & 1043.149 & 1037.060 \\
\hline 60 & 38.033 & 33.831 & 101.514 & 897.750 & 1054.659 & 1053.101 & 1048.097 \\
\hline 61 & 33.399 & 23.767 & 79.647 & 908.796 & 1060.105 & 1062.876 & 1060.499 \\
\hline 62 & 34.925 & 31.066 & 89.013 & 939.435 & 1062.846 & 1070.106 & 1070.323 \\
\hline 63 & 36.231 & 32.228 & 90.584 & 939.104 & 1066.339 & 1074.922 & 1076.928 \\
\hline 64 & 36.231 & 32.228 & 90.584 & 918.288 & 1065.999 & 1075.554 & 1079.379 \\
\hline 65 & 39.020 & 41.650 & 108.992 & 897.708 & 1063.702 & 1069.626 & 1069.800 \\
\hline 66 & 39.814 & 38.956 & 107.923 & 900.724 & 1061.814 & 1064.381 & 1063.913 \\
\hline 67 & 39.021 & 34.709 & 101.338 & 926.201 & 1060.793 & 1059.829 & 1059.282 \\
\hline 68 & 39.021 & 34.709 & 101.338 & 912.169 & 1059.575 & 1055.667 & 1053.394 \\
\hline 69 & 39.021 & 34.709 & 101.338 & 891.739 & 1058.219 & 1051.624 & 1049.742 \\
\hline
\end{tabular}




\begin{tabular}{|c|c|c|c|c|c|c|c|}
\hline hour & $\begin{array}{c}\text { Air } \\
\text { Change }\end{array}$ & $\begin{array}{c}\text { Air } \\
\text { Change } \\
(\mathrm{ACH})\end{array}$ & $\begin{array}{l}\text { ASHRAE } \\
\text { Enhanced }\end{array}$ & $\begin{array}{c}\text { Enhanced } \\
\text { Model }\end{array}$ & $\begin{array}{l}\text { Angular } \\
\text { Cracks }\end{array}$ & $\begin{array}{c}\text { Mixed } \\
\text { Cracks }\end{array}$ & $\begin{array}{c}\text { Straight } \\
\text { Cracks }\end{array}$ \\
\hline 70 & 35.905 & 19.163 & 84.802 & 878.612 & 1057.242 & 1048.471 & 1044.954 \\
\hline 71 & 19.072 & 10.179 & 45.044 & 877.880 & 1056.849 & 1046.456 & 1043.551 \\
\hline 72 & 16.263 & 10.127 & 38.032 & 887.916 & 1056.539 & 1044.808 & 1040.812 \\
\hline 73 & 15.608 & 8.330 & 34.726 & 893.023 & 1056.217 & 1043.985 & 1040.622 \\
\hline 74 & 7.529 & 8.036 & 20.530 & 891.277 & 1058.003 & 1043.882 & 1039.399 \\
\hline 75 & 6.758 & 7.214 & 17.979 & 888.099 & 1057.828 & 1043.591 & 1039.478 \\
\hline 76 & 5.638 & 7.021 & 16.730 & 903.968 & 1058.293 & 1042.632 & 1038.205 \\
\hline 77 & 9.135 & 8.126 & 22.617 & 912.507 & 1058.472 & 1042.167 & 1037.599 \\
\hline 78 & 7.269 & 7.759 & 19.660 & 911.357 & 1058.177 & 1041.672 & 1037.676 \\
\hline 79 & 6.075 & 7.566 & 18.271 & 906.798 & 1058.290 & 1041.130 & 1036.522 \\
\hline 80 & 7.529 & 8.036 & 20.530 & 901.171 & 1059.016 & 1040.834 & 1036.411 \\
\hline 81 & 5.585 & 7.451 & 17.732 & 906.733 & 1061.681 & 1045.357 & 1040.873 \\
\hline 82 & 5.178 & 6.909 & 16.247 & 910.173 & 1063.046 & 1052.685 & 1047.467 \\
\hline 83 & 5.424 & 6.754 & 15.987 & 900.871 & 1066.891 & 1061.776 & 1056.596 \\
\hline 84 & 5.213 & 6.491 & 15.261 & 883.197 & 1071.209 & 1070.837 & 1065.964 \\
\hline 85 & 5.253 & 6.542 & 15.276 & 867.753 & 1074.840 & 1079.853 & 1076.733 \\
\hline 86 & 5.776 & 6.166 & 14.855 & 886.048 & 1076.772 & 1086.399 & 1087.372 \\
\hline 87 & 6.792 & 6.041 & 15.478 & 875.963 & 1078.106 & 1089.497 & 1093.414 \\
\hline 88 & 7.645 & 6.800 & 17.990 & 848.479 & 1078.038 & 1088.511 & 1090.917 \\
\hline 89 & 9.501 & 8.451 & 23.522 & 823.820 & 1074.751 & 1081.165 & 1083.912 \\
\hline 90 & 10.461 & 9.306 & 26.663 & 807.704 & 1070.313 & 1074.321 & 1075.268 \\
\hline 91 & 22.729 & 6.065 & 50.207 & 803.538 & 1068.490 & 1068.159 & 1066.724 \\
\hline 92 & 21.750 & 7.738 & 49.124 & 799.680 & 1064.325 & 1061.736 & 1060.435 \\
\hline 93 & 19.297 & 12.015 & 48.684 & 800.593 & 1062.282 & 1056.774 & 1054.707 \\
\hline 94 & 27.544 & 12.250 & 66.112 & 806.198 & 1059.537 & 1052.257 & 1048.950 \\
\hline 95 & 24.657 & 10.966 & 59.850 & 820.664 & 1056.533 & 1047.988 & 1045.467 \\
\hline 96 & 37.321 & 16.599 & 92.590 & 840.110 & 1055.169 & 1044.670 & 1040.912 \\
\hline 97 & 39.324 & 20.987 & 99.162 & 850.459 & 1052.304 & 1041.619 & 1037.555 \\
\hline 98 & 43.275 & 30.794 & 115.343 & 859.202 & 1052.184 & 1039.470 & 1035.540 \\
\hline 99 & 43.348 & 34.703 & 116.819 & 866.632 & 1050.675 & 1037.432 & 1032.500 \\
\hline 100 & 43.348 & 34.703 & 116.819 & 900.801 & 1050.910 & 1036.054 & 1032.481 \\
\hline 101 & 40.788 & 29.025 & 104.609 & 911.522 & 1049.445 & 1034.891 & 1031.238 \\
\hline 102 & 41.557 & 29.572 & 105.524 & 907.667 & 1049.718 & 1034.066 & 1028.978 \\
\hline 103 & 43.349 & 42.415 & 122.490 & 903.244 & 1049.338 & 1034.002 & 1030.044 \\
\hline 104 & 41.818 & 48.357 & 125.350 & 902.529 & 1050.703 & 1033.889 & 1030.173 \\
\hline 105 & 41.575 & 40.679 & 113.656 & 923.514 & 1051.441 & 1038.200 & 1032.917 \\
\hline 106 & 41.070 & 47.492 & 122.244 & 920.919 & 1057.215 & 1046.523 & 1041.714 \\
\hline 107 & 37.540 & 40.070 & 103.196 & 907.708 & 1059.660 & 1056.447 & 1052.080 \\
\hline
\end{tabular}




\begin{tabular}{|c|c|c|c|c|c|c|c|}
\hline hour & $\begin{array}{c}\text { Air } \\
\text { Change }\end{array}$ & $\begin{array}{c}\text { Air } \\
\text { Change } \\
(\mathrm{ACH})\end{array}$ & $\begin{array}{l}\text { ASHRAE } \\
\text { Enhanced }\end{array}$ & $\begin{array}{l}\text { Enhanced } \\
\text { Model }\end{array}$ & $\begin{array}{l}\text { Angular } \\
\text { Cracks }\end{array}$ & $\begin{array}{c}\text { Mixed } \\
\text { Cracks }\end{array}$ & $\begin{array}{c}\text { Straight } \\
\text { Cracks }\end{array}$ \\
\hline 108 & 34.754 & 34.006 & 88.559 & 900.302 & 1064.218 & 1066.303 & 1060.956 \\
\hline 109 & 33.793 & 36.071 & 89.153 & 897.949 & 1068.897 & 1076.005 & 1072.583 \\
\hline 110 & 32.545 & 31.843 & 80.646 & 911.648 & 1073.158 & 1083.300 & 1083.475 \\
\hline 111 & 29.156 & 25.934 & 67.888 & 918.789 & 1073.714 & 1087.343 & 1090.343 \\
\hline 112 & 29.430 & 18.324 & 60.750 & 916.893 & 1074.411 & 1086.789 & 1090.055 \\
\hline 113 & 31.488 & 25.208 & 73.840 & 913.315 & 1069.697 & 1079.704 & 1080.191 \\
\hline 114 & 23.609 & 12.600 & 52.528 & 917.520 & 1067.957 & 1073.520 & 1074.042 \\
\hline 115 & 19.686 & 10.507 & 44.344 & 926.085 & 1064.662 & 1067.488 & 1067.047 \\
\hline 116 & 21.107 & 11.265 & 49.278 & 905.707 & 1062.812 & 1062.199 & 1061.457 \\
\hline 117 & 19.072 & 10.179 & 45.044 & 879.893 & 1060.086 & 1057.634 & 1055.539 \\
\hline 118 & 26.560 & 11.813 & 62.303 & 861.595 & 1058.402 & 1053.460 & 1050.164 \\
\hline 119 & 27.052 & 0.000 & 62.325 & 866.511 & 1057.629 & 1049.949 & 1047.157 \\
\hline 120 & 23.191 & 8.251 & 54.317 & 892.801 & 1056.921 & 1046.943 & 1042.964 \\
\hline 121 & 22.281 & 7.928 & 52.185 & 882.472 & 1053.779 & 1044.573 & 1040.624 \\
\hline 122 & 26.560 & 0.000 & 60.444 & 868.698 & 1053.363 & 1042.755 & 1038.664 \\
\hline 123 & 26.069 & 0.000 & 58.586 & 863.975 & 1052.716 & 1041.156 & 1037.081 \\
\hline 124 & 19.072 & 10.179 & 45.044 & 900.734 & 1053.171 & 1039.949 & 1036.123 \\
\hline 125 & 18.704 & 8.319 & 42.844 & 927.398 & 1052.774 & 1039.109 & 1034.968 \\
\hline 126 & 21.003 & 7.473 & 46.846 & 924.035 & 1051.847 & 1038.336 & 1036.256 \\
\hline 127 & 25.023 & 6.678 & 55.275 & 910.097 & 1052.073 & 1037.368 & 1032.032 \\
\hline 128 & 20.568 & 7.318 & 46.455 & 899.465 & 1051.122 & 1036.664 & 1032.069 \\
\hline 129 & 17.153 & 12.206 & 42.238 & 914.128 & 1053.739 & 1040.895 & 1036.091 \\
\hline 130 & 12.233 & 9.793 & 30.544 & 910.370 & 1055.681 & 1048.061 & 1042.674 \\
\hline 131 & 8.975 & 9.580 & 25.266 & 893.660 & 1059.733 & 1056.269 & 1051.432 \\
\hline 132 & 7.562 & 9.417 & 23.496 & 877.231 & 1063.063 & 1065.487 & 1059.327 \\
\hline 133 & 5.786 & 8.749 & 20.874 & 871.702 & 1066.389 & 1074.349 & 1071.319 \\
\hline 134 & 6.002 & 8.009 & 19.285 & 893.844 & 1069.647 & 1081.091 & 1082.208 \\
\hline 135 & 5.616 & 7.993 & 18.930 & 894.610 & 1070.738 & 1085.421 & 1086.806 \\
\hline 136 & 5.215 & 7.422 & 17.392 & 891.513 & 1072.259 & 1085.946 & 1089.152 \\
\hline 137 & 3.750 & 6.671 & 15.454 & 891.307 & 1068.928 & 1080.125 & 1082.305 \\
\hline 138 & 4.177 & 7.060 & 16.390 & 895.441 & 1068.509 & 1074.893 & 1074.595 \\
\hline 139 & 5.863 & 7.822 & 18.615 & 903.994 & 1066.046 & 1069.760 & 1069.904 \\
\hline 140 & 11.604 & 8.257 & 26.759 & 895.992 & 1065.213 & 1065.439 & 1063.515 \\
\hline 141 & 15.947 & 8.511 & 34.590 & 877.015 & 1063.452 & 1061.736 & 1059.742 \\
\hline 142 & 13.695 & 12.182 & 33.907 & 851.519 & 1063.510 & 1058.919 & 1056.057 \\
\hline 143 & 22.134 & 19.688 & 54.798 & 837.728 & 1062.602 & 1056.241 & 1053.529 \\
\hline 144 & 33.028 & 29.379 & 81.770 & 837.163 & 1061.209 & 1053.774 & 1049.564 \\
\hline 145 & 14.105 & 12.547 & 35.265 & 831.130 & 1061.456 & 1052.100 & 1048.774 \\
\hline
\end{tabular}




\begin{tabular}{|c|c|c|c|c|c|c|c|}
\hline hour & $\begin{array}{c}\text { Air } \\
\text { Change }\end{array}$ & $\begin{array}{c}\text { Air } \\
\text { Change } \\
(\mathbf{A C H})\end{array}$ & $\begin{array}{l}\text { ASHRAE } \\
\text { Enhanced }\end{array}$ & $\begin{array}{c}\text { Enhanced } \\
\text { Model }\end{array}$ & $\begin{array}{l}\text { Angular } \\
\text { Cracks }\end{array}$ & $\begin{array}{c}\text { Mixed } \\
\text { Cracks }\end{array}$ & $\begin{array}{c}\text { Straight } \\
\text { Cracks }\end{array}$ \\
\hline 146 & 4.592 & 7.353 & 17.228 & 823.873 & 1059.562 & 1050.326 & 1046.819 \\
\hline 147 & 5.540 & 7.885 & 18.774 & 817.371 & 1060.471 & 1048.721 & 1044.083 \\
\hline 148 & 5.739 & 8.167 & 19.550 & 836.587 & 1057.826 & 1047.001 & 1043.026 \\
\hline 149 & 6.986 & 8.700 & 21.567 & 844.487 & 1058.090 & 1045.889 & 1042.531 \\
\hline 150 & 5.739 & 8.167 & 19.550 & 1050.527 & 1058.321 & 1045.177 & 1041.557 \\
\hline 151 & 5.344 & 7.606 & 18.014 & 1050.381 & 1058.271 & 1044.184 & 1040.661 \\
\hline 152 & 7.118 & 8.230 & 20.586 & 1050.429 & 1057.374 & 1043.534 & 1038.511 \\
\hline 153 & 7.792 & 8.317 & 21.420 & 1050.429 & 1059.282 & 1046.261 & 1041.730 \\
\hline 154 & 8.714 & 10.076 & 25.203 & 1050.429 & 1061.593 & 1052.698 & 1047.078 \\
\hline 155 & 9.451 & 13.450 & 32.878 & 1050.786 & 1061.683 & 1060.090 & 1055.594 \\
\hline 156 & 6.835 & 13.984 & 33.835 & 1051.056 & 1063.767 & 1067.077 & 1061.481 \\
\hline 157 & 5.207 & 10.652 & 25.976 & 1051.329 & 1064.860 & 1073.647 & 1070.954 \\
\hline 158 & 5.859 & 11.465 & 28.087 & 1051.532 & 1065.437 & 1077.645 & 1077.523 \\
\hline 159 & 6.772 & 12.649 & 31.307 & 1051.795 & 1064.653 & 1078.904 & 1080.910 \\
\hline 160 & 8.662 & 13.869 & 35.206 & 1051.993 & 1061.788 & 1076.558 & 1078.198 \\
\hline 161 & 9.436 & 20.144 & 50.561 & 1052.326 & 1056.299 & 1067.927 & 1068.814 \\
\hline 162 & 6.789 & 14.493 & 36.464 & 1052.463 & 1052.455 & 1059.969 & 1060.682 \\
\hline 163 & 8.177 & 16.001 & 40.692 & 1052.718 & 1048.320 & 1052.717 & 1051.730 \\
\hline 164 & 9.650 & 17.167 & 44.416 & 1052.913 & 1045.828 & 1046.542 & 1045.257 \\
\hline 165 & 9.085 & 16.970 & 43.607 & 1052.958 & 1042.459 & 1041.201 & 1040.219 \\
\hline 166 & 16.611 & 23.641 & 64.774 & 1052.979 & 1039.794 & 1036.566 & 1033.093 \\
\hline 167 & 11.698 & 17.690 & 47.511 & 1052.988 & 1038.449 & 1032.413 & 1028.702 \\
\hline 168 & 12.219 & 18.478 & 50.057 & 1053.134 & 1035.735 & 1028.780 & 1025.137 \\
\hline 169 & 17.190 & 18.348 & 58.825 & 1053.230 & 1034.409 & 1026.775 & 1022.778 \\
\hline 170 & 15.912 & 18.400 & 56.303 & 1053.252 & 1032.699 & 1023.189 & 1019.386 \\
\hline 171 & 16.872 & 19.511 & 60.045 & 1053.334 & 1030.825 & 1020.396 & 1016.050 \\
\hline 172 & 19.996 & 19.565 & 67.216 & 1053.421 & 1028.990 & 1018.059 & 1013.548 \\
\hline 173 & 27.537 & 22.045 & 87.884 & 1053.439 & 1027.365 & 1015.509 & 1011.025 \\
\hline 174 & 31.740 & 19.763 & 98.924 & 1053.590 & 1026.774 & 1013.416 & 1008.694 \\
\hline 175 & 30.277 & 16.159 & 93.769 & 1053.687 & 1024.190 & 1011.607 & 1006.244 \\
\hline 176 & 30.277 & 16.159 & 93.769 & 1053.710 & 1024.542 & 1010.301 & 1005.288 \\
\hline 177 & 26.116 & 18.584 & 82.819 & 1053.649 & 1024.339 & 1013.959 & 1008.700 \\
\hline 178 & 25.550 & 20.454 & 81.543 & 1053.500 & 1027.657 & 1020.786 & 1016.113 \\
\hline 179 & 26.414 & 18.796 & 81.290 & 1053.331 & 1031.422 & 1029.557 & 1023.501 \\
\hline 180 & 25.490 & 15.872 & 75.788 & 1053.155 & 1035.592 & 1038.550 & 1033.693 \\
\hline 181 & 27.841 & 12.382 & 78.440 & 1052.903 & 1038.205 & 1047.261 & 1044.651 \\
\hline 182 & 26.179 & 13.972 & 74.699 & 1052.852 & 1041.171 & 1053.957 & 1053.518 \\
\hline 183 & 21.841 & 15.542 & 64.099 & 1052.758 & 1042.661 & 1058.173 & 1060.358 \\
\hline
\end{tabular}




\begin{tabular}{|c|c|c|c|c|c|c|c|}
\hline hour & $\begin{array}{c}\text { Air } \\
\text { Change }\end{array}$ & $\begin{array}{c}\text { Air } \\
\text { Change } \\
(\mathrm{ACH})\end{array}$ & $\begin{array}{l}\text { ASHRAE } \\
\text { Enhanced }\end{array}$ & $\begin{array}{c}\text { Enhanced } \\
\text { Model }\end{array}$ & $\begin{array}{l}\text { Angular } \\
\text { Cracks }\end{array}$ & $\begin{array}{c}\text { Mixed } \\
\text { Cracks }\end{array}$ & $\begin{array}{c}\text { Straight } \\
\text { Cracks }\end{array}$ \\
\hline 184 & 21.841 & 15.542 & 64.099 & 1052.737 & 1041.751 & 1058.245 & 1061.026 \\
\hline 185 & 31.127 & 13.844 & 88.482 & 1052.870 & 1040.000 & 1051.877 & 1052.858 \\
\hline 186 & 33.079 & 11.770 & 94.014 & 1052.960 & 1036.327 & 1045.536 & 1045.289 \\
\hline 187 & 34.475 & 9.200 & 100.000 & 1053.193 & 1034.379 & 1039.767 & 1038.840 \\
\hline 188 & 35.036 & 12.466 & 103.073 & 1053.307 & 1032.402 & 1035.032 & 1032.247 \\
\hline 189 & 32.901 & 11.706 & 96.792 & 1053.338 & 1031.523 & 1030.796 & 1029.114 \\
\hline 190 & 37.742 & 0.000 & 108.941 & 1053.280 & 1029.880 & 1027.599 & 1024.636 \\
\hline 191 & 33.268 & 11.837 & 96.217 & 1053.203 & 1029.871 & 1024.902 & 1020.858 \\
\hline 192 & 31.782 & 11.308 & 91.124 & 1053.118 & 1028.468 & 1023.035 & 1019.920 \\
\hline 193 & 30.814 & 10.964 & 86.797 & 1052.958 & 1029.368 & 1021.926 & 1018.388 \\
\hline 194 & 26.638 & 14.217 & 76.669 & 1052.928 & 1027.951 & 1020.696 & 1017.455 \\
\hline 195 & 30.017 & 13.350 & 85.327 & 1052.914 & 1029.057 & 1019.473 & 1015.720 \\
\hline 196 & 34.750 & 15.455 & 97.031 & 1052.766 & 1027.689 & 1018.489 & 1013.411 \\
\hline 197 & 28.699 & 12.764 & 80.135 & 1052.740 & 1028.504 & 1017.739 & 1013.219 \\
\hline 198 & 32.194 & 8.591 & 88.494 & 1052.729 & 1027.810 & 1017.284 & 1012.448 \\
\hline 199 & 31.126 & 11.075 & 85.301 & 1052.653 & 1028.789 & 1016.756 & 1011.951 \\
\hline 200 & 27.319 & 12.150 & 75.592 & 1052.639 & 1029.206 & 1016.508 & 1011.617 \\
\hline 201 & 33.742 & 12.005 & 91.605 & 1052.562 & 1031.332 & 1021.009 & 1015.986 \\
\hline 202 & 30.904 & 8.247 & 82.552 & 1052.477 & 1033.767 & 1028.396 & 1023.926 \\
\hline 203 & 29.663 & 10.554 & 78.998 & 1052.388 & 1039.281 & 1037.474 & 1033.407 \\
\hline 204 & 29.318 & 7.824 & 76.782 & 1052.297 & 1042.321 & 1046.954 & 1040.400 \\
\hline 205 & 24.608 & 10.944 & 64.294 & 1052.135 & 1046.055 & 1056.258 & 1054.619 \\
\hline 206 & 23.673 & 10.529 & 60.612 & 1051.961 & 1049.021 & 1063.365 & 1063.984 \\
\hline 207 & 21.086 & 13.129 & 55.369 & 1051.853 & 1050.931 & 1067.175 & 1068.674 \\
\hline 208 & 25.401 & 13.557 & 67.351 & 1052.039 & 1049.422 & 1067.525 & 1069.975 \\
\hline 209 & 25.875 & 13.809 & 69.269 & 1052.132 & 1048.101 & 1061.107 & 1062.738 \\
\hline 210 & 24.719 & 15.391 & 68.028 & 1052.225 & 1046.338 & 1055.336 & 1054.738 \\
\hline 211 & 19.761 & 14.062 & 55.601 & 1052.245 & 1042.765 & 1050.072 & 1049.939 \\
\hline 212 & 19.761 & 14.062 & 55.601 & 1052.254 & 1042.343 & 1045.507 & 1042.717 \\
\hline 213 & 19.761 & 14.062 & 55.601 & 1052.258 & 1041.148 & 1041.504 & 1039.608 \\
\hline 214 & 23.223 & 16.526 & 65.343 & 1052.260 & 1040.776 & 1038.392 & 1036.300 \\
\hline 215 & 19.132 & 18.720 & 58.823 & 1052.261 & 1038.301 & 1035.611 & 1031.759 \\
\hline 216 & 19.132 & 18.720 & 58.823 & 1052.261 & 1037.982 & 1033.269 & 1029.259 \\
\hline 217 & 17.933 & 19.142 & 57.151 & 1052.262 & 1038.182 & 1031.984 & 1029.074 \\
\hline 218 & 17.933 & 19.142 & 57.151 & 1052.262 & 1037.201 & 1030.473 & 1026.450 \\
\hline 219 & 17.933 & 19.142 & 57.151 & 1052.262 & 1037.216 & 1028.771 & 1023.845 \\
\hline 220 & 12.062 & 15.021 & 41.583 & 1052.262 & 1035.632 & 1027.130 & 1023.318 \\
\hline 221 & 15.790 & 19.664 & 54.436 & 1052.262 & 1035.231 & 1025.865 & 1021.819 \\
\hline
\end{tabular}




\begin{tabular}{|c|c|c|c|c|c|c|c|}
\hline hour & $\begin{array}{c}\text { Air } \\
\text { Change }\end{array}$ & $\begin{array}{c}\text { Air } \\
\text { Change } \\
(\mathrm{ACH})\end{array}$ & $\begin{array}{l}\text { ASHRAE } \\
\text { Enhanced }\end{array}$ & $\begin{array}{c}\text { Enhanced } \\
\text { Model }\end{array}$ & $\begin{array}{l}\text { Angular } \\
\text { Cracks }\end{array}$ & $\begin{array}{c}\text { Mixed } \\
\text { Cracks }\end{array}$ & $\begin{array}{c}\text { Straight } \\
\text { Cracks }\end{array}$ \\
\hline 222 & 15.790 & 19.664 & 54.436 & 1052.262 & 1036.176 & 1024.858 & 1020.734 \\
\hline 223 & 13.152 & 19.888 & 51.565 & 1052.262 & 1036.033 & 1023.981 & 1019.944 \\
\hline 224 & 11.191 & 14.932 & 40.230 & 1052.262 & 1034.871 & 1023.321 & 1017.530 \\
\hline 225 & 11.191 & 14.932 & 40.230 & 1052.262 & 1036.806 & 1026.334 & 1021.905 \\
\hline 226 & 13.152 & 19.888 & 51.565 & 1052.262 & 1038.037 & 1032.930 & 1027.867 \\
\hline 227 & 13.152 & 19.888 & 51.565 & 1052.262 & 1042.457 & 1041.289 & 1035.067 \\
\hline 228 & 11.082 & 19.715 & 49.637 & 1052.262 & 1044.594 & 1050.572 & 1045.133 \\
\hline 229 & 12.177 & 19.497 & 49.698 & 1052.190 & 1049.393 & 1059.294 & 1056.135 \\
\hline 230 & 11.885 & 19.029 & 48.308 & 1052.108 & 1049.812 & 1065.267 & 1065.166 \\
\hline 231 & 12.913 & 19.526 & 50.399 & 1052.163 & 1052.195 & 1068.423 & 1070.633 \\
\hline 232 & 10.664 & 15.178 & 40.216 & 1052.309 & 1049.905 & 1067.708 & 1068.816 \\
\hline 233 & 13.234 & 16.481 & 46.678 & 1052.548 & 1046.970 & 1060.350 & 1061.141 \\
\hline 234 & 14.593 & 16.875 & 49.833 & 1052.664 & 1043.655 & 1053.897 & 1054.187 \\
\hline 235 & 16.107 & 17.193 & 53.408 & 1052.766 & 1040.396 & 1047.427 & 1046.049 \\
\hline 236 & 25.744 & 20.610 & 79.791 & 1053.005 & 1038.617 & 1041.889 & 1040.384 \\
\hline 237 & 22.121 & 17.709 & 69.073 & 1053.122 & 1035.729 & 1036.503 & 1034.297 \\
\hline 238 & 25.249 & 17.967 & 78.893 & 1053.367 & 1033.875 & 1031.833 & 1029.202 \\
\hline 239 & 27.729 & 17.266 & 85.767 & 1053.486 & 1030.159 & 1027.676 & 1024.265 \\
\hline 240 & 26.116 & 18.584 & 82.819 & 1053.590 & 1030.285 & 1024.323 & 1021.654 \\
\hline 241 & 28.181 & 17.547 & 87.830 & 1053.616 & 1028.228 & 1021.514 & 1016.522 \\
\hline 242 & 27.729 & 17.266 & 85.767 & 1053.556 & 1025.805 & 1018.921 & 1014.716 \\
\hline 243 & 32.546 & 14.475 & 98.931 & 1053.621 & 1024.682 & 1016.764 & 1012.256 \\
\hline 244 & 34.695 & 12.344 & 104.629 & 1053.630 & 1023.184 & 1015.037 & 1010.845 \\
\hline 245 & 34.208 & 12.171 & 102.324 & 1053.562 & 1024.741 & 1014.718 & 1010.748 \\
\hline 246 & 32.293 & 11.490 & 91.779 & 1053.125 & 1024.349 & 1015.063 & 1011.302 \\
\hline 247 & 24.774 & 13.222 & 69.457 & 1052.768 & 1025.895 & 1015.572 & 1010.256 \\
\hline 248 & 20.030 & 14.254 & 57.335 & 1052.548 & 1027.683 & 1016.204 & 1011.201 \\
\hline 249 & 16.092 & 14.314 & 47.871 & 1052.348 & 1030.602 & 1021.462 & 1016.809 \\
\hline 250 & 10.503 & 14.014 & 37.556 & 1052.229 & 1033.895 & 1028.992 & 1022.876 \\
\hline 251 & 15.042 & 14.718 & 45.912 & 1052.196 & 1037.433 & 1039.049 & 1034.139 \\
\hline 252 & 13.532 & 14.444 & 42.540 & 1052.110 & 1042.786 & 1048.093 & 1041.782 \\
\hline 253 & 13.532 & 14.444 & 42.540 & 1052.093 & 1045.973 & 1058.073 & 1054.035 \\
\hline 254 & 13.263 & 16.516 & 45.192 & 1052.085 & 1048.553 & 1066.684 & 1063.928 \\
\hline 255 & 21.813 & 19.403 & 63.880 & 1052.081 & 1050.203 & 1072.488 & 1070.800 \\
\hline 256 & 20.627 & 20.183 & 62.496 & 1052.080 & 1050.611 & 1074.268 & 1073.297 \\
\hline 257 & 21.813 & 19.403 & 63.880 & 1052.079 & 1048.142 & 1066.333 & 1064.053 \\
\hline 258 & 22.257 & 19.797 & 65.695 & 1052.150 & 1045.603 & 1059.295 & 1057.117 \\
\hline 259 & 23.046 & 20.500 & 69.092 & 1052.304 & 1045.159 & 1053.394 & 1051.825 \\
\hline
\end{tabular}




\begin{tabular}{|c|c|c|c|c|c|c|c|}
\hline hour & $\begin{array}{c}\text { Air } \\
\text { Change }\end{array}$ & $\begin{array}{c}\text { Air } \\
\text { Change } \\
(\mathbf{A C H})\end{array}$ & $\begin{array}{l}\text { ASHRAE } \\
\text { Enhanced }\end{array}$ & $\begin{array}{c}\text { Enhanced } \\
\text { Model }\end{array}$ & $\begin{array}{l}\text { Angular } \\
\text { Cracks }\end{array}$ & $\begin{array}{c}\text { Mixed } \\
\text { Cracks }\end{array}$ & $\begin{array}{c}\text { Straight } \\
\text { Cracks }\end{array}$ \\
\hline 260 & 32.840 & 32.133 & 101.706 & 1052.331 & 1040.939 & 1047.877 & 1044.006 \\
\hline 261 & 33.331 & 38.542 & 111.750 & 1052.415 & 1039.907 & 1043.118 & 1039.267 \\
\hline 262 & 48.038 & 42.730 & 147.326 & 1052.574 & 1038.576 & 1039.273 & 1036.500 \\
\hline 263 & 50.987 & 58.959 & 172.006 & 1052.533 & 1037.743 & 1036.162 & 1031.240 \\
\hline 264 & 51.945 & 64.688 & 182.184 & 1052.535 & 1035.960 & 1033.475 & 1029.424 \\
\hline 265 & 33.331 & 41.507 & 116.235 & 1052.465 & 1037.069 & 1031.631 & 1028.154 \\
\hline 266 & 51.470 & 68.674 & 186.006 & 1052.382 & 1034.978 & 1030.427 & 1025.203 \\
\hline 267 & 53.314 & 61.650 & 177.646 & 1052.366 & 1035.848 & 1028.627 & 1024.048 \\
\hline 268 & 53.352 & 66.440 & 183.927 & 1052.288 & 1034.114 & 1027.142 & 1022.375 \\
\hline 269 & 55.339 & 78.759 & 208.685 & 1052.345 & 1035.017 & 1026.134 & 1021.330 \\
\hline 270 & 54.584 & 77.685 & 204.836 & 1052.278 & 1035.115 & 1025.208 & 1021.060 \\
\hline 271 & 51.746 & 55.234 & 164.908 & 1052.269 & 1033.734 & 1024.381 & 1018.729 \\
\hline 272 & 54.584 & 77.685 & 204.836 & 1052.265 & 1034.643 & 1023.895 & 1019.161 \\
\hline 273 & 54.943 & 87.969 & 224.237 & 1052.192 & 1035.858 & 1028.337 & 1023.158 \\
\hline 274 & 53.727 & 81.243 & 208.759 & 1052.109 & 1039.719 & 1036.686 & 1030.919 \\
\hline 275 & 51.942 & 97.025 & 238.627 & 1051.807 & 1044.074 & 1046.685 & 1040.339 \\
\hline 276 & 46.649 & 70.541 & 176.368 & 1051.612 & 1049.808 & 1056.266 & 1051.671 \\
\hline 277 & 42.675 & 56.940 & 143.610 & 1051.280 & 1053.604 & 1067.322 & 1063.441 \\
\hline 278 & 41.796 & 59.484 & 146.162 & 1051.072 & 1057.538 & 1076.558 & 1076.077 \\
\hline 279 & 42.004 & 56.044 & 138.146 & 1050.878 & 1060.802 & 1083.161 & 1082.370 \\
\hline 280 & 37.246 & 39.757 & 104.860 & 1050.761 & 1061.509 & 1085.683 & 1086.063 \\
\hline 281 & 38.572 & 48.034 & 119.850 & 1050.730 & 1061.087 & 1082.304 & 1083.616 \\
\hline 282 & 37.632 & 33.473 & 95.912 & 1050.644 & 1059.524 & 1076.125 & 1073.160 \\
\hline 283 & 37.627 & 26.775 & 91.681 & 1050.841 & 1057.308 & 1070.328 & 1067.430 \\
\hline 284 & 39.418 & 31.556 & 100.394 & 1050.938 & 1056.866 & 1065.428 & 1062.444 \\
\hline 285 & 36.798 & 32.732 & 96.450 & 1050.890 & 1055.308 & 1061.472 & 1058.106 \\
\hline 286 & 25.085 & 22.313 & 65.750 & 1050.888 & 1055.738 & 1058.186 & 1054.855 \\
\hline 287 & 24.101 & 21.438 & 62.010 & 1050.745 & 1054.150 & 1054.988 & 1050.965 \\
\hline 288 & 36.798 & 32.732 & 96.450 & 1050.865 & 1053.451 & 1052.201 & 1050.122 \\
\hline 289 & 37.417 & 33.282 & 98.972 & 1050.949 & 1053.380 & 1050.567 & 1049.009 \\
\hline 290 & 38.378 & 37.552 & 105.802 & 1050.966 & 1053.030 & 1047.619 & 1042.382 \\
\hline 291 & 39.651 & 38.796 & 111.131 & 1051.116 & 1051.214 & 1045.315 & 1041.792 \\
\hline 292 & 27.052 & 26.469 & 76.440 & 1051.213 & 1050.784 & 1043.766 & 1039.132 \\
\hline 293 & 26.560 & 28.351 & 77.701 & 1051.164 & 1050.779 & 1042.728 & 1037.116 \\
\hline 294 & 13.759 & 15.911 & 41.532 & 1051.021 & 1051.377 & 1042.968 & 1039.130 \\
\hline 295 & 10.186 & 9.967 & 26.668 & 1050.570 & 1052.778 & 1043.095 & 1038.680 \\
\hline 296 & 7.690 & 9.577 & 23.281 & 1050.421 & 1053.106 & 1043.638 & 1038.562 \\
\hline 297 & 4.782 & 8.082 & 18.690 & 1050.161 & 1056.220 & 1049.153 & 1044.367 \\
\hline
\end{tabular}




\begin{tabular}{|c|c|c|c|c|c|c|c|}
\hline hour & $\begin{array}{c}\text { Air } \\
\text { Change }\end{array}$ & $\begin{array}{c}\text { Air } \\
\text { Change } \\
(\mathbf{A C H})\end{array}$ & $\begin{array}{l}\text { ASHRAE } \\
\text { Enhanced }\end{array}$ & $\begin{array}{c}\text { Enhanced } \\
\text { Model }\end{array}$ & $\begin{array}{l}\text { Angular } \\
\text { Cracks }\end{array}$ & $\begin{array}{c}\text { Mixed } \\
\text { Cracks }\end{array}$ & $\begin{array}{c}\text { Straight } \\
\text { Cracks }\end{array}$ \\
\hline 298 & 4.730 & 7.573 & 17.366 & 1049.964 & 1060.990 & 1057.716 & 1052.511 \\
\hline 299 & 3.172 & 5.643 & 12.892 & 1049.775 & 1064.180 & 1067.612 & 1062.755 \\
\hline 300 & 2.836 & 5.298 & 12.121 & 1049.661 & 1070.256 & 1077.478 & 1072.025 \\
\hline 301 & 3.054 & 5.977 & 13.715 & 1049.559 & 1072.741 & 1087.613 & 1084.737 \\
\hline 302 & 2.765 & 4.919 & 11.123 & 1049.463 & 1076.902 & 1095.383 & 1096.541 \\
\hline 303 & 2.967 & 5.014 & 11.287 & 1049.441 & 1077.693 & 1100.210 & 1104.110 \\
\hline 304 & 2.765 & 4.919 & 11.123 & 1049.431 & 1079.233 & 1101.777 & 1105.658 \\
\hline 305 & 2.810 & 4.749 & 10.691 & 1049.426 & 1075.880 & 1097.303 & 1100.219 \\
\hline 306 & 3.170 & 5.076 & 11.441 & 1049.495 & 1073.643 & 1089.352 & 1092.070 \\
\hline 307 & 1.986 & 6.005 & 15.269 & 1050.147 & 1069.883 & 1081.827 & 1083.297 \\
\hline 308 & 2.273 & 7.279 & 18.881 & 1050.680 & 1067.024 & 1074.829 & 1072.902 \\
\hline 309 & 2.515 & 8.052 & 20.945 & 1051.009 & 1062.811 & 1068.235 & 1066.907 \\
\hline 310 & 3.008 & 9.098 & 23.428 & 1051.308 & 1059.779 & 1062.172 & 1061.214 \\
\hline 311 & 3.294 & 9.962 & 25.737 & 1051.594 & 1056.972 & 1057.046 & 1054.541 \\
\hline 312 & 4.471 & 11.135 & 27.860 & 1051.731 & 1054.502 & 1053.003 & 1050.852 \\
\hline 313 & 3.942 & 10.518 & 26.542 & 1051.700 & 1053.380 & 1049.345 & 1044.662 \\
\hline 314 & 4.058 & 10.828 & 27.364 & 1051.778 & 1053.030 & 1046.045 & 1042.067 \\
\hline 315 & 4.175 & 11.141 & 28.199 & 1051.863 & 1051.214 & 1042.636 & 1038.776 \\
\hline 316 & 4.415 & 11.781 & 29.906 & 1052.024 & 1050.784 & 1039.256 & 1035.073 \\
\hline 317 & 7.233 & 14.154 & 35.483 & 1052.268 & 1050.779 & 1036.375 & 1033.670 \\
\hline 318 & 7.002 & 14.324 & 35.958 & 1052.387 & 1051.377 & 1033.757 & 1030.741 \\
\hline 319 & 6.430 & 14.299 & 36.006 & 1052.490 & 1052.778 & 1031.134 & 1025.620 \\
\hline 320 & 7.793 & 15.251 & 38.563 & 1052.587 & 1053.106 & 1029.073 & 1024.598 \\
\hline 321 & 8.789 & 15.636 & 39.910 & 1052.610 & 1055.049 & 1032.197 & 1025.818 \\
\hline 322 & 10.434 & 15.778 & 41.457 & 1052.549 & 1058.983 & 1037.850 & 1032.753 \\
\hline 323 & 9.139 & 15.445 & 39.595 & 1052.542 & 1061.396 & 1046.837 & 1041.719 \\
\hline 324 & 8.701 & 14.706 & 37.420 & 1052.397 & 1066.705 & 1054.916 & 1048.792 \\
\hline 325 & 10.408 & 14.812 & 39.057 & 1052.301 & 1068.556 & 1064.648 & 1061.041 \\
\hline 326 & 12.792 & 14.793 & 42.093 & 1052.208 & 1072.184 & 1072.361 & 1070.321 \\
\hline 327 & 13.012 & 13.889 & 40.904 & 1052.116 & 1072.585 & 1077.654 & 1076.917 \\
\hline 328 & 19.030 & 13.542 & 52.611 & 1052.095 & 1073.813 & 1078.049 & 1077.985 \\
\hline 329 & 18.903 & 13.451 & 52.723 & 1052.157 & 1071.435 & 1072.815 & 1073.103 \\
\hline 330 & 30.077 & 8.026 & 80.343 & 1052.378 & 1069.820 & 1065.515 & 1061.427 \\
\hline 331 & 32.673 & 5.813 & 87.795 & 1052.487 & 1066.545 & 1058.545 & 1055.875 \\
\hline 332 & 42.020 & 14.951 & 115.159 & 1052.586 & 1064.093 & 1052.877 & 1049.023 \\
\hline 333 & 42.509 & 18.906 & 116.541 & 1052.538 & 1060.230 & 1047.507 & 1043.346 \\
\hline 334 & 43.555 & 19.371 & 121.617 & 1052.680 & 1057.500 & 1043.205 & 1039.587 \\
\hline 335 & 48.599 & 30.260 & 137.370 & 1052.560 & 1054.956 & 1039.724 & 1034.863 \\
\hline
\end{tabular}




\begin{tabular}{|c|c|c|c|c|c|c|c|}
\hline hour & $\begin{array}{c}\text { Air } \\
\text { Change }\end{array}$ & $\begin{array}{c}\text { Air } \\
\text { Change } \\
(\mathbf{A C H})\end{array}$ & $\begin{array}{l}\text { ASHRAE } \\
\text { Enhanced }\end{array}$ & $\begin{array}{c}\text { Enhanced } \\
\text { Model }\end{array}$ & $\begin{array}{l}\text { Angular } \\
\text { Cracks }\end{array}$ & $\begin{array}{c}\text { Mixed } \\
\text { Cracks }\end{array}$ & $\begin{array}{c}\text { Straight } \\
\text { Cracks }\end{array}$ \\
\hline 336 & 51.278 & 41.051 & 150.520 & 1052.476 & 1052.714 & 1037.044 & 1032.664 \\
\hline 337 & 49.142 & 34.969 & 139.468 & 1052.387 & 1051.289 & 1035.569 & 1030.551 \\
\hline 338 & 51.883 & 46.150 & 155.542 & 1052.368 & 1049.070 & 1033.757 & 1029.199 \\
\hline 339 & 53.872 & 57.504 & 172.847 & 1052.360 & 1047.403 & 1031.587 & 1026.748 \\
\hline 340 & 53.150 & 56.733 & 169.382 & 1052.285 & 1044.372 & 1030.066 & 1025.227 \\
\hline 341 & 53.538 & 57.147 & 170.618 & 1052.272 & 1043.298 & 1028.687 & 1023.398 \\
\hline 342 & 54.282 & 62.769 & 179.743 & 1052.266 & 1041.380 & 1027.977 & 1023.259 \\
\hline 343 & 54.331 & 67.658 & 186.217 & 1052.193 & 1039.509 & 1027.399 & 1022.662 \\
\hline 344 & 53.240 & 66.300 & 181.414 & 1052.109 & 1038.332 & 1027.176 & 1021.716 \\
\hline 345 & 52.962 & 75.376 & 194.868 & 1051.949 & 1038.391 & 1031.077 & 1026.243 \\
\hline 346 & 52.697 & 74.998 & 193.893 & 1051.919 & 1041.157 & 1039.444 & 1033.804 \\
\hline 347 & 51.492 & 77.865 & 196.476 & 1051.763 & 1043.268 & 1049.463 & 1043.348 \\
\hline 348 & 49.364 & 65.865 & 169.893 & 1051.592 & 1046.637 & 1058.666 & 1053.999 \\
\hline 349 & 48.146 & 68.522 & 171.873 & 1051.414 & 1049.550 & 1069.436 & 1064.581 \\
\hline 350 & 45.506 & 48.574 & 134.125 & 1051.305 & 1051.998 & 1078.619 & 1076.438 \\
\hline 351 & 43.988 & 46.953 & 127.717 & 1051.134 & 1053.440 & 1084.796 & 1083.577 \\
\hline 352 & 43.494 & 50.294 & 131.286 & 1051.028 & 1052.038 & 1086.488 & 1084.065 \\
\hline 353 & 41.863 & 40.961 & 114.444 & 1050.929 & 1050.818 & 1084.207 & 1081.982 \\
\hline 354 & 42.721 & 49.401 & 128.056 & 1050.906 & 1046.854 & 1077.440 & 1075.818 \\
\hline 355 & 33.825 & 18.052 & 78.970 & 1050.967 & 1045.344 & 1071.414 & 1069.026 \\
\hline 356 & 31.984 & 22.760 & 79.581 & 1051.045 & 1043.247 & 1066.187 & 1062.234 \\
\hline 357 & 34.406 & 18.363 & 81.260 & 1051.059 & 1041.061 & 1061.116 & 1057.834 \\
\hline 358 & 40.583 & 25.269 & 100.272 & 1051.208 & 1039.445 & 1056.753 & 1053.215 \\
\hline 359 & 40.133 & 21.419 & 99.083 & 1051.376 & 1038.345 & 1052.888 & 1048.771 \\
\hline 360 & 35.876 & 15.956 & 88.044 & 1051.481 & 1038.961 & 1049.097 & 1045.088 \\
\hline 361 & 34.194 & 15.208 & 86.648 & 1051.721 & 1036.854 & & \\
\hline 362 & 31.408 & 11.175 & 81.182 & 1051.981 & 1036.367 & & \\
\hline 363 & 27.247 & 9.694 & 70.425 & 1052.035 & 1036.676 & & \\
\hline 364 & 31.971 & 0.000 & 82.380 & 1052.130 & 1035.286 & & \\
\hline 365 & 31.895 & 8.511 & 82.693 & 1052.153 & 1036.497 & & \\
\hline 366 & 30.987 & 0.000 & 78.191 & 1052.020 & 1035.639 & & \\
\hline 367 & 26.763 & 9.522 & 68.469 & 1052.001 & 1035.552 & & \\
\hline 368 & 30.428 & 10.826 & 77.038 & 1051.922 & 1036.387 & & \\
\hline 369 & 29.020 & 0.000 & 70.077 & 1051.693 & 1037.357 & & \\
\hline 370 & 26.227 & 9.332 & 63.583 & 1051.582 & 1042.053 & & \\
\hline 371 & 19.960 & 10.653 & 49.806 & 1051.552 & 1044.943 & & \\
\hline 372 & 25.649 & 6.844 & 60.259 & 1051.397 & 1051.088 & & \\
\hline 373 & 21.039 & 7.486 & 48.108 & 1051.154 & 1053.484 & & \\
\hline
\end{tabular}




\begin{tabular}{|c|c|c|c|c|c|c|c|}
\hline hour & $\begin{array}{c}\text { Air } \\
\text { Change }\end{array}$ & $\begin{array}{c}\text { Air } \\
\text { Change } \\
(\mathbf{A C H})\end{array}$ & $\begin{array}{l}\text { ASHRAE } \\
\text { Enhanced }\end{array}$ & $\begin{array}{c}\text { Enhanced } \\
\text { Model }\end{array}$ & $\begin{array}{l}\text { Angular } \\
\text { Cracks }\end{array}$ & $\begin{array}{r}\text { Mixed } \\
\text { Cracks }\end{array}$ & $\begin{array}{l}\text { Straight } \\
\text { Cracks }\end{array}$ \\
\hline 374 & 21.750 & 7.738 & 49.124 & 1051.037 & 1057.787 & & \\
\hline 375 & 22.238 & 9.890 & 50.939 & 1051.005 & 1058.970 & & \\
\hline 376 & 18.171 & 9.698 & 41.930 & 1050.919 & 1061.352 & & \\
\hline 377 & 25.085 & 13.388 & 57.882 & 1050.902 & 1059.615 & & \\
\hline 378 & 20.386 & 7.254 & 45.471 & 1050.894 & 1059.052 & & \\
\hline 379 & 23.465 & 4.174 & 50.866 & 1050.819 & 1055.883 & & \\
\hline 380 & 19.915 & 7.086 & 43.855 & 1050.806 & 1054.829 & & \\
\hline 381 & 10.703 & 9.521 & 27.797 & 1050.801 & 1053.890 & & \\
\hline 382 & 9.259 & 9.884 & 26.273 & 1050.798 & 1052.974 & & \\
\hline 383 & 11.448 & 10.183 & 30.007 & 1050.868 & 1051.610 & & \\
\hline 384 & 10.029 & 9.813 & 27.418 & 1050.879 & 1049.547 & & \\
\hline 385 & 17.328 & 9.248 & 40.457 & 1050.955 & 1047.317 & & \\
\hline 386 & 8.642 & 9.993 & 26.086 & 1050.968 & 1047.225 & & \\
\hline 387 & 12.679 & 11.278 & 34.747 & 1051.259 & 1043.537 & & \\
\hline 388 & 23.207 & 10.321 & 58.807 & 1051.663 & 1042.282 & & \\
\hline 389 & 26.088 & 9.282 & 65.354 & 1051.741 & 1042.174 & & \\
\hline 390 & 26.717 & 9.506 & 65.494 & 1051.633 & 1041.740 & & \\
\hline 391 & 32.446 & 8.658 & 78.016 & 1051.555 & 1041.261 & & \\
\hline 392 & 39.687 & 21.181 & 97.982 & 1051.469 & 1040.451 & & \\
\hline 393 & 39.094 & 20.865 & 95.479 & 1051.380 & 1042.918 & & \\
\hline 394 & 43.696 & 38.868 & 118.714 & 1051.290 & 1046.681 & & \\
\hline 395 & 42.035 & 33.651 & 109.145 & 1051.199 & 1049.823 & & \\
\hline 396 & 42.272 & 37.601 & 112.828 & 1051.107 & 1055.054 & & \\
\hline 397 & 41.001 & 32.823 & 104.424 & 1051.016 & 1057.498 & & \\
\hline 398 & 36.492 & 19.476 & 84.204 & 1050.924 & 1060.458 & & \\
\hline 399 & 35.877 & 19.147 & 81.802 & 1050.833 & 1063.394 & & \\
\hline 400 & 13.310 & 10.656 & 33.235 & 1050.812 & 1063.531 & & \\
\hline 401 & 12.977 & 11.543 & 34.014 & 1050.874 & 1062.639 & & \\
\hline 402 & 11.864 & 11.608 & 32.707 & 1050.953 & 1061.771 & & \\
\hline 403 & 18.886 & 13.440 & 48.437 & 1051.252 & 1059.980 & & \\
\hline 404 & 12.769 & 15.901 & 41.721 & 1051.375 & 1058.283 & & \\
\hline 405 & 10.185 & 16.307 & 40.376 & 1051.481 & 1057.326 & & \\
\hline 406 & 8.486 & 12.078 & 30.604 & 1051.508 & 1056.564 & & \\
\hline 407 & 10.398 & 17.574 & 43.719 & 1051.733 & 1056.445 & & \\
\hline 408 & 7.405 & 13.173 & 32.826 & 1051.915 & 1053.916 & & \\
\hline 409 & 10.873 & 19.343 & 48.535 & 1052.097 & 1054.715 & & \\
\hline 410 & 7.233 & 14.154 & 35.483 & 1052.280 & 1051.904 & & \\
\hline 411 & 7.605 & 14.881 & 37.521 & 1052.464 & 1050.652 & & \\
\hline
\end{tabular}




\begin{tabular}{|c|c|c|c|c|c|c|c|}
\hline hour & $\begin{array}{c}\text { Air } \\
\text { Change }\end{array}$ & $\begin{array}{c}\text { Air } \\
\text { Change } \\
(\mathbf{A C H})\end{array}$ & $\begin{array}{l}\text { ASHRAE } \\
\text { Enhanced }\end{array}$ & $\begin{array}{c}\text { Enhanced } \\
\text { Model }\end{array}$ & $\begin{array}{l}\text { Angular } \\
\text { Cracks }\end{array}$ & $\begin{array}{r}\text { Mixed } \\
\text { Cracks }\end{array}$ & $\begin{array}{l}\text { Straight } \\
\text { Cracks }\end{array}$ \\
\hline 412 & 8.878 & 16.583 & 42.482 & 1052.789 & 1048.159 & & \\
\hline 413 & 10.092 & 17.954 & 46.766 & 1053.067 & 1047.707 & & \\
\hline 414 & 12.453 & 19.939 & 53.977 & 1053.414 & 1047.099 & & \\
\hline 415 & 15.069 & 21.447 & 61.247 & 1053.701 & 1047.116 & & \\
\hline 416 & 18.907 & 21.863 & 69.596 & 1053.839 & 1045.974 & & \\
\hline 417 & 18.907 & 21.863 & 69.596 & 1053.879 & 1049.177 & & \\
\hline 418 & 18.563 & 21.465 & 67.953 & 1053.826 & 1051.279 & & \\
\hline 419 & 18.221 & 21.070 & 66.331 & 1053.752 & 1054.891 & & \\
\hline 420 & 23.765 & 19.026 & 76.393 & 1053.596 & 1058.956 & & \\
\hline 421 & 22.293 & 17.847 & 70.639 & 1053.425 & 1061.865 & & \\
\hline 422 & 27.967 & 14.926 & 83.241 & 1053.319 & 1065.293 & & \\
\hline 423 & 25.365 & 15.793 & 76.026 & 1053.220 & 1066.891 & & \\
\hline 424 & 21.489 & 17.203 & 67.099 & 1053.197 & 1066.728 & & \\
\hline 425 & 20.429 & 18.172 & 65.437 & 1053.187 & 1064.972 & & \\
\hline 426 & 27.087 & 21.685 & 85.828 & 1053.325 & 1061.988 & & \\
\hline 427 & 19.406 & 25.892 & 74.575 & 1053.417 & 1059.519 & & \\
\hline 428 & 20.507 & 27.362 & 79.977 & 1053.651 & 1057.168 & & \\
\hline 429 & 16.266 & 28.937 & 77.408 & 1053.837 & 1054.721 & & \\
\hline 430 & 17.769 & 30.031 & 81.896 & 1054.021 & 1053.139 & & \\
\hline 431 & 11.950 & 22.322 & 59.696 & 1054.134 & 1049.613 & & \\
\hline 432 & 11.330 & 23.179 & 61.631 & 1054.377 & 1049.426 & & \\
\hline 433 & 12.423 & 24.311 & 65.418 & 1054.567 & 1045.502 & & \\
\hline 434 & 12.423 & 24.311 & 65.418 & 1054.611 & 1044.247 & & \\
\hline 435 & 14.167 & 25.203 & 69.426 & 1054.702 & 1040.668 & & \\
\hline 436 & 13.379 & 24.992 & 68.053 & 1054.722 & 1039.207 & & \\
\hline 437 & 11.583 & 24.729 & 66.078 & 1054.802 & 1035.742 & & \\
\hline 438 & 11.798 & 25.186 & 67.462 & 1054.888 & 1033.082 & & \\
\hline 439 & 11.798 & 25.186 & 67.462 & 1054.907 & 1029.231 & & \\
\hline 440 & 11.416 & 25.386 & 67.880 & 1054.986 & 1028.350 & & \\
\hline 441 & 12.014 & 25.647 & 68.860 & 1055.001 & 1027.557 & & \\
\hline 442 & 12.660 & 25.901 & 69.940 & 1055.008 & 1030.229 & & \\
\hline 443 & 12.014 & 25.647 & 68.860 & 1055.010 & 1032.011 & & \\
\hline 444 & 11.209 & 24.927 & 66.505 & 1054.940 & 1035.544 & & \\
\hline 445 & 11.798 & 25.186 & 67.462 & 1054.930 & 1037.735 & & \\
\hline 446 & 11.209 & 24.927 & 66.505 & 1054.925 & 1040.420 & & \\
\hline 447 & 12.655 & 24.765 & 66.822 & 1054.780 & 1041.541 & & \\
\hline 448 & 12.059 & 23.598 & 63.676 & 1054.756 & 1041.882 & & \\
\hline 449 & 11.202 & 22.917 & 61.249 & 1054.675 & 1038.812 & & \\
\hline
\end{tabular}




\begin{tabular}{|c|c|c|c|c|c|c|c|}
\hline hour & $\begin{array}{c}\text { Air } \\
\text { Change }\end{array}$ & $\begin{array}{c}\text { Air } \\
\text { Change } \\
(\mathbf{A C H})\end{array}$ & $\begin{array}{l}\text { ASHRAE } \\
\text { Enhanced }\end{array}$ & $\begin{array}{c}\text { Enhanced } \\
\text { Model }\end{array}$ & $\begin{array}{l}\text { Angular } \\
\text { Cracks }\end{array}$ & $\begin{array}{r}\text { Mixed } \\
\text { Cracks }\end{array}$ & $\begin{array}{l}\text { Straight } \\
\text { Cracks }\end{array}$ \\
\hline 450 & 10.992 & 22.487 & 59.946 & 1054.587 & 1035.987 & & \\
\hline 451 & 14.463 & 23.157 & 65.141 & 1054.497 & 1032.473 & & \\
\hline 452 & 13.408 & 23.853 & 65.073 & 1054.478 & 1030.656 & & \\
\hline 453 & 13.592 & 22.972 & 63.533 & 1054.469 & 1027.269 & & \\
\hline 454 & 16.463 & 23.430 & 69.015 & 1054.465 & 1025.028 & & \\
\hline 455 & 17.374 & 23.182 & 69.407 & 1054.250 & 1023.100 & & \\
\hline 456 & 18.603 & 23.167 & 71.859 & 1054.215 & 1021.411 & & \\
\hline 457 & 19.601 & 22.666 & 72.945 & 1054.128 & 1019.266 & & \\
\hline 458 & 17.941 & 22.342 & 68.598 & 1054.039 & 1016.465 & & \\
\hline 459 & 19.623 & 20.946 & 70.044 & 1053.948 & 1015.191 & & \\
\hline 460 & 19.270 & 20.568 & 68.379 & 1053.857 & 1012.768 & & \\
\hline 461 & 17.878 & 20.673 & 65.445 & 1053.836 & 1011.399 & & \\
\hline 462 & 11.648 & 18.650 & 50.291 & 1053.542 & 1010.069 & & \\
\hline 463 & 13.558 & 20.502 & 56.737 & 1053.635 & 1009.209 & & \\
\hline 464 & 16.962 & 21.123 & 63.856 & 1053.708 & 1007.326 & & \\
\hline 465 & 22.098 & 19.656 & 73.748 & 1053.719 & 1008.717 & & \\
\hline 466 & 16.559 & 19.149 & 59.269 & 1053.510 & 1009.359 & & \\
\hline 467 & 9.189 & 16.348 & 42.297 & 1053.122 & 1013.682 & & \\
\hline 468 & 8.773 & 15.608 & 40.109 & 1052.909 & 1016.218 & & \\
\hline 469 & 9.361 & 15.820 & 40.708 & 1052.712 & 1019.240 & & \\
\hline 470 & 8.494 & 14.356 & 36.666 & 1052.523 & 1020.711 & & \\
\hline 471 & 7.768 & 13.819 & 34.913 & 1052.408 & 1023.496 & & \\
\hline 472 & 7.113 & 13.288 & 33.303 & 1052.307 & 1022.709 & & \\
\hline 473 & 7.573 & 13.472 & 33.920 & 1052.282 & 1021.898 & & \\
\hline 474 & 9.257 & 13.998 & 36.292 & 1052.271 & 1019.006 & & \\
\hline 475 & 10.503 & 14.014 & 37.556 & 1052.194 & 1017.477 & & \\
\hline 476 & 8.848 & 13.379 & 34.378 & 1052.110 & 1015.751 & & \\
\hline 477 & 9.508 & 13.532 & 35.333 & 1052.092 & 1015.273 & & \\
\hline 478 & 9.987 & 13.325 & 35.327 & 1052.013 & 1014.597 & & \\
\hline 479 & 11.401 & 13.184 & 36.803 & 1051.927 & 1013.927 & & \\
\hline 480 & 9.732 & 12.985 & 34.240 & 1051.909 & 1013.570 & & \\
\hline 481 & 8.791 & 12.512 & 32.186 & 1051.830 & 1014.120 & & \\
\hline 482 & 12.574 & 13.422 & 38.710 & 1051.815 & 1012.879 & & \\
\hline 483 & 11.114 & 12.851 & 35.643 & 1051.809 & 1013.197 & & \\
\hline 484 & 11.114 & 12.851 & 35.643 & 1051.806 & 1014.794 & & \\
\hline 485 & 14.747 & 13.117 & 42.498 & 1051.876 & 1014.904 & & \\
\hline 486 & 15.996 & 14.228 & 46.844 & 1052.029 & 1014.810 & & \\
\hline 487 & 14.164 & 13.859 & 42.914 & 1052.057 & 1015.411 & & \\
\hline
\end{tabular}




\begin{tabular}{|c|c|c|c|c|c|c|c|}
\hline hour & $\begin{array}{c}\text { Air } \\
\text { Change }\end{array}$ & $\begin{array}{c}\text { Air } \\
\text { Change } \\
(\mathbf{A C H})\end{array}$ & $\begin{array}{l}\text { ASHRAE } \\
\text { Enhanced }\end{array}$ & $\begin{array}{c}\text { Enhanced } \\
\text { Model }\end{array}$ & $\begin{array}{l}\text { Angular } \\
\text { Cracks }\end{array}$ & $\begin{array}{c}\text { Mixed } \\
\text { Cracks }\end{array}$ & $\begin{array}{l}\text { Straight } \\
\text { Cracks }\end{array}$ \\
\hline 488 & 12.390 & 13.225 & 38.412 & 1051.926 & 1014.456 & & \\
\hline 489 & 12.390 & 13.225 & 38.412 & 1051.909 & 1018.800 & & \\
\hline 490 & 9.458 & 11.778 & 31.092 & 1051.616 & 1021.610 & & \\
\hline 491 & 6.413 & 10.268 & 25.105 & 1051.354 & 1026.390 & & \\
\hline 492 & 5.841 & 9.353 & 22.579 & 1051.085 & 1032.285 & & \\
\hline 493 & 3.794 & 8.099 & 19.420 & 1050.812 & 1035.933 & & \\
\hline 494 & 3.273 & 7.278 & 17.497 & 1050.681 & 1040.534 & & \\
\hline 495 & 5.381 & 8.615 & 20.447 & 1050.643 & 1042.017 & & \\
\hline 496 & 5.786 & 8.749 & 20.874 & 1050.626 & 1044.936 & & \\
\hline 497 & 6.746 & 9.001 & 21.931 & 1050.619 & 1044.057 & & \\
\hline 498 & 5.985 & 9.050 & 21.696 & 1050.687 & 1042.249 & & \\
\hline 499 & 8.490 & 9.818 & 25.270 & 1050.768 & 1041.228 & & \\
\hline 500 & 6.560 & 9.336 & 22.821 & 1050.855 & 1040.019 & & \\
\hline 501 & 5.092 & 9.059 & 21.729 & 1050.944 & 1040.317 & & \\
\hline 502 & 6.029 & 9.654 & 23.405 & 1051.035 & 1039.191 & & \\
\hline 503 & 6.029 & 9.654 & 23.405 & 1051.055 & 1040.008 & & \\
\hline 504 & 7.552 & 10.076 & 25.269 & 1051.064 & 1038.797 & & \\
\hline 505 & 11.703 & 11.451 & 33.068 & 1051.210 & 1040.234 & & \\
\hline 506 & 8.188 & 10.197 & 26.098 & 1051.092 & 1039.376 & & \\
\hline 507 & 6.340 & 10.151 & 24.610 & 1051.080 & 1039.502 & & \\
\hline 508 & 11.679 & 10.388 & 31.172 & 1051.075 & 1039.295 & & \\
\hline 509 & 12.860 & 10.295 & 33.074 & 1051.073 & 1038.441 & & \\
\hline 510 & 12.803 & 11.388 & 34.782 & 1051.214 & 1038.487 & & \\
\hline 511 & 12.803 & 11.388 & 34.782 & 1051.236 & 1038.450 & & \\
\hline 512 & 16.544 & 11.773 & 41.587 & 1051.175 & 1037.759 & & \\
\hline 513 & 16.544 & 11.773 & 41.587 & 1051.168 & 1041.709 & & \\
\hline 514 & 9.628 & 11.990 & 30.494 & 1051.022 & 1044.758 & & \\
\hline 515 & 11.579 & 12.359 & 33.619 & 1051.070 & 1049.911 & & \\
\hline 516 & 8.936 & 11.923 & 29.731 & 1050.999 & 1054.599 & & \\
\hline 517 & 9.342 & 11.634 & 29.403 & 1050.917 & 1060.124 & & \\
\hline 518 & 8.668 & 11.565 & 28.672 & 1050.900 & 1061.972 & & \\
\hline 519 & 10.495 & 15.870 & 38.407 & 1050.893 & 1064.917 & & \\
\hline 520 & 13.385 & 15.478 & 40.121 & 1050.890 & 1066.697 & & \\
\hline 521 & 10.808 & 16.344 & 39.739 & 1050.960 & 1066.194 & & \\
\hline 522 & 12.126 & 17.258 & 42.846 & 1051.113 & 1062.247 & & \\
\hline 523 & 27.544 & 31.851 & 85.455 & 1051.283 & 1060.365 & & \\
\hline 524 & 28.036 & 24.938 & 77.498 & 1051.389 & 1059.867 & & \\
\hline 525 & 21.535 & 15.324 & 56.318 & 1051.487 & 1056.845 & & \\
\hline
\end{tabular}




\begin{tabular}{|c|c|c|c|c|c|c|c|}
\hline hour & $\begin{array}{c}\text { Air } \\
\text { Change }\end{array}$ & $\begin{array}{c}\text { Air } \\
\text { Change } \\
(\mathbf{A C H})\end{array}$ & $\begin{array}{l}\text { ASHRAE } \\
\text { Enhanced }\end{array}$ & $\begin{array}{c}\text { Enhanced } \\
\text { Model }\end{array}$ & $\begin{array}{l}\text { Angular } \\
\text { Cracks }\end{array}$ & $\begin{array}{c}\text { Mixed } \\
\text { Cracks }\end{array}$ & $\begin{array}{l}\text { Straight } \\
\text { Cracks }\end{array}$ \\
\hline 526 & 22.456 & 15.980 & 59.855 & 1051.653 & 1057.027 & & \\
\hline 527 & 29.020 & 18.069 & 74.713 & 1051.614 & 1054.459 & & \\
\hline 528 & 21.995 & 15.652 & 58.074 & 1051.618 & 1053.350 & & \\
\hline 529 & 24.448 & 13.048 & 61.650 & 1051.619 & 1052.860 & & \\
\hline 530 & 17.375 & 12.364 & 44.562 & 1051.406 & 1053.566 & & \\
\hline 531 & 14.038 & 11.239 & 36.798 & 1051.301 & 1051.052 & & \\
\hline 532 & 16.957 & 10.558 & 41.897 & 1051.275 & 1051.676 & & \\
\hline 533 & 18.637 & 9.947 & 45.020 & 1051.263 & 1049.729 & & \\
\hline 534 & 19.736 & 12.289 & 50.304 & 1051.472 & 1049.901 & & \\
\hline 535 & 19.059 & 11.867 & 49.557 & 1051.646 & 1049.577 & & \\
\hline 536 & 25.409 & 13.561 & 65.400 & 1051.754 & 1049.439 & & \\
\hline 537 & 22.456 & 15.980 & 59.855 & 1051.710 & 1051.167 & & \\
\hline 538 & 19.891 & 15.924 & 53.118 & 1051.497 & 1054.137 & & \\
\hline 539 & 13.263 & 11.797 & 35.081 & 1051.108 & 1057.503 & & \\
\hline 540 & 14.905 & 10.607 & 35.932 & 1050.894 & 1059.870 & & \\
\hline 541 & 14.517 & 12.913 & 36.648 & 1050.626 & 1063.558 & & \\
\hline 542 & 11.965 & 12.771 & 32.626 & 1050.425 & 1066.436 & & \\
\hline 543 & 14.654 & 11.731 & 34.738 & 1050.377 & 1067.540 & & \\
\hline 544 & 21.642 & 17.325 & 50.751 & 1050.284 & 1067.581 & & \\
\hline 545 & 14.230 & 11.392 & 33.369 & 1050.263 & 1065.257 & & \\
\hline 546 & 11.592 & 12.374 & 31.353 & 1050.254 & 1062.214 & & \\
\hline 547 & 13.695 & 12.182 & 33.907 & 1050.321 & 1059.175 & & \\
\hline 548 & 7.269 & 7.759 & 19.660 & 1050.259 & 1057.241 & & \\
\hline 549 & 7.595 & 8.107 & 20.543 & 1050.252 & 1053.853 & & \\
\hline 550 & 5.196 & 8.320 & 19.662 & 1050.463 & 1053.475 & & \\
\hline 551 & 5.193 & 8.776 & 20.853 & 1050.638 & 1050.643 & & \\
\hline 552 & 5.023 & 8.935 & 21.284 & 1050.746 & 1049.978 & & \\
\hline 553 & 8.490 & 9.818 & 25.270 & 1050.774 & 1048.519 & & \\
\hline 554 & 8.875 & 9.473 & 25.181 & 1050.786 & 1048.562 & & \\
\hline 555 & 11.811 & 9.456 & 29.492 & 1050.792 & 1047.816 & & \\
\hline 556 & 8.875 & 9.473 & 25.181 & 1050.794 & 1047.903 & & \\
\hline $\mathbf{5 5 7}$ & 14.888 & 9.270 & 35.214 & 1050.866 & 1048.024 & & \\
\hline 558 & 16.896 & 9.017 & 38.986 & 1050.878 & 1046.272 & & \\
\hline 559 & 20.633 & 11.012 & 47.609 & 1050.883 & 1044.884 & & \\
\hline 560 & 21.638 & 5.774 & 47.178 & 1050.814 & 1044.131 & & \\
\hline 561 & 21.833 & 7.768 & 47.455 & 1050.733 & 1047.309 & & \\
\hline 562 & 16.832 & 8.983 & 37.449 & 1050.646 & 1049.544 & & \\
\hline 563 & 15.668 & 11.149 & 35.716 & 1050.414 & 1054.976 & & \\
\hline
\end{tabular}




\begin{tabular}{|c|c|c|c|c|c|c|c|}
\hline hour & $\begin{array}{c}\text { Air } \\
\text { Change }\end{array}$ & $\begin{array}{c}\text { Air } \\
\text { Change } \\
(\mathbf{A C H})\end{array}$ & $\begin{array}{l}\text { ASHRAE } \\
\text { Enhanced }\end{array}$ & $\begin{array}{c}\text { Enhanced } \\
\text { Model }\end{array}$ & $\begin{array}{l}\text { Angular } \\
\text { Cracks }\end{array}$ & $\begin{array}{r}\text { Mixed } \\
\text { Cracks }\end{array}$ & $\begin{array}{l}\text { Straight } \\
\text { Cracks }\end{array}$ \\
\hline 564 & 3.602 & 6.407 & 14.792 & 1050.087 & 1058.329 & & \\
\hline 565 & 3.877 & 7.241 & 17.039 & 1050.379 & 1063.490 & & \\
\hline 566 & 4.766 & 7.207 & 16.872 & 1050.265 & 1065.961 & & \\
\hline 567 & 3.504 & 6.856 & 16.135 & 1050.326 & 1068.826 & & \\
\hline 568 & 5.320 & 13.251 & 32.761 & 1050.974 & 1070.498 & & \\
\hline 569 & 5.226 & 11.622 & 28.750 & 1051.577 & 1070.685 & & \\
\hline 570 & 7.423 & 17.827 & 44.658 & 1051.917 & 1067.523 & & \\
\hline 571 & 4.459 & 12.693 & 32.730 & 1052.292 & 1065.327 & & \\
\hline 572 & 4.494 & 13.192 & 34.280 & 1052.520 & 1064.322 & & \\
\hline 573 & 7.695 & 20.533 & 52.672 & 1052.651 & 1063.734 & & \\
\hline 574 & 9.208 & 22.115 & 56.352 & 1052.832 & 1063.016 & & \\
\hline 575 & 6.396 & 15.360 & 39.139 & 1052.872 & 1059.676 & & \\
\hline 576 & 7.430 & 16.523 & 42.165 & 1053.032 & 1059.150 & & \\
\hline 577 & 7.218 & 16.694 & 42.719 & 1053.134 & 1058.631 & & \\
\hline 578 & 8.966 & 17.546 & 45.135 & 1053.159 & 1057.842 & & \\
\hline 579 & 8.020 & 17.121 & 43.813 & 1053.170 & 1056.804 & & \\
\hline $\mathbf{5 8 0}$ & 9.504 & 17.754 & 45.906 & 1053.174 & 1056.044 & & \\
\hline 581 & 11.443 & 18.321 & 48.822 & 1053.177 & 1054.178 & & \\
\hline 582 & 11.692 & 18.720 & 50.084 & 1053.249 & 1054.329 & & \\
\hline 583 & 14.313 & 19.097 & 54.459 & 1053.261 & 1052.891 & & \\
\hline 584 & 14.008 & 18.690 & 53.564 & 1053.337 & 1052.968 & & \\
\hline 585 & 13.052 & 18.576 & 51.854 & 1053.351 & 1055.480 & & \\
\hline 586 & 17.190 & 18.348 & 58.825 & 1053.286 & 1059.732 & & \\
\hline 587 & 15.274 & 17.662 & 53.417 & 1053.134 & 1063.238 & & \\
\hline 588 & 19.033 & 16.930 & 60.105 & 1053.037 & 1067.692 & & \\
\hline 589 & 18.285 & 16.265 & 56.914 & 1052.871 & 1070.457 & & \\
\hline 590 & 20.103 & 16.093 & 60.430 & 1052.767 & 1072.654 & & \\
\hline 591 & 23.282 & 14.497 & 66.383 & 1052.669 & 1072.555 & & \\
\hline 592 & 29.157 & 15.561 & 81.013 & 1052.575 & 1069.314 & & \\
\hline 593 & 34.311 & 15.260 & 94.938 & 1052.625 & 1066.789 & & \\
\hline 594 & 41.642 & 22.224 & 116.746 & 1052.627 & 1060.729 & & \\
\hline 595 & 43.555 & 19.371 & 121.617 & 1052.699 & 1055.542 & & \\
\hline 596 & 53.229 & 42.613 & 160.012 & 1052.711 & 1053.287 & & \\
\hline 597 & 51.423 & 41.167 & 154.581 & 1052.716 & 1047.766 & & \\
\hline 598 & 52.853 & 47.013 & 163.303 & 1052.718 & 1046.435 & & \\
\hline 599 & 55.187 & 58.907 & 181.804 & 1052.719 & 1041.679 & & \\
\hline 600 & 56.439 & 55.223 & 181.056 & 1052.791 & 1039.443 & & \\
\hline 601 & 57.594 & 71.723 & 203.143 & 1052.660 & 1037.923 & & \\
\hline
\end{tabular}




\begin{tabular}{|c|c|c|c|c|c|c|c|}
\hline hour & $\begin{array}{c}\text { Air } \\
\text { Change }\end{array}$ & $\begin{array}{c}\text { Air } \\
\text { Change } \\
(\mathbf{A C H})\end{array}$ & $\begin{array}{l}\text { ASHRAE } \\
\text { Enhanced }\end{array}$ & $\begin{array}{c}\text { Enhanced } \\
\text { Model }\end{array}$ & $\begin{array}{l}\text { Angular } \\
\text { Cracks }\end{array}$ & $\begin{array}{c}\text { Mixed } \\
\text { Cracks }\end{array}$ & $\begin{array}{l}\text { Straight } \\
\text { Cracks }\end{array}$ \\
\hline 602 & 54.798 & 53.617 & 172.149 & 1052.571 & 1036.603 & & \\
\hline 603 & 56.134 & 64.911 & 189.368 & 1052.552 & 1034.118 & & \\
\hline 604 & 56.094 & 69.854 & 195.616 & 1052.472 & 1033.461 & & \\
\hline 605 & 54.749 & 73.050 & 197.858 & 1052.386 & 1030.843 & & \\
\hline 606 & 54.008 & 72.060 & 194.144 & 1052.297 & 1029.755 & & \\
\hline 607 & 53.352 & 66.440 & 183.927 & 1052.277 & 1029.193 & & \\
\hline 608 & 52.054 & 60.193 & 171.283 & 1052.197 & 1027.453 & & \\
\hline 609 & 50.511 & 53.916 & 158.789 & 1052.111 & 1028.825 & & \\
\hline 610 & 46.557 & 37.272 & 131.109 & 1052.022 & 1030.770 & & \\
\hline 611 & 44.639 & 35.736 & 122.472 & 1051.788 & 1034.850 & & \\
\hline 612 & 44.841 & 47.864 & 133.148 & 1051.461 & 1038.647 & & \\
\hline 613 & 41.070 & 47.492 & 122.244 & 1050.969 & 1041.828 & & \\
\hline 614 & 34.714 & 27.790 & 82.290 & 1050.517 & 1044.122 & & \\
\hline 615 & 3.640 & 7.123 & 16.527 & 1050.061 & 1046.727 & & \\
\hline 616 & 3.703 & 6.259 & 14.364 & 1049.961 & 1045.457 & & \\
\hline 617 & 3.703 & 6.259 & 14.364 & 1049.916 & 1045.764 & & \\
\hline 618 & 3.456 & 6.148 & 14.144 & 1049.896 & 1042.213 & & \\
\hline 619 & 4.635 & 6.597 & 15.212 & 1049.887 & 1040.193 & & \\
\hline 620 & 3.979 & 6.372 & 14.611 & 1049.883 & 1038.055 & & \\
\hline 621 & 3.843 & 6.837 & 15.949 & 1050.167 & 1037.375 & & \\
\hline 622 & 11.751 & 12.544 & 33.084 & 1050.567 & 1036.232 & & \\
\hline 623 & 8.399 & 11.206 & 28.424 & 1051.071 & 1034.600 & & \\
\hline 624 & 7.452 & 11.268 & 27.914 & 1051.244 & 1034.867 & & \\
\hline 625 & 12.277 & 16.380 & 42.252 & 1051.443 & 1033.636 & & \\
\hline 626 & 6.444 & 11.464 & 28.078 & 1051.491 & 1034.020 & & \\
\hline 627 & 14.553 & 12.945 & 41.258 & 1051.654 & 1032.249 & & \\
\hline 628 & 12.260 & 13.086 & 37.475 & 1051.686 & 1033.826 & & \\
\hline 629 & 14.553 & 12.945 & 41.258 & 1051.701 & 1032.612 & & \\
\hline 630 & 17.406 & 12.386 & 46.394 & 1051.707 & 1033.781 & & \\
\hline 631 & 14.553 & 12.945 & 41.258 & 1051.710 & 1033.021 & & \\
\hline 632 & 15.905 & 12.733 & 43.637 & 1051.711 & 1034.374 & & \\
\hline 633 & 10.707 & 13.334 & 35.842 & 1051.783 & 1035.989 & & \\
\hline 634 & 8.345 & 12.618 & 31.840 & 1051.723 & 1040.733 & & \\
\hline 635 & 8.966 & 12.761 & 32.663 & 1051.717 & 1044.887 & & \\
\hline 636 & 7.785 & 12.464 & 31.121 & 1051.714 & 1050.838 & & \\
\hline 637 & 7.785 & 12.464 & 31.121 & 1051.713 & 1055.925 & & \\
\hline 638 & 9.401 & 12.544 & 32.536 & 1051.641 & 1062.173 & & \\
\hline 639 & 7.412 & 11.868 & 29.633 & 1051.701 & 1065.049 & & \\
\hline
\end{tabular}




\begin{tabular}{|c|c|c|c|c|c|c|c|}
\hline hour & $\begin{array}{c}\text { Air } \\
\text { Change }\end{array}$ & $\begin{array}{c}\text { Air } \\
\text { Change } \\
(\mathbf{A C H})\end{array}$ & $\begin{array}{l}\text { ASHRAE } \\
\text { Enhanced }\end{array}$ & $\begin{array}{c}\text { Enhanced } \\
\text { Model }\end{array}$ & $\begin{array}{l}\text { Angular } \\
\text { Cracks }\end{array}$ & $\begin{array}{c}\text { Mixed } \\
\text { Cracks }\end{array}$ & $\begin{array}{l}\text { Straight } \\
\text { Cracks }\end{array}$ \\
\hline 640 & 10.431 & 12.989 & 34.708 & 1051.707 & 1068.894 & & \\
\hline 641 & 11.886 & 13.744 & 38.368 & 1051.852 & 1068.096 & & \\
\hline 642 & 15.100 & 13.431 & 43.868 & 1051.947 & 1068.412 & & \\
\hline 643 & 15.455 & 13.747 & 45.259 & 1052.041 & 1066.426 & & \\
\hline 644 & 16.092 & 14.314 & 47.871 & 1052.204 & 1065.868 & & \\
\hline 645 & 26.433 & 11.756 & 72.469 & 1052.450 & 1062.450 & & \\
\hline 646 & 31.270 & 8.345 & 85.151 & 1052.569 & 1061.539 & & \\
\hline 647 & 33.444 & 8.925 & 91.929 & 1052.673 & 1058.604 & & \\
\hline 648 & 35.781 & 19.097 & 102.987 & 1052.842 & 1056.493 & & \\
\hline 649 & 30.527 & 13.577 & 87.538 & 1052.947 & 1053.916 & & \\
\hline 650 & 41.381 & 18.404 & 117.629 & 1052.903 & 1052.934 & & \\
\hline 651 & 42.665 & 15.180 & 121.258 & 1052.974 & 1050.379 & & \\
\hline 652 & 46.151 & 20.526 & 134.636 & 1053.128 & 1049.049 & & \\
\hline 653 & 49.076 & 26.192 & 146.070 & 1053.228 & 1046.681 & & \\
\hline 654 & 52.727 & 37.521 & 161.029 & 1053.180 & 1047.368 & & \\
\hline 655 & 52.727 & 37.521 & 161.029 & 1053.179 & 1044.831 & & \\
\hline 656 & 52.727 & 37.521 & 161.029 & 1053.179 & 1045.366 & & \\
\hline 657 & 53.877 & 43.132 & 166.985 & 1053.107 & 1046.249 & & \\
\hline 658 & 52.853 & 47.013 & 163.303 & 1052.811 & 1049.717 & & \\
\hline 659 & 51.746 & 55.234 & 164.908 & 1052.404 & 1051.094 & & \\
\hline 660 & 52.056 & 64.826 & 177.381 & 1052.182 & 1055.656 & & \\
\hline 661 & 50.430 & 67.287 & 176.457 & 1051.911 & 1056.832 & & \\
\hline 662 & 49.893 & 66.570 & 172.669 & 1051.709 & 1059.536 & & \\
\hline 663 & 47.614 & 59.294 & 156.528 & 1051.588 & 1061.337 & & \\
\hline 664 & 46.259 & 53.492 & 144.487 & 1051.484 & 1061.341 & & \\
\hline 665 & 44.746 & 43.782 & 128.480 & 1051.458 & 1057.561 & & \\
\hline 666 & 44.746 & 43.782 & 128.480 & 1051.446 & 1055.141 & & \\
\hline 667 & 45.558 & 48.629 & 136.274 & 1051.441 & 1051.005 & & \\
\hline 668 & 45.558 & 48.629 & 136.274 & 1051.439 & 1049.463 & & \\
\hline 669 & 43.801 & 38.962 & 121.078 & 1051.438 & 1046.081 & & \\
\hline 670 & 43.126 & 38.361 & 118.189 & 1051.366 & 1043.170 & & \\
\hline 671 & 42.048 & 33.662 & 111.254 & 1051.355 & 1041.736 & & \\
\hline 672 & 40.788 & 29.025 & 104.609 & 1051.350 & 1038.913 & & \\
\hline 673 & 40.788 & 29.025 & 104.609 & 1051.347 & 1037.519 & & \\
\hline 674 & 34.484 & 18.404 & 84.220 & 1051.346 & 1035.861 & & \\
\hline 675 & 35.700 & 15.878 & 85.689 & 1051.346 & 1032.950 & & \\
\hline 676 & 39.094 & 20.865 & 95.479 & 1051.346 & 1032.826 & & \\
\hline 677 & 33.955 & 18.122 & 82.023 & 1051.274 & 1031.112 & & \\
\hline
\end{tabular}




\begin{tabular}{|c|c|c|c|c|c|c|c|}
\hline hour & $\begin{array}{c}\text { Air } \\
\text { Change }\end{array}$ & $\begin{array}{c}\text { Air } \\
\text { Change } \\
(\mathbf{A C H})\end{array}$ & $\begin{array}{l}\text { ASHRAE } \\
\text { Enhanced }\end{array}$ & $\begin{array}{c}\text { Enhanced } \\
\text { Model }\end{array}$ & $\begin{array}{l}\text { Angular } \\
\text { Cracks }\end{array}$ & $\begin{array}{c}\text { Mixed } \\
\text { Cracks }\end{array}$ & $\begin{array}{l}\text { Straight } \\
\text { Cracks }\end{array}$ \\
\hline 678 & 33.955 & 18.122 & 82.023 & 1051.263 & 1029.214 & & \\
\hline 679 & 27.052 & 19.250 & 68.693 & 1051.258 & 1028.803 & & \\
\hline 680 & 38.721 & 24.110 & 95.671 & 1051.256 & 1028.604 & & \\
\hline 681 & 39.531 & 28.130 & 99.371 & 1051.183 & 1031.378 & & \\
\hline 682 & 41.085 & 36.545 & 109.659 & 1051.100 & 1034.238 & & \\
\hline 683 & 40.400 & 35.936 & 106.862 & 1051.013 & 1039.627 & & \\
\hline 684 & 37.627 & 26.775 & 91.681 & 1050.923 & 1044.149 & & \\
\hline 685 & 16.806 & 13.454 & 41.963 & 1050.832 & 1048.406 & & \\
\hline 686 & 5.551 & 9.381 & 22.464 & 1050.883 & 1052.913 & & \\
\hline 687 & 4.931 & 9.649 & 23.368 & 1051.171 & 1053.910 & & \\
\hline 688 & 5.576 & 10.416 & 25.375 & 1051.359 & 1056.079 & & \\
\hline 689 & 5.912 & 11.044 & 27.077 & 1051.545 & 1056.424 & & \\
\hline 690 & 8.174 & 12.360 & 31.332 & 1051.729 & 1053.460 & & \\
\hline 691 & 12.891 & 13.760 & 39.966 & 1051.842 & 1053.227 & & \\
\hline 692 & 12.186 & 14.091 & 39.589 & 1051.943 & 1050.624 & & \\
\hline 693 & 7.804 & 13.883 & 34.834 & 1052.110 & 1050.633 & & \\
\hline 694 & 8.705 & 14.712 & 37.715 & 1052.428 & 1048.820 & & \\
\hline 695 & 11.200 & 15.941 & 43.059 & 1052.631 & 1049.805 & & \\
\hline 696 & 8.445 & 15.776 & 40.413 & 1052.823 & 1047.576 & & \\
\hline 697 & 11.162 & 17.872 & 47.815 & 1053.153 & 1037.927 & & \\
\hline 698 & 11.391 & 19.252 & 51.572 & 1053.503 & 1033.927 & & \\
\hline 699 & 12.108 & 20.463 & 55.407 & 1053.792 & 1031.863 & & \\
\hline 700 & 14.948 & 22.604 & 63.871 & 1054.001 & 1027.229 & & \\
\hline 701 & 9.425 & 20.959 & 54.812 & 1054.054 & 1025.137 & & \\
\hline 702 & 12.422 & 22.099 & 59.507 & 1054.077 & 1023.313 & & \\
\hline 703 & 13.705 & 23.162 & 63.610 & 1054.230 & 1022.090 & & \\
\hline 704 & 13.340 & 22.545 & 62.136 & 1054.328 & 1019.936 & & \\
\hline 705 & 19.273 & 24.001 & 75.200 & 1054.352 & 1021.254 & & \\
\hline 706 & 13.705 & 23.162 & 63.610 & 1054.291 & 1023.000 & & \\
\hline 707 & 15.294 & 21.767 & 62.999 & 1054.142 & 1026.658 & & \\
\hline 708 & 15.658 & 22.284 & 64.211 & 1054.045 & 1028.431 & & \\
\hline 709 & 17.252 & 21.484 & 65.963 & 1054.022 & 1032.026 & & \\
\hline 710 & 17.286 & 21.527 & 65.417 & 1053.869 & 1034.074 & & \\
\hline 711 & 19.250 & 23.972 & 72.467 & 1053.771 & 1035.878 & & \\
\hline 712 & 18.895 & 23.531 & 70.763 & 1053.676 & 1035.523 & & \\
\hline 713 & 17.722 & 23.646 & 68.778 & 1053.654 & 1035.353 & & \\
\hline 714 & 23.047 & 22.550 & 78.472 & 1053.645 & 1031.738 & & \\
\hline 715 & 22.330 & 23.835 & 79.239 & 1053.783 & 1029.401 & & \\
\hline
\end{tabular}




\begin{tabular}{|c|c|c|c|c|c|c|c|}
\hline hour & $\begin{array}{c}\text { Air } \\
\text { Change }\end{array}$ & $\begin{array}{c}\text { Air } \\
\text { Change } \\
(\mathbf{A C H})\end{array}$ & $\begin{array}{l}\text { ASHRAE } \\
\text { Enhanced }\end{array}$ & $\begin{array}{c}\text { Enhanced } \\
\text { Model }\end{array}$ & $\begin{array}{l}\text { Angular } \\
\text { Cracks }\end{array}$ & $\begin{array}{r}\text { Mixed } \\
\text { Cracks }\end{array}$ & $\begin{array}{c}\text { Straight } \\
\text { Cracks }\end{array}$ \\
\hline 716 & 22.330 & 23.835 & 79.239 & 1053.804 & 1027.134 & & \\
\hline 717 & 26.348 & 23.437 & 89.680 & 1053.956 & 1025.392 & & \\
\hline 718 & 28.570 & 22.872 & 95.719 & 1054.054 & 1023.658 & & \\
\hline 719 & 27.999 & 29.887 & 99.944 & 1053.934 & 1022.119 & & \\
\hline 720 & 24.996 & 31.127 & 94.591 & 1053.851 & 1021.979 & & \\
\hline 721 & 41.173 & 36.624 & 139.230 & 1053.905 & 1017.068 & & \\
\hline 722 & 41.663 & 40.766 & 145.453 & 1053.980 & 1017.738 & & \\
\hline 723 & 31.706 & 28.202 & 108.613 & 1054.065 & 1015.237 & & \\
\hline 724 & 33.630 & 26.923 & 113.428 & 1054.153 & 1015.482 & & \\
\hline 725 & 43.134 & 30.694 & 143.734 & 1054.243 & 1013.184 & & \\
\hline 726 & 55.128 & 39.230 & 184.956 & 1054.334 & 1013.092 & & \\
\hline 727 & 58.738 & 52.248 & 205.074 & 1054.355 & 1012.557 & & \\
\hline 728 & 42.644 & 41.725 & 150.703 & 1054.221 & 1014.883 & & \\
\hline 729 & 41.663 & 48.178 & 154.208 & 1054.059 & 1015.244 & & \\
\hline 730 & 40.683 & 47.044 & 148.928 & 1053.886 & 1019.472 & & \\
\hline 731 & 16.643 & 23.686 & 67.032 & 1053.707 & 1022.938 & & \\
\hline 732 & 14.202 & 20.213 & 56.942 & 1053.597 & 1028.775 & & \\
\hline 733 & 14.610 & 19.493 & 55.866 & 1053.425 & 1030.938 & & \\
\hline 734 & 11.944 & 19.123 & 51.364 & 1053.390 & 1034.757 & & \\
\hline 735 & 13.016 & 19.683 & 54.011 & 1053.446 & 1035.416 & & \\
\hline 736 & 15.210 & 20.294 & 58.740 & 1053.521 & 1036.224 & & \\
\hline 737 & 20.371 & 19.932 & 68.917 & 1053.535 & 1034.587 & & \\
\hline 738 & 20.063 & 19.631 & 68.312 & 1053.612 & 1031.302 & & \\
\hline 739 & 35.181 & 12.518 & 106.956 & 1053.697 & 1030.366 & & \\
\hline 740 & 37.148 & 9.913 & 112.348 & 1053.715 & 1027.498 & & \\
\hline 741 & 39.079 & 6.952 & 117.834 & 1053.722 & 1026.245 & & \\
\hline 742 & 40.683 & 10.856 & 124.034 & 1053.797 & 1023.751 & & \\
\hline 743 & 41.173 & 14.649 & 127.170 & 1053.881 & 1023.359 & & \\
\hline 744 & 33.906 & 18.096 & 107.430 & 1053.970 & 1020.565 & & \\
\hline
\end{tabular}




\section{Cumulative Data for Southwest Wall}

\section{Cumulative Southwest (SW) Wall Data (Watts)}

\begin{tabular}{|c|c|c|c|c|c|c|c|}
\hline \multirow[b]{2}{*}{ hour } & \multicolumn{3}{|c|}{$\begin{array}{l}\text { eUEST/DOE-2 Hourly Values } \\
\text { (no reduction multiplier) }\end{array}$} & \multirow[b]{2}{*}{$\begin{array}{c}\text { Enhanced } \\
\text { Model }\end{array}$} & \multicolumn{3}{|c|}{ CFD Multiphysisc Simulation } \\
\hline & $\begin{array}{c}\text { Air } \\
\text { Change }\end{array}$ & $\begin{array}{c}\text { Air } \\
\text { Change } \\
\text { (ACH) }\end{array}$ & $\begin{array}{l}\text { ASHRAE } \\
\text { Enhanced }\end{array}$ & & $\begin{array}{l}\text { Angular } \\
\text { Cracks }\end{array}$ & $\begin{array}{l}\text { Mixed } \\
\text { Cracks }\end{array}$ & $\begin{array}{l}\text { Straight } \\
\text { Cracks }\end{array}$ \\
\hline $\mathbf{1}$ & 27.84 & 12.38 & 78.44 & 562.56 & 1033.90 & 1001.09 & 990.94 \\
\hline 2 & 56.10 & 24.95 & 158.07 & 1327.44 & 2066.05 & 2000.65 & 1979.63 \\
\hline 3 & 84.53 & 40.12 & 243.37 & 2144.17 & 3097.34 & 2998.44 & 2966.69 \\
\hline 4 & 118.03 & 55.02 & 346.84 & 3012.62 & 4124.58 & 3994.01 & 3950.35 \\
\hline 5 & 151.66 & 72.97 & 455.77 & 3896.21 & 5149.73 & 4987.48 & 4932.26 \\
\hline 6 & 193.86 & 84.23 & 592.51 & 4754.37 & 6173.16 & 5979.10 & 5912.85 \\
\hline 7 & 233.43 & 98.31 & 721.36 & 5591.74 & 7194.17 & 6968.84 & 6893.16 \\
\hline 8 & 279.02 & 118.59 & 872.91 & 6422.64 & 8213.30 & 7957.18 & 7869.75 \\
\hline 9 & 324.11 & 134.63 & 1020.79 & 7295.84 & 9233.76 & 8949.11 & 8849.66 \\
\hline 10 & 361.47 & 151.25 & 1143.25 & 8177.70 & 10255.10 & 9947.88 & 9837.58 \\
\hline 11 & 399.26 & 168.05 & 1265.34 & 9050.24 & 11280.40 & 10955.20 & 10833.30 \\
\hline 12 & 429.71 & 189.73 & 1365.44 & 9919.51 & 12308.13 & 11971.55 & 11838.96 \\
\hline 13 & 460.72 & 209.03 & 1463.53 & 10799.16 & 13340.32 & 12997.12 & 12855.38 \\
\hline 14 & 494.34 & 229.97 & 1568.32 & 11723.12 & 14374.74 & 14030.52 & 13881.98 \\
\hline 15 & 527.48 & 250.60 & 1670.82 & 12651.24 & 15410.45 & 15067.82 & 14914.22 \\
\hline 16 & 567.18 & 275.32 & 1794.57 & 13571.78 & 16445.63 & 16104.15 & 15945.12 \\
\hline 17 & 618.85 & 307.49 & 1961.67 & 14492.86 & 17475.82 & 17133.68 & 16969.23 \\
\hline 18 & 673.75 & 336.79 & 2139.49 & 15438.39 & 18504.92 & 18157.48 & 17986.74 \\
\hline 19 & 731.11 & 372.51 & 2327.65 & 16424.57 & 19531.50 & 19175.70 & 18997.44 \\
\hline 20 & 785.33 & 406.27 & 2509.25 & 17391.58 & 20554.21 & 20189.10 & 20003.11 \\
\hline 21 & 841.79 & 436.40 & 2696.09 & 18331.75 & 21577.09 & 21198.64 & 21004.63 \\
\hline 22 & 885.91 & 459.95 & 2841.04 & 19253.05 & 22596.96 & 22204.75 & 22002.35 \\
\hline 23 & 944.89 & 496.67 & 3038.60 & 20189.41 & 23614.80 & 23207.99 & 22997.18 \\
\hline 24 & 1001.36 & 526.81 & 3225.44 & 21151.18 & 24632.32 & 24208.52 & 23988.59 \\
\hline 25 & 1063.22 & 565.33 & 3434.07 & 22099.81 & 25648.40 & 25207.54 & 24980.11 \\
\hline 26 & 1124.87 & 614.68 & 3643.39 & 23033.46 & 26664.83 & 26204.64 & 25967.62 \\
\hline 27 & 1185.62 & 657.91 & 3848.56 & 23958.25 & 27679.17 & 27200.27 & 26954.61 \\
\hline 28 & 1240.82 & 682.46 & 4028.22 & 24884.50 & 28693.85 & 28194.97 & 27941.02 \\
\hline 29 & 1297.84 & 712.89 & 4212.92 & 25814.74 & 29708.43 & 29188.85 & 28925.32 \\
\hline
\end{tabular}




\begin{tabular}{|c|c|c|c|c|c|c|c|}
\hline hour & $\begin{array}{c}\text { Air } \\
\text { Change }\end{array}$ & $\begin{array}{c}\text { Air } \\
\text { Change } \\
\text { (ACH) }\end{array}$ & $\begin{array}{l}\text { ASHRAE } \\
\text { Enhanced }\end{array}$ & $\begin{array}{c}\text { Enhanced } \\
\text { Model }\end{array}$ & $\begin{array}{l}\text { Angular } \\
\text { Cracks }\end{array}$ & $\begin{array}{r}\text { Mixed } \\
\text { Cracks }\end{array}$ & $\begin{array}{c}\text { Straight } \\
\text { Cracks }\end{array}$ \\
\hline 30 & 1358.02 & 750.37 & 4411.73 & 26743.47 & 30723.26 & 30181.91 & 29909.18 \\
\hline 31 & 1421.98 & 801.56 & 4628.86 & 27669.47 & 31737.88 & 31174.62 & 30893.38 \\
\hline 32 & 1484.69 & 851.77 & 4838.99 & 28593.44 & 32751.87 & 32167.50 & 31878.06 \\
\hline 33 & 1542.04 & 892.58 & 5024.82 & 29516.13 & 33768.97 & 33165.30 & 32867.95 \\
\hline 34 & 1603.24 & 947.02 & 5227.71 & 30422.17 & 34790.80 & 34171.50 & 33866.13 \\
\hline 35 & 1660.32 & 992.71 & 5407.25 & 31304.57 & 35816.77 & 35187.55 & 34874.80 \\
\hline 36 & 1715.08 & 1041.43 & 5580.20 & 32168.79 & 36848.37 & 36213.57 & 35893.15 \\
\hline 37 & 1768.96 & 1084.56 & 5743.42 & 33033.97 & 37883.49 & 37249.48 & 36924.41 \\
\hline 38 & 1821.54 & 1126.65 & 5900.25 & 33947.21 & 38923.19 & 38292.74 & 37965.73 \\
\hline 39 & 1875.90 & 1179.84 & 6071.01 & 34853.36 & 39964.33 & 39340.78 & 39013.58 \\
\hline 40 & 1928.46 & 1226.59 & 6229.79 & 35739.11 & 41007.79 & 40390.38 & 40062.85 \\
\hline 41 & 1981.02 & 1273.34 & 6388.58 & 36612.25 & 42049.15 & 41435.19 & 41105.53 \\
\hline 42 & 2034.68 & 1325.84 & 6555.95 & 37483.78 & 43089.58 & 42475.16 & 42144.81 \\
\hline 43 & 2089.27 & 1384.12 & 6732.29 & 38366.95 & 44128.29 & 43510.78 & 43178.44 \\
\hline 44 & 2140.55 & 1425.17 & 6882.81 & 39249.62 & 45165.81 & 44542.76 & 44208.12 \\
\hline 45 & 2195.14 & 1483.44 & 7059.14 & 40126.71 & 46203.96 & 45572.18 & 45233.98 \\
\hline 46 & 2249.15 & 1555.50 & 7253.28 & 40998.93 & 47242.09 & 46599.40 & 46257.83 \\
\hline 47 & 2301.75 & 1616.33 & 7427.47 & 41872.12 & 48279.74 & 47624.89 & 47280.11 \\
\hline 48 & 2355.10 & 1682.77 & 7611.40 & 42755.54 & 49317.57 & 48648.44 & 48299.07 \\
\hline 49 & 2406.98 & 1728.92 & 7766.94 & 43628.51 & 50354.58 & 49670.83 & 49318.05 \\
\hline 50 & 2459.94 & 1780.73 & 7930.94 & 44487.22 & 51391.92 & 50692.04 & 50335.20 \\
\hline 51 & 2513.29 & 1842.42 & 8106.48 & 45340.09 & 52429.33 & 51712.84 & 51351.19 \\
\hline 52 & 2564.39 & 1901.52 & 8271.45 & 46227.38 & 53468.16 & 52733.80 & 52366.52 \\
\hline 53 & 2613.31 & 1966.78 & 8440.74 & 47134.38 & 54506.85 & 53754.87 & 53382.64 \\
\hline 54 & 2660.29 & 2016.94 & 8583.33 & 48023.59 & 55547.24 & 54776.03 & 54398.20 \\
\hline 55 & 2708.01 & 2072.12 & 8734.38 & 48898.18 & 56587.66 & 55797.32 & 55414.51 \\
\hline 56 & 2755.74 & 2127.30 & 8885.43 & 49767.14 & 57627.55 & 56818.61 & 56430.20 \\
\hline 57 & 2803.46 & 2182.48 & 9036.49 & 50647.13 & 58671.43 & 57844.40 & 57450.70 \\
\hline 58 & 2847.93 & 2222.04 & 9160.48 & 51539.12 & 59717.35 & 58878.02 & 58479.56 \\
\hline 59 & 2891.98 & 2265.14 & 9285.95 & 52436.22 & 60768.30 & 59921.17 & 59516.62 \\
\hline 60 & 2930.01 & 2298.97 & 9387.46 & 53333.97 & 61822.96 & 60974.27 & 60564.71 \\
\hline 61 & 2963.41 & 2322.74 & 9467.11 & 54242.77 & 62883.06 & 62037.15 & 61625.21 \\
\hline 62 & 2998.34 & 2353.81 & 9556.12 & 55182.20 & 63945.91 & 63107.25 & 62695.54 \\
\hline 63 & 3034.57 & 2386.03 & 9646.71 & 56121.31 & 65012.25 & 64182.17 & 63772.46 \\
\hline 64 & 3070.80 & 2418.26 & 9737.29 & 57039.59 & 66078.25 & 65257.73 & 64851.84 \\
\hline 65 & 3109.82 & 2459.91 & 9846.28 & 57937.30 & 67141.95 & 66327.35 & 65921.64 \\
\hline 66 & 3149.63 & 2498.87 & 9954.21 & 58838.03 & 68203.76 & 67391.74 & 66985.56 \\
\hline 67 & 3188.65 & 2533.58 & 10055.55 & 59764.23 & 69264.55 & 68451.56 & 68044.84 \\
\hline
\end{tabular}




\begin{tabular}{|c|c|c|c|c|c|c|c|}
\hline hour & $\begin{array}{c}\text { Air } \\
\text { Change }\end{array}$ & $\begin{array}{c}\text { Air } \\
\text { Change } \\
(\mathrm{ACH})\end{array}$ & $\begin{array}{l}\text { ASHRAE } \\
\text { Enhanced }\end{array}$ & $\begin{array}{c}\text { Enhanced } \\
\text { Model }\end{array}$ & $\begin{array}{l}\text { Angular } \\
\text { Cracks }\end{array}$ & $\begin{array}{r}\text { Mixed } \\
\text { Cracks }\end{array}$ & $\begin{array}{c}\text { Straight } \\
\text { Cracks }\end{array}$ \\
\hline 68 & 3227.67 & 2568.29 & 10156.88 & 60676.40 & 70324.13 & 69507.23 & 69098.23 \\
\hline 69 & 3266.70 & 2603.00 & 10258.22 & 61568.13 & 71382.35 & 70558.86 & 70147.97 \\
\hline 70 & 3302.60 & 2622.16 & 10343.02 & 62446.75 & 72439.59 & 71607.33 & 71192.93 \\
\hline 71 & 3321.67 & 2632.34 & 10388.07 & 63324.63 & 73496.44 & 72653.78 & 72236.48 \\
\hline 72 & 3337.94 & 2642.46 & 10426.10 & 64212.54 & 74552.98 & 73698.59 & 73277.29 \\
\hline 73 & 3353.54 & 2650.79 & 10460.83 & 65105.57 & 75609.20 & 74742.57 & 74317.91 \\
\hline 74 & 3361.07 & 2658.83 & 10481.36 & 65996.84 & 76667.20 & 75786.46 & 75357.31 \\
\hline 75 & 3367.83 & 2666.04 & 10499.34 & 66884.94 & 77725.03 & 76830.05 & 76396.79 \\
\hline 76 & 3373.47 & 2673.07 & 10516.07 & 67788.91 & 78783.32 & 77872.68 & 77434.99 \\
\hline 77 & 3382.60 & 2681.19 & 10538.68 & 68701.42 & 79841.79 & 78914.85 & 78472.59 \\
\hline 78 & 3389.87 & 2688.95 & 10558.34 & 69612.77 & 80899.97 & 79956.52 & 79510.27 \\
\hline 79 & 3395.95 & 2696.52 & 10576.61 & 70519.57 & 81958.26 & 80997.65 & 80546.79 \\
\hline 80 & 3403.48 & 2704.55 & 10597.14 & 71420.74 & 83017.27 & 82038.48 & 81583.20 \\
\hline 81 & 3409.06 & 2712.00 & 10614.87 & 72327.48 & 84078.96 & 83083.84 & 82624.08 \\
\hline 82 & 3414.24 & 2718.91 & 10631.12 & 73237.65 & 85142.00 & 84136.53 & 83671.54 \\
\hline 83 & 3419.66 & 2725.67 & 10647.11 & 74138.52 & 86208.89 & 85198.30 & 84728.14 \\
\hline 84 & 3424.88 & 2732.16 & 10662.37 & 75021.72 & 87280.10 & 86269.14 & 85794.10 \\
\hline 85 & 3430.13 & 2738.70 & 10677.65 & 75889.47 & 88354.94 & 87348.99 & 86870.83 \\
\hline 86 & 3435.91 & 2744.86 & 10692.50 & 76775.52 & 89431.71 & 88435.39 & 87958.21 \\
\hline 87 & 3442.70 & 2750.91 & 10707.98 & 77651.48 & 90509.82 & 89524.89 & 89051.62 \\
\hline 88 & 3450.34 & 2757.71 & 10725.97 & 78499.96 & 91587.86 & 90613.40 & 90142.54 \\
\hline 89 & 3459.84 & 2766.16 & 10749.49 & 79323.78 & 92662.61 & 91694.56 & 91226.45 \\
\hline 90 & 3470.31 & 2775.46 & 10776.15 & 80131.48 & 93732.92 & 92768.89 & 92301.72 \\
\hline 91 & 3493.03 & 2781.53 & 10826.36 & 80935.02 & 94801.41 & 93837.05 & 93368.44 \\
\hline 92 & 3514.78 & 2789.27 & 10875.48 & 81734.70 & 95865.74 & 94898.78 & 94428.88 \\
\hline 93 & 3534.08 & 2801.28 & 10924.17 & 82535.29 & 96928.02 & 95955.56 & 95483.58 \\
\hline 94 & 3561.62 & 2813.53 & 10990.28 & 83341.49 & 97987.56 & 97007.81 & 96532.53 \\
\hline 95 & 3586.28 & 2824.50 & 11050.13 & 84162.16 & 99044.09 & 98055.80 & 97578.00 \\
\hline 96 & 3623.60 & 2841.10 & 11142.72 & 85002.27 & 100099.26 & 99100.47 & 98618.91 \\
\hline 97 & 3662.93 & 2862.08 & 11241.88 & 85852.73 & 101151.56 & 100142.09 & 99656.47 \\
\hline 98 & 3706.20 & 2892.88 & 11357.22 & 86711.93 & 102203.75 & 101181.56 & 100692.01 \\
\hline 99 & 3749.55 & 2927.58 & 11474.04 & 87578.56 & 103254.42 & 102218.99 & 101724.51 \\
\hline 100 & 3792.90 & 2962.28 & 11590.86 & 88479.36 & 104305.33 & 103255.05 & 102756.99 \\
\hline 101 & 3833.69 & 2991.31 & 11695.47 & 89390.88 & 105354.78 & 104289.94 & 103788.22 \\
\hline 102 & 3875.24 & 3020.88 & 11800.99 & 90298.55 & 106404.50 & 105324.00 & 104817.20 \\
\hline 103 & 3918.59 & 3063.30 & 11923.48 & 91201.79 & 107453.83 & 106358.00 & 105847.25 \\
\hline 104 & 3960.41 & 3111.65 & 12048.83 & 92104.32 & 108504.54 & 107391.89 & 106877.42 \\
\hline 105 & 4001.99 & 3152.33 & 12162.49 & 93027.84 & 109555.98 & 108430.09 & 107910.34 \\
\hline
\end{tabular}




\begin{tabular}{|c|c|c|c|c|c|c|c|}
\hline hour & $\begin{array}{c}\text { Air } \\
\text { Change }\end{array}$ & $\begin{array}{c}\text { Air } \\
\text { Change } \\
\text { (ACH) }\end{array}$ & $\begin{array}{l}\text { ASHRAE } \\
\text { Enhanced }\end{array}$ & $\begin{array}{c}\text { Enhanced } \\
\text { Model }\end{array}$ & $\begin{array}{l}\text { Angular } \\
\text { Cracks }\end{array}$ & $\begin{array}{l}\text { Mixed } \\
\text { Cracks }\end{array}$ & $\begin{array}{l}\text { Straight } \\
\text { Cracks }\end{array}$ \\
\hline 106 & 4043.06 & 3199.82 & 12284.73 & 93948.76 & 110613.19 & 109476.62 & 108952.05 \\
\hline 107 & 4080.60 & 3239.89 & 12387.93 & 94856.46 & 111672.85 & 110533.06 & 110004.13 \\
\hline 108 & 4115.35 & 3273.90 & 12476.49 & 95756.77 & 112737.07 & 111599.37 & 111065.09 \\
\hline 109 & 4149.14 & 3309.97 & 12565.64 & 96654.72 & 113805.97 & 112675.37 & 112137.67 \\
\hline 110 & 4181.69 & 3341.81 & 12646.29 & 97566.36 & 114879.13 & 113758.67 & 113221.14 \\
\hline 111 & 4210.84 & 3367.75 & 12714.18 & 98485.15 & 115952.84 & 114846.02 & 114311.49 \\
\hline 112 & 4240.27 & 3386.07 & 12774.93 & 99402.05 & 117027.25 & 115932.80 & 115401.54 \\
\hline 113 & 4271.76 & 3411.28 & 12848.77 & 100315.36 & 118096.95 & 117012.51 & 116481.73 \\
\hline 114 & 4295.37 & 3423.88 & 12901.29 & 101232.88 & 119164.91 & 118086.03 & 117555.78 \\
\hline 115 & 4315.06 & 3434.39 & 12945.64 & 102158.97 & 120229.57 & 119153.52 & 118622.82 \\
\hline 116 & 4336.16 & 3445.65 & 12994.92 & 103064.67 & 121292.38 & 120215.72 & 119684.28 \\
\hline 117 & 4355.23 & 3455.83 & 13039.96 & 103944.57 & 122352.47 & 121273.35 & 120739.82 \\
\hline 118 & 4381.80 & 3467.64 & 13102.26 & 104806.16 & 123410.87 & 122326.81 & 121789.98 \\
\hline 119 & 4408.85 & 3467.64 & 13164.59 & 105672.67 & 124468.50 & 123376.76 & 122837.14 \\
\hline 120 & 4432.04 & 3475.90 & 13218.90 & 106565.47 & 125525.42 & 124423.70 & 123880.10 \\
\hline 121 & 4454.32 & 3483.82 & 13271.09 & 107447.95 & 126579.20 & 125468.27 & 124920.73 \\
\hline 122 & 4480.88 & 3483.82 & 13331.53 & 108316.64 & 127632.56 & 126511.03 & 125959.39 \\
\hline 123 & 4506.95 & 3483.82 & 13390.12 & 109180.62 & 128685.28 & 127552.18 & 126996.47 \\
\hline 124 & 4526.02 & 3494.00 & 13435.16 & 110081.35 & 129738.45 & 128592.13 & 128032.60 \\
\hline 125 & 4544.72 & 3502.32 & 13478.01 & 111008.75 & 130791.22 & 129631.24 & 129067.56 \\
\hline 126 & 4565.73 & 3509.79 & 13524.85 & 111932.78 & 131843.07 & 130669.58 & 130103.82 \\
\hline 127 & 4590.75 & 3516.47 & 13580.13 & 112842.88 & 132895.14 & 131706.95 & 131135.85 \\
\hline 128 & 4611.32 & 3523.79 & 13626.58 & 113742.35 & 133946.26 & 132743.61 & 132167.92 \\
\hline 129 & 4628.47 & 3535.99 & 13668.82 & 114656.47 & 135000.00 & 133784.51 & 133204.01 \\
\hline 130 & 4640.70 & 3545.79 & 13699.37 & 115566.84 & 136055.68 & 134832.57 & 134246.69 \\
\hline 131 & 4649.68 & 3555.37 & 13724.63 & 116460.50 & 137115.42 & 135888.84 & 135298.12 \\
\hline 132 & 4657.24 & 3564.78 & 13748.13 & 117337.74 & 138178.48 & 136954.32 & 136357.45 \\
\hline 133 & 4663.03 & 3573.53 & 13769.00 & 118209.44 & 139244.87 & 138028.67 & 137428.76 \\
\hline 134 & 4669.03 & 3581.54 & 13788.29 & 119103.28 & 140314.51 & 139109.76 & 138510.97 \\
\hline 135 & 4674.64 & 3589.53 & 13807.22 & 119997.89 & 141385.25 & 140195.18 & 139597.78 \\
\hline 136 & 4679.86 & 3596.96 & 13824.61 & 120889.41 & 142457.51 & 141281.13 & 140686.93 \\
\hline 137 & 4683.61 & 3603.63 & 13840.06 & 121780.71 & 143526.44 & 142361.25 & 141769.24 \\
\hline 138 & 4687.79 & 3610.69 & 13856.45 & 122676.15 & 144594.95 & 143436.15 & 142843.83 \\
\hline 139 & 4693.65 & 3618.51 & 13875.07 & 123580.15 & 145660.99 & 144505.91 & 143913.73 \\
\hline 140 & 4705.25 & 3626.77 & 13901.83 & 124476.14 & 146726.21 & 145571.35 & 144977.25 \\
\hline 141 & 4721.20 & 3635.28 & 13936.42 & 125353.15 & 147789.66 & 146633.08 & 146036.99 \\
\hline 142 & 4734.90 & 3647.46 & 13970.33 & 126204.67 & 148853.17 & 147692.00 & 147093.05 \\
\hline 143 & 4757.03 & 3667.15 & 14025.12 & 127042.40 & 149915.77 & 148748.24 & 148146.58 \\
\hline
\end{tabular}




\begin{tabular}{|c|c|c|c|c|c|c|c|}
\hline hour & $\begin{array}{c}\text { Air } \\
\text { Change }\end{array}$ & $\begin{array}{c}\text { Air } \\
\text { Change } \\
\text { (ACH) }\end{array}$ & $\begin{array}{l}\text { ASHRAE } \\
\text { Enhanced }\end{array}$ & $\begin{array}{c}\text { Enhanced } \\
\text { Model }\end{array}$ & $\begin{array}{l}\text { Angular } \\
\text { Cracks }\end{array}$ & $\begin{array}{l}\text { Mixed } \\
\text { Cracks }\end{array}$ & $\begin{array}{l}\text { Straight } \\
\text { Cracks }\end{array}$ \\
\hline 144 & 4790.06 & 3696.53 & 14106.89 & 127879.57 & 150976.98 & 149802.02 & 149196.14 \\
\hline 145 & 4804.16 & 3709.07 & 14142.16 & 128710.70 & 152038.44 & 150854.11 & 150244.92 \\
\hline 146 & 4808.75 & 3716.43 & 14159.39 & 129534.57 & 153098.00 & 151904.44 & 151291.74 \\
\hline 147 & 4814.29 & 3724.31 & 14178.16 & 130351.94 & 154158.47 & 152953.16 & 152335.82 \\
\hline 148 & 4820.03 & 3732.48 & 14197.71 & 131188.53 & 155216.30 & 154000.16 & 153378.85 \\
\hline 149 & 4827.02 & 3741.18 & 14219.28 & 132033.01 & 156274.39 & 155046.05 & 154421.38 \\
\hline 150 & 4832.76 & 3749.34 & 14238.83 & 133083.54 & 157332.71 & 156091.23 & 155462.93 \\
\hline 151 & 4838.10 & 3756.95 & 14256.84 & 134133.92 & 158390.98 & 157135.41 & 156503.59 \\
\hline 152 & 4845.22 & 3765.18 & 14277.43 & 135184.35 & 159448.35 & 158178.95 & 157542.10 \\
\hline 153 & 4853.01 & 3773.50 & 14298.85 & 136234.78 & 160507.63 & 159225.21 & 158583.84 \\
\hline 154 & 4861.72 & 3783.57 & 14324.05 & 137285.21 & 161569.23 & 160277.91 & 159630.91 \\
\hline 155 & 4871.18 & 3797.02 & 14356.93 & 138335.99 & 162630.91 & 161338.00 & 160686.51 \\
\hline 156 & 4878.01 & 3811.01 & 14390.76 & 139387.05 & 163694.68 & 162405.07 & 161747.99 \\
\hline 157 & 4883.22 & 3821.66 & 14416.74 & 140438.38 & 164759.54 & 163478.72 & 162818.94 \\
\hline 158 & 4889.08 & 3833.13 & 14444.83 & 141489.91 & 165824.97 & 164556.36 & 163896.47 \\
\hline 159 & 4895.85 & 3845.77 & 14476.13 & 142541.71 & 166889.63 & 165635.27 & 164977.38 \\
\hline 160 & 4904.51 & 3859.64 & 14511.34 & 143593.70 & 167951.41 & 166711.83 & 166055.57 \\
\hline 161 & 4913.95 & 3879.79 & 14561.90 & 144646.02 & 169007.71 & 167779.75 & 167124.39 \\
\hline 162 & 4920.73 & 3894.28 & 14598.36 & 145698.49 & 170060.17 & 168839.72 & 168185.07 \\
\hline 163 & 4928.91 & 3910.28 & 14639.06 & 146751.21 & 171108.49 & 169892.44 & 169236.80 \\
\hline 164 & 4938.56 & 3927.45 & 14683.47 & 147804.12 & 172154.32 & 170938.98 & 170282.06 \\
\hline 165 & 4947.65 & 3944.42 & 14727.08 & 148857.08 & 173196.78 & 171980.18 & 171322.28 \\
\hline 166 & 4964.26 & 3968.06 & 14791.85 & 149910.06 & 174236.57 & 173016.75 & 172355.37 \\
\hline 167 & 4975.96 & 3985.75 & 14839.36 & 150963.04 & 175275.02 & 174049.16 & 173384.07 \\
\hline 168 & 4988.17 & 4004.23 & 14889.42 & 152016.18 & 176310.75 & 175077.94 & 174409.21 \\
\hline 169 & 5005.36 & 4022.58 & 14948.25 & 153069.41 & 177345.16 & 176104.72 & 175431.99 \\
\hline 170 & 5021.28 & 4040.98 & 15004.55 & 154122.66 & 178377.86 & 177127.91 & 176451.37 \\
\hline 171 & 5038.15 & 4060.49 & 15064.59 & 155175.99 & 179408.69 & 178148.30 & 177467.42 \\
\hline 172 & 5058.15 & 4080.05 & 15131.81 & 156229.41 & 180437.68 & 179166.36 & 178480.97 \\
\hline 173 & 5085.68 & 4102.10 & 15219.69 & 157282.85 & 181465.04 & 180181.87 & 179492.00 \\
\hline 174 & 5117.42 & 4121.86 & 15318.62 & 158336.44 & 182491.82 & 181195.29 & 180500.69 \\
\hline 175 & 5147.70 & 4138.02 & 15412.39 & 159390.13 & 183516.01 & 182206.89 & 181506.93 \\
\hline 176 & 5177.98 & 4154.18 & 15506.16 & 160443.84 & 184540.55 & 183217.19 & 182512.22 \\
\hline 177 & 5204.09 & 4172.76 & 15588.98 & 161497.49 & 185564.89 & 184231.15 & 183520.92 \\
\hline 178 & 5229.64 & 4193.22 & 15670.52 & 162550.99 & 186592.54 & 185251.94 & 184537.03 \\
\hline 179 & 5256.06 & 4212.01 & 15751.81 & 163604.32 & 187623.97 & 186281.49 & 185560.54 \\
\hline 180 & 5281.55 & 4227.88 & 15827.60 & 164657.47 & 188659.56 & 187320.04 & 186594.23 \\
\hline 181 & 5309.39 & 4240.27 & 15906.04 & 165710.38 & 189697.76 & 188367.31 & 187638.88 \\
\hline
\end{tabular}




\begin{tabular}{|c|c|c|c|c|c|c|c|}
\hline hour & $\begin{array}{c}\text { Air } \\
\text { Change }\end{array}$ & $\begin{array}{c}\text { Air } \\
\text { Change } \\
\text { (ACH) }\end{array}$ & $\begin{array}{l}\text { ASHRAE } \\
\text { Enhanced }\end{array}$ & $\begin{array}{c}\text { Enhanced } \\
\text { Model }\end{array}$ & $\begin{array}{l}\text { Angular } \\
\text { Cracks }\end{array}$ & $\begin{array}{l}\text { Mixed } \\
\text { Cracks }\end{array}$ & $\begin{array}{l}\text { Straight } \\
\text { Cracks }\end{array}$ \\
\hline 182 & 5335.57 & 4254.24 & 15980.74 & 166763.23 & 190738.93 & 189421.26 & 188692.40 \\
\hline 183 & 5357.41 & 4269.78 & 16044.84 & 167815.99 & 191781.59 & 190479.44 & 189752.75 \\
\hline 184 & 5379.25 & 4285.32 & 16108.94 & 168868.73 & 192823.34 & 191537.68 & 190813.78 \\
\hline 185 & 5410.37 & 4299.16 & 16197.42 & 169921.60 & 193863.34 & 192589.56 & 191866.64 \\
\hline 186 & 5443.45 & 4310.93 & 16291.43 & 170974.56 & 194899.67 & 193635.09 & 192911.93 \\
\hline 187 & 5477.93 & 4320.13 & 16391.43 & 172027.75 & 195934.05 & 194674.86 & 193950.77 \\
\hline 188 & 5512.96 & 4332.60 & 16494.50 & 173081.06 & 196966.45 & 195709.89 & 194983.01 \\
\hline 189 & 5545.86 & 4344.31 & 16591.30 & 174134.39 & 197997.98 & 196740.69 & 196012.13 \\
\hline 190 & 5583.61 & 4344.31 & 16700.24 & 175187.67 & 199027.85 & 197768.29 & 197036.76 \\
\hline 191 & 5616.87 & 4356.14 & 16796.45 & 176240.88 & 200057.73 & 198793.19 & 198057.62 \\
\hline 192 & 5648.66 & 4367.45 & 16887.58 & 177293.99 & 201086.19 & 199816.23 & 199077.54 \\
\hline 193 & 5679.47 & 4378.41 & 16974.37 & 178346.95 & 202115.56 & 200838.15 & 200095.93 \\
\hline 194 & 5706.11 & 4392.63 & 17051.04 & 179399.88 & 203143.51 & 201858.85 & 201113.38 \\
\hline 195 & 5736.12 & 4405.98 & 17136.37 & 180452.79 & 204172.57 & 202878.32 & 202129.10 \\
\hline 196 & 5770.87 & 4421.44 & 17233.40 & 181505.56 & 205200.26 & 203896.81 & 203142.52 \\
\hline 197 & 5799.57 & 4434.20 & 17313.54 & 182558.30 & 206228.76 & 204914.55 & 204155.73 \\
\hline 198 & 5831.77 & 4442.79 & 17402.03 & 183611.03 & 207256.57 & 205931.83 & 205168.18 \\
\hline 199 & 5862.89 & 4453.87 & 17487.33 & 184663.68 & 208285.36 & 206948.59 & 206180.13 \\
\hline 200 & 5890.21 & 4466.02 & 17562.92 & 185716.32 & 209314.57 & 207965.10 & 207191.75 \\
\hline 201 & 5923.95 & 4478.02 & 17654.53 & 186768.88 & 210345.90 & 208986.10 & 208207.74 \\
\hline 202 & 5954.86 & 4486.27 & 17737.08 & 187821.36 & 211379.67 & 210014.50 & 209231.66 \\
\hline 203 & 5984.52 & 4496.82 & 17816.08 & 188873.75 & 212418.95 & 211051.97 & 210265.07 \\
\hline 204 & 6013.84 & 4504.65 & 17892.86 & 189926.04 & 213461.27 & 212098.93 & 211305.47 \\
\hline 205 & 6038.45 & 4515.59 & 17957.15 & 190978.18 & 214507.32 & 213155.19 & 212360.09 \\
\hline 206 & 6062.12 & 4526.12 & 18017.77 & 192030.14 & 215556.35 & 214218.55 & 213424.07 \\
\hline 207 & 6083.21 & 4539.25 & 18073.14 & 193081.99 & 216607.28 & 215285.73 & 214492.75 \\
\hline 208 & 6108.61 & 4552.80 & 18140.49 & 194134.03 & 217656.70 & 216353.25 & 215562.72 \\
\hline 209 & 6134.48 & 4566.61 & 18209.76 & 195186.17 & 218704.80 & 217414.36 & 216625.46 \\
\hline 210 & 6159.20 & 4582.01 & 18277.78 & 196238.39 & 219751.14 & 218469.70 & 217680.20 \\
\hline 211 & 6178.96 & 4596.07 & 18333.38 & 197290.63 & 220793.90 & 219519.77 & 218730.14 \\
\hline 212 & 6198.72 & 4610.13 & 18388.99 & 198342.89 & 221836.25 & 220565.27 & 219772.85 \\
\hline 213 & 6218.48 & 4624.19 & 18444.59 & 199395.15 & 222877.39 & 221606.78 & 220812.46 \\
\hline 214 & 6241.71 & 4640.72 & 18509.93 & 200447.41 & 223918.17 & 222645.17 & 221848.76 \\
\hline 215 & 6260.84 & 4659.44 & 18568.75 & 201499.67 & 224956.47 & 223680.78 & 222880.52 \\
\hline 216 & 6279.97 & 4678.16 & 18627.58 & 202551.93 & 225994.45 & 224714.05 & 223909.78 \\
\hline 217 & 6297.90 & 4697.30 & 18684.73 & 203604.19 & 227032.64 & 225746.03 & 224938.86 \\
\hline 218 & 6315.84 & 4716.44 & 18741.88 & 204656.45 & 228069.84 & 226776.51 & 225965.31 \\
\hline 219 & 6333.77 & 4735.58 & 18799.03 & 205708.72 & 229107.05 & 227805.28 & 226989.15 \\
\hline
\end{tabular}




\begin{tabular}{|c|c|c|c|c|c|c|c|}
\hline hour & $\begin{array}{c}\text { Air } \\
\text { Change }\end{array}$ & $\begin{array}{c}\text { Air } \\
\text { Change } \\
\text { (ACH) }\end{array}$ & $\begin{array}{l}\text { ASHRAE } \\
\text { Enhanced }\end{array}$ & $\begin{array}{c}\text { Enhanced } \\
\text { Model }\end{array}$ & $\begin{array}{l}\text { Angular } \\
\text { Cracks }\end{array}$ & $\begin{array}{r}\text { Mixed } \\
\text { Cracks }\end{array}$ & $\begin{array}{l}\text { Straight } \\
\text { Cracks }\end{array}$ \\
\hline 220 & 6345.83 & 4750.61 & 18840.61 & 206760.98 & 230142.68 & 228832.41 & 228012.47 \\
\hline 221 & 6361.62 & 4770.27 & 18895.05 & 207813.24 & 231177.92 & 229858.27 & 229034.29 \\
\hline 222 & 6377.41 & 4789.93 & 18949.49 & 208865.50 & 232214.09 & 230883.13 & 230055.02 \\
\hline 223 & 6390.57 & 4809.82 & 19001.05 & 209917.76 & 233250.12 & 231907.11 & 231074.97 \\
\hline 224 & 6401.76 & 4824.75 & 19041.28 & 210970.02 & 234285.00 & 232930.43 & 232092.50 \\
\hline 225 & 6412.95 & 4839.69 & 19081.51 & 212022.29 & 235321.80 & 233956.77 & 233114.40 \\
\hline 226 & 6426.10 & 4859.57 & 19133.07 & 213074.55 & 236359.84 & 234989.70 & 234142.27 \\
\hline 227 & 6439.25 & 4879.46 & 19184.64 & 214126.81 & 237402.29 & 236030.98 & 235177.34 \\
\hline 228 & 6450.34 & 4899.18 & 19234.28 & 215179.07 & 238446.89 & 237081.56 & 236222.47 \\
\hline 229 & 6462.51 & 4918.67 & 19283.97 & 216231.26 & 239496.28 & 238140.85 & 237278.60 \\
\hline 230 & 6474.40 & 4937.70 & 19332.28 & 217283.37 & 240546.09 & 239206.12 & 238343.77 \\
\hline 231 & 6487.31 & 4957.23 & 19382.68 & 218335.53 & 241598.29 & 240274.54 & 239414.40 \\
\hline 232 & 6497.97 & 4972.41 & 19422.90 & 219387.84 & 242648.19 & 241342.25 & 240483.22 \\
\hline 233 & 6511.21 & 4988.89 & 19469.58 & 220440.39 & 243695.16 & 242402.60 & 241544.36 \\
\hline 234 & 6525.80 & 5005.76 & 19519.41 & 221493.05 & 244738.82 & 243456.49 & 242598.55 \\
\hline 235 & 6541.91 & 5022.95 & 19572.82 & 222545.82 & 245779.22 & 244503.92 & 243644.60 \\
\hline 236 & 6567.65 & 5043.56 & 19652.61 & 223598.83 & 246817.83 & 245545.81 & 244684.98 \\
\hline 237 & 6589.77 & 5061.27 & 19721.68 & 224651.95 & 247853.56 & 246582.31 & 245719.28 \\
\hline 238 & 6615.02 & 5079.24 & 19800.57 & 225705.31 & 248887.44 & 247614.15 & 246748.48 \\
\hline 239 & 6642.75 & 5096.51 & 19886.34 & 226758.80 & 249917.59 & 248641.82 & 247772.74 \\
\hline 240 & 6668.87 & 5115.09 & 19969.16 & 227812.39 & 250947.88 & 249666.15 & 248794.40 \\
\hline 241 & 6697.05 & 5132.64 & 20056.99 & 228866.01 & 251976.11 & 250687.66 & 249810.92 \\
\hline 242 & 6724.78 & 5149.90 & 20142.75 & 229919.56 & 253001.91 & 251706.58 & 250825.64 \\
\hline 243 & 6757.32 & 5164.38 & 20241.69 & 230973.19 & 254026.59 & 252723.34 & 251837.89 \\
\hline 244 & 6792.02 & 5176.72 & 20346.31 & 232026.82 & 255049.78 & 253738.38 & 252848.74 \\
\hline 245 & 6826.23 & 5188.89 & 20448.64 & 233080.38 & 256074.52 & 254753.10 & 253859.49 \\
\hline 246 & 6858.52 & 5200.38 & 20540.42 & 234133.50 & 257098.87 & 255768.16 & 254870.79 \\
\hline 247 & 6883.29 & 5213.61 & 20609.87 & 235186.27 & 258124.76 & 256783.73 & 255881.05 \\
\hline 248 & 6903.32 & 5227.86 & 20667.21 & 236238.82 & 259152.45 & 257799.94 & 256892.25 \\
\hline 249 & 6919.42 & 5242.17 & 20715.08 & 237291.17 & 260183.05 & 258821.40 & 257909.06 \\
\hline 250 & 6929.92 & 5256.19 & 20752.64 & 238343.39 & 261216.94 & 259850.39 & 258931.93 \\
\hline 251 & 6944.96 & 5270.91 & 20798.55 & 239395.59 & 262254.38 & 260889.44 & 259966.07 \\
\hline 252 & 6958.49 & 5285.35 & 20841.09 & 240447.70 & 263297.16 & 261937.53 & 261007.85 \\
\hline 253 & 6972.03 & 5299.79 & 20883.63 & 241499.79 & 264343.14 & 262995.61 & 262061.89 \\
\hline 254 & 6985.29 & 5316.31 & 20928.82 & 242551.88 & 265391.69 & 264062.29 & 263125.82 \\
\hline 255 & 7007.10 & 5335.71 & 20992.70 & 243603.96 & 266441.89 & 265134.78 & 264196.62 \\
\hline 256 & 7027.73 & 5355.90 & 21055.20 & 244656.04 & 267492.50 & 266209.05 & 265269.91 \\
\hline 257 & 7049.54 & 5375.30 & 21119.08 & 245708.12 & 268540.64 & 267275.38 & 266333.97 \\
\hline
\end{tabular}




\begin{tabular}{|c|c|c|c|c|c|c|c|}
\hline hour & $\begin{array}{c}\text { Air } \\
\text { Change }\end{array}$ & $\begin{array}{c}\text { Air } \\
\text { Change } \\
(\mathrm{ACH})\end{array}$ & $\begin{array}{l}\text { ASHRAE } \\
\text { Enhanced }\end{array}$ & $\begin{array}{c}\text { Enhanced } \\
\text { Model }\end{array}$ & $\begin{array}{l}\text { Angular } \\
\text { Cracks }\end{array}$ & $\begin{array}{r}\text { Mixed } \\
\text { Cracks }\end{array}$ & $\begin{array}{l}\text { Straight } \\
\text { Cracks }\end{array}$ \\
\hline 258 & 7071.80 & 5395.10 & 21184.77 & 246760.27 & 269586.25 & 268334.67 & 267391.08 \\
\hline 259 & 7094.85 & 5415.60 & 21253.87 & 247812.57 & 270631.41 & 269388.07 & 268442.91 \\
\hline 260 & 7127.69 & 5447.73 & 21355.57 & 248864.90 & 271672.34 & 270435.95 & 269486.92 \\
\hline 261 & 7161.02 & 5486.27 & 21467.32 & 249917.32 & 272712.25 & 271479.06 & 270526.18 \\
\hline 262 & 7209.05 & 5529.00 & 21614.65 & 250969.89 & 273750.83 & 272518.34 & 271562.68 \\
\hline 263 & 7260.04 & 5587.96 & 21786.65 & 252022.43 & 274788.57 & 273554.50 & 272593.92 \\
\hline 264 & 7311.99 & 5652.65 & 21968.84 & 253074.96 & 275824.53 & 274587.97 & 273623.35 \\
\hline 265 & 7345.32 & 5694.16 & 22085.07 & 254127.43 & 276861.60 & 275619.60 & 274651.50 \\
\hline 266 & 7396.79 & 5762.83 & 22271.08 & 255179.81 & 277896.58 & 276650.03 & 275676.70 \\
\hline 267 & 7450.10 & 5824.48 & 22448.72 & 256232.17 & 278932.43 & 277678.66 & 276700.75 \\
\hline 268 & 7503.45 & 5890.92 & 22632.65 & 257284.46 & 279966.54 & 278705.80 & 277723.13 \\
\hline 269 & 7558.79 & 5969.68 & 22841.34 & 258336.81 & 281001.56 & 279731.93 & 278744.46 \\
\hline 270 & 7613.38 & 6047.36 & 23046.17 & 259389.08 & 282036.67 & 280757.14 & 279765.52 \\
\hline 271 & 7665.12 & 6102.60 & 23211.08 & 260441.35 & 283070.41 & 281781.52 & 280784.25 \\
\hline 272 & 7719.71 & 6180.28 & 23415.92 & 261493.62 & 284105.05 & 282805.42 & 281803.41 \\
\hline 273 & 7774.65 & 6268.25 & 23640.15 & 262545.81 & 285140.91 & 283833.75 & 282826.56 \\
\hline 274 & 7828.38 & 6349.49 & 23848.91 & 263597.92 & 286180.63 & 284870.44 & 283857.48 \\
\hline 275 & 7880.32 & 6446.52 & 24087.54 & 264649.73 & 287224.70 & 285917.13 & 284897.82 \\
\hline 276 & 7926.97 & 6517.06 & 24263.91 & 265701.34 & 288274.51 & 286973.39 & 285949.49 \\
\hline 277 & 7969.64 & 6574.00 & 24407.52 & 266752.62 & 289328.11 & 288040.71 & 287012.94 \\
\hline 278 & 8011.44 & 6633.48 & 24553.68 & 267803.69 & 290385.65 & 289117.27 & 288089.01 \\
\hline 279 & 8053.44 & 6689.53 & 24691.83 & 268854.57 & 291446.45 & 290200.43 & 289171.38 \\
\hline 280 & 8090.69 & 6729.28 & 24796.69 & 269905.33 & 292507.96 & 291286.12 & 290257.45 \\
\hline 281 & 8129.26 & 6777.32 & 24916.54 & 270956.06 & 293569.05 & 292368.42 & 291341.06 \\
\hline 282 & 8166.89 & 6810.79 & 25012.45 & 272006.70 & 294628.57 & 293444.55 & 292414.22 \\
\hline 283 & 8204.52 & 6837.57 & 25104.13 & 273057.54 & 295685.88 & 294514.87 & 293481.65 \\
\hline 284 & 8243.94 & 6869.12 & 25204.52 & 274108.48 & 296742.75 & 295580.30 & 294544.10 \\
\hline 285 & 8280.73 & 6901.85 & 25300.97 & 275159.37 & 297798.05 & 296641.77 & 295602.20 \\
\hline 286 & 8305.82 & 6924.17 & 25366.72 & 276210.26 & 298853.79 & 297699.96 & 296657.06 \\
\hline 287 & 8329.92 & 6945.61 & 25428.73 & 277261.01 & 299907.94 & 298754.95 & 297708.02 \\
\hline 288 & 8366.72 & 6978.34 & 25525.18 & 278311.87 & 300961.39 & 299807.15 & 298758.14 \\
\hline 289 & 8404.13 & 7011.62 & 25624.15 & 279362.82 & 302014.77 & 300857.71 & 299807.15 \\
\hline 290 & 8442.51 & 7049.17 & 25729.96 & 280413.78 & 303067.80 & 301905.33 & 300849.53 \\
\hline 291 & 8482.16 & 7087.97 & 25841.09 & 281464.90 & 304119.02 & 302950.65 & 301891.33 \\
\hline 292 & 8509.21 & 7114.44 & 25917.53 & 282516.11 & 305169.80 & 303994.41 & 302930.46 \\
\hline 293 & 8535.77 & 7142.79 & 25995.23 & 283567.28 & 306220.58 & 305037.14 & 303967.57 \\
\hline 294 & 8549.53 & 7158.70 & 26036.76 & 284618.30 & 307271.96 & 306080.11 & 305006.70 \\
\hline 295 & 8559.72 & 7168.66 & 26063.43 & 285668.87 & 308324.73 & 307123.20 & 306045.38 \\
\hline
\end{tabular}




\begin{tabular}{|c|c|c|c|c|c|c|c|}
\hline hour & $\begin{array}{c}\text { Air } \\
\text { Change }\end{array}$ & $\begin{array}{c}\text { Air } \\
\text { Change } \\
\text { (ACH) }\end{array}$ & $\begin{array}{l}\text { ASHRAE } \\
\text { Enhanced }\end{array}$ & $\begin{array}{c}\text { Enhanced } \\
\text { Model }\end{array}$ & $\begin{array}{l}\text { Angular } \\
\text { Cracks }\end{array}$ & $\begin{array}{l}\text { Mixed } \\
\text { Cracks }\end{array}$ & $\begin{array}{l}\text { Straight } \\
\text { Cracks }\end{array}$ \\
\hline 296 & 8567.41 & 7178.24 & 26086.71 & 286719.29 & 309377.84 & 308166.84 & 307083.95 \\
\hline 297 & 8572.19 & 7186.32 & 26105.40 & 287769.45 & 310434.06 & 309216.00 & 308128.31 \\
\hline 298 & 8576.92 & 7193.90 & 26122.77 & 288819.42 & 311495.05 & 310273.71 & 309180.82 \\
\hline 299 & 8580.09 & 7199.54 & 26135.66 & 289869.19 & 312559.23 & 311341.32 & 310243.58 \\
\hline 300 & 8582.93 & 7204.84 & 26147.78 & 290918.85 & 313629.48 & 312418.80 & 311315.60 \\
\hline 301 & 8585.99 & 7210.81 & 26161.49 & 291968.41 & 314702.22 & 313506.41 & 312400.34 \\
\hline 302 & 8588.75 & 7215.73 & 26172.62 & 293017.87 & 315779.13 & 314601.80 & 313496.88 \\
\hline 303 & 8591.72 & 7220.75 & 26183.90 & 294067.31 & 316856.82 & 315702.01 & 314600.99 \\
\hline 304 & 8594.48 & 7225.67 & 26195.03 & 295116.74 & 317936.05 & 316803.78 & 315706.65 \\
\hline 305 & 8597.29 & 7230.42 & 26205.72 & 296166.17 & 319011.93 & 317901.09 & 316806.87 \\
\hline 306 & 8600.46 & 7235.49 & 26217.16 & 297215.67 & 320085.58 & 318990.44 & 317898.94 \\
\hline 307 & 8602.45 & 7241.50 & 26232.43 & 298265.81 & 321155.46 & 320072.27 & 318982.24 \\
\hline 308 & 8604.72 & 7248.78 & 26251.31 & 299316.49 & 322222.48 & 321147.10 & 320055.14 \\
\hline 309 & 8607.24 & 7256.83 & 26272.26 & 300367.50 & 323285.29 & 322215.33 & 321122.05 \\
\hline 310 & 8610.24 & 7265.93 & 26295.68 & 301418.81 & 324345.07 & 323277.50 & 322183.26 \\
\hline 311 & 8613.54 & 7275.89 & 26321.42 & 302470.40 & 325402.05 & 324334.55 & 323237.80 \\
\hline 312 & 8618.01 & 7287.02 & 26349.28 & 303522.13 & 326456.55 & 325387.55 & 324288.65 \\
\hline 313 & 8621.95 & 7297.54 & 26375.82 & 304573.83 & 327509.93 & 326436.90 & 325333.31 \\
\hline 314 & 8626.01 & 7308.37 & 26403.19 & 305625.61 & 328562.96 & 327482.94 & 326375.38 \\
\hline 315 & 8630.18 & 7319.51 & 26431.39 & 306677.48 & 329614.17 & 328525.58 & 327414.16 \\
\hline 316 & 8634.60 & 7331.29 & 26461.29 & 307729.50 & 330664.95 & 329564.83 & 328449.23 \\
\hline 317 & 8641.83 & 7345.45 & 26496.77 & 308781.77 & 331715.73 & 330601.21 & 329482.90 \\
\hline 318 & 8648.83 & 7359.77 & 26532.73 & 309834.15 & 332767.11 & 331634.97 & 330513.64 \\
\hline 319 & 8655.26 & 7374.07 & 26568.74 & 310886.64 & 333819.89 & 332666.10 & 331539.26 \\
\hline 320 & 8663.06 & 7389.32 & 26607.30 & 311939.23 & 334872.99 & 333695.17 & 332563.86 \\
\hline 321 & 8671.84 & 7404.96 & 26647.21 & 312991.84 & 335928.04 & 334727.37 & 333589.68 \\
\hline 322 & 8682.28 & 7420.73 & 26688.67 & 314044.39 & 336987.03 & 335765.22 & 334622.43 \\
\hline 323 & 8691.42 & 7436.18 & 26728.26 & 315096.93 & 338048.42 & 336812.06 & 335664.15 \\
\hline 324 & 8700.12 & 7450.88 & 26765.68 & 316149.33 & 339115.13 & 337866.97 & 336712.94 \\
\hline 325 & 8710.53 & 7465.70 & 26804.74 & 317201.63 & 340183.68 & 338931.62 & 337773.98 \\
\hline 326 & 8723.32 & 7480.49 & 26846.83 & 318253.84 & 341255.87 & 340003.98 & 338844.31 \\
\hline 327 & 8736.33 & 7494.38 & 26887.74 & 319305.95 & 342328.45 & 341081.64 & 339921.22 \\
\hline 328 & 8755.36 & 7507.92 & 26940.35 & 320358.05 & 343402.26 & 342159.69 & 340999.21 \\
\hline 329 & 8774.26 & 7521.37 & 26993.07 & 321410.21 & 344473.70 & 343232.50 & 342072.31 \\
\hline 330 & 8804.34 & 7529.40 & 27073.42 & 322462.59 & 345543.52 & 344298.02 & 343133.74 \\
\hline 331 & 8837.01 & 7535.21 & 27161.21 & 323515.07 & 346610.06 & 345356.56 & 344189.61 \\
\hline 332 & 8879.03 & 7550.16 & 27276.37 & 324567.66 & 347674.16 & 346409.44 & 345238.64 \\
\hline 333 & 8921.54 & 7569.07 & 27392.91 & 325620.20 & 348734.39 & 347456.94 & 346281.98 \\
\hline
\end{tabular}




\begin{tabular}{|c|c|c|c|c|c|c|c|}
\hline hour & $\begin{array}{c}\text { Air } \\
\text { Change }\end{array}$ & $\begin{array}{c}\text { Air } \\
\text { Change } \\
\text { (ACH) }\end{array}$ & $\begin{array}{l}\text { ASHRAE } \\
\text { Enhanced }\end{array}$ & $\begin{array}{c}\text { Enhanced } \\
\text { Model }\end{array}$ & $\begin{array}{l}\text { Angular } \\
\text { Cracks }\end{array}$ & $\begin{array}{r}\text { Mixed } \\
\text { Cracks }\end{array}$ & $\begin{array}{l}\text { Straight } \\
\text { Cracks }\end{array}$ \\
\hline 334 & 8965.10 & 7588.44 & 27514.53 & 326672.88 & 349791.89 & 348500.15 & 347321.57 \\
\hline 335 & 9013.70 & 7618.70 & 27651.90 & 327725.44 & 350846.84 & 349539.87 & 348356.43 \\
\hline 336 & 9064.97 & 7659.75 & 27802.42 & 328777.91 & 351899.56 & 350576.92 & 349389.10 \\
\hline 337 & 9114.12 & 7694.72 & 27941.89 & 329830.30 & 352950.85 & 351612.49 & 350419.65 \\
\hline 338 & 9166.00 & 7740.87 & 28097.43 & 330882.67 & 353999.92 & 352646.24 & 351448.85 \\
\hline 339 & 9219.87 & 7798.37 & 28270.27 & 331935.03 & 355047.32 & 353677.83 & 352475.59 \\
\hline 340 & 9273.02 & 7855.11 & 28439.66 & 332987.31 & 356091.69 & 354707.90 & 353500.82 \\
\hline 341 & 9326.56 & 7912.25 & 28610.27 & 334039.58 & 357134.99 & 355736.58 & 354524.22 \\
\hline 342 & 9380.84 & 7975.02 & 28790.02 & 335091.85 & 358176.37 & 356764.56 & 355547.48 \\
\hline 343 & 9435.17 & 8042.68 & 28976.23 & 336144.04 & 359215.88 & 357791.96 & 356570.14 \\
\hline 344 & 9488.41 & 8108.98 & 29157.65 & 337196.15 & 360254.21 & 358819.14 & 357591.86 \\
\hline 345 & 9541.37 & 8184.36 & 29352.52 & 338248.10 & 361292.60 & 359850.21 & 358618.10 \\
\hline 346 & 9594.07 & 8259.35 & 29546.41 & 339300.02 & 362333.76 & 360889.66 & 359651.90 \\
\hline 347 & 9645.56 & 8337.22 & 29742.89 & 340351.78 & 363377.03 & 361939.12 & 360695.25 \\
\hline 348 & 9694.93 & 8403.08 & 29912.78 & 341403.38 & 364423.66 & 362997.79 & 361749.25 \\
\hline 349 & 9743.07 & 8471.61 & 30084.65 & 342454.79 & 365473.21 & 364067.22 & 362813.83 \\
\hline 350 & 9788.58 & 8520.18 & 30218.78 & 343506.09 & 366525.21 & 365145.84 & 363890.27 \\
\hline 351 & 9832.57 & 8567.13 & 30346.49 & 344557.23 & 367578.65 & 366230.64 & 364973.85 \\
\hline 352 & 9876.06 & 8617.43 & 30477.78 & 345608.26 & 368630.69 & 367317.13 & 366057.91 \\
\hline 353 & 9917.92 & 8658.39 & 30592.22 & 346659.19 & 369681.51 & 368401.33 & 367139.89 \\
\hline 354 & 9960.64 & 8707.79 & 30720.28 & 347710.09 & 370728.36 & 369478.77 & 368215.71 \\
\hline 355 & 9994.47 & 8725.84 & 30799.25 & 348761.06 & 371773.71 & 370550.19 & 369284.74 \\
\hline 356 & 10026.45 & 8748.60 & 30878.83 & 349812.10 & 372816.95 & 371616.37 & 370346.97 \\
\hline 357 & 10060.86 & 8766.96 & 30960.09 & 350863.16 & 373858.01 & 372677.49 & 371404.81 \\
\hline 358 & 10101.44 & 8792.23 & 31060.36 & 351914.37 & 374897.46 & 373734.24 & 372458.02 \\
\hline 359 & 10141.58 & 8813.65 & 31159.45 & 352965.75 & 375935.80 & 374787.13 & 373506.79 \\
\hline 360 & 10177.45 & 8829.61 & 31247.49 & 354017.23 & 376974.76 & 375836.23 & 374551.88 \\
\hline 361 & 10211.64 & 8844.81 & 31334.14 & 355068.95 & 378011.62 & & \\
\hline 362 & 10243.05 & 8855.99 & 31415.32 & 356120.93 & 379047.98 & & \\
\hline 363 & 10270.30 & 8865.68 & 31485.75 & 357172.97 & 380084.66 & & \\
\hline 364 & 10302.27 & 8865.68 & 31568.13 & 358225.10 & 381119.95 & & \\
\hline 365 & 10334.17 & 8874.20 & 31650.82 & 359277.25 & 382156.44 & & \\
\hline 366 & 10365.15 & 8874.20 & 31729.01 & 360329.27 & 383192.08 & & \\
\hline 367 & 10391.92 & 8883.72 & 31797.48 & 361381.27 & 384227.63 & & \\
\hline 368 & 10422.34 & 8894.54 & 31874.52 & 362433.19 & 385264.02 & & \\
\hline 369 & 10451.36 & 8894.54 & 31944.59 & 363484.89 & 386301.38 & & \\
\hline 370 & 10477.59 & 8903.88 & 32008.18 & 364536.47 & 387343.43 & & \\
\hline 371 & 10497.55 & 8914.53 & 32057.98 & 365588.02 & 388388.37 & & \\
\hline
\end{tabular}




\begin{tabular}{|c|c|c|c|c|c|c|c|}
\hline hour & $\begin{array}{c}\text { Air } \\
\text { Change }\end{array}$ & $\begin{array}{c}\text { Air } \\
\text { Change } \\
\text { (ACH) }\end{array}$ & $\begin{array}{l}\text { ASHRAE } \\
\text { Enhanced }\end{array}$ & $\begin{array}{c}\text { Enhanced } \\
\text { Model }\end{array}$ & $\begin{array}{l}\text { Angular } \\
\text { Cracks }\end{array}$ & $\begin{array}{r}\text { Mixed } \\
\text { Cracks }\end{array}$ & $\begin{array}{c}\text { Straight } \\
\text { Cracks }\end{array}$ \\
\hline 372 & 10523.20 & 8921.37 & 32118.24 & 366639.42 & 389439.46 & & \\
\hline 373 & 10544.24 & 8928.86 & 32166.35 & 367690.57 & 390492.95 & & \\
\hline 374 & 10565.99 & 8936.60 & 32215.47 & 368741.61 & 391550.73 & & \\
\hline 375 & 10588.23 & 8946.49 & 32266.41 & 369792.61 & 392609.70 & & \\
\hline 376 & 10606.40 & 8956.19 & 32308.34 & 370843.53 & 393671.05 & & \\
\hline 377 & 10631.48 & 8969.57 & 32366.23 & 371894.43 & 394730.67 & & \\
\hline 378 & 10651.87 & 8976.83 & 32411.70 & 372945.33 & 395789.72 & & \\
\hline 379 & 10675.33 & 8981.00 & 32462.56 & 373996.15 & 396845.61 & & \\
\hline 380 & 10695.25 & 8988.09 & 32506.42 & 375046.95 & 397900.43 & & \\
\hline 381 & 10705.95 & 8997.61 & 32534.21 & 376097.75 & 398954.32 & & \\
\hline 382 & 10715.21 & 9007.49 & 32560.49 & 377148.55 & 400007.30 & & \\
\hline 383 & 10726.66 & 9017.67 & 32590.49 & 378199.42 & 401058.91 & & \\
\hline 384 & 10736.69 & 9027.49 & 32617.91 & 379250.30 & 402108.46 & & \\
\hline 385 & 10754.02 & 9036.74 & 32658.37 & 380301.25 & 403155.77 & & \\
\hline 386 & 10762.66 & 9046.73 & 32684.45 & 381352.22 & 404203.00 & & \\
\hline 387 & 10775.34 & 9058.01 & 32719.20 & 382403.48 & 405246.53 & & \\
\hline 388 & 10798.54 & 9068.33 & 32778.01 & 383455.14 & 406288.82 & & \\
\hline 389 & 10824.63 & 9077.61 & 32843.36 & 384506.88 & 407330.99 & & \\
\hline 390 & 10851.35 & 9087.12 & 32908.86 & 385558.52 & 408372.73 & & \\
\hline 391 & 10883.80 & 9095.77 & 32986.87 & 386610.07 & 409413.99 & & \\
\hline 392 & 10923.48 & 9116.96 & 33084.86 & 387661.54 & 410454.44 & & \\
\hline 393 & 10962.58 & 9137.82 & 33180.33 & 388712.92 & 411497.36 & & \\
\hline 394 & 11006.27 & 9176.69 & 33299.05 & 389764.21 & 412544.04 & & \\
\hline 395 & 11048.31 & 9210.34 & 33408.19 & 390815.41 & 413593.86 & & \\
\hline 396 & 11090.58 & 9247.94 & 33521.02 & 391866.52 & 414648.92 & & \\
\hline 397 & 11131.58 & 9280.76 & 33625.45 & 392917.53 & 415706.42 & & \\
\hline 398 & 11168.07 & 9300.24 & 33709.65 & 393968.46 & 416766.87 & & \\
\hline 399 & 11203.95 & 9319.39 & 33791.45 & 395019.29 & 417830.27 & & \\
\hline 400 & 11217.26 & 9330.04 & 33824.69 & 396070.10 & 418893.80 & & \\
\hline 401 & 11230.24 & 9341.59 & 33858.70 & 397120.98 & 419956.44 & & \\
\hline 402 & 11242.10 & 9353.19 & 33891.41 & 398171.93 & 421018.21 & & \\
\hline 403 & 11260.99 & 9366.63 & 33939.84 & 399223.18 & 422078.19 & & \\
\hline 404 & 11273.76 & 9382.54 & 33981.57 & 400274.56 & 423136.47 & & \\
\hline 405 & 11283.94 & 9398.84 & 34021.94 & 401326.04 & 424193.80 & & \\
\hline 406 & 11292.43 & 9410.92 & 34052.55 & 402377.55 & 425250.36 & & \\
\hline 407 & 11302.83 & 9428.49 & 34096.27 & 403429.28 & 426306.81 & & \\
\hline 408 & 11310.23 & 9441.67 & 34129.09 & 404481.19 & 427360.72 & & \\
\hline 409 & 11321.10 & 9461.01 & 34177.63 & 405533.29 & 428415.44 & & \\
\hline
\end{tabular}




\begin{tabular}{|c|c|c|c|c|c|c|c|}
\hline hour & $\begin{array}{c}\text { Air } \\
\text { Change }\end{array}$ & $\begin{array}{c}\text { Air } \\
\text { Change } \\
(\mathrm{ACH})\end{array}$ & $\begin{array}{l}\text { ASHRAE } \\
\text { Enhanced }\end{array}$ & $\begin{array}{c}\text { Enhanced } \\
\text { Model }\end{array}$ & $\begin{array}{l}\text { Angular } \\
\text { Cracks }\end{array}$ & $\begin{array}{r}\text { Mixed } \\
\text { Cracks }\end{array}$ & $\begin{array}{c}\text { Straight } \\
\text { Cracks }\end{array}$ \\
\hline 410 & 11328.34 & 9475.16 & 34213.11 & 406585.57 & 429467.34 & & \\
\hline 411 & 11335.94 & 9490.05 & 34250.63 & 407638.03 & 430517.99 & & \\
\hline 412 & 11344.82 & 9506.63 & 34293.11 & 408690.82 & 431566.15 & & \\
\hline 413 & 11354.91 & 9524.58 & 34339.88 & 409743.89 & 432613.86 & & \\
\hline 414 & 11367.36 & 9544.52 & 34393.85 & 410797.30 & 433660.96 & & \\
\hline 415 & 11382.43 & 9565.97 & 34455.10 & 411851.01 & 434708.07 & & \\
\hline 416 & 11401.34 & 9587.83 & 34524.70 & 412904.84 & 435754.05 & & \\
\hline 417 & 11420.25 & 9609.69 & 34594.30 & 413958.72 & 436803.23 & & \\
\hline 418 & 11438.81 & 9631.16 & 34662.25 & 415012.55 & 437854.50 & & \\
\hline 419 & 11457.03 & 9652.23 & 34728.58 & 416066.30 & 438909.39 & & \\
\hline 420 & 11480.80 & 9671.26 & 34804.97 & 417119.90 & 439968.35 & & \\
\hline 421 & 11503.09 & 9689.10 & 34875.61 & 418173.32 & 441030.22 & & \\
\hline 422 & 11531.06 & 9704.03 & 34958.85 & 419226.64 & 442095.51 & & \\
\hline 423 & 11556.42 & 9719.82 & 35034.88 & 420279.86 & 443162.40 & & \\
\hline 424 & 11577.91 & 9737.02 & 35101.98 & 421333.06 & 444229.13 & & \\
\hline 425 & 11598.34 & 9755.20 & 35167.41 & 422386.25 & 445294.10 & & \\
\hline 426 & 11625.43 & 9776.88 & 35253.24 & 423439.57 & 446356.09 & & \\
\hline 427 & 11644.83 & 9802.77 & 35327.82 & 424492.99 & 447415.61 & & \\
\hline 428 & 11665.34 & 9830.13 & 35407.79 & 425546.64 & 448472.77 & & \\
\hline 429 & 11681.60 & 9859.07 & 35485.20 & 426600.47 & 449527.50 & & \\
\hline 430 & 11699.37 & 9889.10 & 35567.10 & 427654.50 & 450580.63 & & \\
\hline 431 & 11711.32 & 9911.42 & 35626.79 & 428708.63 & 451630.25 & & \\
\hline 432 & 11722.65 & 9934.60 & 35688.42 & 429763.01 & 452679.67 & & \\
\hline 433 & 11735.08 & 9958.92 & 35753.84 & 430817.57 & 453725.18 & & \\
\hline 434 & 11747.50 & 9983.23 & 35819.26 & 431872.19 & 454769.42 & & \\
\hline 435 & 11761.67 & 10008.43 & 35888.69 & 432926.89 & 455810.09 & & \\
\hline 436 & 11775.05 & 10033.42 & 35956.74 & 433981.61 & 456849.30 & & \\
\hline 437 & 11786.63 & 10058.15 & 36022.82 & 435036.41 & 457885.04 & & \\
\hline 438 & 11798.43 & 10083.34 & 36090.28 & 436091.30 & 458918.12 & & \\
\hline 439 & 11810.22 & 10108.52 & 36157.74 & 437146.21 & 459947.35 & & \\
\hline 440 & 11821.64 & 10133.91 & 36225.62 & 438201.19 & 460975.70 & & \\
\hline 441 & 11833.65 & 10159.56 & 36294.48 & 439256.19 & 462003.26 & & \\
\hline 442 & 11846.31 & 10185.46 & 36364.42 & 440311.20 & 463033.49 & & \\
\hline 443 & 11858.33 & 10211.10 & 36433.28 & 441366.21 & 464065.50 & & \\
\hline 444 & 11869.54 & 10236.03 & 36499.79 & 442421.15 & 465101.04 & & \\
\hline 445 & 11881.34 & 10261.22 & 36567.25 & 443476.08 & 466138.78 & & \\
\hline 446 & 11892.54 & 10286.14 & 36633.75 & 444531.01 & 467179.20 & & \\
\hline 447 & 11905.20 & 10310.91 & 36700.58 & 445585.79 & 468220.74 & & \\
\hline
\end{tabular}




\begin{tabular}{|c|c|c|c|c|c|c|c|}
\hline hour & $\begin{array}{c}\text { Air } \\
\text { Change }\end{array}$ & $\begin{array}{c}\text { Air } \\
\text { Change } \\
(\mathrm{ACH})\end{array}$ & $\begin{array}{l}\text { ASHRAE } \\
\text { Enhanced }\end{array}$ & $\begin{array}{c}\text { Enhanced } \\
\text { Model }\end{array}$ & $\begin{array}{l}\text { Angular } \\
\text { Cracks }\end{array}$ & $\begin{array}{r}\text { Mixed } \\
\text { Cracks }\end{array}$ & $\begin{array}{c}\text { Straight } \\
\text { Cracks }\end{array}$ \\
\hline 448 & 11917.26 & 10334.51 & 36764.25 & 446640.54 & 469262.62 & & \\
\hline 449 & 11928.46 & 10357.42 & 36825.50 & 447695.22 & 470301.43 & & \\
\hline 450 & 11939.45 & 10379.91 & 36885.45 & 448749.80 & 471337.42 & & \\
\hline 451 & 11953.91 & 10403.07 & 36950.59 & 449804.30 & 472369.89 & & \\
\hline 452 & 11967.32 & 10426.92 & 37015.66 & 450858.78 & 473400.55 & & \\
\hline 453 & 11980.91 & 10449.89 & 37079.19 & 451913.25 & 474427.82 & & \\
\hline 454 & 11997.38 & 10473.32 & 37148.21 & 452967.71 & 475452.85 & & \\
\hline 455 & 12014.75 & 10496.50 & 37217.62 & 454021.96 & 476475.95 & & \\
\hline 456 & 12033.36 & 10519.67 & 37289.47 & 455076.18 & 477497.36 & & \\
\hline 457 & 12052.96 & 10542.34 & 37362.42 & 456130.31 & 478516.62 & & \\
\hline 458 & 12070.90 & 10564.68 & 37431.02 & 457184.34 & 479533.09 & & \\
\hline 459 & 12090.52 & 10585.62 & 37501.06 & 458238.29 & 480548.28 & & \\
\hline 460 & 12109.79 & 10606.19 & 37569.44 & 459292.15 & 481561.05 & & \\
\hline 461 & 12127.67 & 10626.86 & 37634.89 & 460345.99 & 482572.45 & & \\
\hline 462 & 12139.32 & 10645.52 & 37685.18 & 461399.53 & 483582.52 & & \\
\hline 463 & 12152.87 & 10666.02 & 37741.91 & 462453.16 & 484591.72 & & \\
\hline 464 & 12169.84 & 10687.14 & 37805.77 & 463506.87 & 485599.05 & & \\
\hline 465 & 12191.93 & 10706.80 & 37879.52 & 464560.59 & 486607.77 & & \\
\hline 466 & 12208.49 & 10725.95 & 37938.79 & 465614.10 & 487617.13 & & \\
\hline 467 & 12217.68 & 10742.29 & 37981.08 & 466667.22 & 488630.81 & & \\
\hline 468 & 12226.46 & 10757.90 & 38021.19 & 467720.13 & 489647.03 & & \\
\hline 469 & 12235.82 & 10773.72 & 38061.90 & 468772.84 & 490666.27 & & \\
\hline 470 & 12244.31 & 10788.08 & 38098.57 & 469825.37 & 491686.98 & & \\
\hline 471 & 12252.08 & 10801.90 & 38133.48 & 470877.78 & 492710.47 & & \\
\hline 472 & 12259.19 & 10815.18 & 38166.78 & 471930.08 & 493733.18 & & \\
\hline 473 & 12266.77 & 10828.66 & 38200.70 & 472982.36 & 494755.08 & & \\
\hline 474 & 12276.02 & 10842.65 & 38237.00 & 474034.63 & 495774.09 & & \\
\hline 475 & 12286.53 & 10856.67 & 38274.55 & 475086.83 & 496791.56 & & \\
\hline 476 & 12295.37 & 10870.05 & 38308.93 & 476138.94 & 497807.31 & & \\
\hline 477 & 12304.88 & 10883.58 & 38344.26 & 477191.03 & 498822.59 & & \\
\hline 478 & 12314.87 & 10896.91 & 38379.59 & 478243.04 & 499837.18 & & \\
\hline 479 & 12326.27 & 10910.09 & 38416.39 & 479294.97 & 500851.11 & & \\
\hline 480 & 12336.00 & 10923.07 & 38450.63 & 480346.88 & 501864.68 & & \\
\hline 481 & 12344.79 & 10935.59 & 38482.82 & 481398.71 & 502878.80 & & \\
\hline 482 & 12357.37 & 10949.01 & 38521.53 & 482450.53 & 503891.68 & & \\
\hline 483 & 12368.48 & 10961.86 & 38557.17 & 483502.33 & 504904.88 & & \\
\hline 484 & 12379.60 & 10974.71 & 38592.82 & 484554.14 & 505919.67 & & \\
\hline 485 & 12394.34 & 10987.83 & 38635.31 & 485606.02 & 506934.57 & & \\
\hline
\end{tabular}




\begin{tabular}{|c|c|c|c|c|c|c|c|}
\hline hour & $\begin{array}{c}\text { Air } \\
\text { Change }\end{array}$ & $\begin{array}{c}\text { Air } \\
\text { Change } \\
\text { (ACH) }\end{array}$ & $\begin{array}{l}\text { ASHRAE } \\
\text { Enhanced }\end{array}$ & $\begin{array}{c}\text { Enhanced } \\
\text { Model }\end{array}$ & $\begin{array}{l}\text { Angular } \\
\text { Cracks }\end{array}$ & $\begin{array}{r}\text { Mixed } \\
\text { Cracks }\end{array}$ & $\begin{array}{l}\text { Straight } \\
\text { Cracks }\end{array}$ \\
\hline 486 & 12410.34 & 11002.06 & 38682.16 & 486658.05 & 507949.38 & & \\
\hline 487 & 12424.50 & 11015.92 & 38725.07 & 487710.10 & 508964.80 & & \\
\hline 488 & 12436.89 & 11029.14 & 38763.48 & 488762.03 & 509979.25 & & \\
\hline 489 & 12449.28 & 11042.37 & 38801.90 & 489813.94 & 510998.05 & & \\
\hline 490 & 12458.74 & 11054.14 & 38832.99 & 490865.55 & 512019.66 & & \\
\hline 491 & 12465.15 & 11064.41 & 38858.09 & 491916.91 & 513046.05 & & \\
\hline 492 & 12470.99 & 11073.76 & 38880.67 & 492967.99 & 514078.34 & & \\
\hline 493 & 12474.79 & 11081.86 & 38900.09 & 494018.80 & 515114.27 & & \\
\hline 494 & 12478.06 & 11089.14 & 38917.59 & 495069.49 & 516154.80 & & \\
\hline 495 & 12483.44 & 11097.76 & 38938.04 & 496120.13 & 517196.82 & & \\
\hline 496 & 12489.23 & 11106.50 & 38958.91 & 497170.76 & 518241.76 & & \\
\hline 497 & 12495.97 & 11115.51 & 38980.84 & 498221.37 & 519285.81 & & \\
\hline 498 & 12501.96 & 11124.56 & 39002.54 & 499272.06 & 520328.06 & & \\
\hline 499 & 12510.45 & 11134.37 & 39027.81 & 500322.83 & 521369.29 & & \\
\hline 500 & 12517.01 & 11143.71 & 39050.63 & 501373.68 & 522409.31 & & \\
\hline 501 & 12522.10 & 11152.77 & 39072.36 & 502424.63 & 523449.63 & & \\
\hline 502 & 12528.13 & 11162.42 & 39095.76 & 503475.66 & 524488.82 & & \\
\hline 503 & 12534.16 & 11172.08 & 39119.17 & 504526.72 & 525528.83 & & \\
\hline 504 & 12541.71 & 11182.15 & 39144.44 & 505577.78 & 526567.62 & & \\
\hline 505 & 12553.41 & 11193.60 & 39177.50 & 506628.99 & 527607.86 & & \\
\hline 506 & 12561.60 & 11203.80 & 39203.60 & 507680.08 & 528647.23 & & \\
\hline 507 & 12567.94 & 11213.95 & 39228.21 & 508731.16 & 529686.73 & & \\
\hline 508 & 12579.62 & 11224.34 & 39259.38 & 509782.24 & 530726.03 & & \\
\hline 509 & 12592.48 & 11234.63 & 39292.46 & 510833.31 & 531764.47 & & \\
\hline 510 & 12605.28 & 11246.02 & 39327.24 & 511884.52 & 532802.96 & & \\
\hline 511 & 12618.09 & 11257.41 & 39362.02 & 512935.76 & 533841.41 & & \\
\hline 512 & 12634.63 & 11269.18 & 39403.61 & 513986.93 & 534879.16 & & \\
\hline 513 & 12651.17 & 11280.96 & 39445.20 & 515038.10 & 535920.87 & & \\
\hline 514 & 12660.80 & 11292.95 & 39475.69 & 516089.13 & 536965.63 & & \\
\hline 515 & 12672.38 & 11305.30 & 39509.31 & 517140.19 & 538015.54 & & \\
\hline 516 & 12681.32 & 11317.23 & 39539.04 & 518191.19 & 539070.14 & & \\
\hline 517 & 12690.66 & 11328.86 & 39568.44 & 519242.11 & 540130.27 & & \\
\hline 518 & 12699.33 & 11340.43 & 39597.12 & 520293.01 & 541192.24 & & \\
\hline 519 & 12709.82 & 11356.30 & 39635.52 & 521343.90 & 542257.15 & & \\
\hline 520 & 12723.21 & 11371.78 & 39675.64 & 522394.79 & 543323.85 & & \\
\hline 521 & 12734.02 & 11388.12 & 39715.38 & 523445.75 & 544390.05 & & \\
\hline 522 & 12746.14 & 11405.38 & 39758.23 & 524496.87 & 545452.29 & & \\
\hline 523 & 12773.69 & 11437.23 & 39843.68 & 525548.15 & 546512.66 & & \\
\hline
\end{tabular}




\begin{tabular}{|c|c|c|c|c|c|c|c|}
\hline hour & $\begin{array}{c}\text { Air } \\
\text { Change }\end{array}$ & $\begin{array}{c}\text { Air } \\
\text { Change } \\
(\mathrm{ACH})\end{array}$ & $\begin{array}{l}\text { ASHRAE } \\
\text { Enhanced }\end{array}$ & $\begin{array}{c}\text { Enhanced } \\
\text { Model }\end{array}$ & $\begin{array}{l}\text { Angular } \\
\text { Cracks }\end{array}$ & $\begin{array}{c}\text { Mixed } \\
\text { Cracks }\end{array}$ & $\begin{array}{c}\text { Straight } \\
\text { Cracks }\end{array}$ \\
\hline 524 & 12801.72 & 11462.17 & 39921.18 & 526599.54 & 547572.52 & & \\
\hline 525 & 12823.26 & 11477.49 & 39977.50 & 527651.03 & 548629.37 & & \\
\hline 526 & 12845.71 & 11493.47 & 40037.36 & 528702.68 & 549686.40 & & \\
\hline 527 & 12874.73 & 11511.54 & 40112.07 & 529754.29 & 550740.86 & & \\
\hline 528 & 12896.73 & 11527.19 & 40170.14 & 530805.91 & 551794.21 & & \\
\hline 529 & 12921.18 & 11540.24 & 40231.79 & 531857.53 & 552847.07 & & \\
\hline 530 & 12938.55 & 11552.60 & 40276.35 & 532908.94 & 553900.63 & & \\
\hline 531 & 12952.59 & 11563.84 & 40313.15 & 533960.24 & 554951.68 & & \\
\hline 532 & 12969.55 & 11574.40 & 40355.05 & 535011.51 & 556003.36 & & \\
\hline 533 & 12988.18 & 11584.35 & 40400.07 & 536062.78 & 557053.09 & & \\
\hline 534 & 13007.92 & 11596.64 & 40450.37 & 537114.25 & 558102.99 & & \\
\hline 535 & 13026.98 & 11608.50 & 40499.93 & 538165.89 & 559152.57 & & \\
\hline 536 & 13052.39 & 11622.06 & 40565.33 & 539217.65 & 560202.01 & & \\
\hline 537 & 13074.84 & 11638.04 & 40625.19 & 540269.36 & 561253.17 & & \\
\hline 538 & 13094.73 & 11653.97 & 40678.30 & 541320.85 & 562307.31 & & \\
\hline 539 & 13108.00 & 11665.76 & 40713.38 & 542371.96 & 563364.81 & & \\
\hline 540 & 13122.90 & 11676.37 & 40749.32 & 543422.86 & 564424.68 & & \\
\hline 541 & 13137.42 & 11689.28 & 40785.96 & 544473.48 & 565488.24 & & \\
\hline 542 & 13149.38 & 11702.06 & 40818.59 & 545523.91 & 566554.68 & & \\
\hline 543 & 13164.04 & 11713.79 & 40853.33 & 546574.28 & 567622.22 & & \\
\hline 544 & 13185.68 & 11731.11 & 40904.08 & 547624.57 & 568689.80 & & \\
\hline 545 & 13199.91 & 11742.50 & 40937.45 & 548674.83 & 569755.05 & & \\
\hline 546 & 13211.50 & 11754.88 & 40968.80 & 549725.08 & 570817.27 & & \\
\hline 547 & 13225.20 & 11767.06 & 41002.71 & 550775.41 & 571876.44 & & \\
\hline 548 & 13232.47 & 11774.82 & 41022.37 & 551825.67 & 572933.68 & & \\
\hline 549 & 13240.06 & 11782.93 & 41042.91 & 552875.92 & 573987.54 & & \\
\hline 550 & 13245.26 & 11791.25 & 41062.57 & 553926.38 & 575041.01 & & \\
\hline 551 & 13250.45 & 11800.02 & 41083.43 & 554977.02 & 576091.65 & & \\
\hline 552 & 13255.47 & 11808.96 & 41104.71 & 556027.76 & 577141.63 & & \\
\hline 553 & 13263.96 & 11818.77 & 41129.98 & 557078.54 & 578190.15 & & \\
\hline 554 & 13272.84 & 11828.25 & 41155.16 & 558129.32 & 579238.71 & & \\
\hline 555 & 13284.65 & 11837.70 & 41184.65 & 559180.12 & 580286.53 & & \\
\hline 556 & 13293.52 & 11847.18 & 41209.84 & 560230.91 & 581334.43 & & \\
\hline 557 & 13308.41 & 11856.45 & 41245.05 & 561281.78 & 582382.46 & & \\
\hline 558 & 13325.31 & 11865.46 & 41284.04 & 562332.65 & 583428.73 & & \\
\hline 559 & 13345.94 & 11876.48 & 41331.64 & 563383.54 & 584473.61 & & \\
\hline 560 & 13367.58 & 11882.25 & 41378.82 & 564434.35 & 585517.74 & & \\
\hline 561 & 13389.41 & 11890.02 & 41426.28 & 565485.08 & 586565.05 & & \\
\hline
\end{tabular}




\begin{tabular}{|c|c|c|c|c|c|c|c|}
\hline hour & $\begin{array}{c}\text { Air } \\
\text { Change }\end{array}$ & $\begin{array}{c}\text { Air } \\
\text { Change } \\
(\mathrm{ACH})\end{array}$ & $\begin{array}{l}\text { ASHRAE } \\
\text { Enhanced }\end{array}$ & $\begin{array}{c}\text { Enhanced } \\
\text { Model }\end{array}$ & $\begin{array}{l}\text { Angular } \\
\text { Cracks }\end{array}$ & $\begin{array}{r}\text { Mixed } \\
\text { Cracks }\end{array}$ & $\begin{array}{l}\text { Straight } \\
\text { Cracks }\end{array}$ \\
\hline 562 & 13406.24 & 11899.00 & 41463.73 & 566535.73 & 587614.60 & & \\
\hline 563 & 13421.91 & 11910.15 & 41499.44 & 567586.14 & 588669.57 & & \\
\hline 564 & 13425.51 & 11916.56 & 41514.23 & 568636.23 & 589727.90 & & \\
\hline 565 & 13429.39 & 11923.80 & 41531.27 & 569686.61 & 590791.39 & & \\
\hline 566 & 13434.16 & 11931.01 & 41548.15 & 570736.87 & 591857.35 & & \\
\hline 567 & 13437.66 & 11937.86 & 41564.28 & 571787.20 & 592926.18 & & \\
\hline 568 & 13442.98 & 11951.11 & 41597.04 & 572838.17 & 593996.68 & & \\
\hline 569 & 13448.21 & 11962.74 & 41625.79 & 573889.75 & 595067.36 & & \\
\hline 570 & 13455.63 & 11980.56 & 41670.45 & 574941.67 & 596134.88 & & \\
\hline 571 & 13460.09 & 11993.26 & 41703.18 & 575993.96 & 597200.21 & & \\
\hline 572 & 13464.58 & 12006.45 & 41737.46 & 577046.48 & 598264.53 & & \\
\hline 573 & 13472.28 & 12026.98 & 41790.13 & 578099.13 & 599328.27 & & \\
\hline 574 & 13481.49 & 12049.10 & 41846.48 & 579151.96 & 600391.28 & & \\
\hline 575 & 13487.88 & 12064.46 & 41885.62 & 580204.83 & 601450.96 & & \\
\hline 576 & 13495.31 & 12080.98 & 41927.79 & 581257.87 & 602510.11 & & \\
\hline 577 & 13502.53 & 12097.67 & 41970.51 & 582311.00 & 603568.74 & & \\
\hline 578 & 13511.50 & 12115.22 & 42015.64 & 583364.16 & 604626.58 & & \\
\hline 579 & 13519.52 & 12132.34 & 42059.45 & 584417.33 & 605683.39 & & \\
\hline 580 & 13529.02 & 12150.09 & 42105.36 & 585470.50 & 606739.43 & & \\
\hline 581 & 13540.46 & 12168.42 & 42154.18 & 586523.68 & 607793.61 & & \\
\hline 582 & 13552.15 & 12187.14 & 42204.27 & 587576.93 & 608847.94 & & \\
\hline 583 & 13566.47 & 12206.23 & 42258.73 & 588630.19 & 609900.83 & & \\
\hline 584 & 13580.48 & 12224.92 & 42312.29 & 589683.53 & 610953.79 & & \\
\hline 585 & 13593.53 & 12243.50 & 42364.14 & 590736.88 & 612009.27 & & \\
\hline 586 & 13610.72 & 12261.85 & 42422.97 & 591790.16 & 613069.01 & & \\
\hline 587 & 13625.99 & 12279.51 & 42476.38 & 592843.30 & 614132.24 & & \\
\hline 588 & 13645.02 & 12296.44 & 42536.49 & 593896.33 & 615199.94 & & \\
\hline 589 & 13663.31 & 12312.70 & 42593.40 & 594949.20 & 616270.39 & & \\
\hline 590 & 13683.41 & 12328.80 & 42653.83 & 596001.97 & 617343.05 & & \\
\hline 591 & 13706.69 & 12343.29 & 42720.22 & 597054.64 & 618415.60 & & \\
\hline 592 & 13735.85 & 12358.86 & 42801.23 & 598107.22 & 619484.92 & & \\
\hline 593 & 13770.16 & 12374.12 & 42896.17 & 599159.84 & 620551.71 & & \\
\hline 594 & 13811.80 & 12396.34 & 43012.91 & 600212.47 & 621612.43 & & \\
\hline 595 & 13855.36 & 12415.71 & 43134.53 & 601265.17 & 622667.98 & & \\
\hline 596 & 13908.59 & 12458.32 & 43294.54 & 602317.88 & 623721.26 & & \\
\hline 597 & 13960.01 & 12499.49 & 43449.12 & 603370.59 & 624769.03 & & \\
\hline 598 & 14012.86 & 12546.50 & 43612.43 & 604423.31 & 625815.46 & & \\
\hline 599 & 14068.05 & 12605.41 & 43794.23 & 605476.03 & 626857.14 & & \\
\hline
\end{tabular}




\begin{tabular}{|c|c|c|c|c|c|c|c|}
\hline hour & $\begin{array}{c}\text { Air } \\
\text { Change }\end{array}$ & $\begin{array}{c}\text { Air } \\
\text { Change } \\
(\mathrm{ACH})\end{array}$ & $\begin{array}{l}\text { ASHRAE } \\
\text { Enhanced }\end{array}$ & $\begin{array}{c}\text { Enhanced } \\
\text { Model }\end{array}$ & $\begin{array}{l}\text { Angular } \\
\text { Cracks }\end{array}$ & $\begin{array}{r}\text { Mixed } \\
\text { Cracks }\end{array}$ & $\begin{array}{c}\text { Straight } \\
\text { Cracks }\end{array}$ \\
\hline 600 & 14124.49 & 12660.63 & 43975.29 & 606528.82 & 627896.59 & & \\
\hline 601 & 14182.08 & 12732.36 & 44178.43 & 607581.48 & 628934.51 & & \\
\hline 602 & 14236.88 & 12785.97 & 44350.58 & 608634.05 & 629971.11 & & \\
\hline 603 & 14293.02 & 12850.88 & 44539.95 & 609686.60 & 631005.23 & & \\
\hline 604 & 14349.11 & 12920.74 & 44735.56 & 610739.08 & 632038.69 & & \\
\hline 605 & 14403.86 & 12993.79 & 44933.42 & 611791.46 & 633069.53 & & \\
\hline 606 & 14457.87 & 13065.85 & 45127.56 & 612843.76 & 634099.29 & & \\
\hline 607 & 14511.22 & 13132.29 & 45311.49 & 613896.04 & 635128.48 & & \\
\hline 608 & 14563.27 & 13192.48 & 45482.77 & 614948.23 & 636155.93 & & \\
\hline 609 & 14613.78 & 13246.40 & 45641.56 & 616000.34 & 637184.76 & & \\
\hline 610 & 14660.34 & 13283.67 & 45772.67 & 617052.37 & 638215.53 & & \\
\hline 611 & 14704.98 & 13319.40 & 45895.14 & 618104.15 & 639250.38 & & \\
\hline 612 & 14749.82 & 13367.27 & 46028.29 & 619155.62 & 640289.03 & & \\
\hline 613 & 14790.89 & 13414.76 & 46150.54 & 620206.58 & 641330.85 & & \\
\hline 614 & 14825.60 & 13442.55 & 46232.83 & 621257.10 & 642374.98 & & \\
\hline 615 & 14829.24 & 13449.67 & 46249.35 & 622307.16 & 643421.70 & & \\
\hline 616 & 14832.95 & 13455.93 & 46263.72 & 623357.12 & 644467.16 & & \\
\hline 617 & 14836.65 & 13462.19 & 46278.08 & 624407.04 & 645512.92 & & \\
\hline 618 & 14840.11 & 13468.34 & 46292.22 & 625456.94 & 646555.14 & & \\
\hline 619 & 14844.74 & 13474.94 & 46307.44 & 626506.82 & 647595.33 & & \\
\hline 620 & 14848.72 & 13481.31 & 46322.05 & 627556.71 & 648633.39 & & \\
\hline 621 & 14852.56 & 13488.14 & 46338.00 & 628606.87 & 649670.76 & & \\
\hline 622 & 14864.32 & 13500.69 & 46371.08 & 629657.44 & 650706.99 & & \\
\hline 623 & 14872.72 & 13511.89 & 46399.51 & 630708.51 & 651741.59 & & \\
\hline 624 & 14880.17 & 13523.16 & 46427.42 & 631759.76 & 652776.46 & & \\
\hline 625 & 14892.44 & 13539.54 & 46469.67 & 632811.20 & 653810.10 & & \\
\hline 626 & 14898.89 & 13551.01 & 46497.75 & 633862.69 & 654844.12 & & \\
\hline 627 & 14913.44 & 13563.95 & 46539.01 & 634914.34 & 655876.36 & & \\
\hline 628 & 14925.70 & 13577.04 & 46576.48 & 635966.03 & 656910.19 & & \\
\hline 629 & 14940.25 & 13589.98 & 46617.74 & 637017.73 & 657942.80 & & \\
\hline 630 & 14957.66 & 13602.37 & 46664.13 & 638069.44 & 658976.58 & & \\
\hline 631 & 14972.21 & 13615.31 & 46705.39 & 639121.15 & 660009.60 & & \\
\hline 632 & 14988.12 & 13628.05 & 46749.03 & 640172.86 & 661043.98 & & \\
\hline 633 & 14998.82 & 13641.38 & 46784.87 & 641224.64 & 662079.97 & & \\
\hline 634 & 15007.17 & 13654.00 & 46816.71 & 642276.36 & 663120.70 & & \\
\hline 635 & 15016.14 & 13666.76 & 46849.37 & 643328.08 & 664165.59 & & \\
\hline 636 & 15023.92 & 13679.22 & 46880.49 & 644379.79 & 665216.42 & & \\
\hline 637 & 15031.70 & 13691.69 & 46911.62 & 645431.51 & 666272.35 & & \\
\hline
\end{tabular}




\begin{tabular}{|c|c|c|c|c|c|c|c|}
\hline hour & $\begin{array}{c}\text { Air } \\
\text { Change }\end{array}$ & $\begin{array}{c}\text { Air } \\
\text { Change } \\
(\mathrm{ACH})\end{array}$ & $\begin{array}{l}\text { ASHRAE } \\
\text { Enhanced }\end{array}$ & $\begin{array}{c}\text { Enhanced } \\
\text { Model }\end{array}$ & $\begin{array}{l}\text { Angular } \\
\text { Cracks }\end{array}$ & $\begin{array}{r}\text { Mixed } \\
\text { Cracks }\end{array}$ & $\begin{array}{c}\text { Straight } \\
\text { Cracks }\end{array}$ \\
\hline 638 & 15041.11 & 13704.23 & 46944.15 & 646483.15 & 667334.52 & & \\
\hline 639 & 15048.52 & 13716.10 & 46973.78 & 647534.85 & 668399.57 & & \\
\hline 640 & 15058.95 & 13729.09 & 47008.49 & 648586.56 & 669468.46 & & \\
\hline 641 & 15070.84 & 13742.83 & 47046.86 & 649638.41 & 670536.56 & & \\
\hline 642 & 15085.93 & 13756.26 & 47090.73 & 650690.36 & 671604.97 & & \\
\hline 643 & 15101.39 & 13770.01 & 47135.99 & 651742.40 & 672671.40 & & \\
\hline 644 & 15117.48 & 13784.33 & 47183.86 & 652794.60 & 673737.27 & & \\
\hline 645 & 15143.91 & 13796.08 & 47256.33 & 653847.05 & 674799.72 & & \\
\hline 646 & 15175.19 & 13804.43 & 47341.48 & 654899.62 & 675861.25 & & \\
\hline 647 & 15208.63 & 13813.35 & 47433.41 & 655952.29 & 676919.86 & & \\
\hline 648 & 15244.41 & 13832.45 & 47536.39 & 657005.14 & 677976.35 & & \\
\hline 649 & 15274.94 & 13846.02 & 47623.93 & 658058.08 & 679030.27 & & \\
\hline 650 & 15316.32 & 13864.43 & 47741.56 & 659110.99 & 680083.20 & & \\
\hline 651 & 15358.98 & 13879.61 & 47862.82 & 660163.96 & 681133.58 & & \\
\hline 652 & 15405.14 & 13900.14 & 47997.46 & 661217.09 & 682182.63 & & \\
\hline 653 & 15454.21 & 13926.33 & 48143.53 & 662270.32 & 683229.31 & & \\
\hline 654 & 15506.94 & 13963.85 & 48304.56 & 663323.50 & 684276.68 & & \\
\hline 655 & 15559.67 & 14001.37 & 48465.58 & 664376.67 & 685321.51 & & \\
\hline 656 & 15612.39 & 14038.89 & 48626.61 & 665429.85 & 686366.88 & & \\
\hline 657 & 15666.27 & 14082.02 & 48793.60 & 666482.96 & 687413.13 & & \\
\hline 658 & 15719.12 & 14129.04 & 48956.90 & 667535.77 & 688462.84 & & \\
\hline 659 & 15770.87 & 14184.27 & 49121.81 & 668588.17 & 689513.94 & & \\
\hline 660 & 15822.93 & 14249.10 & 49299.19 & 669640.36 & 690569.59 & & \\
\hline 661 & 15873.36 & 14316.38 & 49475.65 & 670692.27 & 691626.42 & & \\
\hline 662 & 15923.25 & 14382.95 & 49648.32 & 671743.98 & 692685.96 & & \\
\hline 663 & 15970.86 & 14442.25 & 49804.84 & 672795.56 & 693747.30 & & \\
\hline 664 & 16017.12 & 14495.74 & 49949.33 & 673847.05 & 694808.64 & & \\
\hline 665 & 16061.87 & 14539.52 & 50077.81 & 674898.51 & 695866.20 & & \\
\hline 666 & 16106.61 & 14583.30 & 50206.29 & 675949.95 & 696921.34 & & \\
\hline 667 & 16152.17 & 14631.93 & 50342.57 & 677001.39 & 697972.35 & & \\
\hline 668 & 16197.73 & 14680.56 & 50478.84 & 678052.83 & 699021.81 & & \\
\hline 669 & 16241.53 & 14719.52 & 50599.92 & 679104.27 & 700067.89 & & \\
\hline 670 & 16284.66 & 14757.88 & 50718.11 & 680155.64 & 701111.06 & & \\
\hline 671 & 16326.71 & 14791.54 & 50829.36 & 681206.99 & 702152.80 & & \\
\hline 672 & 16367.49 & 14820.57 & 50933.97 & 682258.34 & 703191.71 & & \\
\hline 673 & 16408.28 & 14849.59 & 51038.58 & 683309.69 & 704229.23 & & \\
\hline 674 & 16442.77 & 14868.00 & 51122.80 & 684361.04 & 705265.09 & & \\
\hline 675 & 16478.47 & 14883.88 & 51208.49 & 685412.38 & 706298.04 & & \\
\hline
\end{tabular}




\begin{tabular}{|c|c|c|c|c|c|c|c|}
\hline hour & $\begin{array}{c}\text { Air } \\
\text { Change }\end{array}$ & $\begin{array}{c}\text { Air } \\
\text { Change } \\
\text { (ACH) }\end{array}$ & $\begin{array}{l}\text { ASHRAE } \\
\text { Enhanced }\end{array}$ & $\begin{array}{c}\text { Enhanced } \\
\text { Model }\end{array}$ & $\begin{array}{l}\text { Angular } \\
\text { Cracks }\end{array}$ & $\begin{array}{r}\text { Mixed } \\
\text { Cracks }\end{array}$ & $\begin{array}{l}\text { Straight } \\
\text { Cracks }\end{array}$ \\
\hline 676 & 16517.56 & 14904.74 & 51303.97 & 686463.73 & 707330.86 & & \\
\hline 677 & 16551.52 & 14922.86 & 51385.99 & 687515.00 & 708361.98 & & \\
\hline 678 & 16585.47 & 14940.99 & 51468.01 & 688566.26 & 709391.19 & & \\
\hline 679 & 16612.52 & 14960.24 & 51536.71 & 689617.52 & 710419.99 & & \\
\hline 680 & 16651.24 & 14984.35 & 51632.38 & 690668.78 & 711448.60 & & \\
\hline 681 & 16690.78 & 15012.48 & 51731.75 & 691719.96 & 712479.98 & & \\
\hline 682 & 16731.86 & 15049.02 & 51841.41 & 692771.06 & 713514.21 & & \\
\hline 683 & 16772.26 & 15084.96 & 51948.27 & 693822.07 & 714553.84 & & \\
\hline 684 & 16809.89 & 15111.73 & 52039.95 & 694873.00 & 715597.99 & & \\
\hline 685 & 16826.69 & 15125.19 & 52081.91 & 695923.83 & 716646.40 & & \\
\hline 686 & 16832.24 & 15134.57 & 52104.38 & 696974.71 & 717699.31 & & \\
\hline 687 & 16837.17 & 15144.22 & 52127.74 & 698025.88 & 718753.22 & & \\
\hline 688 & 16842.75 & 15154.63 & 52153.12 & 699077.24 & 719809.30 & & \\
\hline 689 & 16848.66 & 15165.68 & 52180.20 & 700128.79 & 720865.72 & & \\
\hline 690 & 16856.84 & 15178.04 & 52211.53 & 701180.52 & 721919.18 & & \\
\hline 691 & 16869.73 & 15191.80 & 52251.49 & 702232.36 & 722972.41 & & \\
\hline 692 & 16881.91 & 15205.89 & 52291.08 & 703284.30 & 724023.03 & & \\
\hline 693 & 16889.72 & 15219.77 & 52325.92 & 704336.41 & 725073.67 & & \\
\hline 694 & 16898.42 & 15234.48 & 52363.63 & 705388.84 & 726122.49 & & \\
\hline 695 & 16909.62 & 15250.42 & 52406.69 & 706441.47 & 727172.29 & & \\
\hline 696 & 16918.07 & 15266.20 & 52447.11 & 707494.29 & 728219.87 & & \\
\hline 697 & 16929.23 & 15284.07 & 52494.92 & 708547.45 & 729257.79 & & \\
\hline 698 & 16940.62 & 15303.32 & 52546.49 & 709600.95 & 730291.72 & & \\
\hline 699 & 16952.73 & 15323.79 & 52601.90 & 710654.74 & 731323.58 & & \\
\hline 700 & 16967.68 & 15346.39 & 52665.77 & 711708.74 & 732350.81 & & \\
\hline 701 & 16977.10 & 15367.35 & 52720.58 & 712762.80 & 733375.95 & & \\
\hline 702 & 16989.53 & 15389.45 & 52780.09 & 713816.87 & 734399.26 & & \\
\hline 703 & 17003.23 & 15412.61 & 52843.70 & 714871.10 & 735421.35 & & \\
\hline 704 & 17016.57 & 15435.16 & 52905.84 & 715925.43 & 736441.29 & & \\
\hline 705 & 17035.84 & 15459.16 & 52981.04 & 716979.78 & 737462.54 & & \\
\hline 706 & 17049.55 & 15482.32 & 53044.65 & 718034.07 & 738485.54 & & \\
\hline 707 & 17064.84 & 15504.09 & 53107.64 & 719088.22 & 739512.20 & & \\
\hline 708 & 17080.50 & 15526.37 & 53171.86 & 720142.26 & 740540.63 & & \\
\hline 709 & 17097.75 & 15547.85 & 53237.82 & 721196.28 & 741572.66 & & \\
\hline 710 & 17115.04 & 15569.38 & 53303.24 & 722250.15 & 742606.73 & & \\
\hline 711 & 17134.29 & 15593.35 & 53375.70 & 723303.92 & 743642.61 & & \\
\hline 712 & 17153.18 & 15616.88 & 53446.47 & 724357.60 & 744678.13 & & \\
\hline 713 & 17170.90 & 15640.53 & 53515.24 & 725411.25 & 745713.49 & & \\
\hline
\end{tabular}




\begin{tabular}{|c|c|c|c|c|c|c|c|}
\hline hour & $\begin{array}{c}\text { Air } \\
\text { Change }\end{array}$ & $\begin{array}{c}\text { Air } \\
\text { Change } \\
(\mathrm{ACH})\end{array}$ & $\begin{array}{l}\text { ASHRAE } \\
\text { Enhanced }\end{array}$ & $\begin{array}{c}\text { Enhanced } \\
\text { Model }\end{array}$ & $\begin{array}{l}\text { Angular } \\
\text { Cracks }\end{array}$ & $\begin{array}{r}\text { Mixed } \\
\text { Cracks }\end{array}$ & $\begin{array}{c}\text { Straight } \\
\text { Cracks }\end{array}$ \\
\hline 714 & 17193.95 & 15663.08 & 53593.72 & 726464.90 & 746745.22 & & \\
\hline 715 & 17216.28 & 15686.91 & 53672.95 & 727518.68 & 747774.62 & & \\
\hline 716 & 17238.61 & 15710.75 & 53752.19 & 728572.48 & 748801.76 & & \\
\hline 717 & 17264.96 & 15734.19 & 53841.87 & 729626.44 & 749827.15 & & \\
\hline 718 & 17293.53 & 15757.06 & 53937.59 & 730680.49 & 750850.81 & & \\
\hline 719 & 17321.53 & 15786.94 & 54037.54 & 731734.43 & 751872.93 & & \\
\hline 720 & 17346.52 & 15818.07 & 54132.13 & 732788.28 & 752894.91 & & \\
\hline 721 & 17387.70 & 15854.69 & 54271.36 & 733842.18 & 753911.97 & & \\
\hline 722 & 17429.36 & 15895.46 & 54416.81 & 734896.16 & 754929.71 & & \\
\hline 723 & 17461.07 & 15923.66 & 54525.42 & 735950.23 & 755944.95 & & \\
\hline 724 & 17494.70 & 15950.59 & 54638.85 & 737004.38 & 756960.43 & & \\
\hline 725 & 17537.83 & 15981.28 & 54782.59 & 738058.62 & 757973.62 & & \\
\hline 726 & 17592.96 & 16020.51 & 54967.54 & 739112.96 & 758986.71 & & \\
\hline 727 & 17651.70 & 16072.76 & 55172.62 & 740167.31 & 759999.26 & & \\
\hline 728 & 17694.34 & 16114.48 & 55323.32 & 741221.53 & 761014.15 & & \\
\hline 729 & 17736.00 & 16162.66 & 55477.53 & 742275.59 & 762029.39 & & \\
\hline 730 & 17776.69 & 16209.70 & 55626.45 & 743329.48 & 763048.86 & & \\
\hline 731 & 17793.33 & 16233.39 & 55693.49 & 744383.18 & 764071.80 & & \\
\hline 732 & 17807.53 & 16253.60 & 55750.43 & 745436.78 & 765100.58 & & \\
\hline 733 & 17822.14 & 16273.10 & 55806.29 & 746490.21 & 766131.51 & & \\
\hline 734 & 17834.09 & 16292.22 & 55857.66 & 747543.60 & 767166.27 & & \\
\hline 735 & 17847.10 & 16311.90 & 55911.67 & 748597.04 & 768201.69 & & \\
\hline 736 & 17862.31 & 16332.20 & 55970.41 & 749650.56 & 769237.91 & & \\
\hline 737 & 17882.68 & 16352.13 & 56039.33 & 750704.10 & 770272.50 & & \\
\hline 738 & 17902.75 & 16371.76 & 56107.64 & 751757.71 & 771303.80 & & \\
\hline 739 & 17937.93 & 16384.28 & 56214.59 & 752811.41 & 772334.17 & & \\
\hline 740 & 17975.07 & 16394.19 & 56326.94 & 753865.12 & 773361.66 & & \\
\hline 741 & 18014.15 & 16401.14 & 56444.78 & 754918.84 & 774387.91 & & \\
\hline 742 & 18054.84 & 16412.00 & 56568.81 & 755972.64 & 775411.66 & & \\
\hline 743 & 18096.01 & 16426.65 & 56695.98 & 757026.52 & 776435.02 & & \\
\hline 744 & 18129.92 & 16444.74 & 56803.41 & 758080.49 & 777455.58 & & \\
\hline
\end{tabular}




\begin{abstract}
Appendix B
Hourly and Cumulative Data for Northwest Wall Obtained from the DOE-2/eQUEST, CFD Analyses, and Enhanced Model Simulations

Supporting Data for Charts 5-8 to 5-14
\end{abstract}




\section{Hourly Data for Northwest Wall}

\section{Hourly Northwest (NW) Wall Data (Watts)}

\begin{tabular}{|c|c|c|c|c|c|c|c|}
\hline \multirow[b]{2}{*}{$\mathbf{r}$} & \multicolumn{3}{|c|}{$\begin{array}{c}\text { eUEST/DOE-2 Hourly Values } \\
\text { (no reduction multiplier) }\end{array}$} & \multirow[b]{2}{*}{$\begin{array}{l}\text { Enhanced } \\
\text { Model }\end{array}$} & \multicolumn{3}{|c|}{ CFD Multiphysisc Simulation } \\
\hline & $\begin{array}{c}\text { Air } \\
\text { Change }\end{array}$ & $\begin{array}{c}\text { Air } \\
\text { Change } \\
(\mathrm{ACH})\end{array}$ & $\begin{array}{l}\text { ASHRAE } \\
\text { Enhanced }\end{array}$ & & $\begin{array}{l}\text { Angular } \\
\text { Cracks }\end{array}$ & $\begin{array}{l}\text { Mixed } \\
\text { Cracks }\end{array}$ & $\begin{array}{l}\text { Straight } \\
\text { Cracks }\end{array}$ \\
\hline 1 & 56.029 & 24.919 & 157.860 & 525.783 & 954.536 & 867.704 & 916.750 \\
\hline 2 & 54.852 & 24.395 & 154.544 & 746.408 & 953.216 & 866.990 & 915.432 \\
\hline 3 & 65.523 & 34.970 & 196.614 & 805.611 & 951.399 & 865.908 & 914.195 \\
\hline 4 & 60.664 & 26.981 & 187.338 & 805.096 & 950.079 & 864.373 & 912.754 \\
\hline 5 & 69.586 & 37.138 & 225.392 & 821.346 & 946.745 & 862.458 & 909.881 \\
\hline 6 & 42.192 & 11.259 & 136.746 & 826.700 & 944.771 & 860.788 & 908.104 \\
\hline 7 & 58.600 & 20.850 & 190.787 & 823.588 & 942.659 & 859.075 & 906.221 \\
\hline 8 & 45.585 & 20.274 & 151.554 & 819.754 & 941.388 & 857.656 & 905.070 \\
\hline 9 & 45.094 & 16.045 & 147.876 & 818.078 & 942.205 & 860.151 & 907.145 \\
\hline 10 & 64.774 & 28.809 & 212.331 & 841.410 & 944.555 & 864.975 & 912.290 \\
\hline 11 & 59.864 & 26.625 & 193.424 & 854.493 & 947.400 & 871.483 & 918.960 \\
\hline 12 & 74.712 & 53.166 & 245.551 & 862.263 & 950.602 & 878.035 & 926.349 \\
\hline 13 & 67.624 & 42.106 & 213.952 & 868.778 & 953.916 & 884.995 & 932.466 \\
\hline 14 & 56.624 & 35.257 & 176.479 & 877.865 & 956.870 & 890.961 & 938.016 \\
\hline 15 & 56.113 & 34.939 & 173.557 & 899.262 & 957.854 & 894.329 & 940.576 \\
\hline 16 & 39.703 & 24.721 & 123.741 & 906.931 & 956.940 & 894.628 & 939.172 \\
\hline 17 & 31.480 & 19.601 & 101.808 & 914.507 & 954.134 & 889.560 & 933.638 \\
\hline 18 & 29.937 & 15.978 & 96.969 & 910.030 & 951.371 & 885.008 & 929.334 \\
\hline 19 & 27.180 & 16.924 & 89.162 & 914.855 & 948.677 & 880.678 & 925.349 \\
\hline 20 & 33.825 & 21.061 & 113.295 & 927.686 & 948.055 & 876.501 & 922.078 \\
\hline 21 & 31.300 & 16.705 & 103.571 & 921.476 & 945.406 & 873.477 & 919.130 \\
\hline 22 & 44.114 & 23.544 & 144.947 & 913.276 & 944.517 & 870.692 & 916.915 \\
\hline 23 & 28.478 & 17.732 & 95.387 & 907.334 & 942.667 & 868.363 & 914.771 \\
\hline 24 & 31.300 & 16.705 & 103.571 & 920.200 & 941.435 & 866.306 & 912.772 \\
\hline 25 & 26.285 & 16.367 & 88.643 & 925.721 & 941.842 & 865.147 & 912.357 \\
\hline 26 & 22.367 & 17.906 & 75.939 & 921.773 & 940.196 & 863.722 & 911.316 \\
\hline 27 & 25.466 & 18.122 & 86.016 & 918.444 & 940.068 & 862.233 & 910.127 \\
\hline 28 & 31.675 & 14.088 & 103.090 & 917.329 & 939.593 & 861.620 & 909.504 \\
\hline 29 & 27.558 & 14.708 & 89.261 & 921.973 & 939.384 & 860.834 & 909.065 \\
\hline
\end{tabular}




\begin{tabular}{|c|c|c|c|c|c|c|c|}
\hline hour & $\begin{array}{c}\text { Air } \\
\text { Change }\end{array}$ & $\begin{array}{c}\text { Air } \\
\text { Change } \\
(\mathbf{A C H})\end{array}$ & $\begin{array}{l}\text { ASHRAE } \\
\text { Enhanced }\end{array}$ & $\begin{array}{c}\text { Enhanced } \\
\text { Model }\end{array}$ & $\begin{array}{l}\text { Angular } \\
\text { Cracks }\end{array}$ & $\begin{array}{c}\text { Mixed } \\
\text { Cracks }\end{array}$ & $\begin{array}{l}\text { Straight } \\
\text { Cracks }\end{array}$ \\
\hline 30 & 25.054 & 15.600 & 82.765 & 923.959 & 939.520 & 860.380 & 908.712 \\
\hline 31 & 19.786 & 15.840 & 67.177 & 923.155 & 940.121 & 860.105 & 909.373 \\
\hline 32 & 19.090 & 15.282 & 63.957 & 921.372 & 940.145 & 860.240 & 909.215 \\
\hline 33 & 23.037 & 16.393 & 74.654 & 914.168 & 943.046 & 863.867 & 913.357 \\
\hline 34 & 15.591 & 13.869 & 51.686 & 896.036 & 946.949 & 870.127 & 920.039 \\
\hline 35 & 16.057 & 12.855 & 50.510 & 874.360 & 951.813 & 877.950 & 928.547 \\
\hline 36 & 15.529 & 13.813 & 49.039 & 857.968 & 956.320 & 885.531 & 936.222 \\
\hline 37 & 14.448 & 11.567 & 43.771 & 841.326 & 961.226 & 892.898 & 944.449 \\
\hline 38 & 13.821 & 11.064 & 41.221 & 831.687 & 963.997 & 899.484 & 951.081 \\
\hline 39 & 10.791 & 10.559 & 33.900 & 849.936 & 966.618 & 903.758 & 953.925 \\
\hline 40 & 11.762 & 10.463 & 35.535 & 855.459 & 967.685 & 905.847 & 954.231 \\
\hline 41 & 11.762 & 10.463 & 35.535 & 857.480 & 967.015 & 902.294 & 950.331 \\
\hline 42 & 10.535 & 10.308 & 32.861 & 861.351 & 965.634 & 898.644 & 947.806 \\
\hline 43 & 9.484 & 10.124 & 30.635 & 871.802 & 965.724 & 895.416 & 945.376 \\
\hline 44 & 13.202 & 10.569 & 38.754 & 874.792 & 963.386 & 892.458 & 943.665 \\
\hline 45 & 9.484 & 10.124 & 30.635 & 871.686 & 964.258 & 890.748 & 941.589 \\
\hline 46 & 8.061 & 10.756 & 28.978 & 867.954 & 963.588 & 888.903 & 940.572 \\
\hline 47 & 9.636 & 11.142 & 31.906 & 865.702 & 963.586 & 887.446 & 939.213 \\
\hline 48 & 8.796 & 10.954 & 30.324 & 867.023 & 962.475 & 886.138 & 938.394 \\
\hline 49 & 11.484 & 10.215 & 34.429 & 861.357 & 963.982 & 885.271 & 937.656 \\
\hline 50 & 10.281 & 10.060 & 31.840 & 851.339 & 963.030 & 884.315 & 937.350 \\
\hline 51 & 7.996 & 9.246 & 26.310 & 848.488 & 964.697 & 884.066 & 937.272 \\
\hline 52 & 7.381 & 8.536 & 23.827 & 844.254 & 965.418 & 884.392 & 937.377 \\
\hline 53 & 6.705 & 8.946 & 23.203 & 856.770 & 965.494 & 884.468 & 937.900 \\
\hline 54 & 8.871 & 9.469 & 26.924 & 864.491 & 965.777 & 884.734 & 938.305 \\
\hline 55 & 8.046 & 9.304 & 25.469 & 865.169 & 966.023 & 884.796 & 938.524 \\
\hline 56 & 8.046 & 9.304 & 25.469 & 865.127 & 967.091 & 884.825 & 938.663 \\
\hline 57 & 8.046 & 9.304 & 25.469 & 872.848 & 968.891 & 888.363 & 942.551 \\
\hline 58 & 10.643 & 9.467 & 29.673 & 888.357 & 972.688 & 894.168 & 948.342 \\
\hline 59 & 9.034 & 8.839 & 25.732 & 896.172 & 976.470 & 901.230 & 955.606 \\
\hline 60 & 12.650 & 11.252 & 33.763 & 898.358 & 981.472 & 909.246 & 963.791 \\
\hline 61 & 13.673 & 9.729 & 32.605 & 902.750 & 984.998 & 916.299 & 972.140 \\
\hline 62 & 10.918 & 9.712 & 27.828 & 913.144 & 989.081 & 922.753 & 977.473 \\
\hline 63 & 7.366 & 6.552 & 18.417 & 922.061 & 990.873 & 927.443 & 981.056 \\
\hline 64 & 7.366 & 6.552 & 18.417 & 907.839 & 991.661 & 928.308 & 980.373 \\
\hline 65 & 6.326 & 6.752 & 17.669 & 890.289 & 989.341 & 923.778 & 975.554 \\
\hline 66 & 7.522 & 7.360 & 20.391 & 866.384 & 987.478 & 919.932 & 972.671 \\
\hline 67 & 8.412 & 7.482 & 21.845 & 862.035 & 986.230 & 916.426 & 968.874 \\
\hline
\end{tabular}




\begin{tabular}{|c|c|c|c|c|c|c|c|}
\hline hour & $\begin{array}{c}\text { Air } \\
\text { Change }\end{array}$ & $\begin{array}{c}\text { Air } \\
\text { Change } \\
\text { (ACH) }\end{array}$ & $\begin{array}{l}\text { ASHRAE } \\
\text { Enhanced }\end{array}$ & $\begin{array}{c}\text { Enhanced } \\
\text { Model }\end{array}$ & $\begin{array}{l}\text { Angular } \\
\text { Cracks }\end{array}$ & $\begin{array}{c}\text { Mixed } \\
\text { Cracks }\end{array}$ & $\begin{array}{l}\text { Straight } \\
\text { Cracks }\end{array}$ \\
\hline 68 & 8.412 & 7.482 & 21.845 & 873.034 & 985.480 & 913.243 & 966.444 \\
\hline 69 & 8.412 & 7.482 & 21.845 & 872.977 & 983.763 & 910.223 & 963.600 \\
\hline 70 & 15.036 & 8.025 & 35.512 & 871.356 & 983.056 & 907.742 & 961.256 \\
\hline 71 & 45.542 & 24.306 & 107.562 & 874.179 & 983.178 & 905.770 & 960.018 \\
\hline 72 & 47.776 & 29.748 & 111.724 & 885.444 & 983.099 & 904.683 & 958.977 \\
\hline 73 & 45.878 & 24.485 & 102.074 & 892.412 & 982.846 & 904.001 & 958.720 \\
\hline 74 & 62.783 & 67.015 & 171.199 & 891.404 & 983.819 & 903.871 & 958.870 \\
\hline 75 & 59.345 & 63.346 & 157.880 & 887.864 & 985.016 & 903.904 & 959.116 \\
\hline 76 & 62.464 & 77.787 & 185.362 & 887.729 & 985.138 & 903.304 & 958.512 \\
\hline 77 & 58.312 & 51.869 & 144.368 & 897.420 & 985.313 & 903.134 & 958.236 \\
\hline 78 & 61.646 & 65.801 & 166.733 & 902.696 & 985.060 & 902.865 & 958.107 \\
\hline 79 & 64.968 & 80.904 & 195.379 & 901.718 & 984.837 & 902.532 & 957.881 \\
\hline 80 & 62.783 & 67.015 & 171.199 & 898.385 & 985.406 & 902.418 & 957.734 \\
\hline 81 & 66.334 & 88.506 & 210.618 & 902.173 & 987.667 & 905.716 & 961.046 \\
\hline 82 & 63.743 & 85.049 & 199.989 & 905.398 & 991.063 & 911.208 & 966.760 \\
\hline 83 & 61.199 & 76.212 & 180.394 & 896.181 & 994.065 & 917.995 & 973.693 \\
\hline 84 & 59.926 & 74.626 & 175.452 & 877.663 & 998.385 & 924.914 & 980.976 \\
\hline 85 & 57.952 & 72.169 & 168.527 & 851.815 & 1000.959 & 931.507 & 987.767 \\
\hline 86 & 54.635 & 58.318 & 140.502 & 840.118 & 1004.137 & 937.154 & 992.953 \\
\hline 87 & 49.948 & 44.429 & 113.829 & 841.821 & 1004.240 & 940.607 & 995.234 \\
\hline 88 & 53.156 & 47.282 & 125.082 & 828.233 & 1003.737 & 940.117 & 993.192 \\
\hline 89 & 57.294 & 50.963 & 141.848 & 810.639 & 999.289 & 934.412 & 986.988 \\
\hline 90 & 60.203 & 53.551 & 153.440 & 796.296 & 997.050 & 929.261 & 981.769 \\
\hline 91 & 31.641 & 8.444 & 69.893 & 790.532 & 993.335 & 924.095 & 977.159 \\
\hline 92 & 36.229 & 12.890 & 81.827 & 789.929 & 990.621 & 919.239 & 972.356 \\
\hline 93 & 52.360 & 32.602 & 132.100 & 793.831 & 988.078 & 915.027 & 968.278 \\
\hline 94 & 27.544 & 12.250 & 66.112 & 801.292 & 985.426 & 911.450 & 964.798 \\
\hline 95 & 37.439 & 16.651 & 90.875 & 811.065 & 983.085 & 907.946 & 961.748 \\
\hline 96 & 19.710 & 8.766 & 48.897 & 828.908 & 981.946 & 905.307 & 958.581 \\
\hline 97 & 17.463 & 9.320 & 44.035 & 843.348 & 979.618 & 902.870 & 956.360 \\
\hline 98 & 14.076 & 10.016 & 37.517 & 854.863 & 978.354 & 900.754 & 954.382 \\
\hline 99 & 11.906 & 9.532 & 32.086 & 860.670 & 977.676 & 899.034 & 953.595 \\
\hline 100 & 11.906 & 9.532 & 32.086 & 862.017 & 977.558 & 897.739 & 951.837 \\
\hline 101 & 12.690 & 9.030 & 32.547 & 882.990 & 976.725 & 896.929 & 951.371 \\
\hline 102 & 10.785 & 7.674 & 27.385 & 892.812 & 976.309 & 896.179 & 950.638 \\
\hline 103 & 8.775 & 8.586 & 24.794 & 895.311 & 977.424 & 896.231 & 950.888 \\
\hline 104 & 6.318 & 7.306 & 18.938 & 894.903 & 977.247 & 896.011 & 951.003 \\
\hline 105 & 6.591 & 6.449 & 18.018 & 892.141 & 979.616 & 899.419 & 954.099 \\
\hline
\end{tabular}




\begin{tabular}{|c|c|c|c|c|c|c|c|}
\hline hour & $\begin{array}{c}\text { Air } \\
\text { Change }\end{array}$ & $\begin{array}{c}\text { Air } \\
\text { Change } \\
\text { (ACH) }\end{array}$ & $\begin{array}{l}\text { ASHRAE } \\
\text { Enhanced }\end{array}$ & $\begin{array}{c}\text { Enhanced } \\
\text { Model }\end{array}$ & $\begin{array}{l}\text { Angular } \\
\text { Cracks }\end{array}$ & $\begin{array}{c}\text { Mixed } \\
\text { Cracks }\end{array}$ & $\begin{array}{l}\text { Straight } \\
\text { Cracks }\end{array}$ \\
\hline 106 & 6.113 & 7.069 & 18.196 & 898.847 & 983.294 & 905.367 & 960.659 \\
\hline 107 & 5.899 & 6.296 & 16.216 & 896.794 & 988.757 & 912.788 & 968.490 \\
\hline 108 & 5.892 & 5.765 & 15.014 & 894.501 & 991.859 & 920.499 & 975.894 \\
\hline 109 & 4.883 & 5.212 & 12.883 & 891.079 & 996.714 & 927.541 & 983.347 \\
\hline 110 & 5.240 & 5.127 & 12.985 & 899.424 & 998.982 & 933.792 & 989.427 \\
\hline 111 & 7.997 & 7.113 & 18.621 & 910.328 & 1001.090 & 937.877 & 993.074 \\
\hline 112 & 8.734 & 5.438 & 18.028 & 911.537 & 1000.347 & 938.429 & 990.991 \\
\hline 113 & 10.599 & 8.485 & 24.856 & 909.831 & 996.933 & 932.814 & 985.312 \\
\hline 114 & 23.609 & 12.600 & 52.528 & 911.207 & 994.534 & 928.334 & 980.465 \\
\hline 115 & 36.389 & 19.421 & 81.968 & 914.198 & 992.575 & 923.357 & 976.407 \\
\hline 116 & 38.017 & 20.290 & 88.759 & 895.264 & 989.526 & 919.179 & 972.760 \\
\hline 117 & 45.542 & 24.306 & 107.562 & 871.610 & 988.098 & 915.476 & 968.919 \\
\hline 118 & 26.560 & 11.813 & 62.303 & 854.984 & 985.489 & 911.853 & 965.596 \\
\hline 119 & 27.052 & 0.000 & 62.325 & 843.055 & 984.927 & 909.166 & 963.151 \\
\hline 120 & 37.799 & 13.449 & 88.532 & 849.075 & 982.596 & 906.610 & 960.706 \\
\hline 121 & 40.332 & 14.350 & 94.465 & 857.616 & 981.810 & 904.957 & 958.990 \\
\hline 122 & 26.560 & 0.000 & 60.444 & 858.589 & 981.162 & 903.305 & 957.582 \\
\hline 123 & 26.069 & 0.000 & 58.586 & 859.912 & 980.451 & 902.340 & 956.447 \\
\hline 124 & 45.542 & 24.306 & 107.562 & 859.054 & 980.681 & 901.071 & 955.771 \\
\hline 125 & 44.705 & 19.883 & 102.403 & 884.846 & 980.523 & 900.510 & 955.124 \\
\hline 126 & 21.003 & 7.473 & 46.846 & 902.204 & 980.082 & 899.702 & 954.809 \\
\hline 127 & 20.575 & 5.491 & 45.449 & 898.389 & 979.625 & 899.036 & 954.114 \\
\hline 128 & 39.517 & 14.060 & 89.254 & 891.877 & 979.401 & 898.603 & 953.423 \\
\hline 129 & 17.153 & 12.206 & 42.238 & 883.783 & 981.194 & 901.541 & 956.869 \\
\hline 130 & 58.995 & 47.228 & 147.304 & 885.382 & 984.187 & 906.850 & 961.964 \\
\hline 131 & 66.202 & 70.665 & 186.381 & 880.069 & 986.862 & 912.945 & 968.187 \\
\hline 132 & 70.135 & 87.339 & 217.922 & 870.799 & 991.400 & 920.129 & 975.576 \\
\hline 133 & 73.218 & 110.716 & 264.166 & 859.157 & 993.813 & 926.456 & 982.813 \\
\hline 134 & 68.892 & 91.920 & 221.348 & 862.443 & 996.222 & 932.218 & 987.110 \\
\hline 135 & 68.107 & 96.931 & 229.575 & 877.823 & 999.295 & 936.116 & 990.189 \\
\hline 136 & 65.501 & 93.222 & 218.450 & 884.583 & 998.798 & 937.349 & 990.136 \\
\hline 137 & 67.718 & 120.472 & 279.079 & 888.605 & 996.850 & 933.085 & 985.359 \\
\hline 138 & 68.390 & 115.583 & 268.348 & 893.309 & 995.008 & 928.925 & 982.057 \\
\hline 139 & 65.559 & 87.473 & 208.159 & 897.776 & 993.722 & 925.047 & 978.256 \\
\hline 140 & 53.302 & 37.930 & 122.913 & 889.597 & 992.402 & 921.562 & 975.500 \\
\hline 141 & 41.214 & 21.996 & 89.397 & 870.388 & 991.201 & 918.958 & 972.807 \\
\hline 142 & 45.620 & 40.579 & 112.944 & 844.273 & 990.674 & 916.572 & 970.887 \\
\hline 143 & 22.134 & 19.688 & 54.798 & 826.535 & 990.071 & 914.371 & 969.161 \\
\hline
\end{tabular}




\begin{tabular}{|c|c|c|c|c|c|c|c|}
\hline hour & $\begin{array}{c}\text { Air } \\
\text { Change }\end{array}$ & $\begin{array}{c}\text { Air } \\
\text { Change } \\
\text { (ACH) }\end{array}$ & $\begin{array}{l}\text { ASHRAE } \\
\text { Enhanced }\end{array}$ & $\begin{array}{c}\text { Enhanced } \\
\text { Model }\end{array}$ & $\begin{array}{l}\text { Angular } \\
\text { Cracks }\end{array}$ & $\begin{array}{c}\text { Mixed } \\
\text { Cracks }\end{array}$ & $\begin{array}{c}\text { Straight } \\
\text { Cracks }\end{array}$ \\
\hline 144 & 9.915 & 8.820 & 24.548 & 824.220 & 989.873 & 912.617 & 968.002 \\
\hline 145 & 46.340 & 41.220 & 115.857 & 821.787 & 988.619 & 911.144 & 966.185 \\
\hline 146 & 70.956 & 113.609 & 266.192 & 818.448 & 988.166 & 909.779 & 964.958 \\
\hline 147 & 70.179 & 99.880 & 237.818 & 815.049 & 987.178 & 908.515 & 963.665 \\
\hline 148 & 71.487 & 101.741 & 243.536 & 810.595 & 987.607 & 907.316 & 962.716 \\
\hline 149 & 69.876 & 87.017 & 215.722 & 820.211 & 986.000 & 906.247 & 961.961 \\
\hline 150 & 71.487 & 101.741 & 243.536 & 1050.527 & 987.070 & 905.857 & 961.166 \\
\hline 151 & 68.864 & 98.007 & 232.125 & 1050.381 & 986.071 & 905.196 & 961.156 \\
\hline 152 & 65.789 & 76.075 & 190.281 & 1050.429 & 985.341 & 904.362 & 960.002 \\
\hline 153 & 63.911 & 68.219 & 175.691 & 1050.429 & 987.235 & 906.844 & 962.170 \\
\hline 154 & 8.714 & 10.076 & 25.203 & 1050.429 & 988.519 & 911.423 & 967.191 \\
\hline 155 & 9.451 & 13.450 & 32.878 & 1050.786 & 990.934 & 917.024 & 971.956 \\
\hline 156 & 6.835 & 13.984 & 33.835 & 1051.056 & 991.288 & 922.012 & 977.551 \\
\hline 157 & 91.576 & 187.352 & 456.876 & 1051.329 & 992.741 & 926.548 & 981.189 \\
\hline 158 & 93.483 & 182.939 & 448.171 & 1051.532 & 992.141 & 929.805 & 984.263 \\
\hline 159 & 96.525 & 180.304 & 446.252 & 1051.795 & 990.979 & 931.613 & 984.076 \\
\hline 160 & 94.986 & 152.082 & 386.073 & 1051.993 & 988.078 & 929.807 & 981.303 \\
\hline 161 & 9.436 & 20.144 & 50.561 & 1052.326 & 983.969 & 923.031 & 973.717 \\
\hline 162 & 109.059 & 232.820 & 585.774 & 1052.463 & 978.981 & 916.742 & 967.163 \\
\hline 163 & 110.759 & 216.746 & 551.210 & 1052.718 & 975.509 & 910.584 & 961.733 \\
\hline 164 & 110.368 & 196.345 & 507.995 & 1052.913 & 973.013 & 905.616 & 957.174 \\
\hline 165 & 111.941 & 209.101 & 537.331 & 1052.958 & 969.689 & 901.094 & 952.914 \\
\hline 166 & 16.611 & 23.641 & 64.774 & 1052.979 & 967.880 & 897.422 & 949.547 \\
\hline 167 & 104.666 & 158.271 & 425.081 & 1052.988 & 965.082 & 893.785 & 946.020 \\
\hline 168 & 106.925 & 161.687 & 438.022 & 1053.134 & 963.141 & 891.216 & 942.985 \\
\hline 169 & 94.945 & 101.345 & 324.914 & 1053.230 & 962.213 & 889.247 & 941.439 \\
\hline 170 & 98.500 & 113.901 & 348.522 & 1053.252 & 960.012 & 886.378 & 938.751 \\
\hline 171 & 97.683 & 112.956 & 347.628 & 1053.334 & 959.503 & 884.110 & 936.405 \\
\hline 172 & 90.842 & 88.885 & 305.362 & 1053.421 & 956.934 & 882.197 & 934.647 \\
\hline 173 & 27.537 & 22.045 & 87.884 & 1053.439 & 955.745 & 880.220 & 932.801 \\
\hline 174 & 31.740 & 19.763 & 98.924 & 1053.590 & 954.097 & 878.460 & 931.171 \\
\hline 175 & 67.792 & 36.181 & 209.954 & 1053.687 & 953.380 & 876.882 & 928.929 \\
\hline 176 & 67.792 & 36.181 & 209.954 & 1053.710 & 951.926 & 875.577 & 927.877 \\
\hline 177 & 77.519 & 55.163 & 245.831 & 1053.649 & 953.772 & 878.036 & 930.359 \\
\hline 178 & 25.550 & 20.454 & 81.543 & 1053.500 & 955.711 & 883.371 & 935.841 \\
\hline 179 & 26.414 & 18.796 & 81.290 & 1053.331 & 960.171 & 889.952 & 942.897 \\
\hline 180 & 68.133 & 42.423 & 202.574 & 1053.155 & 963.315 & 897.013 & 949.741 \\
\hline 181 & 56.029 & 24.919 & 157.860 & 1052.903 & 966.621 & 903.194 & 956.688 \\
\hline
\end{tabular}




\begin{tabular}{|c|c|c|c|c|c|c|c|}
\hline hour & $\begin{array}{c}\text { Air } \\
\text { Change }\end{array}$ & $\begin{array}{c}\text { Air } \\
\text { Change } \\
\text { (ACH) }\end{array}$ & $\begin{array}{l}\text { ASHRAE } \\
\text { Enhanced }\end{array}$ & $\begin{array}{c}\text { Enhanced } \\
\text { Model }\end{array}$ & $\begin{array}{l}\text { Angular } \\
\text { Cracks }\end{array}$ & $\begin{array}{c}\text { Mixed } \\
\text { Cracks }\end{array}$ & $\begin{array}{l}\text { Straight } \\
\text { Cracks }\end{array}$ \\
\hline 182 & 60.654 & 32.371 & 173.073 & 1052.852 & 969.357 & 909.041 & 961.727 \\
\hline 183 & 70.874 & 50.434 & 208.005 & 1052.758 & 970.240 & 913.192 & 965.358 \\
\hline 184 & 70.874 & 50.434 & 208.005 & 1052.737 & 969.863 & 913.604 & 963.897 \\
\hline 185 & 31.127 & 13.844 & 88.482 & 1052.870 & 967.036 & 908.552 & 958.859 \\
\hline 186 & 33.079 & 11.770 & 94.014 & 1052.960 & 965.082 & 903.557 & 953.514 \\
\hline 187 & 46.836 & 12.498 & 135.856 & 1053.193 & 962.833 & 899.139 & 949.543 \\
\hline 188 & 35.036 & 12.466 & 103.073 & 1053.307 & 960.815 & 895.198 & 946.029 \\
\hline 189 & 53.070 & 18.882 & 156.126 & 1053.338 & 959.373 & 891.879 & 942.880 \\
\hline 190 & 37.742 & 0.000 & 108.941 & 1053.280 & 959.281 & 889.175 & 941.160 \\
\hline 191 & 48.341 & 17.200 & 139.810 & 1053.203 & 957.546 & 887.091 & 938.916 \\
\hline 192 & 50.623 & 18.012 & 145.146 & 1053.118 & 957.701 & 885.794 & 937.659 \\
\hline 193 & 49.609 & 17.651 & 139.740 & 1052.958 & 957.109 & 884.734 & 937.374 \\
\hline 194 & 61.231 & 32.679 & 176.237 & 1052.928 & 957.793 & 883.683 & 936.446 \\
\hline 195 & 30.017 & 13.350 & 85.327 & 1052.914 & 957.223 & 882.868 & 935.982 \\
\hline 196 & 24.563 & 10.924 & 68.586 & 1052.766 & 958.376 & 882.151 & 935.119 \\
\hline 197 & 28.699 & 12.764 & 80.135 & 1052.740 & 957.185 & 881.567 & 934.488 \\
\hline 198 & 32.194 & 8.591 & 88.494 & 1052.729 & 958.038 & 881.252 & 934.475 \\
\hline 199 & 31.126 & 11.075 & 85.301 & 1052.653 & 957.556 & 881.091 & 934.352 \\
\hline 200 & 53.771 & 23.915 & 148.784 & 1052.639 & 958.605 & 880.613 & 934.002 \\
\hline 201 & 26.407 & 9.396 & 71.690 & 1052.562 & 960.097 & 884.245 & 937.818 \\
\hline 202 & 30.904 & 8.247 & 82.552 & 1052.477 & 963.217 & 889.633 & 943.398 \\
\hline 203 & 29.663 & 10.554 & 78.998 & 1052.388 & 967.107 & 896.792 & 950.578 \\
\hline 204 & 40.791 & 10.885 & 106.829 & 1052.297 & 970.553 & 903.944 & 958.003 \\
\hline 205 & 50.604 & 22.506 & 132.216 & 1052.135 & 974.456 & 910.906 & 964.981 \\
\hline 206 & 49.483 & 22.008 & 126.698 & 1051.961 & 977.809 & 917.019 & 970.614 \\
\hline 207 & 21.086 & 13.129 & 55.369 & 1051.853 & 978.455 & 920.721 & 973.342 \\
\hline 208 & 25.401 & 13.557 & 67.351 & 1052.039 & 978.100 & 921.378 & 972.298 \\
\hline 209 & 25.875 & 13.809 & 69.269 & 1052.132 & 975.813 & 916.363 & 967.256 \\
\hline 210 & 24.719 & 15.391 & 68.028 & 1052.225 & 973.592 & 911.647 & 962.584 \\
\hline 211 & 67.390 & 47.955 & 189.612 & 1052.245 & 972.057 & 907.674 & 959.171 \\
\hline 212 & 67.390 & 47.955 & 189.612 & 1052.254 & 970.430 & 904.063 & 956.309 \\
\hline 213 & 67.390 & 47.955 & 189.612 & 1052.258 & 970.298 & 901.095 & 953.312 \\
\hline 214 & 23.223 & 16.526 & 65.343 & 1052.260 & 968.492 & 898.397 & 951.318 \\
\hline 215 & 19.132 & 18.720 & 58.823 & 1052.261 & 968.440 & 896.302 & 949.064 \\
\hline 216 & 19.132 & 18.720 & 58.823 & 1052.261 & 966.952 & 894.706 & 947.926 \\
\hline 217 & 17.933 & 19.142 & 57.151 & 1052.262 & 966.676 & 893.325 & 946.730 \\
\hline 218 & 17.933 & 19.142 & 57.151 & 1052.262 & 966.605 & 892.158 & 945.716 \\
\hline 219 & 17.933 & 19.142 & 57.151 & 1052.262 & 965.682 & 891.177 & 944.229 \\
\hline
\end{tabular}




\begin{tabular}{|c|c|c|c|c|c|c|c|}
\hline hour & $\begin{array}{c}\text { Air } \\
\text { Change }\end{array}$ & $\begin{array}{c}\text { Air } \\
\text { Change } \\
\text { (ACH) }\end{array}$ & $\begin{array}{l}\text { ASHRAE } \\
\text { Enhanced }\end{array}$ & $\begin{array}{c}\text { Enhanced } \\
\text { Model }\end{array}$ & $\begin{array}{l}\text { Angular } \\
\text { Cracks }\end{array}$ & $\begin{array}{c}\text { Mixed } \\
\text { Cracks }\end{array}$ & $\begin{array}{l}\text { Straight } \\
\text { Cracks }\end{array}$ \\
\hline 220 & 88.819 & 110.606 & 306.195 & 1052.262 & 965.850 & 889.877 & 943.163 \\
\hline 221 & 15.790 & 19.664 & 54.436 & 1052.262 & 964.850 & 888.826 & 943.499 \\
\hline 222 & 15.790 & 19.664 & 54.436 & 1052.262 & 964.470 & 888.160 & 941.576 \\
\hline 223 & 13.152 & 19.888 & 51.565 & 1052.262 & 964.293 & 887.511 & 941.491 \\
\hline 224 & 91.242 & 121.740 & 327.992 & 1052.262 & 964.608 & 886.712 & 940.607 \\
\hline 225 & 91.242 & 121.740 & 327.992 & 1052.262 & 965.485 & 889.224 & 943.000 \\
\hline 226 & 13.152 & 19.888 & 51.565 & 1052.262 & 968.524 & 894.259 & 948.206 \\
\hline 227 & 13.152 & 19.888 & 51.565 & 1052.262 & 970.874 & 900.442 & 953.790 \\
\hline 228 & 11.082 & 19.715 & 49.637 & 1052.262 & 973.874 & 907.326 & 961.125 \\
\hline 229 & 12.177 & 19.497 & 49.698 & 1052.190 & 976.583 & 913.718 & 968.051 \\
\hline 230 & 11.885 & 19.029 & 48.308 & 1052.108 & 979.789 & 918.816 & 972.237 \\
\hline 231 & 12.913 & 19.526 & 50.399 & 1052.163 & 979.157 & 922.138 & 974.427 \\
\hline 232 & 94.563 & 134.583 & 356.599 & 1052.309 & 978.172 & 921.862 & 972.501 \\
\hline 233 & 92.974 & 115.781 & 327.931 & 1052.548 & 974.246 & 916.353 & 966.283 \\
\hline 234 & 91.046 & 105.282 & 310.911 & 1052.664 & 971.598 & 910.989 & 961.538 \\
\hline 235 & 88.686 & 94.664 & 294.059 & 1052.766 & 968.818 & 905.878 & 956.717 \\
\hline 236 & 25.744 & 20.610 & 79.791 & 1053.005 & 966.348 & 901.320 & 952.937 \\
\hline 237 & 79.366 & 63.537 & 247.822 & 1053.122 & 964.487 & 897.079 & 948.356 \\
\hline 238 & 76.222 & 54.240 & 238.161 & 1053.367 & 961.603 & 893.245 & 945.003 \\
\hline 239 & 71.173 & 44.316 & 220.136 & 1053.486 & 959.255 & 889.872 & 941.637 \\
\hline 240 & 77.519 & 55.163 & 245.831 & 1053.590 & 957.706 & 887.077 & 939.372 \\
\hline 241 & 71.772 & 44.689 & 223.689 & 1053.616 & 956.222 & 884.805 & 936.584 \\
\hline 242 & 71.173 & 44.316 & 220.136 & 1053.556 & 955.368 & 882.539 & 935.053 \\
\hline 243 & 59.623 & 26.517 & 181.238 & 1053.621 & 953.608 & 881.050 & 933.852 \\
\hline 244 & 53.641 & 19.086 & 161.767 & 1053.630 & 953.180 & 879.288 & 931.535 \\
\hline 245 & 53.141 & 18.908 & 158.955 & 1053.562 & 953.197 & 879.055 & 931.548 \\
\hline 246 & 47.345 & 16.846 & 134.559 & 1053.125 & 955.144 & 879.311 & 932.319 \\
\hline 247 & 60.854 & 32.478 & 170.607 & 1052.768 & 955.311 & 879.636 & 932.552 \\
\hline 248 & 70.349 & 50.061 & 201.366 & 1052.548 & 956.724 & 880.102 & 933.750 \\
\hline 249 & 77.602 & 69.028 & 230.857 & 1052.348 & 959.761 & 884.535 & 938.066 \\
\hline 250 & 91.721 & 122.379 & 327.956 & 1052.229 & 963.253 & 890.151 & 943.600 \\
\hline 251 & 79.088 & 77.384 & 241.392 & 1052.196 & 967.328 & 897.729 & 951.831 \\
\hline 252 & 81.430 & 86.918 & 255.984 & 1052.110 & 971.529 & 904.965 & 958.662 \\
\hline 253 & 81.430 & 86.918 & 255.984 & 1052.093 & 974.350 & 911.294 & 965.515 \\
\hline 254 & 82.180 & 102.340 & 280.028 & 1052.085 & 977.620 & 917.183 & 971.711 \\
\hline 255 & 58.382 & 51.931 & 170.971 & 1052.081 & 978.468 & 921.473 & 974.599 \\
\hline 256 & 61.682 & 60.353 & 186.881 & 1052.080 & 978.964 & 922.833 & 974.376 \\
\hline 257 & 58.382 & 51.931 & 170.971 & 1052.079 & 976.415 & 917.366 & 969.038 \\
\hline
\end{tabular}




\begin{tabular}{|c|c|c|c|c|c|c|c|}
\hline hour & $\begin{array}{c}\text { Air } \\
\text { Change }\end{array}$ & $\begin{array}{c}\text { Air } \\
\text { Change } \\
\text { (ACH) }\end{array}$ & $\begin{array}{l}\text { ASHRAE } \\
\text { Enhanced }\end{array}$ & $\begin{array}{c}\text { Enhanced } \\
\text { Model }\end{array}$ & $\begin{array}{l}\text { Angular } \\
\text { Cracks }\end{array}$ & $\begin{array}{c}\text { Mixed } \\
\text { Cracks }\end{array}$ & $\begin{array}{l}\text { Straight } \\
\text { Cracks }\end{array}$ \\
\hline 258 & 59.008 & 52.488 & 174.174 & 1052.150 & 973.342 & 912.848 & 964.171 \\
\hline 259 & 60.101 & 53.460 & 180.180 & 1052.304 & 972.287 & 908.368 & 960.099 \\
\hline 260 & 32.840 & 32.133 & 101.706 & 1052.331 & 970.898 & 904.332 & 956.857 \\
\hline 261 & 33.331 & 38.542 & 111.750 & 1052.415 & 968.293 & 901.260 & 953.313 \\
\hline 262 & 18.916 & 16.826 & 58.014 & 1052.574 & 967.294 & 898.327 & 951.434 \\
\hline 263 & 14.568 & 16.846 & 49.146 & 1052.533 & 966.292 & 895.760 & 948.824 \\
\hline 264 & 13.494 & 16.804 & 47.326 & 1052.535 & 965.944 & 893.907 & 946.951 \\
\hline 265 & 33.331 & 41.507 & 116.235 & 1052.465 & 964.986 & 892.581 & 946.051 \\
\hline 266 & 11.947 & 15.941 & 43.177 & 1052.382 & 965.450 & 891.485 & 944.892 \\
\hline 267 & 9.879 & 11.423 & 32.916 & 1052.366 & 964.263 & 890.423 & 943.736 \\
\hline 268 & 8.796 & 10.954 & 30.324 & 1052.288 & 964.821 & 889.322 & 943.100 \\
\hline 269 & 7.608 & 10.828 & 28.689 & 1052.345 & 963.853 & 888.560 & 942.977 \\
\hline 270 & 7.415 & 10.553 & 27.825 & 1052.278 & 964.289 & 888.040 & 941.752 \\
\hline 271 & 10.597 & 11.312 & 33.773 & 1052.269 & 964.127 & 887.365 & 941.205 \\
\hline 272 & 7.415 & 10.553 & 27.825 & 1052.265 & 963.687 & 886.983 & 940.902 \\
\hline 273 & 6.207 & 9.939 & 25.334 & 1052.192 & 966.448 & 890.269 & 944.230 \\
\hline 274 & 6.528 & 9.871 & 25.364 & 1052.109 & 969.298 & 896.355 & 950.617 \\
\hline 275 & 4.356 & 8.136 & 20.010 & 1051.807 & 973.565 & 903.618 & 958.095 \\
\hline 276 & 8.204 & 12.406 & 31.019 & 1051.612 & 978.277 & 911.496 & 966.426 \\
\hline 277 & 8.487 & 11.324 & 28.560 & 1051.280 & 982.371 & 918.946 & 975.248 \\
\hline 278 & 7.386 & 10.513 & 25.831 & 1051.072 & 986.175 & 925.794 & 980.813 \\
\hline 279 & 5.066 & 6.760 & 16.663 & 1050.878 & 988.953 & 930.465 & 985.110 \\
\hline 280 & 9.359 & 9.989 & 26.347 & 1050.761 & 989.826 & 932.755 & 985.777 \\
\hline 281 & 7.872 & 9.803 & 24.460 & 1050.730 & 989.571 & 930.675 & 983.375 \\
\hline 282 & 7.883 & 7.012 & 20.091 & 1050.644 & 988.147 & 926.594 & 979.414 \\
\hline 283 & 11.019 & 7.841 & 26.849 & 1050.841 & 986.182 & 922.474 & 975.524 \\
\hline 284 & 10.053 & 8.048 & 25.604 & 1050.938 & 986.231 & 919.086 & 973.067 \\
\hline 285 & 11.949 & 10.628 & 31.319 & 1050.890 & 984.332 & 916.448 & 969.933 \\
\hline 286 & 25.085 & 22.313 & 65.750 & 1050.888 & 984.348 & 914.042 & 968.620 \\
\hline 287 & 24.101 & 21.438 & 62.010 & 1050.745 & 983.893 & 911.978 & 966.309 \\
\hline 288 & 11.949 & 10.628 & 31.319 & 1050.865 & 982.599 & 909.977 & 965.175 \\
\hline 289 & 12.298 & 10.939 & 32.529 & 1050.949 & 982.628 & 908.952 & 963.400 \\
\hline 290 & 11.219 & 10.977 & 30.929 & 1050.966 & 981.132 & 906.740 & 962.114 \\
\hline 291 & 11.879 & 11.623 & 33.295 & 1051.116 & 980.313 & 905.084 & 959.646 \\
\hline 292 & 27.052 & 26.469 & 76.440 & 1051.213 & 979.843 & 903.817 & 958.690 \\
\hline 293 & 26.560 & 28.351 & 77.701 & 1051.164 & 979.707 & 902.863 & 957.843 \\
\hline 294 & 58.468 & 67.610 & 176.486 & 1051.021 & 980.667 & 903.267 & 958.607 \\
\hline 295 & 57.247 & 56.014 & 149.875 & 1050.570 & 981.155 & 903.276 & 959.008 \\
\hline
\end{tabular}




\begin{tabular}{|c|c|c|c|c|c|c|c|}
\hline hour & $\begin{array}{c}\text { Air } \\
\text { Change }\end{array}$ & $\begin{array}{c}\text { Air } \\
\text { Change } \\
\text { (ACH) }\end{array}$ & $\begin{array}{l}\text { ASHRAE } \\
\text { Enhanced }\end{array}$ & $\begin{array}{c}\text { Enhanced } \\
\text { Model }\end{array}$ & $\begin{array}{l}\text { Angular } \\
\text { Cracks }\end{array}$ & $\begin{array}{c}\text { Mixed } \\
\text { Cracks }\end{array}$ & $\begin{array}{c}\text { Straight } \\
\text { Cracks }\end{array}$ \\
\hline 296 & 62.333 & 77.624 & 188.699 & 1050.421 & 983.855 & 904.050 & 959.519 \\
\hline 297 & 64.846 & 109.594 & 253.461 & 1050.161 & 985.684 & 908.539 & 963.998 \\
\hline 298 & 61.269 & 98.099 & 224.965 & 1049.964 & 989.631 & 915.222 & 971.300 \\
\hline 299 & 61.884 & 110.092 & 251.523 & 1049.775 & 994.294 & 922.829 & 979.089 \\
\hline 300 & 60.956 & 113.864 & 260.493 & 1049.661 & 997.971 & 930.589 & 987.373 \\
\hline 301 & 58.489 & 114.457 & 262.616 & 1049.559 & 1002.672 & 938.214 & 994.554 \\
\hline 302 & 57.433 & 102.175 & 231.040 & 1049.463 & 1005.163 & 944.179 & 1000.589 \\
\hline 303 & 56.873 & 96.118 & 216.386 & 1049.441 & 1006.867 & 949.336 & 1004.492 \\
\hline 304 & 57.433 & 102.175 & 231.040 & 1049.431 & 1007.212 & 951.432 & 1005.206 \\
\hline 305 & 57.308 & 96.855 & 218.043 & 1049.426 & 1005.797 & 948.132 & 1001.141 \\
\hline 306 & 58.167 & 93.132 & 209.929 & 1049.495 & 1001.680 & 942.443 & 994.823 \\
\hline 307 & 78.212 & 236.536 & 601.449 & 1050.147 & 997.964 & 936.430 & 989.354 \\
\hline 308 & 88.576 & 283.640 & 735.742 & 1050.680 & 995.636 & 930.625 & 984.042 \\
\hline 309 & 93.487 & 299.364 & 778.677 & 1051.009 & 991.446 & 925.455 & 979.098 \\
\hline 310 & 97.695 & 295.460 & 760.817 & 1051.308 & 988.251 & 920.269 & 974.044 \\
\hline 311 & 102.482 & 309.939 & 800.701 & 1051.594 & 985.411 & 916.109 & 969.276 \\
\hline 312 & 101.068 & 251.721 & 629.815 & 1051.731 & 983.086 & 912.338 & 966.457 \\
\hline 313 & 100.680 & 268.665 & 677.989 & 1051.700 & 982.628 & 909.227 & 962.932 \\
\hline 314 & 102.218 & 272.770 & 689.356 & 1051.778 & 981.132 & 906.409 & 960.449 \\
\hline 315 & 103.752 & 276.863 & 700.731 & 1051.863 & 980.313 & 903.800 & 958.392 \\
\hline 316 & 106.806 & 285.015 & 723.500 & 1052.024 & 979.843 & 901.014 & 954.365 \\
\hline 317 & 104.114 & 203.742 & 510.763 & 1052.268 & 979.707 & 898.467 & 952.355 \\
\hline 318 & 106.612 & 218.114 & 547.530 & 1052.387 & 980.667 & 896.289 & 950.313 \\
\hline 319 & 110.056 & 244.740 & 616.250 & 1052.490 & 981.155 & 894.128 & 947.417 \\
\hline 320 & 108.117 & 211.576 & 534.989 & 1052.587 & 983.855 & 892.173 & 945.943 \\
\hline 321 & 105.345 & 187.410 & 478.347 & 1052.610 & 984.585 & 894.457 & 947.679 \\
\hline 322 & 98.913 & 149.573 & 393.018 & 1052.549 & 987.759 & 898.479 & 952.208 \\
\hline 323 & 102.518 & 173.261 & 444.177 & 1052.542 & 991.701 & 904.695 & 958.747 \\
\hline 324 & 100.027 & 169.051 & 430.164 & 1052.397 & 994.683 & 910.967 & 966.233 \\
\hline 325 & 93.423 & 132.960 & 350.585 & 1052.301 & 998.799 & 917.317 & 971.185 \\
\hline 326 & 85.350 & 98.695 & 280.844 & 1052.208 & 1000.823 & 922.425 & 976.582 \\
\hline 327 & 82.878 & 88.465 & 260.538 & 1052.116 & 1002.179 & 926.366 & 979.332 \\
\hline 328 & 66.127 & 47.056 & 182.815 & 1052.095 & 1002.260 & 926.703 & 978.308 \\
\hline 329 & 68.343 & 48.633 & 190.619 & 1052.157 & 1001.770 & 923.239 & 973.859 \\
\hline 330 & 42.387 & 11.311 & 113.226 & 1052.378 & 998.254 & 918.179 & 969.134 \\
\hline 331 & 32.673 & 5.813 & 87.795 & 1052.487 & 995.002 & 912.773 & 963.876 \\
\hline 332 & 25.665 & 9.132 & 70.336 & 1052.586 & 993.055 & 908.315 & 960.420 \\
\hline 333 & 24.077 & 10.708 & 66.009 & 1052.538 & 989.195 & 904.488 & 956.393 \\
\hline
\end{tabular}




\begin{tabular}{|c|c|c|c|c|c|c|c|}
\hline hour & $\begin{array}{c}\text { Air } \\
\text { Change }\end{array}$ & $\begin{array}{c}\text { Air } \\
\text { Change } \\
\text { (ACH) }\end{array}$ & $\begin{array}{l}\text { ASHRAE } \\
\text { Enhanced }\end{array}$ & $\begin{array}{c}\text { Enhanced } \\
\text { Model }\end{array}$ & $\begin{array}{l}\text { Angular } \\
\text { Cracks }\end{array}$ & $\begin{array}{c}\text { Mixed } \\
\text { Cracks }\end{array}$ & $\begin{array}{l}\text { Straight } \\
\text { Cracks }\end{array}$ \\
\hline 334 & 24.984 & 11.112 & 69.762 & 1052.680 & 986.276 & 901.269 & 953.493 \\
\hline 335 & 17.247 & 10.739 & 48.750 & 1052.560 & 983.677 & 898.819 & 951.877 \\
\hline 336 & 13.202 & 10.569 & 38.754 & 1052.476 & 981.559 & 896.868 & 949.592 \\
\hline 337 & 14.558 & 10.360 & 41.318 & 1052.387 & 979.275 & 895.611 & 949.228 \\
\hline 338 & 11.484 & 10.215 & 34.429 & 1052.368 & 978.196 & 894.229 & 947.415 \\
\hline 339 & 9.253 & 9.876 & 29.686 & 1052.360 & 976.010 & 892.964 & 946.646 \\
\hline 340 & 9.023 & 9.631 & 28.754 & 1052.285 & 973.465 & 891.631 & 945.116 \\
\hline 341 & 8.588 & 9.167 & 27.368 & 1052.272 & 972.294 & 890.764 & 944.664 \\
\hline 342 & 7.754 & 8.966 & 25.675 & 1052.266 & 969.894 & 890.210 & 943.925 \\
\hline 343 & 6.894 & 8.585 & 23.627 & 1052.193 & 968.426 & 889.970 & 943.800 \\
\hline 344 & 7.073 & 8.809 & 24.103 & 1052.109 & 966.877 & 890.016 & 943.733 \\
\hline 345 & 5.298 & 7.541 & 19.495 & 1051.949 & 967.887 & 893.004 & 946.850 \\
\hline 346 & 5.596 & 7.964 & 20.589 & 1051.919 & 969.125 & 899.141 & 953.354 \\
\hline 347 & 4.859 & 7.348 & 18.541 & 1051.763 & 972.230 & 906.325 & 960.922 \\
\hline 348 & 5.159 & 6.884 & 17.756 & 1051.592 & 974.882 & 913.931 & 968.579 \\
\hline 349 & 4.438 & 6.316 & 15.843 & 1051.414 & 978.005 & 920.923 & 976.938 \\
\hline 350 & 6.355 & 6.784 & 18.732 & 1051.305 & 980.406 & 927.357 & 982.118 \\
\hline 351 & 5.972 & 6.374 & 17.338 & 1051.134 & 981.084 & 931.944 & 986.280 \\
\hline 352 & 5.482 & 6.339 & 16.548 & 1051.028 & 981.045 & 933.747 & 986.164 \\
\hline 353 & 6.268 & 6.133 & 17.134 & 1050.929 & 978.333 & 931.977 & 984.390 \\
\hline 354 & 5.305 & 6.135 & 15.902 & 1050.906 & 975.600 & 927.629 & 979.750 \\
\hline 355 & 12.077 & 6.445 & 28.195 & 1050.967 & 973.017 & 923.448 & 976.381 \\
\hline 356 & 9.603 & 6.834 & 23.894 & 1051.045 & 971.400 & 919.926 & 972.738 \\
\hline 357 & 12.426 & 6.632 & 29.347 & 1051.059 & 969.347 & 916.497 & 969.594 \\
\hline 358 & 11.878 & 7.396 & 29.347 & 1051.208 & 968.037 & 912.969 & 967.552 \\
\hline 359 & 14.469 & 7.722 & 35.723 & 1051.376 & 967.400 & 910.672 & 964.076 \\
\hline 360 & 16.578 & 7.373 & 40.684 & 1051.481 & 966.500 & 907.971 & 961.581 \\
\hline 361 & 18.340 & 8.157 & 46.474 & 1051.721 & 966.184 & & \\
\hline 362 & 24.166 & 8.598 & 62.462 & 1051.981 & 966.003 & & \\
\hline 363 & 27.247 & 9.694 & 70.425 & 1052.035 & 965.345 & & \\
\hline 364 & 31.971 & 0.000 & 82.380 & 1052.130 & 965.180 & & \\
\hline 365 & 27.303 & 7.286 & 70.787 & 1052.153 & 965.251 & & \\
\hline 366 & 30.987 & 0.000 & 78.191 & 1052.020 & 964.611 & & \\
\hline 367 & 26.763 & 9.522 & 68.469 & 1052.001 & 965.786 & & \\
\hline 368 & 23.232 & 8.266 & 58.818 & 1051.922 & 965.422 & & \\
\hline 369 & 29.020 & 0.000 & 70.077 & 1051.693 & 967.051 & & \\
\hline 370 & 34.930 & 12.428 & 84.681 & 1051.582 & 971.077 & & \\
\hline 371 & 52.375 & 27.953 & 130.693 & 1051.552 & 974.943 & & \\
\hline
\end{tabular}




\begin{tabular}{|c|c|c|c|c|c|c|c|}
\hline hour & $\begin{array}{c}\text { Air } \\
\text { Change }\end{array}$ & $\begin{array}{c}\text { Air } \\
\text { Change } \\
\text { (ACH) }\end{array}$ & $\begin{array}{l}\text { ASHRAE } \\
\text { Enhanced }\end{array}$ & $\begin{array}{c}\text { Enhanced } \\
\text { Model }\end{array}$ & $\begin{array}{l}\text { Angular } \\
\text { Cracks }\end{array}$ & $\begin{array}{r}\text { Mixed } \\
\text { Cracks }\end{array}$ & $\begin{array}{l}\text { Straight } \\
\text { Cracks }\end{array}$ \\
\hline 372 & 25.649 & 6.844 & 60.259 & 1051.397 & 978.812 & & \\
\hline 373 & 40.067 & 14.256 & 91.620 & 1051.154 & 982.781 & & \\
\hline 374 & 36.229 & 12.890 & 81.827 & 1051.037 & 986.186 & & \\
\hline 375 & 34.869 & 15.508 & 79.872 & 1051.005 & 988.088 & & \\
\hline 376 & 44.327 & 23.657 & 102.282 & 1050.919 & 988.945 & & \\
\hline 377 & 25.085 & 13.388 & 57.882 & 1050.902 & 989.726 & & \\
\hline 378 & 38.162 & 13.578 & 85.119 & 1050.894 & 986.618 & & \\
\hline 379 & 27.733 & 4.934 & 60.118 & 1050.819 & 985.751 & & \\
\hline 380 & 37.613 & 13.383 & 82.829 & 1050.806 & 984.022 & & \\
\hline 381 & 63.252 & 56.262 & 164.266 & 1050.801 & 982.944 & & \\
\hline 382 & 67.270 & 71.805 & 190.873 & 1050.798 & 981.253 & & \\
\hline 383 & 63.039 & 56.073 & 165.232 & 1050.868 & 980.152 & & \\
\hline 384 & 66.988 & 65.545 & 183.131 & 1050.879 & 977.886 & & \\
\hline 385 & 48.534 & 25.903 & 113.312 & 1050.955 & 976.890 & & \\
\hline 386 & 72.711 & 84.080 & 219.479 & 1050.968 & 974.804 & & \\
\hline 387 & 68.919 & 61.303 & 188.876 & 1051.259 & 973.332 & & \\
\hline 388 & 48.920 & 21.757 & 123.963 & 1051.663 & 971.656 & & \\
\hline 389 & 40.901 & 14.553 & 102.462 & 1051.741 & 970.968 & & \\
\hline 390 & 35.428 & 12.605 & 86.848 & 1051.633 & 970.779 & & \\
\hline 391 & 24.134 & 6.440 & 58.029 & 1051.555 & 970.212 & & \\
\hline 392 & 14.969 & 7.989 & 36.957 & 1051.469 & 970.204 & & \\
\hline 393 & 14.591 & 7.787 & 35.635 & 1051.380 & 972.498 & & \\
\hline 394 & 8.385 & 7.459 & 22.782 & 1051.290 & 974.901 & & \\
\hline 395 & 9.205 & 7.369 & 23.902 & 1051.199 & 979.805 & & \\
\hline 396 & 7.895 & 7.023 & 21.074 & 1051.107 & 982.974 & & \\
\hline 397 & 8.278 & 6.627 & 21.084 & 1051.016 & 986.866 & & \\
\hline 398 & 12.291 & 6.560 & 28.362 & 1050.924 & 989.353 & & \\
\hline 399 & 11.938 & 6.371 & 27.219 & 1050.833 & 991.900 & & \\
\hline 400 & 13.310 & 10.656 & 33.235 & 1050.812 & 992.861 & & \\
\hline 401 & 12.977 & 11.543 & 34.014 & 1050.874 & 991.382 & & \\
\hline 402 & 11.864 & 11.608 & 32.707 & 1050.953 & 989.330 & & \\
\hline 403 & 18.886 & 13.440 & 48.437 & 1051.252 & 987.927 & & \\
\hline 404 & 12.769 & 15.901 & 41.721 & 1051.375 & 987.864 & & \\
\hline 405 & 10.185 & 16.307 & 40.376 & 1051.481 & 985.805 & & \\
\hline 406 & 84.309 & 119.989 & 304.042 & 1051.508 & 985.072 & & \\
\hline 407 & 10.398 & 17.574 & 43.719 & 1051.733 & 984.445 & & \\
\hline 408 & 96.624 & 171.895 & 428.352 & 1051.915 & 984.294 & & \\
\hline 409 & 10.873 & 19.343 & 48.535 & 1052.097 & 983.117 & & \\
\hline
\end{tabular}




\begin{tabular}{|c|c|c|c|c|c|c|c|}
\hline hour & $\begin{array}{c}\text { Air } \\
\text { Change }\end{array}$ & $\begin{array}{c}\text { Air } \\
\text { Change } \\
\text { (ACH) }\end{array}$ & $\begin{array}{l}\text { ASHRAE } \\
\text { Enhanced }\end{array}$ & $\begin{array}{c}\text { Enhanced } \\
\text { Model }\end{array}$ & $\begin{array}{l}\text { Angular } \\
\text { Cracks }\end{array}$ & $\begin{array}{r}\text { Mixed } \\
\text { Cracks }\end{array}$ & $\begin{array}{c}\text { Straight } \\
\text { Cracks }\end{array}$ \\
\hline 410 & 104.114 & 203.742 & 510.763 & 1052.280 & 981.667 & & \\
\hline 411 & 106.788 & 208.975 & 526.900 & 1052.464 & 979.291 & & \\
\hline 412 & 110.663 & 206.713 & 529.546 & 1052.789 & 978.125 & & \\
\hline 413 & 112.845 & 200.752 & 522.910 & 1053.067 & 976.575 & & \\
\hline 414 & 113.692 & 182.033 & 492.784 & 1053.414 & 976.487 & & \\
\hline 415 & 111.973 & 159.361 & 455.095 & 1053.701 & 975.462 & & \\
\hline 416 & 103.146 & 119.274 & 379.682 & 1053.839 & 975.894 & & \\
\hline 417 & 103.146 & 119.274 & 379.682 & 1053.879 & 977.336 & & \\
\hline 418 & 102.250 & 118.237 & 374.305 & 1053.826 & 980.011 & & \\
\hline 419 & 101.347 & 117.194 & 368.942 & 1053.752 & 983.927 & & \\
\hline 420 & 82.206 & 65.811 & 264.247 & 1053.596 & 987.297 & & \\
\hline 421 & 82.595 & 66.122 & 261.710 & 1053.425 & 990.935 & & \\
\hline 422 & 64.949 & 34.663 & 193.313 & 1053.319 & 993.133 & & \\
\hline 423 & 70.337 & 43.796 & 210.824 & 1053.220 & 994.658 & & \\
\hline 424 & 81.125 & 64.945 & 253.315 & 1053.197 & 994.747 & & \\
\hline 425 & 84.074 & 74.785 & 269.302 & 1053.187 & 993.446 & & \\
\hline 426 & 27.087 & 21.685 & 85.828 & 1053.325 & 989.834 & & \\
\hline 427 & 19.406 & 25.892 & 74.575 & 1053.417 & 987.615 & & \\
\hline 428 & 20.507 & 27.362 & 79.977 & 1053.651 & 984.827 & & \\
\hline 429 & 16.266 & 28.937 & 77.408 & 1053.837 & 984.102 & & \\
\hline 430 & 17.769 & 30.031 & 81.896 & 1054.021 & 980.772 & & \\
\hline 431 & 128.073 & 239.236 & 639.781 & 1054.134 & 978.916 & & \\
\hline 432 & 135.363 & 276.934 & 736.342 & 1054.377 & 976.516 & & \\
\hline 433 & 136.027 & 266.193 & 716.285 & 1054.567 & 974.642 & & \\
\hline 434 & 136.027 & 266.193 & 716.285 & 1054.611 & 972.216 & & \\
\hline 435 & 133.029 & 236.659 & 651.923 & 1054.702 & 970.229 & & \\
\hline 436 & 135.221 & 252.587 & 687.791 & 1054.722 & 966.980 & & \\
\hline 437 & 142.074 & 303.301 & 810.465 & 1054.802 & 964.630 & & \\
\hline 438 & 143.331 & 305.986 & 819.589 & 1054.888 & 961.421 & & \\
\hline 439 & 143.331 & 305.986 & 819.589 & 1054.907 & 958.781 & & \\
\hline 440 & 146.249 & 325.224 & 869.623 & 1054.986 & 956.273 & & \\
\hline 441 & 144.585 & 308.661 & 828.726 & 1055.001 & 956.650 & & \\
\hline 442 & 142.785 & 292.120 & 788.799 & 1055.008 & 957.952 & & \\
\hline 443 & 144.585 & 308.661 & 828.726 & 1055.010 & 960.816 & & \\
\hline 444 & 144.970 & 322.378 & 860.111 & 1054.940 & 963.344 & & \\
\hline 445 & 143.331 & 305.986 & 819.589 & 1054.930 & 965.880 & & \\
\hline 446 & 144.970 & 322.378 & 860.111 & 1054.925 & 968.052 & & \\
\hline 447 & 137.237 & 268.562 & 724.664 & 1054.780 & 969.819 & & \\
\hline
\end{tabular}




\begin{tabular}{|c|c|c|c|c|c|c|c|}
\hline hour & $\begin{array}{c}\text { Air } \\
\text { Change }\end{array}$ & $\begin{array}{c}\text { Air } \\
\text { Change } \\
\text { (ACH) }\end{array}$ & $\begin{array}{l}\text { ASHRAE } \\
\text { Enhanced }\end{array}$ & $\begin{array}{c}\text { Enhanced } \\
\text { Model }\end{array}$ & $\begin{array}{l}\text { Angular } \\
\text { Cracks }\end{array}$ & $\begin{array}{c}\text { Mixed } \\
\text { Cracks }\end{array}$ & $\begin{array}{c}\text { Straight } \\
\text { Cracks }\end{array}$ \\
\hline 448 & 138.896 & 271.808 & 733.421 & 1054.756 & 969.485 & & \\
\hline 449 & 139.428 & 285.250 & 762.380 & 1054.675 & 967.843 & & \\
\hline 450 & 138.158 & 282.653 & 753.489 & 1054.587 & 964.423 & & \\
\hline 451 & 126.642 & 202.768 & 570.399 & 1054.497 & 961.552 & & \\
\hline 452 & 129.578 & 230.522 & 628.883 & 1054.478 & 958.685 & & \\
\hline 453 & 129.065 & 218.128 & 603.277 & 1054.469 & 956.886 & & \\
\hline 454 & 121.076 & 172.316 & 507.573 & 1054.465 & 953.828 & & \\
\hline 455 & 112.975 & 150.738 & 451.307 & 1054.250 & 951.599 & & \\
\hline 456 & 109.555 & 136.430 & 423.181 & 1054.215 & 949.018 & & \\
\hline 457 & 104.924 & 121.329 & 390.477 & 1054.128 & 948.162 & & \\
\hline 458 & 107.690 & 134.107 & 411.758 & 1054.039 & 945.770 & & \\
\hline 459 & 101.153 & 107.972 & 361.067 & 1053.948 & 943.727 & & \\
\hline 460 & 100.283 & 107.043 & 355.860 & 1053.857 & 942.335 & & \\
\hline 461 & 104.157 & 120.442 & 381.287 & 1053.836 & 940.839 & & \\
\hline 462 & 114.077 & 182.650 & 492.521 & 1053.542 & 939.210 & & \\
\hline 463 & 112.470 & 170.072 & 470.649 & 1053.635 & 937.735 & & \\
\hline 464 & 104.851 & 130.571 & 394.724 & 1053.708 & 937.164 & & \\
\hline 465 & 90.555 & 80.549 & 302.210 & 1053.719 & 937.495 & & \\
\hline 466 & 100.408 & 116.108 & 359.383 & 1053.510 & 939.590 & & \\
\hline 467 & 111.649 & 198.625 & 513.894 & 1053.122 & 942.176 & & \\
\hline 468 & 109.098 & 194.087 & 498.769 & 1052.909 & 945.635 & & \\
\hline 469 & 103.754 & 175.352 & 451.209 & 1052.712 & 947.763 & & \\
\hline 470 & 102.458 & 173.160 & 442.266 & 1052.523 & 949.754 & & \\
\hline 471 & 102.624 & 182.570 & 461.246 & 1052.408 & 950.811 & & \\
\hline 472 & 102.592 & 191.638 & 480.307 & 1052.307 & 951.975 & & \\
\hline 473 & 101.313 & 180.236 & 453.793 & 1052.282 & 949.397 & & \\
\hline 474 & 96.627 & 146.115 & 378.838 & 1052.271 & 947.717 & & \\
\hline 475 & 91.721 & 122.379 & 327.956 & 1052.194 & 946.193 & & \\
\hline 476 & 94.468 & 142.851 & 367.065 & 1052.110 & 944.903 & & \\
\hline 477 & 92.630 & 131.831 & 344.214 & 1052.092 & 943.521 & & \\
\hline 478 & 89.436 & 119.331 & 316.366 & 1052.013 & 943.539 & & \\
\hline 479 & 83.640 & 96.717 & 269.990 & 1051.927 & 943.193 & & \\
\hline 480 & 88.284 & 117.794 & 310.599 & 1051.909 & 943.532 & & \\
\hline 481 & 89.042 & 126.726 & 325.993 & 1051.830 & 942.911 & & \\
\hline 482 & 78.513 & 83.806 & 241.703 & 1051.815 & 943.197 & & \\
\hline 483 & 82.579 & 95.491 & 264.842 & 1051.809 & 943.393 & & \\
\hline 484 & 82.579 & 95.491 & 264.842 & 1051.806 & 943.599 & & \\
\hline 485 & 74.328 & 66.115 & 214.206 & 1051.876 & 944.989 & & \\
\hline
\end{tabular}




\begin{tabular}{|c|c|c|c|c|c|c|c|}
\hline hour & $\begin{array}{c}\text { Air } \\
\text { Change }\end{array}$ & $\begin{array}{c}\text { Air } \\
\text { Change } \\
\text { (ACH) }\end{array}$ & $\begin{array}{l}\text { ASHRAE } \\
\text { Enhanced }\end{array}$ & $\begin{array}{c}\text { Enhanced } \\
\text { Model }\end{array}$ & $\begin{array}{l}\text { Angular } \\
\text { Cracks }\end{array}$ & $\begin{array}{r}\text { Mixed } \\
\text { Cracks }\end{array}$ & $\begin{array}{c}\text { Straight } \\
\text { Cracks }\end{array}$ \\
\hline 486 & 74.573 & 66.333 & 218.387 & 1052.029 & 944.710 & & \\
\hline 487 & 79.671 & 77.954 & 241.384 & 1052.057 & 944.938 & & \\
\hline 488 & 80.887 & 86.339 & 250.770 & 1051.926 & 945.559 & & \\
\hline 489 & 80.887 & 86.339 & 250.770 & 1051.909 & 947.670 & & \\
\hline 490 & 81.605 & 101.623 & 268.273 & 1051.616 & 952.700 & & \\
\hline 491 & 84.497 & 135.289 & 330.786 & 1051.354 & 956.135 & & \\
\hline 492 & 80.506 & 128.899 & 311.183 & 1051.085 & 961.056 & & \\
\hline 493 & 80.622 & 172.113 & 412.700 & 1050.812 & 965.886 & & \\
\hline 494 & 80.211 & 178.371 & 428.838 & 1050.681 & 968.914 & & \\
\hline 495 & 74.344 & 119.034 & 282.511 & 1050.643 & 972.953 & & \\
\hline 496 & 73.218 & 110.716 & 264.166 & 1050.626 & 972.752 & & \\
\hline 497 & 70.544 & 94.124 & 229.331 & 1050.619 & 973.306 & & \\
\hline 498 & 74.524 & 112.692 & 270.157 & 1050.687 & 970.894 & & \\
\hline 499 & 69.412 & 80.265 & 206.602 & 1050.768 & 970.243 & & \\
\hline 500 & 76.645 & 109.082 & 266.643 & 1050.855 & 969.268 & & \\
\hline 501 & 82.591 & 146.930 & 352.437 & 1050.944 & 969.370 & & \\
\hline 502 & 81.843 & 131.039 & 317.697 & 1051.035 & 969.297 & & \\
\hline 503 & 81.843 & 131.039 & 317.697 & 1051.055 & 968.765 & & \\
\hline 504 & 77.605 & 103.546 & 259.674 & 1051.064 & 968.594 & & \\
\hline 505 & 69.774 & 68.271 & 197.156 & 1051.210 & 968.747 & & \\
\hline 506 & 75.834 & 94.437 & 241.706 & 1051.092 & 969.422 & & \\
\hline 507 & 80.979 & 129.656 & 314.343 & 1051.080 & 969.155 & & \\
\hline 508 & 66.119 & 58.813 & 176.476 & 1051.075 & 968.481 & & \\
\hline 509 & 62.831 & 50.299 & 161.586 & 1051.073 & 968.376 & & \\
\hline 510 & 66.713 & 59.342 & 181.246 & 1051.214 & 967.535 & & \\
\hline 511 & 66.713 & 59.342 & 181.246 & 1051.236 & 967.376 & & \\
\hline 512 & 54.439 & 38.739 & 136.846 & 1051.175 & 967.250 & & \\
\hline 513 & 54.439 & 38.739 & 136.846 & 1051.168 & 970.594 & & \\
\hline 514 & 69.966 & 87.130 & 221.601 & 1051.022 & 974.032 & & \\
\hline 515 & 66.398 & 70.873 & 192.783 & 1051.070 & 978.699 & & \\
\hline 516 & 71.892 & 95.922 & 239.183 & 1050.999 & 984.427 & & \\
\hline 517 & 68.900 & 85.802 & 216.845 & 1050.917 & 987.891 & & \\
\hline 518 & 70.778 & 94.436 & 234.131 & 1050.900 & 991.613 & & \\
\hline 519 & 65.692 & 99.336 & 240.398 & 1050.893 & 993.586 & & \\
\hline 520 & 57.649 & 66.663 & 172.802 & 1050.890 & 995.715 & & \\
\hline 521 & 66.681 & 100.832 & 245.167 & 1050.960 & 993.470 & & \\
\hline 522 & 66.735 & 94.978 & 235.802 & 1051.113 & 992.377 & & \\
\hline 523 & 27.544 & 31.851 & 85.455 & 1051.283 & 989.374 & & \\
\hline
\end{tabular}




\begin{tabular}{|c|c|c|c|c|c|c|c|}
\hline hour & $\begin{array}{c}\text { Air } \\
\text { Change }\end{array}$ & $\begin{array}{c}\text { Air } \\
\text { Change } \\
\text { (ACH) }\end{array}$ & $\begin{array}{l}\text { ASHRAE } \\
\text { Enhanced }\end{array}$ & $\begin{array}{c}\text { Enhanced } \\
\text { Model }\end{array}$ & $\begin{array}{l}\text { Angular } \\
\text { Cracks }\end{array}$ & $\begin{array}{r}\text { Mixed } \\
\text { Cracks }\end{array}$ & $\begin{array}{c}\text { Straight } \\
\text { Cracks }\end{array}$ \\
\hline 524 & 28.036 & 24.938 & 77.498 & 1051.389 & 987.853 & & \\
\hline 525 & 47.992 & 34.151 & 125.508 & 1051.487 & 986.590 & & \\
\hline 526 & 49.148 & 34.974 & 130.998 & 1051.653 & 984.897 & & \\
\hline 527 & 29.020 & 18.069 & 74.713 & 1051.614 & 984.257 & & \\
\hline 528 & 48.571 & 34.564 & 128.245 & 1051.618 & 982.333 & & \\
\hline 529 & 41.743 & 22.278 & 105.262 & 1051.619 & 982.001 & & \\
\hline 530 & 55.847 & 39.741 & 143.228 & 1051.406 & 981.682 & & \\
\hline 531 & 63.273 & 50.654 & 165.856 & 1051.301 & 981.494 & & \\
\hline 532 & 55.151 & 34.340 & 136.267 & 1051.275 & 980.016 & & \\
\hline 533 & 50.474 & 26.938 & 121.926 & 1051.263 & 980.063 & & \\
\hline 534 & 52.997 & 32.999 & 135.079 & 1051.472 & 978.698 & & \\
\hline 535 & 58.605 & 36.491 & 152.388 & 1051.646 & 979.023 & & \\
\hline 536 & 42.792 & 22.838 & 110.142 & 1051.754 & 978.378 & & \\
\hline 537 & 49.148 & 34.974 & 130.998 & 1051.710 & 980.115 & & \\
\hline 538 & 50.705 & 40.592 & 135.405 & 1051.497 & 982.630 & & \\
\hline 539 & 59.850 & 53.237 & 158.310 & 1051.108 & 986.037 & & \\
\hline 540 & 51.556 & 36.688 & 124.287 & 1050.894 & 989.060 & & \\
\hline 541 & 47.054 & 41.855 & 118.785 & 1050.626 & 991.875 & & \\
\hline 542 & 50.436 & 53.836 & 137.532 & 1050.425 & 994.232 & & \\
\hline 543 & 42.951 & 34.385 & 101.818 & 1050.377 & 995.424 & & \\
\hline 544 & 21.642 & 17.325 & 50.751 & 1050.284 & 995.089 & & \\
\hline 545 & 42.272 & 33.841 & 99.129 & 1050.263 & 993.622 & & \\
\hline 546 & 49.613 & 52.957 & 134.187 & 1050.254 & 989.983 & & \\
\hline 547 & 45.620 & 40.579 & 112.944 & 1050.321 & 988.436 & & \\
\hline 548 & 61.646 & 65.801 & 166.733 & 1050.259 & 984.972 & & \\
\hline 549 & 60.737 & 64.831 & 164.275 & 1050.252 & 983.019 & & \\
\hline 550 & 72.997 & 116.875 & 276.206 & 1050.463 & 981.110 & & \\
\hline 551 & 76.728 & 129.675 & 308.120 & 1050.638 & 980.584 & & \\
\hline 552 & 79.063 & 140.653 & 335.036 & 1050.746 & 978.411 & & \\
\hline 553 & 69.412 & 80.265 & 206.602 & 1050.774 & 978.230 & & \\
\hline 554 & 68.341 & 72.948 & 193.910 & 1050.786 & 977.474 & & \\
\hline 555 & 60.168 & 48.168 & 150.235 & 1050.792 & 977.781 & & \\
\hline 556 & 68.341 & 72.948 & 193.910 & 1050.794 & 976.999 & & \\
\hline 557 & 53.464 & 33.290 & 126.453 & 1050.866 & 976.200 & & \\
\hline 558 & 47.878 & 25.552 & 110.476 & 1050.878 & 976.206 & & \\
\hline 559 & 37.477 & 20.001 & 86.476 & 1050.883 & 974.692 & & \\
\hline 560 & 32.816 & 8.757 & 71.549 & 1050.814 & 973.653 & & \\
\hline 561 & 30.415 & 10.822 & 66.110 & 1050.733 & 975.753 & & \\
\hline
\end{tabular}




\begin{tabular}{|c|c|c|c|c|c|c|c|}
\hline hour & $\begin{array}{c}\text { Air } \\
\text { Change }\end{array}$ & $\begin{array}{c}\text { Air } \\
\text { Change } \\
\text { (ACH) }\end{array}$ & $\begin{array}{l}\text { ASHRAE } \\
\text { Enhanced }\end{array}$ & $\begin{array}{c}\text { Enhanced } \\
\text { Model }\end{array}$ & $\begin{array}{l}\text { Angular } \\
\text { Cracks }\end{array}$ & $\begin{array}{c}\text { Mixed } \\
\text { Cracks }\end{array}$ & $\begin{array}{c}\text { Straight } \\
\text { Cracks }\end{array}$ \\
\hline 562 & 42.473 & 22.668 & 94.497 & 1050.646 & 979.670 & & \\
\hline 563 & 40.129 & 28.556 & 91.476 & 1050.414 & 983.118 & & \\
\hline 564 & 66.270 & 117.895 & 272.164 & 1050.087 & 987.661 & & \\
\hline 565 & 74.809 & 139.740 & 328.814 & 1050.379 & 991.805 & & \\
\hline 566 & 68.611 & 103.751 & 242.875 & 1050.265 & 995.938 & & \\
\hline 567 & 73.986 & 144.784 & 340.728 & 1050.326 & 997.327 & & \\
\hline 568 & 5.320 & 13.251 & 32.761 & 1050.974 & 998.961 & & \\
\hline 569 & 98.965 & 220.074 & 544.382 & 1051.577 & 997.993 & & \\
\hline 570 & 7.423 & 17.827 & 44.658 & 1051.917 & 995.859 & & \\
\hline 571 & 113.688 & 323.603 & 834.452 & 1052.292 & 995.339 & & \\
\hline 572 & 117.299 & 344.317 & 894.692 & 1052.520 & 993.118 & & \\
\hline 573 & 7.695 & 20.533 & 52.672 & 1052.651 & 992.997 & & \\
\hline 574 & 9.208 & 22.115 & 56.352 & 1052.832 & 990.320 & & \\
\hline 575 & 117.571 & 282.365 & 719.510 & 1052.872 & 989.812 & & \\
\hline 576 & 118.400 & 263.294 & 671.897 & 1053.032 & 987.717 & & \\
\hline 577 & 120.844 & 279.479 & 715.184 & 1053.134 & 987.558 & & \\
\hline 578 & 115.979 & 226.960 & 583.815 & 1053.159 & 986.306 & & \\
\hline 579 & 118.613 & 253.216 & 647.974 & 1053.170 & 985.808 & & \\
\hline 580 & 114.481 & 213.847 & 552.943 & 1053.174 & 984.325 & & \\
\hline 581 & 109.087 & 174.660 & 465.436 & 1053.177 & 984.102 & & \\
\hline 582 & 110.246 & 176.516 & 472.250 & 1053.249 & 983.004 & & \\
\hline 583 & 102.952 & 137.365 & 391.721 & 1053.261 & 983.138 & & \\
\hline 584 & 105.657 & 140.973 & 404.022 & 1053.337 & 982.488 & & \\
\hline 585 & 108.315 & 154.155 & 430.307 & 1053.351 & 984.586 & & \\
\hline 586 & 94.945 & 101.345 & 324.914 & 1053.286 & 988.572 & & \\
\hline 587 & 96.569 & 111.668 & 337.726 & 1053.134 & 992.466 & & \\
\hline 588 & 84.252 & 74.943 & 266.064 & 1053.037 & 995.287 & & \\
\hline 589 & 82.623 & 73.494 & 257.169 & 1052.871 & 998.577 & & \\
\hline 590 & 75.711 & 60.611 & 227.594 & 1052.767 & 1000.722 & & \\
\hline 591 & 65.008 & 40.477 & 185.354 & 1052.669 & 1000.231 & & \\
\hline 592 & 46.801 & 24.978 & 130.036 & 1052.575 & 997.603 & & \\
\hline 593 & 34.311 & 15.260 & 94.938 & 1052.625 & 993.447 & & \\
\hline 594 & 26.089 & 13.924 & 73.142 & 1052.627 & 988.676 & & \\
\hline 595 & 24.984 & 11.112 & 69.762 & 1052.699 & 984.011 & & \\
\hline 596 & 14.133 & 11.314 & 42.486 & 1052.711 & 979.934 & & \\
\hline 597 & 16.159 & 12.936 & 48.576 & 1052.716 & 976.954 & & \\
\hline 598 & 14.555 & 12.947 & 44.972 & 1052.718 & 973.049 & & \\
\hline 599 & 11.938 & 12.743 & 39.329 & 1052.719 & 971.099 & & \\
\hline
\end{tabular}




\begin{tabular}{|c|c|c|c|c|c|c|c|}
\hline hour & $\begin{array}{c}\text { Air } \\
\text { Change }\end{array}$ & $\begin{array}{c}\text { Air } \\
\text { Change } \\
\text { (ACH) }\end{array}$ & $\begin{array}{l}\text { ASHRAE } \\
\text { Enhanced }\end{array}$ & $\begin{array}{c}\text { Enhanced } \\
\text { Model }\end{array}$ & $\begin{array}{l}\text { Angular } \\
\text { Cracks }\end{array}$ & $\begin{array}{r}\text { Mixed } \\
\text { Cracks }\end{array}$ & $\begin{array}{c}\text { Straight } \\
\text { Cracks }\end{array}$ \\
\hline 600 & 11.574 & 11.324 & 37.128 & 1052.791 & 967.608 & & \\
\hline 601 & 8.198 & 10.209 & 28.916 & 1052.660 & 966.640 & & \\
\hline 602 & 10.294 & 10.073 & 32.340 & 1052.571 & 964.605 & & \\
\hline 603 & 8.796 & 10.172 & 29.674 & 1052.552 & 962.690 & & \\
\hline 604 & 7.801 & 9.715 & 27.206 & 1052.472 & 961.802 & & \\
\hline 605 & 8.269 & 11.033 & 29.884 & 1052.386 & 960.363 & & \\
\hline 606 & 8.061 & 10.756 & 28.978 & 1052.297 & 959.104 & & \\
\hline 607 & 8.796 & 10.954 & 30.324 & 1052.277 & 957.584 & & \\
\hline 608 & 9.447 & 10.924 & 31.087 & 1052.197 & 956.084 & & \\
\hline 609 & 10.134 & 10.817 & 31.856 & 1052.111 & 957.612 & & \\
\hline 610 & 13.525 & 10.827 & 38.086 & 1052.022 & 960.132 & & \\
\hline 611 & 12.546 & 10.044 & 34.421 & 1051.788 & 963.112 & & \\
\hline 612 & 8.145 & 8.694 & 24.185 & 1051.461 & 967.103 & & \\
\hline 613 & 6.113 & 7.069 & 18.196 & 1050.969 & 969.650 & & \\
\hline 614 & 8.025 & 6.424 & 19.023 & 1050.517 & 973.614 & & \\
\hline 615 & 64.303 & 125.835 & 291.970 & 1050.061 & 973.942 & & \\
\hline 616 & 64.126 & 108.377 & 248.719 & 1049.961 & 975.538 & & \\
\hline 617 & 64.126 & 108.377 & 248.719 & 1049.916 & 973.346 & & \\
\hline 618 & 64.815 & 115.306 & 265.265 & 1049.896 & 970.824 & & \\
\hline 619 & 61.532 & 87.573 & 201.934 & 1049.887 & 968.799 & & \\
\hline 620 & 63.358 & 101.443 & 232.633 & 1049.883 & 966.994 & & \\
\hline 621 & 71.181 & 126.631 & 295.394 & 1050.167 & 965.827 & & \\
\hline 622 & 11.751 & 12.544 & 33.084 & 1050.567 & 964.802 & & \\
\hline 623 & 78.970 & 105.366 & 267.254 & 1051.071 & 963.655 & & \\
\hline 624 & 83.467 & 126.215 & 312.664 & 1051.244 & 962.822 & & \\
\hline 625 & 12.277 & 16.380 & 42.252 & 1051.443 & 963.499 & & \\
\hline 626 & 89.993 & 160.099 & 392.119 & 1051.491 & 962.347 & & \\
\hline 627 & 71.146 & 63.284 & 201.699 & 1051.654 & 962.319 & & \\
\hline 628 & 77.528 & 82.754 & 236.982 & 1051.686 & 962.126 & & \\
\hline 629 & 71.146 & 63.284 & 201.699 & 1051.701 & 963.398 & & \\
\hline 630 & 63.204 & 44.976 & 168.462 & 1051.707 & 962.496 & & \\
\hline 631 & 71.146 & 63.284 & 201.699 & 1051.710 & 963.340 & & \\
\hline 632 & 67.383 & 53.944 & 184.872 & 1051.711 & 963.072 & & \\
\hline 633 & 83.710 & 104.245 & 280.221 & 1051.783 & 966.542 & & \\
\hline 634 & 88.425 & 133.712 & 337.396 & 1051.723 & 969.511 & & \\
\hline 635 & 86.695 & 123.384 & 315.812 & 1051.717 & 974.181 & & \\
\hline 636 & 89.983 & 144.073 & 359.728 & 1051.714 & 979.452 & & \\
\hline 637 & 89.983 & 144.073 & 359.728 & 1051.713 & 986.304 & & \\
\hline
\end{tabular}




\begin{tabular}{|c|c|c|c|c|c|c|c|}
\hline hour & $\begin{array}{c}\text { Air } \\
\text { Change }\end{array}$ & $\begin{array}{c}\text { Air } \\
\text { Change } \\
\text { (ACH) }\end{array}$ & $\begin{array}{l}\text { ASHRAE } \\
\text { Enhanced }\end{array}$ & $\begin{array}{c}\text { Enhanced } \\
\text { Model }\end{array}$ & $\begin{array}{l}\text { Angular } \\
\text { Cracks }\end{array}$ & $\begin{array}{c}\text { Mixed } \\
\text { Cracks }\end{array}$ & $\begin{array}{c}\text { Straight } \\
\text { Cracks }\end{array}$ \\
\hline 638 & 83.623 & 111.574 & 289.398 & 1051.641 & 990.464 & & \\
\hline 639 & 91.020 & 145.733 & 363.871 & 1051.701 & 994.681 & & \\
\hline 640 & 82.619 & 102.886 & 274.916 & 1051.707 & 996.419 & & \\
\hline 641 & 82.291 & 95.157 & 265.635 & 1051.852 & 997.197 & & \\
\hline 642 & 75.207 & 66.897 & 218.493 & 1051.947 & 996.213 & & \\
\hline 643 & 76.079 & 67.672 & 222.796 & 1052.041 & 995.747 & & \\
\hline 644 & 77.602 & 69.028 & 230.857 & 1052.204 & 993.715 & & \\
\hline 645 & 54.382 & 24.187 & 149.092 & 1052.450 & 991.931 & & \\
\hline 646 & 42.773 & 11.414 & 116.474 & 1052.569 & 989.193 & & \\
\hline 647 & 38.578 & 10.295 & 106.042 & 1052.673 & 987.004 & & \\
\hline 648 & 35.781 & 19.097 & 102.987 & 1052.842 & 984.426 & & \\
\hline 649 & 52.261 & 23.243 & 149.864 & 1052.947 & 983.706 & & \\
\hline 650 & 29.501 & 13.121 & 83.860 & 1052.903 & 980.672 & & \\
\hline 651 & 29.101 & 10.354 & 82.707 & 1052.974 & 979.343 & & \\
\hline 652 & 27.271 & 12.129 & 79.556 & 1053.128 & 977.603 & & \\
\hline 653 & 25.031 & 13.359 & 74.501 & 1053.228 & 976.943 & & \\
\hline 654 & 19.896 & 14.158 & 60.762 & 1053.180 & 975.305 & & \\
\hline 655 & 19.896 & 14.158 & 60.762 & 1053.179 & 974.557 & & \\
\hline 656 & 19.896 & 14.158 & 60.762 & 1053.179 & 974.481 & & \\
\hline 657 & 17.566 & 14.063 & 54.445 & 1053.107 & 975.823 & & \\
\hline 658 & 14.555 & 12.947 & 44.972 & 1052.811 & 977.791 & & \\
\hline 659 & 10.597 & 11.312 & 33.773 & 1052.404 & 980.901 & & \\
\hline 660 & 8.401 & 10.462 & 28.626 & 1052.182 & 983.105 & & \\
\hline 661 & 7.094 & 9.465 & 24.822 & 1051.911 & 986.041 & & \\
\hline 662 & 5.609 & 7.484 & 19.413 & 1051.709 & 987.555 & & \\
\hline 663 & 7.122 & 8.869 & 23.414 & 1051.588 & 989.396 & & \\
\hline 664 & 7.599 & 8.787 & 23.734 & 1051.484 & 987.994 & & \\
\hline 665 & 9.295 & 9.095 & 26.690 & 1051.458 & 985.914 & & \\
\hline 666 & 9.295 & 9.095 & 26.690 & 1051.446 & 982.188 & & \\
\hline 667 & 8.385 & 8.950 & 25.080 & 1051.441 & 979.963 & & \\
\hline 668 & 8.385 & 8.950 & 25.080 & 1051.439 & 976.528 & & \\
\hline 669 & 10.355 & 9.211 & 28.623 & 1051.438 & 974.173 & & \\
\hline 670 & 10.069 & 8.956 & 27.594 & 1051.366 & 971.679 & & \\
\hline 671 & 11.277 & 9.028 & 29.839 & 1051.355 & 969.332 & & \\
\hline 672 & 12.690 & 9.030 & 32.547 & 1051.350 & 967.662 & & \\
\hline 673 & 12.690 & 9.030 & 32.547 & 1051.347 & 966.046 & & \\
\hline 674 & 19.761 & 10.546 & 48.262 & 1051.346 & 963.862 & & \\
\hline 675 & 18.396 & 8.182 & 44.156 & 1051.346 & 962.252 & & \\
\hline
\end{tabular}




\begin{tabular}{|c|c|c|c|c|c|c|c|}
\hline hour & $\begin{array}{c}\text { Air } \\
\text { Change }\end{array}$ & $\begin{array}{c}\text { Air } \\
\text { Change } \\
\text { (ACH) }\end{array}$ & $\begin{array}{l}\text { ASHRAE } \\
\text { Enhanced }\end{array}$ & $\begin{array}{c}\text { Enhanced } \\
\text { Model }\end{array}$ & $\begin{array}{l}\text { Angular } \\
\text { Cracks }\end{array}$ & $\begin{array}{l}\text { Mixed } \\
\text { Cracks }\end{array}$ & $\begin{array}{c}\text { Straight } \\
\text { Cracks }\end{array}$ \\
\hline 676 & 14.591 & 7.787 & 35.635 & 1051.346 & 960.573 & & \\
\hline 677 & 19.310 & 10.306 & 46.646 & 1051.274 & 960.207 & & \\
\hline 678 & 19.310 & 10.306 & 46.646 & 1051.263 & 958.861 & & \\
\hline 679 & 27.052 & 19.250 & 68.693 & 1051.258 & 957.592 & & \\
\hline 680 & 13.966 & 8.696 & 34.507 & 1051.256 & 957.934 & & \\
\hline 681 & 12.013 & 8.549 & 30.199 & 1051.183 & 960.287 & & \\
\hline 682 & 9.227 & 8.208 & 24.628 & 1051.100 & 964.088 & & \\
\hline 683 & 8.952 & 7.963 & 23.680 & 1051.013 & 968.178 & & \\
\hline 684 & 11.019 & 7.841 & 26.849 & 1050.923 & 972.904 & & \\
\hline 685 & 46.266 & 37.038 & 115.522 & 1050.832 & 977.645 & & \\
\hline 686 & 79.453 & 134.280 & 321.530 & 1050.883 & 980.613 & & \\
\hline 687 & 88.622 & 173.426 & 420.000 & 1051.171 & 983.724 & & \\
\hline 688 & 90.548 & 169.141 & 412.067 & 1051.359 & 984.516 & & \\
\hline 689 & 93.334 & 174.343 & 427.436 & 1051.545 & 984.689 & & \\
\hline 690 & 90.761 & 137.245 & 347.893 & 1051.729 & 982.536 & & \\
\hline 691 & 79.492 & 84.851 & 246.446 & 1051.842 & 980.977 & & \\
\hline 692 & 83.317 & 96.344 & 270.685 & 1051.943 & 979.975 & & \\
\hline 693 & 99.235 & 176.539 & 442.962 & 1052.110 & 978.941 & & \\
\hline 694 & 103.726 & 175.303 & 449.410 & 1052.428 & 978.536 & & \\
\hline 695 & 100.488 & 143.016 & 386.316 & 1052.631 & 977.831 & & \\
\hline 696 & 111.866 & 208.961 & 535.304 & 1052.823 & 977.617 & & \\
\hline 697 & 111.721 & 178.877 & 478.565 & 1053.153 & 965.331 & & \\
\hline 698 & 118.501 & 200.274 & 536.486 & 1053.503 & 963.073 & & \\
\hline 699 & 122.070 & 206.306 & 558.616 & 1053.792 & 958.890 & & \\
\hline 700 & 117.873 & 178.243 & 503.645 & 1054.001 & 957.002 & & \\
\hline 701 & 133.247 & 296.310 & 774.924 & 1054.054 & 954.030 & & \\
\hline 702 & 124.904 & 222.206 & 598.338 & 1054.077 & 952.671 & & \\
\hline 703 & 125.044 & 211.331 & 580.390 & 1054.230 & 949.916 & & \\
\hline 704 & 127.913 & 216.180 & 595.799 & 1054.328 & 949.421 & & \\
\hline 705 & 111.399 & 138.726 & 434.657 & 1054.352 & 949.711 & & \\
\hline 706 & 125.044 & 211.331 & 580.390 & 1054.291 & 951.936 & & \\
\hline 707 & 116.911 & 166.389 & 481.577 & 1054.142 & 954.840 & & \\
\hline 708 & 114.044 & 162.308 & 467.684 & 1054.045 & 957.324 & & \\
\hline 709 & 109.608 & 136.496 & 419.093 & 1054.022 & 960.182 & & \\
\hline 710 & 105.803 & 131.757 & 400.387 & 1053.869 & 963.137 & & \\
\hline 711 & 98.484 & 122.643 & 370.757 & 1053.771 & 963.845 & & \\
\hline 712 & 97.615 & 121.561 & 365.563 & 1053.676 & 964.517 & & \\
\hline 713 & 100.882 & 134.602 & 391.520 & 1053.654 & 963.188 & & \\
\hline
\end{tabular}




\begin{tabular}{|c|c|c|c|c|c|c|c|}
\hline hour & $\begin{array}{c}\text { Air } \\
\text { Change }\end{array}$ & $\begin{array}{c}\text { Air } \\
\text { Change } \\
\text { (ACH) }\end{array}$ & $\begin{array}{l}\text { ASHRAE } \\
\text { Enhanced }\end{array}$ & $\begin{array}{c}\text { Enhanced } \\
\text { Model }\end{array}$ & $\begin{array}{l}\text { Angular } \\
\text { Cracks }\end{array}$ & $\begin{array}{r}\text { Mixed } \\
\text { Cracks }\end{array}$ & $\begin{array}{c}\text { Straight } \\
\text { Cracks }\end{array}$ \\
\hline 714 & 86.060 & 84.206 & 293.024 & 1053.645 & 960.630 & & \\
\hline 715 & 91.765 & 97.950 & 325.632 & 1053.783 & 957.751 & & \\
\hline 716 & 91.765 & 97.950 & 325.632 & 1053.804 & 955.556 & & \\
\hline 717 & 84.289 & 74.976 & 286.890 & 1053.956 & 954.029 & & \\
\hline 718 & 79.961 & 64.013 & 267.898 & 1054.054 & 952.245 & & \\
\hline 719 & 77.839 & 83.086 & 277.847 & 1053.934 & 951.344 & & \\
\hline 720 & 84.345 & 105.035 & 319.186 & 1053.851 & 950.072 & & \\
\hline 721 & 41.173 & 36.624 & 139.230 & 1053.905 & 947.405 & & \\
\hline 722 & 41.663 & 40.766 & 145.453 & 1053.980 & 946.151 & & \\
\hline 723 & 71.232 & 63.361 & 244.016 & 1054.065 & 945.744 & & \\
\hline 724 & 67.731 & 54.222 & 228.442 & 1054.153 & 944.196 & & \\
\hline 725 & 43.134 & 30.694 & 143.734 & 1054.243 & 943.939 & & \\
\hline 726 & 30.721 & 21.862 & 103.071 & 1054.334 & 942.475 & & \\
\hline 727 & 26.673 & 23.726 & 93.123 & 1054.355 & 943.127 & & \\
\hline 728 & 42.644 & 41.725 & 150.703 & 1054.221 & 943.502 & & \\
\hline 729 & 41.663 & 48.178 & 154.208 & 1054.059 & 946.290 & & \\
\hline 730 & 40.683 & 47.044 & 148.928 & 1053.886 & 948.855 & & \\
\hline 731 & 103.885 & 147.850 & 418.420 & 1053.707 & 953.136 & & \\
\hline 732 & 108.824 & 154.879 & 436.319 & 1053.597 & 957.078 & & \\
\hline 733 & 103.980 & 138.737 & 397.612 & 1053.425 & 960.809 & & \\
\hline 734 & 111.401 & 178.364 & 479.080 & 1053.390 & 963.164 & & \\
\hline 735 & 110.269 & 166.744 & 457.551 & 1053.446 & 964.905 & & \\
\hline 736 & 106.019 & 141.457 & 409.442 & 1053.521 & 964.809 & & \\
\hline 737 & 91.655 & 89.681 & 310.087 & 1053.535 & 963.339 & & \\
\hline 738 & 94.366 & 92.333 & 321.303 & 1053.612 & 960.226 & & \\
\hline 739 & 54.141 & 19.264 & 164.595 & 1053.697 & 957.846 & & \\
\hline 740 & 48.668 & 12.987 & 147.189 & 1053.715 & 957.264 & & \\
\hline 741 & 43.294 & 7.702 & 130.546 & 1053.722 & 954.380 & & \\
\hline 742 & 40.683 & 10.856 & 124.034 & 1053.797 & 953.315 & & \\
\hline 743 & 41.173 & 14.649 & 127.170 & 1053.881 & 951.212 & & \\
\hline 744 & 63.253 & 33.758 & 200.412 & 1053.970 & 951.220 & & \\
\hline
\end{tabular}




\section{Cumulative Data for Northwest Wall}

\section{Cumulative Northwest (NW) Wall Data (Watts)}

\begin{tabular}{|c|c|c|c|c|c|c|c|}
\hline \multirow[b]{3}{*}{ our } & \multirow{2}{*}{\multicolumn{3}{|c|}{$\frac{\text { eUEST/DOE-2 Hourly Values }}{\text { (no reduction multiplier) }}$}} & & \multirow{2}{*}{\multicolumn{3}{|c|}{ CFD Multiphysisc Simulation }} \\
\hline & & & & & & & \\
\hline & $\begin{array}{c}\text { Air } \\
\text { Change }\end{array}$ & $\begin{array}{c}\text { Air } \\
\text { Change } \\
(\mathbf{A C H})\end{array}$ & $\begin{array}{l}\text { ASHRAE } \\
\text { Enhanced }\end{array}$ & $\begin{array}{c}\text { Enhanced } \\
\text { Model }\end{array}$ & $\begin{array}{l}\text { Angular } \\
\text { Cracks }\end{array}$ & $\begin{array}{l}\text { Mixed } \\
\text { Cracks }\end{array}$ & $\begin{array}{c}\text { Straight } \\
\text { Cracks }\end{array}$ \\
\hline 1 & 56.03 & 24.92 & 157.86 & 525.78 & 954.54 & 867.70 & 916.75 \\
\hline 2 & 110.88 & 49.31 & 312.40 & 1272.19 & 1907.75 & 1734.69 & 1832.18 \\
\hline 3 & 176.40 & 84.28 & 509.02 & 2077.80 & 2859.15 & 2600.60 & 2746.38 \\
\hline 4 & 237.07 & 111.26 & 696.36 & 2882.90 & 3809.23 & 3464.98 & 3659.13 \\
\hline 5 & 306.65 & 148.40 & 921.75 & 3704.24 & 4755.98 & 4327.43 & 4569.01 \\
\hline 6 & 348.85 & 159.66 & 1058.49 & 4530.94 & 5700.75 & 5188.22 & 5477.12 \\
\hline 7 & 407.45 & 180.51 & 1249.28 & 5354.53 & 6643.40 & 6047.30 & 6383.34 \\
\hline 8 & 453.03 & 200.79 & 1400.84 & 6174.29 & 7584.79 & 6904.95 & 7288.41 \\
\hline 9 & 498.12 & 216.83 & 1548.71 & 6992.36 & 8527.00 & 7765.10 & 8195.55 \\
\hline 10 & 562.90 & 245.64 & 1761.04 & 7833.77 & 9471.55 & 8630.08 & 9107.84 \\
\hline 11 & 622.76 & 272.26 & 1954.47 & 8688.27 & 10418.95 & 9501.56 & 10026.80 \\
\hline 12 & 697.48 & 325.43 & 2200.02 & 9550.53 & 11369.55 & 10379.60 & 10953.15 \\
\hline 13 & 765.10 & 367.54 & 2413.97 & 10419.31 & 12323.47 & 11264.59 & 11885.62 \\
\hline 14 & 821.72 & 402.79 & 2590.45 & 11297.17 & 13280.34 & 12155.55 & 12823.63 \\
\hline 15 & 877.84 & 437.73 & 2764.01 & 12196.44 & 14238.19 & 13049.88 & 13764.21 \\
\hline 16 & 917.54 & 462.45 & 2887.75 & 13103.37 & 15195.13 & 13944.51 & 14703.38 \\
\hline 17 & 949.02 & 482.05 & 2989.55 & 14017.87 & 16149.27 & 14834.07 & 15637.02 \\
\hline 18 & 978.96 & 498.03 & 3086.52 & 14927.90 & 17100.64 & 15719.08 & 16566.35 \\
\hline 19 & 1006.14 & 514.96 & 3175.69 & 15842.76 & 18049.32 & 16599.75 & 17491.70 \\
\hline 20 & 1039.96 & 536.02 & 3288.98 & 16770.44 & 18997.37 & 17476.26 & 18413.78 \\
\hline 21 & 1071.26 & 552.72 & 3392.55 & 17691.92 & 19942.78 & 18349.73 & 19332.91 \\
\hline 22 & 1115.38 & 576.27 & 3537.50 & 18605.20 & 20887.29 & 19220.42 & 20249.82 \\
\hline 23 & 1143.86 & 594.00 & 3632.89 & 19512.53 & 21829.96 & 20088.79 & 21164.59 \\
\hline 24 & 1175.16 & 610.70 & 3736.46 & 20432.73 & 22771.40 & 20955.09 & 22077.37 \\
\hline 25 & 1201.44 & 627.07 & 3825.10 & 21358.45 & 23713.24 & 21820.24 & 22989.72 \\
\hline 26 & 1223.81 & 644.98 & 3901.04 & 22280.22 & 24653.43 & 22683.96 & 23901.04 \\
\hline 27 & 1249.27 & 663.10 & 3987.05 & 23198.67 & 25593.50 & 23546.20 & 24811.17 \\
\hline 28 & 1280.95 & 677.19 & 4090.14 & 24116.00 & 26533.10 & 24407.82 & 25720.67 \\
\hline
\end{tabular}




\begin{tabular}{|c|c|c|c|c|c|c|c|}
\hline hour & $\begin{array}{c}\text { Air } \\
\text { Change }\end{array}$ & $\begin{array}{c}\text { Air } \\
\text { Change } \\
\text { (ACH) }\end{array}$ & $\begin{array}{l}\text { ASHRAE } \\
\text { Enhanced }\end{array}$ & $\begin{array}{c}\text { Enhanced } \\
\text { Model }\end{array}$ & $\begin{array}{l}\text { Angular } \\
\text { Cracks }\end{array}$ & $\begin{array}{l}\text { Mixed } \\
\text { Cracks }\end{array}$ & $\begin{array}{c}\text { Straight } \\
\text { Cracks }\end{array}$ \\
\hline 29 & 1308.51 & 691.89 & 4179.41 & 25037.97 & 27472.48 & 25268.65 & 26629.73 \\
\hline 30 & 1333.56 & 707.49 & 4262.17 & 25961.93 & 28412.00 & 26129.03 & 27538.45 \\
\hline 31 & 1353.35 & 723.33 & 4329.35 & 26885.09 & 29352.12 & 26989.13 & 28447.82 \\
\hline 32 & 1372.44 & 738.61 & 4393.31 & 27806.46 & 30292.27 & 27849.37 & 29357.03 \\
\hline 33 & 1395.47 & 755.01 & 4467.96 & 28720.63 & 31235.31 & 28713.24 & 30270.39 \\
\hline 34 & 1411.06 & 768.88 & 4519.65 & 29616.66 & 32182.26 & 29583.37 & 31190.43 \\
\hline 35 & 1427.12 & 781.73 & 4570.16 & 30491.02 & 33134.07 & 30461.32 & 32118.98 \\
\hline 36 & 1442.65 & 795.54 & 4619.19 & 31348.99 & 34090.39 & 31346.85 & 33055.20 \\
\hline 37 & 1457.10 & 807.11 & 4662.97 & 32190.32 & 35051.62 & 32239.75 & 33999.65 \\
\hline 38 & 1470.92 & 818.17 & 4704.19 & 33022.00 & 36015.62 & 33139.23 & 34950.73 \\
\hline 39 & 1481.71 & 828.73 & 4738.09 & 33871.94 & 36982.23 & 34042.99 & 35904.65 \\
\hline 40 & 1493.47 & 839.20 & 4773.62 & 34727.40 & 37949.92 & 34948.84 & 36858.88 \\
\hline 41 & 1505.24 & 849.66 & 4809.16 & 35584.88 & 38916.93 & 35851.13 & 37809.22 \\
\hline 42 & 1515.77 & 859.97 & 4842.02 & 36446.23 & 39882.57 & 36749.77 & 38757.02 \\
\hline 43 & 1525.25 & 870.09 & 4872.65 & 37318.03 & 40848.29 & 37645.19 & 39702.40 \\
\hline 44 & 1538.46 & 880.66 & 4911.41 & 38192.82 & 41811.68 & 38537.65 & 40646.06 \\
\hline 45 & 1547.94 & 890.78 & 4942.04 & 39064.51 & 42775.94 & 39428.40 & 41587.65 \\
\hline 46 & 1556.00 & 901.54 & 4971.02 & 39932.46 & 43739.52 & 40317.30 & 42528.23 \\
\hline 47 & 1565.64 & 912.68 & 5002.92 & 40798.17 & 44703.11 & 41204.75 & 43467.44 \\
\hline 48 & 1574.43 & 923.64 & 5033.25 & 41665.19 & 45665.59 & 42090.88 & 44405.83 \\
\hline 49 & 1585.92 & 933.85 & 5067.68 & 42526.55 & 46629.57 & 42976.15 & 45343.49 \\
\hline 50 & 1596.20 & 943.91 & 5099.52 & 43377.88 & 47592.60 & 43860.47 & 46280.84 \\
\hline 51 & 1604.20 & 953.16 & 5125.83 & 44226.37 & 48557.29 & 44744.53 & 47218.11 \\
\hline 52 & 1611.58 & 961.69 & 5149.66 & 45070.63 & 49522.71 & 45628.93 & 48155.49 \\
\hline 53 & 1618.28 & 970.64 & 5172.86 & 45927.40 & 50488.21 & 46513.40 & 49093.39 \\
\hline 54 & 1627.15 & 980.11 & 5199.78 & 46791.89 & 51453.98 & 47398.13 & 50031.69 \\
\hline 55 & 1635.20 & 989.41 & 5225.25 & 47657.06 & 52420.01 & 48282.93 & 50970.22 \\
\hline 56 & 1643.25 & 998.72 & 5250.72 & 48522.18 & 53387.10 & 49167.75 & 51908.88 \\
\hline 57 & 1651.29 & 1008.02 & 5276.19 & 49395.03 & 54355.99 & 50056.11 & 52851.43 \\
\hline 58 & 1661.93 & 1017.49 & 5305.86 & 50283.39 & 55328.68 & 50950.28 & 53799.77 \\
\hline 59 & 1670.97 & 1026.33 & 5331.59 & 51179.56 & 56305.15 & 51851.51 & 54755.38 \\
\hline 60 & 1683.62 & 1037.58 & 5365.36 & 52077.92 & 57286.62 & 52760.76 & 55719.17 \\
\hline 61 & 1697.29 & 1047.31 & 5397.96 & 52980.67 & 58271.62 & 53677.06 & 56691.31 \\
\hline 62 & 1708.21 & 1057.02 & 5425.79 & 53893.81 & 59260.70 & 54599.81 & 57668.78 \\
\hline 63 & 1715.58 & 1063.57 & 5444.21 & 54815.87 & 60251.57 & 55527.25 & 58649.84 \\
\hline 64 & 1722.94 & 1070.12 & 5462.62 & 55723.71 & 61243.23 & 56455.56 & 59630.21 \\
\hline 65 & 1729.27 & 1076.88 & 5480.29 & 56614.00 & 62232.57 & 57379.34 & 60605.77 \\
\hline
\end{tabular}




\begin{tabular}{|c|c|c|c|c|c|c|c|}
\hline hour & $\begin{array}{c}\text { Air } \\
\text { Change }\end{array}$ & $\begin{array}{c}\text { Air } \\
\text { Change } \\
(\mathrm{ACH})\end{array}$ & $\begin{array}{l}\text { ASHRAE } \\
\text { Enhanced }\end{array}$ & $\begin{array}{c}\text { Enhanced } \\
\text { Model }\end{array}$ & $\begin{array}{l}\text { Angular } \\
\text { Cracks }\end{array}$ & $\begin{array}{l}\text { Mixed } \\
\text { Cracks }\end{array}$ & $\begin{array}{c}\text { Straight } \\
\text { Cracks }\end{array}$ \\
\hline 66 & 1736.79 & 1084.24 & 5500.68 & 57480.38 & 63220.05 & 58299.27 & 61578.44 \\
\hline 67 & 1745.20 & 1091.72 & 5522.53 & 58342.42 & 64206.28 & 59215.70 & 62547.31 \\
\hline 68 & 1753.61 & 1099.20 & 5544.37 & 59215.45 & 65191.76 & 60128.94 & 63513.76 \\
\hline 69 & 1762.02 & 1106.68 & 5566.22 & 60088.43 & 66175.52 & 61039.16 & 64477.36 \\
\hline 70 & 1777.06 & 1114.71 & 5601.73 & 60959.79 & 67158.58 & 61946.91 & 65438.61 \\
\hline 71 & 1822.60 & 1139.01 & 5709.29 & 61833.97 & 68141.76 & 62852.68 & 66398.63 \\
\hline 72 & 1870.38 & 1168.76 & 5821.02 & 62719.41 & 69124.86 & 63757.36 & 67357.61 \\
\hline 73 & 1916.26 & 1193.25 & 5923.09 & 63611.82 & 70107.70 & 64661.36 & 68316.33 \\
\hline 74 & 1979.04 & 1260.26 & 6094.29 & 64503.23 & 71091.52 & 65565.23 & 69275.20 \\
\hline 75 & 2038.39 & 1323.61 & 6252.17 & 65391.09 & 72076.54 & 66469.13 & 70234.31 \\
\hline 76 & 2100.85 & 1401.39 & 6437.53 & 66278.82 & 73061.68 & 67372.44 & 71192.82 \\
\hline 77 & 2159.16 & 1453.26 & 6581.90 & 67176.24 & 74046.99 & 68275.57 & 72151.06 \\
\hline 78 & 2220.81 & 1519.06 & 6748.63 & 68078.93 & 75032.05 & 69178.44 & 73109.17 \\
\hline 79 & 2285.78 & 1599.97 & 6944.01 & 68980.65 & 76016.89 & 70080.97 & 74067.05 \\
\hline 80 & 2348.56 & 1666.98 & 7115.21 & 69879.04 & 77002.29 & 70983.39 & 75024.78 \\
\hline 81 & 2414.89 & 1755.49 & 7325.83 & 70781.21 & 77989.96 & 71889.10 & 75985.83 \\
\hline 82 & 2478.63 & 1840.54 & 7525.82 & 71686.61 & 78981.02 & 72800.31 & 76952.59 \\
\hline 83 & 2539.83 & 1916.75 & 7706.21 & 72582.79 & 79975.09 & 73718.31 & 77926.28 \\
\hline 84 & 2599.76 & 1991.38 & 7881.66 & 73460.45 & 80973.47 & 74643.22 & 78907.26 \\
\hline 85 & 2657.71 & 2063.54 & 8050.19 & 74312.27 & 81974.43 & 75574.73 & 79895.03 \\
\hline 86 & 2712.35 & 2121.86 & 8190.69 & 75152.38 & 82978.57 & 76511.88 & 80887.98 \\
\hline 87 & 2762.29 & 2166.29 & 8304.52 & 75994.21 & 83982.81 & 77452.49 & 81883.21 \\
\hline 88 & 2815.45 & 2213.57 & 8429.60 & 76822.44 & 84986.54 & 78392.60 & 82876.41 \\
\hline 89 & 2872.74 & 2264.54 & 8571.45 & 77633.08 & 85985.83 & 79327.02 & 83863.39 \\
\hline 90 & 2932.95 & 2318.09 & 8724.89 & 78429.37 & 86982.88 & 80256.28 & 84845.16 \\
\hline 91 & 2964.59 & 2326.53 & 8794.79 & 79219.90 & 87976.22 & 81180.37 & 85822.32 \\
\hline 92 & 3000.82 & 2339.42 & 8876.61 & 80009.83 & 88966.84 & 82099.61 & 86794.68 \\
\hline 93 & 3053.18 & 2372.02 & 9008.71 & 80803.67 & 89954.92 & 83014.64 & 87762.95 \\
\hline 94 & 3080.72 & 2384.27 & 9074.82 & 81604.96 & 90940.34 & 83926.09 & 88727.75 \\
\hline 95 & 3118.16 & 2400.93 & 9165.70 & 82416.02 & 91923.43 & 84834.03 & 89689.50 \\
\hline 96 & 3137.87 & 2409.69 & 9214.60 & 83244.93 & 92905.38 & 85739.34 & 90648.08 \\
\hline 97 & 3155.33 & 2419.01 & 9258.63 & 84088.28 & 93884.99 & 86642.21 & 91604.44 \\
\hline 98 & 3169.41 & 2429.03 & 9296.15 & 84943.14 & 94863.35 & 87542.96 & 92558.82 \\
\hline 99 & 3181.32 & 2438.56 & 9328.24 & 85803.81 & 95841.02 & 88442.00 & 93512.42 \\
\hline 100 & 3193.22 & 2448.09 & 9360.32 & 86665.83 & 96818.58 & 89339.74 & 94464.26 \\
\hline 101 & 3205.91 & 2457.12 & 9392.87 & 87548.82 & 97795.31 & 90236.66 & 95415.63 \\
\hline 102 & 3216.70 & 2464.80 & 9420.25 & 88441.63 & 98771.61 & 91132.84 & 96366.26 \\
\hline
\end{tabular}




\begin{tabular}{|c|c|c|c|c|c|c|c|}
\hline hour & $\begin{array}{c}\text { Air } \\
\text { Change }\end{array}$ & $\begin{array}{c}\text { Air } \\
\text { Change } \\
\text { (ACH) }\end{array}$ & $\begin{array}{l}\text { ASHRAE } \\
\text { Enhanced }\end{array}$ & $\begin{array}{c}\text { Enhanced } \\
\text { Model }\end{array}$ & $\begin{array}{l}\text { Angular } \\
\text { Cracks }\end{array}$ & $\begin{array}{l}\text { Mixed } \\
\text { Cracks }\end{array}$ & $\begin{array}{l}\text { Straight } \\
\text { Cracks }\end{array}$ \\
\hline 103 & 3225.47 & 2473.38 & 9445.05 & 89336.94 & 99749.04 & 92029.07 & 97317.15 \\
\hline 104 & 3231.79 & 2480.69 & .99 & 1.84 & 100726.29 & 92925.09 & 98268.16 \\
\hline 105 & 3238.38 & 2487.14 & 2.00 & 91123.98 & 101705.90 & 93824.50 & 99222.25 \\
\hline 106 & 3244.49 & 2494.21 & 9500.20 & 92022.83 & 102689.20 & 94729.87 & 100182.91 \\
\hline 107 & 3250.39 & 2500.50 & 9516.42 & 92919.62 & 103677.95 & 95642.66 & 101151.40 \\
\hline 108 & 3256.28 & 2506.27 & 9531.43 & 93814.13 & 104669.81 & 96563.16 & 102127.30 \\
\hline 109 & 3261.17 & 2511.48 & 9544.31 & 94705.20 & 105666.53 & 97490.70 & 103110.64 \\
\hline 110 & 3266.41 & 2516.61 & 9557.30 & 95604.63 & 106665.51 & 98424.49 & 104100.07 \\
\hline 111 & 3274.41 & 2523.72 & 9575.92 & 96514.96 & 107666.60 & 99362.37 & 105093.15 \\
\hline 112 & 3283.14 & 2529.16 & 9593.95 & 97426.49 & 108666.94 & 100300.80 & 106084.14 \\
\hline 113 & 3293.74 & 2537.64 & 9618.80 & 98336.33 & 109663.88 & 101233.61 & 107069.45 \\
\hline 114 & 3317.35 & 2550.24 & 9671.33 & 99247.53 & 110658.41 & 102161.95 & 108049.91 \\
\hline 115 & 3353.74 & 2569.66 & 9753.30 & 100161.73 & 111650.98 & 103085.30 & 109026.32 \\
\hline 116 & 3391.75 & 2589.95 & 9842.06 & 101057.00 & 112640.51 & 104004.48 & 109999.08 \\
\hline 117 & 3437.30 & 2614.26 & 9949.62 & 101928.61 & 113628.61 & 104919.96 & 110968.00 \\
\hline 118 & 3463.86 & 2626.07 & 10011.92 & 102783.59 & 114614.10 & 105831.81 & 111933.59 \\
\hline 119 & 3490.91 & 2626.07 & 10074.25 & 103626.64 & 115599.02 & 106740.98 & 112896.75 \\
\hline 120 & 3528.71 & 2639.52 & 10162.78 & 104475.72 & 116581.62 & 107647.59 & 113857.45 \\
\hline 121 & 3569.04 & 2653.87 & 10257.24 & 105333.33 & 117563.43 & 108552.54 & 114816.44 \\
\hline 122 & 3595.60 & 2653.87 & 10317.69 & 106191.92 & 118544.59 & 109455.85 & 115774.02 \\
\hline 123 & 3621.67 & 2653.87 & 10376.27 & 107051.84 & 119525.04 & 110358.19 & 116730.47 \\
\hline 124 & 3667.21 & 2678.18 & 10483.84 & 107910.89 & 120505.72 & 111259.26 & 117686.24 \\
\hline 125 & 3711.92 & 2698.06 & 10586.24 & 108795.74 & 121486.25 & 112159.77 & 118641.37 \\
\hline 126 & 3732.92 & 2705.53 & 10633.09 & 109697.94 & 122466.33 & 113059.47 & 119596.17 \\
\hline 127 & 3753.49 & 2711.02 & 10678.54 & 110596.33 & 123445.95 & 113958.51 & 120550.29 \\
\hline 128 & 3793.01 & 2725.08 & 10767.79 & 111488.21 & 124425.36 & 114857.11 & 121503.71 \\
\hline 129 & 3810.16 & 2737.29 & 10810.03 & 112371.99 & 125406.55 & 115758.65 & 122460.58 \\
\hline 130 & 3869.16 & 2784.52 & 10957.33 & 113257.37 & 126390.74 & 116665.50 & 123422.54 \\
\hline 131 & 3935.36 & 2855.18 & 11143.71 & 114137.44 & 127377.60 & 117578.45 & 124390.73 \\
\hline 132 & 4005.50 & 2942.52 & 11361.63 & 115008.24 & 128369.00 & 118498.58 & 125366.31 \\
\hline 133 & 4078.71 & 3053.24 & 11625.80 & 115867.40 & 129362.81 & 119425.03 & 126349.12 \\
\hline 134 & 4147.61 & 3145.16 & 11847.15 & 116729.84 & 130359.03 & 120357.25 & 127336.23 \\
\hline 135 & 4215.71 & 3242.09 & 12076.72 & 117607.66 & 131358.33 & 121293.36 & 128326.42 \\
\hline 136 & 4281.21 & 3335.31 & 12295.17 & 118492.24 & 132357.13 & 122230.71 & 129316.56 \\
\hline 137 & 4348.93 & 3455.78 & 12574.25 & 119380.85 & 133353.98 & 123163.80 & 130301.91 \\
\hline 138 & 4417.32 & 3571.37 & 12842.60 & 120274.16 & 134348.99 & 124092.72 & 131283.97 \\
\hline 139 & 4482.88 & 3658.84 & 13050.76 & 121171.93 & 135342.71 & 125017.77 & 132262.23 \\
\hline
\end{tabular}




\begin{tabular}{|c|c|c|c|c|c|c|c|}
\hline hour & $\begin{array}{c}\text { Air } \\
\text { Change }\end{array}$ & $\begin{array}{c}\text { Air } \\
\text { Change } \\
\text { (ACH) }\end{array}$ & $\begin{array}{l}\text { ASHRAE } \\
\text { Enhanced }\end{array}$ & $\begin{array}{c}\text { Enhanced } \\
\text { Model }\end{array}$ & $\begin{array}{l}\text { Angular } \\
\text { Cracks }\end{array}$ & $\begin{array}{l}\text { Mixed } \\
\text { Cracks }\end{array}$ & $\begin{array}{l}\text { Straight } \\
\text { Cracks }\end{array}$ \\
\hline 140 & 4536.18 & 3696.77 & 13173.67 & 122061.53 & 136335.11 & 9.33 & 133237.73 \\
\hline 141 & 4577.40 & 3718.77 & 13263.07 & 122931.92 & 137326.31 & 126858.29 & 134210.54 \\
\hline 142 & 4623.02 & 3759.35 & 13376.02 & 123776.19 & 138316.99 & 127774.86 & 135181.42 \\
\hline 143 & 4645.15 & 3779.03 & 13430.81 & 124602.73 & 139307.06 & 128689.23 & 136150.58 \\
\hline 144 & 4655.07 & 3787.85 & 13455.36 & 125426.95 & 140296.93 & 129601.85 & 137118.59 \\
\hline 145 & 4701.41 & 3829.07 & 13571.22 & 126248.73 & 141285.55 & 130512.99 & 138084.77 \\
\hline 146 & 4772.36 & 3942.68 & 13837.41 & 127067.18 & 142273.71 & 131422.77 & 139049.73 \\
\hline 147 & 4842.54 & 4042.56 & 14075.23 & 127882.23 & 143260.89 & 132331.29 & 140013.39 \\
\hline 148 & 4914.03 & 4144.30 & 14318.76 & 128692.83 & 144248.50 & 133238.60 & 140976.11 \\
\hline 149 & 4983.91 & 4231.32 & 14534.49 & 129513.04 & 145234.50 & 134144.85 & 141938.07 \\
\hline 150 & 5055.39 & 4333.06 & 14778.02 & 130563.57 & 146221.57 & 135050.71 & 142899.24 \\
\hline 151 & 5124.26 & 4431.07 & 15010.15 & 131613.95 & 147207.64 & 135955.90 & 143860.39 \\
\hline 152 & 5190.05 & 4507.14 & 15200.43 & 132664.38 & 148192.98 & 136860.27 & 144820.40 \\
\hline 153 & 5253.96 & 4575.36 & 15376.12 & 133714.80 & 149180.22 & 137767.11 & 145782.57 \\
\hline 154 & 5262.67 & 4585.44 & 15401.32 & 134765.23 & 150168.74 & 138678.53 & 146749.76 \\
\hline 155 & 5272.12 & 4598.89 & 15434.20 & 135816.02 & 151159.67 & 139595.56 & 147721.71 \\
\hline 156 & 5278.96 & 4612.87 & 15468.04 & 136867.08 & 152150.96 & 140517.57 & 148699.26 \\
\hline 157 & 5370.53 & 4800.23 & 15924.91 & 137918.40 & 153143.70 & 141444.12 & 149680.45 \\
\hline 158 & 5464.02 & 4983.16 & 16373.08 & 138969.94 & 154135.84 & 142373.92 & 150664.72 \\
\hline 159 & 5560.54 & 5163.47 & 16819.33 & 140021.73 & 155126.82 & 143305.54 & 151648.79 \\
\hline 160 & 5655.53 & 5315.55 & 17205.41 & 141073.72 & 156114.90 & 144235.34 & 152630.10 \\
\hline 161 & 5664.96 & 5335.69 & 17255.97 & 142126.05 & 157098.87 & 145158.37 & 153603.81 \\
\hline 162 & 5774.02 & 5568.51 & 17841.74 & 143178.51 & 158077.85 & 146075.11 & 154570.98 \\
\hline 163 & 5884.78 & 5785.26 & 18392.95 & 144231.23 & 159053.36 & 146985.70 & 155532.71 \\
\hline 164 & 5995.15 & 5981.60 & 18900.95 & 145284.14 & 160026.37 & 147891.31 & 156489.88 \\
\hline 165 & 6107.09 & 6190.71 & 19438.28 & 146337.10 & 160996.06 & 148792.41 & 157442.80 \\
\hline 166 & 6123.70 & 6214.35 & 19503.05 & 147390.08 & 161963.94 & 149689.83 & 158392.34 \\
\hline 167 & 6228.37 & 6372.62 & 19928.13 & 148443.07 & 162929.02 & 150583.62 & 159338.36 \\
\hline 168 & 6335.29 & 6534.31 & 20366.15 & 149496.20 & 163892.16 & 151474.83 & 160281.35 \\
\hline 169 & 6430.24 & 6635.65 & 20691.07 & 150549.43 & 164854.38 & 152364.08 & 161222.79 \\
\hline 170 & 6528.74 & 6749.55 & 21039.59 & 151602.68 & 165814.39 & 153250.46 & 162161.54 \\
\hline 171 & 6626.42 & 6862.51 & 21387.22 & 152656.02 & 166773.89 & 154134.57 & 163097.94 \\
\hline 172 & 6717.26 & 6951.39 & 21692.58 & 153709.44 & 167730.82 & 155016.77 & 164032.59 \\
\hline 173 & 6744.80 & 6973.44 & 21780.46 & 154762.88 & 168686.57 & 155896.98 & 164965.39 \\
\hline 174 & 6776.54 & 6993.20 & 21879.39 & 155816.47 & 169640.67 & 156775.44 & 165896.56 \\
\hline 175 & 6844.33 & 7029.38 & 22089.34 & 156870.15 & 170594.05 & 157652.33 & 166825.49 \\
\hline 176 & 6912.12 & 7065.56 & 22299.30 & 157923.86 & 171545.97 & 158527.90 & 167753.37 \\
\hline
\end{tabular}




\begin{tabular}{|c|c|c|c|c|c|c|c|}
\hline hour & $\begin{array}{c}\text { Air } \\
\text { Change }\end{array}$ & $\begin{array}{c}\text { Air } \\
\text { Change } \\
\text { (ACH) }\end{array}$ & $\begin{array}{l}\text { ASHRAE } \\
\text { Enhanced }\end{array}$ & $\begin{array}{c}\text { Enhanced } \\
\text { Model }\end{array}$ & $\begin{array}{l}\text { Angular } \\
\text { Cracks }\end{array}$ & $\begin{array}{c}\text { Mixed } \\
\text { Cracks }\end{array}$ & $\begin{array}{l}\text { Straight } \\
\text { Cracks }\end{array}$ \\
\hline 177 & 6989.64 & 7120.72 & 22545.13 & 158977.51 & 172499.74 & 159405.94 & 168683.73 \\
\hline 178 & 7015.19 & 7141.18 & 22626.67 & 160031.01 & 173455.45 & 160289.31 & 169619.57 \\
\hline 179 & 7041.60 & 7159.97 & 22707.96 & 161084.34 & 174415.63 & 161179.26 & 170562.46 \\
\hline 180 & 7109.74 & 7202.40 & 22910.53 & 162137.50 & 175378.94 & 162076.28 & 171512.21 \\
\hline 181 & 7165.77 & 7227.32 & 23068.40 & 163190.40 & 176345.56 & 162979.47 & 172468.89 \\
\hline 182 & 7226.42 & 7259.69 & 23241.47 & 164243.25 & 177314.92 & 163888.51 & 173430.62 \\
\hline 183 & 7297.29 & 7310.12 & 23449.47 & 165296.01 & 178285.16 & 164801.70 & 174395.98 \\
\hline 184 & 7368.17 & 7360.56 & 23657.48 & 166348.75 & 179255.02 & 165715.31 & 175359.88 \\
\hline 185 & 7399.29 & 7374.40 & 23745.96 & 167401.62 & 180222.06 & 166623.86 & 176318.73 \\
\hline 186 & 7432.37 & 7386.17 & 23839.97 & 168454.58 & 181187.14 & 167527.42 & 177272.25 \\
\hline 187 & 7479.21 & 7398.67 & 23975.83 & 169507.77 & 182149.97 & 168426.56 & 178221.79 \\
\hline 188 & 7514.25 & 7411.13 & 24078.90 & 170561.08 & 183110.79 & 169321.75 & 179167.82 \\
\hline 189 & 7567.32 & 7430.02 & 24235.03 & 171614.42 & 184070.16 & 170213.63 & 180110.70 \\
\hline 190 & 7605.06 & 7430.02 & 24343.97 & 172667.70 & 185029.44 & 171102.81 & 181051.86 \\
\hline 191 & 7653.40 & 7447.22 & 24483.78 & 173720.90 & 185986.99 & 171989.90 & 181990.78 \\
\hline 192 & 7704.02 & 7465.23 & 24628.93 & 174774.02 & 186944.69 & 172875.69 & 182928.44 \\
\hline 193 & 7753.63 & 7482.88 & 24768.67 & 175826.98 & 187901.80 & 173760.43 & 183865.81 \\
\hline 194 & 7814.86 & 7515.56 & 24944.90 & 176879.90 & 188859.59 & 174644.11 & 184802.26 \\
\hline 195 & 7844.88 & 7528.91 & 25030.23 & 177932.82 & 189816.81 & 175526.98 & 185738.24 \\
\hline 196 & 7869.44 & 7539.83 & 25098.82 & 178985.58 & 190775.19 & 176409.13 & 186673.36 \\
\hline 197 & 7898.14 & 7552.60 & 25178.95 & 180038.32 & 191732.38 & 177290.70 & 187607.84 \\
\hline 198 & 7930.33 & 7561.19 & 25267.45 & 181091.05 & 192690.41 & 178171.95 & 188542.32 \\
\hline 199 & 7961.46 & 7572.26 & 25352.75 & 182143.71 & 193647.97 & 179053.04 & 189476.67 \\
\hline 200 & 8015.23 & 7596.18 & 25501.53 & 183196.35 & 194606.57 & 179933.65 & 190410.67 \\
\hline 201 & 8041.64 & 7605.57 & 25573.22 & 184248.91 & 195566.67 & 180817.90 & 191348.49 \\
\hline 202 & 8072.54 & 7613.82 & 25655.77 & 185301.38 & 196529.89 & 181707.53 & 192291.89 \\
\hline 203 & 8102.20 & 7624.37 & 25734.77 & 186353.77 & 197496.99 & 182604.32 & 193242.47 \\
\hline 204 & 8142.99 & 7635.26 & 25841.60 & 187406.07 & 198467.55 & 183508.27 & 194200.47 \\
\hline 205 & 8193.60 & 7657.77 & 25973.82 & 188458.20 & 199442.00 & 184419.17 & 195165.45 \\
\hline 206 & 8243.08 & 7679.77 & 26100.51 & 189510.16 & 200419.81 & 185336.19 & 196136.07 \\
\hline 207 & 8264.17 & 7692.90 & 26155.88 & 190562.02 & 201398.27 & 186256.91 & 197109.41 \\
\hline 208 & 8289.57 & 7706.46 & 26223.23 & 191614.06 & 202376.37 & 187178.29 & 198081.71 \\
\hline 209 & 8315.44 & 7720.27 & 26292.50 & 192666.19 & 203352.18 & 188094.65 & 199048.96 \\
\hline 210 & 8340.16 & 7735.66 & 26360.53 & 193718.41 & 204325.77 & 189006.30 & 200011.55 \\
\hline 211 & 8407.55 & 7783.62 & 26550.14 & 194770.66 & 205297.83 & 189913.97 & 200970.72 \\
\hline 212 & 8474.94 & 7831.57 & 26739.75 & 195822.91 & 206268.26 & 190818.04 & 201927.03 \\
\hline 213 & 8542.33 & 7879.53 & 26929.37 & 196875.17 & 207238.56 & 191719.13 & 202880.34 \\
\hline
\end{tabular}




\begin{tabular}{|c|c|c|c|c|c|c|c|}
\hline hour & $\begin{array}{c}\text { Air } \\
\text { Change }\end{array}$ & $\begin{array}{c}\text { Air } \\
\text { Change } \\
\text { (ACH) }\end{array}$ & $\begin{array}{l}\text { ASHRAE } \\
\text { Enhanced }\end{array}$ & $\begin{array}{c}\text { Enhanced } \\
\text { Model }\end{array}$ & $\begin{array}{l}\text { Angular } \\
\text { Cracks }\end{array}$ & $\begin{array}{l}\text { Mixed } \\
\text { Cracks }\end{array}$ & $\begin{array}{l}\text { Straight } \\
\text { Cracks }\end{array}$ \\
\hline 214 & 8565.56 & 7896.05 & 26994.71 & 197927.43 & 208207.05 & 7.53 & 1.66 \\
\hline 215 & 8584.69 & 7914.77 & 2705 & 198 & 5.49 & 13.83 & 204780.72 \\
\hline 216 & 8603.82 & 7933.49 & 271 & 200031.96 & 2.44 & 194408.54 & 205728.65 \\
\hline 217 & 8621.75 & 7952.63 & 27169.51 & 4.22 & 211109.12 & 195301.86 & 206675.38 \\
\hline 218 & 8639.69 & 7971.78 & 27226.66 & 202136.48 & 212075.73 & 196194.02 & 207621.09 \\
\hline 219 & 8657.62 & 7990.92 & 27283.81 & 203188.74 & 213041.41 & 197085.20 & 208565.32 \\
\hline 220 & 8746.44 & 8101.52 & 27590.00 & 204241.00 & 214007.26 & 197975.07 & 209508.48 \\
\hline 221 & 8762.23 & 8121.19 & 27644.44 & 205293.26 & 214972.11 & 198863.90 & 210451.98 \\
\hline 222 & 8778.02 & 8140.85 & 27698.88 & 206345.53 & 215936.58 & 199752.06 & 211393.56 \\
\hline 223 & 8791.17 & 8160.74 & 27750.44 & 207397.79 & 216900.87 & 200639.57 & 212335.05 \\
\hline 224 & 8882.41 & 8282.48 & 28078.43 & 208450.05 & 217865.48 & 201526.28 & 213275.66 \\
\hline 225 & 8973.66 & 8404.22 & 28406.43 & 209502.31 & 218830.96 & 202415.51 & 214218.66 \\
\hline 226 & 8986.81 & 8424.11 & 28457.99 & 210554.57 & 219799.49 & 203309.77 & 215166.86 \\
\hline 227 & 8999.96 & 8444.00 & 28509.56 & 211606.83 & 220770.36 & 204210.21 & 216120.65 \\
\hline 228 & 9011.04 & 8463.71 & 28559.19 & 212659.10 & 221744.24 & 205117.53 & 217081.78 \\
\hline 229 & 9023.22 & 8483.21 & 28608.89 & 213711.29 & 222720.82 & 206031.25 & 218049.83 \\
\hline 230 & 9035.10 & 8502.24 & 28657.20 & 214763.39 & 223700.61 & 206950.07 & 219022.07 \\
\hline 231 & 9048.02 & 8521.76 & 28707.60 & 215815.56 & 224679.77 & 207872.21 & 219996.49 \\
\hline 232 & 9142.58 & 8656.35 & 29064.20 & 216867.87 & 225657.94 & 208794.07 & 220968.99 \\
\hline 233 & 9235.55 & 8772.13 & 29392.13 & 217920.41 & 226632.18 & 209710.42 & 221935.28 \\
\hline 234 & 9326.60 & 8877.41 & 29703.04 & 218973.08 & 227603.78 & 210621.41 & 222896.81 \\
\hline 235 & 9415.29 & 8972.07 & 29997.10 & 220025.84 & 228572.60 & 211527.29 & 223853.53 \\
\hline 236 & 9441.03 & 8992.68 & 30076.89 & 221078.85 & 229538.95 & 212428.61 & 224806.47 \\
\hline 237 & 9520.40 & 9056.22 & 30324.71 & 222131.97 & 230503.43 & 213325.69 & 225754.82 \\
\hline 238 & 9596.62 & 9110.46 & 30562.87 & 223185.34 & 231465.04 & 214218.93 & 226699.83 \\
\hline 239 & 9667.79 & 9154.78 & 30783.01 & 224238.83 & 232424.29 & 215108.80 & 227641.46 \\
\hline 240 & 9745.31 & 9209.94 & 31028.84 & 225292.42 & 233382.00 & 215995.88 & 228580.84 \\
\hline 241 & 9817.08 & 9254.63 & 31252.53 & 226346.03 & 234338.22 & 216880.69 & 229517.42 \\
\hline 242 & 9888.25 & 9298.94 & 31472.66 & 227399.59 & 235293.59 & 217763.22 & 230452.47 \\
\hline 243 & 9947.88 & 9325.46 & 31653.90 & 228453.21 & 236247.20 & 218644.27 & 231386.32 \\
\hline 244 & 10001.52 & 9344.55 & 31815.67 & 229506.84 & 237200.38 & 219523.56 & 232317.86 \\
\hline 245 & 10054.66 & 9363.45 & 31974.62 & 230560.40 & 238153.57 & 220402.62 & 233249.41 \\
\hline 246 & 10102.00 & 9380.30 & 32109.18 & 231613.53 & 239108.72 & 221281.93 & 234181.73 \\
\hline 247 & 10162.86 & 9412.78 & 32279.79 & 232666.30 & 240064.03 & 222161.56 & 235114.28 \\
\hline 248 & 10233.21 & 9462.84 & 32481.16 & 233718.84 & 241020.75 & 223041.67 & 236048.03 \\
\hline 249 & 10310.81 & 9531.87 & 32712.01 & 234771.19 & 241980.51 & 223926.20 & 236986.09 \\
\hline 250 & 10402.53 & 9654.24 & 33039.97 & 235823.42 & 242943.77 & 224816.35 & 237929.69 \\
\hline
\end{tabular}




\begin{tabular}{|c|c|c|c|c|c|c|c|}
\hline hour & $\begin{array}{c}\text { Air } \\
\text { Change }\end{array}$ & $\begin{array}{c}\text { Air } \\
\text { Change } \\
(\mathrm{ACH})\end{array}$ & $\begin{array}{l}\text { ASHRAE } \\
\text { Enhanced }\end{array}$ & $\begin{array}{c}\text { Enhanced } \\
\text { Model }\end{array}$ & $\begin{array}{l}\text { Angular } \\
\text { Cracks }\end{array}$ & $\begin{array}{l}\text { Mixed } \\
\text { Cracks }\end{array}$ & $\begin{array}{l}\text { Straight } \\
\text { Cracks }\end{array}$ \\
\hline 251 & 10481.62 & 9731.63 & 1.36 & 236875.62 & 1.09 & 4.08 & 1.53 \\
\hline 252 & 105 & 981 & .35 & 237 & 244 & 226619.05 & 239840.19 \\
\hline 253 & 10644.48 & 9905.47 & .33 & 238 & 6.97 & 227530.34 & 240805.70 \\
\hline 254 & 10726.66 & 10007.80 & .36 & 1.90 & 246 & 228447.52 & 241777.41 \\
\hline 255 & 10785.04 & 10059.74 & 4.33 & 241 & 247813.06 & 229369.00 & 242752.01 \\
\hline 256 & 10846.72 & 10120.09 & 34431.21 & 242136.06 & 248792.02 & 230291.83 & 243726.39 \\
\hline 257 & 10905.10 & 10172.02 & 34602.18 & 243188.14 & 249768.44 & 231209.20 & 244695.43 \\
\hline 258 & 10964.11 & 10224.51 & 34776.35 & 244240.29 & 250741.78 & 232122.04 & 245659.60 \\
\hline 259 & 11024.21 & 10277.97 & 34956.53 & 245292.60 & 251714.07 & 233030.41 & 246619.70 \\
\hline 260 & 11057.05 & 10310.10 & 35058.24 & 246344.93 & 252684.97 & 233934.74 & 247576.55 \\
\hline 261 & 11090.38 & 10348.64 & 35169.99 & 247397.34 & 253653.26 & 234836.00 & 248529.87 \\
\hline 262 & 11109.30 & 10365.47 & 35228.00 & 248449.92 & 254620.55 & 235734.33 & 249481.30 \\
\hline 263 & 11123.87 & 10382.31 & 35277.15 & 249502.45 & 255586.84 & 236630.09 & 250430.12 \\
\hline 264 & 11137.36 & 10399.12 & 35324.48 & 250554.99 & 256552.79 & 237524.00 & 251377.08 \\
\hline 265 & 11170.69 & 10440.63 & 35440.71 & 251607.45 & 257517.77 & 238416.58 & 252323.13 \\
\hline 266 & 11182.64 & 10456.57 & 35483.89 & 252659.83 & 258483.22 & 239308.06 & 253268.02 \\
\hline 267 & 11192.52 & 10467.99 & 35516.80 & 253712.20 & 259447.49 & 240198.49 & 254211.75 \\
\hline 268 & 11201.31 & 10478.94 & 35547.13 & 254764.49 & 260412.31 & 241087.81 & 255154.85 \\
\hline 269 & 11208.92 & 10489.77 & 35575.82 & 255816.83 & 261376.16 & 241976.37 & 256097.83 \\
\hline 270 & 11216.34 & 10500.32 & 35603.64 & 256869.11 & 262340.45 & 242864.41 & 257039.58 \\
\hline 271 & 11226.93 & 10511.64 & 35637.42 & 257921.38 & 263304.58 & 243751.77 & 257980.79 \\
\hline 272 & 11234.35 & 10522.19 & 35665.24 & 258973.64 & 264268.27 & 244638.76 & 258921.69 \\
\hline 273 & 11240.55 & 10532.13 & 35690.57 & 260025.84 & 265234.71 & 245529.03 & 259865.92 \\
\hline 274 & 11247.08 & 10542.00 & 35715.94 & 261077.94 & 266204.01 & 246425.38 & 260816.54 \\
\hline 275 & 11251.44 & 10550.13 & 35735.95 & 262129.75 & 267177.58 & 247329.00 & 261774.63 \\
\hline 276 & 11259.64 & 10562.54 & 35766.97 & 263181.36 & 268155.85 & 248240.49 & 262741.06 \\
\hline 277 & 11268.13 & 10573.86 & 35795.53 & 264232.64 & 269138.22 & 249159.44 & 263716.31 \\
\hline 278 & 11275.52 & 10584.38 & 35821.36 & 265283.72 & 270124.40 & 250085.23 & 264697.12 \\
\hline 279 & 11280.58 & 10591.14 & 35838.02 & 266334.59 & 271113.35 & 251015.70 & 265682.23 \\
\hline 280 & 11289.94 & 10601.13 & 35864.37 & 267385.35 & 272103.18 & 251948.46 & 266668.01 \\
\hline 281 & 11297.81 & 10610.93 & 35888.83 & 268436.08 & 273092.75 & 252879.13 & 267651.38 \\
\hline 282 & 11305.70 & 10617.94 & 35908.92 & 269486.73 & 274080.90 & 253805.72 & 268630.79 \\
\hline 283 & 11316.71 & 10625.78 & 35935.77 & 270537.57 & 275067.08 & 254728.20 & 269606.32 \\
\hline 284 & 11326.77 & 10633.83 & 35961.37 & 271588.51 & 276053.31 & 255647.28 & 270579.39 \\
\hline 285 & 11338.72 & 10644.46 & 35992.69 & 272639.40 & 277037.64 & 256563.73 & 271549.32 \\
\hline 286 & 11363.80 & 10666.77 & 36058.44 & 273690.28 & 278021.99 & 257477.77 & 272517.94 \\
\hline 287 & 11387.90 & 10688.21 & 36120.45 & 274741.03 & 279005.88 & 258389.75 & 273484.25 \\
\hline
\end{tabular}




\begin{tabular}{|c|c|c|c|c|c|c|c|}
\hline hour & $\begin{array}{c}\text { Air } \\
\text { Change }\end{array}$ & $\begin{array}{c}\text { Air } \\
\text { Change } \\
\text { (ACH) }\end{array}$ & $\begin{array}{l}\text { ASHRAE } \\
\text { Enhanced }\end{array}$ & $\begin{array}{c}\text { Enhanced } \\
\text { Model }\end{array}$ & $\begin{array}{l}\text { Angular } \\
\text { Cracks }\end{array}$ & $\begin{array}{l}\text { Mixed } \\
\text { Cracks }\end{array}$ & $\begin{array}{l}\text { Straight } \\
\text { Cracks }\end{array}$ \\
\hline 288 & 11399.85 & 10698.84 & 36151.77 & 275791.90 & 8.48 & 73 & 49.42 \\
\hline 289 & 11412.15 & 107 & 30 & 276 & 280 & 260 & 275 \\
\hline 290 & 11423.37 & 10720.75 & 5.23 & 277 & 281 & 261115.42 & 276374.94 \\
\hline 291 & 11435.25 & 10732.38 & .52 & 278 & 2.55 & 262020.51 & 277334.58 \\
\hline 292 & 11462.30 & 10758.85 & 4.96 & 2799 & 283 & 262924.32 & 278293.27 \\
\hline 293 & 11488.86 & 10787.20 & 2.66 & 281047.30 & 284892.10 & 263827.19 & 279251.12 \\
\hline 294 & 11547.33 & 10854.81 & 36579.15 & 282098.32 & 285872.77 & 264730.45 & 280209.72 \\
\hline 295 & 11604.57 & 10910.82 & 36729.02 & 283148.89 & 286853.92 & 265633.73 & 281168.73 \\
\hline 296 & 11666.91 & 10988.44 & 36917.72 & 284199.31 & 287837.78 & 266537.78 & 282128.25 \\
\hline 297 & 11731.75 & 11098.04 & 37171.18 & 285249.48 & 288823.46 & 267446.32 & 283092.25 \\
\hline 298 & 11793.02 & 11196.14 & 37396.15 & 286299.44 & 289813.09 & 268361.54 & 284063.55 \\
\hline 299 & 11854.91 & 11306.23 & 37647.67 & 287349.22 & 290807.39 & 269284.37 & 285042.64 \\
\hline 300 & 11915.86 & 11420.09 & 37908.17 & 288398.88 & 291805.36 & 270214.96 & 286030.01 \\
\hline 301 & 11974.35 & 11534.55 & 38170.78 & 289448.44 & 292808.03 & 271153.17 & 287024.56 \\
\hline 302 & 12031.79 & 11636.72 & 38401.82 & 290497.90 & 293813.19 & 272097.35 & 288025.15 \\
\hline 303 & 12088.66 & 11732.84 & 38618.21 & 291547.34 & 294820.06 & 273046.69 & 289029.65 \\
\hline 304 & 12146.09 & 11835.02 & 38849.25 & 292596.77 & 295827.27 & 273998.12 & 290034.85 \\
\hline 305 & 12203.40 & 11931.87 & 39067.29 & 293646.20 & 296833.07 & 274946.25 & 291035.99 \\
\hline 306 & 12261.57 & 12025.00 & 39277.22 & 294695.69 & 297834.75 & 275888.69 & 292030.82 \\
\hline 307 & 12339.78 & 12261.54 & 39878.67 & 295745.84 & 298832.71 & 276825.13 & 293020.17 \\
\hline 308 & 12428.36 & 12545.18 & 40614.41 & 296796.52 & 299828.35 & 277755.75 & 294004.21 \\
\hline 309 & 12521.84 & 12844.54 & 41393.09 & 297847.53 & 300819.80 & 278681.20 & 294983.31 \\
\hline 310 & 12619.54 & 13140.00 & 42153.90 & 298898.84 & 301808.05 & 279601.47 & 295957.35 \\
\hline 311 & 12722.02 & 13449.94 & 42954.60 & 299950.43 & 302793.46 & 280517.58 & 296926.63 \\
\hline 312 & 12823.09 & 13701.67 & 43584.42 & 301002.16 & 303776.54 & 281429.92 & 297893.09 \\
\hline 313 & 12923.77 & 13970.33 & 44262.41 & 302053.86 & 304759.17 & 282339.15 & 298856.02 \\
\hline 314 & 13025.99 & 14243.10 & 44951.76 & 303105.64 & 305740.30 & 283245.56 & 29981 \\
\hline 315 & 13129.74 & 14519.96 & 45652.49 & 304157.50 & 306720.62 & 284149.36 & 300774.86 \\
\hline 316 & 13236.54 & 14804.98 & 46375.99 & 305209.52 & 307700.46 & 285050.37 & 301729.22 \\
\hline 317 & 13340.66 & 15008.72 & 46886.76 & 306261.79 & 308680.17 & 285948.84 & 302681.58 \\
\hline 318 & 13447.27 & 15226.83 & 47434.29 & 307314.18 & 309660.83 & 286845.13 & 303631.89 \\
\hline 319 & 13557.33 & 15471.57 & 48050.54 & 308366.67 & 310641.99 & 287739.25 & 304579.31 \\
\hline 320 & 13665.44 & 15683.15 & 48585.53 & 309419.26 & 311625.84 & 288631.43 & 305525.25 \\
\hline 321 & 13770.79 & 15870.56 & 49063.87 & 310471.87 & 312610.43 & 289525.88 & 306472.93 \\
\hline 322 & 13869.70 & 16020.13 & 49456.89 & 311524.42 & 313598.19 & 290424.36 & 307425.14 \\
\hline 323 & 13972.22 & 16193.39 & 49901.07 & 312576.96 & 314589.89 & 291329.06 & 308383.89 \\
\hline 324 & 14072.25 & 16362.44 & 50331.23 & 313629.35 & 315584.57 & 292240.03 & 309350.12 \\
\hline
\end{tabular}




\begin{tabular}{|c|c|c|c|c|c|c|c|}
\hline hour & $\begin{array}{c}\text { Air } \\
\text { Change }\end{array}$ & $\begin{array}{c}\text { Air } \\
\text { Change } \\
\text { (ACH) }\end{array}$ & $\begin{array}{l}\text { ASHRAE } \\
\text { Enhanced }\end{array}$ & $\begin{array}{c}\text { Enhanced } \\
\text { Model }\end{array}$ & $\begin{array}{l}\text { Angular } \\
\text { Cracks }\end{array}$ & $\begin{array}{c}\text { Mixed } \\
\text { Cracks }\end{array}$ & $\begin{array}{l}\text { Straight } \\
\text { Cracks }\end{array}$ \\
\hline 325 & 14165.67 & 16495.40 & 50681.82 & 314681.66 & 316583.37 & 293157.34 & 310321.31 \\
\hline 326 & 14251.02 & 16594.10 & 50962.66 & 315733.86 & 317584.19 & 294079.77 & 311297.89 \\
\hline 327 & 14333.90 & 16682.56 & 51223.20 & 316785.98 & 318586.37 & 295006.13 & 312277.22 \\
\hline 328 & 14400.02 & 16729.62 & 51406.01 & 317838.07 & 319588.63 & 295932.84 & 313255.53 \\
\hline 329 & 14468.37 & 16778.25 & 51596.63 & 318890.23 & 320590.40 & 296856.07 & 314229.39 \\
\hline 330 & 14510.75 & 16789.56 & 9.86 & 3199 & 321588.66 & 297774.25 & 315198.52 \\
\hline 331 & 14543.43 & 16795.38 & 51797.65 & 320995.10 & 322583.66 & 298687.03 & 62.40 \\
\hline 332 & 14569.09 & 16804.51 & .99 & 322047.68 & 323576.71 & 299595.34 & 2.82 \\
\hline 333 & 14593.17 & 16815.22 & 4.00 & 323100.22 & 324565.91 & 300499.83 & 318079.21 \\
\hline 334 & 14618.15 & 16826.33 & 52003.76 & 324152.90 & 325552.18 & 301401.10 & 319032.70 \\
\hline 335 & 14635.40 & 16837.07 & 52052.51 & 325205.46 & 326535.86 & 302299.92 & 319984.58 \\
\hline 336 & 14648.60 & 16847.64 & 52091.26 & 326257.94 & 327517.42 & 303196.79 & 320934.17 \\
\hline 337 & 14663.16 & 16858.00 & 52132.58 & 327310.32 & 328496.69 & 304092.40 & 321883.40 \\
\hline 338 & 14674.64 & 16868.21 & 52167.01 & 328362.69 & 329474.89 & 304986.63 & 322830.82 \\
\hline 339 & 14683.90 & 16878.09 & 52196.70 & 329415.05 & 330450.90 & 305879.59 & 323777.46 \\
\hline 340 & 14692.92 & 16887.72 & 52225.45 & 330467.34 & 331424.37 & 306771.22 & 324722.58 \\
\hline 341 & 14701.51 & 16896.89 & 2.82 & 331519.61 & 332396.66 & 307661.98 & 325667.24 \\
\hline 342 & 14709.26 & 1690 & 52278.50 & 332571.87 & 333366.55 & 308552.19 & 326611.17 \\
\hline 343 & 14716.15 & 16914.44 & 523 & 33362 & 34.98 & 309442.16 & 327554.97 \\
\hline 344 & 14723.23 & 16923.24 & 52326.23 & 334676.18 & 335301.86 & 310332.18 & 328498.70 \\
\hline 345 & 14728.52 & 16930.79 & 52345.72 & 335728.13 & 336269.74 & 311225.18 & 329445.55 \\
\hline 346 & 14734.12 & 16938.75 & 52366.31 & 336780.04 & 337238.87 & 312124.32 & 330398.90 \\
\hline 347 & 14738.98 & 16946.10 & 52384.85 & 337831.81 & 338211.10 & 313030.65 & 331359.83 \\
\hline 348 & 14744.14 & 16952.98 & 52402.61 & 338883.40 & 339185.98 & 313944.58 & 332328.41 \\
\hline 349 & 14748.58 & 16959.30 & 52418.45 & 339934.81 & 340163.99 & 314865.50 & 333305.34 \\
\hline 350 & 14754.93 & 16966.08 & 52437.18 & 340986.12 & 341144.39 & 315792.86 & 334287.46 \\
\hline 351 & 14760.90 & 16972.46 & 52454.52 & 342037.25 & 342125.48 & 316724.80 & 335273.74 \\
\hline 352 & 14766.39 & 16978.80 & 52471.07 & 343088.28 & 343106.52 & 317658.55 & 336259.91 \\
\hline 353 & 14772.65 & 16984.93 & 52488.20 & 344139.21 & 344084.85 & 318590.53 & 337244.30 \\
\hline 354 & 14777.96 & 16991.06 & 52504.11 & 345190.12 & 345060.45 & 319518.16 & 338224.05 \\
\hline 355 & 14790.04 & 16997.51 & 52532.30 & 346241.08 & 346033.47 & 320441.61 & 339200.43 \\
\hline 356 & 14799.64 & 17004.34 & 52556.19 & 347292.13 & 347004.87 & 321361.53 & 340173.16 \\
\hline 357 & 14812.06 & 17010.97 & 52585.54 & 348343.19 & 347974.22 & 322278.03 & 341142.76 \\
\hline 358 & 14823.94 & 17018.37 & 52614.89 & 349394.40 & 348942.26 & 323191.00 & 342110.31 \\
\hline 359 & 14838.41 & 17026.09 & 52650.61 & 350445.77 & 349909.66 & 324101.67 & 343074.39 \\
\hline 360 & 14854.99 & 17033.46 & 52691.30 & 351497.25 & 350876.16 & 325009.64 & 344035.97 \\
\hline 361 & 14873.33 & 17041.62 & 52737.77 & 352548.98 & 351842.34 & & \\
\hline
\end{tabular}




\begin{tabular}{|c|c|c|c|c|c|c|c|}
\hline hour & $\begin{array}{c}\text { Air } \\
\text { Change }\end{array}$ & $\begin{array}{c}\text { Air } \\
\text { Change } \\
(\mathrm{ACH})\end{array}$ & $\begin{array}{l}\text { ASHRAE } \\
\text { Enhanced }\end{array}$ & $\begin{array}{c}\text { Enhanced } \\
\text { Model }\end{array}$ & $\begin{array}{l}\text { Angular } \\
\text { Cracks }\end{array}$ & $\begin{array}{c}\text { Mixed } \\
\text { Cracks }\end{array}$ & $\begin{array}{c}\text { Straight } \\
\text { Cracks }\end{array}$ \\
\hline 362 & 14897.50 & 17050.22 & 52800.23 & 353600.96 & 352808.34 & & \\
\hline 363 & 14924.74 & 17059.91 & 52870.66 & 354652.99 & 353773.69 & & \\
\hline 364 & 14956.71 & 17059.91 & 52953.04 & 355705.12 & 354738.87 & & \\
\hline 365 & 14984.02 & 17067.20 & 53023.82 & 356757.27 & 355704.12 & & \\
\hline 366 & 15015.00 & 17067.20 & 53102.01 & 357809.29 & 356668.73 & & \\
\hline 367 & 15041.77 & 17076.72 & 53170.48 & 358861.30 & 357634.52 & & \\
\hline 368 & 15065.00 & 17084.99 & 53229.30 & 359913.22 & 358599.94 & & \\
\hline 369 & 15094.02 & 17084.99 & 53299.38 & 360964.91 & 359566.99 & & \\
\hline 370 & 15128.95 & 17097.42 & 53384.06 & 362016.49 & 360538.06 & & \\
\hline 371 & 15181.32 & 17125.37 & 53514.75 & 363068.04 & 361513.01 & & \\
\hline 372 & 15206.97 & 17132.21 & 53575.01 & 364119.44 & 362491.82 & & \\
\hline 373 & 15247.04 & 17146.47 & 53666.63 & 365170.60 & 363474.60 & & \\
\hline 374 & 15283.27 & 17159.36 & 53748.46 & 366221.63 & 364460.79 & & \\
\hline 375 & 15318.14 & 17174.87 & 53828.33 & 367272.64 & 365448.87 & & \\
\hline 376 & 15362.46 & 17198.52 & 53930.61 & 368323.56 & 366437.82 & & \\
\hline 377 & 15387.55 & 17211.91 & 53988.49 & 369374.46 & 367427.55 & & \\
\hline 378 & 15425.71 & 17225.49 & 54073.61 & 370425.35 & 368414.16 & & \\
\hline 379 & 15453.44 & 17230.42 & 54133.73 & 371476.17 & 369399.91 & & \\
\hline 380 & 15491.06 & 17243.81 & 54216.56 & 372526.98 & 370383.94 & & \\
\hline 381 & 15554.31 & 17300.07 & 54380.83 & 373577.78 & 371366.88 & & \\
\hline 382 & 15621.58 & 17371.87 & 54571.70 & 374628.58 & 372348.13 & & \\
\hline 383 & 15684.62 & 17427.95 & 54736.93 & 375679.44 & 373328.29 & & \\
\hline 384 & 15751.61 & 17493.49 & 54920.06 & 376730.32 & 374306.17 & & \\
\hline 385 & 15800.14 & 17519.40 & 55033.38 & 377781.28 & 375283.06 & & \\
\hline 386 & 15872.85 & 17603.48 & 55252.85 & 378832.25 & 376257.87 & & \\
\hline 387 & 15941.77 & 17664.78 & 55441.73 & 379883.50 & 377231.20 & & \\
\hline 388 & 15990.69 & 17686.54 & 55565.69 & 380935.17 & 378202.85 & & \\
\hline 389 & 16031.59 & 17701.09 & 55668.15 & 381986.91 & 379173.82 & & \\
\hline 390 & 16067.02 & 17713.69 & 55755.00 & 383038.54 & 380144.60 & & \\
\hline 391 & 16091.15 & 17720.13 & 55813.03 & 384090.10 & 381114.81 & & \\
\hline 392 & 16106.12 & 17728.12 & 55849.99 & 385141.57 & 382085.02 & & \\
\hline 393 & 16120.71 & 17735.91 & 55885.62 & 386192.95 & 383057.51 & & \\
\hline 394 & 16129.10 & 17743.37 & 55908.41 & 387244.24 & 384032.42 & & \\
\hline 395 & 16138.30 & 17750.74 & 55932.31 & 388295.44 & 385012.22 & & \\
\hline 396 & 16146.20 & 17757.76 & 55953.38 & 389346.54 & 385995.19 & & \\
\hline 397 & 16154.48 & 17764.39 & 55974.46 & 390397.56 & 386982.06 & & \\
\hline 398 & 16166.77 & 17770.95 & 56002.83 & 391448.48 & 387971.41 & & \\
\hline
\end{tabular}




\begin{tabular}{|c|c|c|c|c|c|c|c|}
\hline hour & $\begin{array}{c}\text { Air } \\
\text { Change }\end{array}$ & $\begin{array}{c}\text { Air } \\
\text { Change } \\
(\mathrm{ACH})\end{array}$ & $\begin{array}{l}\text { ASHRAE } \\
\text { Enhanced }\end{array}$ & $\begin{array}{c}\text { Enhanced } \\
\text { Model }\end{array}$ & $\begin{array}{l}\text { Angular } \\
\text { Cracks }\end{array}$ & $\begin{array}{r}\text { Mixed } \\
\text { Cracks }\end{array}$ & $\begin{array}{c}\text { Straight } \\
\text { Cracks }\end{array}$ \\
\hline 399 & 16178.70 & 17777.32 & 56030.05 & 392499.31 & 388963.31 & & \\
\hline 400 & 16192.01 & 17787.98 & 56063.28 & 393550.13 & 389956.17 & & \\
\hline 401 & 16204.99 & 17799.52 & 56097.30 & 394601.00 & 390947.55 & & \\
\hline 402 & 16216.86 & 17811.13 & 56130.00 & 395651.95 & 391936.89 & & \\
\hline 403 & 16235.74 & 17824.57 & 56178.44 & 396703.21 & 392924.81 & & \\
\hline 404 & 16248.51 & 17840.47 & 56220.16 & 397754.58 & 393912.68 & & \\
\hline 405 & 16258.70 & 17856.77 & 56260.54 & 398806.06 & 394898.48 & & \\
\hline 406 & 16343.00 & 17976.76 & 56564.58 & 399857.57 & 395883.55 & & \\
\hline 407 & 16353.40 & 17994.34 & 56608.30 & 400909.30 & 396868.00 & & \\
\hline 408 & 16450.03 & 18166.23 & 57036.65 & 401961.22 & 397852.29 & & \\
\hline 409 & 16460.90 & 18185.58 & 57085.19 & 403013.32 & 398835.41 & & \\
\hline 410 & 16565.01 & 18389.32 & 57595.95 & 404065.60 & 399817.08 & & \\
\hline 411 & 16671.80 & 18598.29 & 58122.85 & 405118.06 & 400796.37 & & \\
\hline 412 & 16782.47 & 18805.01 & 58652.40 & 406170.85 & 401774.49 & & \\
\hline 413 & 16895.31 & 19005.76 & 59175.31 & 407223.92 & 402751.07 & & \\
\hline 414 & 17009.00 & 19187.79 & 59668.09 & 408277.33 & 403727.55 & & \\
\hline 415 & 17120.97 & 19347.15 & 60123.18 & 409331.03 & 404703.02 & & \\
\hline 416 & 17224.12 & 19466.43 & 60502.87 & 410384.87 & 405678.91 & & \\
\hline 417 & 17327.27 & 19585.70 & 60882.55 & 411438.75 & 406656.25 & & \\
\hline 418 & 17429.52 & 19703.94 & 61256.85 & 412492.57 & 407636.26 & & \\
\hline 419 & 17530.86 & 19821.13 & 61625.80 & 413546.33 & 408620.18 & & \\
\hline 420 & 17613.07 & 19886.94 & 61890.04 & 414599.92 & 409607.48 & & \\
\hline 421 & 17695.67 & 19953.06 & 62151.75 & 415653.35 & 410598.42 & & \\
\hline 422 & 17760.61 & 19987.73 & 62345.07 & 416706.67 & 411591.55 & & \\
\hline 423 & 17830.95 & 20031.52 & 62555.89 & 417759.89 & 412586.21 & & \\
\hline 424 & 17912.08 & 20096.47 & 62809.21 & 418813.08 & 413580.95 & & \\
\hline 425 & 17996.15 & 20171.25 & 63078.51 & 419866.27 & 414574.40 & & \\
\hline 426 & 18023.24 & 20192.94 & 63164.34 & 420919.59 & 415564.23 & & \\
\hline 427 & 18042.64 & 20218.83 & 63238.91 & 421973.01 & 416551.85 & & \\
\hline 428 & 18063.15 & 20246.19 & 63318.89 & 423026.66 & 417536.68 & & \\
\hline 429 & 18079.42 & 20275.13 & 63396.30 & 424080.50 & 418520.78 & & \\
\hline 430 & 18097.19 & 20305.16 & 63478.19 & 425134.52 & 419501.55 & & \\
\hline 431 & 18225.26 & 20544.39 & 64117.97 & 426188.65 & 420480.47 & & \\
\hline 432 & 18360.62 & 20821.33 & 64854.31 & 427243.03 & 421456.98 & & \\
\hline 433 & 18496.65 & 21087.52 & 65570.60 & 428297.60 & 422431.62 & & \\
\hline 434 & 18632.68 & 21353.71 & 66286.88 & 429352.21 & 423403.84 & & \\
\hline 435 & 18765.71 & 21590.37 & 66938.81 & 430406.91 & 424374.07 & & \\
\hline
\end{tabular}




\begin{tabular}{|c|c|c|c|c|c|c|c|}
\hline hour & $\begin{array}{c}\text { Air } \\
\text { Change }\end{array}$ & $\begin{array}{c}\text { Air } \\
\text { Change } \\
\text { (ACH) }\end{array}$ & $\begin{array}{l}\text { ASHRAE } \\
\text { Enhanced }\end{array}$ & $\begin{array}{c}\text { Enhanced } \\
\text { Model }\end{array}$ & $\begin{array}{l}\text { Angular } \\
\text { Cracks }\end{array}$ & $\begin{array}{r}\text { Mixed } \\
\text { Cracks }\end{array}$ & $\begin{array}{l}\text { Straight } \\
\text { Cracks }\end{array}$ \\
\hline 436 & 18900.93 & 21842.96 & 67626.60 & 431461.63 & 425341.05 & & \\
\hline 437 & 19043.00 & 22146.26 & 68437.06 & 432516.44 & 426305.68 & & \\
\hline 438 & 19186.33 & 22452.25 & 69256.65 & 433571.32 & 427267.10 & & \\
\hline 439 & 19329.66 & 22758.23 & 70076.24 & 434626.23 & 428225.88 & & \\
\hline 440 & 19475.91 & 23083.46 & 70945.86 & 435681.22 & 429182.15 & & \\
\hline 441 & 19620.50 & 23392.12 & 71774.59 & 436736.22 & 430138.80 & & \\
\hline 442 & 19763.28 & 23684.24 & 72563.39 & 437791.22 & 431096.76 & & \\
\hline 443 & 19907.87 & 23992.90 & 73392.11 & 438846.24 & 432057.57 & & \\
\hline 444 & 20052.84 & 24315.28 & 74252.22 & 439901.18 & 433020.92 & & \\
\hline 445 & 20196.17 & 24621.26 & 75071.81 & 440956.11 & 433986.80 & & \\
\hline 446 & 20341.14 & 24943.64 & 75931.92 & 442011.03 & 434954.85 & & \\
\hline 447 & 20478.37 & 25212.20 & 76656.59 & 443065.81 & 435924.67 & & \\
\hline 448 & 20617.27 & 25484.01 & 77390.01 & 444120.57 & 436894.15 & & \\
\hline 449 & 20756.70 & 25769.26 & 78152.39 & 445175.24 & 437861.99 & & \\
\hline 450 & 20894.86 & 26051.91 & 78905.88 & 446229.83 & 438826.42 & & \\
\hline 451 & 21021.50 & 26254.68 & 79476.28 & 447284.33 & 439787.97 & & \\
\hline 452 & 21151.08 & 26485.20 & 80105.16 & 448338.80 & 440746.65 & & \\
\hline 453 & 21280.14 & 26703.33 & 80708.44 & 449393.27 & 441703.54 & & \\
\hline 454 & 21401.22 & 26875.65 & 81216.01 & 450447.74 & 442657.37 & & \\
\hline 455 & 21514.19 & 27026.38 & 81667.32 & 451501.99 & 443608.97 & & \\
\hline 456 & 21623.75 & 27162.81 & 82090.50 & 452556.20 & 444557.98 & & \\
\hline 457 & 21728.67 & 27284.14 & 82480.97 & 453610.33 & 445506.15 & & \\
\hline 458 & 21836.36 & 27418.25 & 82892.73 & 454664.37 & 446451.92 & & \\
\hline 459 & 21937.51 & 27526.22 & 83253.80 & 455718.32 & 447395.64 & & \\
\hline 460 & 22037.80 & 27633.26 & 83609.66 & 456772.17 & 448337.98 & & \\
\hline 461 & 22141.95 & 27753.71 & 83990.95 & 457826.01 & 449278.82 & & \\
\hline 462 & 22256.03 & 27936.36 & 84483.47 & 458879.55 & 450218.03 & & \\
\hline 463 & 22368.50 & 28106.43 & 84954.12 & 459933.19 & 451155.76 & & \\
\hline 464 & 22473.35 & 28237.00 & 85348.84 & 460986.90 & 452092.93 & & \\
\hline 465 & 22563.91 & 28317.55 & 85651.05 & 462040.61 & 453030.42 & & \\
\hline 466 & 22664.32 & 28433.66 & 86010.43 & 463094.13 & 453970.01 & & \\
\hline 467 & 22775.97 & 28632.28 & 86524.33 & 464147.25 & 454912.19 & & \\
\hline 468 & 22885.06 & 28826.37 & 87023.10 & 465200.16 & 455857.82 & & \\
\hline 469 & 22988.82 & 29001.72 & 87474.30 & 466252.87 & 456805.59 & & \\
\hline 470 & 23091.28 & 29174.88 & 87916.57 & 467305.39 & 457755.34 & & \\
\hline 471 & 23193.90 & 29357.45 & 88377.82 & 468357.80 & 458706.15 & & \\
\hline 472 & 23296.49 & 29549.09 & 88858.12 & 469410.11 & 459658.13 & & \\
\hline
\end{tabular}




\begin{tabular}{|c|c|c|c|c|c|c|c|}
\hline hour & $\begin{array}{c}\text { Air } \\
\text { Change }\end{array}$ & $\begin{array}{c}\text { Air } \\
\text { Change } \\
(\mathrm{ACH})\end{array}$ & $\begin{array}{l}\text { ASHRAE } \\
\text { Enhanced }\end{array}$ & $\begin{array}{c}\text { Enhanced } \\
\text { Model }\end{array}$ & $\begin{array}{l}\text { Angular } \\
\text { Cracks }\end{array}$ & $\begin{array}{c}\text { Mixed } \\
\text { Cracks }\end{array}$ & $\begin{array}{c}\text { Straight } \\
\text { Cracks }\end{array}$ \\
\hline 473 & 23397.80 & 29729.32 & 89311.92 & 470462.39 & 460607.52 & & \\
\hline 474 & 23494.43 & 29875.44 & 89690.75 & 471514.66 & 461555.24 & & \\
\hline 475 & 23586.15 & 29997.82 & 90018.71 & 472566.85 & 462501.43 & & \\
\hline 476 & 23680.62 & 30140.67 & 90385.78 & 473618.96 & 463446.33 & & \\
\hline 477 & 23773.25 & 30272.50 & 90729.99 & 474671.06 & 464389.86 & & \\
\hline 478 & 23862.69 & 30391.83 & 91046.36 & 475723.07 & 465333.39 & & \\
\hline 479 & 23946.33 & 30488.55 & 91316.35 & 476775.00 & 466276.59 & & \\
\hline 480 & 24034.61 & 30606.34 & 91626.94 & 477826.91 & 467220.12 & & \\
\hline 481 & 24123.65 & 30733.07 & 91952.94 & 478878.74 & 468163.03 & & \\
\hline 482 & 24202.17 & 30816.87 & 92194.64 & 479930.55 & 469106.23 & & \\
\hline 483 & 24284.74 & 30912.36 & 92459.48 & 480982.36 & 470049.62 & & \\
\hline 484 & 24367.32 & 31007.85 & 92724.32 & 482034.17 & 470993.22 & & \\
\hline 485 & 24441.65 & 31073.97 & 92938.53 & 483086.04 & 471938.21 & & \\
\hline 486 & 24516.22 & 31140.30 & 93156.92 & 484138.07 & 472882.92 & & \\
\hline 487 & 24595.90 & 31218.26 & 93398.30 & 485190.13 & 473827.86 & & \\
\hline 488 & 24676.78 & 31304.60 & 93649.07 & 486242.05 & 474773.42 & & \\
\hline 489 & 24757.67 & 31390.94 & 93899.84 & 487293.96 & 475721.09 & & \\
\hline 490 & 24839.27 & 31492.56 & 94168.11 & 488345.58 & 476673.79 & & \\
\hline 491 & 24923.77 & 31627.85 & 94498.90 & 489396.93 & 477629.92 & & \\
\hline 492 & 25004.28 & 31756.75 & 94810.08 & 490448.02 & 478590.98 & & \\
\hline 493 & 25084.90 & 31928.86 & 95222.78 & 491498.83 & 479556.86 & & \\
\hline 494 & 25165.11 & 32107.23 & 95651.62 & 492549.51 & 480525.78 & & \\
\hline 495 & 25239.46 & 32226.27 & 95934.13 & 493600.15 & 481498.73 & & \\
\hline 496 & 25312.67 & 32336.98 & 96198.30 & 494650.78 & 482471.48 & & \\
\hline 497 & 25383.22 & 32431.11 & 96427.63 & 495701.40 & 483444.79 & & \\
\hline 498 & 25457.74 & 32543.80 & 96697.78 & 496752.09 & 484415.68 & & \\
\hline 499 & 25527.15 & 32624.06 & 96904.39 & 497802.85 & 485385.93 & & \\
\hline 500 & 25603.80 & 32733.14 & 97171.03 & 498853.71 & 486355.19 & & \\
\hline 501 & 25686.39 & 32880.07 & 97523.47 & 499904.65 & 487324.56 & & \\
\hline 502 & 25768.23 & 33011.11 & 97841.16 & 500955.69 & 488293.86 & & \\
\hline 503 & 25850.08 & 33142.15 & 98158.86 & 502006.74 & 489262.63 & & \\
\hline 504 & 25927.68 & 33245.70 & 98418.53 & 503057.81 & 490231.22 & & \\
\hline 505 & 25997.45 & 33313.97 & 98615.69 & 504109.02 & 491199.97 & & \\
\hline 506 & 26073.29 & 33408.41 & 98857.40 & 505160.11 & 492169.39 & & \\
\hline 507 & 26154.27 & 33538.06 & 99171.74 & 506211.19 & 493138.54 & & \\
\hline 508 & 26220.39 & 33596.88 & 99348.22 & 507262.26 & 494107.02 & & \\
\hline 509 & 26283.22 & 33647.18 & 99509.80 & 508313.33 & 495075.40 & & \\
\hline
\end{tabular}




\begin{tabular}{|c|c|c|c|c|c|c|c|}
\hline hour & $\begin{array}{c}\text { Air } \\
\text { Change }\end{array}$ & $\begin{array}{c}\text { Air } \\
\text { Change } \\
\text { (ACH) }\end{array}$ & $\begin{array}{l}\text { ASHRAE } \\
\text { Enhanced }\end{array}$ & $\begin{array}{c}\text { Enhanced } \\
\text { Model }\end{array}$ & $\begin{array}{l}\text { Angular } \\
\text { Cracks }\end{array}$ & $\begin{array}{c}\text { Mixed } \\
\text { Cracks }\end{array}$ & $\begin{array}{c}\text { Straight } \\
\text { Cracks }\end{array}$ \\
\hline 510 & 26349.93 & 33706.52 & 99691.05 & 509364.55 & 496042.94 & & \\
\hline 511 & 26416.64 & 33765.86 & 99872.29 & 510415.79 & 497010.31 & & \\
\hline 512 & 26471.08 & 33804.60 & 100009.14 & 511466.96 & 497977.56 & & \\
\hline 513 & 26525.52 & 33843.34 & 100145.99 & 512518.13 & 498948.16 & & \\
\hline 514 & 26595.49 & 33930.47 & 100367.59 & 513569.15 & 499922.19 & & \\
\hline 515 & 26661.89 & 34001.34 & 100560.37 & 514620.22 & 500900.89 & & \\
\hline 516 & 26733.78 & 34097.26 & 100799.55 & 515671.22 & 501885.32 & & \\
\hline 517 & 26802.68 & 34183.06 & 101016.40 & 516722.14 & 502873.21 & & \\
\hline 518 & 26873.46 & 34277.50 & 101250.53 & 517773.04 & 503864.82 & & \\
\hline 519 & 26939.15 & 34376.84 & 101490.93 & 518823.93 & 504858.41 & & \\
\hline 520 & 26996.80 & 34443.50 & 101663.73 & 519874.82 & 505854.12 & & \\
\hline 521 & 27063.48 & 34544.33 & 101908.90 & 520925.78 & 506847.59 & & \\
\hline 522 & 27130.21 & 34639.31 & 102144.70 & 521976.89 & 507839.97 & & \\
\hline 523 & 27157.76 & 34671.16 & 102230.15 & 523028.17 & 508829.34 & & \\
\hline 524 & 27185.79 & 34696.10 & 102307.65 & 524079.56 & 509817.19 & & \\
\hline 525 & 27233.78 & 34730.25 & 102433.16 & 525131.05 & 510803.78 & & \\
\hline 526 & 27282.93 & 34765.22 & 102564.16 & 526182.70 & 511788.68 & & \\
\hline $\mathbf{5 2 7}$ & 27311.95 & 34783.29 & 102638.87 & 527234.32 & 512772.94 & & \\
\hline 528 & 27360.52 & 34817.86 & 102767.12 & 528285.94 & 513755.27 & & \\
\hline 529 & 27402.27 & 34840.13 & 102872.38 & 529337.55 & 514737.27 & & \\
\hline 530 & 27458.11 & 34879.87 & 103015.61 & 530388.96 & 515718.96 & & \\
\hline 531 & 27521.39 & 34930.53 & 103181.46 & 531440.26 & 516700.45 & & \\
\hline 532 & 27576.54 & 34964.87 & 103317.73 & 532491.54 & 517680.47 & & \\
\hline 533 & 27627.01 & 34991.81 & 103439.65 & 533542.80 & 518660.53 & & \\
\hline 534 & 27680.01 & 35024.81 & 103574.73 & 534594.27 & 519639.23 & & \\
\hline 535 & 27738.61 & 35061.30 & 103727.12 & 535645.92 & 520618.25 & & \\
\hline 536 & 27781.41 & 35084.13 & 103837.26 & 536697.67 & 521596.63 & & \\
\hline 537 & 27830.55 & 35119.11 & 103968.26 & 537749.38 & 522576.74 & & \\
\hline 538 & 27881.26 & 35159.70 & 104103.67 & 538800.88 & 523559.37 & & \\
\hline 539 & 27941.11 & 35212.94 & 104261.98 & 539851.99 & 524545.41 & & \\
\hline 540 & 27992.67 & 35249.62 & 104386.26 & 540902.88 & 525534.47 & & \\
\hline 541 & 28039.72 & 35291.48 & 104505.05 & 541953.51 & 526526.35 & & \\
\hline 542 & 28090.16 & 35345.32 & 104642.58 & 543003.93 & 527520.58 & & \\
\hline 543 & 28133.11 & 35379.70 & 104744.40 & 544054.31 & 528516.00 & & \\
\hline 544 & 28154.75 & 35397.03 & 104795.15 & 545104.59 & 529511.09 & & \\
\hline 545 & 28197.02 & 35430.87 & 104894.28 & 546154.86 & 530504.71 & & \\
\hline 546 & 28246.63 & 35483.82 & 105028.47 & 547205.11 & 531494.70 & & \\
\hline
\end{tabular}




\begin{tabular}{|c|c|c|c|c|c|c|c|}
\hline hour & $\begin{array}{c}\text { Air } \\
\text { Change }\end{array}$ & $\begin{array}{c}\text { Air } \\
\text { Change } \\
\text { (ACH) }\end{array}$ & $\begin{array}{l}\text { ASHRAE } \\
\text { Enhanced }\end{array}$ & $\begin{array}{c}\text { Enhanced } \\
\text { Model }\end{array}$ & $\begin{array}{l}\text { Angular } \\
\text { Cracks }\end{array}$ & $\begin{array}{c}\text { Mixed } \\
\text { Cracks }\end{array}$ & $\begin{array}{l}\text { Straight } \\
\text { Cracks }\end{array}$ \\
\hline 547 & 28292.25 & 35524.40 & 105141.41 & 548255.43 & 532483.13 & & \\
\hline 548 & 28353.90 & 35590.20 & 105308.14 & 549305.69 & 533468.10 & & \\
\hline 549 & 28414.64 & 35655.03 & 105472.42 & 550355.94 & 534451.12 & & \\
\hline 550 & 28487.63 & 35771.91 & 105748.62 & 551406.41 & 535432.23 & & \\
\hline 551 & 28564.36 & 35901.59 & 106056.74 & 552457.04 & 536412.82 & & \\
\hline 552 & 28643.42 & 36042.24 & 106391.78 & 553507.79 & 537391.23 & & \\
\hline 553 & 28712.84 & 36122.50 & 106598.38 & 554558.56 & 538369.46 & & \\
\hline 554 & 28781.18 & 36195.45 & 106792.29 & 555609.35 & 539346.93 & & \\
\hline 555 & 28841.34 & 36243.62 & 106942.53 & 556660.14 & 540324.71 & & \\
\hline 556 & 28909.69 & 36316.57 & 107136.44 & 557710.93 & 541301.71 & & \\
\hline 557 & 28963.15 & 36349.86 & 107262.89 & 558761.80 & 542277.91 & & \\
\hline 558 & 29011.03 & 36375.41 & 107373.37 & 559812.68 & 543254.12 & & \\
\hline 559 & 29048.50 & 36395.41 & 107459.84 & 560863.56 & 544228.81 & & \\
\hline 560 & 29081.32 & 36404.17 & 107531.39 & 561914.38 & 545202.46 & & \\
\hline 561 & 29111.73 & 36414.99 & 107597.50 & 562965.11 & 546178.22 & & \\
\hline 562 & 29154.21 & 36437.66 & 107692.00 & 564015.76 & 547157.89 & & \\
\hline 563 & 29194.34 & 36466.21 & 107783.47 & 565066.17 & 548141.00 & & \\
\hline 564 & 29260.61 & 36584.11 & 108055.64 & 566116.26 & 549128.66 & & \\
\hline 565 & 29335.42 & 36723.85 & 108384.45 & 567166.63 & 550120.47 & & \\
\hline 566 & 29404.03 & 36827.60 & 108627.33 & 568216.90 & 551116.41 & & \\
\hline 567 & 29478.01 & 36972.38 & 108968.05 & 569267.23 & 552113.74 & & \\
\hline 568 & 29483.33 & 36985.63 & 109000.81 & 570318.20 & 553112.70 & & \\
\hline 569 & 29582.30 & 37205.71 & 109545.20 & 571369.78 & 554110.69 & & \\
\hline 570 & 29589.72 & 37223.53 & 109589.85 & 572421.69 & 555106.55 & & \\
\hline 571 & 29703.41 & 37547.14 & 110424.31 & 573473.99 & 556101.89 & & \\
\hline 572 & 29820.71 & 37891.45 & 111319.00 & 574526.50 & 557095.01 & & \\
\hline 573 & 29828.40 & 37911.99 & 111371.67 & 575579.16 & 558088.00 & & \\
\hline 574 & 29837.61 & 37934.10 & 111428.02 & 576631.99 & 559078.32 & & \\
\hline 575 & 29955.18 & 38216.47 & 112147.53 & 577684.86 & 560068.13 & & \\
\hline 576 & 30073.58 & 38479.76 & 112819.43 & 578737.89 & 561055.85 & & \\
\hline 577 & 30194.43 & 38759.24 & 113534.61 & 579791.03 & 562043.41 & & \\
\hline 578 & 30310.40 & 38986.20 & 114118.43 & 580844.18 & 563029.71 & & \\
\hline 579 & 30429.02 & 39239.42 & 114766.40 & 581897.35 & 564015.52 & & \\
\hline 580 & 30543.50 & 39453.26 & 115319.35 & 582950.53 & 564999.85 & & \\
\hline 581 & 30652.59 & 39627.92 & 115784.78 & 584003.70 & 565983.95 & & \\
\hline 582 & 30762.83 & 39804.44 & 116257.03 & 585056.95 & 566966.95 & & \\
\hline 583 & 30865.78 & 39941.80 & 116648.75 & 586110.21 & 567950.09 & & \\
\hline
\end{tabular}




\begin{tabular}{|c|c|c|c|c|c|c|c|}
\hline hour & $\begin{array}{c}\text { Air } \\
\text { Change }\end{array}$ & $\begin{array}{c}\text { Air } \\
\text { Change } \\
(\mathrm{ACH})\end{array}$ & $\begin{array}{l}\text { ASHRAE } \\
\text { Enhanced }\end{array}$ & $\begin{array}{c}\text { Enhanced } \\
\text { Model }\end{array}$ & $\begin{array}{l}\text { Angular } \\
\text { Cracks }\end{array}$ & $\begin{array}{c}\text { Mixed } \\
\text { Cracks }\end{array}$ & $\begin{array}{c}\text { Straight } \\
\text { Cracks }\end{array}$ \\
\hline 584 & 30971.44 & 40082.78 & 117052.77 & 587163.55 & 568932.58 & & \\
\hline 585 & 31079.76 & 40236.93 & 117483.08 & 588216.90 & 569917.17 & & \\
\hline 586 & 31174.70 & 40338.28 & 117808.00 & 589270.19 & 570905.74 & & \\
\hline 587 & 31271.27 & 40449.94 & 118145.72 & 590323.32 & 571898.20 & & \\
\hline 588 & 31355.52 & 40524.89 & 118411.79 & 591376.36 & 572893.49 & & \\
\hline 589 & 31438.14 & 40598.38 & 118668.95 & 592429.23 & 573892.07 & & \\
\hline 590 & 31513.86 & 40658.99 & 118896.55 & 593482.00 & 574892.79 & & \\
\hline 591 & 31578.86 & 40699.47 & 119081.90 & 594534.67 & 575893.02 & & \\
\hline 592 & 31625.66 & 40724.45 & 119211.94 & 595587.24 & 576890.62 & & \\
\hline 593 & 31659.98 & 40739.71 & 119306.88 & 596639.87 & 577884.07 & & \\
\hline 594 & 31686.06 & 40753.63 & 119380.02 & 597692.49 & 578872.75 & & \\
\hline 595 & 31711.05 & 40764.74 & 119449.78 & 598745.19 & 579856.76 & & \\
\hline 596 & 31725.18 & 40776.06 & 119492.26 & 599797.90 & 580836.69 & & \\
\hline 597 & 31741.34 & 40788.99 & 119540.84 & 600850.62 & 581813.65 & & \\
\hline 598 & 31755.90 & 40801.94 & 119585.81 & 601903.34 & 582786.70 & & \\
\hline 599 & 31767.83 & 40814.68 & 119625.14 & 602956.06 & 583757.79 & & \\
\hline 600 & 31779.41 & 40826.01 & 119662.27 & 604008.85 & 584725.40 & & \\
\hline 601 & 31787.61 & 40836.22 & 119691.19 & 605061.51 & 585692.04 & & \\
\hline 602 & 31797.90 & 40846.29 & 119723.53 & 606114.08 & 586656.65 & & \\
\hline 603 & 31806.70 & 40856.46 & 119753.20 & 607166.63 & 587619.34 & & \\
\hline 604 & 31814.50 & 40866.18 & 119780.41 & 608219.10 & 588581.14 & & \\
\hline 605 & 31822.77 & 40877.21 & 119810.29 & 609271.49 & 589541.50 & & \\
\hline 606 & 31830.83 & 40887.96 & 119839.27 & 610323.78 & 590500.61 & & \\
\hline 607 & 31839.62 & 40898.92 & 119869.59 & 611376.06 & 591458.19 & & \\
\hline 608 & 31849.07 & 40909.84 & 119900.68 & 612428.26 & 592414.27 & & \\
\hline 609 & 31859.21 & 40920.66 & 119932.53 & 613480.37 & 593371.89 & & \\
\hline 610 & 31872.73 & 40931.49 & 119970.62 & 614532.39 & 594332.02 & & \\
\hline 611 & 31885.28 & 40941.53 & 120005.04 & 615584.18 & 595295.13 & & \\
\hline 612 & 31893.42 & 40950.22 & 120029.23 & 616635.64 & 596262.23 & & \\
\hline 613 & 31899.53 & 40957.29 & 120047.42 & 617686.61 & 597231.88 & & \\
\hline 614 & 31907.56 & 40963.72 & 120066.45 & 618737.13 & 598205.50 & & \\
\hline 615 & 31971.86 & 41089.55 & 120358.42 & 619787.19 & 599179.44 & & \\
\hline 616 & 32035.99 & 41197.93 & 120607.14 & 620837.15 & 600154.98 & & \\
\hline 617 & 32100.11 & 41306.31 & 120855.86 & 621887.06 & 601128.32 & & \\
\hline 618 & 32164.93 & 41421.61 & 121121.12 & 622936.96 & 602099.15 & & \\
\hline 619 & 32226.46 & 41509.19 & 121323.06 & 623986.85 & 603067.95 & & \\
\hline 620 & 32289.82 & 41610.63 & 121555.69 & 625036.73 & 604034.94 & & \\
\hline
\end{tabular}




\begin{tabular}{|c|c|c|c|c|c|c|c|}
\hline hour & $\begin{array}{c}\text { Air } \\
\text { Change }\end{array}$ & $\begin{array}{c}\text { Air } \\
\text { Change } \\
(\mathrm{ACH})\end{array}$ & $\begin{array}{l}\text { ASHRAE } \\
\text { Enhanced }\end{array}$ & $\begin{array}{c}\text { Enhanced } \\
\text { Model }\end{array}$ & $\begin{array}{l}\text { Angular } \\
\text { Cracks }\end{array}$ & $\begin{array}{r}\text { Mixed } \\
\text { Cracks }\end{array}$ & $\begin{array}{c}\text { Straight } \\
\text { Cracks }\end{array}$ \\
\hline 621 & 32361.00 & 41737.26 & 121851.08 & 626086.90 & 605000.77 & & \\
\hline 622 & 32372.75 & 41749.80 & 121884.17 & 627137.47 & 605965.57 & & \\
\hline 623 & 32451.72 & 41855.17 & 122151.42 & 628188.54 & 606929.22 & & \\
\hline 624 & 32535.19 & 41981.38 & 122464.08 & 629239.78 & 607892.05 & & \\
\hline 625 & 32547.46 & 41997.76 & 122506.34 & 630291.22 & 608855.55 & & \\
\hline 626 & 32637.46 & 42157.86 & 122898.45 & 631342.71 & 609817.89 & & \\
\hline 627 & 32708.60 & 42221.15 & 123100.15 & 632394.37 & 610780.21 & & \\
\hline 628 & 32786.13 & 42303.90 & 123337.14 & 633446.05 & 611742.34 & & \\
\hline 629 & 32857.28 & 42367.19 & 123538.83 & 634497.75 & 612705.74 & & \\
\hline 630 & 32920.48 & 42412.16 & 123707.30 & 635549.46 & 613668.23 & & \\
\hline 631 & 32991.63 & 42475.45 & 123909.00 & 636601.17 & 614631.57 & & \\
\hline 632 & 33059.01 & 42529.39 & 124093.87 & 637652.88 & 615594.64 & & \\
\hline 633 & 33142.72 & 42633.64 & 124374.09 & 638704.67 & 616561.19 & & \\
\hline 634 & 33231.14 & 42767.35 & 124711.49 & 639756.39 & 617530.70 & & \\
\hline 635 & 33317.84 & 42890.73 & 125027.30 & 640808.11 & 618504.88 & & \\
\hline 636 & 33407.82 & 43034.81 & 125387.02 & 641859.82 & 619484.33 & & \\
\hline 637 & 33497.81 & 43178.88 & 125746.75 & 642911.53 & 620470.63 & & \\
\hline 638 & 33581.43 & 43290.45 & 126036.15 & 643963.17 & 621461.10 & & \\
\hline 639 & 33672.45 & 43436.18 & 126400.02 & 645014.87 & 622455.78 & & \\
\hline 640 & 33755.07 & 43539.07 & 126674.94 & 646066.58 & 623452.20 & & \\
\hline 641 & 33837.36 & 43634.23 & 126940.57 & 647118.43 & 624449.40 & & \\
\hline 642 & 33912.56 & 43701.12 & 127159.07 & 648170.38 & 625445.61 & & \\
\hline 643 & 33988.64 & 43768.80 & 127381.86 & 649222.42 & 626441.36 & & \\
\hline 644 & 34066.24 & 43837.82 & 127612.72 & 650274.63 & 627435.07 & & \\
\hline 645 & 34120.63 & 43862.01 & 127761.81 & 651327.08 & 628427.00 & & \\
\hline 646 & 34163.40 & 43873.43 & 127878.28 & 652379.65 & 629416.20 & & \\
\hline 647 & 34201.98 & 43883.72 & 127984.33 & 653432.32 & 630403.20 & & \\
\hline 648 & 34237.76 & 43902.82 & 128087.31 & 654485.16 & 631387.63 & & \\
\hline 649 & 34290.02 & 43926.06 & 128237.18 & 655538.11 & 632371.33 & & \\
\hline 650 & 34319.52 & 43939.18 & 128321.04 & 656591.01 & 633352.00 & & \\
\hline 651 & 34348.62 & 43949.54 & 128403.74 & 657643.98 & 634331.35 & & \\
\hline 652 & 34375.89 & 43961.66 & 128483.30 & 658697.11 & 635308.95 & & \\
\hline 653 & 34400.92 & 43975.02 & 128557.80 & 659750.34 & 636285.89 & & \\
\hline 654 & 34420.82 & 43989.18 & 128618.56 & 660803.52 & 637261.20 & & \\
\hline 655 & 34440.72 & 44003.34 & 128679.32 & 661856.70 & 638235.75 & & \\
\hline 656 & 34460.61 & 44017.50 & 128740.09 & 662909.88 & 639210.24 & & \\
\hline 657 & 34478.18 & 44031.56 & 128794.53 & 663962.99 & 640186.06 & & \\
\hline
\end{tabular}




\begin{tabular}{|c|c|c|c|c|c|c|c|}
\hline hour & $\begin{array}{c}\text { Air } \\
\text { Change }\end{array}$ & $\begin{array}{c}\text { Air } \\
\text { Change } \\
(\mathrm{ACH})\end{array}$ & $\begin{array}{l}\text { ASHRAE } \\
\text { Enhanced }\end{array}$ & $\begin{array}{c}\text { Enhanced } \\
\text { Model }\end{array}$ & $\begin{array}{l}\text { Angular } \\
\text { Cracks }\end{array}$ & $\begin{array}{c}\text { Mixed } \\
\text { Cracks }\end{array}$ & $\begin{array}{c}\text { Straight } \\
\text { Cracks }\end{array}$ \\
\hline 658 & 34492.73 & 44044.51 & 128839.50 & 665015.80 & 641163.85 & & \\
\hline 659 & 34503.33 & 44055.82 & 128873.28 & 666068.20 & 642144.75 & & \\
\hline 660 & 34511.73 & 44066.28 & 128901.90 & 667120.38 & 643127.86 & & \\
\hline 661 & 34518.83 & 44075.75 & 128926.72 & 668172.29 & 644113.90 & & \\
\hline 662 & 34524.44 & 44083.23 & 128946.14 & 669224.00 & 645101.45 & & \\
\hline 663 & 34531.56 & 44092.10 & 128969.55 & 670275.59 & 646090.85 & & \\
\hline 664 & 34539.16 & 44100.89 & 128993.28 & 671327.07 & 647078.84 & & \\
\hline 665 & 34548.45 & 44109.98 & 129019.97 & 672378.53 & 648064.76 & & \\
\hline 666 & 34557.75 & 44119.08 & 129046.66 & 673429.98 & 649046.95 & & \\
\hline 667 & 34566.13 & 44128.03 & 129071.74 & 674481.42 & 650026.91 & & \\
\hline 668 & 34574.52 & 44136.98 & 129096.82 & 675532.86 & 651003.44 & & \\
\hline 669 & 34584.87 & 44146.19 & 129125.45 & 676584.30 & 651977.61 & & \\
\hline 670 & 34594.94 & 44155.14 & 129153.04 & 677635.66 & 652949.29 & & \\
\hline 671 & 34606.22 & 44164.17 & 129182.88 & 678687.02 & 653918.62 & & \\
\hline 672 & 34618.91 & 44173.20 & 129215.43 & 679738.37 & 654886.28 & & \\
\hline 673 & 34631.60 & 44182.23 & 129247.97 & 680789.71 & 655852.33 & & \\
\hline 674 & 34651.36 & 44192.78 & 129296.23 & 681841.06 & 656816.19 & & \\
\hline 675 & 34669.75 & 44200.96 & 129340.39 & 682892.41 & 657778.44 & & \\
\hline 676 & 34684.35 & 44208.75 & 129376.02 & 683943.75 & 658739.02 & & \\
\hline 677 & 34703.66 & 44219.05 & 129422.67 & 684995.03 & 659699.22 & & \\
\hline 678 & 34722.97 & 44229.36 & 129469.32 & 686046.29 & 660658.08 & & \\
\hline 679 & 34750.02 & 44248.61 & 129538.01 & 687097.55 & 661615.67 & & \\
\hline 680 & 34763.98 & 44257.30 & 129572.52 & 688148.80 & 662573.61 & & \\
\hline 681 & 34776.00 & 44265.85 & 129602.71 & 689199.99 & 663533.90 & & \\
\hline 682 & 34785.22 & 44274.06 & 129627.34 & 690251.09 & 664497.98 & & \\
\hline 683 & 34794.18 & 44282.02 & 129651.02 & 691302.10 & 665466.16 & & \\
\hline 684 & 34805.20 & 44289.87 & 129677.87 & 692353.02 & 666439.07 & & \\
\hline 685 & 34851.46 & 44326.90 & 129793.39 & 693403.85 & 667416.71 & & \\
\hline 686 & 34930.91 & 44461.18 & 130114.92 & 694454.74 & 668397.32 & & \\
\hline 687 & 35019.54 & 44634.61 & 130534.92 & 695505.91 & 669381.05 & & \\
\hline 688 & 35110.09 & 44803.75 & 130946.99 & 696557.27 & 670365.56 & & \\
\hline 689 & 35203.42 & 44978.09 & 131374.43 & 697608.81 & 671350.25 & & \\
\hline 690 & 35294.18 & 45115.34 & 131722.32 & 698660.54 & 672332.79 & & \\
\hline 691 & 35373.67 & 45200.19 & 131968.77 & 699712.38 & 673313.77 & & \\
\hline 692 & 35456.99 & 45296.53 & 132239.45 & 700764.33 & 674293.74 & & \\
\hline 693 & 35556.22 & 45473.07 & 132682.41 & 701816.44 & 675272.68 & & \\
\hline 694 & 35659.95 & 45648.38 & 133131.82 & 702868.86 & 676251.22 & & \\
\hline
\end{tabular}




\begin{tabular}{|c|c|c|c|c|c|c|c|}
\hline hour & $\begin{array}{c}\text { Air } \\
\text { Change }\end{array}$ & $\begin{array}{c}\text { Air } \\
\text { Change } \\
\text { (ACH) }\end{array}$ & $\begin{array}{l}\text { ASHRAE } \\
\text { Enhanced }\end{array}$ & $\begin{array}{c}\text { Enhanced } \\
\text { Model }\end{array}$ & $\begin{array}{l}\text { Angular } \\
\text { Cracks }\end{array}$ & $\begin{array}{c}\text { Mixed } \\
\text { Cracks }\end{array}$ & $\begin{array}{l}\text { Straight } \\
\text { Cracks }\end{array}$ \\
\hline 695 & 35760.44 & 45791.39 & 133518.14 & 703921.50 & 677229.05 & & \\
\hline 696 & 35872.30 & 46000.35 & 134053.44 & 704974.32 & 678206.67 & & \\
\hline 697 & 35984.02 & 46179.23 & 134532.01 & 706027.47 & 679172.00 & & \\
\hline 698 & 36102.53 & 46379.50 & 135068.49 & 707080.98 & 680135.07 & & \\
\hline 699 & 36224.60 & 46585.81 & 135627.11 & 708134.77 & 681093.96 & & \\
\hline 700 & 36342.47 & 46764.05 & 136130.76 & 709188.77 & 682050.96 & & \\
\hline 701 & 36475.72 & 47060.36 & 136905.68 & 710242.82 & 683004.99 & & \\
\hline 702 & 36600.62 & 47282.57 & 137504.02 & 711296.90 & 683957.66 & & \\
\hline 703 & 36725.66 & 47493.90 & 138084.41 & 712351.13 & 684907.58 & & \\
\hline 704 & 36853.58 & 47710.08 & 138680.21 & 713405.46 & 685857.00 & & \\
\hline 705 & 36964.98 & 47848.81 & 139114.86 & 714459.81 & 686806.71 & & \\
\hline 706 & 37090.02 & 48060.14 & 139695.25 & 715514.10 & 687758.65 & & \\
\hline 707 & 37206.93 & 48226.53 & 140176.83 & 716568.24 & 688713.49 & & \\
\hline 708 & 37320.97 & 48388.83 & 140644.51 & 717622.29 & 689670.81 & & \\
\hline 709 & 37430.58 & 48525.33 & 141063.61 & 718676.31 & 690630.99 & & \\
\hline 710 & 37536.38 & 48657.09 & 141463.99 & 719730.18 & 691594.13 & & \\
\hline 711 & 37634.87 & 48779.73 & 141834.75 & 720783.95 & 692557.98 & & \\
\hline 712 & 37732.48 & 48901.29 & 142200.31 & 721837.62 & 693522.49 & & \\
\hline 713 & 37833.37 & 49035.89 & 142591.83 & 722891.28 & 694485.68 & & \\
\hline 714 & 37919.43 & 49120.10 & 142884.86 & 723944.92 & 695446.31 & & \\
\hline 715 & 38011.19 & 49218.05 & 143210.49 & 724998.70 & 696404.06 & & \\
\hline 716 & 38102.96 & 49316.00 & 143536.12 & 726052.51 & 697359.62 & & \\
\hline 717 & 38187.24 & 49390.97 & 143823.01 & 727106.46 & 698313.65 & & \\
\hline 718 & 38267.21 & 49454.99 & 144090.91 & 728160.52 & 699265.89 & & \\
\hline 719 & 38345.04 & 49538.07 & 144368.76 & 729214.45 & 700217.24 & & \\
\hline 720 & 38429.39 & 49643.11 & 144687.94 & 730268.30 & 701167.31 & & \\
\hline 721 & 38470.56 & 49679.73 & 144827.17 & 731322.21 & 702114.71 & & \\
\hline 722 & 38512.23 & 49720.50 & 144972.63 & 732376.19 & 703060.87 & & \\
\hline 723 & 38583.46 & 49783.86 & 145216.64 & 733430.25 & 704006.61 & & \\
\hline 724 & 38651.19 & 49838.08 & 145445.08 & 734484.40 & 704950.81 & & \\
\hline 725 & 38694.32 & 49868.78 & 145588.82 & 735538.65 & 705894.75 & & \\
\hline 726 & 38725.04 & 49890.64 & 145691.89 & 736592.98 & 706837.22 & & \\
\hline 727 & 38751.72 & 49914.36 & 145785.01 & 737647.34 & 707780.35 & & \\
\hline 728 & 38794.36 & 49956.09 & 145935.71 & 738701.56 & 708723.85 & & \\
\hline 729 & 38836.02 & 50004.27 & 146089.92 & 739755.62 & 709670.14 & & \\
\hline 730 & 38876.71 & 50051.31 & 146238.85 & 740809.50 & 710618.99 & & \\
\hline 731 & 38980.59 & 50199.16 & 146657.27 & 741863.21 & 711572.13 & & \\
\hline
\end{tabular}




\begin{tabular}{|c|c|c|c|c|c|c|c|}
\hline hour & $\begin{array}{c}\text { Air } \\
\text { Change }\end{array}$ & $\begin{array}{c}\text { Air } \\
\text { Change } \\
\text { (ACH) }\end{array}$ & $\begin{array}{l}\text { ASHRAE } \\
\text { Enhanced }\end{array}$ & $\begin{array}{c}\text { Enhanced } \\
\text { Model }\end{array}$ & $\begin{array}{l}\text { Angular } \\
\text { Cracks }\end{array}$ & $\begin{array}{c}\text { Mixed } \\
\text { Cracks }\end{array}$ & $\begin{array}{l}\text { Straight } \\
\text { Cracks }\end{array}$ \\
\hline 732 & 39089.42 & 50354.04 & 147093.59 & 742916.81 & 712529.21 & & \\
\hline 733 & 39193.40 & 50492.78 & 147491.20 & 743970.23 & 713490.02 & & \\
\hline 734 & 39304.80 & 50671.14 & 147970.28 & 745023.62 & 714453.18 & & \\
\hline 735 & 39415.07 & 50837.89 & 148427.83 & 746077.07 & 715418.09 & & \\
\hline 736 & 39521.09 & 50979.34 & 148837.27 & 747130.59 & 716382.90 & & \\
\hline 737 & 39612.74 & 51069.02 & 149147.36 & 748184.12 & 717346.24 & & \\
\hline 738 & 39707.11 & 51161.36 & 149468.66 & 749237.73 & 718306.46 & & \\
\hline 739 & 39761.25 & 51180.62 & 149633.26 & 750291.43 & 719264.31 & & \\
\hline 740 & 39809.92 & 51193.61 & 149780.45 & 751345.15 & 720221.57 & & \\
\hline 741 & 39853.21 & 51201.31 & 149911.00 & 752398.87 & 721175.95 & & \\
\hline 742 & 39893.89 & 51212.16 & 150035.03 & 753452.67 & 722129.27 & & \\
\hline 743 & 39935.07 & 51226.81 & 150162.20 & 754506.55 & 723080.48 & & \\
\hline 744 & 39998.32 & 51260.57 & 150362.61 & 755560.52 & 724031.70 & & \\
\hline
\end{tabular}


VITA

\section{CHADI YOUNES}

Born, Lebanon

2006

B.E. Civil Engineering

Lebanese American University

Byblos, Lebanon

2008

M.S. Civil Engineering

Florida International University

Miami, Florida

2012

Doctoral Candidate

Florida International University

Miami, Florida

PUBLICATIONS, CONFERENCE PAPERS, AND PRESENTATIONS

Younes, C., Abi Shdid, C. \& Bitsuamlak, G. , Air Infiltration In Building Envelopes: A Review, Journal of Building Physics. 35, No. 3, January 2012.

Younes, C., Abi Shdid, C., Developing an Enhanced Model for Combined Heat and Air Infiltration Energy Simulation, Journal of Building Physics. In review

Younes, C., Abi Shdid, C. \& Bitsuamlak, G., Thermal Simulation Approach in DOE-2: Outline \& Methodology Fundamentals. Journal of Computer Aided Design. In review.

Younes C. and Abi Shdid, C., "True Multiphysics Simulation of Air Leakage in Building Envelopes". Proceedings of the 2012 Engineering Mechanics Institute and 11th ASCE Joint Specialty Conference on Probabilistic Mechanics and Structural Reliability (EMI/PMC 2012), pp 16, June 2012.

Issa, Camille A., and Younis, Chadi, “ Integrating Virtual Reality with Structural Aided Design System", Proceedings of 6th International Conference on Construction Applications of Virtual Reality, August 3- 4, 2006, Orlando, FL, USA

USGBC \& LEED Overview, Miami, April 2011

eQUEST, Building Energy Simulation, Miami, April 2011

Air Infiltration Modeling For Building Energy Simulation, Miami, March 2011 